



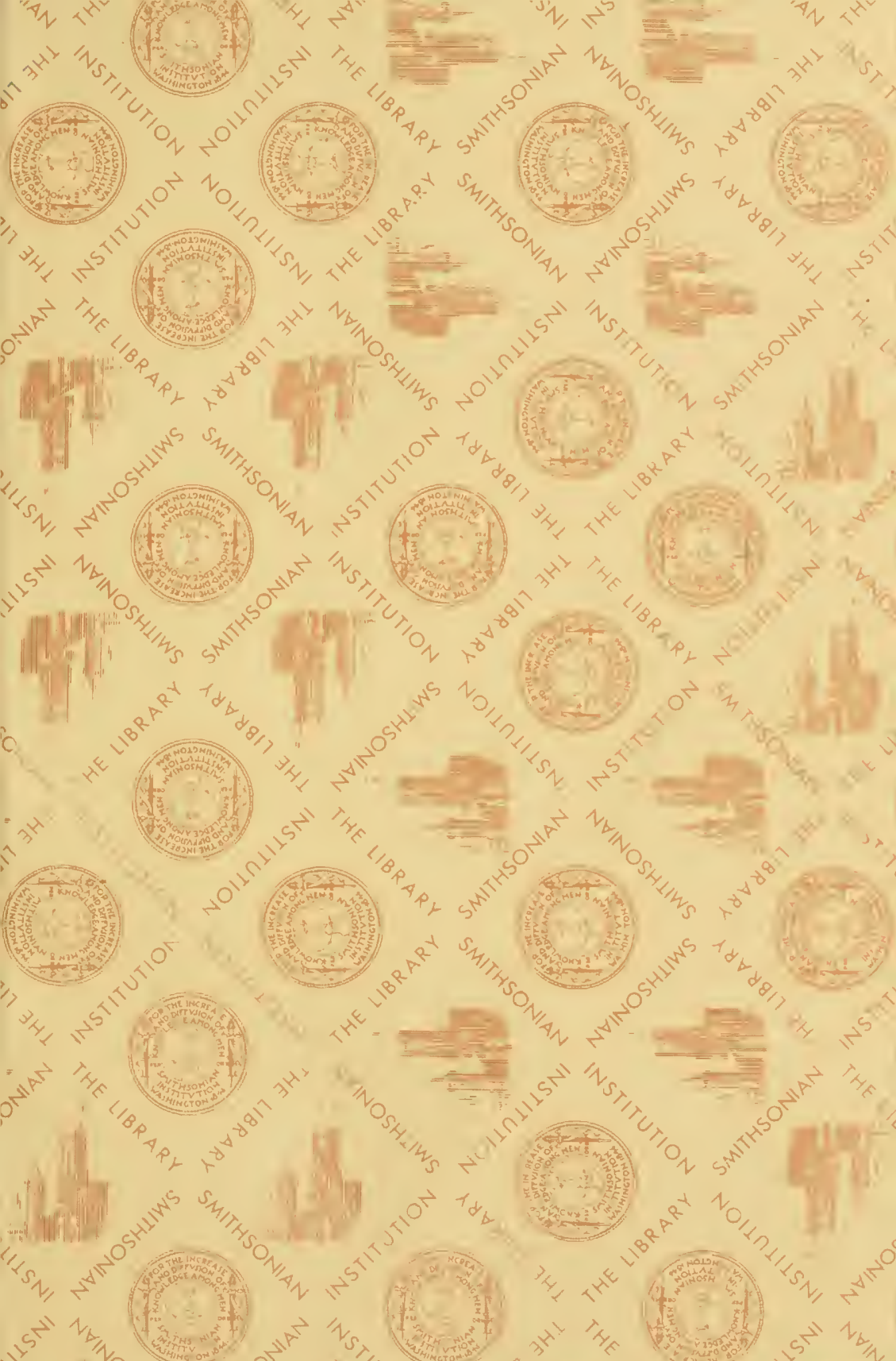





IIRO CELEBERRIMO

\section{STGNORET}

HANC SUI OPERIS PARTEM

IN TESTIMONIUM VERECUNdAE AMICITIAELE

ANIMO GRATO OFFERT

Auctor. 


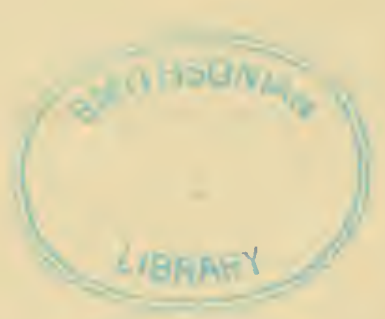




\section{I}

n opere, cujus hee pars prima benevolentiae entomologorum commendatur, Hemiptera Africana omnia, quæcumque examinare ipse potui, describere statui. Quoniam vero ultra limites Faune vere Africanæ terre illæ mari mediterraneo adjacentes, quarum animalia characterem præbent praeipue Europaum, sunt removenda, species nullas ex is terris descripsi, exceptis quibusdam Aegyptiacis insignioribus.

Hemiptera Africana, quæ cum Asiaticis et Australicis affinitatem prabent maximam, ab Europæis maximeque ab) Americanis haud parum divergunt. Quamobrem omnia mihi cognita genera Asiatica et Australica - præterquam quum per ejusmodi additamenta futurum esset, ut in nimiam amplitudinem, legentibus incommodam, cresceret opus, - notis maxime insignibus illustrata in conspectibus generum strictins disposui. Interdum quum de familiis agitur, quarum genera sunt minus numerosa quæve formas continent latius patentes, omnia milhi cognita, Europæa quoque et Americana, memoravi.

Collectiones uberrimæ, quas in Africa meridionali congestas domum misit J. WAHLBERG, inclytissimus ille peregrinator et naturæ perscrutator Suecicus, materiam præbuerunt 
primuifalem hujus operis elaborandi. Copiam Hemijterormm

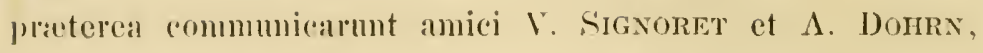
yuormm ergal me liberalitate gratias ago quantas possmm maximas.

Holmiar. Id. rept. MIOCCCLXIV.

\author{
C. Stål.
}




\section{HEMIPTERA HETEROP'TERA LATR.}

\section{Fam. ARTIROPTERIDA FIFB.}

Caput clypeatum. Rostrum quadriartirulatum, versus basin capitis insertum, ab ortu labri remotum. Ścutellum maximum, abdomen totum tegens. Hemelytra longissima, corpore longiora, parte dimidia apicali introrsum flexibili; membrana venis longitudinalibus, simplicibus. Tarsi liarticulati, articulo primo brevissimo.

\section{Conspectus generum.}

1 (2). Thoracis lateribus haud explanatis; capite angusto, producto, Iobis aque Iongis; articulo primo antennarum capitis apicem subsuperante; rostro nltra medium ventris extenso; thorace valde gibhoso, parte gibba antrorsum producta; rentre convexiusculo; pedibus longis. - Probanops WHITE.

2 (1). Thoracis lateribus dilatatis, explanatis; antennarum articulo primo apicem eapitis laud superante.

3 (4). Capite parvo vel mediocri, parum dilatato, plus minus deflexo; antemnis ad oculos insertis; ocellis valde distantibus, ad oculos appropinquatis. - Coptosoma LAP.

4 (3). Capite lato vel latissimo, foliaceo; antennis longius ab oculis insertis; ocellis ab oculis remotis.

5 (16). Lobo medio eapitis distinguendo.

6 (11). Ocellis inter se quam ab oculis paullo longius vel inter se et $a b$ oculis fere rque longe distantibus; corpore depresso vel minus convexo.

7 (10). Lobis lateralihus capitis lobo medio longioribus, antice valvantibus. 
8 (9). Oculis obliquis, profunde immersis; capite basi rotnndato; thorace apice pone caput rotundatim sat profunde sinuato, angulis anticis prominentibus. - Oncylaspis STiL.

9 (8). Oeulis haud obliquis; thorace antice subtruncato, medio obtuse sinuato, angulis anticis obtusis, haud productis. Brachyplatys BOIsD.

10 (7). Lobis capitis lateralibus lobo medio paullo brevioribus, hujus apice prominulo. - Ponsilu STÁL.

11 (6). Ocellis inter se quam ab oculis minus longe remotis:

12(15). Corpore depresso.

13(14). Caypitis margine basali utrimque obliquo, lobo medio apicen capitis fere attingente. - Heterocrates Writs.

14(13). Capitis basi recta, lobo medio longe al apice ablreviato, lohis lateralibus productis, valvantibus. - Aphanopneuma WEsTW.

15(12). Corpore valde convexo. - Platuspis Westw.

16 (5). Lobo medio capitis toto obtecto, lobis lateralibus usque a basi contiguis. - Ceratorcoris WHTE.

Ohs. Genus Chlcenocoris nee ad Arthopterida, ut roluit DALLAs, nec ad Tetyrida, ut voluit Fieber, sed ad Cydnida pertinet.

\section{CERATOCORIS WHTE.}

Ent. 'Trans. 11I. p. 90 (1841).

Corpus late ovatum, supra valde comvexum, suhtus planum. Caput latmm, transversum, lobo medio hand distinguendo. Oculi ab oculis quam inter se plus duplo longius distantes. Thorax lateribus dilatatis, foliaceis, rotundatis. Scutellum retrorsum leviter ampliatum. Pedes breviuseuli, validi.

1. C. Bucephalus Wurte. - Sordide flavescens, supra nigro-nebulosus et remote acervatim nigro-punctatus, subtus niger, exceptis capite, parte laterali dilatata prostethii limhoque lato ventris, hor nigro-mandato. ơ. \&. Long. 11-15, Lat. 8-I0 mill. 


\section{$-3-$}

Plataspis dispar SpIN. Gen. d'ins. artr. p. 104. (1852).

○. Major, capite magis producto, utrimque ante oculos sinuato, ante sinum utrimque cornu brevi, acuto, obliquo, subarcuato armato, limbo exteriore cornum ante sinum supra subtusque nigro.

Plataspis Bucephalus WHITE. Entomol. p. 136. (1841); WESTW. Ent. Trans. IV. p. 243. Pl. 18. fig. 1. (1847).

Ceratocoris Bucephalus DaLL. List of IJem. I. p. T2. 1. (1851).

\&. Minor, capite inermi, apice late subtruncato, subtus nigro, disco maculaque ad oculos flavescentibus.

Patria: Calabar. (Mus. IIolm., Coll. ג. Dohrs, Signoret et Ŝ́TÁL.).

\section{PLATASPIS WESTW.}

Hopk. Cat. of Hem. I. p. 16. (1837).

Corpus latissime ovatum, supra valde convexum, subtus planum. Caput latum, transversum, foliaceum, lobis lateralibus valvantibus, lobo medio distincto, illis breviore. Oculi parvi, haud vel vix transversi. Ocelli ab oculis quam inter se multo longius remoti. Antenna ab oculis remotæ. Thorax lateribus foliaceis, rotundatis, deorsum productis. Scutellum valde convexum. Pedes breves, validi.

a. Capite apice late truncato et medio interdum subsinuato; thoracis margine autico pone oculos nomihil sinuato, angulis anticis rotundatis, sulprominentibus.

1. P. coccinelloidles LaP. - Maxime convexa, nitida, nigra, supra remote distincteque punctata; thorace scutelloque rufescentepiceis; pectore opaco, griseo-induto. $\sigma^{\text {T}}$. o. Long. 14, Lat. 12 mill.

Var. a. - Thoracis plaga transversa basali scutellique fascia media flavo-testaceis; limbo laterali thoracis et posteriore scutelli nigricantibus.

Canopus coccinelloides Lap. Ess. Hém. p. 85. Pl. 55. fig. 5. (1832). 
Patuspis cocciformis WEsTw. in IIOPE. Calt. of IIent. 1. P. 16. (18:37).

Thyreocoris cocciformis GERM. Zeitschr. I. p. 31. 16. (18:39).

Thyreocoris coccinelloides $A$. et $\mathrm{S}$. Ilist. des Ilém. 1) 61. I. (1843).

Plutaspis coccinelloides DALL. List. of Hem. I. 11. 72. I. (18.3 I).

Vur. b. - Thorace testacen-flavescente; capite, thoracis plaga antica, limboque lato basali scutelli nigris.

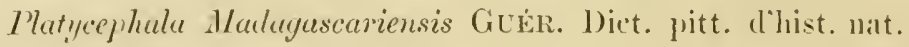
1. P. 623. Pl. 72. fig. 3. (see. SigN.).

Patria: Marlagascar. (Mus. Molm., Coll. SigNoréT et StTAL); val. l. (Coll. Signoret).

2. P. Waluloergi StтáL. - Dilute testaceo-flavescens, sujural acervatim nigro-punctata et confluenter denseque vermicellatoconspersa; pertore interelun leviter infuscato, griseo-induto. o7. ․ Long. I1-12! Lat. thor. 8!-9, Lat. max. seut. $11-12$ mill.

Plutuspis Hahlbergi STAL. Öf. Vet. Ak. Förls. 1863. p. 212. 1 .

Patria: Catfrarial (Mus. Hohm.).

Maxime convexa, gibhosa, nitida, dihute testacen-flavesens, supral tota acervation remote nigro-punctatal et dense atcpure confluenter vermicellato-conspersil. Calput supral subtusque roneolor et nigro-punctatum, superne basi medio minute nigro-maculatum, subtus fascia basali impunctata, fasciacpure nigra, inter antemus posital, ad

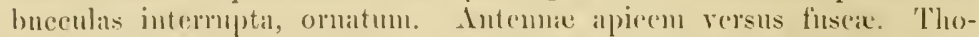
rax lituris rerniecllaribus, imregulariter confluentibus, nigris ronspersus. Seuteftum lituris vermicellanibus, irregulariter confluentibus, nigris, makeulas parrals irregulatres, obsoletissime callosils, flatreseentetestaceals relincucutibus. Hemelytrom pars libera nigro-punetata. Pectus grisco-indutum, diseo nigrmu, lateribus dilatitis nigro-punretatis. Venter, discos execpto, parte nigro-punctatus, incisuris inpressionerpe transwersa lineari laterali segmentormm nigris. Pedes toti testacer)-flaresentes.

3. P. irrorata DaLL. - Nigricans, superme testaleo-Havo-conspersa; capitis fascia basali inferiore, ventre, articulis primo, secunto et interdum tertio antennarum nee non perlibus testaren-flavescentihus; ventris linein transionsis platgaque 
oblonga media, trochanteribus, basi f'enorum, tibiis tarsisque subtus, illarum etiam sulco supero nigris. \&. Loug. 9-11, Lat. thor. $7 !-8$, Lat. max. scut. 9)

I'lutuspis imorutu DALL. List of IIem. I. 1. T3. 4. (I851). I'lutaspis verrucose Sign. in THods. Aleh. ent. 11. p. 275. 50). (1858).

Patria: Calabar. (Mus. Ilolm., Coll. Signoret et S'TíL).

P. Wahlbergi valde affirnis, postice latior, colore nigro thoraris sentellique nagis extensa, maculis hormm flaveserentibus distinctius callosis, capite subtus, basi maculisyue nommulis minutis exceptis, pectore nee non basi femorum nigris distiucta: prostethii parte latterali dilatata thavesente, nigro-conspersa.

4. P. variegata GuÉR. - Nigra; capite superne, thorace anterius maculisque posticis, maculis scutelli majusculis, macula partis costalis libera hemelytrorum maculisque parvis malginalibus ventris testaceo-flarescentibus. ơ. Long. 11, Lat. thor. 8, Lat. max. scut. 9 mill.

Platyceplealu variegata Guér. Dict. pitt. d’hist. nat. suppl. 1X. 6:6. (sec. AM. et SERV.).

Thyreocoris punctutu A. et S. Hist. des Ilém. 1. 62. 2. (1843).

Patria: Madagascar. (Coll. Signoret.).

Pracedentibus duabus subsinilis, minus gibbosa, postice miuus lata, maculis majoribus, thorace anterius capiteque superne flavescentilus, parce nigro-lituratis, margine costali corii flavo-maculato ventreque nigris distinctissima. Nigra. Caput concaviusculum, superue flavescens, parce nigro-punctatum, limbo basali angusto, medio latiore et ibidem profuncle triemarginato, maculis nommllis minutis lateralibus ar oculos, interdum in unam majorem conthentibus, vitta media, posterius abbreviata, limboque apicali medio nigris; subtus nigrum, unicolor. Antenma articulo primo apice imo et secumclo flavescentibus. Thorax flarescens, parce nigro-punctatus, maculis duabus appropinquatis ante medium, macula antica parva, utrimpue pone oculos positi parteque basali nigris, hac parte panllo densius punctata, maculis irregularibus sordide flavescontibus, leviter callosis, notata. Scutellum minus dense distineteque punctatum, maculis irregularibus, hic illic conthentibus, majusculis, leviter callosis, testaceo-flavescentibus conspersum, macula laterali basali reliquis majore, intus erosa. Hemelytrorum pars libera nigra, macula flavesccnte, parce nigro-punctata, supra subtusque notata. Prostethii pars lateralis dilatata macula marginali flavescente, parce nigro-pun- 
ctata, oruata. Marogo lateralis rentris nueulis quinque parvis flavescentibus notatus.

aa. Capite apice late rotundato; thoracis margine antico utrimque pone oculos vix rel levissime simuato, angulis anticis obtusissime rotundatis, deletis.

5. P. semiglohosa STiL. - Niglo-picea, minus nitida; maculis duabus anterioribus transversis thoracis fasciaque abbreviata basali scutelli dilute piceis vel obscure rufo-piceis; articulis primo et secundo antennarum, coxis, trochanteribus femoribusque rufo-piceis; maculis malginalibus ventris dilute flavescentibus. ơ. ㅇ. Long. 10-12, Lat. thor. 8-8 $\frac{1}{2}$, Lat. max. scut. 9-10 mill.

Plataspis semiglobosa STiL. Öfv. V'et. 1k. Förh. 1853. p. 213. 2.

Patria: Caffraria. (Mus. Holm.).

Statura fere $P$. variegate, colore picturaque ab ommibus mihi cognitis congenericis distinctissima. Sat convexa, supra subopaca, dense distincteque punctulata, capite paullo remotius punctato, superne parce mimiteque flavescente-consperso, subtus ad basin prope antemias macula parva flavesecnte notato. Thorax latera rersus paullo fortins punctatus, ibidem siepissine remote, minnte et minus distincte flaresecute-conspersus. Pectus griseo-indutum. Venter nitidus.

\section{APIIANOPNEUMA WESTW.}

Eut. trans. 1V. p. 244. (184i).

Corpus ovale vel subovatum, depressum. Caput maximum, thorace paullo angustius, foliaceun, productum, basi truncatum, lobo medio lobis lateralibus multo breviore. Oculi parvi. Ocelli ab oculis quam inter se multo longius distantes. Thorax transversus, antice truncatus et medio sinuatus, marginibus lateralibus rectis, antice nomnilil rotundatis.

1. A. biloba Westw. - Aenescente-nigra, nitida, supra remote distincteque punctulata et pare flavescente-conspersa; capite, limbo thoracis laterali anteriore areuque scutelli ante medium posita et basin attingente sordide flaveseentibus, nigro-punctatis; capitis lateribus sujra subtusque, regione intraocellari, 
vitta limboque apicali inferis æneo-nigris; antennarum articulis duobus basalibus, rostro pedilusque testaceo-flavescentibus. $\sigma^{7}$. ㅇ. Long. 14-15, Lat. 8 mill.

$\sigma^{7}$. Capite triangulari, apice rotundato, thorace Iongiore, marginibus lateralibus prope oculos leviter sinuatis.

Plataspis (Aphanopneuma) biloba WEsTw. Ent. Trans. IV. p. 244. Pl. 18. tig. 2. (1847).

․ Capite rotundato, subsemicirculari, thoraci fere æquilongo, narginibus lateralibus prope oculos levissime sinuatis.

Patria: Calabar. (Coll. Signorer et STARL).

2. A. sellata Sign. - Aenescente-nigra, nitida, supra remote distincteque punctulata; capite superne parce obsoleteque flavescente-consperso, regione rostri flavescente; macula transversa scutelli basali, leviter arcuata, sordide flavescente, remote nigro-punctata; anteunarum articulis duobus basalibus, rostro pedibusque testaceo-flavescentibus. \&. Long. 16, Lat. 9 mill.

․ Capite subsemicirculari, thorace subbreviore.

Heterocrates sellutus Sign. Rev. et Mag. zool. I851.p. 442. 5. Pl. 12. fig. 3.

Patria: Gabon. (Coll. Signorea').

\section{PONSILA STTAL.}

Öfv. Vet. Ak. Förh. 1858. p. 433.

Corpus latissime ovatum, supra nomnihil convexum. Caput latissimum, transversum, lobo medio toto detecto et lobis lateralibus paullo longiore. Oculi subtransversi. Ocelli inter se quam ab oculis vix longius remoti. Thorax lateribus ante medium ampliatis. Pedes mediocres.

Brachyplatydi affine genus.

1. P. Inctans StảL. - Dilute sordide flavescens, supra minus dense acervatim distincteque fusco-punctulata, subtus cum capite thoraceque ante medium leviuscula; capitis lobo medio, limbo basali, medio subinterrupto, ad ocellos dilatato et 
a regione ocellurm vittas duas obliquas, per partem exteriorem cornum maris proluctas, emittente, thoracis impressionibus transrersis anteriorihus linearibus, pectore, excepta parte dilatata prostethii, ventris disco impressionibusque linearibus lateralibus, nec non macula parva prope apjeem femorum nigrieantibus. or. Long. 6, Latt. 4 mill.

o. Capite utrimque ad oculos cormu porrecto, ohlique depresso, supra longitrorsum late sulcato, ad apicem extus profunde sinuato, parte media capitis nomnihil longiore, armato; scutello apice leviter sinuato.

Ponsile lnctans śTẢs. Öfv. Vet. Ak. Förl. 1858. p. 433.3. 1.

Patria: Calabiar. (Coll. A. Dumrx.).

Thorax ante medium inpressionibus duabus lincaribus transversis, utrimpue abbreviatis, posteriore distinctiore, anteriore medio intermpta, et praterea ante nedium ntrimque impressione obliqua instructus, lateribus medio leriter sinuatis. Scutellum retrorsum ultra medium leviter ampliatum, dein subito valde rotumbatum, basi spatio transverso subtiliter et parce punctulato, postice impressione lineari terminato, instructum, hac impressione prope latera ramulum obli(एuun antrorsum et introrsum all basin sentelli emittente.

\section{BRACHYPLATIS' BOLND.}

Vo! de ladotr. Ent. 11. p. 6:27. (15:35).

Corpus latissime ovatum, sujra nomnilil convexmm, subtus planum. Calut foliaceum, transversum, latum, alpice late rotundatum. Oculi leviter transversi. Ocelli inter se quam ab oculis paullo longius distantes. Intenna ab oculis remota. Thorax utrimque nonnihil dilatitus, antice subtruncatus, medio obtuse sinuatus, angulis anticis obtusis, haud productis.

I. B. pallipes FABR - Leviter convexa, anescente-nigra, nitida; scutello remote punctulato; capitis macula magna media inferiore, fascia antica intramarginali, medio interupta, maculisque parvis nomullis superioribus, thoracis marginibus litteralibus lincapue continua curvata antica intramarginali, utrimque oblique retrorsum ducta, scutelli limbo, limbo ventris, antemnis, rostro pedibusque pallide flavescentibus; ventris limbo nigro-maculate. ơ. ‥ Long. 4-6, Lat. 3:-5 mill. 
Cimex pallipes Fabr. Spec. Ins. II. P. 343. 26. (1781); Fabr. Lint. syst. IV. p. 89. 38. (1794).

Cimex acaroides Thuns. Nov. ins. spec. 11. p. 29. (1783). Tetyra prellipes FABR. Syst. Rhyng. P. 142. 66. (1803).

Tetyra acaroides Tiunb. Hem. rostr. ('ap. 1I. p. 6 (1822).

Thyreocoris pallines GemM. Zeitschr. I. p. 3I. 18. (1839); 11. Scir. Wanz. Ins. V. p. 15 et 31. fig. 477. (1839).

Brachypluty:" pallipes DaLL. List of ILem. 1. p. 68. 1. (1851).

Patria: Terra capensis, Calabar. (IIus. 11olm., Coll. SignoRET et STÁL).

2. B. unicolor Sign, - Sat convexa, renescente-nigra, nitida, impicta; capitis margine latud reflexo; scutello paree distincteque punctulato. $\sigma^{7}$. Long. 7 , Lat. 6 mill.

Brachelyplutys aniculur Sign. Ann. ent. Sér. 3. V'III. 1'. 920. 73. (1861).

Patria: Madagascar. (Coll. Signonet.).

Congenericis mihi cognitis multo convexior.

\section{COPTOSONL LAP.}

Ess. Him. p. 73. (183:).

Corpus latissime ovatum, supra modice convexum, subtus planiusculum vel levissime convexum. Caput sepissime parvum et deflexum. Oculi sat prominuli. Ocelli ad oculos quam inter se magis appropinquati. Antenne ad oculos insertie. Thorax marginibus lateralibus posterius sinuatis, ante sinum sapissime distincte ampliatis et foliaceis. Scutellum retrorsum nomnihil ampliatum. Pedes breviusculi.

a. Corpore remote pilosulo; capitis parte anteoculari subsemicirculari, lobis lateralibus lobo medio paullo longiorilus, totis distantibus; thorace utrimque ante angulos luterales distinctissime sinuato, ante sinum distincte dilutato, parte dilutata truncata; tibiis superne sulcatis.

1. C. Murrayi Sign. - Sordide testaceum, nitidun, subtus, excepto limbo lato indeterminato ventris, nigricans; antennis, scutello, rostro pedibusque sordide flavescentibus, scutelli 
fiscia hasali maculaque anteriore majuseula, cum fascia cohatrente et interdum retrorsum longe angusteque producta, testaceis, fascia illa laterar versus macola parva flavescente notata; thoracis disco interdum infuscato. or. ㅇ. Long. $4 \frac{1}{2}$, Isat. $4 \frac{1}{2}$ 111ill.

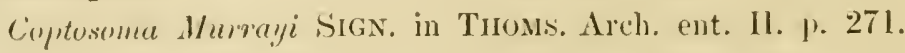
493. PI. 11. tig. 2. (1858).

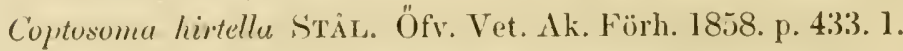
Patria: Calabar. (Coll. A. Domrn, Signorét et Śtál.).

aa. Corpore glabro; tibizs haud sulcatis.

b. Capite flacescente, maculis duabus basulibus vel parte hasali antice incisa, interdum etiam lobo medio narginibusque luteralibus nigris; vel nigno, macula parea posteriore parterne laterali ante medium Hacescentibus.

c. Thorace untice lutp et minus profunde sinuato; capite, apud marem saltem, prodncto, dilatato, lobis lateralibus anterius distincte valvantilus.

2. C. alatum Sign. - Aenescente-nigrum; thorace pone medium scutellofue remote acervatim distincte punctatis et maculis irvegularibus lavibus, pallide flavescentibus conspersis; capite, thorace ante medium, scutelli faseda basali abbreviata, medio interrupta, subcallosa, lavi, impressione lineari postice terminata, nee non limbo, parte laterali dilatata prostethii, ventris limbo angusto maculisque duabus lateralibus transversis segurntorum, antennis pedibusque flavescentibus; capitis limbo angusto, Jobo medio maculisque duabus posticis, thoracis linea obliqua utrimque laterali anteriore, linea subimpressa, punctata, transiersa ante medium, fascia subundata abbreviata vittulaque anterioribus nigris. $\sigma^{7}$. Long. 5, Lalt. $4 ! 3$ mill.

o’. Capite ante oculos valde producto et antrorsum sensim ampliato, ante medium distincte reflexo, apice bilobo, inter lobos late enarginato, lobis hrovihus, divaricatis.

Ceratocoris alcetres SIGN. in THoMs. Areh. ent. II. p. 274. 503. P1. 11. tig. 3. ( 1858 ). 
Patria: Calabar. (Coll. Signoret.).

cc. Thorce antice pone caput sat profuinde sinuato; capite ante oculos subsemicirculari, haud ampliato.

d. Jobis lateralibus capitis apice contiguis.

3. C. maculatum WEstw. - Nigrum, subænescens, distincte, subremote punctatum; capite, maculis irregularibus lavibus, subcallosis, sparsis, magnitudine numeroque variabililus, thoracis scutellique, illius etian marginibus lateralibus, parte costali detecta hemelytrorum, ventris limbo angusto maculaque laterali intramarginali ante medium segmentorum, nee non antennis, rostro pedibusque flavo-testaceis; capitis maculis duabus basilibus, postice comexis, basique lobi medii nigris. ㅇ. Long. 6, Lat. 6 mill.

Coptosoma maculata WEstw. in Hore. Cat. of Ilem. I. p. 17. (1837).

Thureocoris maculatus GERM. Zeitschr. I. 1. 66. 14. (1839). Coptosoma maculatum DALL. List of Hem. I. p. 26. 4. (1851). Patria: Madagascar. (Mus. Ilolm., Coll. Sigroret et STẢL). Scutellum fascia basali lavi, subcallosa destitutum.

4. C. nubilum Germ. - Dilute flavescens, thorace scutelloque remote subacervatim distincte nigro-punctatis, illo anterius plaga transversa levi, lituris clubus subimpressis nigris notata, instructo; capitis maculis luabus basalibus distantibus, limbo angusto basali, marginibus lateralibus basique lobi medii, pectore ventreque nigris; parte dilatata laterali prostethii, ventris limbo maculisque duabus transversis lateralibus connexis segmentorum flavescentibus. $\sigma^{7}$. ㅇ. Long. 5, Lat. $4 \frac{1}{2}$ mill.

Thyreocoris mulilus GEkM. Zeitsehr. I. p. 26. 5. (1839).

Coptosoma nutilum DALL. List of IIem. I. p. 67. 17. (1851). Patria: Sierra Leona, Guinea. (Mus. Holm. et Coll. SIGNORET); Terra capensis, sec. Germar.

Scutellum fiscia basali lavi, postice impressione terminata, destitutum.

Caput nigro-fuscum, flavo-trimaculatum, sec. Germar, l. e. 
5. C. transtersum WEsW. - Nigrum; thorate prone medium sul,tiliter, scutello paullo distinctius acervatim punctatis, ambobus maculis minutis lavibus flarescentibus conspersis; eapite, farte anteriore thoracis, fascia abbreviata, postice impressione subtili terminata, limboque seutelli, parte libera costali corii, lateribus dilatatis prostethii, ventris limbo maculisque duabus transversis lateralibus segmentorum, posteriore minore, antemnis, rustro pedibusque flavescentibus; capitis maculis duabus basalibus, marginibus lateralibus lohoyue medio, thoracis linea obliqua laterali anteriore maculispue duabus transversis anterioribus nigris. ơ q. Long. $4_{3}^{!}$, Lat. 4 mill.

Coptosome transiersa Westw. in Hops. Cat. of. Hem. I. W. 17. (18:37).

Thyreocoris transcersils GELM. Zeitschr. I. p. 27. 7. (1839).

Coptosome limaculicullis STÁL. Öf. Vet. Ak. Förh. 1858. 1. 4.3.3. 2.

Patria: Calabar, Sierra Leona. (Mus. Mloln., Coll. A. DuJns, SIGNOREL Et S'TẢL.).

del. Labis laterolitms copritis totis distantibus, lolo matio pereuriente.

6. C. conspersum STÁl. - Nigrum, nitilum, thorace pone medium scutelloque remote subtiliter punctulatis; capite, exreptis lobo medio maculisque duabus basalibus, oculorum marginem internum hand tangentibus, thoracis parte dimidia anteriore, limbe laterali maculisque parvis sparsis subconfluentibus basalibus, scutelli limbo, fiascia basali abbreviata et interrupta nec non maculis parvis irregularibus sparsis, antennis, rostro, pedibus, ventris limbo maculaque elongata, suboblique longitulinali, pereurrente, laterali segmentorum flavescentibus, levihus; thorate fascia subundata abbreviata lineolatye obliqua laterali subpunctata anterioribus nigris. or. Lomer. $3 \frac{1}{2}$, Lilt. 3 mill.

Paltria: Calahar: (Coll. Stríl.) 
C. transerse subsimile, thorace antice minus profunde simnato, lobo medio eapitis perenrente et reteris distinctissimum. Thorax ante simm laferalem mechum obtuse rotumblato-ampliatus. Sentelli fascia basalis laevis, subeallosa, postiee impressione lineari continna terminatil.

7. C. nigro-punctatum S'TÄL. - Dilute flaveseens; thorace pone medium seutelloque acervatim distincte nigro-punctulatis, hujus spatio basali transverso. postice impressione lineari distincta teminato, maxulisque numeresis, imegularibus, subcallosis, levibus, eapitis lobo medio mareulisque duabus hasalibus, oculorum marginem internum land tangentibus, thoracis impressionibus anterioribus fisciaque angusta irregulari abhreviata antica, pectore rentreque punctulato nigris, hujus limbo angusto fasciolisque duabus angustis lateralibus segmentormm flavescentibus, lavihus, callosis; thoracis laterihus ante sinum distincte ampliatis, parte anpliata sulitruncata. ․ Long. 3, Lat. $2 \frac{1}{2}$ mill.

Coptosoma nigro-pmictatum S'TAL. Öf. Vet. Ak. Färll. 185.5. p. 181. 1; Öfr. Vet. Ak. Förh. 1856. 1. 54. 1.

Patria: Sierra Leona. (Mus. Holm.)

8. C. Afzelii Stal. - Dilute sordide Havescens; thorace pone medium scutelloque sat fortiter, remote, acervatim nigropunctatis, illo ante medium parce nigro-punctulato, hujus maculis parris, irregularibus, confluentibus, levilus, eallosis; capitis loho medio maculisque duibus posticis, antrorsum anguste productis, thoracis lineola obliqua laterali intramarginali anteriore, impressa, punctata, linea transversa punctata. ante melium fasciaque angusta anteriore, pectore rentreque nigris, hujus limbo angusto fasciaque laterali segmentorum, introrsum angustata et sat longe producta, flavescentilus, his fasciis nigro-punctatis. \&. Long. 4, Lat. $3 \frac{1}{2}$ mill.

Patria: Sierra Leona. (Mns. Holm.)

C. nigro-pnenctato simillimum, majus, fortius punctatum, thorace antrorsum valde angustato, medio utrimque levissime simnato, ante. sinum hand vel vix anpliato distinetissimum. Sentellum basi spatio transverso, angusto, postire linea distincte impressa terminato, palree nigro-punctato. instruetmm. 


\section{$-14-$}

hi. Camite niyro, interlum macnlis duabus albidis rel flavescentilus notato.

e. Scutelli limbo Aarescente.

f. Scutelli limbo usque ad basin flucescente.

9. C. pirtulum S'Tís. - Acuescente-nigrum, nitidum, remote punctulatum; macula magna arcuata laterali intramarginali (anpitis, apicem loborum lateralium attingente, ad oculorum marginem internum retrorsmm producta, thoracis marginibus lateralibus, linea apicali intramarginali, utrimque pone oculos flexil et ad medium marginum lateralium ductal, medio interrupta, nec non lineolis quattuor transversis ante medium in seriem transversam dispositis, interdum forte in linean continuam confluentibus, scutelli limbo, maculis duabus basalibus margineque basali ad angulos lasales, ventris margine marulaque elongata laterali oblique longitudinali segmentorum, antennis, rostro pedibusque flavescentibus, his basi fuscis; pictura flava levi. o7. Long. 4, Lat. 4 mill.

Patria: Natalia. (Coll. Signoret.)

Caput majusculum, anterius concaviusculum, foliaceum, rotumdatum, apice emarginatum, lobis lateralibus antice dlistincte coëuntibus, lobo medio longroribus, apiece rotundatis. Thorax lateribus ante medium sat dilatatis, spatio intra margines laterales flavos et partem lateralem obliquam fasciae anticae punctulato. Scutellum basi spatio transverso leviter cilloso instructum.

ff. Scutelli limbo, excepta parte anteriore, flarescente; capitis parte anteoculuri obtuse rotumlato rel subsemicirculari.

g. Capitis lobis lateraliluss apice haud contiguis, licet intershm nomihil courergentibus, lobo medio percurrente.

10. C. affine 1)ALh. - Nigrum, nitidum, subtiliter punctulatum; marculis dualus minutis loborum lateralium capitis, interdum deficientibus, thoracis marginibus lateralibus lineaque obliqua utrimque intramarginali anteriore, posterius cum marginilus lateralihns colaerente, nee non maculis duabus parvis anticis, scutelli limbo maculisque quattuor basalibus, exterioribus minimis, ventris limbo maculaque oblonga latrali segmentorum, antemis, rostro perlibusque flavescenti- 
lous, femorihus hasin rersus fuscis; linea thoracis laterali intramarginali a limbo similiter colorato lineola impressa punctata nigra separata; pictura flava levi. or. \&. Long. 4, Lat. $3 \stackrel{1}{2}$ mill.

Coptosoma affine DALL. List of Hem. I. p. 63. 万. (1851). Coptosoma sex-notatum STRL. Öfv. Vet. Ak. Fïrlh. 1853. p. 212. 1 .

Patria: Caffraria. (Mus. Holm.)

Sentellum maris linea longitudinali posteriore flaveseente notatum.

11. C. nigriceps Sign. - Modice convexum, nigrmm, subtiliter punctulatum; capite impicto; thoracis marginibus lateralibus maculisque duabus anticis, sentelli limbo parteque tertia laterali calli transversi basalis, ventris limbo maculaque oblonga laterali segmentorum, antennis, rostro pedibusque flavescentibus; femoribus, apice excepto, nigricantibus; thorace ante medium laviusculo, lateribus intra marginem punctulatis; pictura flava lievi. ơ. Long. $3 \frac{1}{3}$, Lat. $3 \frac{1}{3}$ mill.

Coptosoma nigriceps Sign. in Thoms. Arch. ent. II. p. 272. 496. (1858).

Patria: Calabar. (Coll. Signoret et ŚtäL.)

Precedenti valule affine.

12. C. marginellum DALL.-Modice convexum, nigrum, subtiliter punctulatum; macula ovali loborum lateralium capitis, thoracis marginibus lateralibus, scutelli limbo, ventris limbo maculaque laterali ovali segmentorum, antennis, rostro pedibusque flavescentibus; femoribus ultra medium piceis; thorace ante medium leviusculo, lateribus intra limbum flavum punctulatis; scutello basi leviter calloso; pictura flava levi. o'. \&. Long. $2 !-3 \frac{1}{3}$, Lat. 2-3 mill.

Var. a. - Thorace apice, scutello basi maculis flavescentibus destitutis.

Coptosoma limbatellum STÂL. Öfv. Vet. Ak. Förh. 1853. p. 212. 3. 
Var. b. - Thoraes apies maculis dualus parvis Haveseentihus notato, scutello basi immaculato.

Coptosome cimendurtum S'Tat. Öfr. Tet. Ak. Förh. 185:3. 1. 212.4 .

lan. a. - Thorace apice scutelloque hasi maculis duabus parvis Harescentilus notatis.

Ci.jposoma marqunellum 1)ALL. List of Hem. I. 1. 64. 9. (1851).

Patria: Caffraria. (Mus. Holm.); retr. l. Calabar. (Coll. Signoret et stads), Calfraria. (Mus. IIolm.)

Pracedentibns maxime aftine, minus.

13. C. Oculator Rescir: et Farra. - Modice conrexum, anescente-nigrum, nitidum, remote subtiliterque functulatum; (a) itis macula utrimque laterali media al oculos, thoracis marginilus lateralibus lineaque untata intramarginali antica, subtrinteruptil, scutelli limbo angusto, macula laterali calli halsalis margineque basali ad angulos basales, ventris limbo maculaque parva laterali segmentorum, antennis, rostro pedibustgue flavescentibus; femoribus, apice excepto, nigricantihus. q. Long. 33 , Lat. 3 mill.

Coptusomu oculator Reiche et Famis. Toy. en. Abyss. Ent. 1. 437 . I. (1848).

Patria: Aligsinia. (Coll. Signoret.)

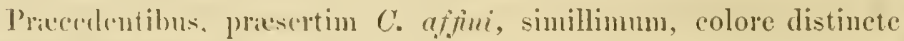
ancsecente presertiun differt.

14. C. bisignalım STAL. - Parum consexum, nigrum, totum distincte densisimeque punctulatum; capite impicto; thoracis matrginilus lateralilus vix sinuatis maculisque duabus apicalibus parvis, scutelli limbo maculisque duabus parris calli obsoleti bisalis, rentris limbo maculaque parra laterali segmentorum flaresentibus; antemis pedihusque flaro-testaceis, femorihus piceis; pietura Hava punctulata. O. Long. 4. Latt. $3 !$ mill.

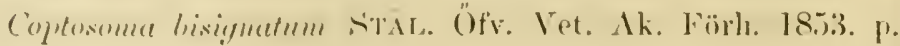
닐. 으. 


\section{Patria: Caffrirria. (Mus. Holm.)}

Pracedentibus simile, minus conrexum, densins ot distinctius punctatum, pietura flava haud levigatis.

\section{gg. Capitis lobis laterulilus antice contiguis.}

15. C. inchusum s'TAL. Modice convexum, nigrum, nitidum, obsolete punctulatum; capitis lohis lateralibus, margine ipso parteque angusta interiore exeeptis, thoracis limbis lateralihus maculisque quattuor anticis, scutelli limbo matulaque laterali calli basalis, rentris limbr lineaque longitudinali laterali segmentorum, antennis, rostro pedibusque flavescentibus; femoribus hasin versus piceis; pictura flara lavi. $\sigma$. Long. $3 \frac{1}{3}$, Latt. 3 mill.

Patria: Caffiraria (Mus. Holm.)

Varietati e ( $\because$ marginelli simillimum. Conput obtusiuscule rotundatum, anterins leviter reflexun, lobis lateralibus antice contignis. Thorax ante medium intra limbos laterales distinctius punctatus.

ee. Sutelli limbo concolore, nigro.

16. C. costale S'TAL. - Parum convexum, nigrum, nitidum, dense distincteque punctulatum; costa limboque angusto ventris flavescentibus; antennis pedibusque piceris. ơ. Long. 3! Lat. 3 mill.

Coptosoma costale S'TAL. Öfr. Vet: Ak. Förh. 1853. p. 212.5. Patria: Caffraria (Mus. Holm.)

C. Globo proximum, minns convexum. Caput, apud marem saltem, productum, apice trmeatmm, marginibus leviter reflexis, lateralibus subparallelis, angulis apicalibus subrectis, parte anteoculari duplo latiore quam longiore. Thorax marginibus lateralibus pone medium vix sinuatis. Scutellum basi callo transverso destitutum.

\section{PROB ENOPS WHITE.}

Entomologist. XXY. p. 406. (1842).

Corpus late ovale, supra subtusque modice convexum. Caput hand dilatatum, subtriangulare, lobis æque longis, lateralibus acutis. Rostrum ultra medium ventris extensum. Antennæ longæ, articulo primo capitis apicem paullo superante. Thorax margi- 
natus, marginibus lateralibus leviter sinuatis, haud dilatatis, disco gibboso. Pedes longi, graciles, tibiis supra sulcatis.

1. P. Dromedarius White. - Niger, subopacus, subtilissime alutaceus; thoracis parte gibba antrorsum valde producta; antennis, rostro pedibusque fusco-piceis, illarum articulo ultimo, basi excepta, flarescente. $\sigma^{7}$. Long. 8, Lat. 6 mill.

Probcenops Dromedarius WHITE. Entomol. XXV. p. 406. (1842); DALl. List. of Hem. I. p. 68. 1. (1851).

Patria: (alabar. (Coll. A. I)OHRN et Mignonet.)

\section{Fam. CYJNIDA STIL.}

Caput ilypeatum. Antennæ articulis quattuor vel quinque compositæ, sub marginibus lateralibus capitis inserta. Rostrum quadriarticulatum, prope labrum et apicem capitis insertum. Scutellum variabile, mediocre rel maximum. Segmentum ventris primum brevissimum, occultum. Pedes plus minus fossorii et spinulosi.

\section{Conspectus subfamiliarum.}

I. Femoribus compressis; tibiis spinosis, anticis plus minus compressis; tarsis gracilibus, filiformibus. - Cýluida STÁL.

II. Femoribus, saltem anterioribus, teretibus, subfusiformibus, tibiis parce et breviter spinulosis. anticis haud compressis; tarsis rrassiusculis, articulo secundo graciliore. - Sehirice STÁL.

\section{Subf. CYINIDA NंTÁL. \\ ('onspectus generum.}

1 (2). Scutello brevi, subrequilatero. - Cycluus FABR.

2 (1). Scutello longiore quam latiore.

3 (4). Capitis margine ante oculos dilatato et ultra horum partem exteriorem producto; oculis in capite profunde immersis; scutello apice lato. - Hiverus A. et S.

4 (3). Oculis in capite leviter immersis, hujus margine ante oculos haud vel leviter ampliato; s'utello apice angusto. 
5) (6). Corporis marginibus pilis vel setis sat numerosis ciliatis; capite intra marginem anticum spinulis vel setis brevibus rigidis sxpissime instructo. - Aethus I)ALL.

6 (5). Corporis marginibus pilis raris ciliatis; capite intra marginem anticum spinulis destituto. - Macroscytus FIEB.

\section{CYDNUS FABR.}

Syst. Rhyng. p. 184. (1803).

Brachypelta A. et S. Hist. des Hém. p. 89. (1813).

Corpus ovale. Caput productum, apice semicirculariter rotundatum et medio leviter emarginatum, lobis lateralibus lobo medio longioribus, apice contiguis, marginibus reflexis, remote ciliatis; bucculis sat elevatis, postice quam antice altioribus. Rostrum articulo primo buceulas postice haud superante. Antennæ quinquearticulatæ, articulo primo capitis apicem hand attingente. Thorax marginibus lateralibus ciliatis. Scutellum latius quam longius, apice angusto; frenis fere ad apicem seutelli extensis. Hemelytra margine costali remote ciliato, margine apicali undato. Prosternum longitrorsum excavatum. Pedes validi, tibiis spinosis, anticis compressis, margine superiore spinoso-pectinato.

1. C. aterrimus Forst. - Niger, subnitidus, dense distincteque punctulatus; membrana albido-lıyalina, basi niggo-marginata ; thorace apud marem anterius intruso et medio transversim leviter elevato. $\sigma^{7}$. ․ Long. $9 \frac{1}{2}-13$, Lat. 5-6 mill.

Cimex atervimus Fonst. Nov. spec. ins. p. 71. (1771).

Cimex tristis Farr. Syst. ent. p. 716. 97. (1775).

Cydnus tristis FABR. Syst. Rhyng. p. 185. 7. (1803); HaHN. Wanz. Ins. I. p. 161. fig. 83. (1831).

Brachypelta tristis A. et S. Hist. des Hém. p. 90. 1. (1843).

Cydnus aterrimus DALL. List of Hem. I. p. 121. I. (1851).

Patria: Terra capensis. (Mus. Holm. et Coll. STÅL); Tunis, Europa meridionalis, Bengalia Asiæ. (Mus. Holm.). 


\section{HIVRLS A. ut $S$.}

Hist. des Hém. p. 88. (1843).

Corpus latissime oratum, suborbieulare, convexum. Caput obtuse rotundatum, sat dense ciliatum, lobis lateralibus lobo medio paullo longroribus et apice ipso contiguis, marginibus lateralibus ante oculos dilatatis et hos includentibus; lucculis lerissime elevatis. Antennæ quinquearticulatie, breves, articulo primo capitis apicem hand attingente. Thorax setis dense ciliatus. Scutellum longius quam latius, apice latiusculum, frenis nonnihil ultra medium scutelli extensis. Corium scutello vix longius, angulo apicali exteriore olitusiusculo, margine costali ciliato, apicali recto. P'rosternum impressum. Pedes validi, tibiis spinosis, anticis modice compressis, margine horum superiore remote spinoso-pectinato.

1. II. torridus ER. - Niger, subnitidus, dense distincteque punctulatus, thoracis disio anterius leviusculo; membrana fusca, apice pallidiore; antennis, rostro tarsisque dilute piceis. \&. Long. 8, Lat. 6 mill.

Cydnus torridus Er. Proiser\%. 1842. 1. 12. 219; knt. Zeit. XX. 1. 86. 219. (1859).

Hiverus hirtus $\Lambda$. ".t $\rightarrow$. Hist. les Hém. 1. 89. (1843); DALI. List of Hem. I. 1. 124. 1. (1851).

Patria: Senegallia. (('oll. Sigxoret et ŚTAl.)

\section{ATHLS 1)ALL.}

list of II I. In. I p. 110. (15:51).

Cydnus Fink. Fur. Hem. p. 83 at 363. (1861).

Corpus ovale vol ovatum, leviter convexum, marginibus, saltem vel prasertim capitis, pilis vel setis ciliatis. Caput apice rotundatum, lobis aefue longis; lurculis percurrentibus, leviter elevatis. Rostrum articulo primo hucenlas postice haud superante. Antennæ quinquearticulatx, sæpissime breviuscule et articulis apicalibus subfusiformibus instructer. Sontellum triangulare. longuss quam latius. frenis fere ad apirem extensis. 
Corium scutello longius, margine apicali recto. Prosternum longitrorsum impressum. Pelles mediocres, femoribus parce setosis, tibiis spinosissimis, anticis valde compressis, margine superiore spinosn-pectinato.

a. Caprite impunctato, lolo medio upice haned angustato, lobis lateralibus ibidem haud convergentibus.

b. Conpore purvo; antemis articulis tribus ultimis breviter fusiformibus, ter longioribus quum crussiorilus.

I. A. Iepiolus StÅL. - Subovatus, piceus, nitidus, articulis duobus basalibus antennarum, rostro, pedibus hemelytrisque dilutioribus, his disco infuscatis; limbo basali thoracis sordide flavescente; membrana sordide lyyalina, abdominis apicem multo superante. $\sigma$. Long. 4, Lat. 23 mill.

Aethus lepidus Stál. Öf. Vet. Ak. Förh. 1853. p. 215.6. Patria: Caffiraria. (Mus. Holm.)

Statura fere A. flavicomis. Margines capitis, laterales thoracis et costalis eorii pilis sat lougis et numerosis ciliati. Capnt obtusiuscule rotundatnm, lieve, intra marginem anticum serie spimularum armatum, margine antico subreflexo. Thorax disco ante medium nomilil impressus, lateribus at pone medium parce punctulatus, basi lavis, antice serie intramarginali punctulorum instructus. Scutellum remote distincteque punctulatum, apice lieve et subimpressum. Hemelytra remote distiucterue punctulata.

2. A. Iantipennis STAL. - Subovatus, dilute piceus, antennis fuscescentibus, articulis duobus basalibus, rostro, limbo basali thoracis, hemelytris pedibusque pallide subpiceo- flavescentibus; membrana vitrea, abdominis apicem multo superante. ․ Long. $3 \frac{2}{3}$, Lat. 2 mill.

Cydnus (Aethus) lautipennis STÅL. Öfr. Vet. Ak. Förh. 1858. p. 312.6 .

Patria: Territorium fluvii Kuisip Africa meridionalis occidentalis. (Mus. Holm.)

Pracedenti maxime affinis, exceptis coloribus vix differt nisi thoracis impressione deficiente magnitudineque minore.

3. A. cruralis STÅL. - Ovalis, nitidus, nigro-piceus; antennarum articulis duobus basalibus, rostro, tibiis tarsisque pallide 
piceo-flavescentibus; membrana subvitrea, ad medimm marginis basalis macula parva fusca notata, abtominis apicem vix superante. ․ Long. $3 \frac{2}{3}$, Lat. 2 mill.

Cydun: eruralis șíl. Öfr. Tet. Ak. Förh. 1856, ґ. 194. 1. Patria: Terra capensis. (Mus. Molm.)

Pracedentibus paullo angustior, pilis marginalibus capitis et prasertim thoracis coriique minus mumerosis. Caput subsemicirculare, margine antico pilis spimulisque sat dense instructo. Thorax levis, medio spatio brevi transverso remote punctulato instructus, marginibus lateralibus pilis sex rel octo ciliatis. Scutellum parce distineteque punctatum, apice subimpresso et subdeflexo. Hemelytra remote punctulata, margine costali pilis quinque vel sex ante medium ciliato.

bb. Corpore maximo vel majusculo; antennis longioribus, articulis tribus ultimis elongatis.

4. A. tartareus STÁL. - Ovalis, nigro-piceus, nitichus; antennis rostroque fusco-piceis; tarsis flaro-piceis; tlorace antice prope marginem, lateribus et pone medium remote distincteque punctato, parte basali lavi. $\sigma^{7}$. Long. 13, Lat. $7 \frac{1}{2}$ mill. Aethus (?) tartareus S'TÁL. Öfv. Vet. Ak. Förh. 1853. p. 214. 1 .

\section{Patria: Caffraria. (Mns. Molm.)}

Inter maximas species familiae mumerandus. C'aput obtusum, setis ciliatum, diseo ante mediun etiam setis dhabus erectis instructmu, intra maloinem anticum angustissime subreflexum spunulis armatum? Antenuce articulis a scoundo longitudine sensim crescentibus, (ultimo in exemplo descripto mutilato). "Thorax ante medium leviter depressus, marginibus lateralibus setis compluribus ciliatis. Scutellum remote distincteque punctatum, apice leve et leviter impressum. Henclytra quam seutellum densius et subtilius punctata, margine costali ante nedium pilis sex rel octo instructo. Membrana obscure vinacea. Ventris latera dense et distincte punctata. Jedes validi, tibiis anticis sat latis, posterioribus nomihil compressis, spinosissimis.

5. A. rufirostris Siál. - Subovatus, nigro-piceus; antennis rostroque dilute piceis; thorace prope marginem anticum, ad latera et medio in seriem transversam diffusam parce distincteque punctulato; scutello latera versus remote punctato; hemelytris remote distincteque punctulatis, membrana sordide vinacea. o. Long. 10, Lat. 5 mill. 
Aethus rufirostrum SIGN. Ann. ent. Sér. 3. VIII. p. 923. 81. (1861).

Patria: Madagascar. (Coll. SignoRetr.)

Exemplum typicum Sigxoreti pessime conservatum examinavi. Pili vel setie marginales corporis ommes desunt, sed, si ab impressionibus setiferis judicare liceat, parmm numerosi. A. tartareo dimidio minor, tibiis posticis gracilioribus.

aa. Capite punctato, apice levissime emarginato, lobo medio apice angustato, lobis lateralibns ibidem nonnilil convergentibus; margine costali corii nec elevato, nec reflexo, linea impressa intracostali mulla.

6. A. perosus STẢL. - Ovalis vel ovatus, nigro-piceus; antennis fusco-piceis, articulis apicalibus dilutioribus. o?. ㅇ. Long. $5 \frac{1}{2}-6$, Lat. $3-3 \frac{1}{2}$ mill.

Aethus inclicus Dall. List of Ilem. I. p. I14. 5. (185I). sec. Mus. Brit.

Aethus perosus STẢL. Öfv. Vet. Ak. Förl. 1853. p. 214. 2. Aethus impressicollis Sign. Ann. ent. Sér. 3. VIII. p. 923.

82. (1861).

Patria: Caffraria. (Mus. IIolm.); Madagascar. (Coll. SigNoRET.); India orientalis et Java. (Mus. Holm.)

Caput subobtuse rotundatum, raro subsemicirculare, distiucte punetatum, basi loboque medio lievigatis, margine leviter reflexo, remote piloso (et spinnloso?). Intenna breviuscula, articulis tribus ultimis nonnihil incrassatis, secundo tertio paullo breviore. Thorax convexus, apud marem ante medium impressus, sat dense et distincte punctatus, basi spatioque transverso ante medium lavigatis, marginibus lateralibus remote pilosis. Scutellum modice dense punctatum. Hemelytra distincte punctata; membrana sordicle hyalina vel levissime infuscata. Tentris latera parce punctata. Tarsi Havo-picei.

\section{MACROSCYTUS FIEB.}

Eur. Hem. p. 83 et 362. (1861).

Corpus ovale, depressum, pilis raris vel rarissimis ciliatum. Caput planum, semicirculare vel obtusiuscule rotundatum, lobis æque longis; bucculis percurrentibus. Antennæ quinquearticulatæ, mediocres, filiformes, articulis secundo et tertio subæqualibus, basali nonnihil longioribus. Scutellum triangulare, longius quam 
latius, frenis fere ad apicem continuatis. Coriun scutello longius, angulo apicali exteriore acuto. Prosternum longitrorsum impressum. Pedes mediocres, tibiis grasilibus, anticis nonnihil compressis, margine superiore spinis remotis pectinato, femoribus posticis iuterdum subtus prope apicem spina vel dente armatis.

letho maxime affine genus, corpore remotissime ciliato, capitis margine spinulis semper destituto et prasertim habitu diversum; cum letho forte optime conjungitur.

a. Corio intra maryinem custalem lavigatum linea subtili impressa destituto, margine apicali prope angulum exteriorem sat distincte sinuato, hoe anyulo nonnithil prodncto.

1. II. madagascariensis SIGN. - Ovalis, nigro-piceus; antennis, rostro, margine posteriore thoracis latera versus, margine costali corii tarsisque dilute ficeis; membrama sordide hyalina. ơ. Long. 12, Lat. 6 mill.

ऽ. Femoribus posticis subtus prope apicen denticulo armatis.

Aethus Madagascariensis SIGN. Ann. ent. Sér. 3. VIII. p. 922. 80. (1861).

Patria: Midagascar. (Coll. Signoret.)

Maxima milhi cognita species generis. Caput impunctatum, marginc apieali leviter reflexo, ciliis mullis (vel in excmplo descripto deficientibus?). Thorax medio transversim levissime depressus, ibidem parec distineteque punctatns, marginibus lateralibus setis et impressionibus punctiformibus destitutis. Sentellum remote subfortiter punctatum. Ilemelytra dense et distincte pmuctulata, margine costali leviusculo, incrissato, setis rel inuressionibus punctiformilus destituto, linea impressa intramarginali nulla. Venter versus margines laterales sat dense distineteque punctulatus.

aa. Coriu linea snbtili impressa intracostali instructo, margine costali, uti videtur, subelevato vel sulweftero, margine apicali prope angulum e.cteriorem vix vel levissime sinuato.

b. Corio linea subtili impressa intracostali subpercurrente, posterius interdum absolctiore, instructo, margine costali fere toto subreflexo.

c. Margine costali impressionibus punctiformibus setiferis destituto. 
2. I. parcimonius SIGN. - Ovalis, nigro-piceus; antennis fuscopiceis; rostro pedibusque dilutioribus; tarsis flavo-piceis. \&. Long. 6, Lat. $3 \frac{1}{2}$ mill.

Oethus parcimonius Sign. in THONs. Arch. ent. II. p. 278. 51 . (1858).

Patria: (alabar. (Coll. Signorer.); Sierra Leona. (Mus. Holm.)

Caput paree punctulatum, margine apicali imo leviter reflexo, setis nommllis instructo. Thorax antice intra marginem pone capitis partem intraocularem serie areuata junctorum subacervatorum distinctoruu instructus, latera versus et medio remote punctulatus, marginibus lateralibus impressionibus punctiformibus setiferis quinque instructis. Scutellum remote distincte punctulatum. Henelytra subremote punctulata, margine costali parce punctulato, impressionibus punctiformibus setiferis destituto. Ventris latera subtiliter rugulosa.

3. I. hirtipes P. 13. - Ovalis, piceus, antennis, rostro pedibusque dilutioribus. $\sigma^{7}$. 우. Long. $4 \frac{1}{3}-5$, Lat. $2 !-2 ! \frac{1}{4}$ mill.

Pentatoma hirtipes 1'. 13. Ins. p. I14. Hém. pl. 8, fig. 9. (1805). sec. ex. typ.

(lethus glaber Sign. in Thoss. Arch. ent. II. p. 279. 513. (1858).

I'ur. l. - Dilute piceus.

Patria: Calabar. (Coll. SigNoret.); Sierra Leona. (Mus. Holm. et Coll. STAL.)

Preeclenti valde affinis, vix differt nisi magnitudine multo minore, statura paullo angustiore thoracisque punctis medis paucioribus, in seriem irregnlarem ordinatis. Puncta thoracis anteriora, in seriem arcuatam aggregata, apud marem quam apud feminam minus mumerosa. Femora postica maris inemia.

cc. Corii margine costali impressionibus setiferis punctiformibus duabus instructo.

4. 11. piciuns STẢL. - Oralis, convexiusçulus, dilute piceus, antennis pedibusque pallidioribus. $\sigma^{7}$. 우. Long. $6-6 \frac{1}{2}$, Lat. $3-3 \frac{1}{2}$ mill.

Aethus picinus STÅL. Öfv. Vet. Ak. Förh. 1853. p. 215. 5. Patria: Caffraria. (Mus. Holm.) 
A reliquis milii cognitis congenericis differt margine costali hemelytrorum pone medium paullo magis curvato. Caput lave, margine imo apicali levissime subreflexo, parce setoso. Thorax convexiusculus, lateribus, medio et prope apicem paree punctulatus, marginibus laterilibus impressionibus setiferis sex instructis. Scutellum remote distincteque punctulatum. Hemelytra remote punctulata, margine costali ante medium impressionibus punctiformibus setiferis duabus instructo; membrana sordide liyalina.

ccc. Corii margine costali impressionibus punctiformibus setiferis tribus instructo.

5. I. opacus STÄL. - Depressus, nigro-piceus; antennis, rostro pedibusque dilute piceis; tarsis flavo-piceis. ․ Long. 8, Lat. 4 mill.

Aethus opacus Siral. Öfv. Tet. Ak. Förh. 1853. 1. 214. 3. Patria: Caffraria. (Mus. Holm.)

Statura fere .\%. brunnei et inter species mili cognitas eidem maxime affinis. Caput impmetatum, margine apicali levissime reflexo, parec setoso. Thorax basi ipsa dilutius piceus, anterius intra marginem pone capitis partem intraocularem acervatim sat dense punctulatus, lateribus et pone medimm mimus dense punctulatus, basi laevigatus, marginibus lateralibus impressionibus punctiformibus setiferis octo vel novem instructis. Scutellum sat dense distincteque pmetulatmm, basi lievigatmm. Hemelytra sat demse pmetulata, margine costali in parte tertia antriore inpressionibus setiferis tribus instructo: membrama sordide hyalina.

bb. Corio linea subtili impressa intracostali pone medium abbreviata instructo, margine costati ante medium subreflexo.

6. I. difficilis STíL. - Ovalis, nigro-piceus; antennis fusco-piceis, articulis trihus ultimis apice tarsisque Havo-piceis. ơ. Long. 6!! L, Lilt. 3! mill.

Aethus difficilis STAt. ()fiv. Yet. Ak. Fürh. 185̆3. p. 214.4. Patria: Caffraria. (Mus. Molm.)

Caput pares punctatum, maregine imo apicali levissime reflexo, setis nommllis imstructo. Thorax comvexiusculns, antice intra marginem, lateribus at medio paree pmuctulatus, punctis disci apud marem pameioribus quam apud feminam, marginibus lateralibus impressionilus setiferis quinque vel septem insturuetis. Sentellum remote distincteque pmetatum. II memelytu remote, ynam scntellum densins, punctulata, area exteriore densius punctata, margine eostali impressione setifera unica prope basin instructo; membrana sordide hyalina. 


\section{Subt. SEHIRIDA STẢL.}

Conspectus generum.

I (6). Scutello mediocri, hemelytra libera relinquente.

2 (5). Scutello apice angusto; capite mediocri.

3 (4). Lobis lateralibus capitis apice contiguis, lobo medio longioribus; articulo primo antennarum capitis apicem paullo superante, articulo secundo tertio longiore; oculis modice prominulis; prosterno haud canaliculato. - Dismegistus $\mathrm{A}$. et $\mathrm{S}$.

4 (3). Lobis capitis aque longis; articulo primo antennarum (apitis apicem haud superante, articulo secundo tertio breviore vel subsquali; oculis sat prominulis; prosterno canaliculato. - Legnotus ŚCHJÖDTr.

5 (2). Scutello apicem versus capiteque latis. - Amaurocoris ŚTÀL.

6 (1). Scutello maximo, hemelytra fere tota tegente. - Strombosoma A. et S.

\section{DISMEGISTUS $\Lambda$. et $\$$.}

Hist. des Húm. p. 99. (1843).

Corpus ovale, supra parum convexum, nudum. Caput deflexum, parviusculum, lobis lateralibus lobo medio longioribus et ante hune contiguis; bucculis modice elevatis. Oculi modice prominuli. Antennæ quinquearticulatie, articulo primo capitis apicem paullo superante, articulo secundo tertio nonnihil longiore. Rostrum articulo primo bucculas haud superante. Thorax marginibus lateralibus rotundatis, leviter explanatis. Scutellum mediocre, triangulare, apice angustum, frenis longe versus apicem extensis. Prosternum haud canaliculatum. Pedes longiusculi, tibiis breviter et parce spinulosis, anticis subtriquetris.

Sehiro affine genus.

1. D. binotatus Westw. - Niger, nitidus, subtus lævis, thorace disco parce subtiliterque, scutello hemelytrisque densius et distinctius punctulatis; thorace, corio, ventris limbis latis 
lateralibus discoque nec non parte laterali prostethii parteque postica metastethii sanguineis; rostro, macula magna transversa trapezoidea thoracis, marginem anticum attingente, clavo maculaque rotundata discoidali corii nigris. ơ. \&. Long. 811, Lait. 5-7! mill.

Pentatoma binotuta Westw. in Hope. Cat. of Hem. I. p. 34. (1837).

Cydnus sanguinolentus GERM. in SILB. Rer. ent. Y. p. 184. 130. (1837); II. Sch. Wanz. Ins. IX. p. 346. fig. I005. (1853). Dismegistus Linotatus IDAL. List. of Hem. I. p. I30. 3. (1851). Patria: Terra capensis, Mozambique. (Mus. Holm. et Coll. STTÀL).

2. 11. costalis ReIche. - Niger, nitidus; limbis latis lateralibus et basali thoracis, limbo omni corii, lateribus prostethii, limbo maculisque discoidalibus ventris, his interkum in unam magnam confluentibus, sanguineis; thorace pone medium remote distincteque, apice subtiliter punctulato, marginibus lateralibus anterius latiuscule leviterque reflexis, impressione intramarginali laterali anteriore lievi; scutello hemelytrisque minus dense distincte punctulatis. f. Long. 11, Lat. 7 mill.

7)ismrgistus costulis REICHE et FAIRM. Voy. en Abyss. Lntom. p. 438. pl. 29. fig. 1. (I850). excl. syn. Axroti.

Cydurs abyssinicus H. SCH. Wanz. Ins. IX. p. 345. tig. 1004. (1853).

Patria: Abysinia. (Mus. Holnu. et Coll. STtâL.)

Statura I). binotati.

3. D. fimbriatus Tutwr.-- Niger vel anescente-niger, supra plus minus dense distincteque punctulatus, spatio transverso anteriore thoracis levi; thorace marginibus lateralibus minus explanatis, anterius intra margines laterales impressione punctata instructo; limbis lateralibus et basali thoracis, limbo costali corii retrorsum angustato limboque lato laterali prostethii sanguineis vel sanguineo-flavestentibus. $\sigma^{7}$. f. Long. $8-9$, Jat. 5- $5 !$ mill. 
Vur. a. Densius ot subtilius punctatus, corii marginibus interiore et apicali, metastethio postice rentreque toto concoInribus, nigris.

Var. b. Corii margine angusto interiore et macula parra ad marginem apicalem limboque abdominis sanguineis.

$V a r$. c. Corii marginibus interiore et apicali, limbo postico metastethii, ventris limbo discoque sanguineis.

Cimex fimliriatus Thunb. Nor. spec. ins. I. p. 47. Tab. 2. fig. 61. (1783).

Alydus fimbriatus Thunb. Hem. rostr. cap. III. p. 3. (1822).

Cydnus cirenmeinctus WaHx. Wan\%. Ins. II. p. 115. fig. 195. (18:34).

Jimegistus cirenneinctus A. et $\rightarrow$. Hlist. des Hém. p. 99. 1. (I843).

Patria: Terra (apensis: (Mus. Holu., Coll. Signonet et ŚTÁl.)

D. abyssinico minor, thoracis marginibus lateralibus minus explanatis et minus rotmulatis, impressione laterali intramareriuali anteriore punctata differt.

\section{LEGNOTUS SCHJODTE.}

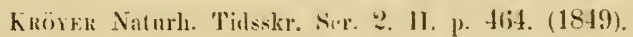

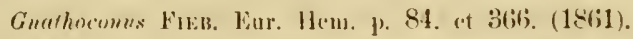

Corpus ovale, supra leviter convexum. Caput parvum, deflexum, lobis subaqualibus, medio percurrente. Antenna quinquearticulatre, articulo primo capitis apicem hand superante, articulo secundo tertio breviore vel subrquali. Oculi valde prominuli. Thorax usque ad margines laterales transversim convexus, his subtiliter "arinato-subelevatis. Scutellum triangulare, apice angustum. Prostermum canaliculatmm. Pedes mediocres, parce spinulosi.

Sehiro*) maxime aftine genus, oculis valde prominulis differt.

1. L. tibialis S'TȦL. - Nigro-piceus, nitidus; hemelytris ventreque fusco-piceis; antennarum articulis tribns basalibus,

7) Obs. Selims cinclus (= Pentrtoma cincta P. B.), cujus exemplum typicum ramminavi, idem est ar Sehinus ligatus SAY, species amerientua, nee a fricana. 
thoracis marginibus imis lateralibus limboque basali, scntelli apice, maculis marginalibus pone medium rentris tarsisque dilute testaceo-flavescentibus, his basi apiceque nigro-piceis; marula levigata ante medium corii albida; membrana sordide hyalina. ․ Long. 5, Lat. 3 mill.

Strachia tibialis STÅL. Öf. Vet. Ak. Förh. 1853. p. 221. 2. Patria: Caffraria, Nubia. (Mus. Ilolm. et Coll. S'TÁL.)

Caput punctulatum, lobis lateralibus rugulosis, marginibus imis leviter reflexis. Antennie articulo sceundo tertio paullo breviore. Thorax antice et pone medium sat distincte et minus dense pumctatus, spatio transverso ante medium basique levigatis, marginibus lateralibus nomihil rotumdatis. Scutellum et hemelytra distincte punctulata, horum macula lievi. Subtus subtiliter punctulatus.

2. L. melaleuens Thuvi. - Aenescente-niger, nitidus, sat dense distincteque punctulatus, thoracis basi spatioque transverso medio levigatis; antennis fusco-piceis, harum articulis tribus basalibus, thoracis marginibus inis lateralibus angulisque posticis, hemelytris pedibusque pallide piceo-flavescentibus; hemelytris nigro-punctulatis, disco infuscatis et ante medium marula parva pallida notatis; membrana grisescente. ㅇ. Long. 4, Lat. $2 \frac{1}{2}$ mill.

Cimer melalencus Tünis. Nov. spec. ins. 11. p. 50. (1783). Aligdus melateucus Тнгх13. Hem. rostr. cap. III. 1. 3. (1822). Sehirus melaleacas 1)ALL. List of Hem. I. p. 128. 3. (185I). l'atria: Terra capensis. (Mns. Holm.)

Statura precelentis. Caput apice late rotundatum, lobis aequalibus, margine haud reflexo. Margines laterales thoracis subtilissime carinati.

STROMBOSOMA $A$. et S.

Hist. Iles Ilem. p tit. (1843).

Coppus ohovatum, valde convexum. Caput perpendiculare, transversum, apice truncatum, lobis lateralibus lobum medium includentibus, apice ipso contignis. Antennæ breves, articulo secundo brevissimo. Thorax valde convexus, anterius valde dedivis, marginibus lateralibus anticis rotundatis. Scutellum maximum, ahdomine vix angustius et apicem ejusdem attingens. 
partem rostalem anteriorem hemelytrorum liberam relinquens. Prosternum antice leviter dilatatum, sulcatum, marginibus sulci dilatatis. Tibia parce spinulosæ.

Thyreocoridi affine genus, corpore multo convexiore, scutello latiore structuraque capitis diversum.

1. S. impictum STẢL. - Nigrum, nitidulum, totum densissime distincteque punctulatum; antennis tarsisque flavo-testaceis; (apite apice leviter reflexo. $\sigma^{7}$. Long. $3 \frac{1}{4}$, Lat. 21 mill.

Corimelana impicta STẢL. Öfr. Vet. Ak. Förh. 185\%. p. 212. 1 .

Patria: Caftriaria. (Mus. Holm.)

S. unipunctatum A. et S. S. impicto maxime est affine, punctura paullo minus densa maculaque thoracis tantum differt; an varietas S. impicti? Exemplum typicum olim examinavi.

\section{AMAUROCORIS S'TÁL.}

Corpus ovale, supra convexiusculum. Caput deflexum, latum, thorace dimidio angustius, latius quam longius, apice late rotundatum, lobis aque longis; bucculis distincte elevatis. Antenne quinquearticulatie, articulo primo capitis apicem attingente, secundo tertio paullo breviore. Rostrum articulo primo bucculas postice haud superante. Sicutellum apice latiusculum; firenis nonnihil ultra medium scutelli extensis. Prosternum impressum. Pedes mediocres, tibiis parce spinulosis.

1. A. laticeps STAL. - Niger, nitidus, distincte punctulatus; antennis, rostro tarsisque dilute fusco-piceis; membrana griseo-hyalina, margine basali picescente. o $\sigma^{7}$. Long. 5. Lat. 4 mill.

Patria: Chartum Nubiæ. (Mus. Holm.)

Caput planiusculum, dense et distincte punctatum, margine imo subreflexo. Thorax minus dense distincte punctulatus, ante medium spatio transverso levigato instructus, marginibus lateralibus leviter rotundatis. Scutellum minus dense distincte punctulatum, inarginibus lateralibus rectis, haud sinuatis. Hemelytra distinete et mimus dense, disco parcius et subtilius punctulata. Subtus remote punctulatus. 
Fim. PENTATEMHIA STAL.

Caput sapissime distincte clypeatum. Antemne in latere inferiore capitis sub marginbus lateralibus inserta. Rostrum raro versus basin rapitis insertum, sapissime prope labrum versus apicem ortum. Scutellum variabile, mediocre vel maximum, apud genera, rostro versus basin capitis inserto præedita, semper mediocre et maximam partem hemelytrorum liberam relinquente. Segmentum primum rentris distinguendum.

$$
\text { Conspertus subfimiliarum. }
$$

I. Alarum venis primaria et subtensa remotis, aream medio latiorem includentibus; hamo alarum presente; scutello maximo. - Scutellerila SitiL.

II. Alarum venis primaria et subtensa sepissime appropinquatis ot parallelis, rarius nonnihil remotis; hamo alarum sepissime nullo; scutello variabile, raro tamen maximo et hemelytra tota tegente, apud genera hamo alarum predita semper mediocri vel proportionaliter parro.

1. Spiraculis segmenti basalis rentris parte postica metastethii tertis.

A. Tirsis triartirulatis.

a. Rostra varialili, longissimo vel breviusculo, coxas anticas tamen superante, articulo basali facile distingnendo, buceulis raro nonnihil breviore.

b. Rostro, articulo basali saltem, crasso, ald labrum inserto; bucculis postice conjunctis, retrorsum plus minus convergentibus. - Asopida DALL.

b6. Rostro graciliore, a labro sxpissime paullo remoto, articulo primo raro subincrassato; bucrulis parallelis, postice haud eoujunctis. Pentatomida Stat.

aa. Rostro brevissimo, roxas anticas haud superante, articulo primo hrevissimo et magna parte articuli secundi inter hucculas oceultis. - Phyllorephelislı sitín. 
13. Tarsis biarticulatis. - Acanthosomida STÅL.

2. Spiraculis segmenti basalis ventris parte postica metastethii haud tectis, lateribus segmenti illius basalis segmento secundo vix brevioribus. - Tessaratomida STí.

\section{Subf. SCUTELLERIDA STIL.}

Conspectus generum.

1 (2). Angulo apicali exteriore corii longe et acute producto; angulis posticis thoracis retrorsum productis. - Cantao A. et $S$.

2 (1). Angulo apicali exteriore corii haud longe producto.

3 (4). Antennis difformibus; marginibus lateralibus scutelli basi reflexis. - Peltophora Burm.

4 (3). Seutelli marginibus lateralibus basi haud reflexis.

5 (46). Sternis interdum sulcatis, sulci marginibus tamen haud elevatis.

6 (13). Corpore puberulo, nec sericeo.

7 (8). Antennis quadriarticulatis. - Tetrarthria Dabl.

8 (7). Antemnis quinquearticulatis.

9 (12). Corpore oblongo rel oblongo-obovato.

10 (11). Ventre distincte sulcato; tibiis supra sulcatis. - Scu- tellera Làr.

11 (10). Ventre tibiisque sulco destitutis. - Procilia STál.

12. (9). Corpore obovato; tibiis eylindricis, hand sulcatis. Plitya ŚTAL.

13 (6). Corpore supra glabro, subtus intertum puberulo, raro toto dense sericeo.

14 (45). Tibiis superne numquam bisulcatis.

15 (20). Capitis marginibus lateralibus acutiusculis, leviter reflexis.

16 (17). Capitis marginibus lateralibus rectis. - Tectocoris HAHN.

17 (16). Capitis marginibus lateralibus sinuatis.

18 (19). Articulo primo rostri bucculas postice superante; rentre modice convexo. - Poccilocoris DALL. 
19 (18). Articulo primo rostri bucculas postice haud superante; rentre, presertim lateribus, valde convexo. - Chcerocoris DALL.

20 (15). Capitis mareinibus obtusis, haud reflexis.

21 (40). Basi antennarum prostethii margine haud tecta.

22 (39). Corpore glalno. subtus interdum parce puberulo.

23 (26). Scutello abrlonine distinete angustiore, marginem totum costalem hemelytrorum liberum relinquente; capite ante oculos vistincte sinmato.

24 (25). Tibiis supra suleatis. - Calliphara GERM.

25) (24). Tibiis cylindricis, haud suleatis. - Lamprophara STÁL.

26 (23). Scutello abdomine haud vel vix angustiore.

27 (32). Antennarm artirulo tertio secundo permulto longiore.

28 (29). Thorace pone angulos literales distincte impresso, anterius apud marem impressione triangulari sat profunda instrurto, marginibus lateralibus anticis distincte sinuatịs; scutello basi transversim valde elevato. - Cosmocoris tital.

29 (28). Thorace marginilus lateralibus fere rectis rel rotundatis; scutello basi haud vel levissime elevato.

30 (31). Tibiis superne totis sulcatis; capite utrimque leviter sinuato. - Eucorysses A. et $\mathrm{S}$.

31 (30). Tibiis subcylindricis, non nisi apicem versus leviter suleatis; capitis lateribus sxpissime distincte sinuatis. Chrysocomis IIAHs.

32 (27). Antennarum articulo tertio secundo numquam phus quam dupho longiore.

33 (36). Tiliis cylindriris, supral nee planis, nee sulcatis.

34 (35). Antennarum articulo tertio secundo duplo longiore. Lamprocoris STAL.

35 (34). Antenuarum articulo sermudo longo, tertio vix breviore. - Graptophlara Stral.

36 (33). Tibiis supra planis rel suleatis.

37 (38). Thorace modice convexo, anterius leviter declivi; capitis lateribus vix vel leviter simmatis. - Graptocoris STÃL. 
38 (37). Thorace valde convexo, anterius sat declivi; capitis lateribus profunde simnatis. - Cullidea Burm.

39 (22). Corpore dense sericeo, subtomentoso. - Alphocoris GERM.

40 (21). Basi antennarum prostethii margine antico dilatato tecta.

41 (44). Scutello abdomineque rque latis.

42 (43). Angulis lateralibus thoracis acuminatis, productis. Hotea A. et S.

43 (42). Angulis lateralibus thoracis nee acmminatis, nee productis. - Sergia STẢ.

44 (41). Scutello abdomine angustiore. - Euryguster LAP.

45 (14). Tibiis superne leviter lisuleatis, inter suleos ruga instructis. - Spherecoris BuRM.

46 (5). Sternis ventreque suleatis, marginibus sulei sternorum elevatis; prostethio antice ralde dilatato.

47 (50). Thorace postice rotundato.

48 (49). Ventre ante medium leviter sulcato; scutello apice obtuso. - Coleotichus DALL.

49 (48). Tentre percurrenter, distincte lateque suleato; scutello apice spinula armato. - Elvisure SPIN.

50 (47). Thorace posterius late truncato. - Coeloglossa Germ.

\section{PROCILIA STAL.}

Corpus oblongo-obovatum, parce puberulum, supra parum, subtus admodum convexum. Caput modice deflexum, convexum, ante oculos utrimque leviter sinuatum, paullo longius quam latius. Rostrum ultra medium segmenti ventralis secundi productum. Antennæ quinquearticulatre, articulo secundo tertio multo breviore. Thorax sexangularis, ante medium transversim nomnihil impressus, angulis posticis distinctis, haud rotundatis. Scutellmm et abdomen æque lata. V'enter basi haud vel vix sulcatus, incisuris totis curvatis. Tibia supra convexiusculæ, non nisi apiceǹ versus interdum obsolete sulcatæ.

Scutellerce affine genus. 
1. P. nigrirornis SIGN. - Viridi-ænea vel viridi-cærulea, nitidula, supra cum lateribus ventris sat dense distincteque punctulata; antemnis, rapitis vitta metia pereurrente maculisque quattuor parvis, duabus mediis, duabus intraocularibus, thoracis maculis octo, tribus anterioribus minoribus, quinque posterioribus, mediis tribus majusculis, ovalibus, lateralibus parvis, scutelli maculis septem, duabus prope basin, duabus fere mediis, duabus pone medium et una ad apjecem positis nee non vitta a hasi faullo ultra medium ducta, posterius dilatata, maculis nommullis pectoris, fiscia basali utrimque abbreviata maculaque daterali segmentorum rentris, segmento hujus sexto etian in disco tarsisque nigris; gula, macula media semmentorum rentris serundi, tertii, quarti et quinti, coxis, trochanteribus fimoribusque a basi longe ultra medium croceis vel subcinubarinis; sulco laterali metastethii ab ostiis odoriferis extrursum dusto distincte areuato, articulo primo antennarum dimilio longiore; antennarum articulo secunde primo subbreviore tertio serendo plus duplo longiore. ․ Long. 22, Latt. 8 mill.

Calliphare nignicomis Sigs. Rer. et Mag. Zool. 1851. p. 438. 1. P. 12. ti.s. 1.

Patria: Ciabon. (Mus. Molm. ot Coll. Sigsuret.)

2. P. scintillans STAL. - Viridi-axneal, nitidal, plus minus cupreotincta, sufra cum lateribus ventris sat demse punctata; antemnis, capitis vitta medial freremrente maculisque duabus intracularilus, thoracis maculis octo, trilus anterioribus, quinque posterioribus. mediis trilus majoribus et ovalibus, scutelli vitta ante medium posita malenlisque septem, pectoris marculis lateralibus sex, rentris disco oblongo, utrimque profunde eroso maculisque lateralibus in seriem dispositis nee non tarsis nigris; gnla, coxis, trochanteribus femoribunque basin versus sordirle croceis; sulco laterali metastethii ab ostio odorifero extrorsum ducto brevi, vix curvato, articulo basali antennarum aquilongo; antennarum articulis 
primo et secundo æqualibus, tertio secundo plus duplo longiore. or. Long. 17, Lat. 7 mill.

Patria: Calibar. (Coll. A. DoHRN et Signoret.)

Pracedenti maxime affinis, magis nitidit, defectu macularum mediarum eapitis et presertim brevitudine sulci ostii ouloriferi distinicta.

3. P. pratoria Stås. - Obsemre cexulea, nitila, supra sat dense distincteque punctata, ventre lavi, aciculato, ad margines laterales parce obsoleteque punctulato; s'utello prope apicem macula indeterminata viridi-ieneal ornato; antennis, thoracis maculis parvis duabus anterioribus et duabus pone medium positis nec non vittula posteriore, scutelli maculis duabus minoribus ante medium, marnla transversa basali aliaque subrotundata laterali segmentorum ventris nigris; gula, coxis, trochanteribus femoribusigue a basi vix ultra medium sordide croceis; antennarum articulo secundo primo nonnihil breviore, articulo tertis secundo circiter ter longiore; sulco ostii orloriferi brevi, recto, articulo primo antennarum nonnihil longiore. or. Long. 13, Lat. $5 \frac{1}{2}$ mill.

Patria: Gabon. (Coll. Signorer.)

S. scintillanti uaxine affinis, minor, pareius nigro-maculata, capite impicto, longitudineque articulorum basalium antennarum differt.

Variat verisimiliter interdum viridi-zenea et magis nigro-picta.

\section{GRAPTOCORIS STAL.}

Corpus ovale vel oboratum, supra subtusque modice convexum. Caput antrorsum angustatum, ante oculos utrimque leviter sinuatum. Antenna quinque-articulate, mediocres vel breviusculæ, articulo secundo basali nonnihil breviore, numquam dimidio breviore, tertio secundo duplo vel saltem dimidio longiore. Rostrum articulo secundo tertio multo longiore. Thorax sexangularis, margine basali recto, scutelli basi equilato, angulis posticis distinctis, loaud rotundatis, interdum acute productis. Scutellum et abdomen æque lata. Sterna levissime sulcata. Venter lateribus valde convexum, incisuris totis curvatis, maculis seri- 
ceis nullis. Tibia superne planæ vel latissime subsulcatæ, sulco fundo plano.

Eucoryssi affine genus.

a. Corpore oborato, superne plus minus dense et distincte, subtus remotius punctato; capite nonnilil longiore quam latiore, distincte convero; rostro ultra coxas posticas paullo producto; thoracis angulis posticis in dentem acutum prominentilus; scutello thorace plus duplo longiore; incisuris ventralibus utrimque nonnihil recurvis.

b. Rostri articulo secundo apicalibus duobus ad unum vix breviore; scutello apice nee producto nee apicen abdominis superante.

1. G. Comes Fabr. - Viridi-ieneus; thoracis macula oblonga discoidali nec non limbis latis lateralibus anticis ab apice ultra medium, anterius intus subito quadratim sinuatis, scutelli macula lunata in angulis anticis, maculis duabus transversis ante medium positis, utrique interdum cum macula angulorum hasalium in arcum magnum confluente, fascia subarcuata inæquali posteriore margineque imo apicali nec non ventre sordide flavescentibus, hujus vittis duabus latis, posterius cö̈untibus, interdum in discum maximum confluentibus, maculis parris lateralibus anoque nigro-aneis. ơ. \&. Long. 17-19, Lat. 9-10 mill.

Tetyra comes Fabr. Syst. Rhyng. p. 130. 8. (1803); Schü̈dte in KRöY. Nat. Tilsskr. IV. p. 282. 3. (18t2).

Scutellera comes Germ. Zeitschr. I. p. 137. 10. (1839).

Puecilucoris (?) comes DALL. List of Ilem. 1. p. 15. 14. (1851). Patria: Guinea, Calabar. (Coll. Sigroret et Stal.)

2. (i. piuguis GisM. - Nigro-ieuescens, scutello plus minus flarotestaceo-pellucente vel in flavo-testaceum vergente; thoracis macula discoidali limbisque lateralibus anticis, ante merlium intus quadratim sinuatis, scutelli maculis duabus distantibus basalitus, maculis duabus obsoletioribus ante medium fasciaque irregnlari posteriore, nec non ventre rufescente- vel 
pallide flavescente-testaceis, hujus maculis lateralibus ad stigmata, maculis marginalibus magnitudine variabilibus nec non vittis duabus latis, in exemplis pallidioribus deficientibus, anoque nigro-æneis. $\sigma^{7}$. ․ Long. 16-19, Lat. 9-10 mill.

Scutellera pinguis Germ, in Sulub. Rev. ent. V. p. 191. 146. (1837).

Puchycoris rufilabris GERM. Leitschr. 1. 1. 88. 10. Tab. I. fig. II. (1839).

Poecilocoris (?) pinguis DALL. List of Hem. 1. p. 15. 15. (1851).

Patria: Natalia. (Mus, Holm., Coll. Sigxorel et Stil.)

$G$. Comiti valde affinis et verisimiliter ejus varietas; exceptis coloribus haud differt nisi punctura piullo lemotiore et fortiore.

bb. Rostri articulo secundo aricalibus drobus ad umum distincte breviore; scutello apice angustato et jrodncto, abdominis apicem superante.

3. G. moremmaculatus SIGN. - Oliscure æenels, tlorace scutelloque sordide flavescentibus, illius nargine antico medio, marginibus imis lateralibus anticis, maculis duabus majusculis anterioribus maculaque in angulis lateralibus, scutelli fascia basali utrinque angustata, medio subinterrupta, maculis orbicularibus duabus anterioribus et duabus fere mediis, magnitudine variabilibus, obscure xneis; rentris fasciis lateralibus sanguineis. ㅇ. Long. 20. Lalt. 10 mill.

Calliclea novemmaculata SigN. Rer. et Mag. Lool. 1851. p. 439. 2. Pl. 12. fig. 2.

Patria: Gabon. (Mus. Ilolm. et Coll. ŚIGNuRET.)

aa. Corpore oculi, sat concero, supra subtiliter et sat dense, subtus remote punctuto; capite trianyulari, aryuilatero, distincte convexo; rostro segmentum secundum ventiss subsuperante, articulo secundo apicalibus duobus ad unum subarnitongo, ultimo penultimo panllo longiore; thoracis angulis posticis haud productis; scutello thorace duplo longiore; incisuris ventris ad latera oblique retrorsum curvatis. 


\section{$-40$}

4. t. nigricollis Sigr. - Arnescente- vel subcæruleo-niger; scutello ventreque dilute flavo- rel rufo-testaceis, illius inacula magna transversa hasali, maculis quattuor mediis, intermediis duabus orbicularibus, lateralibus oblongis, margines tangentibus, nee non macula apicali, ventris disco maximo utrimque eroso anoque caruleo- vel wneo-nigris. or. Long. I3, Lat. 8 mill.

Choerocoris nigricollis SIGs. in THOMS. Arch. ent. II. p. 270. 489. Pl. 11. fig. 1. (18,5).

Patrial: Calalıar. (Mus. Molm., Coll. Signoret et Stál.)

aaa. Corpore lute ocali, minus dense, sat distincte punctato; capite leviter concero, triangulari, apice rotundato, paullo breviore quam latione; rostro coucas prosticas nomihil superante, articulo secundo apicalibus duobus ad unum nonnilit breviore; thoracis angulis posticis hued productis; scutello thorace duplo longiore; incisuris rentralibns ad lutera rectis, ibidem obsoletis.

5. A. aulieus GERM. - Capite, pectore pedibusque obscure æneis vel nigro-reneis; ventre eroceo, vittis duabus latis posterius coëuntibus marulisque parvis lateralibus pone stigmata aliisque marginalihus nigro-æneis; antemnis nigris. o’. ‥ Long. $11-$ 13, Lat. $7-8 \frac{1}{2}$ mill.

Charocoris anlicas DALL. List of Hem. 1. p. 30. 3. (1851). I ar. a. - Maculis dualus maxinis lateralibus capitis ante oculos, thorace, soutello, limlo costali hemelytrorum ante medium inaculisque nonnullis indistinctis peetoris croceis; thoracis maculis irregularibus dualus magnis anteriorilus et quattuor posticis minoribus, his interlum defieientibus, seutelli maculis duabus anticis appropinquatis, quattuor mediis in serien arenatam dispositis unaque posteriore, intertum deficiente, nee non ano femine nigro-ancis. $\sigma^{7}$. $q$.

Choerocoris personatus STAL. Öfv. Vet. Ak. Förh. 1853. p. 210. 1 .

I'ur. b. - Supra nigro-xneus, macula ntrimque laterali capitis, thoracis marginibus lateralibus anticis, vitta irregulari me- 
dia maculisque duabus transversis pone medium, quie interdum (sec. GERMar) cum vita illa in lituram cruciformem confluunt, scutelli arcu ante medium posito, cujus brachia antice in angulis scutelli dichotoma sunt, fascia angusta arcuata posteriore lineaque longitudinali media croceis, in rufescentem vergentibus.

Pachycoris aulicus Germ. in Silb. Rev. ent. V. p. 189. 141. (1837); Germ. Zeitschr. I. p. 90. 15. (1839); H. Sch. Wanz. Ins. V. p. 10. fig. 467. (1839).

Var. c. - Varietati b similis, sed maculis capitis, fascia posteriore lineaque media scutelli deficientibus; marginibus lateralibus anticis thoracis medio tantum croceis, maculis ejusdem transversis pone medium positis minimis vel oblitteratis. $\sigma^{2}$.

Pachycoris ornatus Germ. in Silis. Rev. ent. V. p. 190. 142. (1837).

I ar. d. - Supra obscure æneus, linea longitudinali irregulari discoidali scutelli crocea. $\sigma^{7}$.

Patria: Terra capensis, Natalia. (Mus. Holm. et Coll. SIGNORE'T.)

\section{CALLIDEA BURM.}

Culider Lap. Ess. Hém. p. 71. (1832).

Liby:sa DalI. List of Ilem. I. p. 20. (1851).

Corpus anguste obovatum vel oblongo-obovatum, crassum, subtus valde convexum. Caput vilde deflexum, breviusculum, crassum, convexiusculum, ante oculos utrimque sat profunde sinuatum. Antenne quinquearticulatie, articulo tertio secundo longiore. Rostrum ad vel paullo ultra coxas posticas extensum. Thorax sat convexus, anterius sat declivis, sexangularis, angulis posticis distinctis, laud rotundatis. Scutellum maximum, abdomini iequilatum. Venter lateribus valde convexus, incisuris totis curvatis. Tibiæ superne planiusculie vel sulcatæ.

a. Articulis antemarum prino et secundo fere cque longis, tertio secundo haud duplo longiore; tibiis superne distincte sulcatis. 1. C. signata FABR. - Viridi-ænea vel argenteo-cærulescens, nitida, supra cum pectore lateribusque ventris sat dense di- 
stincteque punctata, disco ventris lavigato; antennis, thoracis maculis octo, tribus anterioribus, quinque posterioribus, intermediis tribus magnis, oblongis, scutelli maculis sex transversis, per paria dispositis, vitta angusta a basi all rel ultra medium ducta apiceque nec non tarsis nigris; gula, articulo primo rostri, articulo primo antennarum fere toto, limbis lateralibus anticis thoracis, sternis, marginibus lateralibus et angustissimo antico prostethii, ventre, coxis, trochanteribus femoribusque, horum apice excepto, croceis; lineis duabus longitudinalibus capitis, pectoris maculis nonnullis, fascia laterali segmentorum secundi, tertii, quarti et quinti rentris, hujus etiam segmento basali maculaque laterali segmenti sexti nigro-caruleis; ano maculaque media fasciolarum ventris viridi-aureis vel chalybeis; segmentis ventralibus medio fusco-maculatis; margine costali hemelytrorum stramineo. o?. ㅇ. Long. 18, Lat. 8 mill.

Cimex signatus FABR. Ent. syst. IV. p. 80. 4. (1794); WolfF. Ic. cim. III. p. 91. Tab. 9. fig. 85. (1802).

Tetyra signata FABR. Syst. Rlynng. p. 129. 7. (1803).

Scutellera signatu LATR. Gen. ins. 1II. p. 112. 1. (1807); P. B. Ins. p. 2:32. Hém. Pl. 5. b. fig. 1 et 2. (1805).

Callidea signata 13tru. Handh. II. 1. p. 394. 4. (1835); H. Scri. Wanz. Ins. III. p. 98. fig. 323. (1836); GErM. Zeitschr. I. p. 119. 18. (1839).

Libyssa siguatu IALL. List of IJem. 1. P. 21. 1. (1851).

Patria: Senegal. (Mus. Ilohm., Coll. Signoret et Stal.)

aa. Articulo primo antennarum secundo longiore.

b. Tentris marginilus luterulibus immaculatis.

c. Antemis longioribus, articulo tertio secundo duplo longiore, tertio basali multo longiore.

2. C. Dregii Germ. - Plus minus obscure chalybeo-cxrulea, thorace scutelloque disco plus minus pallide purpurascentibus; antennis, tarsis, thoracis maculis tribus anterioribus et quinque posterioribus, intermediis tribus magnis, oblongis, scutelli 
maculis sex rotundatis vittaque a basi ultra medium ducta nigris; articulo primo antennarum, gula, rostri articulis primo et secundo, limbis lateralibus anticis thoracis totis, marginibus prostetliii, laterali lato, sulco ostioli odoriferi, ventre, coxis, trochanteribus femoribusque totis croceo-cinnabarinis; macula majuscula laterali transversim rhomboidea segmentorum ventris chalybeo-carulescente. $\sigma^{7}$. \&. Long. 10-15, Lat. $4-7$ mill.

§. Segmento anali apice profunde sinuato, viridi-æneo, pone medium croceo.

ㅇ. Valvulis analibus viridi-æneis.

Callidea Dregii Germ. in Silb. Rev. ent. V. p. 191. 145. (1837).

Callidea examinans White. Ent. Trans. III. p. 85. (1842). Libyssa Dregii DaLl. List. of Hem. I. p. 22. 3. (1851).

Libyssa drodecimpunctata DALL. List of Hem. I. p. 21. 2. (1851). ad partem.

Libyssa Signoreti StåL. Öfv. Vet. Ak. Förh. 18533. p. 210. 1. Callidea duodecimpunctata Schanm in PETERS Reise nach Mossamib. Ins. 35. (1862).

Patria: Natalia. (Mus. Holm.); Senegal, an recte? (Coll. SigNoRET).

Variat colore purpurascente in purpureo-flarescentem vergente, pectoreque flavo-vario.

3. c. madagaseariensis SIGN. - Distincte denseque punctata, supra sordide purpurascens, capite pectoreque purpnreo-cæruleis; antennis totis, excepta basi ipsa testacea articuli primi, tarsisque nigris; thoracis maculis tribus anterioribus et quinque posterioribus, intermediis tribus oblongis, nigro-cinctis; scutello ænescente-limbato, maculis sex annularibus vittaque obsoleta anteriore nigricantibus; prostethio croceo-limbato; ventre pedibusque croceis, macula laterali rhomboidea segmentorum illius anoque feminæ viridi-æneis; femorum apice tibiisque nigro-cæruleis. q. Long. 12, Lat. 6 mill. 
Libyssa Madagascariensis Sign. Ann. ent. Sér. 3. VIII. p. 917. 67. (1861).

Patria: Madagascar. (Coll. Signoretr.)

C. Dregii maxime affinis, vix differt nisi capite magis nutante, thorace anterius paullo magis declivi staturaque crassiore; exemplum typicum pallidım, decoloratum vel immaturmm descripsi.

cc. Antennis crassioribus et brevioribus, articulo tertio secundo haud duplo longiore, basali crquilongo vel vix longiore.

4. C. duoleciumuurtata FABR. - Distincte et sat dense punctata, disco ventris lavigato; varicolor, capite pectoreque viridiæneis; antennis tarsisque nigris; maculis thoracis tribus anterioribus et quinque posterioribus, intermediis tribus oblongis, magnis, scutelli maculis sex vittaque abbreviata anteriore nigricantibus, maculis thoracis interdum cæruleo-cinctis; articulo primo antennarum, rostri articulo primo et interdum secundo, limbis lateralibus anticis thoracis totis rel ad partem, limbo laterali prostethii, rentre femoribusque totis croceis; macula obsoleta laterali rhomboidea libera segmentorum ventris virescente-renea, spiraculis nigro-cinctis. or. Long. 10-11, Lat. 4: mill.

$\sigma$. Segmento anali cærulescente-chalybeo, late aureo-faseiato.

Ver. a. - Supra cum tibiis maculisque rentris viridi-ienea, subcæruleo-induti, tibiis subtus in croceum vergentibus.

Callider nana H. Scr1. Wanz. Ins. III. P. 100. fig. 325. (18:35).

Far. b. - Thorace scutelloque pallide albido-purpurascentibus, maculis nigris mims distinctis, sepe sat parvis; maculis ventris pallide purpurascentibus; tibiis croceis, anesente vel purpureo-tinctis.

Cïnex 12-punctatus FABR. Ent. syst. S̈mpl. 1. 527. 4-5. (1798).

Cimex duodecimpunctatus COQuEB. 11l. icon. I. p. 36. Tab. 9. fig. 7. (1799).

Tetyra 12-punctata FaBk. Syst. Rlyyng. p. 132. 16. (1803). 
Callidea duodecimpunctata Gery. Zeitschr. I. p. 120. 20. (1839).

Libyssa duodecimpunctata DALL. List of Hem. 1. p. 21. 2. (1851) ad partem.

Patria: Natalia. (Mus. Holm.)

C. Dregii valde affinis, capite magis deflexo, segmento anali maris mims profunde sinuato structuraque antemnarum distincta.

5. C. distinguenla REICHE et FAJrm. - Dense distincteque punctata, disco ventris levi; supra dilute purpurascente-testacea, subaureo-nitens; antennis tarsisque nigris; capite, exceptis maculis duabus oblongis purpurascente-aureis, pectoreque obscure crerulen-chalybeis; articulo primo antennarum et rostri, limbis lateralibus anticis thoracis et lateralibus prostethii, ventre, coxis, trochanteribus femoribusque croceis; maculis tribus anterioribus thoracis, tibiis, maculis lateralibus magnis transversis et nomullis parvis discoidalibus rentris nec non ano cieruleo-nigris, hoc aureo-maculato; thoracis maculis quinque posterioribus, mediis oblongis, scutelli maculis $\operatorname{sex}$ vittaque ultra medium dncta obscurioribus, haud aureo-indutis. or. Q. Long. 11-12, Lat. 5 mill.

Callidea distinguenda ReICHE et FaIrm. Voy. ell Abyss. Entom. p. 433. 1. (1848).

Patria: Abyssinia. (Mus. Holm. et Coll. Stál.)

Præcedenti maxime affinis.

bb. Ventris marginilus lateralibus nigro-maculatis; antennis totis nigris; femorilus apice nigro-ceruleis.

6. C. Bohemani STÅL. - Obscura chalybeo-cærulea, subviolaceonitens, dense punctata, ventris disco lævigato; limbis lateralibus anticis thoracis et lateralibus prostethii, coxis, trochanteribus, femoribus rentreque luteis; antemnis, rostro, thoracis maculis tribus subrotundatis anterioribus et quinque posterioribus, intermediis tribus magnis, oblongis, scutelli maculis sex, per paria dispositis, maculaque subbasali minore oblonga, ventris maculis marginalibus nonnullisque discoidalibus seriac= 
tim dispositis nec non tarsis nigris; rentris segmento basali maculaque laterali segmentorum transversa nec non ann chalyben-caruleis; apice femorum tibiisque nigro-caruleis. q. Long. 13-15, Lat. 6-7 mill.

Libyssa Bohemani STÁl. Öfv. Vet. Ak. Förh. 1853. p. 210. 2 .

Patria: Caftraria. (Mns. Ifolm.)

Variat maculis discoidalibus nigris ventris in unam confluentibus.

Congenericis mihi eognitıs latior, crassior, angulis lateralibus thoracis mimus rotundatis et paullo prominulis, cietero cum illis quoad puncturam picturamque maximam ad parten conveniens. Antemne gracilinsculie, articulo primo secundo fere dimidio longiore, tertio basalibus duobus ad unum sublongiore. Tibia superne late sulcate, fundo sulci plano.

\section{SPII ÆROCORIS BURM.}

Handb. II. 1. p. 390. (1835).

Corpus oboratum, supra plus minus convexum, subtus planiusculum. Caput valde deflexum, interdum perpendiculare, planum. Antenna breviuscula, articulo secundo tertio breviore. Thorax margine antico medio recto, angulis posticis obtusissimis, valde rotundatis. Scutellum abdomen totum tegens, margine basali utrimque paullo sinuato. Sulcus sternalis nullus vel vix ullus. Venter maculis sericeis destitutus.

a. Corpore valde conrexo, obsolete punctulato; capite perpendiculari, triangulari, apice rotundato: thorace anterins valde declivi, ntrimque ante angulos laterales nomilit impresso, marginibus lateralilus ilvidem leviter sinuatis; segmento rentris ultimo apud marem apice truncato, apul feminam simuato.

b. Thoracis maryine basuli tersistue nigris; rostro apicem segmenti rentralis secundi hand superante.

1. S. ocellatus KLug. - Stramineus, supra suboliraceo-stramineus; antemnis, excepto articulo primo, rostri articulis duobus apicalibus, capitis marginibus lateralibus, limbo basali lineisque duabus longitudinalibus, thoracis linea anteriore transversa albreviata et medio interrupta, lineola obliq̨ua angu- 
lorum laterilium, margine basali fere toto lineaque transversa distincte undata posteriore, utrimque reflexa et ad marginem basalem producta, scutelli maculis annularibus undecim (5, 4, 2), apicalibus duabus oblongis, apicem attingentibus et postice apertis, hemelytris, excepta parte anteriore, tarsisque nigricantibus; alis apice fuscis; lineis maculisque thoracis et scutelli purius stramineo-limbatis, linea undata thoracis antice maculisque scutelli interdum anguste diluteque rufo-marginatis. $\sigma^{7}$. \&. Long. 10-11, Lat. 8 mill.

Tetyra ocellata KLUG. Symb. phys, V. pl. 43. fig. I-3. (1834).

Splewrocoris annulus H. ScH. Wan\%. Ins. I11. p. 105. fig. 330. (1836).

Splecerocoris vcellatus Burm. Handb. II. 1. p. 391.

1. (1835); A. et S. Hist. des Hém. p. 40. 1. (184:3); H. ScH. Wanz. Ins. V. p. 49. (1839); DALL. List of Hem. p. 8. 3. (1851). Puchycoris ocellutus GerM. Zeitschr. I. p. 82. 1. (1839).

Patria: Caffraria, Ahyssinia. (Mus. Holm., Coll. Sigsoret et STAL.)

2. S. Argus DruRY. - Stramineus, supra subolivaceo- vel fuscescente-stramineus; antennis, excepto articulo primo, rostro toto vel articulis duobus ultimis, capitis limbo basali, marginibus lateralibus lineisque duabus longitudinalibus, thoracis linea transversa anteriore, medio sape interrupta, interdum cum lineola obliqua angulorum lateralium cohærente, margine basali fere toto nec non linea transversa posteriore levissime undata, scutelli maculis amularibus undecim $(5,4,2)$, duabus posticis oboratis, postice acuminatis et clausis, hemelytris, excepta parte anteriore, tarsisque nigricantibus; pictura nigra thoracis scutellique purius stramineo-marginata, linea posteriore thoracis antice semper scutellique maculis plurimis sæpissime rufo-marginatis; alis apice fuscis. $\sigma$. \&. Long. 911, Lat. $6 \frac{1}{2}-8$ mill.

Cimex Argus Drurr. 11l. nat. hist. III. p. 67. Pl. 46. fig. 9. (1782); Panz. Voёт. Col. IV. p. 111. Tab. 47. fig. 9. (1798). 
Cimex annulus FABr. Ent. syst. IV. P. 82. 10. (1794).

Tetyra annulue FABR. Syst. Rhyng. p. 132. 20. (1803); SciJönte in Krǚr. Nat. Tilsskr. JV. p. 289. 9. (1842).

Scutellera gibbosa P. B. Ins. p. 232. Hem. pl. 5. b. fig. 3. (1805).

Pachycoris ammulus Grens. Zeitschr. I. p. 83. 2. (1839).

Spherecoris distinctus SIGN. Rev. et Mag. Zool. 185̃1. p. 441. 3.

Stoll. Pun. P. 148. fig. 268.

Var.? - Linea subundatil posteriore thoracis deficiente.

Patria: Sierra Leona, Gabon. (Nus. Holm. et Coll. SigsoRET.); Calalar. (Coll. Signonet et STÁL.)

S. ocellato maxime affinis, corpore pone medium paullo convexiore, maculis apicalibus scutelli obovatis, postice clausis lineaque posteriore thoracis multo minus undata distinctus videtur.

bb. Thoracis maryine basali concolore, tarsis leciter infuscatis; rostro segmentum ventrale quartum subsuperante.

3. S. poecilus DALL. - Latissime obovatus, sordide stramineus; antemarum articulis tribus ultimis fuscis; capitis marginibus lateralibus, limbo basali lineisque duabus longitudinalibus, thoracis maculis annularibus quattuor posticis, basin subattingentibus, maculisque annularibus compluribus scutelli nigris. o. Long. 9, Lat. 7 mill.

Var. a. - Scutello maculis annularibus undecim, $(5,4,2)$, tribus intermediis anticis basin attingentibus, media oblongal, medio constricta, apicalibus dualus oblongis.

Spherocoris poecilus DALL. List of Hem. I. P. 9. 6. (1851).

Var. $b$. - Varietati a similis, sed scutelli maculis lateralibus anterioribus deficientilus.

Spharocoris niluicus STit. Öfv. Vet. Ak. Förh. 185t. p. 232. 1 .

Vur. c. - Varietati a similis, sed scutelli maculis lateralibus anterioribus et mediis duabus seriei media deficientibus.

Patria: Nubia. (Mus. Holm. et Coll. Signoret); Gambia. (Mus. Brit.) 
S. ocellato minor et latior, pietura thoracis, scutelli maeulis anticis mediis basin fere attingentibus rostroque longiore distinrtissimus.

bbb. Tersiss stremineis erel fluev-testereris.

4. S. punctarius WEsTw. -- Varicolor; pedibus totis stramineis vel flaro-testaceis; corio stramineo, maculis duabus parvis anticis et magna posteriore nigro-fuscis; membrana fusca; alis antennisque interdum apicem rersus fuscis. o’ . . Long. $7 \frac{1}{2}-8 \frac{1}{2}$, Lat. $6-6 \frac{1}{2}$ mill.

Jur. a. - Testaceo-flavescens, superne minute ot irregulariter nigro-conspersus.

$I^{\prime} a r . b$. - Testaceo-flavescens, superne minute et irregulariter nigro-conspersus, thoracis maculis nndecim, scutelli maculis undecim $(5,4,2)$ brunnescentilus, maculis tribus anticis mediis scutelli basin attingentibus, media oblonga, medio coarctata.

Spherocoris prenctaria WESTW. in HopE Cat. of Hem. I. p. 13. (18:37).

Spharocoris polystirin WEsTw. in HopE Cat. of Hem. 1. p. 13. (1837).

Spharocoris tigrinus Germ. Zeitschr. 1. p. 77. 3. (1839); H. Sch. Wanz. Ins. V. p. 8. fig. 465. (1839).

Spharocoris mencturius DALL. List of Hem. I. p. 9. 7. (1851). SToll. Pun. p. 145. fig. 261.

Var. c. - Sordide stramineus; capitis marginibus lateralibus, limbo basali lineisque duabus longitudinalibus nigris; maculis testaceis thoracis plus minus distinctis, in series duas transversas dispositis, anterioribus postice, posterioribus antice anguste nigro-marginatis, maculisque scutelli undecim, uti in var. $l$ dispositis, plus minus distincte nigro-marginatis; macula magna laterali pectoris cinerea; ventre toto rel disco piceo.

Sphcerocoris cafjer STÁL. Öfv. Vet. Ak. Förh. 1853. p. 210.2.

J'ar. d. - Sordide stramineus vel testaceo-flavescens; capitis marginibus lateralibus parteque basali, medio producta et flavo-notata, thoracis maculis undecim, quinque anterioribus, 
quattuor posterioribus unaque in angulis lateralibus, scutelli maculis undecim, basali media oblonga, medio coaretata, nigris.

Spharocoris pumlalimus Scinaum. Ber. Ak. Berl. 1853. p. 357; Scinaly in Peters Reise nach Mossamb. Ins. p. 36. Taf. I1. fig. 1. (186; $)$.

Var. e. - Varietati d similis, sed macula laterali magna pertoris cinerea; ventre piceo.

Var. f. - Superne nigricans, maculis undecim thoracis et undecim scutelli testaceis; pectore pedibusque stramineis, illius marula magna laterali cinerea; ventre piceo.

Patria: Africa meridionalis et occidentalis. (Mus. Holm., Coll. Signorete et Strál.); erv. d. et e. Sierra Leona, Senegal. (Mus. Holm.); inr. f. Guinea. (Coll. Signorfi.); ıur. a. etiam in Madagasear occurrit.

Statura S. poecili, cui proximus, pictura diversa et valde variabili rostroçue breviore distinctissimus.

aa. Corpore modice convero, supra sat dense munctulato, subtus acervatim distinctius punctato; capite obtuso, rotumlato, ante oculos utrimque leviter simuato; antemarum articulo tertio secundo circiter duplo longiore; thorace ad angulos luterales hand impresso, margine ibiden integro; segmento ventrali nltimo utriusipue sprus postice mofunde sinuato.

5. S. multipunctutus 'Tu NB. - Varicolor; hemelytris nigris, basi sapissime flavescente-limbatis. ơ. f. Long. 8-11, Lat. 68 mill.

Spluprocoris impluviatus GErs. Zeitschr. I. p. 77. 2. (1839). Spherocoris Aryus DALL. List of Ilem. I. p. 8. 5. (I85I). lar.a. - Dilute testaceo-flarescens, superne plus minus remote minte fusco-conspersus, subtus nigro-punctatus et variegatus; antemnis al partem siepe nigro-fuscis; thorace anterius mareulis pallidioribus interelum ornato.

Cimex multipunctatus TичNB. Nov. ins. spec. II. p. 30. (IT83).

Tetyra multipunetata TuLxis. Hem. rostr. cap. I1. p. 6. (1822).

sphorocoris simpler H. ŚCH. Wanz. Ins. III. p. 104. fig. 329. (18:35); Gris. in Silu. Rev. ent. V. P. 18.9. 140. (1837). 
Sphcerocoris adspersus STÅL. Öfv. Vet. Ak. Förh. 185.3. p. 210. 3 .

Stoll. Pun. p. 40. fig. 60.

Var. b. - Varietati a similis, sed thorace anterius et scutello basi maculis duabus appropinquatis purius coloratis, substramineis, anguste nigro-marginatis, ormatis; pectore ventreque impictis, pallidis.

Spherocoris 4-notata WESTW. in HOPE Cat. of Hem. I. p. 13. (1837).

Spharocoris quadrinotatus GERM. in SILB. Rev. ent. V. p. 189. 139. (1837); GERM. Zeitschr. I. p. 80. 6. (1839); H. ScII. Wanz. Ins. V. p. 8 et 49. fig. 464. (1839); DALl. List of Hem. 1. p. 10. 9. (1851).

Var. c. -- Supra niger, subtus cum capite maculisque undecim (6.5) thoracis et tredecim (6. 4. 3) scutelli testaceo-flavescens; capitis vitta nigra, antrorsum angustata, maculis duabus vel tribus testaceo-flavis notata; pectore ventreque nigro-punctatis et variegatis; antemis pedibusque flavo-testaceis vel nigricantibus, femoribus apicem versus testaceo-maculatis.

Cimex Argus Fabr. Ent. syst. 1V. p. 83. 15. (1794).

Tetyra Argus FABR. Syst. Rhyng. p. 133. 24. (1803); SCHJŐDTE in KRör. Nat. Tidsskr. IV. p. 76. I. (1842).

Spherocoris Argus Buru. Handb. II. 1. p. 391. 2. (1835).

Sphcerocoris impluviatus GERM. Zeitschr. 1. p. 77. 2. (1839); H. Sch. Wanz. Ins. V. p. 49 et 52. fig. 499. (1839).

Stoll. Pun. p. 35. fig. 50.

Var, d. Varietati a similis, sed colore flavo-testaceo in rufo-testaceum vergente; antennis testaceis, articulo primo nigro; pedibus nigris, femoribus apicem versus superne, apice tibiarum tarsisque testaceis.

Sphcerocoris simulans STẢL. Öfv. Vet. Ak. Förh. 1858. p. 310. 2.

Var.e. - Varietati $d$ similis, sed corpore subtus pedibusque testaceo-flavescentibus, impictis; thorace postice maculis tribus magnis ornato, maculis duabus lateralilius in mam conjunctis. 
Splureconis hamiferms stril. Öf. Vet. Nk. Förh. $185 \tilde{3}$. p. 209. 1.

P'altria: Africa meridionalis. (Mfus. IIolm., Coll. Signoret et STal.); ror. c etiam in Calabar Guinex. (Coll. Signoret.)

\title{
COELOGLOSSA GERM.
}

\author{
\%(itschr. I. p. 1:30. (1-39).
}

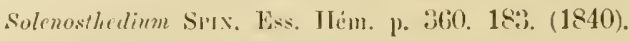

Corpus olovatum, supra subtusque minus convexum. Caput triangulare, parum convexum. Antennæ brevinscula, quinquearticulatie, articulo tertio secundo plus duplo longiore. Thorax sexingularis, margine basali recto, angulis posticis et lateralibus rotundatis. Scutellum maximum, abromini zequilatum. Sterna et venter sulcata, illius sulco utrimque carina alta terminato. Venter marium maculis duabus magnis, opacis, remote pilosinsculis, instructus. Tibir superne subtiliter bisulcate, inter sulcos ruga instructe.

1. C. liligera Tuunz. - Dense subtiliterque, subtus remotius et paullo fortius punctata, varicolor, lateribus thoracis concoloribus; scutello posterins maculis tribus stranineis, sape confluentibus et ante medium latera versus macula orbiculari parva atra ornato. $\sigma^{7}$. \&. Long. 13-15, Lat. $8 \frac{1}{2}-10$ mill. Cimex liligerus Tucnis. Nor. ins. spec. II. p. 32. (1783).

Scutelleva furcifera Burn. Handb. II. 1. p. 395. 2. (1835). Coeloglossu Sehestedti Grin. Zeitschn. I. p. 132. 2. (1839). Solenosthedium liligernm DALL. List of Hem. 1. 1. 6. 2. (1851). Var. a. - Supra obscure cinnamomea, in subviolacemu et subsanguineum plus minus vergens, subtus cum antemnis, rostro pedibusque flaro-cinnamomea; supra plus minus obsolete reneo vel viridi-axneo-punctata, subtus maculis viridi-aneis ornata; scutelli maculis tribus stramineis liberis.

lar. L. - Varietati a similis, sed maculis tribus posterioribus scutelli in fasciam, antice posticeque bisinuatam, latitudine variabilem, confluentilus.

Cimer furrifer Fabr. lint. syst. IV. p. 84. 19. (1794). 
'Tetyra furcifera FABR. Syst. Rhyng. 1. 130. 11. (1803).

Tetyra liligeru Tinunb. Hem. rostr. cap. II. p. 6. (1822).

Coeloglossu furciferce GERM. Zeitschr. I. p. 131. 2. (I839).

STOLL. Pun. p. 40. fig. 59.

$V a r$. c. - Dilutior, cinnamomeo-flavescens, supra interdum hic illic levissime violaceo-induta, punctis cinnamomeis vel anescentibus; scutelli maculis posticis liberis; pectore parce ieneomaculato.

Sulenosthedium pallescens STiL. Öfv. Vet. Ak. Förh. 1858. p. 310. 1 .

Patria: Terra capensis, T'kons fontain. (Mus. Moln., Coll. Signoret et Stil.)

2. C. Sehestedti FABR. - Olscure cimmmomea, antennis pedibusque vix dilutioribus, supra deuse rueo-punctata, subtus minus dense sed fortius punctata; pectore aneo-maculato; thoracis limbis lateralibus anticis latiuscule aureo-æneis; scutello ante medium utrimque macula atra minore, posterius fascia sordide straminea, postice tridentata ornato. \&. Long. 15, Lat. 9 mill.

Tetyra Sehestedti FABr. Syst. Rhyng. p. 130. 9. (1803); SCIIJÖDTE in KrRöY. Nat. Tidsskr. IV. p. 284. 4. (18+2).

Cimex furcifer WolfF. Ic. cim. IV. p. 134. 128. Tab. XIII. fig. 128. (1804).

Solenosthedium Sehestedti DALL. List of IIem. I. p. 6. 2. (1851).

Patria: Calabar. (Coll. Signoret et STiz.) varietas?

C. liligerce maxime affinis, exceptis coloribus vix differt, all ejus HOTEA A. et S.

Hist. des Hem. p. 41. (1843).

Corpus nudum, supra subtusque convexum. Caput admodum convexum, lobo medio percurrente, bucculis ante medium sat elevatis. Antemne articulis secundo et tertio subæqualibus vel secundo tertio paullo longiore. Thorax sexangularis, marginibus lateralibus anticis distincte sinuatis, angulis lateralibus productis, plus minus acuminatis, angulis posticis rotundatis', 
margine postico recto. Sicutellum abdomini apuilatum, apice rotundatum, haud productum. Prostethium antice dilatatum, basin antennarum tegens. Sterna leviter sulcata. Venter disco maculis duabus sericeo-nitidis instructus, segmento ultimo apice sinuato. Pedes validiusculi, tibiis superne planis.

a. Corpore latissime sulocato; capite triangulari; ventris marginibns depressis, acutis, inernilnus.

1. Yentris segmentis duobus ultimis basi in angulum antrorsum sat longe productis; bucculis antice rotundatis; angulis lateralibus thoracis apice sulito acuminatis.

1. II. Gambia WEstw. - Testaceo-flavescens, supra obscurior, fusco-fermugeo-tincta et punctata, transversim fusco-multilineata; lineis longitudinalibus nomnullis capitis et anticis obliquuis thoracis nee non maculis duabus maximis pone medium scutelli grisen-stramineis, his antice fascia nigra terminatis. $\sigma^{7}$. \&. Long. 11, Lat. 8 mill.

Triyonosoma apicale WESTW. in HOPE Cat. of Hem. I. p. 11. (18:37).

Pachycoris apicalis GERM. Zeitschr. I. p. 106. 51. (1839). Hotea triangulum $\Lambda$. et $\mathrm{S}$. Hist. des Hém. p. 41. 1. Pl. 1. fig. 7. (184:3).

Hotea Gambice DaLL. List of Hem. I. p. 39. 2. (1851) ex parte.

Tar. 6. - Pallidior, griseo-straminea, fusco-ferrugineo-punctata, had nigro-lineata, fascia media scutelli, medio late interrupta, fusca vel nigricante.

Trigonosoma Gambire Westw. in Hope Cat, of Hem. 1. p. 11 (I8:37).

Pachycoris Gambia Gerr. Zeitschr. I. p. 106. 50. (1839). Patria: Senegal, Gambia. (Mus. Holm. et Coll. Sigroret.)

L.b. Margine basuli segmenturum ventris medio subrecto, utvimpue ubliquo, seymenti ultimi interdum medio lexissime angulato.

2. II. subfasciata WESTW. - Griseo-straminea vel pallide ferrugineo-flavescens, fusco-ferrugineo-punctata, supra obscurior 
et lineis transversis interuptis nigris ornata; lineis longitudinalibus capitis in thoracem oblique productis nee non maculis duabus maximis pone medium scutelli pallidis, scutello fascia media, late interrupta, nigra ornato; capitis lobo medio apice obtuso, haud vel vix prominulo; bucculis antice rotundatis; angulis lateralibus thoracis minus prominulis, apice subito acuminatis. $\sigma^{7}$. 8 . Long. 9! 11 , Lat. $5-6 \frac{1}{2}$ mill.

Trigonosoma sulifasciatum WEsTw. in Hope Cat. of Hen. I. p. 11. (1837).

Pachycoris fulcatus Gers. in SiLb. Rev. ent. V. p. 191. 144. (1837).

- Hotea Gambia DALL. List of IIent. I. p. 39. 2. (18j1) ex parte.

Var. b. - Corpore supra haud nigro-lineato, capitis lineis pallidis maculisque pallidis posticis scutelli haud vel vix distinguendis.

Hotea vicinum Sign. Rev. et Mag. Zool. 1851. p. 441. 4.

Patria: Caffraria. (Mus. IIolm.); Gabon, Calabar. (Coll. SignORET.)

II. Gambice maxime affinis et simillima, structura ventris distinctissima.

3. II. acú́a STÂL. - Ferrugineo-flavescens, nigro-punctata et variegata; capite thoracisque antieo nigricantibus, lineis longitudinalibus nomnullis pallidis ornatis; capitis lobo medio subacuminato, apice leviter prominulo; bucculis antice subito abbreviatis et in angulum acutiusculum prominulis; thoracis angulis lateralibus sat productis, apice oblique sinuatis et antice acuminatis. \%. Long. 10, Lat. 7 mill.

Patria: Calabar. (Coll. Signoret.)

$H$. subfasciate valde aftinis, forma lobi medii capitis, buceulis antice angulatim terminatis angulisque lateralibus thoracis magis productis et apice oblique sinuatis differt.

aa. Corpore ovali, capitis marginibus lateralibus ultra modium subparallelis vol via conceryentilns, dein subito obtuse an- 


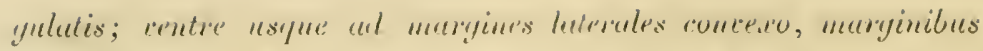
hand dejeressis, ungulis apiculibns segmentorme tuberculo purro armatis, margine basali segrrentionm medio smlnecto, hand anyulato.

4. II. Nenticnlata stTaL. - Fiscescente-subferruginea, nigro yallidoque variegata, sat dense distincteque punctulata; capite ante medium utrimque denticulo marginali armato; ventre ante medium sulcato. \&. Long. $8 \frac{1}{2}$, Lat. 5 mill.

\section{Patria: Madagascal: (Coll. Sigrorér.)}

Species insignis, precedentibus angustior, fusco-subfermginca. Capnt pallidum, basi fuscum, utrimque inpressionibus nommllis instructum. Antemne fuscesecentes, intieulis basi apiceque pallidis. Thorax latera versus lineis tribus ollique longitudinalibus et postice maculis duabus oblongis oblicpuis distantibus pallidis ormatus, angulis anticis denticulo armatis, angulis latcralibus prominentibus, vix acuminatis, postice sulsinuatis. Scutellum hic illic infuscatum, fascia angulata media, antrorsum ad maculas basales thoracis ramos duos cmittente, nee non macula apieali pallidis ornatum, margine postico fascie medix in rugam subelevato. Subtus pallidior, fusco-ferrugineo-punctata. Pedes fusco-fermginei, pallislo-rariegati.

\section{SERGIA STAL.}

Corpus nudum, ovale, modice conrexum. Caput triangulare, convexum, lobo medio percurrente; bucculis ante medium sat clevatis. Antenna mediocres, articulo secunclo tertio paullo longiore. Thorax sexangularis, marginilus lateralibus anticis vix vel leviter sinuatis, angulis lateralibus vix prominulis, haul acuminatis. Scutellum abdomini aquilatum, apice rotundatum, haud productum. Prostethium antice dilatatum, lobatum, basin antemnarum oceultans. Sterna distincte sulcata. Venter convexus, incisuris medio late rectis, utrimque obliquis. Pedes ralidiusculi, tibiis superne planis.

lotrec aftine genus.

a. Scrutello hund ruyoso.

b. Marginibus lateralibus anticis thoracis ante medium tuberculis nonmellis minutis instructis; scutello thorace circiter dimitio longiore; lobis mostethii angulum subrectum formantilus. 
1. S. obesa STẢL. - Ovalis, sat convexa, griseo-straminea, supra remote et subacervatim, subtus densius fortiusque nigro-punctata; capitis vittis quattuor nigricantibus, vitta media lævi, per thoracem continuata. ㅇ. Long. 12, Lat. 7 mill.

\section{Patria: Senegal. (Coll. Signoret.)}

Congenericis angustior et convexior, thorace longiore insignis species. Griseo-straminea, supra remote, subacervatim, distincte nigro-punctulata, punetis fortioribus interspersis. Caput sat convexum, subtus nigrum, supra vitta laevi media instructum, limbis lateralibus latis vittisque quattuor nigris vel c punctis nigris acervatis compositis ornatum. Antenna fusce, basin versus griseo-straminca. Thorix scutello circiter tertia parte brevior, marginibus lateralibus antieis distincte sinuatis, angulis lateralibus leviter prominentibus, medio vitta angusta pereurrente levigata instructus, punctis nigris ante medium in vittas obsoletas acervatis. Seutellum ruga subtili longitudinali minus distincta instructum, spatiis inter puncta levissime callosis, punetis pone medinm in vittas duas angustas obsoletas, retrorsun couvergentes, subicervatis. Peetus remote, acervatim, distincte nigro-punctatum. Venter obscurior, distinete acervatim nigro-punctatus. Pedes sordide subferruginei.

bb. Thorace scutello circiter dimidio breviore, marginibus lateralibus anticis inermibus.

c. Corpore caricolore, raro nigro, prostethio tunc toto unicolore.:

\section{d. Limbo angusto ventris levi.}

2. S. nigro-punctata STÅL. - Ovalis, sat convexa, grisescentestraminea, dense subtiliterque, subtus paullo fortius nigropunctata; capite subtus, marginibus lateralibus superioribus lineisque duabus longitudinalibus, antennis, basi excepta, maculis minutissimis raris sparsis thoracis scutellique nec non tarsis nigris. ㅇ. Long. 11, Lat. 6 mill.

\section{Patria: Senegal. (Coll. Signonet et STÅL.)}

Statura s.: caffree, sed convexior. Tota dense subtiliter(fue, subtus nomihil fortius punctata, ventris disco pareius punctato, limbo angusto levi. Caput totum punctatum, vitta nulla levi. Thorax marginibus lateralibus anticis leviter sinuatis, pallidis, angulis lateralibus levissime promimulis, linca longitudinali laevi nulla vel obsoletissima, vix nisi in disco perspicua. Scntellum linea levi longitudinali subtilissima instructun. 
dd. Vertre usque ad margines laterales punctato, limbo etiam punctato.

3. S. olscura DALL. - Ovalis, varicolor, dense distincteque punctata. o'. \&. Long. 10, Lat. 6 mill.

$V$ ar. a. - Dilute griseo-flavescens, interdum in ferrugineum vergens, nigro-punctata, ventre pallicliore, punctis decoloribus, spiraculis maculisque nonnullis minutissimis disci nigris; punctis thoracis in vittas sex, punctis scutelli in vittas angustas nonnullas anticas et pone medium in vittas duas retrorsum nonnihil convergentes, minus distinctas, acervatis; marginibus lateralibus vittisque duabus angustis capitis nigris; antennis flavo-ferrugineis, apice fuscis; thoracis marginibus lateralibus anticis pallidis.

Odontotarsus obscurus DALL. List of Hem. I. p. 40. 3. (1851). Eurygaster natalensis STÅL. Öf. Vet. Ak. Förh. 1853. p. 211. 1 .

Var. $b$. - Obscurior, nigra vel subferrugineo-nigra, antennis dilute ferrugineis, apice nigricantibus.

Patria: Caffraria. (Mus. Holm.)

Ovalis, modice convexa, sat dense distincteque punctata, rentris disco levi. Caput totum punctatum, vitta mulla levi. Thorax marginibus lateralibus anticis vix simuatis, angulis lateralibus vix prominulis, linea longitudinali media subpercurrente levigata. Scutellum linea subtili longitudinali, posterius evanesecnte, levi instructum. Lobi prostethii rotundati. Pedes distincte punctulati.

4. S. illota StåL. - Latiuscule ovalis, griseo-flavescens, cum pedibus sat dense distincteque fusco-punctata, rentris disco lavi, parce fusco-consperso; antennarum articulis duobus ultimis fuscis; capitis vitta media, in thoracem anguste continuata, hujus marginibus lateralibus anticis callisque duobus parris hasalihus scutelli pallidis; scutello lineolis brevibus vermicellaribus parce consperso. \&. Long. 10, Lat. $6 \frac{1}{2}$ mill. Odontotursus illoius S'TÁL. Öfv. Vet. Ak. Förl. 1858. p. 311. 8. Patria: N'Gami. (Mus. Holm.)

S. obscurce maxime affinis, nomnilil latior. Caput totmm punctatum, vitta nullat levi. Thorax antiec linea longitudinali subtili leviuscula, marginibus lateralibus anticis vix sinuatis, angulis 
lateralibus levissime prominentibus. Seutellum linea longitudinali levi destitutum.

cc. Corpore magnam ad partem nigro, prostethio pallidolimbato.

5. S. silphoides Thunb. - Nigricans, distincte punctata; thorace, scutelli parte basali, maculis duabus mediis, margine posteriore, linea longitudinali levi, per thoraceu continuata, costa anterius, prostethii limbis lateralibus retrorsum ultra medium et antico flavescente-griseis, excepta linea longitudinali thoracis scutellique, nigro-punctatis; thoracis maculis quattuor anticis unaque utrimque angulorum lateralium plus minus confluentibus, magnis, maculisque duabus parvis obsoletis basalibus nigris; ventre disco lævi, flavescente-fasciato, vel flavescente, nigro-vario. ơ. Long. $10-11 \frac{1}{2}$, Lit. $6-7$ mill.

Var. a. - Thorace postice maculis magnis nigris destituto; capite impicto.

Cimex silphoides Thunb. Nov. ins. spec. II. p. 29. (1783).

Tetyra silphoides Thunb. Hem. rostr. cap. II. p. 6. (1822).

$V a r$. b. - Thorace postice maculis nigris magnis destituto; capite vittis duabus flavescente-griseis notato.

Var. c. - Thorace postice-maculis magnis quattuor, scutello in angulis basalibus macula una nigris notatis; maculis duabus mediis pallidis scutelli disco nigricantibus; capitis vittis duabus flavescente-griseis.

Cimex stigma FABR. Ent. syst. Suppl. p. 528. 10-11. (1798).

Tetyra stigma FABR. Syst. Rhyng. p. 133. 21. (1803).

Pachycoris stigma Burs. Handb. II. 1. p. 392. 4. (1835); GERM. Zeitschr. I. p. 90. 16. (1839).

Odontotarsus silphoides DALL. List of Hem. I. p. 41. 4. (1851). Patria: Terra capensis. (Mus. Holm. et Coll. S'TAL.)

6. S. Coquerelii Sign. - Nigra, distincte punctulata; scutello ferrugineo-fusco; thorace, scutelli parte basali, linea lævi media, per thoracen continuata, annulis duobus mediis margi- 
neque angusto, prostethii limbis antico et lateralibus ultra medium nee non ventre flavescente-griseis; thoracis maculis quattuor anticis, quattuor basalibus et una in angulis lateralibus, scutelli maculis quattuor in parte basali pallida, ventris lateribus parteque apicali nigris; rentris limbo anguste pallido. ơ' Long. 12, Lat. 8 mill.

Odontotarsus Corpuevelii SIGs. Ann. ent. Sér. 3. VIII. p.918. 68. Pl. 13. fig. 1. (1861). differt.

Praecedenti maxime affinis, capite paullo longiore præsertim

aa. Scutello rugoso.

7. S. afra H. ScH. - Grisea, fortiter punctata, nigro-conspersa, supra remote rugosa; scutello rugis valde elevatis, irregulariter anastomosantibus, callis duobus parvis levibus, pallidis, basalibus, carinaque obtusa valde elevata, antice posticeque abbreviata, instructo; antennis dilute ferrugineis, apice fuscis. ․ Loug. 9, Lat. 6 mill.

Psacusta afia H. ScH. Wanz. Ins. V. p. 47. fig. 497. (1839). Patria: Guinea. (Coll. Signorer.)

\section{ALPHOCORIS GERM.}

Zeitschr. I. p. 55. (1837).

Corpus crassmu, prisertim subtus convexum, anguste ovale vel oblongum, griseo-tomentosum. Caput crassum, valde convexum, immarginatum, bucculis sat elevatis. Antennæ breves, capite nounihil longiores. Thorax sexangularis, angulis posticis obtuse rotundatis, lateralibus haud prominentibus, obtusis. Scutellum apice paullo productum, parte producta apice sinuata vel subtruncita. Prostethium antice nomihil dilatatum. Sterna profunde sulcata. Incisuræ ventris curvata.

Golontuturse aftine genus,

a. Bucenlis antice in dentem distinctnm eleratis.

1. A. lixoides GEry. - Oblongus, angustus, flavo-testaceus, subtus cum pedibus, excepto limbo ventris, nigricans; supra salt dense distincteque punctulatus, obsolete fusco-quadrivit- 
tatus; scutelli apice subtruncato vel leviter sinuato. ơ. Long. $9 \frac{1}{2}-10$, Lat. $3-3 \frac{1}{2}$ mill.

Alphoconis lixoides Germ. Zeitschr. I. p. 59. Tab. I. fig. III. (1839); A. et S. Hist. des Hém. p. 44. 1. (1843); DALL. List of Hem. I. p. 41. 2. (1851).

Patria: Senegal. (Mus. IIolm. et Coll. Sigronet.)

Variat ventre flavo-testaceo, in disco nigro-bivittato.

b. Bucculis antice in dentem hand elevatis, ibidem minus altis.

2. A. indutus STẢL. - Oblongus, testaceo-flavescens, capite subtus, vittis duabus superis marginibusque lateralibus, ventris vittis duabus pedibusque nigris; thorace scutelloque fuscovittatis, hoc apice angulatim distincte emarginato. ㅇ. Long. 9-11, Lat. 3-4 mill.

Patria: Caffraria. (Mus. Holm.)

A. lixoidi maxime affinis, structura bnccularum, corpore distincte nonnihil crassiore, seutelli apice distincte emarginato differt.

3. A. crassus Stảl. - Subanguste ovalis, testaceo-flavescens; pedibus nigris; supra vittis pluribus fuscescentibus ornatus; scutello apice medio leviter emarginato. ㅇ. Long. 8, Lat. vix 4 mill.

Patria: Senegal. (Coll. Sigroret.)

A precedentibus differt statura breviore et multo latiore; Odontotarso gramnico quoad formam hand dissimilis, licet nomnihil angustior, ovalis, nec obovatus.

\section{EURYGASTER LAP.}

Ess. Hén. p. 69. (1832).

Corpus ovale rel ovatum, parum convexum. Caput planum vel levissime convexum, lobo medio percurrente vel incluso. Antenna breves, graciles. Thorax sexangularis. Scutellum lateribus parallelis, abdomine multo angustius, partem costalem totam hemelytrorum liberam relinquens. Sterna sulcata. Tibiæ supra sulcatie.

1. E. sculpturatus STÁL. - Ovatus, pallide sordide testaceo-flavescens, supra fortiter rugosus; lohis capitis lateralibus antice 
contiguis, lobo medio longioribus; scutello ruga longitudinali media, valde elevata, utrimque abbreviata instructo; ventris marginibus lateralibus erosulis, fusco-maculatis; pedibus ferrugineo-fusco-punctatis. \&. Long. 10, Lat. $6 \frac{1}{2}$ mill.

Eurygaster sculpturatus STiL. Öfv. Vet. Ak. Förh. 1858. p. 311.5 .

Patria: Srakop Africæ meridionalis orientalis. (Mus. IIolm.)

\section{Subf. ASOPIDA STiL.}

Conspectus generum.

1 (12). Femoribus omnibus vel anticis solis subtus prope apicem spina armatis.

2 (3). Femoribus omnibus subtus spina armatis. - Cazira A. et $\mathrm{S}$.

3 (2). Femoribus anticis solis spina armatis.

4 (5). Capitis lobis lateralibus valde dilatatis, foliaceis. Leptolobus SigN.

5 (4). Capitis lobis lateralibus haud foliaceis.

6 (7). Segmento ventrali secundo basi spina brevi, lata, depressa, apice emarginata, instructo. - Glypsus DALL.

7 (6). Segmento rentrali secunto spina longitudine variabili, conica, raro compressa armato, raro subinermi.

8 (9). Spina basali ventris longa, fere ad coxas anticas producta, apicem versus sensim compressa. - Macrorhaphis DALL.

9 (8). Spina basali rentris minus longa, coxas intermedias raro aquante, interdum deficiente.

10 (11). Thoracis marginibus lateralibus anticis plus minus distincte crenulatis; spina basali rentris brevissima vel deficiente. - Canthecona A. et S.

11 (10). Thoracis marginibus lateralibus anticis integris, obtusis, convexis, sxpissime ruga subtili instructis; spina basali ventris longiore. - Platynopus $\mathrm{A}$. et $\mathrm{S}$.

12 (1). Femoribus ommibus inermibus.

1:3 (20). Veutris hasi spina armata. 
14 (15). Mesosterno longitrorsum impresso, carina destituto; angulis posticis thoracis retrorsum productis. - Cechalia STÅL.

15 (14). Mesosterno haud impresso, carina instructo; angulis posticis thoracis interdum prominulis, land tamen retrorsum productis.

16 (19). Tibiis superne sulcatis.

17 (18). Articulis secundo et tertio antennarum æque longis; ventris spina basali longa. - Mecosoma DALL.

18 (17). Articulo secundo antennarum tertio multo longiore; ventris spina brevi. - Cermatulus DALL.

19 (16). Tibiis cylindricis, superne haud sulcatis. - Claudia STÅL.

20 (13). Ventris basi inermi vel obsolete tuberculata.

21 (22). Rostro crasso; bucculis sat elevatis, percurrentibus; pedibus validiusculis. - Murmessus STÅL.

22 (21). Rostro gracili; bucculis levissime elevatis. - Asopus BURM.

\section{GLYPSUS DALL.}

List of Hem I. p. 93. (1851).

Caput planiusculum, lobis lateralibus lobo medio paullo longioribus, apice subcontiguis, bucculis modice elevatis. Rostrum crassum, articulis duobus apicalibus æque longis, singulatim secundo paullo brevioribus. Thorax marginibus lateralibus anticis ante medium crenulatis. Scutellum parte posteriore retrorsum angustata; frenis paullo ultra medium scutelli extensis. Carina sternalis lata, depressa, sulcata. Venter maris maculis sericeis destitutus, segmento secundo basi tuberculo depresso, antrorsum leviter prominulo, apice sinuato, armato. Femora antica subtus apicem versus spina armata.

1. G. moestus GERM. - Dilute griseo-flavescens, acervatim et plus minus dense fusco-ferrugineo-punctatus, capite, thorace scutelloque anterius, connexivo, lateribus ventris pedibusque obscure fuscis vel subferrugineo-nigricantibus; antennis nigris, 
articulis basi apiceque flavo-ferrugineis; parte basali liturisque apicalibus femorum nee non amulo lato tibiarum griseo-flavescentihus; maculis marginalibus abdominis maculisque ventris, in series quinque dispositis, indeterminatis, læviusculis, pallidis; angulis lateralibus thoracis nonnihil productis, apice subrotundatis. ㅇ. Long. 14, Lat. 8 mill.

Lidessa moesta Germ. in SiLb. Rev. ent. V. p. 161.87. (1837).

Asopus moestus H. ScII. Wanz. Ins. VII. p. 113 et 121. fig. 778. (1844).

Glypsus moestus DaLL. List of Hem. I. p. 93. 3. (1851).

Patria: Terra eapensis. (Mus. Holm. et Coll. Signoret).

Caput lineis tribus abbreviatis, lacrigatis, longitudinalibus. Thorax marginibus lateralibus anticis pone medium nomnihil simnatis, ante sinum crenulatis, linea longitudinali media levi, interdum subclevata. Scntellum basi maculis tribus minutis pallidis, lievibus. Hemclytra disco maculis duabus irregularibus, plus minus distinctis, e punctis densins acervatis ortis. Membrana infuscata.

2. G. conspicus WESTW. - Sordide ferrugineus, acerratim distincte punctatus, capite, thoracis antico et angulis lateralibus nee non lateribus ventris obseurioribus; thoracis, scutelli hemelytrorumque maculis irregularibus parvis, pallidis, levigatis, in disco thoracis majoribus et interdum in plagam transversam subcallosam eburneam confluentibus; maculis minutis tribus basalibus scutelli, basi femorum, annulo versus basin tibiarum, basi apiceque articulorum trium ultimormm antennarum ferrugineo-flavescentibus; maculis marginalibus abdominis maculisque ventris in series quinque dispositis testaceis; membrana infuscata; angulis lateralibus thoracis productis, apice oblique truncatis et antice sapissime in dentem prominulis. $\sigma^{7}$. ㅇ. Long. 12-16, Lat. $7-81$ mill.

Aelia conspicua Westw. in llope Cat. of Hem. I. p. 33. (18:37).

Glypsus pictiventris S'TẢ L. Öv. Vet. Ak. Förh. 1853. p. 2 I3. I. Patria: Africa meridionalis. (Mus. Holm. et Coll. SignonET.)

G. moesto maxime affinis, ohscurior, thoracis angulis lateralibus nomihil magis productis, apiec oblique truncatis, differt. 


\section{MACRORHAPHIS DALL.}

List of Hem. I. p. S7. (1851).

Caput apice subtruncatum, lobis aquilongis. Rostrum articulis duobus apicalibus subequilongis, singulatim tertio paullo brevioribus, Thorax marginilus lateralibus subcallosis, vix transversim rugosis. Scutellum parte apicali retrorsum angustata, frenis ultra medium seutelli continuatis. Carina stemalis lata, depressa, sulcata. Venter spina basali longa, compressa armatus, apud marem maculis dnalus sericeis instructus. Femora antica subtus apicem versus spina armata. Tibie antica superne leviter dilatatio.

1. I. tristis H. SCH. - Pallide sordide straminea, ferrugineo fuseoque punctata; thorace ante medium maculis phribus levigatis, suleallosis, palliclis ornato; antennarum articulis tertio, quarto et quinto ante medium nigro-fuscis; femoribus, parte hasali exceptal, ferrugineo-punctatis; tibjis basin et apicem versus infuscatis vel subferrugineis; macula segmenti rentralis sexti nigricante. $\sigma$. Y. Long. 9-13,, Lat. 4!-7 mill.

Var. b. - Obscurior, supra infuscata, nigro-punctate, maculis anterioribus thoracis parteque alpicali scutelli pallidis; connexivo, lateribus pectoris et ventris nigro-maculatis.

Asopus tristis II. ŚCH. Win\%. Ins. VIl. 1. I20. fig. 777 (1844).

Patria: Terra capensis. (Nus. Ilolm. et Coll. Signoker.)

Obovata, supra sat dense, subtus parce punctata. Caput lincis tribus lievigatis, anterins evanusenentibus, instruetum. Thorax ante medium maculis compluribus leviusculis, subeallosis, plus minus distinctis, pallidis instructus, angulis latcralibus acutiusculis, extrorsmu sat productis, validis, angulis anticis spina parral aruatis, marginibus lateralibus anticis paullo pone medium distinete siunatis. Sentellum pone medimm linea longitulinali clevata, posterius lievigatta, instructum. Tibia antica distincte punctulatie.

A Dom. Dallas pro Asopo leproso Germ., qua mili ignotir species, ventris basi spina brevi praediti, ad alind gemus certe pertinet, verisimiliter habita. 


\section{GANTHLCONA $\mathrm{A}$. et S.}

Hist. des I'́m. p. 81. (1813).

Caput planiusculum. Rostrum articulis duobus apicalibus aque longis, singulatim secundo paullo brevioribus. Thorax marginibus lateralibus anticis plus minus distincte crenulatis rel transversim lugosis. Frena ad vel paullo ultra medium scutelli extensa. Venter basi tuberculo vel spina brevi, obtuse conica, armatus. Femora antica spina armata.

1. C. figurata Gers. - Thoracis angulis lateralibus nomnihil prominentibus, oblique subtruneatis, apice inermibus; antennis nigris; membrana fusca, apice dilutiore; ventre maris maculis duabus sericeis instructo. o’. \&. Long. 9-12, Lat. $5-6 \frac{1}{2}$ mill.

Var. a. - Caruleo-nigricans rel nigro-carulea; capitis vittis tribus, interdum ad magnam partem oblitteratis, thoracis vittis quinque sublevigatis, media pereurrente exeptta abbreviatis, scutelli macula in angulis hasalibus, linea vel vitta media percurrente apiceque lavigatis, callis minutis sparsis hemelytrorum, pectoris maculis compluribus, nee non rentre Havescentibus, lutescentibus vel sangumeis; maculis connexivi, ventris fasciolis mediis maculisque transversis marginalibus nigro-carnleis rel obscure cieruleis; rostro, apice excepto, annulo tibiarum posteriorum, interdum etiam vitta supera femorum posteriorum stramineis. $\sigma^{7}$.

Asopus figuratus GerM. in Silds. liev. ent. T. p. 185. 132. (18:37); 11. ScIr. Wanz. Ins. VII. p. 11 3 et 118. fig. 710. (1844).

Canthecona Volofa I)Alu. List of Ilem. I. 1) 89. 1. (1851). excl. syn. Guḱr. et $\Lambda$. et $\mathbf{S}$.

I'ar. b. - Dilute sanguinea, supra sordicle straminea, in subsanguinem vergens; vittis quinque et afice angulorum lateralium thoracis, scutelli vittis tribus ante medium sanguineis; capitis vittis duabus, thoracis maculis indeterminatis inter vittas ante medium positis, scutelli maculis duabus majusculis basalibus, maculis nonullis pectoris, rentris fasciolis angustis discoidalibus maculisque parvis stignata inchulentibus, ammulo subapicali et 
interdum vitta supera femorum, basi apiceq̨ue tibiarmm nec non tarsis olsseure cæruleis.

Canthecona miniatescens StåL. Öfv. V'et. $\Lambda \mathrm{k}$. Förh, 1853. p. 213. 1.

Patria: Caffraria. (Mus. Holm.)

Supra sat deuse distincteque, subtus paullo remotius et fortius punctati, ventris diseo angusto subtilius punctato. Thorax marginibus lateralibus anticis ante medium cremulatis, medio nomihil simatis. Tibie antice superne rix rel levissime dilatate.

2. C. Yolofa Guér. - Angulis lateralibus thoracis nomnihil prominulis, apice spinula acuta distincta, extrorsum rergente, armatis; antennis nigris; membrana fusca, apice sordide hyalina. q. Long. $11-12$, Lat. 6 mill.

Var. a. - Straminea, supra fusco-caruleo-punctata; seutelli maculis duabus milusculis basalibus, maculis lateralibus pectoris, ventris maculis parvis discoidalibns, in series quattuor dispositis, maculisque stigmatum cæruleis.

I'ar. b. - Cruleo-ænea, vittis tribus capitis, thoracis marginibus antico et lateralibus anticis nee non vittis quinque plus minus abbreviatis, seutelli rittis trilus basin attingentibus, media percurrente, nec non apice, hemelytrorum callis nomullis minutis sparsis, maculis pectoris, rentris disco fasciisque lateralibus flarescentibus; fasciis angustis abbreviatis disci ventris creruleis.

Pentatoma yolofa Guér. Icon. Règne an. Ins. p. 344. Pl. 55. fig. 2. (1829).

Canthecona Solofi A. et S. Hist. des Ilém. p. 82 2. (1843).

I'ur. c. - Obscure cærulea, in violaceum vergens; marginibus abdominis croceis; rostro fere toto, carina sternali, coxis, trochanteribus basique femorum stramineis. (see. Daclas).

Canthecona murginella DALL. List of Hem. I. p. 89. 2. (1851).

Var. d. - Obscure cærulea, in violaceum vergens; maculis marginalibus.abdominis croceis; rostro fere toto, coxis, trochanteribus basique femornm stramineis. 


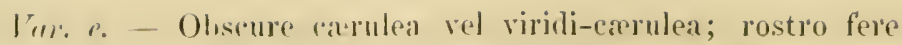
toto, rarina stemali, coxis, trochanteribus fere totis nec non hasi frmolum stramineis.

Conthecona cormleu 1)ALL. List of Hem. I. H. 89. 3. (1851). Patria: Tras: a et l. Cuninea, Senegal. (Mus. Holm. et Coli. SIRNORET); rar. d. Guinea. (Coll. SignoreT); iar.e. Fernando Po. (Mus. Holm.), Senegal. (Coll. Signoret).

C. figmeate maxime affinis, angulis lateralibus thoracis spinula armatis tiutum rliffert.

3. C. discolor P'. 33. - Sordide testaceo-flavescens, fusco-æeneopunctata; capite superne et marginibus lateralihus inferiorilus, thorace, exceptis parte hasali maculisque anterioribus plus minus confluentibus, nee non hemelytrorum margine imo costali a hasi ultra medimm fusco-xueis; membrama fuscescente; ventre apud marem marulis duabus sericeis instructo. ơ. ‥ Long. 9-11, Lat. 5-6 mill.

Pentatoma discolor P. B. Ins. p. 112. Hem. Pl. 8. fig. 3. (1805). sec. ex. typ. a Hom. SignoRE' missum.

Cunthecona discolor A. ế. Ś. IIist. des Hém. P. 81. 1. (184.3). Patria: Oware. (Coll. Signoret); Calabar. (Coll. STÃL).

P'inomero bidenti quoad statmam hamel dissimilis, spinis lateralibus thoracis quam in illo paullo gracilioribus. Capout apjee leviter bicmarginatmo. Thorax angulis latralibus in spinam smpli("em, acutiusculam, horizontalem, ('xtrorsum productis. Sentellum pone - mestimm linea fongitudiuali suberevata, sublevigata, instructum. Puncta liemelytrorm acervata. fiemora fusco-ieneo-conspersa. Tibie, partc apicali fibiam anticarmm racrpta, fusco-aence.

4. C. Havirostris STAL. - Nigra; antemuis, lostro ad parten, callis minutis sparsis thoracis, callo paro in angulis basalibus marginepue apicali sentelli, manulis parvis marginalibus abdominis, basi femorum, ammulo lato tibiarum nec non tarsis stramineis, interlum finsescente-stramineis; articulis duobns apicalibus antemuanum, basi rexeptat, nec non apice anticulorum tarsolum nigris; angulis posticis pretoris fusco-pmuctatis; rentre ntriusque sexus maunlis serieris elestituto. o’. q. Lonֻ. I)! Lat. in! mill. 
Pieromerus fluvirostrum Sign. Ann. ent. Sér. 3. VIII. p. 920. 77. (1861).

Patria: Madagascar. (Coll. SignoreT et STẢL.)

Supra dense, subtus remotius, distincte punctata. Caput appice integrum et obtusissime rotundatum, lobo medio apice depresso. Thorax marginibus lateralibus anticis uedio distincte sinuatis, ante medium obsoletissime eremulatis, angnlis lateralibus in spinam horizontalem acutiusculan, appice posterius sinuatam, extrorsum produetis, linea media longitudinali obsolete cheviata. Mr'mbramil fusca. Venter disco lieviusculus, angulis posticis segmentorum leviter prominulis.

\section{PLATYNOPUS' $\Lambda$. et s.}

Hist. des Hén. p. 79. (1843).

Caput haud dilatatum. Thorax marginibus lateralibus anticis convexis vel obtusis, integerrimis, ruga subtili lavigata sapissime instructis. Frena ad vel ultra medium scutelli contimuata. Venter segmento secundo basi spina distincta, graciliuscula, haud compressa, armato. Femoral antica spina amata.

Mares hujus generis mili sunt ignoti.

a. Angulis lateralibus thoracis spinosis.

b. Tilieis anticis sat lilatutis.

1. P. Thomsonii Sigs. - Rufo-testaceus, nitidus; antemnis nigris; capite, angulis spinisque lateralibus, vitta uredia, interdum abbreviata, maculisque duabus magnitudine variabilibus thoracis, maculis pectoris tribus lateralibus, sxpe confluentibus, ano pedibusque obscure creruleo-ieneis, interdum in nigrum vergentibus; rostro fusco, articulo hujus secundo, disco pectoris, spina basali ventris, coxis, trochanteribus femoribusque basin versus stramineis; tibiis anticis violaceo-indutis; membrana riolaceo-fusca, apice albido-hyalina. \&. Long. 10-11, Lat. $4 \frac{1}{2}$ mill.

Platynopus Thomsonii Sign. in Thons. Arch. ent. 1I. p. 277. 509. (1858).

Var. a. - Vitta scutelli postice abbreriata hemelytrisque nigricantibus, his apice rufo-testaceis.

Var. b. - Scutello impicto; hemelytris rufo-testaceis. 
Patria: Calabar. (Coll. A. DonRs, Signoret et S'Tal.)

Subovalis, nitislus. Caput, thorax et seutcllum remote et distinete punctatil, thoracis spatjo transverso antico elevato, levigato. Hemelytra levia, opaca, apies limboque costali corii distinete punetulatis. Pretus paree punetatum. Venter lavis, ad margines laterales rlistincte punctulatus, angulis inis apicalibus segmentorum levissime acute prominulis. Thorax marginibus lateralibus anticis pone mediun distincte simlatis, ruga subtili lievi instucuetis, angulis lateralibus in spinam cylindricam, horizontalcm, mediocrem, extrorsmm productis. Sentelhm apiee late rotmulatmm, marginibus lateralibus partis dimidie postice parallelis. Carnina sternalis distinctissima, hiatusl suleata.

2. P. rostratus DrtrY. - Niger vel subanescente-niger; thoracis maculis nonullis ante medium, lateralibus interelum in magnam irregularem confluentibus, nec non macula marginali ante angulos posticos, scutelli maculis duabus magnis et interelum media minore basalibus apicegue nee non macula apicali corii croceis; rostro, maculis compluribus pectoris carinaque sternali, rentris disco maculisque compluribus latteralibus, coxis, trochanterilıs, basi maculisque suhapicalilus femorum, annulo tibiarum tarsisque stranineis; membrana fusea, apice dilutiore. \&. Long. $11-12$, Lat. $5 \frac{2}{3}-6 !$ mill.

Cimex rostratus DrenY. III. nat. list. III. p. 59. PI. 43. fig. 3. (1782).

Cimex calens FAnR. Syst. Rhyng. p. 163. 41. (1803).

Platynopus rostratus DALL. List of IIem. I. p. 163. 41. (1851).

I'ar. 1. - Dilutior, fusco-testaceus, corpore subtus, pedibus maculisque superiorihus sordide stramineis; ventre subimmaculate vol parce fusco-maculato; pedibus pilre fusco-notatis.

Pentatomu 17-maculata P. B. Ins. p. 112. 11em. PI. 8. fig. 4. (1805).

A.sepus calens 11. Scir. Wanz. Ins. VI1. p. 113 et 117. fig. 709. (1844).

Patrial Calibill. (Mus. Holm., Coll. Sigronet et Stril); Nierral Leona ot Congo. (Mus. Brit.)

Obovalus, subnitidus, supran remote distincte punetulatus, hemeIytris opacis, levibus, claro, corii apiec limboeque costali parec pum- 
ctatis. Pectus parce punctatum. Venter latera versus punctis raris conspersus, prope margines laterales nomilil densius punctatus, angulis posticis segmentorum levissime prominulis. Caput marginibus lateralibus parallelis, vix sinuatis. Thorax marginibus lateralibus anticis subrectis, angulis lateralibus in spinan obtusan, subcylindricam, breviusculam, horizontalem, productis.

bb. Tibiis anticis levissime dilatatis.

3. P. Reichii Sign. - Supra fusco-subferrugineus, subtus cum rostro pedibusque stramineus, lateribus pectoris ventrisque obscurioribus; antennis nigro-fuscis, horum articulo primo toto, quarto et quinto basi, maculis parvis callosis, irregularibus, sparsis thoracis, macula majuscula callosa in aneulis basalibus, linea longitudinali elevata pone medium magineque apicali lævigatis scutelli nec non callis nonnullis sparsis hemelytrorum stramineis; femoribus fusco-conspersis; tibiis basin et apicem versus fuscis; membrana fuscescente, apice pallidiore, vitta obscure fusca ornata. ․ Long. 11! , Lat. $5 \frac{1}{3}$ mill.

Platynopus Rrichii Sign. in Tirosis. Areh. ent. Il. 1. 276. 508. (1858).

\section{Patria: Calabar. (Coll. Signoker.)}

Secundum exemplum typicum in spiritu olin asservatum descriptus. Anguste suboralis. Caput, thorax et scutellum subfortiter et minus dense, hemelytra paree subtiliterque, lastera pectoris et ventris distincte et minus dense punctata, spatio parvo pone medium corii lievigato. Caput ante oculos utrimque distincte nomnihil simuatum, apice obtuse rotundatum, lineis vel vittis duabus angustis, laevigatis, pereurrentibus, extrorsum convergentibus, iustruetum. 'Thorax linea media subelevata instructus, marginibus lateralibus anticis pone medium leviter sinuatis, ruga subtili laevi instructis, angulis lateralibus in spinam minorem, integram, horizontalem, extrorsum productis. Venter disco laevis, angulis posticis segmentorum leviter prominulis, spina basali coxas posticas haud superante.

aa. Angulis lateralibus thoracis inermilnus.

4. P. innocus STÅ. - Rufo-testaceus; antennis, rostro, oculis pedibusque nigris; pectore, excepto limbo laterali prostethii, segmentis basali et apicali ventris anoque rnescente-nigris; membrana fusca, apice sordirle hyalina. ㅇ. Long. 13, Lat. 6 mill. 
Patria: (inineat. (Cull. sirisurkt.)

Verisimiliter sprecies variabilis. Oblongus, nitidus, sat dense distinetergue punetatus, hemelytris subtiliter punctulatis; vittis duabus angustis retrorsun convergentibus eapitis, linual longitudinali media maculisyue duabus irregulinribus antrioribus thoracis, ruga lougitudinali perenrente: undia, antrins obsoletione, vittisque duabus obsoletis posterioribus scutelli, maculat laterali mesostethii et unctastethii nec nou diseo angusto rentris lievigatis. C'aput apice truncatum, angulis apicalibus rotundatis, marginibus latcralibus parallelis, vix sinnatis; bueculis levissime elevatis. Thorax convexinsculus, marginilus latcralibus anticis pone unedium distincte simuatis, ruga subtili levi instructis, angmlis laterialibus subprominentibus, rectis, apice rotunclatis. ineruilus. Sicotcllum apiee semicireulariter rotundatum, marginibus lateralihus partis dimiliat posticat parallelis. Henclytra opacia. Carina strmalis stramina, latinseula, anterins latior. Spina basalis ventris straninueid, conica, sulggracilis, coxas intermedias hand superans. Anguli postici segurntormu ventris acutiusenli, leviter prominuli. Articuli duo ultini antennarmu ('x'mpli descripti mutilati.

\section{LEPTOLOBUS' SIGN. \\ Inn. ('n1. Ser 3 III. p. 62. (1855).}

Caput concavum, lobis lateralibus loho meslio longioribus, valde dilatatis, foliaceis; hurculis sat elevatis, postice angulatim conjunctis. Oculi sat prominentes. Rostrum articulis duobus apricalibus an unum secundo nomihil longioribus. Thorax medio constrictus, lateribus convexis, marginibus lateralibus ruga subtili instructis, integerimis. Scutellum parte apjicali sat angusta, retrorsum angustata, frenis ultra medium sentelli continuatis. Segmentum rentris secundum basi tuberenlo parro, antrorsum levissime prominulo, armatmu. Pedes gralciles, longiusculi, femoribus antiris subtus apicem rersus spina armatis, tibiis anticis simplicibus.

1. I. Murrayi Sigs. -- Corallinus, nitidus; antennis rostroque nigris; eapite, thoracis spinis lateralibus maculaque maxima utrimqque laterali lubi postici, macula ante medium scutelli, marula magua menlia rorii, Haga ohlonga laterali pectoris, sermentis rentris duobus ultimis, excepta macula basali segnenti penultimi, nec non ano pedibusque violaceo-caruleis; regione aretabulorum coxisque pallide stramineis; membrana fuscal, apice decolore. \%. Lome. 15, Lat. 5 mill. 
Leptolobus Murrayi Sign. Ann. ent. Sér. 3. III. p. 63. Pl. 7. fig. IV. (1855).

Patria: Calabar. (Coll. STÁL.)

Oblongus. Caput, thoracis margo anticus et lobus posticus nec non scutellum remote distincteque punctata, hujus ruga longitudinali media levigata. Thoracis lobus anticus convexus, lobus posticus lobo antico vix duplo latior, angulis lateralibus in spinam sat longam, gracilem, extrorsum et subsursum prominentem, produetis. IIemelytra levia, opaca. Prostethimn parce punctatum. Venter levis, latera versus punctis raris conspersus.

\section{MECOSOMA I)ALL.}

List of IIem. I. p. 104. (1851).

Caput apice obtuse subrotundatum, marginibus levissime reflexis. Rostrum articulis tertio et quarto aquilongis, singulatim secundo paullo brevioribus. Antemne breviuscula, minus graciles, articulis secundo et tertio subaqualibus. Thorax marginibus lateralibus anticis acutiusculis, levissime reflexis. Scutellum parte apicali retrorsum leviter angustata; frenis ultra medium scutelli continuatis. Carina sternalis distineta. Venter basi spina longa, apicem versus compressa, ultra medium mesosterni producta, armatus. Pedes mediocres, femoribus inermibus, tibiis superne sulco lato, fundo plino, instructis, anticis simplicibus.

1. II. Ilenser Germ. - Anguste obovatum, flavo- vel rufo-testaceum, dense distincteque punctatum; antennis nigris; pedibus, interdum etiam rostro, nigro-piceis; capitis lobis lateralibus maculisque duabus triangularibus basalibus, thoracis fascia antica et vitta laterali obliqua intramarginalibus, continuis, nec non macula trausversa maxima pone medium posita, interdum pallidiore et obsoleta, scutelli vitta basin versus dilatata impressioneque angulorum basalium, clavo, corii vitta marginali postice abbreviata fasciaque obliqua posteriore, nigricantibus vel subieneo-fuscis; membrana fusca, apice decolore. f. Long. 12, Lat. 5 mill. 
l'ar. l. - Impressionibus pectoris, ventris fasciis utrimque abbreviatis et medio interruptis, macula segmenti sexti anoque rnescente-nigris.

Asopus mensor Geru. in Silb. Rev. ent. V. p. 186.134. (18.37).

lihuphiguster mensor II. Scir. Wanz. Ins. VIII. p. 7. fig. 713. (1848).

Mecosoma mensor DaLl. List of IJem. I. p. 105. 1. (1851). Patria: Caftraria. (Mus. Holm.)

2. I. Coquerelii Sigs. - Oblongo-obovatum, supra rufo-testaceum, subtus dilute flaro-testaceum, totum dense distincteque punctatum; capitis apice et basi, rostro, thoracis fascia antica et macula magna transversa posteriore, scutelli macula ovali ante medium, apice impressioneque angulorum basalium, corii fiscia recta posteriore, macula laterali prostethii, macula laterali segmentorum ventris secundi et tertii discoque segmenti ultimi, nee non pedibus ænescente-nigris; membrana fusca, apice decolore; femoribus ante medium linea flavescente. q. Long. 13, Lat. 5 mill.

Mecosuma Cornerelii Sign. Ann. ent. Sér. 3. V'III. p. 922. 79. Pl. 13. fig. 2. (1861).

Patria: Mallagascar. (Coll. Sigronet.)

M. Mensori simillimum, statura angustiore fisciaque posteriore corii hatud obliqua differt.

\section{CLAUDIA STAL.}

Corpus obovatum. Caput apice subtruncatum, lobis aquilongis. Rostrum articulo secundo primo paullo longiore. Antemna articulis secundo et tertio rquilongis rel secundo tertio paullo longiore. Thorax convexiusculus, marginibus lateralibus anticis oltusis, integerrimis, haud callosis. Scutellum parte apicali retrorsum angustata; frenis ad medium scutelli extensis. Carina sternalis distincta. V'enter basi spina annatus. Femora incrmia, Tibia superne convexinsculie, haud suleate.

Zicrome atfine genus. 
1. C. paronina Westw. - Viridi-ænea, cupreo-ænea vel obscure crerulea, minus dense punctulata, nitida; carina sternali, ventris spina basali, raro etiam vitta media, angulis apicalibus segmenti ultimi ventris, coxis, trochanteribus, basi et interdum fascia subapicali femorum, annulo latitudine variabili tibiarum, nec non basi tarsorum stramineis; ventre maris maculis duabus magnis griseo-sericeis instructo. $\sigma^{7}$. ㅇ. Long. $7-8$, Lat. $4-4 \frac{1}{2}$ mill.

Pentatuma paconinu WEsTw. in Hope Cat. of Hem. I. p. 39. (18:37).

Asopus cumulipw's Germ. in Silb. Rev. ent. V. P. 187. 136. (1837).

Zicronce paconiua DALI. List of 11 em. I. p. 108. 3. (I851). Patria: Africa meridionalis. (Mus. Holm.)

Variat rostri articulis duobus basalibus, vitta ventris maculisque ani (apud individua riridi-ienca) stramincis, fascia subapicali fenorum anmuloque tibiarum fere omnino deficientibus.

2. C. Iulirentris STẢL. - Cærulea, nitida, punctulata; rostri articulo secundo et interdum tertio, carina sternali, spina basali angulisque segmenti ultimi ventris, coxis, trochanteribus, basi et interdum fascia prope apicem femorum, annulo lato tibiarum basique tarsorum stramineis; ventre utriusque sexus maculis sericeis destituto, o?. \&. Long. 7-8, Lat. $4-4 ! \frac{1}{2}$ mill.

Patria: Sierra Leona. (Mus. Ilolm.)

Precedenti maxime aftinis et simillima; femina specierum ambarum difficillime et 100 nisi capite apud $C_{\text {. mediventrem anterius }}$ angustiore et thorace paullo latiore inter se distinguuntur.

\section{MARMESSUS STÅL.}

Corpus ovale. Caput apice truncatum, ante oculos utrimque sinuatum, marginibus lateralibus ante sinum parallelis; bucculis distincte elevatis. Rostrum crassum, articulo secundo apicalibus duobus ad unum paullo breviore, ultimo penultimo vix duplo longiore. Antenne articulo secundo tertio paullo longiore. Thorax marginibus lateralibus anticis leviter crenulatis. Scutellum 
parte apicali latiusculi, retrorsum leviter angustata; frenis vix ultra mediun scutelli extensis. Mesosternum leviter carinatum. Venter basi tuberculo minuto instructus. Pedes inermes, tibiis simplicibus, supra sulcatis.

1. M. nigricornis STẢL. - Sordide testaceo-flavescens, totus acervatim distincte subæneo-nigro-punctatus; comnexivo æneonigro-maculato; antennis nigris. ơ. Long. 14, Lat. 8 mill. Patria: Natalia. (Coll. SignoneT.)

Thorax linea longitudinali lievi instructus, marginibus lateralibus anticis pone medium leviter simnatis, angulis lateralibus nonnihil productis. Scutellnm basi in angulis impressione nigral et ad impressionem callo minuto laevi pallido instructun, rugal longitudinali levi. Membrana fuseesecns. Venter maris maeulis sericeis destitutus.

\section{Subf. PENTATOMII) STÅL.}

\section{Conspectus generum.}

1 (12). Scutello maximo vel magno, frenis bullis vel brevissimis instructo; thorace angulis lateralibus numquan emarginatis, ante angulos laterales dente destituto; lobis lateralibus capitis anterius sapissime contiguis.

2 (7). Capitis lobis aque longis; scutello maximo.

3 (6). Tibiis cylindricis, supra haud sulcatis.

4 (5). Capite perpendiculari, basin versus sat convexo; frenis nullis. - Cyptocoris Burs.

5 (4). Capite oblique declivo, frenis brevibus. - Sepontia STAL.

6 (3). Tibiis prismaticis; capite perpendiculari. - Tarisa 1. et $\mathrm{S}$.

7 (2). Cajitis lohis lateralibus Iobo medio longioribus, anterius contiguis.

8 (I1). P'rostethio antice distinete dilitato.

9 (10). Corpore (rasso, subtus valde convexo; scutello latissimo, a basi sensim ampliato. - Trigonosomu LaP.

10 (9). Corpore depresso, subtus parum convexo; scutello abdomine hemelyt risque angustion. - Leprosome Bäressple. 
11 (8). Prostethio antice haud vel vix dilatato; scutello abdomine hemelytrisque nonnihil angustiore. - Bollocoris A. et $\mathrm{S}$.

12 (1). Scutello mediocri, raro magno; frenis sxpissime ad vel ultra medium scutelli extensis, raro brevissinis.

13 (14). Corpore pedibusquie tuberculatis; scutello mediocri, triangulari. - Phymatocoris STẢL.

14 (13). Pedibus hand tuberculatis.

15 (86). Ventris basi nec spinosi nec tubereulo antrorsum prominulo instructo.

16 (17). Thoracis angulis posticis lobatis, retrorsum productis; capite crisso, subcylindrico. - Eurhinocoris STAR.

17 (16). Thoracis angulis posticis nec lobatis, nec retrorsum prominulis.

18 (83). Bucculis sæpissime modice rel parum elevatis; venis alarum primaria et subtensa parallelis, subcontiguis vel leviter distantibus, apice divaricatis, aream angustissimam, apice angulato-dilatatam, includentibus.

19 (22). Frenis brevissimis vel brevibus, medium scutelli haud attingentibus; thorace paullo ante angulos laterales dente armato, angulis anticis dente extrorsum vergente instructis; scutello sæpissime longo.

20 (21). Scutello abdominis apicem attingente. - Podops LAP.

21 (20). Scutello abdomine breviore. - Thoria STAL.

22 (19). Frenis medium scutelli sæpissime attingentibus vel superantibus; thorace, apud genera frenis breviusculis instructa, ante angulos laterales dente destituto.

23 (28). Antennis quadriarticulatis.

24 (25). Capitis marginibus lateralibus ante oculos tuberculisque antenniferis spina longa armatis; pedibus inermibus. Phricodus SPIN.

25 (24). Capite ante oculos inermi; femoribus spinosis.

26 (27). Antennarum articulo secundo dilatato, compresso. Atelocera LAP.

27 (26). Antennarum articulo secundo tereti. - Memmiu STá. 
28 (23). Antennis quinquearticulatis, articulo serumblo marium apurl species quasdam brevissimo, annuliformi.

29 (30). Capitis marginibus lateralibus irregulariter serratis rel crenulatis. - Urthoschizops SPIN.

30 (29). Capitis marginibus integris.

31 (38). Capite triangulari, longo vel longiusculo, antrorsum seusim angustato, lobis lateralibus plus minus acuminatis, lobo medio longioribus et anterius contiguis, apice interdum leviter hiscentibus; articulo basali rostri bucculis breviore.

32 (35). Bucculis sat elevatis, postice subito abbreviatis et retrorsum angulatim prominulis rel in lobulum productis.

33 (34). Corpore obovato; antennarum articulo secundo tertio fere ter longiore; pedibus validis, tibiis supra late sulcatis. - Antonia S'TiL.

34 (33). Corpore anguste obovato vel suboblongo-obovato; antennarum articulis secundo et tertio longitudine variabilibus; pedibus mediocribus, tibiis sulcatis. - Ni- $_{i}$ jloxys A. et S.

35 (32). Bucculis minus eleratis, postice humilioribus, nec sublobatis; pedibus mediocribus, femoribns apice inermibus.

36 (37). Corpore anguste obovato; thoracis angulis anticis antrorsum prominentibus. - Curatia STiL.

37 (36). Corpore oblongo; thoracis angulis anticis haud productis. - Michelueppluelu STÁL.

38 (31). Capite raro triangulari, apice truncato vel rotundato, lobis lateralibus apice sapissime obtusatis, rarissime acutiusculis et lobo medio paullo longioribus, articulo primo rostri bucculas tunc postice aquante.

39 (56). Marginibus hateralibus capitis thoracisque distincte explanatis, acutis, his integris, raro obsoletissime crenulatis.

40) (5.3). Tihiis haud rel breviter setulosis; tarsorum postienrum articulo primo apicalibus duobus ad unum breviore vel vix longiore. 
41 (52). Scutello apice angusto, pone medium utrimque sinuato; frenis ultra medium scutelli extensis.

42 (43). Rostri articulo secundo duobus apicalibus ad unum longiore. - Dymantis STALL.

43 (42). Rostri articulo secundo apicalibus duobus ad unum breviore.

44 (45). Articulo basali antennarum capitis apicem æquante vel subsuperante. - Caystrus STÅL.

45 (44). Articulo basali antemnarum capitis apicem haud attingente.

46 (51). Femoribus apice superne inermibus.

47 (50). Corpore ovali.

48 (49). Capite ovato vel rotundato, tuberculis antenniferis a supero hand distinguendis. - Paramecocoris ŚTÂL.

49 (48). Capite triangulari, apice angulato, tuberculis antenniferis a supero distinguendis. - Cocalus STÅL.

50 (47). Corpore valde oblongo. - Sephela $\mathrm{A}$. et S.

51 (46). Femoribus apice superne spinula armatis. - H/yrochea A. et $\mathrm{S}$.

52 (41). Scutello apice lato vel latiusculo, lateribus rectis, haud vel vix sinuatis; frenis medium scutelli haud attingentibus, ultra medium saltem haud extensis. - Scivcoris FALL.

53 (40). Tibiis longe setosis; tarsorun posticorum articulo primo apicalibus duobus ad unum longiore.

54 (55). Tarsormm posticorum articulo primo apicalibus duobus ad nnum duplo longiore. - Pododus $\mathrm{A}$. et $\mathrm{S}$.

55 (54). Tarsorum posticorum articulo primo apicalibus duobus ad unmm nomnihil longiore. - Menaccurus $A$. et S.

56 (39). Marginibus lateralibus capitis thoracisque simul haud explanatis, marginibus lateralibus thoracis integris vel serrulatis, raro dilatatis.

57 (58). Capite triangulari, longo, lobis lateralibus lobo medio longioribus, acuminatis, anterius contiguis; corpore subelongitt). - Mecideca DaLL. 
58 (57). Capite ovato vel ovali, raro subtriangulari, apice rotundato vel truncato; corpore haud elongato.

59 (60). Corpore toto piloso; rostro longo vel longissimo; tibiis cylimlricis, superme haud sulcatis. - Agonoscelis SPIx.

60 (59). Corpore nudo, raro piloso; rostro variabili; tibiis apud genera pilosa superne sulcatis.

61 (70). Ventre plus minus distincte sulcato; rostro longo.

62 (69). Thoracis marginibus lateralibus anticis crenulatis rel serratis, nec incrassatis, nec reflexis.

63 (68). Ocellis pone lineam fictam, inter basin oculorum ductam, positis.

64 (65). Membrana venis paucis, furculatis vel ramulosis, instructa; capite anterius angustato, apicem articuli primi antemnarum longe superante; rostro longissimo; ventre profunde sulcato. - Halys FABR.

65 (64). Membrana renis compluribus, simplieibus rel furcatis, instructa.

66 (67). Corpore nudo; capitis lobis lateralibus apice extus oblique truncatis; articulo primo antennarum capitis apicem haud attingente. - Coenomorpha DALL.

67 (66). Corpore piloso; capitis lobis lateralibus apice extus rotundatis; articulo primo antemarum capitis apicen aquante. - Scribonia STÀL.

68 (63). Ocellis in linea ficta, inter basin oculorum ducta, positis. - Dalpada A. et S.

69 (62). Thoracis marqinibus lateralibus reflexis, incrassatis, integris vel crenulatis. - Agaus DALL.

70 (61). Ventre haud sulcato; rostro mediocri.

71 (72). Capitis lobis lateralibus lobo medio multo longioribus et anterius contiguis; marginibus lateralibus anticis thoracis denticulatis. - Eurus DALL.

72 (71). Capitis lobis lateralibus lobo medio sxpissime haul longioribus, raro longioribus et apice contiguis, marginilus lateralibus thoracis tune integris.

$73(80)$. Orulis sessilibus. 
74 (79). Rostri articulo secundo tertio distincte longiore, apicalibus duobus ad unmm interdum requali.

75 (76). Thoracis marginibus lateralibus anticis et antico simul numquam elevatis vel reflexis, lateralibus anticis solis vel antico solo rarissime anguste subelevatis. - Pentatoma OL.

76 (75). Thoracis marginihus lateralibus anticis et antico vel antico solo (hoc late) elevatis rel reflexis.

77 (78). Thoracis margine antico latiuscule elevato. - Afronio STAL.

78 (77). Thoracis marginibus antico et lateralibus anticis sinul elevatis vel reflexis. - Antestia Stí.

79 (74). Rostri articulo secundo tertio aquali vel sublreviore. Catacanthus SipIN.

80 (73). Oculis brevissime stylatis.

81 (82). Thorace distincte sexangulari. - Stenozygum Fieß.

82 (81). Thorace subquadrangulari, inter angulos laterales posterius late rotundato, angulis posticis deletis. - $\mathrm{Ba}$ grada S'TẢL.

83 (18). Bucculis valde elevatis, interdum subsemiorbicularibus; venis primaria et subtensa alarum distantibus, aream angustam, apice nee dilatatan, nee angulatan, includentibus.

84 (85). Antennis quadriarticulatis. - Dinidor LATr.

85 (84). Antennis quinquearticulatis. - Aspongopus LAP.

86 (15). Ventris basi spinosa vel tuberculata.

87 (96). Bucculis leviter elevatis, postice quam antice haud rel vix altioribus.

88 (89). Ventre sulcato. - Bathycoelia A. et S.

89 (88). Ventre haud sulcato.

90 (95). Thoracis marginibus lateralibus anticis et antico nec elevatis nec reflexis, vel marginibus lateralibus anticis solis rel margine antico solo leviter calloso-elevatis.

91 (94). Scutello retrorsum sat angustato, apice angustulo; frenis ad vel ultra medium scutelli extensis. 
92 (93). Thoracis margine antico haud rel medio tantum leviter sulialluso. - Nezara A. et S.

93 (92). Thoracis margine antico toto calloso. - Mautia ŚTẢL. If (91). Scutello apice lato, frenis medium seutelli haud attingentibus; metasterno elevato. - Flaminic STÁL.

95 (90). Thoracis marginibus antico et lateralibus anticis distincte reflexis rel calloso-elevatis. - Antestia S'TAL.

96 (87). Bueculis valde elevatis, postice quam antice altioribus; lobis lateralibus capitis antice contignis. - Platacantha H. Sícil.

\section{CYPTOCORIN BURM.}

Handb. 11. 1. p. 387. (1835).

Corpus ovatum vel ovale, supra subtusque modice convexum. Caput breve, valde deflexum, subperjendiculare, sat convexum, ante oculos utrimque nomilial sinuatum, apice rotundatum; bucculis postice altioribus. Oculi parum prominentes. Rostrum coxas intermedias attingens, articulo primo bucculis paullo breviore. Antenna gracillime, articulo primo sequentibus duobus singulatim breviore, secundo et tertio subxqualibus $\left(\sigma^{\top}\right)$ vel tertio secumblo nomiluil longiore (f). Thorax vix sexangularis, angulis posticis obtusissime rotuntatis, vix distinguendis, marginilus lateralibus anticis longis, olstusis, lateralibus posticis brevilus. Scotellum maximum, abdomini aquilatum. Sterna sulcata. Prostethium antice simplex. Pedes mediocres, subgrit,iles, tiliis subcylindricis, haud sulcatis.

1. C. Lumbii JABR, - Oratus, sat fortiter punctatus, anescenteniger, nitidus; antemnis, rostro, limbis lateralibns anticis thoracis, limbo lato libero scutelli, limbo costali hemelytrorum, marginibus lateralibus prostethii ventrisque nece non tibiis frallide flaveseentilus, his apice subtus nigris; eapite ante medium transversim sat distincte impresso, basin versus sat comvexo; thorace retrorsum minus ampliato; scutelli limbo flavo minus dense nigro-punctate, punctis plurimis in seriem agreregatis. f. Long. 11, Lat. 7 mill, 
Tetyra Lundii FABR. Syst. Rhyng. p. 133. 25. (1803).

Cypitocoris Jundii BurM. Ilandb. II. I. p. 388. I. (I835); DALL. List of Hem. I. p. 4:3. 1. (1851).

Patria: Guinea. (Mus. Holm. et Coll. S'TaL.)

2. C Walbergi STAL. -- Subovalis, distincte punctatus, anescente-niger; antennis, rostro, limbis lateralibus anticis thoracis, limbo lato libero scutelli, limbo costali hemelytrorum, marginibus lateralibus prostethii rentrisque nec non tibiis pallide flavescentibus; capite ante medim hand vel vix inpresso, posterius minus convexo; thorace retrorsum sat ampliato; scutelli limbo flavo parce nigropunctato, punctis in seriem, sape minus distinctam, aggregattis. o*. \&. Long. 1011, Latt. 6-7 mill.

Cyptocoris Lumelii GerM. Zeitschr. I. 1. 50. 1. P’. 1. fig. IV. (1839). excl. syn.

Patria: Caffraria, Terra capensis. (Mus. Holm.)

Precedenti maxime affinis, ante medium antrorsum minus angustatus, corpore igitur magis ovali, nee ovato, punctis limbi flavi seutelli minus muncrosis, in seriem minus distinetan dispositis, differt.

TARISA \. et S.

llist. des 1lém. 1. 59. (18433).

Corpus obovatum. ('aput convexum, leflexum. Iobis axualibus; bucculis value elevatis. Antenne breviuscule. Scutellum maximum, hemelytris vix vel paullo angustius, apice rotundatum, frenis nullis. Sterna profuncle sulcata. Pedes breviusculi, tibiis supra planis.

1. T. subspinosa Gikn. - Obovata, subtus modice convexa, flavo-virescens, sat dense punctulata; thorace tuberculis destituto, margine basali recto, angulis posticis haud prominulis; scutello disco tuberculo oblongo, leviter elevato, posterius altiore, instructo. ơ. Long. 4!

Graphosoma subspinosa GERм. Zeitschr. I. p. 54. 10. (1839). Tetyra (Trigonosoma) subspinosa KLUG. Symb. phys. V. Tab. 43. fig. 7. (1845).

Patria: Aegyptus. (Mus. Holm.) 


\title{
TRIGONOTOMA LAP.
}

\author{
Ess. Hém. 1) 69. (153\%).
}

Corpus late olovatum, subtus valde convexum. Caput deHexum, planiusculum, antrorsum angustatum, apice rotundatum, marginibus lateralibus leviter sinuatis, lobis lateralibus lobo medio longioribus et ante hunc contiguis; bucculis valde elevatis. Rostrum pedes posticos attingens. Antenna mediocres, articulo primo (apitis apicem haud attingente. Thorax anterius valde declivis, margine basali recto. Scutellum maximum, abdomine hemelytrisque haud vel farum angustius. Prostethum margine antico utrinclue lobato, producto. Sterna profunde sulcata. Pedes valicliusculi, tibiis subtriquetris.

I. T. lischeri H. Scr. - Griseo-flarescens, distincte, remote, minus obseure fusco vel subferrugineo-functatum, supra obscurior et interdum in ferrugineo-fuscescentem vergens, capite thoracisque parte dimidia antica semper pallidioribus, hujus angulis lateralibus extrorsum et leviter antrorsum modice productis, apice rotundatis, marginibus lateralibus anticis leviter sinnatis, ruga latiuscula inter angulos laterales extensa levigata, parum elevata, antice latera versus fusco-marginata; seutello liemelytris paullo angustiore. 우 Long. I0 $\frac{1}{2}$, Lat. $7 \frac{1}{2}$ mill.

Trigonosoma Fischeri II. ScII. Wanz. Ins. IX. p. 331. (18533).

Trigonosoma Barenspmengi STîL. Berl. Ent. Zeitschr. IV. p. $277 .(1860)$.

Patria: Aegyptus. (Mus. Holm. et Coll. StäL.)

2. T. obesmm STÄL. - Dilute griseo-flavescens, totum sat dense distincteque punctatum; capite ante sinus laterales haud ampliato; thorace angulis lateralibus extrorsum et leviter antrorsum modice productis, apice rotundatis, marginibus lateralitus anticis sinuatis, ruga transversa lavigata uulla; scutello pone medium hemelytra occultante, basi transversim leviter alerato; rentris margine haud tuberenlato. $\sigma$. Long. 9. Lalt. (5 mill. 
Patria: Aegyptus. (Coll. STÂL.)

T. Nigelle proximum, colore dorsi, thoracis angulis lateralibus productis marginibusque lateralibus anticis sinuatis differt.

\section{LEPROSOMA BERENSPR.}

\section{. Berl. Ent. Zeitschr. 11I. p. 336. (1859).}

Corpus subovale, subdepressum, subtus parum convexum. Caput subproductum, antrorsum nomihil angustatum, apice rotundatum, lobis lateralibus lobo medio longioribus et antice contiguis; bucculis sat elevatis. Rostrum coxas posticas attingens. Antenna mediocres, articulo primo capitis apicem haud attingente. Thorax anterius parum declivis. Scutellum abdomine hemelytrisque multo angustius, apicem abdominis attingens. Prostethiun antice lobatum. Sterna profunde sulcata. Pedes breviusculi, tibiis subtriquetris.

Trigonosomati affine genus.

1. I. reticulatum H. ScH. - Griseum, sat fortiter punctatorugosum; thorace callis minutis irregularibus disco instructo, angulis lateralibus rotundatis, leviter prominulis, marginibus lateralibus anticis ante medium distincte sinuatis; scutello parte basali retrorsum leviter angustata, marginibus lateralibus dein subparallelis, callo obliquo in angulis basalibus rugaque longitudinali minus elerata percurrente instructo, angulis basalibus impressis, fuscis; abdominis marginibus obsolete crenulatis, angulis apicalibus segmentorum distincte prominulis; pedibus parce minuteque nigro-conspersis. $\sigma$. Long. $5 \frac{1}{2}$, Lat. $3 \frac{1}{2}$ mill.

Trigonosona reticulatum H. ScH. Wanz. Ins. IX. p. 332. (1853).

Patria: Aegyptus. (Coll. Signoret.)

\section{BOLBOCORIS A. et $\mathrm{S}$.}

Hist. d's Hén. p. 50. (1843)

Corpus crassum, breve, late ovale vel obovatum. Caput deflexum, triangulare, convexiusculum, lobis lateralibus lobo me- 
dio longioribus et ante hunc contiguis; bueculis sat elevatis. Antemna breviusculie. Thorax convexus, anterius modice declivis, angulis posticis obtuse rotundatis, haud productis. Scutelfum latum, abolomine hemelytrisque tamen angustius, abdominis apirem attingens, frenis brevissimis. Hemelytrorum pars exterior scutello haud tecta. Sterna profunde sulcata. Venter, presertim latera versus, valde comvexus. Pedes breviusculi, tibiis supra leviter sulcatis.

1. B. rufus WEsTW. - Varicolor, remote subfortiter punctatus; antemnis pedibusque dilute flavescentibus, illarum articulis ultimo vel duobus ultimis, coxis, trochanteribus basique femorum posteriorum nigris; thoracis rugi transversa, scutelli rallis tribus bassalibus, lateralibus majoribus, rugaque longitudinali, posterius distinctiore, lavigatis; scutello anterius utrimque oblique impresso, lateribus ultra medium parallelis, haud sinuatis; bucculis dente acuto armatis; tibiarum angulis integris. \%. ₹. Long. 5, Lat. 4 mill.

Var. u. - Supra rufescens, parce nigro-varius; rugat transrersa thoracis callisque scutelli albidis; subtus dilute flavescens, pectoris maculis, ventris vittis duabus irregularibus maculisque parvis marginalibus nigris.

Trigonosoma rufum WEsTw. in Hlope. Cat. of Ilem. I. p. 12. (18:37).

Trigonosoma carinata (ikrn. in sills. Rev. ent. V. p. 188. 138. (18:37).

Trigonosoma rufu (iહам. Zeitselı. I. р. 57. 5. (1839); Н. Scr. Wanz. Ins. V. 1. 42. fig. 494. (184:3).

Bolbocoris tricolor $\mathrm{A}$. et S. Hist. des Hém. p. 50. 1. (1843).

Vur. b. - Pedibus antennisque exceptis totus niger vel ferrugineo-niger.

Trigonosoma variolosia H. Scrr. Wanz. Ins. V. p. 43. tig. 493. (1839). nee GiskM.

Bolbocoris menthopus S'TÄ. Öf. Vet. Ak. Förh. 185̄3.p. 211.2.

Patria: Terra capensis, Caffirial. (Mus. Ilolm., Coll. Sig-

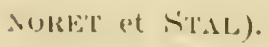


2. B. variolosis GERM. - Varicolor, remote subfortiter functatus, antennis pedibusque pallide flavescentibus, illarum apice, coxis, trochanteribus basique femorum posteriorum nigris; thoracis ruga transversa irregulari, scutelli callis duobus basalibus rugaque longitudinali lavigatis; scutello anterius utrimque oblique impresso, marginibus lateralibus a basi ultra medium parallelis, haud sinuatis; bucculis inermibus; tibiarum angulis integris. $\sigma^{7}$. ㅇ. Long. 5, Lat. 4 mill.

Tar. 1. - Griseo-flavescens, nigro-punctatus et variegatus.

Trifunosoma variolosa GerM. Zeitschr. I. 1. 58. 6. (1839).

Trignomenue curiolosum KLCG. Preisver\%. p. 12. (1842); Ent. Zeit. XX. p. 86. 220. (1859).

Bolbocoris mfus DaLl. List of Hem. I. p. 45. 1. (1851).

Vur. b. - Niger vel ferrugineo-niger.

Patria: Senegal. (Mus. Holm., Coll. Signoret et S'TAL.)

Praecedenti maxime affinis, magnitudine minore bucculisque inermibus differt.

3. B. indequalis Gern. - Griseo-albidus, rémote, subtus nonnihil densius, nigro-punctatus; pedibus nigricantibus, tibiis posticis, basi excepta, tarsisque pallide griseo-flavescentibus; thorace ante medium multimpresso; scutello in angulis basalibus callo albido levi instructo, disco subtuberculato-elevato, apice rotundato, integro, marginibus lateralibus ante medium distincte sinuatis, pone sinum leviter ampliatis, ante medium utrimque leviter impresso; tibiarum angulis minute crenulatis; bucculis inermibus. $\sigma$. Long. 5, Lat. 4 mill.

Trigonosoma incoqualis Gern. in SiLb. Rev. ent. V. I' 188. 137. (1837).

Bolbocoris sordidus STÅL. Öfv. Vet. Ak. Förh. 18533. p. 211.1. Var. l. - Nigricans.

Patria: Caffraria. (Mus. Holm.); icur. b. Zanzibar. (Colf. SIGNORET.)

4. B. obscuricornis S'TẢL. - Griseo-albidus, remote nigro vel fusco-ferrugineo-punctatus; antennis tarsisque nigris; scutello. 
basi in angulis callo litri instructo, anterius ntrimque oblique impresso, marginibus lateralibus ante medium sinuatis, pone simum parallelis, laud anpliatis; angulis tibiarum integris.

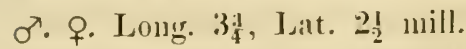

Bolbocoris olscuricomis STAL. Öf: Vet. Ak. Förh. 1858. 1. 311.4 .

Vur. b. - Canpite disco et posterius, maculis anticis thoracis, basi scutelli, maculis pectoris discoque magno ventris nigris.

Patria: Territorium lacus NGGami. (Mns. Holm.)

Precedentibus minor, colore antemnarum scutelloque angustiore distinctissimus.

\section{PHYMATOCORIS STÅL.}

Öfv. Yet. Ak. Förh. 1853. p. „13.

Corpus latum, inæquale. Caput valde deflexum, utrimque sinuatum, apice rotundatum, lobis lateralibus lobo medio longioribus et anterius contiguis; bucculis sit elevatis. Rostrum coxas posticas attingens. Antennæ breviusculæ, articulo primo capitis apicem haud attingente. Thorax anterius vilde declivis. Scutellum triangulare, apice rotundatum, disco tuberculo magno instructum, frenis brevibus. Hemelytra libera. Prostethium antice leviter dilatatum. Sterna profunde sulcata. Pedes breviusculi, minute tuberculati.

Bolbocoridi affine genus, scutello triangulari, breviore differt.

1. P. strum nsus STẢL. - Obscure ferrugineo-flavescens, fuscoindutus, tuberculatus. ㅇ. Long. 6, Lat. $4 \frac{2}{3}$ mill.

Phymatocoris stmumosus STÁL. Öfv. Vet. Ak. Förh. 1853. p. 213.1 .

Patria: Caffraria. (Mus. Holm.)

Caput vix convexum, inxequale. Thorax callis parvis conspersus, disco tuberculis duobus ulagruis, minus eleratis, instructum, angulis lateralibus rotundatis, tumidis, leviter prominulis, marginibus lateralibus anticis ante medium leviter sinuatis. Scutellum inaquale, ante nuedium nomilil devatum it tuberculo magno, longitrorsum leviter impresso, instruetum, apice longitrorsum elevatum. Subtus callosus. Margines abdominis tuberculati. 


\section{EURHINOCORIS STÅL.}

Öfv. Vet. Ak. Förh. 1853. p. 214.

Aeschrus Sprx. Gen. d'ins, artroid. p. 136. (1852).

Corpus obovatum, subtus valde convexum. Caput crassum, cylindricum, lobis æquilongis, tuberculis antenuiferis spinosis; bucculis basin capitis attingentibus, sat elevatis. Rostrum graciliusculum, pedes posticos nonnilil superans, articulo primo capitis basin haud attingente. Antennæ breviusculæ, quinquearticulatie, articulo primo brerissimo, articulis secundo et tertio subæqualibus. Thorax convexus, anterius modice declivis, marginibus lateralibus anticis obtusis, angulis posticis in lobum retrorsum productis. Scutellum parte apicali lata; frenis medium scutelli haud attingentibus. Membranx venæ simplices. Strrna nonnihil sulcata. Venter leviter sulcatus. Pedes mediocres, tibiis superne leviter sulcatis.

1. E. inrqualis Spin. - Niger vel cupreo-niger, inæqualis, sat dense punctulatus; macula discoidali irregulari, transversa, magna, antice trifida thoracis maculisque nonnullis apicalibus scutelli flavo-ferrugineis; antennis pedibusque stramineis; thoracis marginibus lateralibus anticis medio late emarginatis, angulis lateralibus nonnihil prominulis; angulis apicalibus segmentorum ventris tuberculo parvo instructis. $\sigma^{7}$. ․ Long. 10, Lat. 5 mill.

Aeschrus incequalis SpIN. Gen. d'ins. artroid. p. 138. (1852). Eurhinocoris straminipes STẢ. Öfv. Vet. Ak. Förh. 1853. p. 214.1.

Patria: Caffraria. (Mus. Holm.)

\section{PODOPS LAP.}

Ess. Hền. p. 72. (1832).

Corpus ovale vel subobovatum, parum convexum. Caput convexiusculum, parvum, tuberculis antenniferis extus spinosis, a supero totis distinguendis; bucculis distincte elevatis, basin capitis attingentibus. Oculi valde prominentes. Antennæ breviuscula, articulo primo capitis apicen haud vel vix attingente, 
articulo secundo tertio breviore. Thorix marginibus lateralibus acutis, integris, angulis anticis spina rel processu armatis, angulis lateralibus leviter sinuatis, ante sinum dente sxpissime armatis. Scutellum magnum, abdominis apicem attingens, hemelytris multo angustius; frenis brevissimis. Sterna suleata. Pedes mediocres, tibiis superne subsulcatis.

I. P. fibulata GERM. - Flavescente-grisea, sat dense fusco-punctata, subtus cum femoribus nigricans, lateribus ventris pallirlis; antennis, tibiis tarsisque sorlide griseo-flavescentibus; maculis minutis duabus ante medium disci thoracis et tribus basalibus scutelli pallidis; lobis lateralibus a a jitis lobo medio haud vel parum longioribus; thoracis marginibus lateralibus nonnihil sinuatis, angulis anticis et lateralibus spina extrorsum vergente armatis. $\sigma^{7}$. ㅇ. Long. 6-9, Lat. 3-4 mill.

Podops filmlatus Gern. Zeitschr. I. p. 65. 5. (1839); DALL. List of Ilem. I. p. 53. 6. (1851).

Podops pullipes DALL. List of Hem. I. p. 65. 4. (1851).

Podops spinicollis STÅL. Ör. Vet. Ak. Förh. 1853. p. 211.1.

Podops tibialis Sign. Ann. ent. Sér. 3. VII1. p. 919. 70. (1861).

I ar. b. - Fere tota nigricans.

Patria: Caffraria, Senegal, Sierra Leona, Madagascar. (Mus. Ilolm., Coll. Signoret et S'TÁL.)

I. pullipes (= tibialis), thoracis spinis anticis brevibus et spinis latcrialibus longioribus instructa, a $I$ '. fibulatu (= spinicolli), cujns spinie apicales longiores sunt quam laterales, nx specifice differt; variant etian margines laterales antici phus minus profunde sinnati.

\section{THORIA STAL.}

Corpus ovale. Caput parviusculum, planiusculum, lobis lateralibus lobo medio nomulhil longioribus et anterius contignis; tuberculis antenniferis extus spinula armatis, a supero totis distinguendis; buceulis sat clevatis, basin eapitis attingentibus. Rostrum minus longum, articulo primo buceulas postice haud superante. Antennar quinqueartieulatie. Irevinsenlap. articulo 
primo capitis apicem haud attingente, secunclo tertio breviore. Thorax marginibus lateralibus leviter explanatis, angulis anticis denticulo armatis, angulis lateralibus sinuatis, ante sinum denticulo instructis. Scutellum abdomine brevius, corio haud longius, farte basali retrorsum angustata, parte apicali sat lata, frenis medium scutelli haud attingentibus. Hemelytra maximam ad partem libera. Sterna leviter sulcata. Pedes mediocres, graciliusculi, tibiis superne subsulcatis.

1. T. matalensis S'TÁL. - Livida, sat dense fusco-punctata, ventris disco nigricante; thorace medio tramsversim leviter impresso, ante et pone impressionem leviter rugoso, marginibus lateralibus anticis subrectis, integris, dente angulorum lateralium et anticorum brevi; scutello parte posteriore angustiuscula; antennis pedibusque pallidis. $\sigma^{7}$. Long. 8, Lat. $4 \frac{1}{2}$ mill.

Podops natalensis STAL. Öf. Vet. Ak. Förh. 1853. p. 211.2. Patria: Caffraria. (Mus. Holm.)

2. T. siunata SIGN. - Livida, sat dense fusco-punctata, ventris disco nigricante; thorace medio transversim leviter impresso, ante et pone impressionem obsolete calloso, marginibus lateralibus anticis pone medium leviter sinuatis, ante medium parum rotundatis, obsolete crenulatis, dente angulorum anticorum et lateralium distincto; scutello parte apicali lata; antennis pedibusque pallidis, his remote fusco-conspersis. \&. Long. 9, Lat. $4 \frac{1}{2}$ mill.

Podops sinuatus Sign. Ann. ent. Sér. 3. VIII. p. 919. 69. (1861).

\section{Patria: Madagascar. (Coll. SignoRetr.)}

Precedenti valde affinis, thoracis marginibus lateralibus crenulatis scutelloque latiore distinctissima.

\section{PHRICODUS SPIN.}

Mag. Zool. 1840.

Stenotoma Wrstw. Ent. trans. IV. p. 248. (1847)

Corpus ovale, depressum. Caput utrimque ante oculos spina Ionga armatum, lobis lateralibus lobo medio longioribus, in spinam 
longam productis; tuberculis antenniferis spina longa extus armatis. Antenna quadriaticulate, sat longe, articulo primo brevi, crasso, secundo longo, apicem versus sensim incrassato, tertio et quarto crassissimis, fusiformibus. Rostrum inter coxas posticas extensum, articulo primo basin capitis haud attingente. Thorax marginibus lateralibus spinis pluribus longis armatus. Scutellum triangulare, apice valde angustatum. Venx membrane simplices. Sterna subsulcata. Anguli apicales segmentorum abdominis nomnihil prominuli. Pedes graciles, tibiis supra suleatis.

1. P. Ilystrix Germ. - Griseus vel Havescente-grisens, asper, remote punctatus et sepissime minute fusco-conspersus; intemnis fuscis, basin versus pallidis; parte apicali corii plus minus obscure infuscata; membrana grisea, fusco-conspersa. o'. \&. Long. 6 $6 \frac{1}{2}$, Lat. 3 mill.

Aradus hystrix GERM. in SILb. Rev. ent. V. p. 134. 34. (18:37).

Phricodus hystrix SpIN. Mag. Zool. 1840. Pl. 40; Sign. Ann. ent. Sér. 2. VII. p. 327. Pl. 9. fig. III. (1849).

Stenotoma Desjardinsii WEsTw. Ent. trans. IV. p. 249. 1. 1). 18. fig. 6. (1847).

Phricolus fasciatus Sign. Ann. ent. Sér. 3. VIII. p. 924. 85. (1861).

Patria: Caffraria. (Mus. Ilolm.); Madagascar, Mauritius. (Coll. SignoRET).

\section{ATELOCERA LAP.}

Ess. Hém. p. 65. (183:).

Corpus ovale. Caput productum, antrorsum angustatum; bucculis sat elevatis, capitis basin attingentibus. Oculi globosi. Rostrum longitudine varians, articulo primo bueculas postice haud vel vix superante. Antenna quadriarticulatie, articulo primo capitis apicem raro subsuperante, articulo secundo compresso, ampliato. Thorax marginibus lateralibus anticis crenulatis. Scutellum pone medium utrimeque sinuatum. Corium 
margine apicali prope angulum apicalem costalem leviter sinuato. Membrana remote venosa. Mesosternum carinatum. Venter interdum sulcatus, apud feminas plagis duabus maximis opacis, remote sericeis, instructus. Pedes validi, femoribus sæpe incrassatis et subtus spinosis; tibiis triquetris, supra sulcatis.

\section{a. Femoribus subtus inermibus.}

1. A. armata LAP. - Supra sordide flavescens, acervatim nigropunctata, interstitiis subcallosis, subtus ferrugineo-flavescens; capite, antennis, parte laterali angusta intramarginali thoracis prostethiique, limbo lato abdominis pedibusque nigricantibus; vittis tribus angustis capitis, media a basi al medium producta, lateralibus subpercurrentibus, pone medium interruptis, thoracis marginibus lateralibus anticis, margine angusto antico lineaque longitudinali subcallosa media, scutelli maculis tribus parvis basalibus callosis, corii macula parva lævigata pone medium, maculisque marginalibus abdominis sordide flavescentibus; pectore fortiter nigro-punctato; femoribus ultra medium flavo-ferrugineis; membrana grisea, fuscovenosa. ơ. ㅇ. Long. 18, Lat. 9 mill.

Atelocera armata LAP. Ess. IIém. p. 65. Pl. 55. fig. 2. (1832); A. et S. Ilist des Hém. p. 104. 1. o’. ㅇ. (1843).

Atelocerus armatus BurM. Handb. II. p. 362. I. o' (1835); H. Sch. Wanz. Ins. VII. p. 5 I et 52. fig. 720. o7. (1844).

Halys armata Blanch. Hist. des Ins. Hém. p. I46. 3. o’. $\sigma^{7}$. Lobis lateralibus capitis ante lobum medium libere productis, apice reflexis, prope apicem extus denticulo acuto armatis.

ㅇ․ Capitis lobis lateralibus inermibus, lobo medio vix vel paullo longioribus.

Patria: Senegal. (Coll. Signoret et STÅL.)

2. A. serrata FABR. - Nigra, supra acervatim distincte punctata; thoracis, scutelli hemelytrorumque maculis numerosis rotundatis, parvis, sparsis, irregulariter confluentibus, vittulisque capitis stramineis, lavigatis; maculis margiualibus - 
abdominis marginibusque thoraris lateralibus anticis subsanguineis vel flavo-ferrugineis; capite apice emarginato, lobis latralibus lobo medio paullo longiorihus. ․ Long. 20, Lat. 10 mill.

Mulys serrata FABR. Syst. Rliyng. p. 181. 2. (1803).

Atelocerus serratus II. SCH. Wanz. Ins. V11. p. 51 et 53. fig. 721. (1844).

Atelocera serrata DALL. List of Hem. 1. p. 177. 2. (1851). Stoll. Pun. p. 31. figr. 43.

Patria: Guinea, Calabar, Gahon. (Coll. A. Donrs, SignoRET et S'TẢ.)

aa. Femoribus subtus spinosis.

b. Scutello basi in angulis impressionr majuscrela instructo;

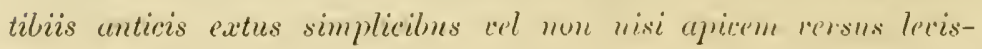
sime dilatatis.

C. Ventre sulcato.

3. A. stietica Westw. - Fusco-ferruginea, sulutus dilutior, supra acervatim distincte punctata et maculis parris callosis irregularibus flavescentibus conspersa; capite, antennis, parte angusta laterali intramarginali thoracis, laterilus pectoris ventrisque, frmoribus tibiisque apicem rersus nee non tarsis nigris; capitis marginibus lateralibus, linea longituclinali media, apicem haud attingente, lineolisıue duabus intraocularibus, thoracis marginibus lateralibus anticis lineaque media per seutellum continuata, maculis angustis, intus late rotundatis, marginalibus ventris fascialute sergmentorum connexivi flavescentilus; membrana grisea, fisco-renosa. ơ \&. Long. 18, Lat. 9 mill.

Itelocerus sticticus WENT. in Ilops Cat. of Hen. 1. p. 20. (18:3T).

Patria: Mozambique. (Coll. А. DomkN et STÁL.)

Caput triangulare, longum, apice angustatum, integrum, lobis iequilongis, lateralibus sensim acuminatis, marginibus lateralibus medio levitur simatis. Rostrum apicem segmenti quarti ventris attingrals. Antemie: articulo primo rapitis apicem hand attingente, 
articulo secundo apicalibus duobus ad umum paullo breviore, basin versus ferrugineo. Thorax marginibus lateralibus anticis medio leviter siuuatis, angulis lateralibus vix prominulis. Scutellum longum. Venter sulco distiucto, ad apicem seguenti quinti extenso, instructus; segmento anali maris disco profunde impresso, marginibus lateralibus impressionis medio profunde sinuatis. Pedes validi, femoribus incrassatis, apud utrumque sexum apicem versus distincte spinosis, apud marem etiam basin versus spiumlosis.

4. A. natalensis S'TiL. - Nigricans, supra acervatim, sat dense distincteque punctata; capitis marvinibus lateralibus, linea obsoleta media anterius evanescente lineolisque duabus intraocularibus obsoletis, thoracis marginibus imis antico et lateralibus anticis, maculis minutis callosis sparsis thoracis, scutelli hemelytrorumque, illorum etian linea obsoleta longitudinali pereurrente, nec non maculis marginalibus abominis sordide stramineis; rostro, pectore ad coxas, disco ventris femoribusque basin versus ferrugineis; membrana grisea, fusco-venosa; calpite antrorsum sat angustato, apice subintegro. ơ. Long. 16, Lat. 9 mill.

Atelocera natalensis STAL. Öfv. Tet. Ak. Förh. 1853. p. 216. 2 .

\section{Patria: Caffraria. (Mus. Holm.)}

A. stictice maxime affinis, obscurior, minus dense pallido-conspersa, fasciis comnexivi medio intermptis capiteque subbreviore differt.

5. A. limata GERm. - Supra griseo-flavescens, acervatim distincte nigro-punctata, subtus cum pedibus ferruginea vel flavo-ferruginea; antennis, capite, parte angusta laterali intramarginali thoracis, lateribus pectoris, limbo abdominis, femoribus subtus, tibiis apicem versus tarsisque nigricantibus; capitis marginibus lateralibus, linea abbreviata media lineolisque duabus obsoletis intraocularibus, thoracis marginibus antico angustissimo et lateralibus anticis nec non linea media per scutellum obsolete continuata, corii maculis minutissimis sparsis, interdum obsoletis et una paullo majore distinctiore pone medium, fascia segmentorum connexivi maculisque semiorbicularibus marginalibus ventris sordide flare- 
scentibus vel fermuinen-flavescentibus; membrana grisea, fusen-venosa, apul marem apice sinuata; capite lobis lateralibus lol,o medio vix vel parum longioribus, apice leviter rotundatis; antenuarum articulo primo capitis apicem vix attingente. o. ㅇ. Long. 13-16, Lait. 7-9 mill.

Atelocems limatus Germ. in Suß, Rev, ent. V. p. 163.90. (1837); II. SCH. Wanz. Ins. VIl. p. 51 et 52.' (1844).

Halys cinctu H. Scrr. Wan\%. Ins. V. p. 67. fig. 511. (1839). Atelocera limata 1)ALL. List of Hem. 1. p. 177. 6. (18.il). Atelocera Spinole STÅL. Öf. Vet. Ak. Förh. 1853. p. 216.4.

Patria: Terra capensis, Caftraria. (Mus. Holm., Coll. $\Lambda$. DOIIRN et SIGNORET.)

6. A. caffra STÅL. - Nigricans; thorace pone medium, scutello hemelytrisque fuscis, acervatim nigro-punctatis et callis ninutis remote adspersis; sulitus cum pedibus rostroque ferruginea, jectoris lateribus, limbo abdominis, femoribus subtus, tibiis apicem rersus tarsisque nigris; capitis linea abbreviata media lineolisque duabus intraocularibus obsoletissimis, ma"ulis parvis marginalibus comnexivi ventrisque ferrugineo-flareseentibus; membrana fusca, nigro-renosia. or. ㅇ. Long. 1t-16, Lat. 8-8! mill.

Atelocera coffra S'TÁs. Öfv. Vet. Ak. Förh. 1853. p. 216. 3. Patria: Caffraria. (Mus. Ilolm.)

A. limate maxime affinis, verisimiliter ejus varietas obscura, exceptis coloribus obscurioribus, marginibus lateralibus capitis thoracisque concoloribus, maculisque mimutis rlistinctis pallidis sparsis thoracis et scutelli haud differt. Caput thoraci aequilongum, lobis lateralibus lobo medio land rel vix longioribus, marginibus imis lateralibus in ferrugineum vix vergentibus. Rostrum ultra segmentum tertinm rentris nomnilil extensun. Thorax marginibus lateralibus anticis ah apice ultra medium eremulatis, medio leviter sinuatis, linca media obsoletissima ferrugineo-flavescente. Membrana maris apice simuata. Ventris sulcus latus, distinctus, ad apicem segmenti quinti extensus. Femora incrassata, subtus pone merlium distincte spinosa, apud marem etiam basin versus spinulosa.

7. A. spinulosa P. B. - Nigricans, supra sat dense distincteque acervatim punctata ot minutissime fermginen-flaveseente-eon- 
spersa; capitis linea media et interdum marginibus lateralibus pone medium, thoracis marginibus lateralibus anticis lineaque longitudinali media per scutellum olsolete continuata, maculis marginalibus ventris fasciaque segmentorum connexivi ferrugineo-flavescentibus; membrana grisea, fusco-renosa, basi fusca; capite thorace paullo breviore, lobis lateralibus lobo medio vix longioribus. $\sigma$. Long. 14-15, Lat. $7-8$ mill.

Pentatoma spinulosa P. B. In.s. p. 83. H'm. pl. 7. tig. 5. (1805). Atelocerus spimulosus H. ScH. Winz. Ins. VII. p. 50 et 5 I. fig. 722. (1844).

Atelocera spinulosa DALL. List of Ilem. 1. p. 177. 4. (18:31). Patria: Calabar. (Coll. Signoket et sital.)

8. A. foveata DaLL. - Nigricuns, supra dense distinctryue acerratim punctata et callis minutis sordide Havescentilus adspersa; antennarum articulo ultimo et dimidio apicali articuli tertii, capitis marginibus lateralihus, linea media anterius abbreviata lineolisque duabus intraocularibus, thoracis marginibus antico et lateralibus anticis angustis nee non linea longitudinali obsoleta media, per scutellum obsoletissime continuata, maculisque marginalibus abdominis ferrugineo-Havescentibus; ventris disco magno femorihusque superne ferrugineis; rostro segmentum tertium ventris nonnilil superante; ventris sulco fere ad apicem segmenti quinti continuato; membrana grisea, nigro-renosa, apud marem apice subtruncata. ơ. \&. Long. 17, Lat. 9 mill.

Atelocera foreata Dall. List of Hem. I. p. 178. 11. (1851). Atelocera lentiginosa STAL. Öfv. Vet. Ak. Förh. 1853. p. 216. 1 .

Patria: Caftraria. (Mus. Holm. et Coll. A. Dohrx.)

cc. Ventre haud sulcato.

9. I. notatipennis STẢL. - Ferruginea, supra griseo- rel fuscoflavescens, nigro-punctata, punctis fundo griseis; antennis, Hemiptera africana. 
capite, pante angusta laterali intramarginali thoracis, foreis hasalibus scutelli. lateribus pectoris, limbo abdominis, femorihus subtus, tibiis tarsisque nigris; capitis marginibus lateralibus et linea media ante medium abhreviata, thoracis marginibus antico et lateralihus anticis nec non linea media, per scutellum distincte continuata, hujus macula parva in angulis basalibus, corii margine costali anterius, macula parva pone melimm margineyue angusto apicali, pectoris maculis ad coxas, fasciis comexivi maculisque marginalibus ventris sordide flavescentibus; membrana grisea, fusco-renosa; thoracis marginibus lateralibus anticis rectis; capitis lobis lateralibus lobo medio vix longioribus; femoribus subtus totis spinulosis; rostro paullo pone pedes posticos extenso. o Longr. 16, Lat. 8! mill.

Atelocera notatipenis sitat. Öfv. Vet. Ak. Förh. 1858. p. 312. 9.

Jatria: Srakop Africa meridionalis occilentalis. (Mus. Molm.)

bb. Scutello in anyulis basalibus impressione minuta instructo; tilieis anticis ratus leviter dilututis; ventre haud sulcato.

10. 1. obsipata Gikr. - Fermginea, supra griseo-flavescens, sat anse fusco-lunctata; antemnis, vitta obliqua laterali intramaromali thoracis, limbo ablominis, femoribus subtus tarsisque nigris; capitis marginibus lateralibus lineaque media, thoracis marginibus antico et lateralibus anticis lineafue media. per scutellum continuata, nec non maculis manginalitus abdominis dilute formegineis; corii macula mimuta fone medium posita, sordide flavescente, lavi; memhrana grisea, Jallide fusco-venosa; caprite thorace breviore, apice emaremato; rostro coxas posticas haud superante; fomorihus subtus spimulosis. ㅇ. Long. 17. Lat. 9 mill.

Atelocerus obsipatus Girr. in sirb. Rev. ent. V. p. 162. 88. (18:37); H. Ассн. Winz. Ins. VII. 1. 50 et 52. fig. 723. (1844). Atelorera olsipata I)ALL. I,ist of Hem. I. p. 177. 3. (1851). Jatria: Terra capensis. (Mus. Holm.) 


\section{MEMLII STAL.}

Corpus ovale. Ciput parviusculum, antrorsum sensim angustatum, apice leviter emarginatum, lobis lateralibus lobo medio paullo longioribus; bucculis valde elevatis. Antenna yuadriarticulatx, articulo primo capitis apicem superante, crassiusculo, secundo longo, tereti, hand incrassato. Rostrum coxas posticas attingens. Thorax marginibus laterilibus anticis distincte crenulatis. Scutellum pone medium utrimque sinuatum. Hemelytra margine apicali prope angulum apicalem extermum leviter sinuato. Membrana vena simplices. Mesosternum carinatum. Venter haud vel vix sulcatus. Pedes validi, fenorihus subtus spinulosis, tibiis triquetris, supra suleatis.

Atelocera proximum genus.

1. I. femoralis SIGN. - Nigral, in ferrugineum nomilnil vergens, supra acervatim distincte punctata et callis parvis laevibus flavo-ferrugineis conspersa, corii callo uno pone medium posito majore; capitis vittis duabus ante oculos maculisque nonnullis intraocularibus, nee non maculis submarginalibus connexivi rentrisque dilute ferrugineis; rentris disco maximo ferrugineo; bucculis, prasertim posterius, maxime elevitis; membrana fusco-grisea; thoracis marginilus lateralibus anticis subrectis, angulis lateralibus rectis, leviter prominulis. ơ. Long. 16, Lat. 10 mill.

Atelocera femoralis Sigs. Ann. ent. Sér. 3. V'III. p. 925. 87. Pl. 13. fig. 3. (1861).

Patria: Madagalscir. (Coll. SignuRET.)

2. II. vieina SIGN. - Ferrugineo-nigrimans, supra sat dense distincteque punctata et callis parvis, sordide flavescentibus, conspersa; capitis vittis duabus anteocularibus maculisque quiinque pone medium, fasciis connexivi maculisque marginalibus ventris sordide flavescentibus; membrana grisea, subfusco-venosa; bucculis sat elevatis, postice haud altioribus; thoracis marginibus lateralibus anticis rectis. ơ. Long. Ij, Lat. 9 mill. 
Ateloceru vicina Sirsis. Ann. ent. Sim. 3. VIII. p. 926. 88. (186il).

Patria: Madagatiall. (Coll. Silinokert.)

P'recedenti affinis, bucculis multo minus elevatis differt.

\author{
IIALYS FABR. \\ Sy st. Rhy n. p. p. 180), (1803).
}

Corpus oratum. ('aput triangulare, longum, lobis hateralibus acuminatis, Joho medio anpulongis vel paullo hrevioribus; bucculis hasin rappitis attingentilus. Antemma quinquearticulatex, graciles, artirulo primo capitis apicem haud attingente. Orelli paullo pone linean fictam inter basin oculorum ductam positi. Thorax medio tramsersim leviter impuessus, marginibus lateralibus antie is remulatis, medio leviter sinuatis. Scutellum pone medimm utrimque sinuatum, pusterius modice angustatum. Membrana vena billeal, ramulosal. Vesosternum sulcatum. Venter sulco, ad vel in segmentum ultimum extenso, instructus. Peeles longiusculi, inemes, tiliis triquetris, supra late suleatis.

1. Il. Inelenborgi STÁL. - Jilute grisen-flavescens, acervatim nigro- vel formginen-nigro-punctata, ventris lateribus, limbo excepto, infuscatis; membrama fusco-variegata, pedibus antemisque sordide ferruginen-flavescentilus, his ferrugineofunctatis; alpite comvexiusenlo. f. Long. 20, Latt. 10 mill. Patria: Nubia, Balur el Aliad. (Mus. Holm.); Africal centrialis. (Coll. SHixuRbi.)

II. dentute milor, (aipite conrexinsenlo, angulis lateralibus thoracis apice subrotumdatis sulcofule rentris al, nee in, segmentum ultimum lucto priesurtion diffirt. ('aput thorace paullo longins, anterius magis angnstatum, lobis lateralibus lobo medio acyuilongis; bueculis anterius altioribus, angulo apicali subrotundato. Thorax angulis latrablibus vix promiunlis, apiec sulrotundatis, marginibus lateralibus antieis medio levissime sinmatis. Commexivi segmenta ad incisuras densius punctutit.

2. II. marulipentis STẢL - Dilute grisen-flaveserns, acervatim nigro-punctata, prectore rentrisige disco, hujus etiam limbo remotins fumetatis; manolis tribus parvis basalihus scutelli

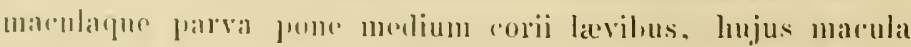


irregulari pone maculam illam levem dense nigro-punctata; connexivi segmentis basi apiceque nigro-fitsciatis; ventris margine nigro-maculato. or. Long. 16, Lat. 8 mill.

Patria: Senegal. (Coll. Signurkr.)

$H$. dentatce maxime affinis, capite breviore, apice minus angustato, corioque pone medium macula parviuscula levi notato differt. Caput planiusculuin, thorace paullo longius, lobis aquilongis, lobo medio posterius leviter elevato; buccularum angulo apicali hand rotundato. Antenne exempli descripti mutilatie. Thorax angulis lateralibus rectis, subpromimulis. Ventris sulcus in segmentum apicale longe productus. Pedes parce nigro-punctati, tibiis basi apiceque nigro-fasciatis.

\section{DALPADA $A$. et $\mathrm{S}$.}

Hist. des Hém. ‥ 105. (1813).

Corpus ovale vel ovatum. Caput vix vel levissine convexum, lobis lateralibus apice extus plus minus distincte sinuatis vel oblique truncatis; bucculis basin capitis attingentibus, antice angulatis. Antennæ quinquearticulatæ, graciles, articulo primo capitis apicem attingente. Oculi globosi. Ocelli in linea ficta, inter basin oculorum ducta, positi. Rostrum pedes posticos paullo superans, articulo primo bucculas haud superante. Thorax narginibus lateralibus anticis crenulatis. Membrana venis circiter sex longitudinalibus, simplicibus, instructa. Mesosternum carinatum. Venter basi leviter sulcatus. Pedes longiusculi, tibiis supra late sulcatis, anticis interdum dilatatis.

1. D. vittata SIgn. - Anguste ovalis, obscure ferrugineo-renescens, distincte punctata, supra maculis minutis callosis lævibus flavescentibus acervatim conspersa; abdomine subtiliter punctato, obscure ferrugineo-fuseo; thoracis marginibus angustis antico fere toto et lateralibus anticis, scutelli maculis tribus basalibus apiceque, nec non macula pone medium corii, pectoris carina maculisque ad coxas, ventris vittis duabus discoidalibus maculisque angustis, elongatis, marginalibus, fascia segmentorum comexivi, pedibus rostroque dilute flavescentibus; membrana grisescente, renis leviter infuscatis. ․ Long. 18, Lat. 8 mill. 
Talpalu vittutu sisis. Amm. ('nt. Sér. 3. VIII. p. 924. 86. (1861).

Patria: Madagascar. (Coll. Signoret.)

Caput lobis lateralibus loho medio subhrevioribus, anterius extus oblique leviter truneatis, planis. Thorax marginilus lateralibus auticis vix sinuatis. pare subtiliterpue crenulatis, angulis lateralibus hamb prominulis. Seutellum apice valde angustatum. Tibia antice simplices. Autenne rostrumque exempli descripti maximam ad parteni mutilata.

\section{SORIBONIA ŚTAL.}

Corpus subovale, remote pilosum. Caput majusculum, antrorsum listincte angustatum, apice obtuse rotundatum, lobis requilongis; bucculis basin aphitis attingentibus, modice elevatis. Rostrum fere ad medium ventris extensum; articulo primo bucculas postice subsuperante. Oculi valde prominuli. Ocelli ab oculis remoti, sat longe pone lineam fictam, inter oculorum basin ductam, positi. Antennie quinquearticulate, crassiuscula, articulo primo capitis apicem subaquante. Thorax marginibus lateralibus anticis obsolete crenatis. Corii margo apicalis prope angulum apicalem extrriorem leviter sinuatus. Membrana venis longitudinalibus, subfuratis, instructa. Mesosternum carinatum. Venter sulco levi, lato, instructus, apul feminam saltem maculis dualus maximis sericeis prieditus. Tibie supra sulcate, antica simplices.

1. S. pilosa STAL. - Nigra, supra cum pectore distinete et sat dense punctatil; thorace postrusius, scutello hemelytrisque fusco-flareserntihus, nigro-punctatis, illorum linea media percmrente subelevata, sublevigata; thoracis marginibus lateralibus anticis marginepae corii costali anterins, coxis, trochanteribus, femoribus ultra medium, annulo lato tibiarmm posteriorum maculisque parvis obsoletis marginalibus abdominis rufo-forrugineis; corii matula parva pone medium calloque lavigato in angulis basalibus scutelli nigris, nitidis; membrana grisescente, basi nigro-fusea. \&. Long. 17, Lat. 9 mill. 
Coenomorpha pilosa S'TAL. Öfv. V'et. Ak. Förh. IS5̇8. p. 436. Patria: Mozambique. (Coll. $\Lambda$. Dohrs.)

\section{COLNOMORPIIA DALL.}

List of Ilem. I. p. 191. (1851).

Corpus ovale vel ovatum. Caput antrorsum nonniliil angrustatum, majusculum, lobis aquilongis, lateralibus apice oblique truncatis; bucculis basin capitis attingentibus, anterius magis elevatis. Oculi globosi. Ocelli paullo pone lineam fictam, inter basin oculorum ductam, positi. Rostrum longiusculum, interdum ad medium ventris extensum, articulo primo bucculas haud rel vix superante. Thorax marrinibus lateralibus anticis serulatis. Scntellum pone medium utrimque sinuatum, parte apicali modice lata. Mesosternum carinatum. Abdomen hemelytris latius, ventre sulco ultra medium ducto instructo. Pedes longiusculi, tibiis triquetris, supra late sulcatis, sulco fundo plano, anticis simplicibus.

\section{a. Antennis nigris.}

I. C. nerrosa DALL. - Pallide Havescente-grisea, acervatim et maculatim obscure ferrugineo-punctata, vittis duabus pone medium parteque angusta laterali thoracis, maculis iregularibus nonnullis confluentibus scutelli maculisque irregularibus corii, una paullo ante medium nomnullisıue posterioribus, densissime punctatis; membrana grisea, fusco-renosa; rentre fusco-ferrugineo-punctato, hujus maculis marginalibus, nec non fascia angusta margineque laterali medio segmentorum comnexivi impunctatis; antenuis crassiusculis tibuisque nigris; basi apiceque ipsis articuli tertii, annulo articuli quarti parteque basali articuli quinti antennarum, annulo lato medio tibiarum tarsisque croceis, his apice nigris; capite antrorsum distincte angustato, thorace vix longiore; rostro apicem segmenti quarti rentris subattingente. $\sigma^{>}$. ‥ Long. 20, Lat. 10 mill.

Coenomorpha nervosa DALL. List of Hem. I. p. 192. 2. (185̃1). sec. Mus. Brit. 
C. nebulose et variegate similis, antennis crassioribus capiteque longiore et antrorsum migis angustato differt.

2. A. Vuringala P'. 13. - Sordide straminea, minus dense obscure ferrugineo-punctata, thoracis maculis nonnullis parvis lateralibus vittisque duabus posterioribus, scutelli maculis nonnullis parvis irregularibus, corii macula fere media majuscula nonnullisque parvis dense punctatis; thoracis marginibus lateralibus anticis angustis totis sordide stramineis, angulis lateralihus distinctis, paullo prominulis; vitta submarginali laterali inferiore cippitis obscure renea; membrana subcupreofuscescente; connexivi segmentis basin et apicen versus maculisque marginalihus ventris dense ferrugine-punctatis; antemnis tibiisque nigris; antemnarum articulo tertio basi ipsa, ammlo articuli quarti partreque basali articuli quinti croceis; ammulo tiliarum tarsisque stramineis, his apice nigris; capite antrorsum leviter angustato, thoraci aquilongo; rostro fere ad apicem segmenti tertii rentris extenso. ơ ․ . Long. 1620, Lat. 8-10 mill.

Pentatoma variegata P'. B. Ins. p. 82. H'm. PI. 7. fig. 3. (1805). sec. ex. typ.

IIulys variegata A. et S. Ilist. des IIém. p. 109. I. (1843). nec calem Dablasi, que verisimiliter at /lulydem /ledenborgi pertinet.

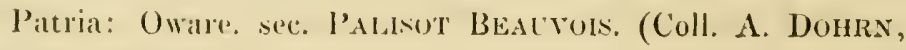
Sigrorkit it S'TAL.)

C. nebulosic Bเฉм., H. Son, maxime aftinis, densius subtilinsque punctata, punctis hic illic in maculas multo distinctius aggregatis marginibusque totis lateralibus anticis thoracis stranincis differt.

3. C. Iroloulosa Burm. - Sordide straminea, remote distincteque ferrugineo fuseoque punctata, maculis nonnullis indistinctis thoracis, hasalibus scutelli malque media corii paullo densius punctatis; thoracis marginibus lateralibus anticis anguste nigris, anterius stramineis; membrana cupresente-fusca; vitta laterali inferiore capitis, marginibus lateralibus angustis prostethii pusterius, maculis angustis marginalibus ventris ma- 
culisque comnexivi anescente-nigris; antennis tibiisque nigris; anmulo articuli quarti basique artieuli ultimi antennarum croceis; fascia lata tibiarum tarsisque stramineis, his apice nigris; capite antrorsum leviter angustato, thorace subbreviore; rostro segmentum secundum ventris paullo superante; angulis lateralibus thoracis apice subrotundatis, vix prominulis; ventre disco parce subtiliterque punctato. ․ Long. I7, Lat. 9 mill.

Halys nebulosa Burm. Handb. II. 1. p. 363. 3. (I835); H. Scu. Wanz. Ins. VII. 1. 59. fig. 725 . (I844).

Coenomorpha nebulosa DALL. List of Ilem. I. p. 192. 3. (1851).

Patria: Terra capensis. (Mus. Holm.)

aa. Antennis sordide stramineis.

4. C. insubida Gers. - Dilute sordide straminea vel stramineoalbida, æneo vel ferrugineo-æneo-punctata, punctis in thorace, scutello, hemelytris comnexivoque in maculas irregulares densius acervatis; membrana sordide flavescente-grisea, cupreasubnitida; tibiis fusco-æneis, horum angulis, antennis, rostro femoribusque sordide stranineis, articulis duobus ultimis antennarum longarum apicem versus fuscis; angulis lateralibus thoracis distinctis, nomnihil prominentibus. $\sigma^{7}$. . Long. 1620 , Lat. 9-10 mill.

Halys insubila GERM. in Sinb. Rev. ent. V. p. I64. 91. (1837); H. SсH. Wanz. Ins. VII. p. 59. fig. 727. (I844).

Cuenomorpha insulida DALL. List of Hem. 1. p. 192. 1. (1851).

Coenomorpha ochripes STAL. Öfv. Vet. Ak. Förh. 1853. p. 216.1 .

Patria: Catfiraria. (Mus. Holm. et Coll. SignoneT.)

\section{ORTIIOSCHIZOPS SPIN.}

Gen. d'ins. artroid. p. 131. (1852).

Corpus ovatum. Caput productum, marginibus lateralibus, anterius saltem, denticulatis vel crenulatis, lobis lateralibus lobo 
neetin Inngioribus; buceulis al basin capitis extensis, modice elevatis. Rostrum pedes posticos attingens rel paullo superans. Antenna quinqueaticulata, graciles, articulo primo capitis apicem laaul attingente. Thorax marginibus lateralibus anticis irregulariter denticulatis. Scutellum triangulare, marginibus lateralibus medio sinuatis; frenis ad rel paullo pone medium scutelli extensis. Membrana reticulata. Sterna sat profunde sulrata. Venter interdum leviter sulcatus. Pedes longiusculi, validi, tibiis triquetris.

a. Corii margine apicali vecto, angulo apicali exteriore distincto, haud rotundato; margine apicali segmentorum centris haud levigato.

\section{b. T'entre unte mediun distincte sulcato.}

1. O. frondusa GERM. - Sordide albida, acervatim fusco-ferrugineo-punctata, ventre pedibusque ferrugineo-punctulatis; lineis nomullis abbreviatis longitudinalibus thoracis et ubsoletiorilus seutelli, hujus etiam parte apicali, maculis nomnullis irregularibus indistinctis hemelytrorum vittisque duabus interruptis angustis laterum pectoris laviusculis vel minus dense functatis; maculis parris ventris, spirateula includentibus, pallidis, lavilugs; segmentis romnexivi basin et apicem versus olscurioribus; margine rentris nigro-lineolato; capite fusco-lilineato; membrana grisea, fusco-renosil. o?. Long. 13, Lat. 6! mill.

Hulys frondosa (ilik. in sills. Rev. ent. V. p. 16t. 92. (1837); H. sicu. Wan\%. lns. Y'I. J. is. fig. T20. (184t).

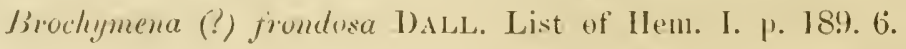
(18.)1).

J'atria: 'Trumal capensis. (Mus. Hohns.)

Capur antrorsum nomilil angustatum, marrinibus litclalibus

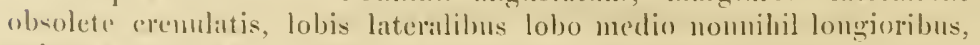
aprese arominatis. Thorax mareginilsus lateralibus anticis pone medium distimete simutis, irregulariter dentatis, angulis Jaterabibus distimere productis, obtusis, postice haul eremulatis. Tibia antice simplices.s. 


\section{bb. Ventre haud sulcato.}

2. O. obsoleta STÅL. - Grisescens, supra distincte ferrugineopunctata, subtus cum pedibus pallidior et subtilius dilute punctata; pectore parce ferrugineo-punctato; femoribus apicem versus fuseis; membrana griseo-albida. $\sigma$. Long. 11, Lat. 6 mill.

Patria: Terra capensis. (Mus. Holm.)

Caput antrorsum leviter angustatum, marginibus lateralibus apicem versus oblique subtruncatis, ibidem parce denticulatis, lobis lateralibus lobo medio nomnihil longioribus et ante hunc contiguis, apice panlo hiscentibus, subacuminatis. Thorax marginibus lateralibus sinnatis, distincte dentatis, angulis lateralibus distincte nonnihil productis, apice subrotundatis, postice haud denticulatis. Connexivum ferrugineo-punctatum. Venter pallirlus, limbo impicto. Tibix antice angulo superiore exteriore subampliato.

3. O. conspurcata StảL. - Sordide flavescente-grisea, distincte et acervatim fusco-ferrugineo-punctata; capitis vitta media angulisque lateralibus thoracis nigricantibus; vittula posteriore capitis, vittis sex angustis thoracis, lateralibus curvatis, nec non ajice scutelli pallidioribus, parce punctatis; pectoris lateribus vittulis lavibus instructis; ventre latera versus vittis duabus nigro-punctatis ornato, margine ipso fusco-maculato, maculis parvis stigmata includentibus pallidis, subcallosis; comnexiro fusco, segmentis medio dilutioribus; membrana grisea, fusco-renosa et dense reticulata. ㅇ. Long. 13, Lat. $6 ! 2$ mill.

\section{Patria: Terra capensis. (Coll. Signoret.)}

Priecedenti proxima. Caput antrorsum vix angustatum, apice utrimque oblique truncatum, marginibus lateralibus ibidem obsolete crenulatis, lohis lateralibus lobo medio longioribus, ante hunc tamen hand contiguis. Thorax marginibus lateralibus anticis sinuatis, irregulariter et distincte denticulatis, angulis lateralibus sat productis, apice obtusis, postice hand denticulatis. Tibice anticae simplices.

4. D. Lumeralis STẢL. - Sordide albida, supra densius, subtus remotius acervatim ferrugineo-punetata; capitis lobis lateralibus dilute punctatis; vittula posteriore capitis, vittis duabus mediis percurrentibus distinctis et una vel duabus lateralibus angustis ohsoletioribus thoracis, vittis quattuor seutelli, la- 
teralibus ablureviatis, pectoris vitta laterali, ventris linea media vittaque laterali, hac utrimque obscmius punctata, palliclis, parce punctatis; venis hemelytrorum levibus; menLrama grisea, parce venosil. or. Long. 12, Lat. 6 mill.

Patria ignota. (Mus. Holm.)

Caput antrorsum nomnihil angustatun, marginibus lateralibus totis remote distincteque denticulatis, lobis lateralibus lobo medio longioribus, hiscentibus, apice extus oblique subtruncatis. Thorax marginibus lateralibus anticis sinuatis, irregulariter dentatis, angulis lateralibus in cornu validiusculum, extrorsum et leviter antrorsum vergens, sat longe productis, marginibus hujus cornu denticulatis. Limbus abdominis ferrugineo-maculatus. Tibia antica simplices.

5. O. linenticeps Stål. - Griseo-albida, ferrugineo-fusco-punctita, subtus cum pedibus dilutius ferrugineo-punctata; capite parteque laterali thoracis nigris vel dense nigro-punctatis; capitis marginibus lateralibus, linea media pereurrente, lineolis duabus intracularibus regioneque ipsa oculorum, vittis nonnullis angustis thoracis venisque hemelytrorum læviusculis vel parcius punctatis; connexivo nigro, Havescente-fiasciato; margine ventris nigro-maculato. $\sigma^{7}$. Long. 13, Lat. 7 mill. Patria: Terra capensis. (Coll. Signoner.)

Caput introrsum nomnilil angustatum, marginibus latcralibus anterius parce obsoleteque crenulatis, lobis lateralibus lobo medio longioribus, hiscentibus, subacuminatis. Thorax marginibus lateralibus anticis subrectis, irregulariter denticulatis, angulis lateralibus sat prominentibus, apice obtusatis, postice pallido-marginatis et denticulatis. Maculae parve ventris spiracula includentes pallidie, lieves. Tibia anticie simplices.

aa. J/aryine apicali angnlorge upicali exterione corii rotundatis; margine apicali segmentorum ventris lavigato.

6. 0. reficulata Thunb. - Pallide flavescente-griseal, distincte nigro-punctatia, ventre fusco-ferruginen-junctulato; capite, angulis lateralibus thoracis, connexivo maculisque indistinetis marginalibus ventris nigris; apitis linea media regioneque oculormm, lineis sex longitulinalibus thoracis, apice lineisque nonnullis longitudinalihus scutelli nec non venis hemelytrorum fallidis, parce punctatis; membrana grisea, nigro-renosa; vitta laterali pertoris, in caput continuata. levi; margine 
abdominis supra subtusque pallido-lineolato. Long. 14, Lat. 7 mill.

Cimex reticulatus Thuns. Nov. ins. spec. 11. p. 42. (178:3); Thunb. Henl. rostr. cap. II. p. 6. (1822).

Brochymena (?) reticulatı DALL. List of Hem. I. p. 189. 5. (1851).

STOLL. Pun. fig. 111.

Patria: Terra capensis. (Coll. Signoret.)

Praecedenti simillima. Caput antrorsum angustatum, marginibus lateralibus ante medium dentieulatis, lobis lateralibus acuminatis, lobo medio longioribus et hiseentibus. Thorax marginibus lateralibus antieis dentieulatis, dentieulis pallidis, angulis lateralibus extrorsum et nonnilil antrorsum sat productis, subelevatis, nigris, erenulatis. Tibia antiere inerassate, angulo exteriore leviter dilatato.

Apex abrlominis exempli descripti lesus.

\section{EURUS DALL.}

List of Hem. I. p. 189. (1851).

Corpus ovatum, subtus sat convexum. Caput antrorsum angustatum, apice rotundatum, con'aviusculum, lobis lateralibus subfoliaceis, lobo medio longioribus et ante hunc contiguis; bucculis distincte elevatis, basin capitis attingentibus. Rostrum coxas posticas attingens, articulo primo bucculas postice haud superante. Antennæ quinquearticulatæ, articulo primo capitis apicem haud attingente. Thorax marginibus lateralibus anticis denticulatis. Scutellum parte apicali latiuscula, frenis ad medium scutelli extensis. Membrana parviuscula, parce venosa, venis ramulosis. Abdomen ampliatum. Sterna leviter sulcata. Pedes validi, tiliis triquetris; articulo primo tarsorum incrassato.

1. E. dilatatus Turvi. - Pallide griseo-flavescens, acervatim fusco-ferrugineo-punctatus, thoracis angulis lateralibus, ventris limbo vittaque utrimque laterali nigris vel nigro-punctatis, vitta ventris inter limbum et vittam nigram pallida; membrana grisea, venis infuscatis; thoracis angulis lateralibus extrorsum nomnihil productis, apice obtusis et leviter emarginatis; angulo exteriore tibiarum anticarum subdilatato. $\sigma$. ․ Long. 11-141, Lat. $6 \frac{1}{2}-7 \frac{1}{2}$ mill. 
Cimpx dilatatus Thexus. Hem. rostr. cap. II. p. 5. (1822).

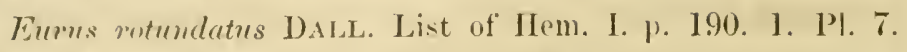
fig. 2. (1851).

Patria: Terra cipensis. (Mus. Holm. et Coll. Signoretr.)

Antemie excmplorum descriptorum mulilatie, articulis duobus ultimis aplee nigris, sece. Daldas.

\section{DYMANTIS STARL.}

Öfv. Vet. Ak. Förł. 1861. p. 199.

Corpus ovale vel ovatum, subtus modice convexum. Caput ovatum, marginibus lateralibus explanatis, acutis; lobis lateralibus lobo medio paullo longioribus; tubereulis antemiferis a supero haud distinguendis; buceulis percurrentibus, parum elevatis, antice altiorifus. Rostrum coxas posticas attingens vel vix superans, articulo primo bucculas postice aquante vel paullo superante, articulo secundo articulis duobus apicalibus ad unum distincte longiore. Ocelli inter se quam ab oeulis vix duj]o longius remoti. Antenne articulo primo brevi, secundo tertio lomgiore. Thorax marginibus lateralibus anticis integris, explatnatis, acutis, angulis lateralibus laud prominulis. Scutellum triangulare, frenis longe ultra medium extensis. Membrane vence longitulinales, simplices. Prostethum antice haud ampliatum. Mesosternum sul'atum. Abdomen hemelytris nomihil latius. Pedes mediocres; femoribus subtus apicem rersus spinulis nonnullis armatis; tibiis triquetris, supra planis.

1. I. plana FABr. - Griseo-flivescens, sat dense fusco-punctulata; linea longitudinali capitis thoracisque, nec non vitta seutelli leviusculis, pallidis; rentris lateribus densius punctatis, lineis duabus longitudinalibus levibus, subcallosis, pallidis, exteriore subtiliore, pluries interrupta, notatis; capitis lobis lateralibus lobo medio levissime superantibus; membrana grisescente, venis fusco-punctatis; corio pone medium macula minutissima leviuscula, pallida; antennarum articulis duobus ultimis fuscis. $\sigma$. ㅇ․ Long. $12-14$, Lat. $6-7$ mill. 
Halys plana FABR. Syst. Rhyng. p. 183. 12. (1803); II. Scir. Wanz. Ins. V. p. 75. fig. 519. (1839).

Sciocoris planus DALL. List of ILem. I. p. 136. 15. (1851).

Var. b. - Tota infuscata, linea capitis thoracisque vittaque scutelli concoloribus; macula minuta corii pallida.

delice elliptice 1I. Sch. Wanz. Ins. V. p. 79. fig. 524. (18399). patriam incorrecte indicat IlerRICH SCH.EFFER.

Paramecocoris linotatus S'TÁL. Öfv. Vet. Ak. Förh. 1855. p. ${ }^{181 . ~ 1 ; ~ S T A ̊ L . ~ O ̈ f v . ~ V e t . ~ A k . ~ F o ̈ r l ı . ~ 1856 . ~ p . ~ 55 . ~} 1$.

Patria: Guinea, Sierra Leona. (Mus. Molm., Coll. Signoret et STẢL.)

2. D. sulvittata S'TẢL. - Pallicle griseo-flavescens, sat dense fusco-punctulata; antennis rufescentibus, articulis duobus ultimis, basi articuli ultimi excepta, nigro-fuscis; linea obsoletiuscula capitis thoracisque nec non vitta scutelli pallidis, lævigatis; nembrana grisescente, venis minute fusco-macuJatis; lobis lateralibus capitis lobo medio distincte nonnilil longioribus et apice contiguis. o7. \&. Long. 11-12, Lat. 6$6 \underset{2}{1}$ mill.

Dymantis subvittata STẢL. Öf. Vet. Ak. Fürh. 1861. p. 200. 1 .

Patria: Caffraria. (Mus. Holn.)

D. plance similis, minor, antemnis brevioribus, aliter coloratis, capitis lobis lateralibus longioribus et apice contiguis distinctissima.

\section{PARAMECOCORIS STÅL.}

Öfv. Vet. Ak. Förh. 1861. p. 199.

Corpus subovale vel late ovale, subtus modice convexum. Caput apice rotundatum, marginibus lateralibus explanatis, acutis, lobis lateralibus lobo medio nonnihil longioribus et anterius contiguis; tuberculis antemniferis a supero haud distinguendis; bucculis leviter elevatis, percurrentibus. Rostrum mediocre vel breviusculum, articulo primo basin capitis attingente, secundo apicalibus duobus ad unnm nonnihil breviore. Ocelli ab oculis longe remoti. Antennæ mediocres, articulo primo capitis apicem 
haud attingente. Thorax marginibus lateralibus anticis explatnatis, arutis, integris, angulis lateralibus haud prominulis. Siutellum triangulare, apice angustatum, frenis ultra medium extensis. Pedes mediocres, tibiis triquetris, supra planis vel sulcatis.

Dynanti affine genus.

a. Corpore ovali vel anguste ovali; rostro inter pedes intermedios vel ad pedes posticos extenso; mesostemo nonnilit sulcuto.

b. Antennis nigris; ocellis inter se quam al oculis rix duplo longius remotis; thorace antice levissime sinuato; femorilus subtus apicem versus vix rel obsoletissime spinulosis.

Ėmius Stål. Öfv. Vet. Ak. Förh. 1861. p. 199.

1. P. ater DALL. - Ovalis, niger, dense punctulatus; thoracis marginibus lateralibus anticis concoloribus, subrectis; hemelytris interdum in ferrugineo-nigrum vergentibus; membrana obscure fusca; antennarum articulis secundo et tertio subæqualibus; venis hemelytrorum haud lævigatis; femoribus subtus apicem rersus spinulis nonnullis obsoletissimis armatis. ․ Long. $10 \frac{1}{2}$, Lat. 4 mill.

Sciveoris ater DALL. List of Hem. I. p. 137. 19. (1851). sec. Mus. Brit.

Patria: Sierra Leona. (Mus. Holm.)

2. P. longulus GERM. - Subanguste ovalis, sordide flavescentegriseus, sat dense fusco-punctulatus; antennis, capite superue, pedibus anticis fomoribusque intermediis nigrieantibus; tibiis tarsisque posterioribus dilute griseo-flavescentibus; thoracis vittis angustis quattuor vel quinque pallidis, parce punctatis; marginibus lateralibus anticis thoracis, linea subtili longitudinali percurrente scutelli, renis hemelytrorum margineque angusto abdominis pallidioribus, impunctatis; membrana fuseo-griseal rostro et ventris disco fuscis; thoracis marginibus lateralibus anticis subrotundatis; antemnarum articulo secundo tertio tertial parte longiore; femoribus subinermibus. \&. Long. 10, Lat. $4 \frac{1}{2}$ mill. 
Cimex longulus GerM. in Silb. Rev. ent. V. p. I80. 121. (1837).

Sciocoris longulus 1I. ScH. Wanz. Ins. V1I. p. 86. fig. 753. (1844); DaLL. List of Hem. 1. p. 134. 10. (1851).

Patria: Terra capensis. (Mus. Holm.)

Ad hane divisioncm verisimiliter pertinet Sciocoris Morio DaLl., uti videtur $P$. longulo valde affinis.

bb. Antennis pallidis; ocellis inter se quam ab oculis paullo longins remotis; thorace antice sut profunde sinzato; fenoribus, anterioribus saltrm, subtus apicem rersus distincte spinulosis.

Paranecocoris Stíl. Öfv. Vet. Ak. Fürh. 1861. p. 199.

c. Marginilus lateralilus ventris immaculatis.

3. P. phaleratus StÂL. - Griseo-stranineus, sat dense fuscopunctulatus; vitta continua capitis, thoracis scutellique, thoracis vitta utrimque laterali distincta renisque hemelytrorum lævigatis; maculis tribus minutis lateralibus pectoris prope coxas spiraculisque nigris. $\sigma^{7}$. Long. 11, Lat. $6 !$ mill.

Paranecocoris plealeratus STiL. Öfr. Vet. Ak. Förlı. 1853. p. 215.1 .

Patria: Caffiraria. (Mus. Holm.)

Caput parte anteoculari subsemicireulari, parte basali latcrali inter occllos et oculos levigata. Antenuie articulo sceunclo tertio nonnihil longiorc. Thorex preter vittas tres distinctas rittulis duabus vel quattuor discoidalibus obsoletissimis, parcius punctatis, instructus, angulis anticis in denticulum minutum prominulis, marginibus lateralibus anticis nomilial rotmudatis. Scutellum prater vittam lævem mediam vittis duabus lateralibus anterioribus obsoletissimis, pareins punctatis, instructum. Membrana grisescens, venis panllo obscurioribus.

4. P. Iautus STÅL. - Ovalis, pallide griseo-flavescens, sat dense subtiliterque dilute punctulatus, punctis interdum, præsertim in scutello hemelytrisque, dilute fuscescentibus; scutelli apice imo pallidiore; membrana concolore; punctis tribus lateralibus pectoris spiraculisque nigris; thoracis angulis anticis obtusis, marginibus lateralibus anticis nomnilil rotundatis; hemelytris sordidis, limbo costali pallidiore; antennis in luteHemiplera africanu. 
scenten verentilus, articulo secundo tertio longiore. \&. Long. 12, Latt. $T$ mill.

Paremecocuris lautus Sital. Öf. Vet. Ak. Förh. 1861. p. 201. 2 .

Patria: Caffraria. (Mus. Holm.)

5. P. viltirentris S'TAL. - Ovalis, dilute grisen-flavescens, sat dense subtiliterque finsco-punetulatus, limbo costali hemelytrorum a hasi ulta medium retrorsum angustato ventreque punctis deroloribus instrurtis; maculis duabus minutissimis anterioribus thoracis et quattuor lateralibus pectoris, spiraculis vittanue laterali disci rentris, sapissime etiam membrana nigris; antennis apicen rersus subinfuscatis, articulo secundo tertio nomnihil lomgiore; angulis anticis thoracis obtusis. marginibus lateralihus antiris nomihil rotundatis. or. Long. 10, Lat. 6 mill.

Puramecocoris rittiventris Fis. Öf. Vet. Ak. Förh. 1861. p. 200. 1.

Patria: Caflraria, Territorium flurii Srakop. (Mus. Ilolm.)

Variat membrana griscesente rentrisque vittis dilutioribus, nigro-punctitis.

Pracerentent mixime affinis, punctis duobus thoracis vittisque ventris differt.

cc. I'entris marginibus luteralibus in angulis basalibus segnuentornm macule minute nigra notetis.

6. P. vatmalis Glekr. - Suburatus, griseo-flaruscens, sat dense subtiliterque fusco-jumctatus; antemnis rufescentibus, articulo apicali interdum infuscato, articulo secundo tertio nomihil longiore; thoracis scutellique maculis duabus anterioribus minutissimis, ventris vitta laterali, posterius abbreviata, spiraculis maculisque minutis marginalibus nigris; membrana grisescente, venis obsolete fusco-maleulatis; thoracis angulis anticis obtusis. marginibus lateralibus anticis nonnibil rotunlatis; capitis parte anteoculari subsemicirculari. o. \&. Long. 14, Litt. 8 mill.

Cimer ventralis Gerм. in Sil. Rev. eut. V. p. 181.122.(1837). 
Sciocoris ventralis DALL. List of Hem. 1. p. 134. T. (1851).

Paramecocoris fatidicus STìl. Öfi. Vet. $\Lambda \mathrm{k}$. Förh. 1853. p. 215.2.

Patria: Africa meridionalis. (Mus. IIolm. et Coll. Sigronet.) ornatus.

Thorax interins interdum maculis quattuor nigris minutissimis

7. P. atomarins DALL. - Subanguste ovalis, sordide griseo-flavescens, sat dense ferrugineo-fusco-punctulatus; antennis subrufescentibus, articulo apicali infuscato, secundo tertio nonnihil longiore; ventris maculis minutis marginalibus spiraculisque nigris, vitta laterali, pone medium abbreviata, dense nigro-punctata; capite distincte longiore quam inter oculos latiore; thoracis angulis anticis obtusis, marginilus lateralibus anticis leviter rotundatis; membrana grisea. \&. Long. 10 , Lat. $4 \frac{2}{3}$ mill.

Sciocoris atomarius 1)ALL. List of JIem. 1. 1. 136. 17. (1851). sec. Mus. Brit.

Paramecocoris ellipticus STẢ. Öfv. Vet. Ak. Förh. 1853. 215. 4 .

Patria: Caffraria. (Mus. Holm.)

aa. Corjore late ovali; rostro pedes intermedios attingente; ocellis ab oculis sat remotis; mesostemo leviter carinato; fenorilnus sultus apicem versus distincte spinulosis.

Erachtheus Stål. Öfv. Vet. Ak. Förh. 1861. p. 199.

8. P. Intulentus STAL. - Griseo-flavescens, dense obscure ferrugineo-punctatus; articulis duobus apicalibus antennarum nigro-fuscis; scutello in angulis basalibus macula parva nigra ornato, apice flaro-albido, lavi; rentris disco limboque remotius punctatis, spiraculis maculisque parvis marginalibus, angulos apicales et basales segmentorum occupantibus, nec non connexivi fasciis nigricantibus vel fuscis; pedibus fusco-ferrugineo-conspersis. ㅇ. Long. 11, Lat: 7 mill.

Paramecocoris lutulentus STẢL. Öfv. Vet. Ak. Förh. 1853. p. 215. 3. 


\section{Patria: Catlraria. (Mus. Holm.)}

Caput fere brevins quam inter oculos latius, concaviusculum, antice rotunlatmm. Antemne articulo secundo tertio nounihil longrome. Thorax antice: sat profunde cmarginatus, angulis anticis obtusis, mareinibus lateralibus anticis nomulhil rotunclatis. Hemelytra abdomine panllo ançustiora. Venter disco paree punctatus, punctis in medio et latribus disci allute remotioribus.

Sciocoris Boris DALL. Pur. lutulento similis, capite longriore distinctus. sce. Mus. Brit.

9. P. spinosus Sign. - Griseo-flavescens, supra fusco, subtus ferrugineo-punctatus, pedibus impunctatis; scutello basi in angulis macula parva nigra notato, apice sordide flavo-albido; ventris limbo discogue magno remotissime punctatis, illo immaculato, hoc utrimque vitta pallidiore ornato; membrana dilute fuscescente; antennis articulis secundo et tertio fere xqualibus; capite fere aque longo ac inter oculos lato; thoracis marerinibus lateralibus anticis levissime rotundatis. o’ Long. 10, Lilt. 5̦

Pentatoma spinosa Sigx. Rev et Mag. Zool. 1851. p. 442. 6. Patria: Calabar. (Coll. Signoret et ŚTẢL.)

Priecerlenti simillimus.

Sciocoris tibialis DAlL. I'ar. spinoso similis, capite longiore vittis(ue pallidis ventris deficientibus differt.

\section{CA INTTRUS STAL. \\ Öfr. Vet. Ak. Fïrh. 1861. p. 199.}

Corpus ovale, sululpressum. Caput marginibus lateralibus explanatis, acutis, leviter sinuatis, lohis lateralibus lobo medio nomihil longioribus et antioe contiguis, apice conjunctim rotundatis; tubremlis antemiferis a supero distinguendis. Rostrum peles posticos attingens, articulo primo capitis basin attingente, secumdo et tertio subaqualibus. Intenna quinquearticulatie, articulo primo capitis apicem apquante vel subsuperante, secundo tertio vix aquilongo. Thorax marginibus lateralibus anticis explanatis, acutis, integris. sentellum triangulare, frenis ultra medium sat longe continuatis. Hemelytra abdomine nomniluil angustiora; membrana venis simplicibus. Mesosternum leviter 


\section{$-117-$}

sulcatum. Pedes longiusculi, femoribus inermibus, tibiis superne late sulcatis.

Paramecocoridi affine genus.

1. C. marginirentris STÅL - Pallide griseo-flavescens, sat dense nigro-punctatus, pedibus vix punctatis; corii venis sublævigatis; membrana grisescente, venis obscurioribus; ventre, excepto limbo, nigricante; thoracis angulis anticis apice brevissime dentatis, marginibus lateralibus anticis subrectis, medio levissime sinuatis. or. Long. 12, Lat. 611 mill.

Paramecus marginiventris S'TẢL. Öf. Vet. Ak. Fürh. 1858. p. 435 . I.

Patria: Calabar. (Coll. A. Dorns.)

MYROCHEA A. et. S.

Hist. des Hém. p. 135. (1843).

Corpus ovale. Caput ovatum, apice rotundatum, integrum, marginibus lateralibus explanatis, acutis, lobis lateralibus lobo medio nonnihil Iongioribus et apice contiguis; tuberculis antenniferis a supero land distinguendis; bucculis levissime elevatis, percurrentibus. Ocelli pone lineam inter basin oculorum ductam positi. Rostrum pedes posticos attingens, articulo primo capitis apicem haud attingente, secundo tertio nonnihil longiore. Thorax marginibus lateralibus anticis explanatis, acutis, integris. Scutellum triangulare, frenis longe ultra medium extensis. Membranæ venæ simplices. Mesosternum sulcatum. Pedes mediocres, femoribus apice superne spina armatis, subtus apicem versus spinula una alterave instructis; tibiis triquetris, superne late sulcatis.

Paramecocoridi affine genus.

1. II. aculeata WEstw. - Pallide griseo-flavescens, supra cum pectore remote diluteque fusco-punctulata; thoracis vittis sex, scutelli vittis duabus angulisque basalibus nec non corii vitta una dense nigro-punctatis; capitis lobo medio toto vel apicem versus, antennis, sternis, pectoris vitta lata laterali, ventris vittis duabus lateralibus, valde appropinquatis, 
imterdum subconfluentibus, maculis magnis transversis discoidalibus maculisque minutis marginalibus, connexivi fasciis, femoribus apicem rersus, tibiis tarsisque nigris; tibiarum annulo lato griseo-flarescente; membrana grisea, fusco-venosa; thoracis marginibus lateralibus anticis rectis, angulis lateralibus spina sat magna armatis. $\sigma^{3}$. Long. 12, Lat. 6 mill.

Pentatoma aculeata WEsTw. in Hope Cat. of Hem. I. p. 44. (1837). sec. Coll. Hope.

Myrochea vittata A. et S. Hist. des Hém. p. 136. 1. (1843). Patria: Senegal. (Coll. Sigroret et Stíl.)

\section{SLPIIELA A. et S.}

Hist. des Hém. p. 123. (1843).

Corpus angustum, oblongum, depressum. Caput productum, ovatum, apice rotundatum, integrum, marginibus lateralibus explanatis, acutis, lolis lateralibus lobo medio.longioribus et anterius contiguis; tuberculis antenniferis a supero haud distinguendis; bucculis leviter elevatis. Ocelli pone lineam fictam inter basin oculorum ductam positi. Rostrum pedes intermedios vix superans, articulo primo bucculas haud superante, secundo tertio longiore. Antennie breviusculie, articulo primo capitis apicem hand attingente, secundo tertio nonnilil longiore. Thorax marginilus lateralibus anticis explanatis, acutis, integris, angulis latcralibus haud prominulis. Scutellum triangulare, apice valde angustatum, frenis longe ultra medium extensis. Hemelytra abdomine rix angustiora; membrane venis simplicibus. Mesosternum sulcatum. Pedes mediocres, femoribus inermibus, tibiis supra leviter sulcatis.

Paramecocoridi : Iffine genus.

1. S. liuraris $\Lambda$. et $\mathbf{S}$. - Dilute griseo-straminea, supra subtiliter et sat dense dilute fusco vel ferrugineo-punctata, ventre remotissime dilute punctato; vitta scutelli levigata; maculis tribus lateralibus minutissimis pectoris spiraculisque nigris; membrana sordide hyalina. $\sigma^{3}$. 9 . Long. 14, Lat. 5 mill. 
Sephela linearis A. et S. Hist. des Hém. P. 124. P'l. 12. fig. 7. (1843); Fieber. Rhynchotogl: p. 36. 1. (1851).

Patria: Senegal. (Coll. Signorét et STẢL.)

\section{COCALUS S'TÂL.}

Öfv, Vet. Ak. Förh. 1861. p. 200.

Corpus ovale. Caput triangulare, marginibus lateralibus explanatis, acutis, lobis lateralibus lobo medio longioribus et anterius contiguis, apice acutiusculis; tuberculis antemniferis a supero ad partem distinguendis; bucculis basin capitis subattingentibus, leviter elevatis. Ocelli in linea ficta, inter basin oculorum ducta, positi. Rostrum coxas intermedias attingens, articulo primo bucculas postice iejuante, articulis secundo et tertio subæqualibus. Antenna mediocres, articulo primo capitis apicem haud attingente, secundo tertio nomnihil longiore. Thorax marginibus lateralibus anticis explanatis, acutis, subcrenulatis, angulis lateralibus haud prominulis. Scutellum triangulare, frenis longe ultra medium extensis. Membranæ venæ simplices. Mesosternum leviter carinatum. Pedes mediocres, femoribus anterioribus subtus obsoletissime spinulosis, tibiis superne suleatis.

Paramecocoridi affine genns.

1. C. lencogrammus GerM. - Griseo-flavescens, supra sat dense ferrugineo-fusco-punctatus, subtus subtiliter dilute punctulatus; thoracis marginibus lateralibus, vitta media distinctiore vittisque nommulis obsoletissimis lateralibus nec non scutelli vitta obsoleta parcius punctatis; venis hemelytrorum levigatis; membrana grisescente; vitta laterali pectoris ventrisque fusco-punctata; pectoris maculis lateralibus duabus vel tribus prope coxas nigris; thoracis marginibus lateralibus anticis

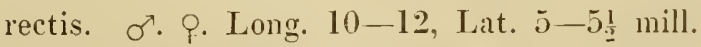

Cimex leucogrammus Gers. in Silb. Rev. ent. V. p. 179. 120. (1837).

Sciocoris leucogrammus H. ScH. Wanz. Ins. VII. p. 88. fig. 756. (1844); DaLl. List of Hem. 1. p. 134. 9. (1851). 
Patria: Terra capensis, Sierra Leona. (Mus. Holm., Coll. Sigroret et S'TiL.)

\section{SCIOCORIS FALL.}

Hem, Suce. p. 20. (1829).

Corpus ovile, depressum, subtus leviter convexum. Caput majusculum, explanatum, foliaceum, lobis lateralibus lobo medio longioribus et antice contiguis. Oculi parvi. Rostrum coxas posticas subattingens, articulo primo bucculas postice haud superante, secundo apicalibus duobus ad unum subequali. Thorax antice late sinuatus, marginibus lateralibus explanatis. Scutellum retrorsum angustatum, lateribus haud vel levissime sinuatum, frenis brevibus. Membranæ venæ simplices. Prosternum et mesosternum sulcata. Pedes mediocres; tarsis posticis articulo primo apicalibus duobus ad unum-paullo breviore.

a. Thorace toto concolore, nigro-punctato, lateribus nec dilutioribus nec palliclius punctatis.

1. S. Wolfii Sign. - Ovalis, griseo-stramineus, sat dense et distincte nigro-punctatus, ventris disco vittaque angusta obsoleta latera versus posita nec non femoribus parcius punctatis; capitis macula parval laterali prope oculos scutellique maculis basalibus minutissimis quattuor (quinque?) lavigatis; scutelli angulis basilibus imis impressis, abdominis dorso, excepto connexivo, segmentis comnexivi basin et ajicem versus nec non maculis parvis marginalibus ventris, angulos segmentorum occupantibus, nigricantibus; membrana infuscata, venis pallido-lineolittis. ơ. Long. 6, Lat. $3 \frac{1}{3}$ mill.

Sriocoris IIolfii Sign. Ann. ent. Sier. 3. VIll. p. 924. 83. (1861).

\section{Patria: Madagascar. (Coll. Signoret.)}

Marroine's corporis ciliis destituti. ('aput late oratum, antrorsum sensim angustatum, fere aeque longum ace inter orulos latum, ad ocnlos leviter emarginatum, narginibus lateralibus pone medium levissime simutis. Thorax eapite vix brevius et hand duplo latius, marginibus lateralibus vix rotundatis, modio rectis. Scutellum retrorsum sensim ilugustatum, apice ino pallido-limbatun. Corium 
scutello nomnihil longius, angulo apicali exteriore subacuto. Membrana corio tertia parte brevior.

aa. Thoracis lateribus ante medinm pallidis et dilute punctatis.

b. Ventris disco concolore.

2. S. Amyoti SigN. - Griseo-stramineus, sat dense ferrugineofusco-punctulatus, subtus subtilius et paullo remotius punctatus; macula parva marginum thoracis lateralium prope angulos laterales, macula parva distinctiore marginali prope angulos posticos prostethii, impressione parva angulorum basalium scutelli, mesosterno, dorso abdominis, segmentis connexivi basi et apice nec non macula parva angulorum basalium segmentorum ventris nigris; pedibus non nisi obsoletissime fusco-punctulatis. ․ Long. 5, Lat. vix 3 mill.

Sciocoris Amyoti Sign. Ann. ent. Sér. 3. VIII. p. 924. 84. (1861).

Patria: Madagascar. (Coll. SignoRet.)

Corporis margines ciliis destituti. Caput ovatum, paullo longius quam inter oculos latius, ad oculos vix emarginatum, marginibus lateralibus pone medium leviter sinnatis, prope oculos macula parva levi notatum. Thorax capiti subaquilongus, eapite cum oculis circiter duplo latior, marginibus lateralibus anticis rectis, posterius leviter rotundatis, latcribus ante medium pallidis et dilute punctatis. Scutellum retrorsuu sensim angustatum, ad angulos basales callo obsoleto minutissimo levi instructum. Corium scutello vix longius, angulo apicali exteriore subacnto. Venter linea abbreviata longitudinali lievi instructus.

bb. Ventris disco nigricante.

3. S. rusticus STÅL. - Ovalis, griseo-stramineus, subferrugineofusco-punctulatus, lateribus thoracis ante medium pallidioribus et dilutius punctatis; scutelli apice imo concolore et punctato. $\sigma^{7}$. Long. $4 \frac{1}{2}$, Lat. $2 \frac{1}{2}$ mill.

Sciocoris rusticus STÅL. Öf. Vet. Ak. Förh. 1853. p. 215.1.

Patria: Caffraria. (Mus. Holm.)

Margines corporis ciliis destitnti. Caput thoraci aquilongum et eodem circiter dimidio angustius, antrorsum leviter angustatum, apice semicirculariter rotundatum, ad oculos levissime incisum, marginibus lateralibus pone medium leviter sinuatis, prope oculos ma- 
cula minuta levi notatum. Thorax marginibus lateralibus rix rotumclatis, lateribus ante medism pallidioribus, apice nuclio lincola brevissina longitudinali et disco ante medium maculis duabus irregrnlaribus obsoletis levigatis instructus. Scutellum retrorsum sensim amgustatum, lateribus rix simmatum, ad angulos basales nigros et impressos callo minuto pallido laevi notatmu, pone medium ruga longitudinali, ablureviata, parmm elevata, pallida, lacvi instructum. Coriun sentello sublongins, angulo apicali exteriore acuto. Membrana corio trotia parte brevior, sordicle hyalina, immanenata. Prostethium utrimcunc punctis nigris, in maculam magnam incleterminatam acervatis, marginibus lateralibus postice nigris. Sterma nigra. Abdomen dorso nigricans, commexivo grisco-stramineo, segunentis basin et apiecm rersus fusco-punctatis; ventre subferrugineopunctato, disco angusto nigricante, lateribus fusco-punctatis, intus linea subcallosa irregulari pallicla termiuatis, margine laterali pallicla, fusco-maculato. Pedes impunctati.

4. S. fusco-sparsus sitic. - Ovalis, pallide griseo-stramineus, sat dense nigro-punctatus; thoracis lateribus ante medium scutellique apice dilute stramineis et pallicle punctatis; membrana sordide hyalina, fusco-conspersa; thoracis marginibus lateralibus postice ad angulos laterales, prostethii macula minuta marginali prope angulos posticos, angulis basalibus impressis scutelli, sternis, dorso abdominis, disco angusto ventris, macular angulormm segmentorm comnexivi ventrisque nierris. o. Long. 4 ! , Lat. 3 mill.

Sciocoris fusco-sparsus ŚrÂl. Öfr. Vet. Ak. Fürh. 1858. p. 312.7 .

Patria: T'kons fountain Africe meridionalis occidentalis. (Mıs. Holı.)

Caput oratum, thorace dimidio angustius ot vix brevius, ad oculos leviter emanginatmm, lateribus posterius nomilil simuatum. Thorax marginibus latralibus anticis posterius leviter rotundatis, disco ante medium allis minutis duobus et apies lineola longitudimali brevissiuna obsoleta lievigatis, pallidis notatus. sentellum retrorsmu se'nsim angustatum, litcribus vix sinuatum. C'orium scoutcllo nomilil lomgriss, angulo apicali nomihil aento. Membrama corio tertia parte hrevior. Venter pare punctatus, disco utrimple serie maculanm parrarum fuscarmu notatus, lateria versus prope stignata densius punctatus, ad stigmata callis minutis obsoletis palliclis instructus. Femora parce fusco-punctulata, apicem rersus macula parva fusca notati. 


\section{MENACCARUS A. et s.}

Hist. des IIém. p. 100. (1843).

Corpus ovale, subdepressum, subtus leviter convexum. Caput magnum, explanatum, foliaceum, planum, setis ciliatum, lobis lateralibus lobo medio nonnihil longioribus et antice contiguis; bucculis percurrentibus, modice elevatis. Oculi parvi. Ocelli inter se quam ab oculis duplo longius remoti. Rostrum coxas intermedias haud attingens, articulo primo bucculas postice vix aquante, secundo apicalibus duobus ad unum patillo longiore. Antenne articulo secundo tertio longiore. Thorax antice late sinuatus, marginibus lateralibus anticis ciliatis. Scutellum latum, retrorsum sensim angustatum, lateribus haud sinuatis, frenis brevibus. Corium margine costali ciliato. Membrana venis simplicibus: Prosternum et mesosternum sulcata. Pedes mediocres, femoribus subtus tibiisque setosis; tarsis posticis articulo primo apicalibus duobus ad unum nomnihil longiore.

Sciocoridi valcle affine genus.

1. II. ciliosus STÁL. - Lividus, sat dense fusco-punctulatus; capite subseniorbiculari, margine ad oculos leviter inciso; thorace antrorsum leviter angustato, medio transversim obsolete impresso, ante impressionem maculis duabus minutis lævibus instructo, marginibus lateralibus anticis levissime rotundatis, angulis posticis obtusis, apice rotundatis; scutello thorace dimidio longiore, angulis imis basalibus nigris; corio scutello nonnihil breviore, pone medium linea longitudinali lavi instructo, margine apicali subrotundato, extus recto, angulo apicali exteriore recto; membrana grisescente, dilute fusco-venosa; angulis basalibus segmentorum abdominis supra subtusque nigricantibus; ventris disco utrimque in segmentis secunclo, tertio, quarto et quinto lineola oblique longitudinali pallida lævi instructo; femoribus obsolete fusco-variis. ơ. Long. 6, Lat. 4 mill.

Menaccarus piceus A. et S. Hist. des Hém. p. 100. 1. (1843). Patria: Nubia superior. (Mus. Holm.) 
Exemplum typicum Lurors, male conservatum, obscurc infuscatum, a Dom. Sigivoner amicissime transmissum, diligenter examinavi.

\section{PODODUS $\Lambda$. et $\mathrm{S}$.}

Hist. des Hém. p. 101. (1843).

Corpus ovale, subtus modice convexum. Margines capitis, thoracis henelytrorumque nee non pedes setosi. Caput sat magnum, latum, foliaceum, planum, lobis lateralibus lobo medio paullo longioribus et apice contiguis; bucculis percurrentibus. Oculi parvi. Ocelli inter se quam ab oculis duplo longius remoti. Rostrum pedes intermedios attingens, articulo primo bucculas postice aquante, secundo apicalibus duobus ad unum longitudine rquali. Antennæe mediocres, articulo secundo tertio longiore. Thorax marginibus lateralibus explanatis, foliaceis. Scutellum retrorsum sensim angustatum, lateribus haud sinuatum, apice latum; frenis medium scutelli haud attingentibus. Membrana venis simplicibus. Prosternum et mesosternum leviter sulcata. Pedes, præsertim tibiæ, setosi. Tarsorum posticorum articulus primus apicalibus duobus ad unum duplo longiore.

Menaccaro affine genus.

1. P. orbicularis Burs. - Late ovalis, stramineo-albidus, supra sat dense, subtus parce, plus minus distincte ferrugineo- vel nigro-punctatus; capite semiorbiculari, margine laterali ad oculos distincte inciso; thoracis marginibus lateralibus subrotundatis, angulis lateralibus retrorsum leviter acute productis, prope margines laterales anticos vittula abbreviata pallida et pallide punctata instrueto; seutello basi ipsa obsolete pallido-notulata; corio scutello æequilongo, apice truncato, angulo apicali exteriore obtusiusculo; membrana grises'ente, angustula; connexiro in angulis exterioribus segmentorum fusco-maculato; pectore lateribus nigro-maculatis; ventris disco ferrugineo-punctulato, lateribus late ferrugineis vel nigricantibus, vitta laterali a basi ad segmentum ultimum extensi nee non maculis marginalibus stramineo-albidis; pedibus interdum, in exemplis obscurioribus et nigro-punctatis, 
nigro-fuscis; antennis dilute ferrugineis apice interdum infuscatis. c7. ㅇ. Long. $7 \frac{1}{2}$, Lat. 5 mill.

Sciocoris orticularis BURM. Handb. II. 1. p. 373. 6. (1835); Fieber Rhynchotogr. p. 14. 2. (1851).

Sciocoris capensis WESTW. in 11OPE. Cat. of Hem. I. p. 18. (1837).

Pododus orbicularis A. et S. Hist. des Hém. p. 101. 1. (1843). Patria: Terra capensis. (Mus. Hohm. et Coll. Signoretr.)

2. P. obtusangulus STÅL. - Latiuscule ovalis, sordide albidus, supra sat dense, subtus remotius ferrugineo-punctulatus; capite semiorbiculari, margine ad oculos distincte inciso; thorace marginibus lateralibus anticis subrotundatis, angulis lateralibus obtusis, lateribus pallidius punctatis; scutello hemelytrisque parce nigro-conspersis, corio apice truncato, angulo apicali costali subrecto; membrana griseo-albida, fuscoconspersa; connexivi segmentis basi et apice fusco-punctatis, angulis exterioribus fuscis; pectoris lateribus nigro-variis; ventris lateribus distinctins punctatis, disco utrimque in segmento singulo, excepto ultimo, vittula obliqua pallida lævi notato, angulis basalibus et apicalibus segmentorum nigricantibus; femoribus nigro-conspersis; antennis ferrugineis, apicem versus fuscis. \&. Long. 8, Lat. 5 mill.

Patria: Terra capensis. (Mus. Holm.)

$P$. orbiculari simillimus, thoracis angulis lateralibus haud retrorsum acute productis distinctissimus.

\section{ANTONIA STÅL.}

Corpus ovale vel obovatum, subtus modice convexum. Caput planiusculum, productum, triangulare, marginibus lateralibus rectis, lobis lateralibus lobo medio multo longioribus, ante hunc contiguis, tuberculis antenniferis extus spina distincta armatis; bucculis distincte elevatis, basin capitis attingentibus, postice in lobulum parvum retrorsum leviter prominulis. Rostrum pedes intermedios vix superans, articulo primo basin capitis haud attingente. Antemnæ crassiusculæ, articulo primo capitis apicem 
haud attingente, articulo secundo longo, sequentibus duobus sublongiore. Thorax marginibus lateralibus anticis integris. Scutellum mediore. Membrane vene longitudinales, simplices. Sternal sulcata. Pedes validi, tibiis tripuetris.

Diplorydi affine genus.

1. A. Comma Thunz. - Grisea vel fusco-grisea, sat dense distincteque fusco-punctata, subtus pallidior; antennis ferrugineoflavescentibus, articulo ultimo et apice articuli penultimi fuscis; sentelli vitta percurrente sordide flarescente; membrana albida, renis fusco-maculatis; thoracis marginibus lateralibus anticis subrectis rel leviter sinuatis, angulis lateralibus rotundatis, interdum nonnihil productis. o?. \&. Long. 12-13, Lat. $6-7$ nill.

Cimex comma Thusb. Nor. ins. spec. 11. 1. 41. Tab. 2 fig. 56. (1783).

Dichelops comma 11. SCH. Win\%. Ins. V11. p. 73. fig. T4t. (18+4).

Patria: Terra capensis, Caffraria. (Mus. Holm., Coll. SigroRET et STẢL.)

Specimina caffra magnituline majore, thoracis marginibus lateralibus anticis rectis rel rix simutis ingulisque loteralibus obtusioribus, levissine prominulis, a capensibus differunt; an species distincta:

\section{DIPLOXIS 1 . et Ss.}

Hist. des Hém. p. 138. (1843).

Corpus anguste ohovatum vel oblongo-ohovatum. Caput triangulare, productum, convexinseulum, lobis lateralibus lobo medio unulto Inngioribus; bueculis distincte elevatis, hasin capitis attingentibns, postire in lobulum libere prominentibus. Rostrum coxas posticas subattingens, articulis secundo et tertio subequilongis vel illo hoc nomnihil longiore. Thorax marginibus lateralibus anticis obtusis, integris. Sentellum corio aque longum vel paullo brevius, utrimque levissime sinuatum, parte apicali latinscula. Membrane rene simplices. Sterna sulcata. Pedes mediocres, graciliuseuli, femoribus apice superne interdum spina armatis, tibiis superne sulcatis. 
a. Lobis lateralibus capitis apice obtusis, anterins totis contignis: thoracis angulis lateralibus obtnsis, rotundatis, hand rel vix prominentibns; scutello ante medium utrineque mgu longitudinali lcevi instructo; femoribus apice inermibus; angmlis posticis segmenti ultimi abdominis apice rotundatis.

Coponicr STAL olim.

1. I. rostrata FABR. - Oblougo-obovata, dilute griseo-straminea, distincte et minus dense fusco-punctata, subtus pallidior, remotius punctata; antennis rufescentibus, apicem versus nigris; thorace posterius hemelytrisque dilute ferrugineis, illius margine angusto antico distincte lavigato, marginibus lateralibus anticis levissime sinuatis; scutello ante medium utrimque ruga lavi callosa intramarginali pallicla instructo; ventre utrimque vitta laterali nigro-punctatil ornato; membrana subvitrea. $\sigma^{7}$. Q. Long. 11, Lat. 4 ! mill.

Cimex rostrutus Fabr. Spec. ins. 11. p. 363. 146. (1781); Mant. Ins. II. 1. 298. I91. (1787).

Lygerus rostratus FABR. Ent. syst. IV. p. 150. 52. (17.94); Syst. Rhỵng. p. 219. 68. (1803).

Aeliu hastata FABr. Syst. Rlyyng. p. 189. 4. (1803). II. SCII. Wanz. Ins. VII. p. 90. fig. 752. (1844).

Megarlynchus (?) capensis DALL. List of Hem. I. p. 362.6. (185I). sec. Mus. Brit.

Patria: Terra capensis, Caffraria. (Mus. Ilolm.)

2. D. confusa Strá - Anguste obovata, griseo-straminea, distincte et minus dense fusco-punctata, subtus pallidior, remotius punctata; antenuis rufescentibus, articulis duobus apicalibus, basi articuli penultimi excepta, nigris; scutello basin versus utrimque ruga longitudinali intramarginali callosa, lavi, pallida notato, marginibus lateralibus ante medium nigro-punctatis; membrana subvitrea; rentris vitta utrimque laterali nigro-punctata. $\sigma^{7}$. . Long. 11, Lat. 5 mill.

Patria: Caffraria. (Mus. Holm.)

Precedenti.maxime affinis, vix differt nisi statura robustiore et latiore; exempla quattuor lustravi. 
aa. Jobis lateralibus capitis acutis, apice saltem liscentilus; angulis lateralibus thoracis acutis, procluctis; scutello ante medium utrimque callo longitudinali destituto, in angulis basalibus interdum macnla lavi instructo; femoribus apice spina armatis; angulis posticis segmenti abdominis ultimi productis, acutis.

Jiploxys A. et S.

b. Scutello basi in angulis macula majuscula lari instructo.

3. 10. bipunctata $A$. et S. - Pallide griseo-flavescens, remote fusco-punctata; thorace posterius nonnihil obscurior, angulis lateralibus nigricantibus, in spinam acutissimam extrorsum productis; scutello maculis basalibus pallidis, levibus; membrana sordide vitrea; ventris lateribus dilute punctatis, pallidis, marginibus lateralibus in basi segmentorum macula minutissima nigra notatis, angulis posticis segmenti ultimi leviter divergentibus; capitis lobis lateralibus ante lobum medium contiguis, apice leviter hiscentibus; pedibus immaculatis. $\sigma^{7}$. Long. 10! Lat. 5 mill.

Diploxys bipunctata A. et S. Hist. des Hém. p. 138. 3. (1843). sec. ex. typ.

Gonopsis limaculata STÁL. Öfv. Vet. Ak. Förh. 1858. p. 134. 14 .

Patria: N'Gami. (Mus. IIolm.); Senegal. (Coll. SignoreT.)

bb. Scutello in angulis busalibus macula larigatu destituto. c. Ventris marginilus luteralibus in angulis basalibus segmentomem macula minuta nigra notatis.

4. D. acanthra Westw. - Dilute griseo-flavescens, remote, supra distincte, subtus subtilius, dilute fusco-punctata; capitis lobis lateralibus acutissimis, apicem versus hiscentibus, margrinibus lateralibus anguste nigricantibus; thorace inter angulos laterales linea transiersil, obsoleta, laviuscula instructo, angulis lateralibus leviter prominentibus, nonnihil acutis, apice spinula armatis, parce nigro-punetatis; ventris marginibus lateralibus maculis minutis nigris ormatis; antennis 
apice fuscis, articulo secundo tertio sublongiore. $\sigma$.. . Long. 11, Lat. 5 mill.

Megarlynchus acanthurus WESTw. in HOPE Cat. of Hem. I. p. 20. (1837).

Diploxys senegalensis A. et S. Hist. des Hém. p. 138. 1. (1843).

Dichelops fissa I. ScII. Wanz. Ins. VII. p. 72. fig. 743 . (1844).

Macrina acanthura DALL. List of Hem. I. p. 360. 1. (1851). Patria: Senegal. (Mus. Holm. et Coll. Sigyoret.)

cc. Ventris marginibus lateralibus immaculatis.

5. D. fallax StÅL. - Sordide straminea, remote diluteque fuscopunctulata; capitis marginibus lateralibus concoloribus vel levissime infuscatis, lobis lateralibus acutissimis, apicem versus sat hiscentibus; thorace inter angulos laterales ruga transversa angusta levigata instructo, angulis lateralibus acutis, sat productis, apice spinula nigra armatis; marginibus lateralibus ventris immaculatis; pedibus remotissine minute nigro-conspersis; antennarum articulo secundo tertio nonnibil longiore, articulo apicali interdum leviter infuscato. $\sigma$. ㅇ. Long. 12, Lat. 6 mill.

Patria: Caffraria. (Mus. Holm.); Madagascar. (Coll. SigroRET.)

Statura $D$. acanthurce, sed major.

6. D. fissa Er. - Sordide straminea, remote fusco-punctulata; capitis marginibus lateralibus anguste fuscis, lobis lateralibus acutissimis, apicem versus sat hiscentibus; thorace inter angulos laterales linea transversa lævi, interdum obsoleta, instructo, angulis lateralibus in spinam longam, gracilem, acutissimam, nigram, extrorsum productis; ventre utrimque vitta remote fusco-punctata ornato, marginibus lateralibus immaculatis; pedibus immaculatis; antennarum articulo secundo tertio subbreviore. \&. Long. 11, Lat. 5 mill. 
Cimex fissa Er. Preisverz. 1842. p. 12. 217; Ent. Zeit. XX. p. 86. 217 . (1859).

Diploxys acutispina $\Lambda$. et $\$$. Hist. des IÍm. p. 138. 2. (1843).

Patria: Senegal. (Mus. Holm. et Coll. Sigxorer.)

\section{CURATIA S'TẢL.}

Corpus anguste obovatum. Caput longum, productum, triangulare, acutum, convexum, lobis lateralibus acuminatis, lobo medio multo longioribus; bucculis leviter elevatis, basin capitis attingentibus, postice lobulo, retrorsum prominulo, destitutis. Rostrum pedes posticos attingens, articulo primo basin capitis haud attingente. Thorax angulis anticis antrorsum prominulis, angulis lateralibus longe cornutis, marginibus lateralibus anticis obtusis, integris. Seutellum breviusculum, utrimque leviter sinuatum, corio brevius. Membrama venis simplicibus. Sterna leviter sulcata. Abdomen hemelytris vix latius. Pedes mediocres, femoribus apice inermibus, tibiis superne sulcatis.

Diploxydi affine genus.

1. C. Mentiromis STAL. - Pallide griseo-Havescens, remote dilute subferugineo-punctata, rentris lateribus densius punctatis, obseurioribus; pedibus parce nigro-conspersis; thoracis angulis lateralibus cornutis, comulus apicem versus anterius dente armatis. f. Long. 15, Lat. ( $\mathrm{d}$ mill.

Patria ignota. (Coll. SigNokET.)

Thorax marginibus latcralibus anticis simnatis, angulis anticis apice extus spinula antrorsum proninente armatis, cormubus angulorum lateraliun longis, oblique antrorsum productis, apiecm versus depressis et interins dente distincto armatis, apice truncatis, angulo apicali posteriore acutiusculn, angulo auteriore rotumdato. Anguli apicales segmentorum abdominis leviter prominuli. Capitis pars apicalis et antemie mutilata in cxemplo descripto.

2. c. truncaticornis STAL. - Dilute griseo-flarescens, minus dense ferrugineo-punctulata; thoracis cornubus lateralibus antice inermibus, apice trunciatis ef nigro-marginatis. L,ong. 14, Isat. 6 mill. 


\section{Patria: Keis Kamama. (Coll. Signorlet.)}

Statura priecedentis. Caput thorace nomnihil longins, lobis lateralibus anterins contignis. Anteme articulo tertio seenndo dimidio longiore, articulis apicalibus mutilatis. Thorax angulis anticis apice subinermibus; cornubus lateralibus longis, oblique antrorsum productis, depressis, supra convexiusculis, subtus concaviusculis, anterius ineruibus, apice truncatis, margine apicali et anteriore apicen versus nigris, angulis apicalibus distinctis, anteriore subrecto, posteriore acuto, producto. Membrana grisea, fusco-renosa. Pedes immaculati.

Ablomen exempli descripti mutilatmu.

\section{DICIELOCKPHALA S'TAL.}

Öfv. Vet. 1 k. Wörh. 1853, p. 226.

Corpus oblongum. Caput Iongum, triangulare, acutum, basin rersus convexiusculum, lobis lateralibus valde acuminatis, lobo medio multo longioribus; bueculis leviter elevatis, basin capitis attingentibus, postice in lobulum haud productis. Rostrum pedes posticos subattingens, articulo primo basin capitis haud attingente. Antenne breves, articulo primo brevi, secundo tertio breviore. Thorax marginibus lateralibus anticis integris. Scutellum corio nonnihil brevius, pone medium utrimque leviter sinuatum, parte apicali angusta. Membranæ venæ simplices. Sterna sulcata. Pedes mediocres, tibiis supra sulcatis.

Diploxydi affine genus.

1. D. lauceolata FABR. - Pallide flavescens, supra viridi-punctulata et hic illic induta, subtus dilute punctata et utrimque vitta percurrente virescente ornata; antennis rufescentibus; rapitis marginibus lateralibus, thoracis vittula laterali anteriore punctisque duobus appropinquatis, anterioribus, maculis pectoris tribus parvis lateralibus prope coxas, spiraculis nec non articulis duobus apicalibus antennarum, excepta basi articuli jenultimi, nigris; membrana vitrea. $\sigma^{7}$. ․ Long.

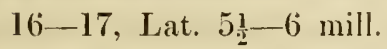

Aelia lanceolata FABr. Syst. Rhyng. p. 189. 3. (1803).

Aelia (?) gracilis WhiTE. Ent. Trans. III. p. 91. (1842),

Megarhynclus (?) gracilis DALL. List of Hem. I. p. 362. 5. $(18.51)$. 
Dichelocephalu virescens STiL. Öf. Vet. Ak. Förh. 1853. p. 226. I.

Patria: Caffraria. (Mus. Holm.); Guinea. (Coll. Sigroker.)

Lobi latcrales capitis nunc contigui, nunc nonnihil hiscentes.

Exemplum femininum caffrmm a me l. c. descriptum statura latiore lobisque eapitis hisecutibus a specimino maseulino guineensi differt.

\section{MECIIJEA DALL.}

List of Hem. I. p. 139. (1851).

Cercitulatax Sicix. Ann. ent. Sir. 2. IX. p. 335. (1851).

Corpus subelongatum, subdepressum. Caput oblongo-triangulare, productum, convexiusculum, lobis lateralibus lobo medio multo longioribus, anterius contiguis vel leviter hiscentibus, marginibus lateralibus haud explanatis; tuberculis antenniferis a supero totis distinguendis; bucculis leviter elevatis. Ocelli in linea ficta inter basin oculorum ducta positi. Rostrum coxas intermedias attingens, articulo primo bucculas postice subrequante, secundo tertio multo longiore. Antennæ quinquearticulata, crassiuscule, basin versus sensin crassiores, articulo primo capitis apicem haud attingente, secundo triquetro. Thorax marginibus lateralibus anticis obtusis, subintegris vel obsoletissime crenulatis, leviter sinuatis. Scutellum triangulare, apice valde angustatum, frenis longe ultra medium extensis. Hemelytra abdomine vix angustiora. Membrana renis simplicibus. Mesosternum subsulcatum. Pedes mediocres, femoribns apice inermibus, tibiis subsulcatis.

1. M. pallida STAI. - Pallide straminea, sujra cum pectore sat dense punctata, ventre lavi, lateribus olsolete punctulatis; ruga subtili longitudinali thoracis scutellique lavi; abdominis dorso nigro-bivittato; antennarum articulo secundo tertio vix ter longiore; macula minuta laterali, pone medium segmentorum ventris posita, nigral. \%. Long. 13, Lat. 4 mill.

Mecidea pullida Stris. Öf. Vet. Ak. Förl. 1854. 233. 1; Öf. V'et. Ak. Förh. 1856. p. 56. 1.

Patria: Nubia superior. (Mus. Holm.) 
2. M. quadrivittata SIGN. - Pallide griseo-straminea, supra cum pectore dilute fusco-punctata; lineis vel vittis duabus posterioribus capitis, vittis quattuor, sæpe sat latis, thoracis densius et obscurius punctatis; vitta laterali pectoris ventrisque plus minus obscure fusco-punctata; vittis duabus dorsalibus abdominis nigris; membrana sordide hyalina; macula minuta laterali segmentorum ventris, nonnihil pone spiracula posita, nigra; antennarum articulo secundo tertio paullo plus quam duplo longiore; thoracis scutellique ruga subtili lævi. $\sigma^{7}$. Long. 10-11 $1 \frac{1}{2}$, Lat. 3-3 $\frac{1}{2}$ mill.

Cerataulax quadrivittatus SIGx. Ann. ent. Sér. 2. IX. p. 336. Pl. 10. fig. 9. (1851).

Mecidec longula SträL. Öfv. Vet. Ak. Förh. 1854. p. 233. 2; Öfv. Vet. Ak. Förh. 1856. p. 57. 2.

Patria: Insula Mauritii. (Mus. Holm. et Coll. Signorer.)

3. M. prolixa STÅL. - Pallide straminea, supra cum pectore pallidissime fusco-punctata; vittis duabus capitis, quattuor thoracis unaque laterali pectoris rentrisque obscurius fuscopunctatis; vittis duabus dorsalibus abdominis nigris; ruga subtili longitudinali thoracis scutellique levigata; membrana vitrea; antennis pedibusque interdum in olivaceum vergentibus, illarum articulo secundo tertio paullo longiore. \&. Long. $9-10$, Lat. $3 \frac{1}{2}-3 \frac{2}{3}$ mill.

Mecidea molixa STÄL. Öfv. Vet. Ak. Förh. 1858. p. 312. 8. Patria: Territorium lacus N'Gami. (Mus. Holm.)

\section{SEPONTIA STÄL.}

Corpus obovatum, supra leviter, subtus valde convexum. Caput subperpendiculare, antrorsum sensim angustatum, apice obtuse rotundatum, lobis æque longis; bucculis leviter elevatis. Rostrum segmentum ventris tertium subattingens, articulo primo bucculas postice superante, articulo secundo apicalibus duobus ad unum nonuihil longiore. Antennæ quinquearticulatæ, articulo primo capitis apicem haud attingente. Thorax anterius valde 
declivis, marginibus hateralibus anticis rectis. scutellum maximun, convexiusculum, abdomine hemelytrisque paullo angustius, illo haud brevius, marginibus lateralibus ad basin leviter sinuatis; frenis brevissimis. Mesosternum subsulcatum. Pedes mediocres, tibiis hand sulcatis.

Pentatome, prasertim subgeneri Eysarcocoricli, aftine et stattura simile genus, scutello maximo mox distinctum.

1. S. misella S'TAL. - Pallide straminea, supra sit dense subferrugineo-fusco-punctulata; capite, maculis duabus anterioribus, transversim triangularibus, thoracis nec nou disco maximo ventris fusco-aneis; rentris limbo fusco-punctulato, margine ifso lavi, calloso, fusco-maculato; maculis duahus parvis prope apicem femorum fuscescentibus. ơ ㅇ. Long. 4-5, Lat. 3-4 mill.

Bolbocoris misellus StÂL. Öf. Vet. Ak. Förh. 1853. p. 211. 3.

Patria: Caffraria. (Mus. Holm.)

Pentatome (Eysarcocoricli) miselle prime intuitu simillima.

Ad hoe gemus rerisiniliter pertinet C'hlemocoris pusillus louLE.SH.

\section{PENTATOMLOL.}

Enc. Ineth. Ins. IV. Introd. p. 25. (1789).

Corpus ovale rel obovatum, subtus interdum valde convexum. Capput mediocre, apicem versus plus minus angustatum, apice rotundatum vel subtruncatum, marginibus lateralibus haud vel vix explanatis; buceulis sapissime percurrentibus, leviter vel modice elevatis. Rostrum mediocre. Antenna quinquearticulata, articulo frimo capitis apicem haud superante. Thorax marginibus lateralibus et antico numquam simul elevatis vel reHexis. Membrana vente simplices, interdum nomilil furcate. l'rostethim antice haul vel vix dilatatum. Mesosternum leviter carinitum. Tenter hasi inermis. Pedes mediocres, tibiis supra plus minus late suleatis. 


\section{Subg. EISARCOCORIS STÂL.}

Eysarcoris HaHx. Wanz. Ins. II. p. 66. (1834).

Eusarcoris Fieb. Eur. Hent. p. 79. et 331. (1861).

Corpus obovatum, sapissime latum, subtus valde convexum. Caput deflexum, apice rotundatum, lobo medio apicem attingente; bucculis percurrentibus, sat elevatis. Antennæ mediocres, articulo primo capitis apicem subrquante, articulis secundo et tertio variabilibus. Rostrum articulo secundo apicalibus duobus ad unum æquali vel paullo longiore. Thorax anterius sat declivis, marginibus lateralibus anticis obtusis, leviter callosis, integris. Scutellum postice latum, nonniliil longius quam basi latius; frenis ad medium scutelli haud extensis. Pedes mediocres, femoribus apice inermibus, tibiis supra haud vel obsolete sulcatis.

1. P. (Eysarcocoris) misella STÂL. - Latiuscule obovata, pallide griseo-straminea, fusco-punctata; capite, maculis duabus anticis thoracis, nec non plaga maxima media longitrorsun percurrente, retrorsum angustata, plus quam tertiam partem latitudinis ventris occupante, fusco-æneis; capite sxpissime vitta pallida, fusco-punctata instructo, ad oculos macula minuta marginali levi, subcallosa, pallida notato; thoracis marginibus lateralibus et antico nec non scutelli macula parva in angulis basalibus lævibus, callosis, pallidis; naculis minutissimis marginalibus ventris nigris; rostro articulo primo bucculas haud vel vix superante, articulo secundo apicalibus duobus ad unum paullo longiore; ventre interdum vitta obsoleta laterali rnescente-fusca notato; antennarum articulo tertio secundo paullo breviore. $\sigma^{7}$. \&. Long. $4 \frac{1}{2}-5 \frac{2}{3}$, Lat. $3-4$ inill.

Eysarcoris misellus STÅL. Öfv. Vet. Ak. Förh. 1853. p. 217. 1 .

Eusarcoris Helferi Fieb. Eur. Hem. p. 332. 3. (1861). Patria: Terra capensis, Caffraria, Nubia, Aegyptus, Sicilia. (Mus. Holm. et Coll. S'TíL.)

Variat antennis apicem rersus fuscis. 
Specimina africana speciminibus e Sicilia missis panllo minora, nullam tamen, quantam videre possum, diversitatem spceificam prabent.

\section{Subg. ASPAVIA STÅ̊.}

Corpus ovatum, subtus valde convexum. Caput planiusculum vel levissime convexum, antrorsum distincte angustatum, apice rotundatum, lobo medio lobis lateralibus sublongiore, marginibus lateralibus haud explanatis, haud tamen convexis; bucculis basin capitis attingentibus; tuberculis antenniferis a supero distinguendis. Rostrum coxas posticas aquans vel paullo superans, articulo primo bucculas interdum paullo superante. Antenna articulis secundo et tertio aquilongis, vel illo hoc paullo breviore. Thorax marginibus lateralibus obtusissinis, integris, ruga levigata terminatis, angulis lateralibus productis. Scutellum triangulare, paullo longius quam latius, apice sat angustatum, frenis nonnihil pone medium extensis. Hemelytra abdomine vix vel paullo angustiora. Ostiola odorifera leviter auriculata. Anguli apicales segmenti ultimi abdominis in spinam sæpissime producti, semper acuti. Femora apice superne spinula armata. Tibiæ graciliusculæ, supra leviter angusteque sulcatix.

a. Capite lineis quinque longitudinalibus lavibus, pallidis, ommilus distinetis, notato.

b. Spinis lateralibus thoracis nigris.

2. P. (Asparia) armigera FABR. - Sordide straminea, ferrugineofusco-punctata; punctis capitis in lineas sex acervatis, interstitiis linearum lavibus; angulis lateralibus thoracis acutissimis, sat longe extrorsum productis, nigris; marginibus antico angusto et lateralibus anticis thoracis, scutelli macula majuscula in angulis basalibus apiceque nec non margine corii anterius levibus, allido-stramineis; membrana sordide straminea, angulo basali interiore fusco; vittis duabus latis discoidalibus limbisque latissimis lateralibus rentris laviusculis, spiraculis fuscis; angulis apicalibus segmenti ultimi abdominis in spinam acutam gracilem productis; femoribus 


\section{$-137$}

apicem versus maculis duabus minutissimis fuscis notatis. $\sigma$. Long. 7, Lat. $4 \frac{1}{2}$ mill.

Cimex armiger FABR. Spec. ins. II. p. 348. 64. (I781); Mant. ins. II. p. 286. 74. (1787). sec. Coll. Banks.

Coreus armiger FABR. Ent. syst. IV. p. I28. 6. (I794); Syst. Rhyng. p. 195. 16. (1803).

Cimex debellator FaBR. Syst. Rhyng. p. 165. 53. (1803); H. ScH. Wanz. Ins. V1. p. 63. fig. 625. (1842).

Pentatoma 1)ebellator H. ScH. Wanz. Ins. VII. p. 95. (1844). Mormidea debellator DALL. List of Hem. I. p. 2I4. 10. (185I).

Patria: Sierra Leona. (Mus. Holm.); Grand Bassam. (Coll. SIGNORET.)

\section{bb. Spinis thoracis pallidis.}

3. P. (Aspavia) pallidispina S'TẢL. - Sordide straminea, minus dense fusco-punctulata, ventre parce punctato, lateribus pallidis, læviusculis vel dilute punctatis; punctis capitis nigris, in lineas sex longitudinales acervatis, interstitiis linearum lævibus, pallidis; thoracis marginibus angusto antico et lateralibus anticis, scutelli macula mediocri in angulis basalibus apiceque callosis, nec non margine angusto costali corii anterius Iævigatis, purius et pallidius stramineis; membrana sordide hyalina; femoribus remote fusco-conspersis; angulis apicalibus segmenti ultimi abdominis in spinam acutam gracilem productis; antennis articulis secundo et tertio aqualibus vel illo hoc paullo breviore; angulis lateralibus thoracis in spinam longam, acutan extrorsum productis. $\sigma^{7}$. ‥ Long. 8, Lat. 5 mill.

Patria: Terra capensis. (Mus. Holm.)

Statura $P$. armigerce, cum qua in collectionibus confunditur.

4. P. (Asparia) longispina STÅL. - Sordide straminea, distincte fusco-punctulata, punctis capitis in lineas sex longitudinales acervatis, interstitiis linearum lævibus, pallidis; ventris lateribus laviusculis vel dilute punctatis, disco vittis duabus remotius punctatis instructo, inter vittas posterius nigro- 
-fusco; thoracis marginibus antico angusto et lateralibus anticis, scutelli macula minuta in angulis basalibus apiceque nec non margine imo costali corii anterius levibus, pallidis; membranil sordide hyalina; femoribus remote fusco-conspersis; antennarum articulo secundo tertio nonnihil breviore; spinis angulorum apicalium segmenti ultimi abdominis gracilibus, sat longis, leviter divergentibus, spinis lateralibus thoracis longis, acutissimis, extrorsum productis. $\sigma^{7}$. ‥ Long. 8, Lat. 5 mill.

Patria: Insula Mauritii. (Mus. IIolm. et Coll. Signoret.)

Precedenti maxime affinis et similis, spinis thoracis longioribus, gracilioribus, maeulisque angulormm basalium scutelli multo minoribus differt.

ail. C'upite vaye punctuto lineis quinque distinctis levibus destituto.

c. Scutelli apice pallido, levi.

5. P. (Ispavia) albidn-maculata STȦ. - Sordide straminea, supra interdum stranineo-grisea et sat dense fusco-punctata, subtus parcius et distinctius nigro-punctata; ventre lateribus pallidis, dilute punctatis, disco vittis tribus indistinctis leviusculis vel remotissime nimro-punctatis; capitis linea longitudinali pereurrente distincta, thoracis marginibus angusto antico et lateralibus anticis, scutelli macula magna in angulis basalibus ipicerfue, ner non margine imo costali corii anterius lavibus, palliclis; membrana subsordide hyalina; pedibus impictis; antenmarum articulis secundo et tertio subxqualibus vel illo hoc paullo breviore; spina angulorum apicalium segmenti ultimi abdominis fuscescente; thoracis angulis lateralibus acutis, nigris, extrorsum longe productis. \&. Long. 8, Lat. 5 mill.

Mormidea albido-maculate STiL. Öf. Vet. Ak. Förh. 1853. I. 217. 1 .

Mormidere melacantha sigs. in THoms. Arch. ent. 11. 1). 281. 5)20. (18.i8). excl. synt.

Patria: Caffrarial. (Mus. Holm.); Madagascalr, Nossi Bé. (Coll. SigNoREt.) 
6. P. (Aspavia) brunnea SIGN. - Straminea, dilute fusco-punctata; thorace pone medium, scutello hemelytrisque leviter infuscatis, obscurius punctatis; capite spinisque thoracis lateralibus acutis, extrorsum sat productis, nigris, illo dense punctato, linea longitudinali distincta media lineisque quattuor obsoletissimis leviusculis; thoracis marginibus angustis antico et lateralibus anticis, scutelli litura callosa maxima trivia, ramulos ad angulos emittente, margineque angusto costali corii ante medium levibus, albido-stranineis; membrana sordide hyalina; ventre paree diluteque punctato, disco lavi, utrimque vitta parce fusco-punctata instructo; pedibus impictis; antennarum articulo secundo tertio vix breviore; angulis apicalibus segmenti ultimi abdominis acutis, leviter productis; spina apicali femorum brevi. $\sigma^{3}$. Long. 61, Lat. 4 mill.

Mormidea brnmea Sigs. in Thous. Arch. ent. II. p. 281. 521. (1858).

Patria: Calabar. (Coll. Sigronet.)

cc. Scutelli apice concolore, punctato.

7. P. (Aspavia) llastator FABR. - Sordide straminea, sat dense fusco-punctulata; ventris Iateribus pallidis, dilute punctatis, disco parce punctato, maculis duabus pone medium, una in segmento quinto, altera in segmento sexto, vittaque irregulari laterali subcupreo-nigris vel fuscis; marginibus angustis lateralibus anticis maculisque duabus minutissimis ante medium thoracis, macula minutissima in angulis basalibus scutelli margineque angusto costali corii anterius pallidis, lævibus; membrana levissime infuscata, venis obscurioribus; pedibus minute fusco-conspersis; capitis linea longitudinali, pone medium abbreviata, laviuscula; antennarum articulis secundo et tertio subæqualibus vel hoc illo paullo longiore, tertio quartoque apice imo, ultimo fere toto leviter infuscatis; thoracis angulis lateralibus nigris, in spinam acutam sat longam extrorsum productis, linea obsoletissima, interdum defi- 
ciente, subundulata, laviuscula; spiraculis nigris; angulis apicalibus segmenti ultimi abdominis in spinam nigram distincte productis. ơ. ㅇ. Long. 8, Lat. 5 mill.

Coreus hastator FABr. Ent. syst. IV. p. 129. 8. (1794).

Cimex yladiator (jaculator) FABR. Syst. Rhyng. p. 165. 50. (1803).

Mormidea hastator DALL. List of Hem. I. p. 214. 11. (1851). Patria: Calabar. (Coll. Signoret et Stall.)

\section{Subg. CARBULA STîl.}

Corpus late ovale vel obovatum, subtus valde convexum. Cilput apice rotundatum vel subtruncatum, lobis subæquilongis, lateralibus obtusis, marginibus lateralibus obtusiusculis; bucculis modice elevatis, basin capitis attingentibus; tuberculis antenniferis ad partem a supero distinguendis. Rostrum mediocre, articulo primo bucculas postice aquante rel superante, secundo apicalibus duobus ad unum subequali vel paullo longiore. Antenna mediocres vel longiusculæ, articulo primo capitis apicem haud attingente, secundo tertio raro paullo longiore. Thorax marginibus lateralibus anticis sapissime obtusissimis, numquam acutis, ruga levi, ipsa interdum transversim rugulosa, terminatis, raro anterius crenulatis. Ścutellum triangulare, breviusculum, paullo longius quam basi latius, frenis paullo ultra medium extensis. Ifemelytra abdomine paullo angustiora; membrane renis simplicibus. Anguli apicales segmenti abdominis ultimi stepissime obtusi, raro in spinulam producti. Pedes mediocres, graciliusculi, tibiis superne leviter sulcatis.

\section{a. Ventris maryine immaculato.}

8. P. (Carbula) decorata Sigx. - Late obovata, sordide straminea, supra cum pectore nigro-punctata; thorace posterius scutello hemelytrisque ferrugineis; capite sat dense punctato; thorace plaga transversa media, irregulari, lavi, straminea, punctis raris acervatis instructa, notato, marginibus lateralibus anticis rectis, ruga pallida, levi terminatis, angulis lateralibus nigris, acutissimis, extrorsum valde prominentibus; 
scutelli macula ovali sat magna in angulis basalibus nec non corii macula minutissima, pone medium posita, lævibus, calIosis, stramineo-albidis; membrana vitrea; abdominis dorso nigro, connexivo toto concolore; ventris lateribus dilute punctatis, disco lavi et latera versus vitta nigro-punctata ornato, spiraculis nigris; femoribus apice, tibiis antennisque dilute ferrugineis. ơ? Long. 8, Lat. 5 mill.

Mormidea decorata Sign. Ann. ent. Sér. 3. VIII. p. 928. 92. (1861).

Patria: Zanzibar. (Coll. Signoretr.)

Articulus secundus antenna sinistrae exempli descripti tertio requalis, idem antennic dextrae tertio distincte longior. Articulus primus rostri bucculis postice nonnilil superans.

9. P. (Carbula) melacantha FABR. - Late obovata, griseo-flavescens vel dilute flavo-testacea, supra dense fusco vel ferrugineo-fusco-punctata; thoracis marginibus lateralibus anticis ruga pallida terminatis, margine imo antico lavi, angulis lateralibus acutis, extrorsum modice productis, nigris; scutello basi maculis tribus minutissimis margineque imo apicali pallidis, lavibus; membrana grisescente; pectore minus dense nigro-punctato; abdominis dorso nigro, connexiro extus stramineo-limbato; ventre punctato, disco lavi, nigricante vel ferrugineo-fusco, parte laterali vittisque duabus discoidalibus stramineis; femoribus apicem versus maculis duabus vel tribus minutissimis nigris vel fuscis; antennarum articulis secundo et tertio subæqualibus. $\sigma^{7}$. ㅇ. Long. $7 \frac{1}{2}$, Lat. 5 mill.

Cimex melacanthus FABR. Ent. syst. IV. p. 103. 94. (1794); Syst. Rhyng. p. 165. 48. (1803). sec. Coll. BAnks.

Mormidea maculipes Sign. Rev. et Mag. Zool. 1851. p. 444. 9.

Patria: Sierra Leona, Gabon. (Mus. Holm., Coll. Signonet et $\operatorname{S} T \hat{A} L$.

aa. Ventris margine maculis minutis nigris notato.

b. Angulis apicalitus segmenti ultimi abdominis ol,tusis, hand productis. 


\section{$-142-$}

c. Capite sut comrexo, nsque al apicem sensim augnstato, apice angusto, rotundato.

10. P. (Carbula) blanda STÀL. - Late ovalis, pallide straminea, supra sat dense, subtus remote ferrugineo-fusco-punctata; capitis lateribus dense cupreo-nigro-punctatis; thoracis spatio transverso medio paree punctato, marginibus lateralibus anticis convexis, callosis, lavibus, integris; callo parvo in angulis basalibus scutelli isec non margine costali corii anterius pallidis, levibus; membrana sordida, venis subinfuscatis, abdomine dorso dilute flavo-testaceo, posterins nigricante, connexivo fusco-punctato, margine exteriore pallido, angulis basalibus et apicali imis segmentorum fuscis; ventris plaga basali transversa, apicem segmenti tertii attingente nec non maculis marginalibus parvis, angulos hasales et apicales segmentorum oceupantibus, nigris; femoribus apicem versus maculis duabus minutis nigricantibus notatis; alis vitreis. $\sigma^{7}$. ㅇ. Long. $6 \frac{3}{4}$, Lat. $4_{2}^{1}$ mill.

Pentutoma blamla STAL. Öfv. Iet. $A$ k. Förls. 1853. p. 218.3. Patria: Caffraria. (Mus. IIolm.)

Capitis forma a reliquis subgeneris speriebus divergit. Caput sat convexum, antrorsun angustatum, apice rotundatum, marginibus lateralibus medio levissime simuatis. Rostri articulus primus hucenlis postice multo superans. Anteme articulis secumelo et tertio iequalibus, ultimn prope apjecm infuseato. Thorax marginibus lateralibus anticis vix simnatis, angulis literalibus acutis, extrorsun nonnihil productis.

ce. Capite pleminsculo, upice ubtusissimo, marginibus lateralibns monniliel simuris, ante simm parallelis.

11. P. (Carbula) trisignata Giks. - Late subobovata, dilute straninea, supra leviter infuscatal et sat dense nigro-punctulata, pectore ventrisque disco maximo fortius nigro-punetatis, hujus punctis in vittas quattuor latissimas subacervatis; ahdominis dorso nigro; thoracis marginibus lateralibus anticis ohtusissimis, callosis, scutelli macula majuscula callosa in angulis hasalibus nee non apice, corii margine costali anterius mor mก comnexivi manolis marginalihus dilute stramineis; 
thoracis angulis lateralibus nigris, "xtrorsum modice productis; membrana infuscata; ventris lateribus dilute punctatis, spiraculis, angulis imis basalibus segmentorum nec non macula minuta, in angulis apicalibus segmentorum posita, nigris; pedibus parce minuteque nigro-conspersis, antemnarum articulo secundo tertio subbreviore. $\sigma^{2}$. \&. Long. 7, Lat. $4 \frac{2}{3}$ mill.

Cimex trisignatus Germ. in Silb. Rev. ent. V. p. 171. 104. (1837).

Pentatoma trisignatum H. SCH. Wanz. Ins. VII. 1. 93 et 97. fig. 760. (1844).

Pentatoma trisignata 1)ALL. List of Hem. I. p. 233. 1. (1851).

Pentatoma trigemmis STÃL. Öfr. Vet. Ak. Förls. 1853. p. 219. 6 .

Patria: Natalia. (Mus. IIoln., Coll. SigNonet et S'TÁL.)

12. P. (Carbula) Limpoponis STẢL. - Late subovata, dilute straminea, supra sat Jense distincteque ferrugineo-fusco-punctulata, subtus remote nigro-punctulata; thoracis marginibus lateralibus anticis scutellique macula callosa in angulis basalibus lævibus, stramineo-albidis; abdomine dorso nigro, connexivi segmentis macula magna marginali straminea notatis; membrana vitrea, angulo basali interiore infuscato; thoracis angulis lateralibus nigris, proluctis; ventris plaga maxima obtriangulari, a basi ad apicem extensa, nec non vitta laterali densius nigro-punctatis, plaga illa interdum fere tota nigricante, angulis imis basalibus et apicalibus segmentorum nec non spiraculis nigris; femoribus interdum parce nigropunctatis, maculis duabus parvis pone medium unaque subapicali nigricantibus. \&. Long. $7 \frac{1}{2}$, Lat. 5 mill.

Pentatoma Limpoponis STÄL. Öfr. Vet. Ak. Fürlı. 1853. p. 219. 5.

Patria: Caffraria. (Mus. Holm.)

$P$. marginella maxime affinis, angulis lateralibus thoracis nigris et magis productis uaculisque basalibus scutelli majoribus diffurt, quoad staturam ad $P$. trisignutan magis appropinquat. Rostri articulus primus bucculas postice subsupcrans. Antemne articulis serundo et tertio subiequalibus. Thorax marninibus lateralibus anticis 
obtusis, convexis, transversim leviter rugosis, leviter sinuatis, angulis lateralibus extrorsum modice productis, interdum subacutis.

\section{P. (Carbula) marginella THuns. - Late obovata, pallide stra-} minea, supra sat dense, subtus remote ferrugineo-fusco-punctata, pectore nigro-punctato; thoracis marginibus lateralibus anticis et margine postico angulorum lateralium nonnilil prominentium, scutelli maculis tribus minutissimis basalibus, una media et una in angulis basalibus, levibus, albidis; membrana sordide hyalina, angulo basali interdum subinfuscato; dorso abdominis nigro, connexivi segmentis macula magna, marginem exteriorem attingente, pallida notatis; ventris plaga maxima obtriangulari, a basi ad apicem extensa fere tota nigra vel subeneo-nigra, angulis imis basali et apicali segmentorum nigris; femoribus parce minuteque nigro-punctulatis, pone medium maculis duabus et prope apicem macula una minutis nigris notatis. $\sigma^{7}$. 9 . Long. 7, Lat. $4 \frac{1}{2}$ mill.

Cimex marginellus Thunb. Hem. rostr. cap. II. p. 4. (1822).

Patria: Terra capensis. (Mus. Holm. et Coll. S'TÁL.)

Preecelenti valde aftinis. Antennarum articuli sccundus et tertius subaequales. Rostri articulus primus bucculas postice paullo superans. Thorax marginibus lateralibus anticis obtusis, callosis, leviter simuatis, ante medium olsolete cremulatis, angnlis lateralibus apiee rotunlatis, nomnihil prominulis.

\section{P. (Carbula) abolomiualis Sigx. - Obovata, pallide strami-} nea, supra sat dense, subtus remote distincteque nigro-punctulita; thoracis marginibus lateralibus anticis, scutelli macula parva callosa in angulis basalibus maculaque minntissima hasali media stramineo-allidis, lavibus; membrana sordide lıvalina; abdominis dorso nigricante, medio sape in flavotestaceun vergente, comnexivo dilute stramineo, marginibus segmentorum basali et apicali nigris rel nigro-punctatis; ventris maculis diseoidalibus magnis, in plagam maximam obtriangularem, basin et apicem ventris attingentem, subconfluentibus, nec non angulis imis basalibus et apicalibus segmentorm nigris; femorihus interdum minutissime parceque nigrn-conspersis, apicem versus maculis minutis duabus vel 
tribus sæpissime notatis; thoracis marginibus lateralibus callosis, subacutis, ante medium leviter crenulatis, nomnihil simuatis, angulis lateralibus' nomihil productis, modice acuminatis; antennarum articulo primo bucculas postice æquante. \%. ‥ Long. 7, Lat. 4 mill.

Mormidea abdominalis Sigr. Ann. ent. Sér. 3. VIII. p. 929. 94. (1861).

Patria: Madagasear, Mayotte. (Coll. SigroRet et Śtíl.)

$P$. marginella simillima, thoracis angulis lateralibus acutis, magis productis, marginibusque lateralibus anticis multo minus obtusis, potius subacutis, differt.

bb. Angulis apicalibus segmenti ultimi abdominis acutis, in spinulam productis.

15. P. (Carbula) curtana DALI, - Late obovata, sordide straminea, supra sat dense, subtus remote ferrugineo-fusco-punctata; thoracis marginibus lateralibus anticis angustis nec non maenla scutelli parva, in angulis basalibus posita, callosis, lavibus, pallidis, marginibus illis obtusiusculis, subintegris; membrana sordida, renis subinfuscatis; abdominis dorso nigro, basin rersus in testaceum vergente, connexiro stramineo, margine angusto interiore nec non fasciis, margines basalem et apicalem segmentorum occupantibus, nigris; ventris plaga magna transversa anteriore nec non macula media segmentorum posteriorum ferrugineo-nigris, angulis imis basalibus et apicalibus segmentorum nigris; pedibus parce minuteque nigro-conspersis, femoribus apicem versus maculis tribus minutis nigris notatis; rostri articulo primo bucculas postice æquante; thoracis marginibus lateralibus anticis nonnihil sinuatis, angulis lateralibus fuscis, in spinam acutam graciliusculam mediocrem extrorsum productis; capite mediocri. $\sigma^{\top}$. Long. 7 , Lat. $4 \frac{1}{2}$ mill.

Mormidea curtana DALL. List of Hem. I. p. 215. 13. (1851). Patria: Sierra Leona. (Mus. Holm.)

Autemne exempli descripti mntilate.

llemipterar africanu. 
16. P. (Carbula) Capito Stis. - Griseo-straminea, distincte fusco-punctulata; antennarum articulis apice nigris; scutelli macula minuta in angulis basalibus callosa, lævi, maculaque minuta laterali media dense nigropunctata notato; corio maculis compluribus parvis levigatis consperso; membrana sordida, venis leviter infuscatis; abdomine dorso posterius fusco, connexivi margine fusco-maculato; pedibus parce fusco-punctulatis, femoribus maculis tribus parvis apicem versus notatis; ventris macula basali, macula segmentorum duorum ultimorum media nec non angulis imis apicalibus et basalibus segmentorum nigris. ․ Long. 9, Lat. $5 \frac{1}{2}$ mill.

Patria: Guinea. (Coll. Sigroret.)

$P$. curtance affinis, major, capite majore, thoracis marginibus lateralibus hand callosis priesertim differt. Caput majusculum, apice rotundatum, anterius nonnihil defiexum; bucculis postice in angulum acutinsculum retrorsum prominulis. Rostri articulus primus bueculas postice requante. Antenue articulis secundo et tertio acqualibus, ultimo exempli deseripti mutilato. Thorix marginibus lateralibus anticis sinuatis, subobtusis, anterius crenulatis, angulis lateralibus in spinam acutissimam mediocrem extrorsum productis.

\section{Sulgg. DURMIA STriL.}

Corpus obovatum. Caput planiusculum vel levissime convexum, apice latissime rotundatum vel rotundato-truncatum, lobis lateralibus obtusis; bucculis distincte elevatis, basin capitis attingentibus. Antemnarum articulus secundus tertio sæpissime nonnihil longior. Thorax marginibus lateralibus anticis obtusiusculis, callosis vel subcallosis, interdum leviter crenulatis. Scutellum distincte longius quam latius, apice modice angustatum, frenis nomihil ultra medium scutelli extensis. Hemelytra abdomine paullo angustiora. Ventris segmenta apice medio pilis erectis, apud feminam raris, instructa.

a. Thoracis ruga callosa transversa nec non scutelli rugis vel vittis duabus callusis, ex angulis basalibus emissis, al medium scutelli converyentibus et ibilem in mam, al apicem contimatam, conjunctis: rentris rittis trilues nigris rel fuscis. 
b. Angulis lateralibus thoracis angulisque apicalibus segmenti ultimi abdoninis acutis, productis.

17. P. (Durmia) bellicosa STÅL. - Subanguste ovalis, straminea, supra dilute sordide ferruginea, nigro-punctata; thóracis spatio transverso medio liviusculo stramineo; scutello ante medium vittis duabus obliquis, ex angulis basalibus emissis, in medio scutelli in unam, ad apicem productam, conjunctis, levibus, callosis, stramineo-albidis; membrana sordide vinacea; abdominis dorso nigro, connexivo, margine exteriore excepto, stramineo; ventre vittis tribus dilute ferrugineis notato, spiraculis nigris; pedibus minute remoteque nigro-conspersis. ơ. Long. 9, Lat. 5 mill.

Mormidea albido-fuscata STẢL. Öfv. Vet. Ak. Förl. 1853. P. 217.2.

\section{Patria: Caffraria. (Mus. Holm.)}

Quoar colores et pieturam P'. conjungenti simillima. Caput longiusculum, leviter convexum, stramineum, supra sat dense punctatum, postice lineolis duabus longitudinalibus obsoletis levinseulis notatum, lateribus ante uedium parallelis. Antenne articulo secunclo tertio vix longiore. Thorax ante medium stramineus et nigro-punctatus, parte hac straminea posterius subcallosa et minus dense subacervatim punctata, angulis lateralibus nigris, acutis, extrorsum sat longe productis, marginibus lateralibus anticis leviter simuatis, pallidis, obtusis, callosis, transversum rugosis. Corium pone medium macula minuta pallida levi notatum. Pectus nigro-punctatum. Abdomen dorso nigrum, connexivo stramineo, intus anguste nigro; ventre disco parce nigro-punctato, vittis tribus subferrugineis, nomnibil densius punctatis, ornato, lateribus dilute punctatis.

bb. Thoracis angulis lateralibus productis, apice rotundatis; angulis apiculilus segmenti ultimi abdominis subobtusis vel rectis. 18. P. (IIurmia) conjungens GERM. - Obovata, sordide straminea, supra subferrugineo-induta, sat dense fusco-punctata, pectore dense, ventre parce nigro-punctatis; capite ante medium angustulo; thorace ante medium subtilius punctato, ibidem haud ferrugineo-induto, medio spatio transverso subcalloso, acervatim punctato, instructo; scutello ante medium vittis duabus obliquis, ex angulis basalibus emissis, in medio scutello in unam. ad apicem productam, conjunctis, stramineo-albidis, 
callosis, levigatis; corio pone mediun macula minutissima lavi pallida notato; aldominis dorso ferrugineo-nigro, connexivo stramineo, margine interiore nigricante; ventre vittis trilus latiusculis fermgineo-fuscis, densius nigro-punctatis, ornato, lateribus dilute punctatis; pedibus parce minuteque nigro-conspersis; thoracis marginibus lateralibus anticis callosis, lavibus, ante medium transversim rugosis, nomnihil sinuatis, pallidis, angulis lateralibus extrorsum sat productis, apice rotundatis; antemarum articulis secundo et tertio subaqualibus. o'. Long. 8, Lat. 4! mill.

Cimea conjungens Gers. in Sillb. Rev. ent. V. p. 168. 99. (18:37).

Pentatuma conjungens H. S̈cH. Wanz. Ins. VII. p. 94 et 99. fig. $763 .(1844)$.

Mormidea conjungens DALL. List of IJem. I. p. 216. 19. (1851).

l'atria: Terra cipensis. (Coll. Sigsonetr.)

19. P. (Muruiia) Mulsanti Stíl. - Obovata, stramineo-albida, supra infuscata et sat dense nigro-punctata, thoracis marginibus lateralibus anticis nee non fascia angusta media percurrente, scutelli rittis duabus, ex angulis basalibus emissis, ad medium oblique ductis, dein parallelis et inter se ralde appropinquatis, corii margine laterali anterius et macula minutissima pone medium pallidis, lavibus, callosis; membrana subvitrea; abdomine dorso nigro, connexivo extus stramineo-albido-limbato; pectore nigro-punctato; ventre punctato, disco levi, vittis tribus latiusculis violaceo-nigris ornato; pedibus minute nigro-conspersis. o’. ․ Long. 7-81, Lat. 4-5 mill.

P'entatoma Mulsanti STÁ. Öfr. Vet. Ak. Förh. 1853. p. 219. 7 .

Patria: Caftraria. (Mus. IIolm.)

P. conjungenti statura ef pictura sat similis, angulis lateralibus thoracis nounilial minus promimulis, apite antice latiore. Caput densissime punctitum. Antemuse articulo secundo tertio distincts: 
nomihil longiore. Thorax marginibus lateralibus anticis obtusis, leviter sinuatis, angulis lateralibus nonnihil prominulis.

aa. Thoracis miga transversa lavi pallida deficiente vel obsoleta; scutello in angulis basalibus macula subcallosa lavi, interdum vitte instar retrorsum nonnihil producta, notato.

c. Thoracis angulis lateralibus in spinan acutam productis.

d. Angnlis apicalibus segmenti ultimi abdominis acutis, productis.

20. P. (Durmia) Capreola ŚtàL. - Subanguste obovata, dilute straminea, supra sat dense nigro-punctata; thoracis marginibus lateralibus anticis crenulatis, sinuatis, angulis lateralibus in spinam sat magnam, oblique antrorsum vergentem, subsanguineam, apice nigram, productis, ruga subtili transversa media lavi, minus distincta; scutello parce punctato, ante medium utrimque vitta obliqua laterali, sublevigata, instructo; hemelytris, excepta parte angusta marginali costali dilute punctata, levissime incarnatis, membrana vitrea; abdomine dorso nigro, connexivo stramineo, angulis apicalibus segmentorum acutiusculis, prominulis, angulis apicalibus segmenti ultimi acutissimis, productis; pectore parce nigro-punctato, prope coxas maculis minutis tribus nigris notato; ventre dilute punctato, diseo lævi, utrimque vitta, remotissime nigropunctata, ornato; antennis interdum in rufescentem vergentibus, articulo secundo tertio vix duplo longiore; femoribus pone medium maculis duabus parvis nigris interdum notatis. q. Long. 8, Lalt. 4 mill.

Patria: Madagascal. (Coll. Signoret et ŚTẢL.)

$P$. tomentiventri maxime affinis et simillima, angustior, thoracis angulis lateralibus multo magis antrorsum vergentibus, fere totis subsanguineis, angulisque apicalibus segmenti ultimi abdominis acute productis distinctissima.

21. P. (Burmia) Iladula STÁL. - Obovata, dilute straminea, remote nigro-punctata; thorace pone medium ruga transversa obsoleta lavigata notato, marginibus lateralibus anticis sinuatis, callosis, subcrenulatis, angulis lateralibus in spinam 
magnau, nigram, hasi ipsa incarnatam, extrorsum et plus minus antrorsum vergenten, productis; scutello in angulis basalibus matcula majuscula callosa levi notato; hemelytris, excepta parte costali dilute punctata, levissime infuscatis vel incarnatis; membrana subvitrea; abdomine dorso nigro, connexivo stramineo, angulis apicalibus segmenti ultimi acute productis; pectore parce nigro-punctato, prope coxas maculis tribus minutis nigris notato; ventre lateribus punctatis, disco remotissime nigro-punetato, vittis tribus nigricantibus ornato, spiraculis nigris; femoribus pone medium maculis duabus parvis fiscis interdun notatis; antennarum articulo secundo tertio dimido longiore. $\sigma^{7}$. ㅇ. Long. $6 !-7$, Lat. $3 \frac{1}{2}-4$ mill. $\sigma^{7}$. Ventre maculis duabus magnis sericeis instructo.

․ Ventre maculis sericeis destituto.

Cimex typhoeus H. ScH. Wanz. Ins. VI. p. 65̃. fig. 628. (1842). excl. syn.

Patria: Caffraria. (Mus. Holm, et Coll. Signoret); Sierra Leona. (Mus. Holn. et Coll. StTÁL.)

$P$. Capreole maxime affinis, minus angustata, thoracis spinis lateralibus nigris et minus antrorsum vergentibus vittisque nigris ventris differt.

dd. Angulis apicalibus segmenti ultimi abdominis rectis, haud productis.

22. P. (Inrmia) tomentiventris GERM. - Obovata, dilute straminea, supra sat dense nigro-punctulata, subtus distinctius dilute punctata; thorace posterius hemelytrisque, horum parte angusta costali dilute punctata excepta, leviter subincarnatis; thoracis angulis lateralibus in spinam nigram, basi dilute sanguineam, extrorsum et nonnilil antrorsum et sursum vergentem, sat magnam, productis, marginibus lateralibus anticis sinuatis, ante medium crenulatis; scutello in angulis basalibus macula majuscula callosa levigata notato; membrana subvitrea; abdomine dorso nigro, connexivo stramineo, angulis apicalibus segmenti ultimi subrectis; ventre vitta laterali parce nigro-punctata notato; spiraculis, maculis tribus parvis 
pectoris prope coxas nec non maculis duabus parvis, interdum deficientibus, pone medium femorum, nigris; antennarum articulo secundo tertio distincte nomnihil longiore; bucculis postice in angulum acutum retrorsum prominulis. $\sigma^{7}$. ․ Long. 7-10, Lat. 4-5 mill.

$\sigma^{7}$. Ventre maculis duabus magnis oblongis sericeis notato.

Cimex tomentiventris Germ. in Silb. Rev. ent. V. p. 168. 100. (1837).

Mormidea boschjesmana StẢL. Öfv. Vet. Ak. Förh. 1853. p. 217. 3.

ㅇ. Ventre maculis sericeis destituto.

Patria: Terra capensis. (Mus. IIolm.)

cc. Thoracis angulis lateralibus leviter prominentibus, obtusis vel olitusiusculis.

23. P. (Durmia) lutulenta STÅL. - Obovata, sordide straminea, supra sat dense fusco-punctulata, thorace posterius hemelytrisque, excepto limbo costali, leviter incarnatis vel subinfuscatis; angulis lateralibus thoracis interdum nigro-punctatis; scutello vittis duabus obliquis ante medium, lineis duabus abbreviatis mediis, interdum confusis, maculaque minuta basali media pallidis, lævigatis; membrana subvitrea; abdomine dorso nigro, connexivo stramineo, hujus segmentis in angulis hasalibus prope marginem puncto nigro sæpissime notatis; corpore subtus dilute punctato, maculis tribus parvis pectoris prope coxas nigris; ventris disco lævi, vitta utrimque laterali remotisse nigro-punctata, interdum deficiente, spiraculis nigris; femoribus pone medium maculis duabus parvis nigris notatis. o․ ㅇ․ Long. 7-9, Lat. $4-4 \mathbf{4}_{4}^{3}$ mill.

Pentatoma lutulenta STÅl. Öfv. Vet. Ak. Förh. 1853. p. 220. 12.

Patria: Caffraria, Terra capensis. (Mus. Holm., Coll. SIGNORET et STÅL.)

Antennarum articulus secundus tertio nonnihil longior. Bucculae postice retrorsum angulatim prominentes. Thorax marginibus lateralibus anticis levissime sinuatis, callosis, obtusiusculis, ante me- 
dium crenulatis, angulis lateralibus nomilil prominulis, apiec rotmdatis. Inguli apicales segmenti nltimi abolominis subrecti, haud producti.

Specimina supra inearnata, e Terra capensi reportata, angulis lateralibus thoracis paullo nagis prominulis, apice minus rotundatis et vix nigro-punctatis ab exemplis caffris divergunt.

\section{Sulog. IJIPIA STRL.}

Corpus late ovale vel suboratum, subtus sat convexum. Caput planum, apice late rotundatum, marginibus lateralibus leviter sinuatis; tubereulis antenniferis a supero ad partem distinguendis; buceulis basin capitis attingentibus. Antenne mediocres, articulo primo capitis apicem laaud attingente, articulis secundo et tertio subiequalibus. Rostrum articulo primo buceulas postice squante, secundo apicalibus duobus ad unum aquali. Thorax marginibus lateralibus anticis subexplanatis, vix acutis. Scutellum magnum, Jongiusculum, apice latum; frenis medium scutelli haud attingentibus. Hemelytra abdomine nounihil angustiora, corio scutello haud vel paullo longiore. Membrana venis obsoletis. Mesosternum leviter carinatum. Pedes mediocres, tibiis supra sulcatis.

24. P. (Ilipla) cenosula STi̊s. - Straminea, minus dense nigropunctata, rentre dilute punctato vittisque quattuor remotissime niglo-punctatis ornato; capitis linea percurrente media, thoracis marginilus antico et lateralibus anticis nec non rugis duabus subtilibus transrersis percurentibus, scutelli margine apicali lineisque tribus, lateralibus a medio antrorsum divergentibus et ad angulos basales ductis, levigatis; abdomine dorso nigro, comexiro stramineo, segmentis hujus basi apiceque nigro-fisciatis; pedibus parce minutissimeque nigroconspersis, femoribus apicen versus maculis tribus minutis nigris notatis; antennis ante medium dilute rufescentibus; macula farva in angulis apicilibus segmentorum ventris nigria, $\sigma$. f. Long. $T$, Lait. $4 \frac{1}{2}$ mill.

Pentutuma conosulu STAL. Öfi. Tet. Ak. Förh. 1853. ן. 218. 1 . 


\section{Patria: Caftiraria. (Mus. Holm.)}

P. depresse H. Scrr. (sec. Wanz. Ins. fig. 631) similis videtur, sentello multo majore, longiore et apice latiore divergit. Antenne articulis secundo et tertio iequalibus vel hoe illo subbreviore. Thorax marginibus latcralibus anticis rectis vel médio levissime simnatis, ante medium leviter cremulatis, angulis lateralibus vix prominulis, apiec rotundatis.

\section{Subg. VETERNA STÅL.}

Corpús orale vel obovatum. Caput sapissime planum, antrorsum angustatum, apice rotundatum, lobis aqualibus, lateralibus apice sat angustis, interdum subacuminatis, marginibus lateralibus sipissime acutis; bucculis basin eapitis attingentibus; tuberculis antemniferis a supero ad partem distinguendis. Rostrum articulo primo capitis basin attingente, bucculas haud superante. Antennæ articulo secundo tertio semper distincte longiore. Thorax marginibus lateralibus anticis subobtusis, raro obtusissimis. Scutellum distincte longius quam basi latius, posterius modice angustatum; frenis nonnihil ultra medium scutelli extensis. Abdomen hemelytris latius, angulis apicalibus segmenti ultimi haud acute productis; ventris segmentis apice haud ciliatis. Pedes mediocres, tibiis supra sulcatis.

a. Corpore pallide flavescente vel rirescente, supra intertum incarnato, toto vel fere toto dilute punctato; capite concolore, ruro nigro-marginato, vitta nedia nigra semper destituto.

b. Corpore pallide flurescente vel stramineo; supra interdum incarnato; capite plano; oculis modice prominentibus; thoracis marginibus lateralibus anticis subobtusis, interdum anterius obsoletissime cremulatis.

c. Abulomine dorso toto concolore vel regione scutelli, saltem basi, nigricante; scutelli naculis tribus basalibus loeviqutis nullis rel parvis.

25. P. (Yeterna) nigru-marginata Sign. - Sordide straminea, sat dense dilute punctata, supra subincarnata, thorace posterius hemelytrisque, excepta horum parte costali, nigro-punctatis; antennis, excepto articulo primo supra subtusque, capitis 


\section{$-154-$}

marginibus lateralibus, thoracis marginibus imis lateralibus anticis, apice angulorum lateralium maculisque duabus parvis discoidalibus ante medium, seutelli maculis duabus minutis basalibus mediis; peetoris maculis duabus minutis prope coxas anteriores nee non spiraculis nigris; scutello basi maculis lavibus destituto; membrana fusca; alis infuscatis; abdominis dorso toto concolore, in luteum vergente; thoracis marginibus lateralibus anticis sinuatis, angulis lateralibus extrorsum et leviter antrorsum sat longe acute productis. o'. Long. 11, Lat. 6 mill.

Euschistus nigromarginatus SIGN. Ann. ent. Sér. 3. VIIl. p. 927. 89. (1861).

Patrial: Maldagasear. (Coll. SigNoret.)

l. sanguincirostri quoad staturam proxima, antennis nigris et gracilioribus scutelloque nomihil breviore differt.

26. P. (Yeterni) sanguneirostris TuLxis. -- Sordide straminea, sat dense distincteque dilute punctata, thorace posterius hemelytrisque, excepta horum parte costali, incarnatis vel in olivaceum vergentibus, obscurius punctatis; antennis dilute olivaceis vel rufescentibus, apicem versus infuscatis; thorace ante medium maculis duabus vel quattuor minutissimis nigris notato, marginibus lateralibus anticis sinuatis, angulis laterilibus incarnatis, apice interdum nigris, extrorsum et nonnihil antrorsm sat productis; scutello basi maculis tribus parvis levibus stranineo-allidis notato; hemelytris maculis parvis obsoletis lavigatis conspersis; membrana interdum leviter infuscata; margine imo capitis, saltem parte posteriore, regione scutellari dorsi abdominis, maculis duabus parvis pectoris prope coxas anteriores nec non spiraculis nigris. $\sigma^{7}$. f. Long. 10-11, Lait. 6 mill.

Cimex sanguineirostris Thusis. Iеm. rostr. cap. II. p. 4. $(18 \cdot 2)$.

Cimex quadridens Tirsis. Hem. rostr. cap. II. p. 4. (1822). I'entutoma crulelis WEsTw. in Hope. Cat. of Hem. I. p. 40. (18:37). 
Cimex pugnax GerM. in Silb. Rev. ent. V. p. 167. 97. (1837).

Pentatoma pugnax H. Scir. Wanz. Ins. VII. p. 94 et 103. fig. 712. (1844).

Mormidea pugnax DALl. List of Hem. I. p. 216. 17. (1851).

Patria: Terra capensis. (Mus. Holm., Coll. Signonet et S'TÅL.)

27. P. (Veterma) subrufa S'TẢL. - Rufescente-straminea, dense dilute punctata, thorace pone medium hemelytrisque, excepta horum parte costali, nigro-punctatis; margine imo laterali capitis, maculis duabus minutissimis ante medium thoracis, basi dorsi abdominis, maculis duabus minutis lateralibus peetoris prope coxas anteriores nec non spiraculis nigris; thoracis angulis lateralibus rotundatis, vix prominulis. $\sigma$. Long. $7 \cdot \frac{2}{3}$, Lat. $4 \frac{1}{2}$ mill.

Pentatoma subrufa S'TÅ. Öfv. Vet. Ak. Förh. 185.3. p. 219. 8 .

Patria: Caffraria. (Mus. IIolm.)

Statura $P$. aberrantis GerM. Thorax in angulis auticis nigropunctatus, marginibus lateralibus anticis rectis, angulis lateralibus vix prominulis, obtuse rotundatis. Scutellum medio utrimque punetis nommullis nigris instructum. Corium diseo vitta angusta, indeterminata, obsoletissima, leviuscula. Antennae apicem versus, menbrana alieque infuscatie.

cc. Abdoninis dorso, excepto limbo, nigricunte; scutello basi maculis tribus listinctis, lavibus, pallielis notato.

28. P. (Yeterma) aberrans GERM. - Obovata, dilute sordide straminea, sat dense punctata, thorace posterius hemelytrisque, excepta horum parte costali, leviter incarnatis et fusco-punctatis; antennis in rufescentem vergentibus, apice infuscatis; thorace inter angulos laterales ruga transversa læviuscula instructo, marginibus lateralibus anticis rectis, angulis lateralibus extrorsum nomihil prominulis, apice rotundatis; scutello lateribus medio fusco-punctato, basi maculis tribus oblongis distinctis margineque ino apicali albidis, lavigatis; hemelytrorum spatio elongato discoidali, apicem attingente, 


\section{$-156$}

minus dense punctato vel laviusculo; membrana leviter infuscata; abdominis dorso nigricante, limbo lato laterali et apicali sordide stramineo; pectoris maculis duabus minutissimis prope coxas anteriores nigris; ventris vittis duabus albidis, subcallosis, punctatis; spiraculis fuscis. $\sigma^{7}$. Long. 7, Lat. 4 mill.

Cimex aberrans Germ. in Silb. Rev. ent. V. p. 168. 98. (1837).

Pentatoma alerrans H. Sch. Winz. Ins. VII. p. 95 et 104. fig. 715. (1844); Dall. List of Hem. I. p. 234. 3. (1851). Patria: Terra capensis. (Mus. IIolm.)

29. P. (Yeterua) natalensis STÁL, - Pallide straminea vel subolivaceo-straminea, sat dense punctata, thorace posterius hemelytrisque, excepta horum parte costali, incarnatis et dilute subsanguineo- rel fusco-punctatis; antennis in sanguineum vergentibus; thorace ruga transversa levi destituto, ante medium maculis quattuor minutis nigris notato, marginibus lateralibus anticis sinuatis, angulis lateralibus extrorsum et nonnihil antrorsum acute productis, dilute sanguineis; scutello pone medium utrimque fusco-punctato, maculis tribus basalibus levilims, subcallosis, albidis, apice pallido; hemelytris vitta abbreviata, eurrata, minus distincta, leviuseula, instructis; membrana levissime infuscata; alis subalbidis, venis primariis fuseis; aldomine dorso nigro, late stramineo-limbato; pectoris punctis duobus prope coxas anteriores nigris; rentris vitta laterali angusta subcallosa, parce punctata, albisla, spiraculis haud rel vix infuscatis. ․ Long. 9, Lat. 5 mill.

Pentatoma natalensis STiL. Öfr. Vet. Ak. Fürh. 1853. p. 219. 9.

Patria: Cafliaria. (Mus. Holm.)

P. alerrenti quoad staturam picturameque similis, sed major, angulis lateralibus thoracis multo magis productis et acutis differt.

30. P. (Veterua) Imgionata STAL. - Dilute straninea vel subolivaceo-straminca, sat ilense punctata, thorace posterins he- 
melytrisque, excepta horum parte costali, leviter incarnatis, carneo vel pallide subfusco-punctatis; antennis rufescentibus; thorace ruga transversa lævi media destituto, ante medium punctis duolous obsoletis fuscis notato, marginibus lateralibus anticis sinuatis, angulis lateralibus acutissimis, longe productis, extrorsum, sursum et nomnilil antror'sum rergentibus, sanguineis, apice nigris; scutello pone medium utrimque subfusco-punctato, maculis tribus distinctis basalibus albidis, lavibus, subcallosis, apice angustissime albido-limbato; hemelytris vitta abbreviata, currata, angusta, indeterminata, leviuscula disco instructis; membrana sordida, angulo basali interiore fuseo; abdomine dorso nigro, limbo lato stramineo; alis subalbidis, venis primariis fuscis; pectore utrimque maculis duabus albidis, irregularibus, subeallosis instructo; ventris vitta utrimque laterali albida, subcallosa, punctata, spiraculis fuscis. $0^{7}$. ㅇ. Jong. 9, Lat. $5 \frac{1}{2}$ mill.

Mormider pregionatu STÂL. Öfv. Vet. Ak. Förh. 1858. p. 313. 12.

Patria: Eikhams Africæ meridionalis occidentalis.(Mus. IIolm.)

P. natulensi maxime affinis et similis, angulis lateralibus thoracis multo acutioribus et longius productis, sursum valde vergentibus differt.

bb. Corpore virescente vel dilute flaro-virescente.

d. Corpore virescente; capite pluno, murginibus lateralibus acutis; oculis modice mominulis; thoracis marginibus lateralibus anticis acutis.

31. P. (Veterma) nigro-pumctata Sign. - Ovalis vel subobovata, virescens, supra dense, subtus remotius, distincte punctata, ventris disco lævi; marginibus lateralibus thoracis ventrisque, nee non antennarum articulis duobus ultimis substramineis; membrana vitrea; margine imo capitis, apice ipso articuli tertii antennarum, macula minutissima in angulis apicalibus segmentorum ventris nec non puncto, interdum deficiente, pone medim femorum posita, nigris; abdominis dorso concolore. ơ. q. Long. 11-13, Lat. 6-7 mill. 
Pentatoma nigro-punctata SIGN. in THoms. Arch. ent. II. p. 285. 529. (1858).

l'atria: Gabon. (Coll. Signorex et STí.)

32. P. (Veterua) unicolor STiL. - Dilute viridis, supra densissime, sulitus remote punctata, ventris disco lavigato; abdominis dorso dilute sanguineo; antenuarum articulis tertio apice nec non quarto quintoque, horum basi excepta, nigris; scutelli apice imo subalbido; thoracis ventrisque maroninibus lateralibus, hujus etiam disco virescente-stramineis; membrana sordida, angulo basali infuscato; macula media segmentorum ventris trium anteriorum nec non angulis imis apicalibus segmentorum nigris. ơ. ㅇ. Long. 11-12, Lat. 5!-6 mill.

Yar. b. - Maculis ventris, etiam marginalibus, deficientibus.

Patria: Guinea. (Coll. Signoret et StTal.)

Procedenti valde affuis et simillima, punctura fortiore, colore antenuarum, capite et scutelli parte apieali nomilhil angustioribus differt.

dd. Corpore pallide flaro-virescente; capite conrexinsculo, marginibus lateralilus distincte simatis, tuberculis antenniferis a supero totis distinguendis; oculis globosis, valde prominulis; thorucis maryinilus laterdibus anticis obtusissimis, comeris.

33. P. (Yeterua) oruatula II. Scir. - Jallide flavo-virescens, dense diluteque punctulata; scutello maculis basalibus leviusculis apiceque stramineo-albidis, apice imo luteo; corio disco interlum incarnato, ibidem maculis compluribus minutis subalbidis levibus, dense acervatis, instructo; membrana subritrea; abdominis dorso infuscato, connexivo stramineo, virescentemaculato; ventris margine stramineo-maculato; thoracis marginibus lateralibus anticis distincte sinuatis, angulis lateralihus apice rotundatis, nonnihil prominentibus. $\sigma^{7}$. ‥ Long. 9, Lat. $5 \frac{1}{3}$ mill.

Cimex ornutulus H. ScII. Wanz. Ins. VI. p. 93. fig. 664. (1842); KLlG. Nymh. pliys. V. (Cimex notatus) Tab. XLIV. tig. 9. $(184,1)$. 
Pentatoma humerosa DaLL. List of Hem. I. p. 240. 18. (1851).

Patria: Aegyptus. (Mus. Holm. et Coll. Signoret.)

aа. Corpore superne albido, nigro-punctato et variegato, vel sulfuse-griseo, fuseo-punctato.

34. P. (Yeterna) tristicula STẢ́L. - Fusco-grisescens, tota densissime fusco vel subferrugineo-fusco-punctata, subtus valde convexa; thoracis vitta media angusta, subgemina, albida, per caput et scutellum obsolete continuata; hemelytris maculis minutissimis pallidis leviusculis parce conspersis, disco pone medium macula parva oblonga nigricante notatis; membrana infuscata et obscurius fusco-conspersa; abdominis dorso, excepto connexivo, nigro; ventris disco utrimgue vitta obsoleta fusca ornato; thoracis marginibus lateralibus anticis obtusis, angulis lateralibus acutiusculis, oblique antrorsum sat productis. \&. Long. 9! Lat. 6 mill.

Mormidea trisiciculu STAL. Öfv. Vet. Ak. Förh. 185̃8. p. 313. 11 .

Patria: Territorium fluvii Svakop Africa meridionalis occidentalis. (Mus. Holm.)

35. P. (Veterna) vittaticeps StÅL. - Sat dense distincteque punctata, supra sordide albida, dense nigro-conspersa, subtus cum femoribus stramineo-grisea, remote nigro-conspersa; capite, thoracis maculis duabus anterioribus, ipsis macula pallida notatis, angulisque lateralibus, scutello basin versus, dorso abdominis, parte apicali femorum, basi apiceque tibiarum olivacearum, tarsis antennisque nigris; vittis duabus capitis, maculis tribus basalibus apiceque scutelli albidis vel flavo-albidis; macula magna quadrata media segmentorum connexivi margineque ventris dilute lutescentibus, angulis basalibus et apicalibus segmentorum ventris nigris; membrana subalbida, venis nigro-maculatis; thoracis marginibus lateralibus anticis leviter sinuatis, obtusiusculis, posterius acutiusculis, angulis lateralibus extrorsum nonnilil prominulis, 
subacutis, apice interdum rotundatis. ơ. ㅇ. Long. 10-12, Lit. 5-6 mill.

Pentatoma vittaticeps STAl. Öfv. Vet. Ak. Förh. 1858. p. 314. 3.

Patria: Terra capensis, Territorium fluvii siakop. (Mus. Holm. et Coll. Signore:T.)

P. (C'arpocoridi) maculicolli DALt. quoad colores haud dissimilis, sed minor, angustior, antemis gracilioribus predita.

\section{Subg. CAPPALA ELIENR.}

Nat. Tijdschr. Niderl. Ind. XNIV. p. 146. (1862).

Corpus ovale vel obovatum, subtus modice couvexum. Caput planum, marginibus lateralihus acutis, lobis subequalibus; bucculis basin capitis attingentibus, modice elevatis. Rostrum articulo primo buceulas postice aquante, articulo secundo apicalibus dnobus ad unum sxpissime hreviore. Antenne articulo secundo et tertio iequalibus vel illo hoe breviore. Thorax marginilus lateralibus siepissime acutis rel acutiusculis, raro anterius obsolete crenulatis. Scutellum longius quam latius, apice sat angustatum, frenis sat Innge ultra medium extensis. Abulomen hemelytris latius; rentris segnentis apice haud ciliatis. Femora apice inermia.

a. I'entris margine in angulis apicalibns scgmentorum macula parra nigra destitnto; corpone magno cel mediocri.

b. Thoracis namginilus lateralibus unticis anterins obsolete crennlatis; scutello in anyulis busalelus impressione parva nigra destituto; alduminis. dorso basi et sapissine etiam apice niygro.

36. P. (Cappea) corticina Gern. - Ovalis, pallide testaceo-flavescens, subtus cum pedibus pallide griseo-Havescens, supra sit dense diluteque fusco rel subferugineo-punctata, subtus remote punctati, rentris disco lavi; hemelytris subtus sanguineis; menbrana grisescente, renis obsoletissime et interrupte fusco-lineatis, angulo basili interiore nigro-fuseo; alis fuscescentibus; abdominis dorso crocen, basi et sapissime etian apice nigro: connexirn pallide griseo-flavescente, segmentis 
basin et apicem versus nigro-punctatis; thoracis maculis minutis duabus vel quattuor ante medium positis, maculis duabus parvis pectoris prope coxas anteriores spiraculisque nigris; antennarum articulo primo capitis apicem haud attingente, articulo secundo et tertio æque longis, vel hoc illo nonnilil longiore; capite apicem versus nonnihil angustato; thoracis marginibus lateralibus anticis rectis, anterius obsolete crenulatis, angulis lateralibus apice rotundatis, vix prominulis. o7. ㅇ. Long. 111-14, Lat. $6-7$ mill.

Cimex corticimus Germ. in Silb. Rer. ent. V. p. 178. 118. (1837).

Pentatoma corticinum H. Scir. Wanz. Ins. V1I. p. 96 et 98. fig. 761. (1844).

Pentatoma corticina DALL. List of Hem. I. p. 245. 30. (1851). Patria: Terra capensis. (Mus. Holm. et Coll. Signonet.)

bb. Thoracis marginibus lateralibus anticis integerrimis; scutello in angulis basalibus impressione mimuta nigra notato.

c. Membrana immaculata vel irregulariter fusco-conspersa; abdominis dorso toto pallide flarescente vel subsanguineo.

37. P. (Capprea) cerviua GERM. - Suborata, griseo-straminea, supra sat dense subacervatim nigro-punctulata, subtus ferrugineo-punctulata, capite basi ntrimque macula levigata notato; thorace ad margines laterales anticos densius punctato, in medio disci maculis duabus minutis nigris notato; scutello in angulis basalibus macula parva pallida lævi et in ipsis angulis impressione minutissima nigra notato, pone medium vitta obsoletissima pallidiuscula instructo; corio pone medium macula parva lævi instructo; membranæ venis fusco-conspersis; alis albido-hyalinis; abdominis dorso dilute sanguineo, connexivo griseo-flavescente, dense punctato, segmentis basin et apicem versus fusco-punctatis; maculis duabus minutis pectoris prope coxas anteriores, spiraculis nec non femorum macula parva pone medim nigris; antennarum articulo primo IIemiptera afrienna. 
capitis apicem subsuperante, articulo secundo tertio vix breviore; capite antrorsum sat angustato, lobo inedio apicem versus angustiore; thoracis marginibus lateralibus anticis rectis, integris, angulis lateralibus apice rotundatis, vix prominulis. ㅇ. Long. 12, Lat. $6 !$ mill.

Cimex cervinus Gery. in Silb. Rev. ent. V. p. 178. 117. (1837).

Pentatoma cervinum II. SCrr. Wanz. Ins. VII. p. 96 et 99. fig. 764. (1844).

Patria: Terra capensis. (Mus. Holm.)

$P$. corticince similis, suborata, nee ovalis, capite antrorsum magis angustato, thoracis marginibus lateralibus anticis integris, impressione nigra in angulis basalibus scutelli, pictura dorsi abdominis et ceteris distinctissimia.

38. P. (Cappan) taruiata STÁL. - Subovata, dilute griseo-flavescens, sat dense et distincte, subtus subtilius, nigro-punctata; capite antrorsum sat angustato, basi utrimque ad oculos macula levigata notato, lobo medio antrorsum haud angustato; thorace intra margines laterales anticos densius punctato, marginibus lateralibus rectis, integris, angulis lateralibus vix prominulis, apice rotundatis; scutello hasi in angulis impressione parva nigria instructo; membrana levissime infuscata, sat dense fusco-conspersa; abdomine dorso, excepto connexivo, lutescente vel subsanguineo, comnexivi segmentis fusco-punctatis, margine corum exteriore medio pallido; mesosterno, maculis minutis duabus pectoris prope coxas anteriores, ventris vittis tribus spiraculisque nigricantibus; femoribus parce obsoleteque fusco-conspersis; antennarum articulo secundo tertio distincte breviore. $\sigma$. Long. 13, Lat. 7 mill.

Patria: Terra capensis. (Coll. Signoretr.)

P. cervince maxime affinis, statura majore, punctura fortiore et obscuriore, capitis lobo medio autrorsum haud angustato, articulo sccundo antemarum tertio distincte breviore, maculis duabus minutis disci thoracis deficientibus, nembrana densius fusco-conspersa et renis numerosioribus instructa ner non ventre vittis tribus nigricantibus notato differt. 
39. P. (Cappra) pavila STÁL. - Latiuscule ovata, pallide sordide straminea, supra remote fusco-punctulata, subtus dilute punctata; antennarum articulo primo capitis apicem vix attingente, secundo tertio circiter tertia parte breviore; capite basi ad oculos macula lævigata notato, regione ocellorum ænescente vel rneo-punctata; thorace disco maculis duabus minutis nigris notato; scutello in angulis basalibus impressione minutissima nigra instructo; corio subacervatim punctato et maculis parvis lavibus consperso, membrana grisescente, obsoletissime fusco-conspersa, angulo basali interiore nigro-fusco; abdomine dorso concolore; connexivo dense punctato, segmentis basin et apicen versus fusco-punctatis; maculis duabus ninutissimis pectoris prope coxas anteriores, spiraculis, nec non margine exteriore imo angulorum segmentorum ventris nigricantibus. $\sigma^{7}$. Long. $11 !$, Lat. $6 \frac{1}{2}$ mill.

\section{Patria: Caffraria. (Mus. Holm.)}

P. Victorini affinis, sed brevior, ovata, quoad staturam ad $P$. cervinam magis appropinquat. Caput ante medium antrorsum haud angustatum, apice late rotundatum. Thorax marginibus lateralibus anticis rectis, integris, angulis lateralibus paullo promimulis, apice rotundatis.

40. P. (Cappra) Vietorini Stál. - Ovalis vel subobovata, dilute straminea, supra remote subferrugineo-punctulata, subtus dilute punctata, ventris disco lavi; capite antrorsum leviter angustato, regione ocellorum viridi-ænea; antennis articulo secundo tertio circiter quarta parte breviore; thorace disco maculis duabus parvis fuscis notato, marginibus lateralibus anticis subsinuatis, integris, leviter angustissimeque reflexis et lævibus, angulis lateralibus extrorsum nonnihil productis; scutello basi in angulis impressione parva nigra instructo; membrana sordide hyalina, obsoletissime fusco-conspersá; abdomine dorso dilute lutescente; maculis duabus parvis punctiformibus prope coxas anteriores spiraculisque nigris. $\sigma$. Long. 13, Lat. 7 mill.

Pentatoma Victorini STẢL. Öfv. Vet. Ak. Förh. 1856. p.,194. 2 Patria: Terra capensis. (Mus. Holm.) 
ec. Membrana sordida, lineolis brexibus fuscis, in series tres transversas arcuatas dispositis, venas occupantilus, ornata; abdominis dorso fusco vel violaceo-fusco.

41. P. (Cappra) anumlicornis SIGN. - Ovalis, griseo-straminea, supra distincte, sat dense et acervatim nigro- vel fusco-ferrugineo-punctata, capite subtus pectoreque lateribus nigropunctatis, his vitta bis interrupta lævigata instructis; antennarum articulo secundo tertio equali vel nonnihil breviore; thoracis marginibus lateralibus anticis rectis, integris, angulis lateralibus leviter prominulis, apice vix rotundatis; scutello in angulis basalibus impressione parva nigra, adjecto callo levi pallido, instructo; membrana sordida, lineolis brevibus fuscis, venas occupantibus, in series tres transversas arcuatas dispositis, notata; abdomine dorso, excepto connexivo, subviolaceo-fusco, connexivi segmentis basin et apicem versus fuscis vel fusco-punctatis, ventre disco parce, lateribus densius ferrugineo-punctulato, marginibus lateralibus immaculatis rel maculis fuscis, angulos apicales et hasales segmentorum occupantibus, notatis, segmentis, saltem posterioribus, macula fusca vel ferrugineo-fusca medio ornatis; femoribus apicem versus tibiisque superne ferrugineo- vel nigro-conspersis; antennis crassiusculis, basin versus interdum fusco vel ferrugineo-punctatis, articulis tribus ultimis, basi excepta, nigris vel ferrugineo-fuscescentibus. $\sigma$. ․ Long. 11, Lat. 6 mill.

Pentatoma amulicomis sigx. in Thoms. Arch. ent. II. p. 284. 527. (1858).

Patria: Senegal, Sierra Leona, Calabar, Gabon. (Mus. Holm., Coll. Signoret et StäL.)

Statura fere $P$. corticince Germ.

42. P. (Cappra) reflexa Sigs. - Latiuscule ovalis, supra fuscovel griseo-straminea, dense nigro-punctulata, subtus cum antennis pedibusque pallidior; pectore ventreque remote ferrugineo-fusco-punctatis, hujus disco levi; antennis gracilibus. 
articulo secundo tertio tertia parte breviore, articulo tertio apice nigro-fusco; thoracis marginibus lateralibus anticis integris, rectis, acutis, angulis lateralibus vix prominulis, apice rotundatis; scutello basi maculis nonnullis parvis obsoletis pallidis, læviusculis, et in angulis basalibus impressione minutissima nigra instructo; membrana subinfuscata, lineolis vel maculis parvis, venas occupantibus, in series tres transversas arcuatas dispositis, fuscis ornata; abdomine dorso subviolaceofusco, connexivo subæneo-nigro vel fusco, dense punctato, segmentis medio macula parva marginali, interdum deficiente, pallida notatis; pedibus fusco-conspersis. ơ. ㅇ. Long. 13$15 \frac{1}{2}$, Lat. $7 \frac{1}{2}-8 \frac{1}{2}$ mill.

Pentatoma reflexa Sign. in Thoms. Arch. ent. II. p. 284. 528. (1858).

Patria: Calabal. (Coll. Signoret et StíL.)

$P$. annulicomi affinis, latior, obscurior, subtilius et densius punctata, capite latiore, antennis gracilioribus, colore picturaque connexivi differt; segmento anali maris maximo.

Spccimen femininum maximun, obscurum, subtus densins punctatum, ventre medio vitta lata nigricante ornato, antennis nigricantibus, articulis quarto et quinto basi pallidis, thoracisque marginibus lateralibus anticis leviter subrotundatis instructum, vix specifice distinctum, misit amicissimus Sigxore't.

aa. Ventris margine maculis parvis nigris, angulos apicales segmentorum occupantibus, notato; femoribus pone medium maculis tribus parvis nigris ornatis; corpore parvo.

d. Abdominis dorso fulvescente vel lutescente.

43. P. (Cappra) apicalis H. ScH. - Ovalis, dilute olivaceo-straminea vel olivaceo-albida, renote fusco-punctata, subtus pallidior et parcius punctata; antennis infuscatis; capite thoraceque anterius modice declivibus, hujus marginibus lateralibus anticis rectis, integris, subacutis, angulis lateralibus rotundatis, haud prominulis; scutello apice flavescente vel fulvescente, in angulis basalibus impressione minutissima nigra notato; membrana levissime infuscata, fusco-venosa; abdominis dorso lutescente, macula posteriore nigro-fusca; con- 
nexivo al apicem et basin segmentorum fusco vel fusco-punctato; maculis tribus minutissimis pectoris prope coxas, macula media segmenti ultimi angulisque imis apicalibus segmentorum ventris, nec non maculis tribus parvis pone medium femorum nigricantibus; antennarum articulo secundo tertio paullo breviore; rostri articulo secundo articulis duobus ultinis ad unum distincte breviore. $\sigma$. ․ Long. 7-8, Lat. $4-5$ mill.

Cimed apicalis H. Scr. Wan\%. Ins. VI. p. 95. fig. 666. (I842). Pentatoma apicale H. ScH. Wanz. Ins. V'II. p. 96. (1844). Pentutoma apiculis DALL. List of Hem. I. p. 250. 41. (1851). Pentatoma inquinate STAL. Öfv. Vet. Ak. Förl. 1853. p. 218. 2.

Pentatoma bipunctipes Sign. in Thoms. Arch. ent. II. p. 282. 523. (1858).

Patria: Caffraria, Terra capensis, Calabar. (Mus. Holm., Coll. Signoret et StåL.)

Specimina calabarensial ( $P$. bipnetipes Sigx.) al capensibus hand differunt nisi magnitudine nonnihil majore.

Species italica, sub nomine $P$. analis Costa mihi missa, $P$. apicali maxime est aftuis et similis, differt tautum statura majore, capite breviore et apice latiore nee non rostri articulo secundo apicalibus duobus ad unum longitudine sequali.

dd. Ablominis dorso, excepto comexico, nigro.

44. P. (Cappra) scapularis Tulvib. - Late obovata, dilute straminea, supra in olivaceum vergens, supra remote, hemelytris densius, subtus parce fusco-punctata; capite valde deflexo; antennis interdum rufesientibus, articulo secundo tertio nonnihil breviore; rostri articulo secundo apicalibus duobus ad unum breviore; thorace anterius sat declivi, margine imo antico lavigato, marginibus lateralibus anticis integris, rectis, obtusiusculis, angulis lateralibus haul prominulis, rotundatis; scutello apice stramineo-albido, in angulis basalibus impressione minutissima nigra instructo; membrana sordile fuscovenosa; alis infuscatis; abdominis dorso nigro, commexivo stramineo, immaculato: maculis nonnullis minutissimis late- 
- ralibus pectoris, una in angulis posticis prostethii, angulis imis apicalibus segmentorum ventris nec non maculis tribus interdum obsoletis vel evanescentibus, pone medium femorum positis, nigris. $\sigma^{7}$. \&. Long. $6 \frac{1}{2}$, Lat. 4 mill.

Cimex scapularis Thunb. Hem. rostr. cap. II. p. 1. (1822).

Cimex plinthacrus Geru. in Silb. Rev. ent. V. p. 172. 107. (1837).

Pentatoma plinthacra DALl. List of Hem. I. p. 244. 28. (1851).

Pentatoma moerens STÃL. Öfv. Vet. Ak. Förh. 185̌3. p. 219. 4 .

Patria: Caffraria, Terra capensis. (Mus. Holm.)

$P$. apiculi similis, sepissime minor, latior, capite thoraceque anterius multo magis declivibus divergit.

45. P. (Cappra) Goniodes DALL. - Late obovata, dilute olivaceostraminea, supra remote, hemelytris densius, subtus remotissime nigro-punctata; antennis apicem versus dilute sordide lutescentibus, articulo secundo tertio breviore; capite thoraceque anterius sat declivibus, hujus margine antico lævi, marginibus lateralibus anticis vix sinuatis, angulis lateralibus extrorsum nonnihil productis, apice rotundatis; scutello apice albido; membrana sordida; alis infuscatis; abdomine dorso nigro, connexivo stramineo, immaculato; maculis tribus minutissimis pectoris prope coxas, angulo apicali segmentorum ventris nec non maculis minutis duabus vel tribus pone medium femorum, interdum evanescentibus, nigris. $\sigma^{7}$. ‥ Long. $6-7 \frac{1}{2}$, Lat. $4-5$ mill.

Var. a. - Thoracis angulis lateralibus fasciaque angusta transversa, obsoleta, læviuscula lutescentibus.

Pentatoma inops STÅl. Öfv. Vet. Ak. Förh. 1853. p. 220. 10. Var. b. - Thoracis angulis lateralibus nigricantibus.

Pentatoma goniodes DaLL. List of Hem. I. p. 233. 2. (1851). Pentatoma patruelis STÅL. Öfv. Vet. Ak. Förh. 1853. p. 220. 13.

Patria: Caffiraria. (Mus. Holm.) 
Subg. CAURA STRL.

Corpus subovale, subtus modice convexun. Caput planum, antrorsum angustatum, apice rotundatum, lobo medio lateralibus vix longiore, marginibus lateralibus acutis; tuberculis antemiferis a supero distiuguendis; bucculis basin capitis haud attingentibus. Rostrum mediocre, articulo primo bucculas postice distincte saperante, articulo secundo apicalibus duobus ad unum subxquali. Antennæ mediocres, articulo primo capitis apicem haud vel vix attingente; secundo et tertio subæqualibus vel illo hoc paullo breviore. Thorax marginibus lateralibus anticis acutis, integris, laad reflexis. Scutellum apice modice angustatum, frenis ultra medium scutelli extensis. Ilemelytra abdomine nonnihil angustiora, corio scutello nonnihil longiore, margine apicali recto, obliquo; membrana venis septem vel octo simplicibus. Abdomen angulis apicalibus segmenti ultimi obtusis, haud productis; ventris segmentis apice pilis destitutis. Pedes mediocres, tibiis supra distincte sulcatis.

46. P. (Caura) Pugillator FABr. - Ovalis, supra fusco-cinnamomea, levissime fusco-ieneo-induta, sat dense punctulata, subtus parce punctulata; articulo primo antemnarum, rostro, capite subtus, marginibus loboque medio capitis, marginibus lateralibus anticis thoracis, margine angusto laterali corii ante medium, pectore, abdomine femoribusque rufo-testaceis; antennis, rostro apicem versus, maculis connexivi, tibiis tarsisque nigris, maculis parvis compluribus pectoris ventrisque, in illo in series duas laterales, in hoe in series quinque dispositis, obscure creruleis, serie media ventris interdum gemina; membrana nigro-fusca; thoracis angulis lateralibus rotundatis, haud prominulis, apice dente vel spinula, magnitudine variabili, sæpissime acuta, leviter antrorsum vergente, armatis, marginibus lateralibus anticis rectis; antennarum articulis secundo et tertio subæqualibus. $\sigma$. Long. 14, Lat. 8 mill. 
Cimex pugillator FaBr. Ent. syst. IV. p. 102. 89. (1794); Syst. Rhyng. p. 162. 39. (1803); H. Sch. Wanz. Ins. VI. p. 62. fig. 627. (1842).

Halys Jaculus FABR. Syst. Rhyng. p. 181. 5. (1803).

Pentatoma maculate Sign. Rev. et Mag. Zool. 1851, p. 443.7.

Pentatoma puyillator Dall. List of Hein. I. p. 242. 23. (1851).

Patria: Sierra Leona. (Mus. Holm. et Coll. StåL.); Gabon. (Coll. Signoret.)

47. P. (Cauria) rufiventris GERM. - Late ovalis, supra fuscornea, interdum fusco-cinnamomea et fusco-induta, dense punctulata, subtus parce punctulata; capite subtus apiceque lobi medii, antennarum articulo primo, rostro, pectore abdomine femoribusque rufo-testaceis; antennis, rostro apicem versus, maculis una vel duabus pone medium, interdum etiam parte basali femorum, tibiis tarsisque nigris; maculis compluribus pectoris ventrisque, in series dispositis, maculisque marginalibus ventris fusco-æneis vel fusco-cæruleis, connexivo fusco-æneo, segmentis apice rufo-testaceo-fasciatis; thoracis marginibus lateralibus subrectis vel levissime rotundatis, angulis lateralibus rotundatis, inermibus, haud prominulis; antemnarum articulis secundo et tertio sæpissime subæqualibus, illo hoc interdum distincte breviore. $\sigma^{7}$. ㅇ. Long: 1I-14, Lat. $7 \frac{1}{2}-8 \frac{1}{2}$ mill.

Cimex rufiventris Germ. in Silb. Rev. ent. V. p. 167. 96. (1837).

Pentatoma rufiventre H. ScH. Wanz. Ins. VII. p. 96. fig. 757. (1844).

Pentatoma rufiventris DaLl. List of Hem. I. p. 242. 22. (1851).

Patria: Terra capensis, Caffraria. (Mus. Holm., Coll. SIGNORET et STÅL.)

48. P. (Caura) bipartita Sign. - Latissime ovalis, viridi-ænea, supra sat dense distincteque, subtus parce subtiliterque punctulata; antennis, rostro pedibusque nigris; capite subtus 
parteque anteoculari, antennarum articulo primo, articulo primo rostri, ventre, coxis, trochanteribus, femoribus apicem versus tibiisque basi dilute sordide flavescentibus; maculis parvis ventris marginalibus aliisque in series quinque longitudinales dispositis fusco-æneis; antennarum articulo primo tertio nonnihil longiore; thoracis marginibus lateralibus anticis levissime rotundatis, angulis lateralibus obtusiusculis, haud rotundatis, inermibus. $\sigma^{7}$. Long. I3, Lat. 9 mill.

Pentatoma bipartita Sign. Rev. et Mag. Zool. 1851. p. 444. 8. Patria: Gabon. (Coll. Signonet et Stål.)

$$
\text { Subg. ILLRDA STÅL. }
$$

Corpus oboratum, subtus sat convexum. Caput productum, planum, antrorsum distincte angustatum, apice rotundatum, lobis aqualibus vel lobo medio paullo prominulo; marginibus lateralibus acutis; tuberculis antemniferis a supero ad partem distinguendis; bucculis basin capitis vix attingentibus. Rostrum mediocre, articulo primo bucculas postice distincte superante, articulo secundo apicalibus duobus ad unum æquilongo vel subbreviore. Antennx graiciles, articulo primo capitis apicem attingente, secundo tertio nonnihil breviore. Thorax marginibus lateralibus anticis acutiusculis, haud explanatis, integris vel leviter erenulatis, angulis lateralibus prominentibus. Scutellum apice salt angustatum, longins quam latius, frenis ultra medium extensis. Henelytra aldomine nonnihil angustiona, corii margine apicali recto; membrana venis septem vel octo simplicibus instructa. Segmentum abrlominis ultimum angulis apicalibus subrectis, haud productis. Ventris segmenta apice pilis destituta. Pedes mediocres, femoribus apice inermibus, tibiis superne distincte sulcatis.

49. P. (Ilerda) rubicmula STẢL. - Dilute straminea, supra cum pedibus in pallide rufo-testaceum vergens, minus dense punctata, supra dilute fusco-punctata; antennis, capitis marginibus lateralibus lineaque inferiore pone antennas, thoracis marginibus lateralibus anticis, margine imo costali corii, antennis nee non spiraculis nigris; antennarum articulo primo 
supra subtusque sordide stramineo-lineato, articulis tertio et quarto basi sordide albidis; apice scutelli lævi, eburneo; membrana sordide subvinacea. \&. Long. 14, Lat. 8 mill.

Patria: Madagascar. (Mus. Ilolm.)

Caput lobo medio subprominulo. Thorax marginibus lateralibus anticis subrectis, anterius leviter crenulatis, angulis lateralibus acutis, extrorsum distincte productis. Antemarum articulus ultimus mutilatus in exemplo descripto.

50. P. (Ilerda) pumctata P. B. - Dilute sordide straninea, supra sat dense fusco-punctulata, subtus fortius dilute punctata; lineola inferiore capitis pone antennas sjiraculisque nigricantibus; thorace macula anteriore majuscula, læviuscula, pure dilute straminea, interdum etiam macula utrimque laterali ante medium posita pallidiuscula notato, marginibus lateralibus anticis levissime simuatis, integris, angulis lateralibus acutissimis, extrorsum valde prominentibus; antennarum articulis tertio, quarto et quinto apicem versus interdum infuscatis; hemelytris pone medium puncto lævi albido notatis; margine imo apicali scutelli pallido; membrana sordide subvinacea. \&. Long. 10, Lat. 6! mill.

Pentatoma punctata P. B. Ins. p. 84. Hem. Pl. 7. fig. 6. (1805). Mormidea punctata DaLL. List of Hem. I. p. 214. 12. (1851). Patria: Sierra Leona. (Mus, Holm., Coll. Signoner et STÅL.)

51. P. (llerda) petulaus STẢL. - Sordide straminea, supra fusca et sat dense obscurius punctulata, subtus remote punctata; antennarum articulis duobus ultimis apicem versus fuscis; thorace ante medium fascia lata percurrente straminea, læviuscula vel parce punctata, ornato, marginibus lateralibus anticis subrectis, integris, angulis lateralibus acutis, extrorsum sat productis; scutelli apice stramineo, læviusculo; hemelytris pone medium macula minutissima lævi albida notatis; membrana sordide hyalina; spiraculis nigris. ․ Long. $11 \frac{1}{2}$, Lat. $6 \frac{1}{2}$ mill. 
Mormidea annulicornis SIGN. Ann. ent. Sér. 3. VIII. p. 927. 90. (1861).

Patria: Madagascar. (Coll. SignoneT.)

\section{Subg. THLLLRIS STR̊.}

Corpus ovale, subtus sat convexum. Caput planum, antrorsum angustatum, lobis æque longis, marginibus lateralibus acutis; tuberculis antemiferis a supero distinguendis; bucculis distincte elevatis, basin capitis attingentibus. Rostrum mediocre, articulo basali bucculas postice superante, secundo apicalibus duobus ad unum distincte breviore. Antennæ longæ, articulo primo calitis apicem æquante, secundo tertio subbreviore. Thorax marginibus lateralibus acutiusculis, integris. Scutellum apice modice angustatum, frenis nonnilil ultra medium extensis. Hemelytra abdomine angustiora, corio apice producto, scutello multo longiore; membrana parvinscula, venis paucis, simplicibus. Anguli apicales segmenti ultimi abdominis obtusi. Pedes mediocres, validiusculi; tibiis supra distincte sulcatis.

52. P. (Theloris) costata Thunz. - Grisescente-straminea, supra fusco-, subtus dilute sat dense punctata; thorace marginibus lateralibus anticis rectis, angulis lateralibus haud prominulis, apice rotundatis; scutello vitta media apiceque pallidis, leviusculis, vittis duabus, priesertim anterius, infuscatis; hemelytris linea longitudinali nigricante ornatis, parte exteriore inter linean nigram et marginem pallida, parte interiore in sordide testaceum vergente. $\sigma^{3}$. ․ Long. $8 \frac{1}{2}-11$, Lat. 5-7 mill.

Cimex costatus Thunis. Nor. ins. spec. II. p. 50. Tab. 2. fig. 63. (178:3).

Cimex lilineatus Thusib. Hem. rostr. cap. I1. p. 2. (1822). excl. syn.

Cimex civilis Germ. in Silb. Rev. ent. V. p. 179. 119. (1837).

Patria: Terra capensis. (Mus. Holm., Coll. Signonet et STiL.) 
Subg. AELIOMORPHA STîL.

Öfv. Vet. Ak. Förh. 1858. p. 313.

Tetratoma Sign. Ann. ent. Sér. 2. IX. p. 339. (1851).

Corpus ovale vel obovatum, subtus modice convexum. Caput productum, antrorsum angustatum, sat convexum, marginibus lateralibus obtusis, lobis fere æque longis, lateralibus apice acuminatis; bucculis percurrentibus, modice elevatis. Antennæ difformes, apud mares crassiusculæ, articulo secundo brevissimo, subannuliformi, obsoleto, apud feminas graciles, articulo secundo elongato, tertio tamen multo breviore; articulo basali capitis apicem haud attingente. Rostrum mediocre, articulo primo bucculas postice aquante, secundo apicalibus dnobus ad unum nonnihil breviore vel vix rquali. Thorax marginibus lateralibus obtusiusculis. Frena ad vel vix ad medium scutelli, raro ultra medium extensa. Anguli apicales segmenti ultimi abdominis subrecti, haud producti. Pedes mediocres, tibiis superne sulcatis vel planiuseulis.

a. Corpore griseo-albido vel sordide pallide stramineo.

b. Frenis panllo ultra medium scutelli extensis.

53. P. (Aeliomorpha) senegalensis SIGN. - Subanguste ovalis vel subobovata, griseo-albida, supra sat dense fusco-punctulata, subtus dilute punctulata; antennis, exceptis articulis primo et secundo, nigro-fuscis; thorace scutelloque linea longitudinali percurrente pallida, lævigata, in thorace subcallosa, instructis; membrana griseo-hyalina, venis leviter infuscatis; abdominis dorso nigro, connexivi segmentis extus latissime griseo-limbatis; angulis basalibus et apicalibus segmentorum ventris macula minuta fusca notatis; pedibus parce nigroconspersis. ơ' Long. 8, Lat. 4 mill.

o'. Antennarum articulo secundo annuliformi, articulo tertio apicalibus duobus ad unum paullo breviore.

Tetratoma senegalensis Sign. Ann. ent. Sér. 2. IX. p. 340 1. Pl. 10. fig. 8. (185̃1).

Patria: Senegal. (Coll. Signoretr.) 
bb. Frenis ad vel vix ad medium scutelli extensis.

54. P. (Meliomorpha) Matalicula Stỉl. - Obovata, pallide sordide straminea, dense punctata; capitis marginibus lateralibus imis maculaque magna oblongo-subtriangulari, basin attingente, thoracis spatio maximo medio, antrorsum angustato, nec non vitta laterali obliqua, scutelli vittula brevi basali prope angulos basales nec non vitta lata media, hemelytrorum parte coriacea, excepta parte costali, nec non lateribus pectoris fusco-punctatis; linea media percurrente capitis, thoracis scutellique pallida, levi; abdominis dorso, excepto connexivo, nigro, hoc intus anguste nigricante; pectoris maculis minutis tribus prope coxas fuscis; membrana alisque subsordide hyalinis. o'. Long. 6, Lat. 4 mill.

त?. Antennis, exceptis articulis duobus hasalibus, pallide testaceis, leviter incrassatis, articulo secundo brevissimo, duplo longiore quam crassiore; ventre maculis duabus opacis, impunctatis, destituto; segmento anali apice late sinuato, sinu ipso medio levissime bisinuato, inter sinus levissime rotundato-producto.

Aelia natalicola șт̇̀. Öfr. Vet. Ak. Förh. 18533. p. 218. 3. Patria: Caffraria, Terra capensis. (Mus. Ilolm.)

Caput antrorsum sat angustatum, marginibus lateralibus medio leviter sinuatis. Thorax marginibus lateralibus anticis rectis, angulis lateralibus haud prominulis, subrectis. Corium apice maculis duabus obscurius fusco-punctatis notatum. Latera ventris interdum fuscopunctata.

55. P. (Aeliomorpha) grisen-flara S'TÅ. - Obovata, dilute sordide straminea, dense punctata; capitis macula elongata, antrorsum angustatil, basin attingente, thoracis medio vittaque obsoleta laterali, scutelli vittula brevi prope angulos basales, hemelytris lateribusque pectoris fusco-punctatis; linea subtili obsoleta percurrente capitis, thoracis scutellique pallida, leviuscula; abdoninis dorso, excepto connexivo, nigro, hujus segmentis postice nigro-fasciatis vel dense nigro-punctatis; membrana sordida, venis leviter infuscatis. o?. Long. $6 \frac{1}{2}$, Lat. 4 mill. 
ऽ. Antennis in pallidissime subtestaceum vergentibus, leviter incrassatis, articulo secundo brevissimo, duplo longiore quam crassiore; ventre maculis duabus oblongis, per segmenta quartum, quintum et partem segmenti sexti extensis, impunctatis, opacis, instructo, segmento anali apice late sinuato, sinu ipso medio levissime bisubsinuato, inter sinus levissime subrotundato-producto.

Aelia griseo-flava ṠTÀL. Öfv. Vet. Ak. Förh. 1853. p. 218. 2. Patria: Caffraria. (Mus. Hohu.)

$P$. Natalicole maxime affinis et ab illa difficillime distinguenda, scutello ad linean mediam levem vix fusco-punctata, pectoris lateribus obscurius fusco-punctatis vel subinfuseatis, ventris maculis duabus opacis, apud marem saltem priesentibus, divergit. Ventris segmenta interdum macenla media fusca notata.

56. P. (Aeliomorpha) pmmila STẢL. - Obovata, dilute sordide straminea, dense punctata; capitis marginibus angustis lateralibus vittaque lata media postice fissa, thoracis vittis angustis quattuor obliquis, scutelli maculis duabus basalibus prope angulos positis nec non vittula obsoleta utrimque laterali fuscis; abdominis dorso nigro, parte apicali connexivoque stramineis, illa vittula nigra ornata, hoc maculis fuscopunctatis notato; membrana decolore; pectoris lateribus fuscopunctatis; ventre vitta utrimque laterali pallide subtestaceopunctata, segmentis prope angulos basales macula minuta fusca notatis; mesosterno fusco-bivittato. $\sigma^{7}$. Long. 5, Lat. 3 mill.

o. Antennis incrassatis, articulo secundo brevissimo, ægre perspiciendo; ventre maculis duabus opacis destituto, segmento anali apice late emarginato, medio subinciso. Aelia pumila StåL. Öfv. Vet. Ak. Förh. 1853. p. 218. 4. Patria: Caffraria. (Mus. Holm.)

Præcedentibus duabus maxime affinis, minor, paullo angustior.

57. P. (Aeliomorpha) simulans STÅL. - Obovata, dilute straminea, supra in albidum vergens et sat dense distincteque fusco-punctata; capite, exceptis vitta media marginibusque lateralibus, nec non thoracis marginibus lateralibus pallidius punctatis; thoracis linea media, per scutellum continuata, nec non hujus 
macula oblonga in angulis basalibus marginibusque imis pone medium lavibus; scutelli lateribus pallidis et pallide fuscopunctatis; hemelytris obscure fusco-punctatis vel subinfuscatis, parte costali pallida; membrana subinfuseata et obscurius venosa; pectore fusco-punctato, vitta utrimque laterali læriuscula; abdominis dorso nigro, connexivo stramineo, incisuris hujus anguste fusco-fasciatis; ventre remote pallide fuscopunctato, prope margines laterales interdum obscurius punctato, vitta media vel macula posteriore nec non macula parva segmentorum prope angulos basales nigris; alis infuscatis. $\sigma$. ㅇ. Long. 6-7, Lat. $3 \frac{1}{2}-4$ mill.

o?. Antennis incrassatis, in sordide testaceum vergentibus, articulo secundo brevissimo, haud longiore quam crassiore; ventre posterius maculis duabus opacis obsolete punctitis, minus distinctis, instructo; segmento anali apice medio biemarginato.

ㅇ․ Antennis gracilibus, articulo secundo basali subæquali. Aeliomorpha simulans StÅL. Öfr. Vet. Ak. Förh. 1858. p. 313. 10 .

Patria: 'T'kons fountain Africæ meridionalis occidentalis. (Mus. Holni.)

Pracedentibus maxime affinis, magis nitida.

\section{aa. Corpore virescente.}

58. P. (Aeliomorpha) bella STÁL. -- Subanguste ovalis, dilute viridis, sat dense punctata; antennis, excepto articulo primo, marginibus lateralibus capitis, thoracis et prostethii, margine costali corii anterius nec non tibiis dilute testaceis; scutello apice testaceo-albido; thoracis marginibus lateralibus anticis medio levissime simuatis; membrana sordide hyalina. ․ Long. $8 \frac{1}{2}$, Lat. $3 \stackrel{1}{2}$ mill.

․ Antennis gracilibus, articulo secundo basali longitudine aquali.

Aclia bella Stàl. Öfv. Vet. Ak. Förh. 1853. p. 217. 1.

Patria: Caffraria. (Mus. Holm.) 


\section{AGONOSCELIS SPIN.}

\section{Ess. Hlém. p. 327. (1840).}

Nenroscia A. et S. Hist. des Hém. p. 109. (1841).

Corpus remote pilosum, ovale. Caput sapissime longiusculum, antrorsum sensim angustatum, apice rotundatum, integrum, lobis aque longis; bucculis percurrentibus, distincte eleratis. Rostrum longum vel longiusculum, articulo primo capitis basin attingente. Thorax marginibus lateralibus anticis integris, acutiusculis, rectis, margine antico, medio saltem, angustissime subcalloso. Scutellum triangulare, apice sat angustatum, frenis paullo ultra medium ductis. Hemelytra abdomine nomnihil angustiora et multo longiora; membrane venis simplicibus. Mesosternum leviter carinatum. Venter interdum obsolete subsulcitus. Pedes medincres, tibiis cylindricis, supra haud sulcatis.

\section{a. Abdomine durso flaco-testaceo iel lietescente. \\ b. Abelomine dorso unicolure.}

1. A. sangunea Westw. - Flavescente-testacea, minus dense distincte punctata; antennis, articulo primo ad partem rel fere toto excepto, nigris, articulo secundo tertio nonnihil breviore; capitis marginibus literalibus interdum anguste nigris; membrana sordide hyalina, angulo basali interiore fusco, venis interdum levissime infuscatis; alis dilute fuscescescentibus; pectoris maculis tribus minutis prope coxas, ventris maculis parvis marginalibus, maculis parvis discoidalibus, utrimque in. seriem dispositis, spiraculis, connexivi maculis, femorum macula parva pone medium aliaque apicali, nec non tarsorum apice nigris; rostro longo, segmentum ultimum ventris attingente. $\sigma^{7}$. ㅇ. Long. 11, Lat. 5 mill.

Aelia sanguinea Westw. in IIope. Cat. of Hem. I. p. 32. (1837).

Pentatoma miniatocollis Westw. in Hope. Cat. of Hem. I. p. 43. (1837).

Patria: Terra capensis. (Mus. Holm. et Coll. Signoretr.) 
1.b. Abelominis dorso basi apiceque nigro.

2. A. rersicolor FABR. - Pallide sordide straminea, supra distincte dilute ferrugineo-punctata, hemelytris acervatim densius punctitis, parte costali nigro vel fusco-punctata; subtus leviuscula; abdominis dorso lutescente; antennis, parte interiore articuli primi excepta, capitis marginibus lineisque duabus longitudinalibus, basi apiceque dorsi abdominis, parte hasali et apicali seamentorum comexivi, maculis quattuor Jarvis lateralibus pectoris, ventris maculis parvis marginalibus in angulis basalibus et apicalibus segmentorum aliisque discoidalibus in series quattuor dispositis nee non spiraculis, femorum macula parva pone medium, apice tibiarum tarsisque nigris; thoracis marginibus lateralibus leviusculis, dilute lutescentibus, posterius nigro-punctatis; scutello pone medium utrimpue nigro-punctato, parte apieali pallicla, dilute punctata; membranal sordide sulvinacea, fusco-venosal alis totis infuscatis; antemarum articulo secundo tertio nonnihil breviore; rostro medium ventiis attingente. o?. ‥ Long. 10I2, Lat. 5-6 $\frac{1}{2}$ mill.

Cimex rersicolor FAnR. Ent. syst. IV. p. 120. 155. (1794). Syst. Rhyng. 1\% 175. 101. (1803).

(imex mbescons Tiuxis. Hem. rostr. cap. Il. p. 2. (I822).

Aplia gumbiensis Wratw. in Hople. Cat. of Hem. I. p. 32. (18:37).

Aclin infuscutu Westw. in IIope. Cat. of Hem. I. p. 32. $(18: 37)$.

Cimer acinom Gekn. in SiLb. Rev. ent. V. 1. 177. 116. (18:37).

Pentatoma acinorum H. ŚCII. Wanz. Ins. VII. p. I05. fig. 769. (1844).

Ayonoscelis versicolor DaLL. Cat. of IIem. I. p. 179. I. (18j]).

Patria: Caffraria, Abyssinia, Senegal. (Mus. Holm., Coll. SIGXORET ot itids.) 
aа. Abdominis dorso nigro, connexivo flavescente, interdum nigro-fusciato.

3. A. crosa Wferw. - Grisen-straminea, supra plus minus in ferruginenu vergens et distincte fusco ferrugineoque punctata, hemelytris sape distincte dilute ferugineis, punctis nigris adspersis, parte laterali nigro-punctata; membrana subdecolore, angulo basali interiore nigricante; antennis, excepta parte interiore articuli prini, capitis marginibus lateralibus et lineis duabus longitudinalibus, dorso ablominis, maculis parvis quinque lateraliuns pectoris, ventris maculis parvis discoirlalibus in series quattuor dispositis alisque marginalihus in angulis basalibus ot apicalibus segumentorum nec non spiraculis, macula parva, interdum deficiente, pone medium femorum, tibiis totis vel apicem versus nec non tarsis nigris; comnexivo flavescente, nimro-fasciato; marginibus lateralibus thoracis apiceque scutelli pallidis, laviusculis, illis posterius nigro-punctatis; alis subaluidis, disco magno fusco; antennarum articulo secundo longitudine varialili, tertio subcrpuilongo vel distincte breviore; rostro longissimo, apicem abdo-

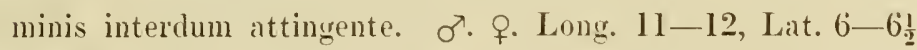
nill.

Aelia erosa WVEsTw. in Hope. Cat. of Hem. 1. 1. 33.3. (18:37). Patria: Caffraria, Africa meridionalis occidentalis. (Mus. Holm. et Coll. SignoreT); Sierra Leona. (sec. Hope.)

Statura A. versicoloris, cum qua confunditur, excepta pictura dorsi abdominis etiam differt capite longiore.

4. A. puberula ŚTAL. - Dilute straminea, supra minus dense nigro-punctata, scutello basin versus densius punctato; hemelytris interdum in ferrugineum vergentibus; antennis, parte interiore articuli primi excepta, dorso abdominis, maculis parvis tribus vel quattuor lateralibus pectoris, ventris maculis parvis discoidalibus in series quattuor dispositis aliisque maroinalibus in angulis basalibus et apicalibus segmentorum nec non spiraculis, puncto pone medium femorum tarsisque ad partein nigris; thoracis marginibus lateralibus anticis ante 
mediun, scutelli macula parva basali apiceque pallidis, laviusculis vel dilute punctatis; alis levissime infuscatis, apice decoloribus; membrana vitrea, angulo basali interiore fusco, venis sxpissime leviter infuscatis; connexivo stramineo, nigrofasciato; antennarum articulis secundo et tertio subiequalibus; rostro medium ventris attingente. $\sigma^{7}$. ․ Long. $7-8 \frac{1}{2}$, Lat. $4-4 \frac{1}{2}$ mill.

Agonoscelis puberula STÀL. Öfv. Vet. Ak. Förh. 1853. p. 216. 1 .

Patria: Caffraria, Terra Damararum. (Mus. Holm.)

$\Lambda$ congenericis divergit capite breviore.

\section{AFRANIA STAL.}

Corpus ovale, latiusculum, subtus sat convexum. Caput antrorsum angustatum, marginibus lateralibus inis leviter reflexis, acutiusculis, lobis rque longis; buceulis percurrentibus, distincte elevitis. Rostrum mediocre, coxas posticas paullo superans, articulo primo bucculas postice requante, secundo apicalibus duobus ad unum nomihil breviore. Antemne quinquearticulata, articulo primo capitis apicem hand attingente. Thorax breviusculus, margine antico toto late sinuato, late calloso, angulis anticis land truncatis, marginibus lateralibus obtusiusculis, hand reflexis. Scutellum postice latiusculum, frenis ultra medium extensis. Ilenelytra abdomine paullo angustiora, angulo apicali corii nonnihil rotundato; membrana parviuscula, venis longitudinalibus, simplicibus. Mesosternum carinatum. Venter haud sulcatus. Pedes longi, tibiis superne distincte sulcatis; tarsis articulo frimo apicalibus duobus ad unum aquali.

Syao et Hologustro aftine genus.

I. A. Wahllorgi Stíl. - Dilute testaceo-Havescens, supra sat dense distincteque, subtus obsolete punctata; antennis, rostro aficem versus, caphitis marginibus lateralibus et basali nec non vitta media, thoracis fasciis duabus latiusculis, utrimque abbreviatis et medio interruptis, scutello, linea longitudinali media partenue angusta laterali exceptis, hemelytris, maculis 
pectoris tribus lateralibus transversis, margine interiore connexivi, ventris vitta utrimque laterali intramarginali fasciisque discoidalibus cum vittis lateralibus cohærentibus nec non pedibus nigris; corii vitta posterius abbreviata limboque api-

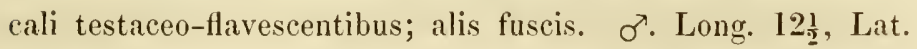
$6 \frac{1}{2}$ mill.

Strachia Wahlbergi STÅL. Öfv. Vet. Ak. Förh. 1853. р. 220. 1 .

an Agonoscelis brachyptera Scmaun in PETERs Reise nach Mossamb. Ins. p. 37. Tat. 2. fig. 2. (1862)?

Patria: Caffraria. (Mus. Holm.)

Thorax capite subbrevior, margine antico late clevato, calloso, punctulato, marginibus lateralibus anticis rectis, integris, angulis lateralibus haud prominulis. Membrana apicem abdominis attingens.

\section{AGAUS DALL.}

List of Hem. I. p. 185. (1851).

Corpus anguste ovale, subtus modice convexum. Caput productum, longiusculum, antrorsum angustatum, lobo medio prominulo, marginibus lateralibus leviter reflexis, bucculis percurrentibus; tuberculis antenniferis a supero ad partem distinguendis. Rostruin longiusculum, articulo primo bucculas postice haud superante, secundo apicalibus duobus ad mum breviore. Antenne graciles, quinquearticulate, articulo primo capitis apicem haud attingente, secundo tertio breviore. Thorax marginibus lateralibus anticis anguste reflexis, integris vel crenulatis. Scutellum triangulare, parte apicali valde angustata, frenis ultra medium extensis. Hemelytra abdomine nonnihil angustiori; membranæ venis simplicibus. Mesosternum distincte carinatum. Venter nonnihil sulcatus. Pedes longi, postici inter se nonnihil remoti; tibiis superne distincte sulcatis; tarsorum articulo primo apicalibus duobus ad unum breviore.

1. A. discolor DALL. - Niger, nitidus; capite, thorace scutelloque parce, hemelytris dense punctatis; subtus cum dorso abdominis dilute flavescens, lavis, pectore pirce punctato; 
capitis vittis duabus, thoracis limbo omni vittaque media, scutelli marginibus lateralibus, parte dimidia apicali vittanue anteriore, corii margine apicali fasciaque posteriore, extus subabbreviata, nec non lineis femorum dilute sordide Havescentibus; macula parva in angulis lateralibus thoracis maculisque tribus mannis lateralibus pectoris nigris; thoracis marginibus lateralibus anticis integris, rectis, medio vix sinuatis, angulis lateralibus haud vel vix prominulis; alis fuscis. $\{$. Long. 18, Lat. 7 mill.

Agaus discolor DALL. List of Hem. I. p. 186. 2. (1851).

Patria: Guineil. (Coll. Sigixoret.)

\section{STENOZTGUM FIEB.}

Ear. H'm. p. 345. (1861).

Corpus ovale vel ovatum. Caput planiusculum, marginihus reflexis, lohis fere aque longis, lobo medio antrorsum nomnihil angustato; bucculis percurrentibus, sat elevatis. Oculi sat prominuli, brevissime stylati. Rostrum mediocre, articulo primo bucculas postice interdum paullo superante, articulo secundo apicalibus duobus ad unum breviore. Antenna quinquearticulata, articulo primo eapitis apicem aquante vel subsuperante, articulis secundo et tertio longituline variabilibus, illo hoc sepissime breviore. Thorax sexangularis, angulis posticis valde obtusis, marginibus lateralibus anticis et sapissime etiam antico reflexis vel elevatis. Membrane vene simplices. Mesostemum leviter carinatum. Pedes mediocres, tibiis superne planiusculis vel sulcatis; tarsis posticis articulo primo apicalibus duobus ad untum breviore.

Strachice aftine grenus.

a. Internarum articulo secundo tertio lreviore: thorace ante medium spatio transererso sulielevato, untice medio producto, lacri, toto impressione lineavi circumscripto, instructo, murginibus laterulibus unticis et antico reflexis vel elevatis; scutello upice sut anymstuto, fienis ultru medium scutelli extensis. 
1. S. madagascariense Sign. - Orale, sulviolaceo-caruleum, nitidum, lave, impressionibus thoracis, scntello, parte basali elevata excepta, hemelytrisque, disco excepto, punctatis; maculis duabus minutissimis mediis capitis, thoracis ritta lata, medio coarctata, percurrente, angulis imis anticis, maculis duabus parvis mediis late distantibus marginibusque lateralibus anticis postice, scutelli maculis tribus, una in angulis basalibus unaque majore fere media, nec non apice, corii macula parva costali prope basin maculaque majuscula ad medium marginis apicalis, abdominis dorso, exceptis limbis latis lateralibus a basi ad segmentum penultimum, pectoris vitta ad coxas ventreque dilute lutescentibus; macula magna marginali segmentorum ventris primi, secmdi, tertii, quarti et quinti, maculis duabus mediis segmenti ultimi, nec non valvulis duabus posticis analibus feminæ cieruleis; macula parva ante medium corii anguloque apicali segmentorum connexivi stramineo-albidis; membrama albido-limbata; alis infuscatis; articulo primo rostri buceulas postice distincte superante; antennarum articulo tertio secundo duplo longiore; tibiis distincte sulcatis. \&. Long. 11, Lat. $5^{3}$ mill.

Strachia Madagascariensis SIGN. Ann. ent. Sirr. 3. VIII. I. 933. 103. Pl. 13. fig. 5. (1861).

Patria: Madagascar. (Coll. Signoret.)

2. S. mirabile Sign. - Obscure cæruleum, læve, thoricis impressionibns parteque posteriore, scutello hemelytrisque nec non segmentis pectoris antice et postice distincte punctatis; capitis maculis dnabus mediis superioribns et dnabus lateralibus inferioribus, thoracis limlis lateralibus anticis maculaque anteriore, scutelli maculis tribus basalibus unaque media nec non apice, hemelytrorum macula elongata costali anteriore maculaque ad marginem apicalem, limbo laterali prostethii, maculis tribus mesosterni, macnlis tribus pectoris prope coxas, abdominis dorso, excepto connexivo, nec non ventre lutescentibus; maculis duabus marginis antici, macnlis quattuor parvis ante medium in seriem transversam dispositis, 
linea transversa interrupta media lineaque longitudinali posteriore thoracis, macula parva ante medium corii, angulis apicalibus segmentorum abdominis, acetabulis, coxis, trochanteribus lineisque femorum albidis vel stramineo-albidis; ventris maculis magnis marginalibus aliisque discoidalibus in series duas longitudinales dispositis, reneo-caruleis; membrana nigro-fusca, late albido-limbata; alis infuscatis. or. Long. 7, Lat. 4 mill.

Strachia mirabilis SIGN. Ann. ent. Sér. 3. VIII. p. 932. 101. (1861).

\section{Patria: Madagasear. (C'oll. SIGxoRET.) \\ Statura $S$. alienati, cui valde affinis et similis.}

3. S. alienatum FABR. - Ohscure creruleum, nitidum, læve, thoracis impressionibus parteque posteriore, scutello, parte basali elevata excepta, hemelytrisque punctitis; capitis maculis parvis tribus, duabus mediis unaque subbasali, nec non margine interiore loborum lateralium, thoracis vitta lata inæquali media, scutello ventreque lutescentibus; thoracis maculis nonnullis minutis discoidalibus, macula marginis lateralis antici posteriore, marginibus lateralibus posticis et angustissimo angulorum lateralium, corii maculis tribus, una minuta costali anteriore, una ante medium prope clarum unaque majore transversa posteriore, pectore, excepta vitta latissima laterali, parce flavo-notulata, coxis, trochanteribus, basi femorum nec non lineis femorum tibiarumque albidis, in lutescentem interdum vergentibus; membrana sneo-fusca, late albido-limbata; seutelli maculis duabus basalibus mediis irregularibus, forma varialilibus, maculisque duabus prope apicem, linea subtili separatis, maculis connexivi, maculis rentris marginalibus aliisque discoidalibus in series duas longitudinales dispositis, lis interdum deficientibus, ceruleis; abdomine dorso lutescente vel violaceo-fuscescente; alis infuscatis. $\sigma^{7}$. ㅇ. Long. 7--9, Lat. $4-5$ mill.

Cimex alienutus Fabr. Syst. Rhyng. p. 173. 97. (1803).

Pentutoma elegans P. B. Ins. p. 113. Hem. Pl. S. fig. 5. (1805). 
Strachia alienata DALL. List of IIem. I. p. 261. 9. (1851).

Patria: Caffraria, Guinea. (Mus. Holm., Coll. Sigronet et STÅL.)

4. S. sculpticolle STẢL. - Flavo-testaceum, nitidum, læve, thoracis impressionibus parteque posteriore, scutello, excepta parte basali leviter elevata, pectore, hemelytris, illis parce, his densius punctatis; antennis, maculis tribus lateralibus pectoris, mesosterno lineisque femorum et tibiarum nigris; membrana reneo-fusca, late albido-limbata, alis infuscatis. ․ Long. 10, Lat. $5_{2}$ inill.

Strachia sculpticulle ṠTẢu. Öfv. Vet. Ak. Fürl. 1855. p. 182. 1; Öfv. Vet. Ak. Fürh. 1856. p. 59. 1.

Patria: Sierra Leona. (Mus. Holm.)

Statura S. ulienati, cui, exceptis coloribus, maxime est affuis.

aa. Corpore ovato; scutello posterius latiusculo, frenis aul rel vix ultra medium scutelli extensis.

b. Antennarum articulo secundo tertio breviore; thorace ante medium spatio transverso, leviter elevato, antice medio nonnithil producto, impressione continua lineari circumscripto, instructo, marginibus antico et lateralilus anticis elevatis.

5. S. gloriosum WEstw. - Nigrum vel cæruleo-nigrum, subnitidum, læve, thorace pone medium, scutello hemelytrisque punctatis; abdominis dorso, excepto connexivo, fusco-testaceo; capitis macula parra posteriore maculisque duabus maximis subtriangularibus, lobos laterales fere totos occupantibus, horum etiam margine interiore apicem versus, nec non parte inferiore, exceptis lineis nonnullis, thoracis marginibus antico et postico maculisque pluribus, quarum una laterali marginali ad angulos laterales, scutelli macula in angulis basalibus, linea longitudinali antica, fascia lata media, medio interrupta, nec non apice, clavi lineola anteriore, corii margine imo costali anteriore nec non maculis duabus irregularibus, una ante medium, altera pone medium posita, maculis comnexivi, maculis compluribus pectoris, ventre, maculis li- 


\section{$-186^{\circ}-$}

neisque pedum stramineis vel in lutescentem vergentibus; ventre maculis discoidalilus in series tres longitudinales dispositis nigris, macula flavescente angulorum apicalium segmentorum intus nigro-marginata. q. Long. 8! , Lat. 5 mill.

Pentatoma gloniosa Westw. in Hope. Cat. of Hem. p. 34. $(1837)$.

Cimex musicus Geru. in Silb. Rev. ent. V. p. 176. 114. (I837).

Eurydema musiva II. Scu. Wanz. Ins. VIl. p. 84. fig. 751. (1844).

Strachia gloriosa DALL. List of IIem. I. 1) 259. 7. (I851). Patria: Terra capensis. (Mus. Holı. et Coll. S'Tís.)

bb. Antennarum articulo secundo tertio nonnitil longiore; thorace sputio transverso elevuto destituto, marginibus lateralibus anticis unguste et leviter reflexis, antico hand elevato.

6. S. rarium WEsT. - Stramineum rel stramineo-albidum, supra cum lateribus pectoris ventrispue minus dense distincte nigro-punctatum; capite, thoracis limbis lateralibus anticis, scutelli linea media percurrente maculaque in angulis basalibus pallide lutescentibus; antennis, capitis lineolis nonnullis posticis lineayue intramarginali lobormm lateralium, dorso abdominis, excepto comnexiro, lineis maculisque minutis sparsis pedum nec non commexivi segmentis ante medium nigris, his ilidem macula straninea notatis. ․ Long. 8-9, Lat. $4 \frac{1}{2}-$ 5 mill.

Pentatuma raria WEsTw. in Hupe. Cat. of Hem. p. 34. (1837). Strachia angularis Schand. Ber. Akad. Berl. 1853. p. 357; Peters Reise nitch Mossamb. Ins. p. 39. Tat. 2. fig. 3. (1862).

Patria: Terra cajensis. (Mus. Holn. et Coll. StT̃̉L); Mozambiyue. (Mus. BERot.)

Ad Stenosyymm pricterea pertinent Strachice bicolor DaLL. et speciosu Dsı., Cimex variegatus (coloratus) Kutci (= Steno:ygun

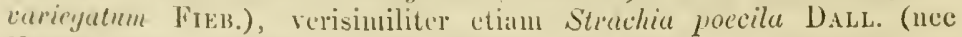
Kitu(i.) 


\section{BAGRADA STAL.}

Stett. Ent. Zeit. XXIII. p. 105. (1862).

Corpus ovale vel obovatum. Caput sat deflexum, triangulare, apice rotundatum, marginibus leviter reflexis, lobis fere זque longis, lobo medio antrorsum angustato; bucculis percurrentibus, modice elevatis. Oculi brevissime stylati. Ocelli inter se quam ab oculis fere ter longius remoti. Rostrum mediocre, articulo primo bucculas postice vix superante, articulo secundo apicalibus dnobus ad unum subxquali. Antennæ quinqquearticulatre, articulo primo capitis apicem subrquante, secundo tertio aquali vel paullo longiore. Thorax subquadrangularis, postice inter angulos laterales late rotundatus, angulis posticis deletis, obtusissime rotundatis. Mesosternum leviter carinatum. Tibie superne leviter sulcatie.

Stenozygo affine genus.

1. B. hilaris Burm. - Ovalis, nigra, nitidula, punctulata, subtus cum eapite levigata; vitta utrimque laterali obliqua capitis, margine antico, vittis tribus, una media, maque utrimque laterali intramarginali obliqua, interdum etiam fascia angusta abbreviata pone medium thoracis, scutelli maculis tribus basalibus vittaque pone medium posita, antice utrimque ampliata, corii vitta intracostali, pone medium abbreviata, maculaque posteriore, connexivi maculis, pectoris maculis tribus lateralibus, acetabulis, sternis, rentris maculis marginalibus discoque maximo, nec non lineis pedum stramineis, Jnteotinctis; ventris disco anguste nigro-fasciato; membrana albida vel leviter infuscata, basi fusca; alis albido-hyalinis. o’. ․ Long. 6, Lat. 3 mill.

Cimex hilaris Burar. Handb. II. 1. p. 368. (1835).

Cimex hebraicus Germ. in Silb. Rev. ent. V. p. 177. 115. (1837).

Cimex pictus II. Scir. Wanz. Ins. V. p. 64. fig. 508. (1839). Cimex jucundus Klug. Symb. phys. V. Tab. 4t. fig. 6. (1845). 
Strachia hilaris DALL. List of Hem. I. p. 259. 6. (1851). STOLL. Cim. fig. 237.

Patria: Africa meridionalis. (Mus. Holm., Coll. Signoret et STÅL.)

Ad hoc genus verisimiliter pertinent Strachia picta Fabr. ct Cimer poecilus KLUG.

\section{CATACANTIUUS SPIN.}

Ess. Hém. p. 352. (1840).

Corpus oratum, subtus modice convexum. Caput proportionaliter parvum, planum, marginibus leviter elevatis, lobis aque longis; bucculis basin capitis subattingentibus, modice elevatis; tuberculis antenniferis a supero fere totis distinguendis, inermibus. Oculi globosi, sessiles. Antennæ quinquearticulatæ, articulo primo capitis apicem leviter superante. Rostrum mediocre, articulo primo bucculas postice subæquante, secundo et tertio subrqualibus. Thorax margine antico leviter elevato, marginibus lateralibus anticis acutis, reflexis vel foliaceo-dilatatis. Scutellum postice sat angustatum, frenis ultra medium extensis. Membrana apicem abdominis multo superans, venis numerosis, simplicibus. Mesosternum carinatum. Abdomen hemelytris latius, lateribus explanatum; ventre basi inermi vel spinoso vel tuberculato. Pedes longinsculi, tibiis supra distincte sulcatis, anticis extus interdum leviter dilatatis.

a. Thoracis marginibus lateralibus anticis rectis, anguste reflexis, hand foliaceis; ventre basi inermi; tiliis anticis extns leciter dilatutis.

\section{Cheleocoris Dalu. List of Hem. I. 1. 271. (1851).}

I. C. Anchorago Drurs:- Laviusculus, virili-ieneus, subtus cum parte apicali scutelli, dorso ablominis, angulo imo apicali corii, interdum etiam clavo flavescens; antemnis, rostro pedibusque nigris; maculis connexivi maculisque marginalibus sat magnis ventris viridi-atneis; macula media segmentorum ventris anco-nigra; membrana aneo-fusea; alis fuscis; scu- 
tello pone medium hemelytrisque punctatis, illo ante medium convexo. ơ. Long. 23, Lat. $11 \frac{1}{2}$ mill.

Cimex anchorago Drurx. Ill. Nat. Hist. III. p. 66. Pl. 46. fig. 5. (1782).

Cimex rutilans FaBr. Ent. syst. IV. p. 108. 108. (1794).

Edessa mutiluns FABR. Syst. Rhyng. p. 151. 25. (1803).

Catacanthus anchorago DALL. List of Hem. I. p. 271. 3. (1851).

STOLl. Cim. fig. 122.

Patria: Guinea. (Mus. Ilolm. et Coll. Signoret.)

aa. Thoracis maryinilus lateralibus anticis explanatis, foliaceis, late leviternue reflexis, rotundatis; ventris basi inerni; tibiis unticis simplicilus.

Coquerelia Sign. Ann. ent. Sér. 3. VIII. p. 934. (1861).

2. C. pectoralis SigN. - Niger, supra punctulatus, thorace, scutello, hemelytrorum parte coriacea, prostethio, parte postica metastethii segmentoque basali abdominis coccineis; maculis duabus magnis basalibus scutelli maculaque magna media corii, marginèm costalem tangente, nigris; capitis vitta utrimque laterali inferiore, fascia segmentorum connexivi, fascia laterali segmentorum tertii et quarti nec non fascia apicali percurrente segmentorum quinti et sexti ventris flavescentibus; alis fuscis; scutello basin versus elevato. \&. Long. 21, Lat. 11 mill.

Coquerelia pectoralis Sign. Ann. ent. Sér. 3. VIII. p. 934. 104. Pl. 13. fig. 6. (1861).

Patria: Madagascar. (Coll. Signoret.)

\section{BATHICOELIA A. et. S.}

Hist. des Hém. p. 110. (1843).

Caput ovatum, apice rotundatum, Iobis æquilongis. Rostrum longissimum, articulo primo bucculas postice hand superante, secundo tertio breviore. Antenne articulo primo capitis apicem haud attingente. Thorax margine antico, parte laterali excepta, leviter calloso. Scutellum apice angustmm, frenis ultra medium 
extensis. Mesosternum arina altiuscula instructum. Venter suleo lato instructus. Tiljix siepissime distincte sulcatie.

1. IB. buenopoziensis P. B. - Subobovata, dilute sordide olivarenflavescens red virescens, nitida, thorace scutelloque remote, hemelytris dense functatis, subtus remote functulata; thoracis marginibus lateralibus anticis rectis, anguste callosoelevatis; capitis lineola subtili inferinre ante oculos imjressioneque parva in angulis basalibus scutelli nigris; hemelytris (an semper?) dilute sordide olivareo-testareis; rostro apicem segmenti ventralis quarti attingente; ingulis lateralibus thoraris leviter prominulis. \&. Long. 18, Lat. 9 mill.

I'entatoma buonopoziensis P'. B. Ins. p. 82. Ilém. 11. 7. tig. 2. (1805). sec. ex. typ.

Bathycoeha Buonopoziensis A. et S. Ilist. des Hém. J. 110. 1. (1843); DALL. List of Ilem. I. p. 269. 2. (1851).

Patrial: Oware. (Coll. Signoretr.)

2. I. oralis STÂL. - Oralis, dilute olivaceo-virescens; thorace scutelloque remote, lremolytris dense punctatis, subtus remote punctulata; lineola inferiore capitis ante oculos, maculis connexivi angulisque inis segmentorum ventris nigris; corio basi intra marginem costalem nigro-punctato; scutello in angulis lasalibus impressione minuta instructo; rostro medium segmenti rentralis quarti attingente; angulis lateralibus thoracis haud vel vix prominulis; marginibus lateralibus anticis thoracis anguste callosis. \&. Long. 17, Lat. 9 mill.

latria: Calabar. (Coll. A. I)onrs et stril.)

Pracedenti maxime aftinis, matgis ovalis, commexivo nigro-marulito angulisque thoracis lateralibus haud prominulis differt.

3. I. thalassina H. Scr. - Ovalis, subolivaceo-riridis, supra distincte et sat dense functata, subtus pallidior, remote subtiliterque punctulata; antemnis, geniculis, tibiis tarsisque pallide rosen-olivaceis; articulo tertin antennarum apice, margiue caphitis, marginibus lateralibus anticis thoracis maculisque comnexivi nigris; rostro paullo pone segmentum ventrale 
quartum producto; angulis lateralibus thoracis haud prominulis. \&. Long. 20, Lat. 10 mill.

Gastraulax thalassinus II. Scir. Wanz. Ins. VII. p. 62. fig. 731. (1844).

Bathycoelia thalassina DALL. List of Hem. I. p. 269. 1. (1851).

Patria: Calabar. (Coll. Signorex.)

Antenne exempli descripti mutilatie.

\section{PLAUTIA S'TAL.}

Corpus obovatum. Caput planum, apice rotmolatum, ante oculos utrimque leviter sinuatum, lobo medio lobis lateralibus aquilongo. Rustrum pone coxas posticas paullo productum, articulo primo bucculas postice haud superante, articulo secundo tertio paullo breviore. Antenne articulo primo capitis apicem haud attingente, articulo secundo tertio numquam longiore. Thorax marginibus lateralibus anticis integris, haud callosis, antico toto calloso, levigato, pone oculos utrimque haud vel vix truneato. Scutellum breviusculum, frenis nonnihil ultra medium continuatis. Mesosternum rarinatum. Venter basi inermis vel tuberculo obtuso armatus. Tilix supra sulcatæ.

1. P. fimbriata FABR. - Dilute virescens, minus dense punctata, ventris disco angusto lævi; antemnarum articulis tribus ultimis apicem versus infuscatis; hemelytris dilute sanguineis, fusco-punctatis, parce pallido-conspersis, limbo costali virescente; membrana vitrea, basi fuscescente; abdomine dorso dilute subviolaceo-testaceo; angulis apicalibus segmentorum abdominis lineolaque inferiore capitis ante oculos nigris; marginibus imis lateralibus anticis thoracis interdum infuscatis. ․ Long. $9 \frac{1}{2}$, Lat. 6 mill.

Cimex fimbriatus FABR. Ent. syst. IV. p. 121. 159. (1794); Syst. Rhyng. p. 175. 107. (1803); HI. ŚcH. Wanz. Ins. V. p. 63. fig. 505. (1839).

Pentatoma fimbriolatum H. ScH. Wanz. Ins. VII. p. 95. fig. $505 .(1844)$. 
Pentatoma virilicollis WEsTw. in Hope. Cat. of Hem. I. p. 35. (18:37); 1)ALL. List of Hen. 1. p. 251. 48. (1851).

Pentatoma fimbriata 1)ALL. List of 11em. I. p. 251. 47. (1851). Patria: Madagiscar. (Coll. Signoret); China, Jengalia. (Mus. Holm. et Coll. S'TẢL.)

Ad hoc genus preterea pertinent Pentatoma crossota DALL., affinis DALL. ct inconspicua D.ILL.

\section{NEZARA $A$, et $\mathrm{S}$.}

\section{Hist. des Him. p. 143. (1843).}

Corpus ovale vel obovatum. Caput planum, oratum, apice rotundatum, marginibus lateralibus nonnhil sinuatis, lobo medio percurrente. Rostrum articulo primo bucculas postice haud superante, interdum bucculis nomilil breviore. Antenna articulo primo capitis apicem vix attingente. Thorax marginibus lateralibus anticis raro levissime reflexis rel subcallosis, margine antico inter oculos sinuato, pone oculos utrimque truncato, medio rarissime leviter calloso. Frena ultra medium scutellum continuata. Mesostermum carinatum. Venter basi tuberculatus vel sp̧inosus. "Tibia superne sapissime sulcatie.

a. Corpore virescente, superne interdum pallido-consperso, raro sordide stramineo et rividi-inaculato.

b. Ventre lasi tuberculato.

c. Capite infra maryines laterales ante oculos macula vel lineula nigra destituto; loho medio untrorsum leriter angustato. Aerostermum Fieb. Eur. Hem. p. 79 et 331. (1861).

1. N. incerta Sigs. - Obovata, dilute virescens, supra subtusque dense distincteque punctata; aldominis margine angusto obsolete stramineo-limbato, angulis apicalibus segmentorum apice imo nigris; antennarum articulis duolus apicalibus interdum leviter infuscatis, basi pallidis, secundo tertioque fere aque longis; membrana vitrea. \&. Long. 10, Lat. 6 mill.

Far. a. - Thoracis marginibus lateralibus anticis margineque costali corii sordide stramineis.

lihaphygaster incertu Sigx. Ann. ent. Sér. 3. VIII. p. 935. 8. (1861). 
Far. b. - Thoracis marginibus lateralibus anticis margineque costali anterius sanguineis.

lihaplligaster submaryinatus STAL. Ent. Zeit. XXII. p. 144. 1. (1861).

Patria: var. a. Dalmatia. (Coll. STÅL); Aden Arabir [nec Madigascir]. (Coll. Signoret); var. l. Aegyptus. (Mus. Holm.)

Pentatome Lemuri Donkx, cui est articulus antennarum secundus tertio distinctc brevior, maxime affinis. Antemnarum articuli secundus et tertius longitudine paullo variabiles, subrequilongi, vel secundus tertio nume paullo brevior, nune paullo longior.

cc. Capite infra maryines laterales ante uculos lineula nigra notuto.

Nezura A. et S.; Fieb. Eur. 11em. 1) 78 et 329. (1861).

2. I. viridula LIN. - Subanguste obovata, varicolor, tota dense punctata, carina lata obtusissima ventris levigata; antemnarum articulis tertio apice, quarto quintoque fere totis brunnescentibus; marginibus imis lateralibus anticis thoracis nec non margine ventris pallide substramineis; angulis inis apicalibus segmentorum abdominis maculaque minuta rel lineola inferiore capitis ante oculos nigris. ơ. \&. Long. 12-16, Lat. 6-9 mill.

Rhupligaster prasinus DALL. List of Ilem. I. p. 274. 2. (1851).

Nezara smuragdula Fieb. Eur. Hém. p. 330. 1. (I861).

Var. a. - Virescens, scutello basi punctis quinque pallidis.

Cimex smaragdulus FABR. Ent. syst. IV. P. 109. 114. (1794); WolfF. 1c. Cim. p. 56. 53. fig. 53. (1801); FABR. Syst. Rhyng. p. 167. 61. (1803).

Cimex viridissimus Wolfp. Ic. cim. p. 55. 52. fig. 52. (1801).

Pentutoma unicolor WEstw. in Hope. Cat. of Hem. I. p. 38. (1837).

Pentutoma subsericea WESTw. in Hope. Cat. of Hem. I. p. 38. (1837).

Pentatona le ii Westw. in Hlope. Cat. of Ilem. 1. '’38. (1837). 
Pentatoma 3-punctigera WESTw. in Hope. Cat. of Hem. I. p. 38. (18:37).

Pentatoma proxima Westw. in Hope. Cat. of Hem. I. p. 38. (18:37).

Pentatoma chinensis Westw. in HoPE. Cat. of Hem. I. p. 38. (1837).

Pentatoma chloris Westw. in Hope. Cat. of Hem. I. p. 38. (1837).

Pentatoma propinqua Westw. in Ilope. Cat. of Ilem. I. p. 39. (1837).

Nezara smaragdula A. ct S. Ilist. des Ilém. p. 144. 1. (1843).

Nezara approximata Reiche et FaIRn. Voy. en Alyss. Entom. p. 443. 1. (1847).

Rhaphigaster subsericeus Dall. List of Hem. I. p. 275. 3. (1851).

Var. b. - Virescens, capite thoraceque anterius sordide stramineis; punctis quinque basalibus scutelli pallidis.

Cimex torquatus FABR. Ent. syst. IV. p. 108. 107. (1794); Syst. Rliyng. p. 166. 56. (1803).

Pentatoma Aluricollis P. B. Ins. p. 185. Hém. Pl. I1. fig. 4. $(1805)$.

Rhaphigaster torquatus II. Scir. Wanz. Ins. IV. p. 100. fig. 447. (18:39).

Var. c. - Virescens, supra sordide straminea; maculis duabus basalibus capitis, maculis tribus anterioribus thoracis, maculis tribus anterioribus et apice scutelli nec non macula pone medium hemelytrorum virescentibus.

Cimex viridulus Lix. Syst. nat. Ed. X. I. p. 444. 28. (1758); Mus. Lud. Ulr. p. 172. 6. (1764); Syst. nat. Ed. X1I. p. 721. 39. (1767); Fabr. Ent. syst. IV. p. 109. 110. (1794); Syst. Rhyng. 1. 166. 57. (1803).

Cimer hemichloris Gers. in Silb. Rev. ent. V. p. 166. 94. $(1837)$.

lihaphingaster orbus STÃL. Öfv. Vet. Ak. Förl. 1853. p. 221. 1. 
Patria: Africa tota cum insulis adjacentibus, Europa et $\Lambda$ sia meridionales, Insulæ Indiæ occidentalis, Columbia. (Mus. IIolm.)

Sulcus metastethii ab ostiolio odorifero cxtrorsum ductus brevissimus, subito abbreviatus, marginibus distincte elevatis.

3. N. Capicola Wrstw. - Latiuscule ovalis vel subobovata, dilute virescens, densissime distincteque punctata; maculis tribus vel quinque minutissimis basalibus scutelli pallidis; antennis totis vel apicem versus testaceis, articulis duobus ultimis basi virescentibus. ơ. ㅇ. Long. 12-15, Lat. 8$9 \frac{1}{2}$ mill.

Rhaphigaster capicola DALL. List of IIem. I. p. 276. 5. (1851). V'ar. a. - Totus virescens.

Pentatoma capicola Westw. in Hope. Cat. of Hem. I. p. 39. (18:37).

Pentatoma lata Westw. in Ilope. Cat. of Ilem. I. p. 39. (1837).

Var. b. - Capite thoraceque anterius sordide stramineis.

Pentatoma frontalis Westw. in Hope. Cat. of Hem. I. p. 37. (1837).

Var.c. - Supra flavescens, thoracis maculis anticis, scutelli maculis tribus basalibus apiceque, nec non macula hemelytrorum virescentibus. (sec. Dallas.)

Var. d. - Virescens, supra pallido-conspersa et variegata.

1 Patria: Terra capensis. (Mus. Holm.)

4. N. Dohrni STÅL. - Ovalis, dilute virescens, nitida, minus dense punctata; antennarum articulis tribus ultimis apice infuscatis; capitis margine lineolaque inferiore ante oculos nigris; thoracis marginibus imis lateralibus anticis dilute. fusco-testaceis, margine antico, parte laterali postoculari excepta, distincte calloso, lavi. ․ Long. 11, Lat. 7 mill.

Patria: Calabar. (Coll. Signoretr.)

Distincte et minus dense punctulata, thorace remotius punctato. Antemie articulo tertio secundo dimidio longiore. Thorax punctis hic illic in series transversas dispositis, marginibus lateralibus anticis rectis. Membrana vitrea, immaculata. Venter remote punctulatus, tuberculo basali distincto, liand antrorsum prominulo. 
bb. Fentre lasi distincte spinoso.

d. Thoracis marginilus lateralibus anticis lexiter angustissimergue reflewis, angulis lateralibus obtusiusculis, apice hand vel lerissime rotumlatis.

5. N. pallido-conspersa STÅL. - Obovata, dilute virescens, supra callis parvis albidis conspersa, sat dense distincteque punctata, ventre remote obsoleteque punctulato; marginibus capitis, marginibus lateralilus anticis imis thoracis et costali corii anterius, limbo angusto abdominis maculisque callosis rentris ad spiracula pallide sordide stramineis; articulis tribus ultimis antemnarum apicem versus nee non angulis imis apicalibus segmentorum abdominis nigris; articulo secundo antennarum tertio nonnilhil breviore; ventris spina basali coxas intermedias hand superante. $\sigma^{7}$. f. Long. 12-17, Lat. 710 mill.

Rhaphigaster pallido-conspersus STÄL. Öfv. Vet. Ak. Förh. 1858. p. 4:37. 2.

Nezura flaro-punctata Sign. Ann. ent. Sér. 3. VIII. p. 935. 105. (1861).

Patria: Madigascar. (Coll. $\Lambda$. Domrn, Signoret et Stil.)

6. N. punctato-rugosa STÁL. - Ohovata, sordide virescens, supra dense distincteque subruguloso-punctata callisque minutis conspersa; pectore subtiliter, ventre subtilissime et remote punctatis, hoc aciculato; marginibus superioribus capitis, lateralibus anticis thoracis et costali corii anterius superne sordide sanguineis, subtus nigrris; abdominis limbo lutescente, angulis basalibus et apicalibus segmentorum apice nigris; ventris spina basali coxas intermelias attingente. ㅇ․ Long. 17, Lat. 10 mill.

Rihaphigaster punctato-rugusus STÀL. Öf. Vet. $\Lambda \mathrm{k}$. Förh. 1858. p. 437. 1.

Patria: Calabar. (Coll. A. Dohra et StẢL.)

Antenna exempli descripti mutilate.

7. N. Vieberi S'TaL. - Obovata, sordide virescens, supra distincte et dene punctata; marginilus capitis, marginibus lateralibus 
anticis thoracis et costali hemelytrorum anterius superne dilute subsanguineis; abdominis limbo angusto lutescente, angulis apicalibus segmentorum apice nigris; ventre aciculato, parce obsoletissimeque punctulato, maculis parvis subcallosis spiracula infuscata includentibus, pallidis; antemnarum articulis tribus ultimis apicem versus nigricantibus; spina basali ventris brevi, coxas posticas haud superante. $\sigma$. Long. 15, Lat. 9 mill.

\section{Patria: Gabon. (Coll. Signoret.)}

N. punctato-rugose simillima, supra haud rugulosa, spinagues basali ventris breviore differt. Antennarum articulus tertius secundo vix dimidio longior.

dd. Thoracis marginibus latera'ibus anticis haml retteris.

S. N. 0 Sign. - Latissime ovalis, virescens, dense et sat distincte punctulata; ventre parce distinctissimeque punctato, carina media lata obtusissima levi, spina basali coxas intermedias haud superante; antemis dilute ferrugineo-virescentibus, articulis tribus ultimis apicem versus ferrugineis; marginibus capitis, thoracis abdominisque concoloribus; angulis apicalibus segmentorum abdominis apice imo nigris; antennarum articulo tertio secundo nomihil longiore; thoracis angulis lateralibus distincte rotundatis. o?. Long. 13, Lat. $9 \frac{1}{2}$ mill.

Rhaphigaster O Srgn. in Thoss. Arch. ent. II. p. 289.539. (1858).

Patria: Calabar. (Coll. Signoret.)

9. N. acuta DALL. - Subanguste obovata, dilute virescens, dense punctulata; ventre parce obsoleteque punctulato; marginibus capitis, marginibus lateralibus anticis thoracis et costali hemelytrorum anterius, apice scutelli, limbo angusto abdominis nec non maculis parvis ventris ad spiracula sordide stramineis; articulis tribus ultimis antennarum apicem versus nigro-fuscis; angulis lateralibus thoracis valde acuminatis, productis; spina basali ventris coxas posticas haud superante. ․ Long. 13, Lat. 7 mill. 
Rhaphiyaster acutus DALL. List of IIem. I. p. 277. 9. (1851). Patria: Sierra Leona, Senegal, Zanzibar. (Mus. Holm., Coll. SignORET et StÄL.)

aa. Corpore substramineo, immaculato, vel dilute olivaceovirescente, interdum in mfescentem vergente; marginibus lateralibus anticis thoracis angustissime subtiliterque callosis.

Piezodorus Fıв. Eur. Hem. p. 78 et 329. (1861).

e. Autemarum articulo secundo tertio paullo breviore.

10. N. pallescens Germ. - Obovata, dilute straminea, nitida, punctulata; puncto apicali clavi spiraculisque nigris; carina mesosterni antrorsum sensim altiore, inter coxas anticas lamina instar prominula; spina basali ventris coxas intermedias vix superante; tibiis posticis subcylindricis, nee compressis, nec sulcatis. $\sigma^{7}$. \&. Long. 8-11, Lat. 5! $5-7$ mill.

Cimex pallescens Germ. in Silb. Rev. ent. V. p. 175. 112. (18:37).

Rhaphigaster pallescens II. Scr. W'anz. Ins. VIII. p. 11. (1848). Rhapliqgester flavulus STAL. Öfv. Vet. Ak. Förh. 1853. 1. 221. 4.

Patria: Caffraria. (Mus. Holm.)

Articuli tres ultini antemarum interdum rufescentes.

ce. Articulo antennamem secundo tertio nomithil longiore.

11. N. teretipes Stru. - Ovalis, dilute straminea, distincte punctatia; puncto apieali clavi spiraculisque nigris; tibiis subcylindricis. o'. ‥ Long. 8! $\frac{1}{2}$, Lat. 5 mill.

Patria: Nubia superior. (Mus. Hohm.)

$N$. virescente minor. Subfortiter punctata. Thorax inter angulos litcrales fascia obsoletil, remotius punctata, instructus. Carina stermalis distincta, anterius haud altior, nec inter pedes anticos lamine instar prominula. Spina basalis ventris acuta, coxis posticas land superans. Tibie haud compressa, supra levissime sulcate.

12. N. pura STiL. - Ovalis, straminea, in pallidissime rufescenten vergens, sat distincte punctata, supra fuseo-punctatil; puncto apicali clavi spiraculisque nigris; tibiis presertim posticis, compressis. \&. Long. $8_{2}^{1}$, Lat. 5 mill. 
Rhaphigaster purus STÅL. Öfv. Vet. Ak. Förh. 1853. p. 221. 5 .

\section{Patria: Caffraria. (Mus. Holm.)}

Precedenti valde affinis, minus fortiter punetata. Thorax inter angulos latcrales fascia minus dense punctata instructus. Carina sternalis distincta, anterins haud altior, nec inter pedes anticos lamine instar prominula. Spina basalis ventris acuta, coxas posticas haud superans. Tibie, presertim posticee, compressex, supra levissimc sulcatre.

\section{PLATACANTHA H. SCH.}

Wanz. Ins. VII. p. 124, (1844).

Caput breve, apice late rotundatum, lobis lateralibus apice contiguis; bucculis, præsertim postice, valde elevatis. Antennæ articulo basali capitis apicem haud superante, articulis secundo et tertio subequalibus. Rostrum breve, articulo primo buceulis breviore. Scutellum posterius sat latum, frenis ad medimm vix extensis. Mesosternum obtuse carinatum. Venter basi spina longa validaque armatus. Pedes validi, tibiis superne sulcatis.

1. P. Iutea Westw. - Dilute sordide flarescens, remote punctata; marginibus lateralibus angustis ante medium maculaque parva marginali utrimque pone medium seutelli nee non maculis marginalibus abdominis nigris. ᄋ. Long. 14, Lat. 8 mill.

Rhaphigaster lutens Westw. in Hope. Cat. of IIem. I. p. 31. (1837).

Rhaphigaster transversalis WESTw. in IIOpE. Cat. of Hem. I. p. 31. (1837).

Platacantha cerea II. Scr. Wanz. Ins. VII. p. 124. fig. 740. (1844).

Platacantha lutea DALL. List of IIem. I. p. 355. I. (185̃l). Patria: Africa meridionalis. (Mus. Holm. et Coll. Signoret.)

\section{FLAMINIA STÅL.}

Caput mediocre, ante oculos utrinque sinuațum, apice obtuse rotundatum, lobis æquilongis; bucculis parum elevatis. Rostrum articulo primo buceulas postice haud superante, articulis 
sccundo et tertio subaquilongis. Antenna mediocres, crassiusculie, articulo primo capitis apicem vix attingente, secundo tertio nomnihil breviore. Scutellum retrorsum vix vel parum angustatum, apice latum, frenis medium scutelli haud attingentibus. Mesosternum fortiter carinatum. Metasternum elevatum. Venter basi tuberculo, metasternum tangente, armatus.

1. I. malalensis DALL. - Oralis, flavo-testacea, nitida, supra punctulata, subtus leviuscula; thorace hemelytrisque nigris, illius fascia nomnihil arcuata ante medimn scutelloque stramineis, hoc maculis duabus magnis nigris ornato; tibiis superne late sulcatis. 8 . Long. 8, Lat. 4 mill.

Eysarcoris(?) nutulensis DALL. List of Hem. I. p. 225. 4. (1851).

Patria: Natalia. (Coll. Signoret.)

\section{ANTESTIA S'TÁL.}

Caput plus minus deflexum, immarginatum, lobis æequilongis. Rostrum articulo primo bucculas postice haud superante. Antemne articulo primo capitis apicem hand vel vix attingente, articulo secundo tertio breviore. Thorax marginibus antico et lateralibus anticis distincte reflexis vel callosis, elevatis. Scutellum apice latum vel latiusculum. Mesosternum haud vel leviter carinatum. Venter basi interdum distincte spinosus.

a. Ientris basi nee spinosu nec tuberculutu.

b. Corpore varicolore; thoruce fasciu flurescente destituto; capite nonnilil prolucto, ante oculos utrimune leviter simuato; thoracis marginilus lateralibus anticis subrectis vel rectis, anyulis lateralilus hand prominulis.

c. Abdominis dorso flatescente-sunguineo; ventris margine nigro-maculuts.

1. A. maculata DALL. - Ovalis, griseo-straminea, supra subferrugineo-vel olivaceo-induta et sat dense fusco-punctata, subtus dilute punctata, rentre laviusculo; capite limbisque thoracis antico et lateralibus anticis, exceptis uarginibus imis reflexis, 
nigris vel dense nigro-punctatis, illius lituris nonnullis magnitudine variabilibus levibus; thoracis spatio transverso anteriore, e maculis septem confluentibus comprosita, maculisque quattuor in seriem transversam mediam dispositis, scutelli maculis quinque basalibus levibus, subcallosis, pallidis; membrana sordide hyalina, angulo ipso basali interiore nigricante; abdominis dorso flavescente-sanguineo, connexivo sordide stramineo, nigro-fasciato; femoribus apicem versus macula parva fusca interdum notatis; apice femorum, tibiis tarsisque interdum dilnte subviolaceis; antennarum articulis tribus ultimis, basi excepta, maculisque parvis geminis marginalibus ventris nigris; alis sordide albidis. $\sigma^{7}$. ㅇ. Long. 12, Lat. 7 mill.

Pentatoma maculata DALL. List of Hem. I. p. 241. 19. (1851). Patria: Africa meridionalis occidentalis. (Mus. Holm.)

ec. Abdominis dorso toto vel ad partem nigricante vel obscure violaceo.

d. Tentris margine immaculato vel in angulis basalibus segmentorum maculu nigree notato.

2. A. confusa Sign. - Late ovalis, supra olivacea, distincte et minus dense punctata, subtus cum pedibus rostroque sordide straminea, sat dense distincteque dilute punctulata; antennis nigricantibus, articulo primo toto, apice ipso articulorum secundi, tertii et quarti, hujus etiam basi ipsa olivaceo-albidis; capite parce punctulato, pallide olivaceo-flavescente, basin versus obscuriore, apice olivaceo; thorace ante medium parce punctato, ibidem maculis tribus dilute sordide flavescentibus ornato; scutello ante medium macula majuscula et basi in angulis macula minuta pallidis ornato; hemelytris, parte costali excepta, in subsanguineum rergentibus, maculis compluribus pallidis, levibus, subcallosis conspersis; membrana vitrea, basin versus infuscata; abdominis dorso testaceo-flavescente, regione scutellari nigricante, connexivo pallidiore, in basi segmentorum fusco-macnlato; pedibns pallide 
olivaceo-stramineis; alis subinfuscatis. $\sigma^{7}$. Long. 8, Lat. 5 mill.

Pentatoma confusa Sign. Ann. ent. Sér. 3. VIII. p. 932. I00. (1861).

Patria: Madagascar. (Coll. Signoretr.)

A. variegatee simillima, colore dorsi abdominis, antennisque longioribus et gracilioribus mox distinctit.

3. A. variegata Thunв. - Late ovalis, pallide subolivaceo-straminea, supra minus dense olivaceo- vel nigro-punctata, subtus sapissime palliclior et dilute punctata; capitis lobis lateralibus, thoracis marginibus lateralibus anticis maculaque anteriore, scutelli maculis duabus anterioribus, linea vel litura lavigata media, limbo costali anterius margineque apicali corii lutescentibus; membrana subvitrea, versus angulum basalem interiorem nigro-fusca; abdomine dorso nigro, parte marginali exteriore comexivi segmentorum plus minus late olivaceo-straninea, anterius sæpissime angustiore; antennis nigris, articulis primo, secundo et basi articuli tertii flavovel viridi-olivaceis. $\sigma$. 9 . Long. 8, Lat. 5 mill.

Var. a. - Dilutior, supra olivaceo-punctatal, pictura lutescente thoracis, scutelli coriique hand nigro-cincta; capite nigrobilineato; segmentis ventris latera versus macula transversa lntescente notatis. o?.

Cimex olicacens Thunb. Hem. rostr. cap. II. p. 2. (I822).

Pentatoma orbitalis WEsTW. in HOPE. Cat. of Hem. I. p. 35. (18:37).

Var. b. - Supra nigro- vel fusco-olivaceo-punctata; thoracis lineis quinque longitudinalibus, anterius abbreviatis, liturisque anticis pallidis; scutelli macula magna triangulari, dense nigro-punctata rel siepissime tota nigricante, maculas supra commemoratas lineamque longitudinalem dilute lutescentes includente; corii maculis tribus irregularibus dense nigro-punctatis vel totis nigris; capite vittis duabus mediis pereurrentibus, macula basali utrimque ad oculos ruaculaque obsoletiore loborum 


\section{$-203-$}

Jateralium nigris ornato; scutelli apice pallido vel dilute lutescente, læviusculo. $\sigma^{\top}$. 우.

Cimex variegatus Thunb. Nor. ins. spec. II. p. 48. Tarb. 2. fig. 62. (1783); Hem. rostr. cap. II. p. 3. (1822).

Cimex facetus Germ. in Silb. Rev. ent. V. p. 172. 106. (1837)

Pentatoma variegata DALL. List of Hem. I. p. 253. 52. (1851).

Var. e. - Supra nigra, thorace scutelloque parce punctatis; capitis lobis lateralibus, thoracis macula anteriore, scutelli maculis duabus anterioribus, corii limbo costali anterius, litura diseoidali margineque apicali, nec non femormm apice lutescentibus levibus; capitis lineolis tribus posticis, thoracis marginibus antico et lateralibus anticis, nec non lineis quinque longitudinalibus anterius abbreviatis, scutelli linea media marginibusque lateralibus et apicali eburneis, levibus; subtus cum pedibus olivaceoalbida, pectoris vittis dualus subinterruptis lateralibus, ventris maculis parvis lateralibus in seriem dispositis aliisque marginalibus in angulis basalibus segmentorum positis, nec non fascia pone medium femorum nigris. $\sigma^{2}$.

Pentatoma lineaticollis STȦL. Öfv. Vet. Ak. Förh. 18533. p. 220. I1.

Patria: Terra capensis. (Mus. Holm., Coll. Signonet et STÅL.)

4. A. marginata Sign. - Ovalis, dilute virescens, supra sat dense fusco-punctata, subtus dilute punctata, ventris disco leviusculo; capite dilnte fusco-punctato, posterius læviusculo, lineolis duabus longitudinalibus discoidalibus nec non lineis longitudinalibus quattuor posticis mediis et una obliqua laterali nigris, distincte punctatis; scutelli apice viridi-albido, dilute punctulato; membrana fusca, apicem versus pallidiore; abdominis dorso obscure violaceo, connexivo virescente, intus fusco vel fusco-violaceo-marginato; macula parva segmentorum ventris ante spiracula posita nigricante; alis fuscescentibus. ơ. Q. Long. 9, Lat. $5 \frac{1}{2}$ mill.

Pentatoma marginata Sign. in Thoms. Arch. ent. II. p. 283. 524. (1858). 
Patria: Calabar. (Coll. Sigronet et S'riL.)

Antemne exemplorum descriptorum mutilate.

5. A. rotumbata Sigr. - Subobovata, dilute olivaceo-virescens, supra remote sulfusco-punctulata, sultus dilnte punctulata; corii parte apicali in subsanguineum vergente; membrana levissime infuscata, basin versus nomihil obscuriore; abdominis dorso obscure violaceo vel cæruleo, connexiro extus dilute olivaceo-limbato; maculis minutis quattuor lateralibus pectoris nigris; capite punctis in lineas quattuor ordinatis instructo, lobis lateralibus sat dense punctatis; antennarum articulo secundo tertio breviore, apice articuli tertii articuloque quarto, exeepta basi, nigris; alis leviter infuscatis. o7. Long. $6 \frac{1}{2}$, Lat. 4 mill.

Mormidea rotundata SIGN. in TIIOMS. Arch. ent. II. p. 282. 522. (1858).

Patria: Calabar. (Coll. Sigroret et Stâl.)

Articulus ultimus antemnarum mutilatus.

dd. Ventris nargine nigro-maculato, maculis angulos apicales seymentorum occupantibus.

6. A. Mauritii STẢL. - Obovata, pallide virescens vel olivaceoflavescens, supra minus dense dilute fusco-punctulata, capite dense punctulato; subtus dilute functata, ventris disco levi; thorace posterius corioque, hujus parte costali excepta, interdum in dilute sanguineum vergentibus; membrana alisque decoloribus; abdominis durso, exceptis comnexivo immaculato parteque apicali, pectoris maculis minutis lateralibus quinque, rentris maculis parris marginalibus in angulis apicalibus segmentorum, interdum etiam maculis minutissimis, in series duas liscoidales late distantes dispositis, nigris; antennis a medio articuli tertii dilute flaro rel griseo-testaceis, articulis secundo tertiorque subaqualibus. ơ. . Long. 8, Lat. $4 !$ mill. Pentatoma Mauritii S'TAL. Freg. Eug. Resa. Ins. Hen. p. 227. 20. (1858).

Patria: Insula Mauritii. (Mus. Molm.) 
bb. Corpore supra nigro, thorace flacescente-fusciato.

7. A. inermirentris STẢL. - Ovalis, æneo-nigra, interdum violaceo-incluta; thoracis fascia abbreviata media, marginibus lateralibus anticis angustis et antico latiore, excepta hujus parte laterali postoculari, scutelli margine basali medio, vitta submarginali utrimque laterali a basi ultra medium ducta limboque posteriore, margine imo costali corii, rostro pedibusque sordide stramineis, his fusco-punctatis; antennis, articulis duobus basalibus stramineis exceptis, tarsisque nigris. ơ. 오. Long. $7 \frac{1}{2}$, Lat. 5 mill.

Patria: Rondebosch Africe meridionalis. (Mus. Holm.)

$A$. lineatee et bicincte maxime affinis, ventre inermi distinctissima. Tota sat dense punctulatia. Caput longitrorsum convexiusculum. Thorax marginibus lateralibus anticis leviter rotundatis. Scutellum apice latiusculum. Tenter basi tuberculo obsoleto instructus, vitta indistincta media levigata.

8. A. Sparrmani STẢL. - Ovalis, supra æneo-nigra, sat dense punctata, subtus cum pedibus flavo-testacea, fusco-punctata; thoracis fascia media abbreviata, marginibus antico et lateralibus anticis, scutelli margine toto basali, vitta utrimque laterali intramarginali a basi paullo ultra medium ducta limboque partis apicalis, margine costali angusto corii nec non margine abdominis stramineis, hoc nigro-maculato; antennis flavo-testaceis. ㅇ. Long. 6, Lat. $4 \frac{1}{2}$ mill.

Patria: Terra capensis. (Mus. Holm.)

Præecedenti valde affinis.

aa. Ventre basi distincte spinoso.

e. Corpore sumu nigno, thorace fascia pallicla omato.

9. A. bicincta Gerur. - Ovalis, nigra, sat dense punctata; thoracis fascia abbreviata media, marginibus antico fere toto et lateralibus anticis, scutelli margine basali toto, vitta utrimque laterali intramarginali a basi paullo ultra medium ducta limboque apicali, margine imo costali corii nec non maculis marginalibus abdominis stramineis, lævibus; antennis pedibusque flavo-testaceis, his fusco-punctatis; scutello longiusculo, apice lato. ơ. ㅇ. Long. $7 \frac{1}{2}$, Lilt. 5 mill. 


\section{$-206-$}

Cimex licinctus Germ. in Silb. Rev. ent. V. p. 174, 110. (1837).

Rhaphigaster bicinctus H. ScH. Wanz. Ins. VIII. p. 7 et 9. fig. 785. (1848); DALL. List of IIem. I. 1. 288. 41. (I85I).

Patria: Terra capensis. (Mus. Hulm. et Coll. Signorer.)

10. A. lineata ThunB. - Flavo-testacea, supra obscurior et in olivaceum vergens, dense fusco-punctulata; thorace anterius scutelloque subcupreo-nigris; thoracis marginibus antico et lateralibus anticis nec non fascia abbreviata media, scutelli margine basali, vitta utrimque laterali intramarginali a basi paullo ultra medium ducta nee non limbo apicali, margine imo costali ante medium limboque aldominis stramineis, hoc nigro-maculato; scutello longitudine mediocri, parte apicali latiusculit. ㅇ. Long. T!, Lat. 5 mill.

Cimex lineatus Thunb. IIem. rostr. cap. II. p. 2. (1822).

Cimex divisus Hl. Sch. Wanz. Ins. V. p. 62. fig. 504. (1839).

Rhaphigaster divisus DALL. List of Ilem. I. p. 289. 42. (1851).

Patria: Terra capensis. (Mus. Holm. et Coll. Signoret.)

ee. Thorace fascia pallida lavi destituto.

f. Capite producto, apice rotundato, ante oculos utringue leviter sinuato.

11. A. Ioriventris Germ. - Anguste subobovata, subæneo-nigra, dense punctata; ventris disco lato levigato; thoracis macula maxima triangulari nigro-conspersa, marginibus antico et lateralibus anticis, scutelli maculis nomullis parvis anticis vittisque duabus latis, josterius in unam conjunctis et parce nigro-punctatis, margine costali corii angusto, pectoris maculis ad coxas, abdominis limbo angusto nec non maculis octo ventris discoidalibus, in series duas dispositis, stramineis, levigatis; antennis pedibusque testaceo-flavescentibus; membrana fusea. o'. +. Long. 6:, Lat. 3: mill.

Cimex loriventris Germ. in SILB. Rer, ent. V. p. 173. 109. (18:37). 
Rhaphigaster loriventris H. ScH. Wanz. Ins. VIII. p. 8. fig. 782. (1848); DALL. List of Hem. I. p. 289. 43. (1851).

Patria: Caffraria, Terra capensis. (Mus. IIolm. et Coll. SiGNORET.)

12. A. maculireutris DALL. - Anguste obovata, obscure ænea vel fusco-rnea, densissime punctata, ventris disco magno levi; antennis, marginibus imis lateralibus capitis, maculis parvis levigatis sparsis thoracis, scutelli hemelytrorumque, plus minus confluentibus, marginibus angustis antico et lateralibus anticis thoracis, margine costali corii, maculis pectoris ad coxas, maculis oblongis subconfluentibus marginalibus abdominis, ventris spina basali maculisque sex vel octo discoidalibus, interdum in fascias conjunctis, nec non pedibus testaceo-flavescentibus. $\sigma^{7}$. \&. Long. 7-8, Lat. 3 :-4 mill.

Rhaphigaster maculiventris DALL. List of Hlem I. p. 286. 37. (1851).

Rhaphigaster elongatus SIGN. in THoms. Arch. ent. II. p. 289. 541. (1858).

Rhaphigaster cincticeps STȦL. Öfv. Vet. Ak. Förh. 1858. p. 438. 3.

Patria: Calabar. (Coll. A. Dohrn, Signoret et Stảl.)

13. A. decoritula STÅL. - Ovalis, varicolor, distincte punctata, ventris disco magno lævigato; capitis margine angusto apicali, lobo medio anterius lineolisque duabus basalibus obsoletis, thoracis macula antica, scutelli macula basali media apiceque, corii macula parva pone medium, pectoris maculis ad coxas, ventris spina basali discoque nec nou pedibus, rostro antennisque stramineis, his apicem versus fuscis; macula callosa lævi in angulis basalibus scutelli testacea; thoracis marginibus angustis antico et lateralibus anticis maculaque marginali segmentorum abdominis testaceis vel stramineis; membrana vitrea, medio obsolete fuscescente-fasciata. $\sigma$. ‥ Long. $5:-7$, Lat. $3:-4$ mill. 


\section{- $208-$}

Var. a. - Nigra; thorace hemelytrisque parce stramineoconspersis; scutello macula media indeterminata, retrorsum ramulum emittente, straminea, leviuscula.

lihaphigaster decoratulus STAL. Öfv. Vet. Ak. Förh. 1853. p. 222.6 .

Var. b. - Pallidior, griseo-flavescens, acervatim nigro vel ferrugineo-punctata, ventris lateribus interdum nigris.

lihaphigaster scurrilis STAL. Öfv. Vet. Ak. Förh. 1853. p. 222. 8 .

Patria: Caffraria, Territorium lacus N'Gami. (Mus. Holm.)

A. fluvo-varice Dall. maxime affinis et similis. Sat dense punetata, pictura straminea vel testacea licrigatil. Caput lincolis duabus basalibus apiccque lobi medii levigatis. Thorax marginibus lateralibus anticis levissime rotundatis. Corii pars apicalis semper nigra, macula oblonga parra straminea vel subtestacea medio interrupta. Spina basalis ventris coxas posticas subsuperaus.

14. A. amoena StíL. - Ovalis vel subobovata, nigra vel subrneo-nigra, sat dense punctata, ventris disco maximo lævi; capitis limbo angusto, lineolis duabus basalibus et interdum linea lobi medii, thoracis marginibus antico et lateralibus anticis, maculis distincta antica et quattuor ammularibus pone medium positis, his minus distinetis et nigro-punctatis, sentelli maculis tribus basalibus, una utrimque laterali ante medium, nec non parte apicali, costa maculaque corii pone medium, maculis pectoris ad coxas, limbo antico et postico prostethii, limbo postico metastethii, ablominis limbo, ventris spina basali maculisque discoidalibus, interdum in rittas duas latas confluentibus, stramineis, levibus; antennis, rostro pedibusque flaro-testaceis; abdominis margine nigro-macnlato; pictura straminea pectoris nigro-punctata. o7. . Long. 7, Lat. 4 mill.

R'haphigaster amoenus STẢL. Öfv. Vet. Ak. Förh. 18503. p. 222. 7 .

Patria: Caffraria. (Mns. Holm.)

likething. lythrodi Gens. (II. Scu. Wanz. Ins. fig. 787) inaxime affinis villetur. 
15. A. perpumetata SIGN. - Ovalis, dilute sordide straminea, supra sat dense fusco-punctata, punctis in thorace et scutello in lineolas transversas irregulares sat dense acervatis; thoracis marginibus antico et lateralibus anticis lævibus, his rectis; scutello basi maculis tribus minutis apiceque ipso pallidis, laviusculis; membrana vitrea, angulo ipso basali interiore fuscescente; pectore rentreque remote fusco-punctatis, hujus marginibus lateralibus angustis discoque levibus, hoc ante medium macula pallidissime subferruginea ornato; abdomine dorso concolore, connexivo fusco-maculato; antennarum articulo tertio secundo dimidio longiore; ventris spina basali brevissima; capite lasi lineolis duabus leviusculis notato. ㅇ. Long. $7 \frac{1}{2}$, Lat. $4 \frac{1}{2}$ mill.

Pentatoma perpunctata SIGN. in THoms. Mrch. ent. II. p. 283. 525. (1858).

Patria: Calabar. (Coll. Signoretr.)

16. A. gratiosa STÅL. - Ovalis, pallide flarescens, parce æneofusco-pmnctata; macula basali utrinque laterali capitis, thoracis maculis duabus anticis transversis parteque posteriore, scutelli macula ante medium parteque posteriore ænescentibus; scutello apice pallido-limbato; hemelytris fusco-testaceis, macula magna oblongo-triangulari margineque costali sordide dilute flavescentibus; membrana sordida, angulo basali interiore infuscato; abdomine dorso nigro, connexivi segmentis extus latiuscule sordide flavescente-limbatis; ventris margine immaculato, disco levi, vitta lata nigricante ornato, spina basali pallida, coxas intermedias subattingente; pectoris lateribus fusco-variis, mesosterno nigricante; capitis lobo medio vittulisque duabus posticis, thoracis marginibus antico et lateralibus anticis nec non scutelli margine apicali lævigatis; antennarum articulo secundo tertio vix dimidio breviore; marginibus lateralibus anticis thoracis subrotundatis. ㅇ. Long. 7, Lat. 5 mill. 


\section{Patrial: Calabar. (Coll. Signoretr.)}

Antrunarum articuli duo ultimi mutilati in exemplo descripto.

17. A. rersicolor P. B. - Ovilis, subaneo-nigra, nitida, punctata, rentris disco thoracisque antico levilus, hoc spatiis duobus transversis triangularibus circumpunctatis instructo; eapitis lineis longitudinalibus dualus hrevibus posticis, ma media percurente, una loborum lateralium, maculaque parva laterali ad oculus, thoracis marrinibus antico et lateralibus anticis, linea obliqua intramarginali laterali, maculis duabus minutis ralde distantibus anteriorilus fisciatue indeterminatia, abbreviata et intermpta, ante medium posita, scutelli macula parva basali media, vitta laceratil utrimque laterali intramarginali ante medim posita apiceque, pectoris maculis ad coxas angulisque posticis, nee non marginibus lateralibus segmentorum abdominis spinaque basali rentris stramineis, lievibus; hemelytris griseo-flavestentibus, apicem versus nigris, pone medimm macula minuta levi straminea; membrana sordide straminea; thoracis marginibus lateralibus anticis reatis. or. Long. 6, Lat. 4 mill.

Pentatoma versicolor P. B. Ins. p. 114. Hím. Pl. S. fig. 8. (1805).

Patria: Oware. sec. PALIsot-Beauvols; exemplum typicum, antennis pedibusque destitutum, communicavit amicissimus siGNORET.

18. A. Aranswersa SIGx. - Anguste ovalis, nigra, remote distincteque punctatil, lineis pluribus longitudinalibus capitis, ventris disco thoracisque antico levibus, hoc spratiis duobus transversis triangularibus circumpunctatis; linea longitudinali capitis, thoracis marginibus antico et lateralibus anticis, vitta obliqua laterali intramarginali, maculis tribus parvis anterioribus, media transwersa, nec non fiscia abbreviatil media, cum macula anteriore media coharente, scutelli fascia basali, vitta laterali ante medium apicegue, pectoris maculis ad coxas angulisque posticis, limbo abdominis, maculis ventris octo discoidalibus spinaque basali, antennis, rostro, pedibus he- 
melytrisque stramineis, his posterits nigris; membrana vitrea; pistura flara capitis thoracisque levi, scutelli parce nigro-punctata; thoracis marginibus lateralibus anticis rectis.

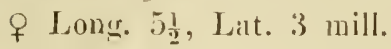

Rhapliquater transeprsus Sign. Amm. ent. Sír. 3. VIII. p. 936. 109. (1861).

Patria: Madagascar. (Coll. Signoret.)

ff. Capite brevissimo, inter oculos obtuse rotundato; thoracis marginilus lateralibus antiris rotumlatis.

19. A. parrula Sign. - Late ovalis, nigra, nitida, punctata, thorace anterius discoque rentris lavibus; capitis margine, thoracis marginibus angustis antico et lateralibus anticis, macula antica maculisque nomullis mediis in seriem transversam dispositis, scutelli macula parva basali medis, macula oblonga subeurvata utrimpue laterali ante medium posita nee nom limbo fusteriore, margine costali corii, pectoris maculis ad coxas, macula transversa laterali basali prostethii, margine angusto ablominis, antennis, rostro pedibusque sordide stramineis. ․ Long. 7 , Lat. 5 mill.

Rhaphigaster parulus Sign. in THons. Arch. ent. H. p. 289. 540. (18:58).

Patrial: Calabar. (Coll. Signonet.)

\section{DINIDOR LATR.}

kigne an. V. p. 195. (1829).

Cyclopelır A. et S. Hist. des Hém. p. 172. (1843).

Corpus ovale vel ovatum. Caput foliacem, parviusculum, lobis lateralibus loho medio paullo longioribus; bucculis valde elevatis, subfoliaceis. Rostrum ad pedes intermedios extensum, articulo primo buceulas superante. Antennæ quadriarticulatæ, articulo primo capitis apicem subsuperante. Thorax angulis lateralibus haud prominulis, obtusis. Scutellum parte apicali lata, apice rotundata; frenis ad vel paullo ultra medium scutelli extensis. Membrana reticulata. Sterna leviter sulcata. Venter basi inermis. Pedes validinsculi. 
1. I. funebris FARR. - Suhovatus, niger, supra subtiliter denseque ruguloso-punctulatus, subtus aciculato-punctulatus, ventris disco paree punctulato. $\sigma^{7}$. Long. 15, Lat. 9 mill.

Cimex funebris Fabk. Ent. syst. IV. 1. 116. 142. (I794); Syst. Rliyng. p. I71. 89. (180:3).

Patria: Guinea lusitanica. (Coll. SIgNonkt.)

Statura D. obseuri, sed nomilill latior, capite breviore, antennis gracilioribus. Caput subsenicirculare, lobis lateralibus apjice contiguis. Oenli breviter stylati. Antemine articulis secundo et tertio leviter compressis, secundo tertio fire plus dimiclio longiore, appicali secundo subbreviore. Thorax marginibus lateralibus explanatis, angoustissime reflexis, distincte rotmudatis. Tenet membrane obsolete. Sternia distincte sulcatil. Femora anteriora biseriatim spimulosa, postica apricem versus spimulis nomullis obsoletis armata. Scgmentum anale maris obtuse rotundatum, apice medio vix emarginatum.

2. I. tristis STẢL. - Subovatus, sulıcupreo-niger, pedibus flavotestaceis. q. Long. 16, Lat. 10 mill.

Patria: Calabar. (Coll. Signoret.)

Pracedenti maxime affinis, an rjus varictils feminea? differt tantum colore pedum, lobis capitis acpue longis, lateralibus totis distantibus, tibiisçue posticis subtus, parte apicali excepta, levissime ampliatis.

\section{ASPONGOPUS LAP.}

Ess. Hém. p. ڤึ. (183:).

Corpus orale rel ovatum. Caput parviusculum, subfoliacenm, lobis lateralibus lobo medio interdum paullo longioribus; bucculis ralde elevatis, foliaceis, subsemicircularibus. Rostrum fere ad coxas intermedias extensum, articulo primo buceulas superante. Antenna quinquearticulate. Thorax angulis lateralibus haud prominentibus, obtusis. Sentellum parte apicali lata; frenis ad rel paullo ultra merlium scutelli extensis. Membrana venis plus minus anastomosantibus. Venter basi inermis. Pedes validi, femoribus sape spinulosis.

a. Corii margine apicali toto sulvecto el latissime rotundato. Spongopodium Sprx. Ess. Hém. p. 305. (1840). Peltugopus Sign. Ann. ent. Siér. 3. VIII. p. 936. (1861). 
b. Antennarum articulo secundo brevissimo.

1. A. patruelis STAL. - Rufo-ferrugineus, subnitidus; antennis, capite, limbis lateralibus anticis indeterminatis thoracis, parte augusta costali hemelytrorum, macula irregulari laterali pectoris pedibusque nigris; articulo ultimo antennarum, basi excepta, nec non apice scutelli ferrugineo-flavescentibus; membrana nigro-fusca; angulis lateralibus thoracis dilutius ferrugineis. o?. Long. 15, Lat. 10 mill.

Cyclopelta patruelis STÂL. Öfv. Vet. Ak. Förl. 1853. 1. 223. 1.

Patria: Caffraria. (Mus. Ilolm.)

Supra dense distincteque, hemelytris subtiliter, ruguloso-punctulatus. Caput marginibus lateralibus medio leviter sinuatis. Antenne articulis tertio et quarto compressis, parum dilatatis, haud sulcatis, tertio apicali panllo breviore et quarto distincte longiore, quarto tertio paullo latiore, Thorax marginibus lateralibus anticis distincte rotundatis, haud reflexis. Tenter remote granulatus. Femora subtus biseriatim spinulosa, spinnlis apicalibus distinctis.

bb. Antennarum articulo secundo elongato; membrana basi areolis nonullis, venas longitudinales subsimplices vel nonnitil furcatas emittentibus, instructa.

c. Capitis marginibus lateralibus distincte sinuatis.

d. Oculis haud vel vix stylatis; corpore ovali; capite apice sulinciso, marginilus lateralibus leviter sinuatis, lobis lateralibus apice obtuse rotundatis, antice contiguis; antennarum articulo secundo tertio dimidio vel tertia parte longiore, quarto nonnihil compresso et ampliato, subsulcato; thorace marginilus lateralibus anticis vix vel parum rotundatis, angustissime reflexis; femorilus subtus vix vel obsolete spinulosis; tibiis posticis jeminamm, basi parteque apicali exceptis, supra subtusque dilatatis, parte dilatata intus distincte excavata.

2. A. castaneus SIGN. - Dilute castaneus, subcupreo-nitens, supra sat dense distincteque punctatus, vix rugulosus, subtus subtiliter rugulosus; antennis nigris, articulo ultimo, basi excepta, sordide flavescente. ㅇ․ Long. 17, Lat. $10_{2}^{1}$ mill. 
Asponyopus custaneus Sign. Alll, ent. Sér. 3. VIII. 1. 937. 111. (1861).

Patria: Madagascar. (Coll. SigroRET.)

3. 1. remipes STALl - Niger, nitidulus, subtus cum pedibus subcupreo-nitens, dense subtiliterque ruguloso-punctulatus; sentello ajicem rersus distincte punctato; ventris disco læriusculo, subaciculato, vix punctato; antennarum alrticulo secundo et tertio ad unum quarto sublongiore, secundo tertio vix duplo longiore. f. Long. 17, Lat. 10 mill.

Aspongopus remipes STAL. Öfr. Tet. Ak. Förh. 1858. p. 438. 1 .

Patria: Calabar. (Coll. A. Dohrs, Sigronet et StäL.)

4. A. xanthopterus FAIRM. - Niger, subtus rnescente-tinctus, densissime subtiliterque ruguloso-punctulatus, rentris disco laviuseulo, aciculato; hemelytris castancis, antennarum articulis secundo et tertio ad unum quartó subbreviore, secundo tertio vix plus quam dimidio longiore. ㅇ. Long. 17, Lat. 10 mill.

Aspongopus ranthopterus FAIRM. in THoms. Arch. ent. II. p. 29I. 546. (1858).

Patria: Gabon. (Coll. Sigroret.)

Pracedenti maxime affinis, an cjus varietas?

5. A. sepuleralis STÄL. - Fusco-cupreus, densissime subtiliterque ruguloso-punctulatus; ventris diseo punctulato; membrana obseure ochracea; antemis articulis secundo et tertio ad. unum quarto vix longioribus, secundo tertio dinidio $(\sigma)$ vel tertia parte (q) longiore. o’. q. Long. 15, Lit. 9 mill.

Patrial: Grand Bassam. (Coll. Signonet.)

lreecedentibus duobus maxime affinis et simillimus, minor, an distinctus?

dd. Oculis distincte stylatis; corpore orali; capite transverso, apice distincte inciso, marginibus lateralilus sat profunde sinuatis, lobis lateralibus antice contiguis vel subcontignis; thorace marginibus lateralibus angustissime reflexis; femoribus anterioribus 
subtus apicem versus distincte, posticis obsoletius spinosis; seymento anali marium apice sinuato.

e. Antenis longioribus, articulo secundo tertio longiore, quarto subcompresso et subsulcato; tibiis posticis feninarum, basi parteque apicali exceptis, supra subtusque dilatatis, parte dilatata intus excavata.

6. A. limbatus SiGN. - Aenescente-niger, subtiliter densissimeque ruguloso-punctulatus, ventris disco magno limboque lavibus; rostro, limbis latis lateralibus anticis thoracis, limbo costali hemelytrorum ultra medium, limbis lateralibus prostethii et omni libero ventris, dorso abdominis, coxis, trochanteribus femoribusque sordide flarescentibus; apice femorum maculaque postica dorsi abdominis nigris. o’. ㅇ. Long. 11-12!, Lat. $7-7 \frac{1}{2}$ mill.

Asponyopus limbatus Sign. Rev. et Mag. Zool. 1851. p. 445. 10. Pl. 12. fig. 4 .

Patria: Calabar, Galbon. (Coll. Signoret et S'TẢL.)

7. A. femoralis StÅL - Niger, cupreo vel æneo-subnitens, densissime subtiliterque ruguloso-punctulatus, rentris disco lævigato; rostro, lorso abdominis, exceptis limbo maculaque postica, coxis, trochanteribus femoribusque, apice excepto, flarotestaceis; alis surdide flavescentibus, apice fuscis. or. Long. 11, Lat. 7 mill.

Patria: Grand Bassam Guiner. (Coll. Signoret.)

A. limbati maxime affinis, exceptis coloribus vix differt. Antenna articulo tertio seeundo circiter duplo longiore. Thorax marginibus lateralibus anticis fere rectis, angustissime reflexis.

ee. Antennis brevioribus, articulis secundo et tertio ceque longis,

8. A. pullus STAiL. - Suboratus, obscure rufo-piceus, subtus cum antennis, bucculis, rostro pedibusque pallidior; apice capitis, limbis lateralibus anticis thoracis, macula minuta basali parteque vix dimidia apicali scutelli, corii limbo costali angusto paullo ultra medium nec non limbis lateralibus prostethii ventrisque testaceo-flavis, hujus segmentis in an- 
gulis basalibus macula minutissima nigra notatis. o?. Long. 12, Lat. 7 mill.

Aspongopus pullus STÅ. Öfv. Vet. Ak. Förh. 1853. p. 223. 4. Patria: Caffraria. (Mus. Holm.)

Sat dense distincteque punctulatus, ventris medio leviusculo, hemelytris subtilissime ruguloso-punctulatis. Caput postice vix convexum, lobis lateralibus lobo medio longioribus, apice subcontiguis. Antemixe articulo quarto vix dilatato, tertio quartoque levissime sulcatis. Thorax marginibus lateralibus anticis leviter angusteque reflexis, antice parmm rotundatis. Scutclli pars postica fluva minus densc punctata. Membrana griseo-livida, basin versus brunnescente, venis minus distinctis.

cc. Capitis marginibus lateralibus haud vel rix sinuatis; segmento anali marium apice medio hand vel vix sinuato.

f. Capite apice distincte inciso; thoracis marginibus lateralibus concoloribus; tibiis posticis sexuun conformious.

9. A. viduatus FABR. - Subovalis, nigricans vel ferrugineo-fuscus, supra varicolor; alis obscure fuscis, basi sordide flavescentibus. ơ. Long. 15-17, Lat. 8-9! mill.

Var. a. - Nigricans, unicolor.

Pentatona nigro-riolacea P. B. Ins. p. 83. 11em. Pl. 7. fig. 4. (I805).

Aspongopus unicolor H. SCII. Wanz. Ins. IV. p. 93. fig. 433. (1839).

Dinidor unicolor. II. SCH. Wanz. Ins. VII. p. 76. (1844).

Aspongopus niger Fieb. Eur. ILem. p. 330. (1861).

Var. b. - Ferrugineo-fuscus, menbrana nigricante.

Var. c. - Nigricans; thorace, scutello parteque coriacea hemelytrorum subferrugineo-flavescentibus, maculis duabus anticis triangularibus thoracis nigris; corio interdum vitta vel macula posteriore fusca ornato.

Cimex viduatus FABR. Ent. syst. IV. p. 117. 145. (1794).

Edessa viduata FABR. Syst. Rhyng. p. 153. 38. (1803).

Aspongopus melanopterus H. SCH. Wanz. Ins. V'II. p. 78. fig. 746 . (184t).

Aspongopus viduatus DaLL. List of Hem. I. p. 348. 2. (1851). 
Patria: var. $a$ et $\ell$. Guinea, Nubia, Syria, Turcia; var. c. Caffraria, Senegal, Nubia. (Mus. IIolm., Coll. Signoret et Stilu.)

ff. Capite apice vix inciso; thoracis marginibus lateralibus anticis flavescentibus.

Peltagopus Sign. Ann. ent. Sér. 3. VIII. p. 936. (1861).

10. A. llavo-marginatus Sign. - Ovatus, niger, subcupreo-indutus; apice scutelli, hemelytris ventreque obscure ferrugineis; abdominis limbo nigro; limbis latis lateralibus anticis thoracis, limbo costali liemelytrorum ad basin, limbo laterali prostethii maculisque magnis quinque limbi lateralis abdominis subferrugineo-flavis. $\sigma^{7}$. Long. 25, Lat. 18 mill.

Peltagopus flavomarginatus Sign. Amn. ent. Sér. 3. VIII. p. 936. 110. Pl. 13. fig. 7. (1861).

\section{Patria: Madagascar. (Coll. Sigronet et StåL.)}

Densissime subtiliterque ruguloso-punctulatns, ventris disco distincte et minus dense vermicellato-aciculato; hemelytris opacis. Caput apice rotundatum, integrum. Antennae articulo secundo et tertio subeylindricis, vix depressis, illo hoc nonnilhil longiore. Thorax apice transversim leviter impressus, marginibus lateralibus distincte rotundatis, nounihil explanatis, latiuscule reflexis. Antennæe exempli descripti mutilatie.

11. 1. rotuudatus Sign. - Ovatus, cuprescente-niger, subnitidus, capite, thorace scutelloque subtilissime denseque rugulosopunctulatis; hemelytris opacis, vix rugulosis; ventre aciculato, disco levi; marginibus lateralibus anticis thoracis, margine costali corii basin versus, marginibus lateralibus prostethii maculaque parva marginali media transversa segmentorum abdominis subferrugineo-flavescentibus. $\sigma^{7}$. Long. 13, Lat. 8 mill. Asponogopus rotundatus Sign. in MAILlard. Notes sur l'ile de la Réun. Ins. p. 26.

Patria: Insula Bourbon [Ile de la Réunion]. (Coll. Signoret.)

A. Aavo-marginato simillimus quoad staturam coloresque, multo minor, supra minus convexus, articulo secundo antennarum tertio subbreviore, thoracis marginibus lateralibus anticis multo angustius reflexis, rectis, non nisi anterius levissime rotundatis, multo minus late flavescentibus, differt. Antennarum articuli duo ultimi in exemplo descripto mutilati. 
aa. Dimidio interiore maryinis apiculis corii sinuato, dimilio exteriore rotundato; capitis lobis lateralibus lobo medio longioribus et anterins.s contignis, marginibus lateralibus nonnihil sinuatis; bucculis valde elevatis, semicircularibus; oculis sessitibus; membrana, saltem basin versus, venulis transversis compluribus instructa: tiliis posticis simplicibus.

Amacosia SPIN. Gen. d'ins. artr. p. 118. (1852).

g. Antennis bicoloribus; margine apicali corii levissime curvato.

12. A. mysticus STiL. - Obscure fusco-cupreus, antenuarum articulis duobus ultimis ferrugineo-flavis; membrana livida, disco fusco-venosa et interdum infuscata. ․ Long. 21, Lat. 12 ! mill.

Patria: Caffraria. (Mus. Holm.)

A. mubilo affinis, latior, obscurior, distincte eupreo-indutus, scutelli parte apicali latiore, leviter transversa, distinctus. Antemua articulo secundo tertio dimidio longiore, ambobus nonnihil depressis, quarto reliquis latiore, secundo longiore. Thorax et seutchlum transversim distincte rugosa ct preterea sat dense ruguloso-punctulata, illins marginibus latcralibus anticis levissime rotundatis, angustissime reflexis. Hemelytra subtiliter ruguloso-punctulata, membrana renulis transversis sparsis sat numerosis. Subtus rermicellato-rugulosus. Femora subtus utrimque subtilissime, apicem rersus distinctius spinulosa.

13. A. mubilus WFstw. - Plus minus obscure ferrugineus, interdum sulempreo-fuscus, pedibus antemnisque nigricantibus, harum articulis duobus ultimis ferrugineo-flavis; membrana. varicolore. ' $\sigma^{7}$. ․ Long. 15-21, Lat. 9!-12 mill.

Var. a. - Membrana nigricante, basi plus minus late flavolivida vel ibidem maculis nomullis vel unica flavo-lividis notata. Aspongopus mubilus Westw. in Hopk. Cat. of Ilem. I. p. 25. (1837); DALI. List of 1lem. 1. p. 350. 12. (1851). Aspongopus erythocerus GERs. in SILB. Rev. ent. V. p. lï8. 82. (1837).

Aspongopus monachus STAL. Öfr. Vet. Ak. Förh. 1853. ए. 223. 1.

Var. $b$. - Membrana livida, renis leviter infuscatis. 
Amacosia Delegorguei SPIN. Gen. d’ins. artr. p. I18. (1852). Aspongopus sutor S'TÅ. Öfv. Vet. Ak. Förh. 1853. p. 223. 2.

Patria: Africa anstralis, Caffraria, Swakop, N'Gami, Mozambique. (Mus. Holm., Coll. A. Dohrs, Signoret et Stål.)

Ovalis, supra distincte subacervatim punctatus, transversim subrugosus, hemelytris subtiliter ruguloso-punctulatis. Antemna articulis secundo, tertio et quarto depressis, lioc latiore et sulcato, illorum longitudine relativa paullo variabili, secundo tertio tamen semper longiore. Pectoris macula lateralis nigrieans, distincte vermicellatorugosa. Venter subtiliter vermicellato-rugulosus, disco mims dense rugulosus et subpunctatus.

gg. Antennis unicoloribus; margine apicali corii ut littera $S$ distinctius currato.

14. A. Sartor StÅL. - Ferrugineus, membrana livida; antennis dilute rufo-ferrugineis, basin versus nomilnil obscurioribus. ‥ Long. 19, Lat. 11 mill.

Aspongopus sartor STiL. Öfv. Vet. Ak. Fürh. 18533. p. 223.3. Patria: Caffraria. (Mus. Holm.)

Subovatus, subtilissime obsoleteque rugulosus, thorace scutelloque pratcrea transversim subrugosis. Antennac breviusculic, articulis sceundo, tertio quartoque depressis, sensim latioribus, secundo tertio paullo longiore. Thorax marginibus laterilibus anticis levissime rotundatis, angustissime reflexis. Membrana venulis transversis numerosis. Femora posteriora apicem versus spinulosa.

\section{Subf. ACANTIOOSOMIDA STAL.}

Conspectus generum.

I (2). Ventre stemisque sulcatis; capite thorace longiore, bucculis vix elevatis; ocellis inter se quam ab oculis paullo longius remotis; rostro longo; antennis quadriarticulatis, articulo primo capitis apicem paullo superante, secundo longissino; scutello equilatero; hemelytris conjunctim retrorsum sat angustatis; membrana reticulata. - Sangarius STÅL.

2 (1). Ventre sternisque omnibus haud sulcatis; antennis quinquearticulatis. 
3 (12). Mesosterno haud vel leviter carinato.

4 (9). Margine antico prostethii recto; prosterno liaud vel levissime sulcato.

5 (6). Articulo primo rostri bueculis fere rque longo, antennis filiformibus. - Anubis STÅ.

6 (5). Articulo primo rostri bncculis breviore.

7 (8). Antennis filiformibus. - Rhopalomorpha DALL.

8 (7). Antennis apicem versus incrassatis. - Anischys Dall.

9 (4). Prosterno sulcato, sulci marginibus elevatis.

10 (11). Capite triangulari, marginibus lateralibus subrectis, lobis lateralibns lobo medio subbrevioribus; angulis anticis thoracis liaud lobatis. - Duadicus DALL.

11 (10). Capite apice obtuso, marginibus lateralibus profunde sinuatis, lobis lateralibus lobo medio longioribus, anterius contiguis; angulis anticis thoracis lobatis. $-\mathrm{Pa}$ natius STAL.

12 (3). Mesosterno carina altissima, laminiformi, instructo.

13 (20). Marginibus lateralibus posticis thoracis nec dilatatis, nec retrorsum leviter produetis.

14 (15). Antennarum artieulo basali capitis apicem haud superante; margine apicali corii apicem versus rotundato. Cyphostethus FIEB.

15 (14). Antennarum articulo basali capitis apicem superante; margine apicali eorii recto.

16 (17). Antennarum articulo secundo tertio breviore; lamina mesosternali retrorsum haud producta. - Sastragala A. et $\mathrm{S}$.

17 (16). Antennarum articulo secundo tertio longiore.

18 (19). Lamina mesosterni retrorsm haud producta. - Acanthosoma Curtis.

19 (18). Lamina mesosterni retrorsum producta. - Elasmostethus Fieb.

20 (13). Marginibus lateralibus posticis thoracis leviter dilatatis et depressis; lamina mesusterni retrorsum producta. Elasmucha STTÂL. 
Genus unicum africanum hujus subfamiliæ mihi est cognitum.

\section{ANUBIS STÅL.}

Corpus subtus inodice convexum. Caput planum, antrorsum angustatum, apice rotundatum, marginibus lateralibus basin versus leviter sinuatis; tuberculis antemniferis a supero distinguendis; bucculis percurrentibus. Antenne filiformes, apicem versus haud vel vix incrassatæ, articulo primo capitis apicem superante, secuncto tertio longiore. Rostrum mediocre, articulo primo bucculas postice requante. Scutellum triangulare, clavo haud vel vix longius, apice valde angustum et leviter prodnctum; frenis fere ad apicem scutelli extensis. Membranæ venæ simplices. Prosternum simplex. Mesosternum leviter carinatum, carina anterius altiore. Venter segmento basali spina armato. Tibire cylindricx, hand sulcatæ.

a. Corpore ovali; thoracis marginilus lateralibns acutis, explanatis, levissime rotundatis.

1. A. sparsus GERM. - Pallide sordide stramineus, fusco-ferrugineo-punctulatus; antennis in flavo-testaceum vergentibus, articulis tertio et quarto apice nec non quinto, basi excepta, nigris; thoracis scutellique linea media percurrente, illius etiam marginibus imis lateralibus anticis impunctatis; hemelytris, interdum etiam thorace, hujus saltem marginibus lateralibus, parce nigro-conspersis; maculis duabus subbasalibus mediis scutelli, macula minuta utrimque laterali antica metastethii nec non maculis minutis marginalibus connexivi ventrisque, angulos segmentorum occupantibus, nigris; membrana griseo-albida, pallide fusco-conspersa; pedibus impunctatis. ○7. ㅇ. Long. 9-10, Lat. 5-5 mill.

Cimex sparsus Germ. in Silb. Rev. ent. V. p. 174. 111. (1837).

Rhaphigaster sparsus H. SCH. Wanz. Ins. VIII. p. 7 et 10. fig. 786. (1848).

Anischys sparsus DaLl. List of Hem. I. p. 292. 1. (1851). 
Rhapligaster fusco-sparsus STiL. Öfr. Vet. Ak. Förh. 18\%3. p. 221. 3.

Patriat: Terra capensis. (Mus. IIolm. et Coll. SigNorbis.)

aa. Corpore subungnste obocato; thoracis maryinilnes lateralibus anticis haud explanatis, rectis.

2. A. fusro-irroratus StåL. - Sordide albido-stramineus, sujra sat dense distincteque nigro-punctatus et remote fusco-conspersus, subtus minus dense fusco-ferrugineo-punctatus, ventris disco, linea media pereurrente thoracis scutellique, hujus etiam apice levibus; antennis in pallide testaceum rergentibus, articulis tertio, quarto et quinto pone medium fuscis vel nigris; marginibus lateralibus anticis thoracis et costali corii immaculatis, illis angustissime levigatis et subcallosis; scutello prope basin medio fusco-bimaculato; membrana griseo-hyalina, fusco-conspersa; matula parva utrimq̣ue laterali ad marginem anticum metastethii nigra; comnexivo nigromaculato; pedibus impunctatis, immaculatis; spina basali ventris fere al coxas anticas preducta; loho medio capitis apicem versus vix ampliato. $\sigma^{7}$. ․ Long. 9-11! Lat. j-6 mill.

Rhapligaster fusco-irroratus STÁL. Öfr. Tet. Ak. Förh. 185.3. p. 221. 2.

Patria: Caffraria. (Mus. Hohn.)

3. A. Lugubris Tнсхв. - Sordicle pallide stramineus, supra distincte nigro vel ferrugineo-fusco-punctatus et farce nigroconspersus, subtus rentote ferrugine(n-punctulatus; ventris disco lineaque medial pereurente thoracis scutellique lacribus; maymibus literalibus anticis thoracis nee non margine costali corii nigro-conspersis; membrana sordicle hyalina, fuscoconspersa; macula parvia utrimque laterali ad milrginem anticum metastethii, angulis apicalibus scgmentorum connexivi rentrisque nigris; pedibus impunctatis, femoribus ajicem rersus macula parva fusea notatis; capitis lobo medio antrorsum sensim nonnilhil ampliato. or. q. Long. 9-10! Lat. $5-5 !+11111$. 
Cimex lugubris Thunb. Hem. rostr. cap. II. p. 2. (1822). Acanthosoma impluviata Germ. in Silb. Rev. ent. V. p. 182. 124. (18:37).

Rhaphigaster impluviatus II. SCH. Wanz. Ins. VIII. p. 7 et 9. fig. 784. (1848); DALL. List of Hem. 1. 1. 289. 44. (1851). Patria: Terra capensis. (Mus. Holm.)

A. fusco-irrorato simillimns, marginibus lateralibus anticis thoracis et costali corii nigro-conspersis, scutello basin versus maculis nigris destitnto, nee non lobo nedio capitis introrsum ampliato differt.

\section{Subf. TESSARATOMIDA STRL.}

Conspectus generum.

1 (42). Tarsis triarticulatis.

2 (3). Rostro longo, gracili, pone coxas posticas producto; antennis gracilibus, quinquearticulatis, articulo primo incrassato; margine apicali corii recto, sutura clivi breviore; stemis basique rentris inermibus. - Sepina Sign.

3 (2). Rostro coxis intermedias haud superante.

4 (19). Margine apicali corii plus minus distincte sinuato vel curvato; venis longitudinalibus membranæ e rena basali transversa emissis; scutello longiore quam latiore.

5 (18). Scutelli apice integro.

6 (9). Ventris basi inermi, nec spinosa, nec tulerculato-elevata.

7 (8). Antennis quinquearticulatis. - Oncoscelis WEstw.

8 (7). Antennis quadriarticulatis. - Stilida STÁL.

9 (6). Ventre basi spinosa, tuberculata vel elevata, parte elevata metasternum elevatum tangente.

10 (17). Ventris basi spina antrorsum producta armato; sternis haud elevatis; thorace postice leviter producto.

II (14). Antemnis quadriarticulatis; tibiis posticis femoribus multo brevioribus.

12 (13). Ocellis ab oculis et inter se fere æeque longe remotis, pone lineam fictam, inter basin oculorum ductam, positis. - Oncomeris LAP. 
13 (12). Ocellis inter se quam ab oculis multo longius remotis, in linea ficta inter basin oculorum ducta positis. Plisthenes StÅL.

14 (11). Antennis quinquearticulatis.

15 (16). Capite haud longiore quam inter oculos latiore; antennarum articulo primo capjitis apicem nonnihil superante; seutello apice acuto. - Lyramorpha WEsTW.

16 (15). Capite longo, articulo basali antennarum capitis apicem haud superante; scutelli apice rotundato. - Arona STTÁL.

17 (10). Ventris basi elevata et basin metasterni valde elevati, antrorsum compresso-producti, tangente; antennis quinque-articulatis; thorace postice sat producto. - Piezostermum A. et. S.

18 (5). Scutello apice emarginato. - Agapophyta Gúkr.

19 (4) Margine apicali corii fere recto vel subrotundato; membrana basi areolis pluribus, venas longitudinales emittentibus, instructa; scutello sæpissime æquilatero; antennis quadriarticulatis; alis hamo sæpissime instructis.

20 (41). Abdominis segmentis utrimque simplicibus, nec acute bilobatis.

21 (30). Metasterno valde elevato et antrorsum sat longe libere producto; scutello pone frena acute vel spatulato-producto.

22 (29). Thorace postice truncito.

23 (26). Thorace basi retrorsum longe producto; metasterni parte producta carinam mesosterni tangente.

24 (25). Scutello ipice acuto, longe producto; mesosterno alte carinato; metasterui parte producta ante coxas anticas extensa, apicem versus oblique descendente. - Mucamum A. et S.

25 (24). Scutello apice obtusiusculo, minus longe producto; mesosterno leviter carinato; metasterni parte producta ad coxas anticas extensa. - Tessaratoma LEP. et SERv.

26 (23). Thorace postice levissime producto. 
27 (28). Metasterni parte antica producta ad vel inter coxas anticas extensa, carinam mesosterni subtangent 8 ; capite majusculo. - Siphnus STÅL.

28 (27). Metasterni parte producta longissima, ante coxas anticas extensa, carinam mesosterni haud tangente, oblique descendente; capite parviusculo. - Hypencha A. et S.

29 (22). Thorace postice rotundato-producto; hamo alarum nullo vel obsoleto. - Pygoplatys DaLL.

30 (21). Metasterno interdum nonnilil elevato, antrorsum tamen haud libere producto; scutello apice pone frena vix vel levissime producto.

31 (34). Metasterno nonnihil elevato, postice nunc truncato, nunc subacuminato; segmento secundo rentris basi medio sxpissime elevato et medium segmenti basalis occultante.

32 (33). Femoribus marium incrassatis, ante medium rel prope basin spina valida armatis. - Eusthenes DALL.

33 (32). Femoribus posticis sexuum conformibus, apud marem nec incrassatis, nec spina valida armatis. - Mattiphus A. et S.

34 (31). Metasterno haud vel vix elevato; medio segmenti primi ventris distinguendo, segmento secundo basi medio haud elevato.

35 (36). Femoribus marium sat incrassatis, ante nedium spina valida armatis. - Eurostus DALL.

36 (35). Femoribus marium haud rel leviter incrassatis, spina magna ante médium subtus destitutis.

37 (38). Tibiis posticis leviter curvatis et femoribus brevioribus, his nonnihil incrassatis. - Virbius STẢL.

38 (37). Tibiis posticis rectis, femoribus æque longis vel brevioribus.

39 (40). Capitis marginibus lateralibus rectis. - Pycanum A. et S. 40 (39). Capitis marginibus lateralibus sinuatis. - Dalcantha A. et $\mathrm{S}$.

41 (20). Abdominis segmentis utrimque acute bilobatis. - Prionogaster STÅL. 
42 (1). Tarsis biarticulatis.

43 (44). Metastemo valde elevato, convexo, antice leviter producto, postice pro receptione tuberculi basalis ventris excavato. - Haplosternce STiL.

44 (43). Metastemo cruciatim elevato, parte elevata excavata; margine costali corii anterius angulato. - Cyclogaster W ENTW.

\section{SEPINA SIGN.}

Ann. ent. Sćr. 3. VIII. p. 980, (18fi1).

Corpus anguste ovale vel suboblongum. Caput mediocre, lobis aque longis, marginibus lateralibus prope oculos sinuatis; bucculis basin capitis subattingentibus, antice sat eleratis et angulum formantibus, retrorsum sensim altitudine decrescentibus. Ocelli in linea ficta, inter basin oculorm ducta, positi, inter se quam ab oculis ter longius remoti. Rostrum longiusculum, pone coxas posticas productum, gracile, articulo primo coxas anticas attingente, secundo apicalibus duobus al unum breviore. Antemie quinquearticulatie, graciles, sat longe, articulo primo capitis apicem aquante, leviter incrassato, secundo lopgissimo, tertio brevi. Thorax subquadrangularis, angulis posticis obtusissime rotundatis, marginibus lateralibus et antico imis levissime reflexis. Ścutellum triangulare, subrquilaterum, apice imo levissime producto; frenis apicem scutelli subattingentibus. Membrana venis longitudinalibus, fere omnibus ex areola in angulo basali interiore posita emissis. Prostetlium simplex. Mesosternum leviter et obtuse carinatum. Metasternum haud elevatum. Venter basi inermis. Pedes mediocres, posteriores nonnihil distantes; femoribus inermibus; tibiis gracilibus, supra leviter sulcatis; tarsis trinticulatis.

I. S. Trolabidodes STAL. - Supa fermgineo-arnescens, dense distincteque punctulata, subtus cum pedibus, autenuis rostroque pallide testaceo-flavescens et lieviuscula, pectoris lateribus remote punctatis; antennarum articulis tertio et quarto apice in albidum vergentibus, quarto medio, ultimo 
toto fuscis; marginibus imis capitis, thoracis marginibus lateralibus anticis et antico nee non linea media longitudinali antice abbreviata, scutelli linea media percurente, hemelytrorum margine costali maculaque parva paullo pone medium sordide dilute flavescentibus; membrana fusca; abdominis dorso nigricante, connexivo maculis marginalibus flavescentibus oruato; vitta lata laterali intramarginali pectoris ventris subferrugineo-fusca. ‥ Long. 12, Lat. 5 mill.

Sepina urolaboides Sign. Ann. ent. Sér. 3. VIII. p. 930. 95. Pl. I3. fig. 4. (1861).

Patria: Madagascar. (Coll. Signoret et s'tál.)

\section{PIEYOSTERNUM A. et S.}

Hist. des Hém. p. 161. (1813).

Corpus magnum, obovatum. Caput parvum, triangulare, lobis lateralibus lobo melio longioribus et anterius contiguis; tuberculis antenniferis a supero totis distinguendis, ad oculos valde appropinquatis, parum prominulis, inermibus; bucculis percurrentibus. valde elevatis, antice quam postice altioribus. Oculi sat prominuli. Ocelli prope oculos positi. Antenna quinquearticulatie, breviuscula, teretes, articulo primo capitis apicem superante, secundo tertio longiore. Rostrum coxas anticas superans, articulo rrimo bucculas postice paullo superante. Thorax marginibus lateralibus angustissime reflexis, parte basali retrorsum producta et basin scutelli tegente. Scutellum triangulare, longius quam latius, apice acutum; frenis ultra medium scutelli extensis. Corium margine apicali sinuato, angulo apicali exteriore acuto. Membrana venis longitudinalibus simplicibus, e vena transversa basali emissis, instructa. Prosternum simplex. Metasternum valde elevatum, postice truncatum, anterius longe productum, parte producta antrorsum sensim compresso-angustata, ad coxas anticas extensa, in mesosterno quiescente. Anguli apicales segmentorum abdominis in dentem prominulis. Venter segmento secundo basi medio subelevato et partem posticam truncatam metasterni tangente. Pedes mediocres, posteriores 
distantes; femoribus inermibus; tibiis supra leviter sulcatis; tarsis triarticulatis.

Hoc genus unum est inter pauca, quæ Africam et Americam simul inhabitant.

1. P. calidum FABR. - Supra olivaceo-virescens, densiscime subtiliterque punctulatum, subtus cum pedibus olivaceo-flarescens, leviusculum; antemarum articulis duobus apicalibus,

- thoracis marginibus imis lateralibus anticis, incisuris spiraculisque ventris nigris; membrana enescente-fusca; abdominis dorso, excepto connexivo, viridi-aneo vel viridi-ceruleo; thorace linea subtili media elevata, per scutellum carina obtusa instar continuata, instructo, marginibus lateralibus anticis rectis, angulis lateralibus vix vel levissime prominulis; scutello apice acuto, haul tamen in spinam producto; abdominis marginibus obsoletissime serrulatis, immaculatis; rostri articulo secundo apicalibus duobus ad unum subbreviore. o7. ․ Long. 20-22, Lat. 9-11 mill.

Cimex papillosus FABR. Ent. syst. IV. p. 106. 103. (1794). excl. syn. (Edessa papillosa FABR. syst. Rhyng. p. 150. 19. ad Tessuratomam pertinet.)

Cimex calilus FAвк. Ent. syst. IV. P. 110. 117. (1794); Syst. Rhyng. p. 168. 67. (1803).

Pentatoma tenelmaria P. B. Ins. P. 46. Hem. Pl. 6. fig. 3 et 4. (1805); ג. et S. Mist. des Hém. p. 162. (1843).

Eilessa vicina Westw. in Hope. Cat. of IIem. I. p. 29. (18:37).

Piezostemum mucronatum 1)ALL. List of Hem. I. p. 338. 1. (1851). excl. syn. Pal. Beauv. et Ar. et Serr.

Patria: Calabar, Gabon. (Coll. Signoret ot StTiL).

Obs. P. subulatum Thiвe (= mucronatum! P. B., A. et S.,) differt a $P$. culido thoracis marginibus latcralibus anticis sinuatis, concoloribus, angulis lateralibus productis, scutelli apice in spinam gracilem producto; Americam praterea inhabitat. Patrian ineorrecte

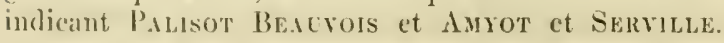




\section{TESSARATOMA LEP, et SERV.}

Enc. meth. X. (1825).

Caput parviusculım, triangulare, apice rotundatum, planum, lobis lateralibus lobo medio longioribus et anterius contiguis; tuberculis antenniferis levissime prominulis, inermibus; bucculis sat elevatis. Ocelli prope oculos positi. Antennæ quadri-articulati, breves, crassiusculæ. Rostrum breve, medium mesosterni subattingens, articulo primo bucculas postice nonnihil superante. Thorax posterius supra basin scutelli sat productus. Scutellum apice nomnihil productum, angulum basalem interiorem membranæ vix tegens; frenis longe ultra medium scutelli extensis. Corium margine apicali versus angulmm apicalem exteriorem rotundato. Membrana basi areolis pluribus, renas longitudinales emittentibus instructa. Prostethinm antice leviter dilatatum, pone oculos sinuatum, medio canaliculatum. Mesosternum carina valida, pone medium sulcata, instructum. Metasternum valde elevatum, postice subsinuatum, anterius longe productum, parte producta antrorsum compresso-angustata, ad coxas anticas extensa, carinam mesosterni tangente. Venter segmento secundo medio in tubercnlum obtusum, basin metasterni tangens, elevato. Pedes validi, femoribus apice subtus sæpissime spinosis; tibiis supra sulcatis; tarsis triarticulatis.

1. T. Afzelii StẢL. - Testaceo-flavescens, supra dense punctulata; antenuis, excepto articulo basali, nigris, articulo secundo tertio nonnilil longiore; thoracis marginibus lateralibus anticis levissime rotundatis, angulis lateralibus rotundatis, haud prominulis; scutelli apice concolore; alis fuscis; abdominis dorso concolore; femoribus inermibus. $\sigma^{7}$. Long. 25, Lat. 14 mill.

ऽ?. Segmento anali apice latissime emarginato.

Tesseratoma papillosa BURu. Handb. II. 1. p. 350. 2. (1835).

Tesseratoma Afzelii STÅL. Öfv. Vet. Ak. Förh. 1854. p. 233 ; et l. c. 1856 . p. 63.

Patria: Sierra Leona. (Mus. Holm.) 
DALCANTHA $\mathrm{A}$. et S. S.

1list. des Hém. p. 170. (1843).

Caput breve, latiusculum, lobis lateralibus lobo medio longioribus, anterins contiguis, apice obtusis, marginibus lateralibus posterius sat profunde sinuatis; tuberculis antenniferis haud jrominulis, inermibus; bucculis sat elevatis, basin capjitis attingentibus. Ocelli ab oculis remoti. Rostrum breve, articulo primo bucculas postice nomihil superante. Thorax postice late rotundatum, angulis posticis deletis. Scutellum parvum, triangulare, subæquilaterum, apice imo leviter producto; frenis fere ad apicem scutelli extensis. Membrana basi areolis pluribus, venas longitudinales emittentibus, instructa. Prostethium antice vix dilatatum, medio sulcatum. Mesosternum carina obtusa subsulcata vel carinis duabus parallelis instructum. Metasternum hand elevatum. Venter basi inermis, haud elevatus. Pedes mediocres, validiusculi, femoribus apice subtus interdum spinosis; tibiis prismaticis, supra sulcatis; tarsis triarticulatis.

A Mattipho et Pycano parum differt hoc genus, nee distinguitur nisi capite latiore et breviore. Forma thoracis et abdominis, ab Marot et SErvilde inter notas genericas citata, notas specificas tantum priebet.

1. D. platygastra WEsTw. - Ovata, supra obscure aneo-ferruginea, densissime punctulata, subtus cum antemis, rostro pedibusque pallide testaceo-flarescens, ventre aciculato, remote alutaceo; antennarum articulis secundo et tertio supra leviter sulcatis, hoc illo nonnihil breviore, ultimo nigro; thorace marginibus lateralibus anticis rotundato-ampliatis, apicem versus sinuatis; scutello apice Havescente, membrana ionescente-fusca; pectoris maculis tribus lateralibus, connexiro limboque lato ventris obscure enescentibus, connexivi segmentis limboque rentris sordide flavo-maculatis; abdomine hemelytris latiore, utrimque rotundato-ampliato, angulis apicalibus segmentorum prominentibus, rectis, apice rotundatis; femoribus inermibus. $\sigma^{7}$. ㅇ. Long. 15-22, Lat. 11-16 mill. 


\section{$-231-$}

Pentatoma platygaster Westw. in Hope. Cat. of Hem. I. p. 43. (1837).

Patria: Grand Bassam Guinex. (Coll. Signoret et StåL.); Sierra Leona. (sec. Hope.)

\section{PRIONOGASTER STÅL.}

Öfv. Vet. Ak. Förh. 1853. p. 224.

Caput foliaceum, longinsculum, lobis lateralibus lobo medio multo longioribus, contiguis, marginibus lateralibus posterius sinuatis; tuberculis antenniferis a supero distinguendis, extus spina sat longa armatis; bucculis basin capitis attingentibus, anterius sat altis, retrorsum sensim humilioribus. Ocelli inter se quam ab oculis duplo longius remoti. Rostrum coxas intermedias attingens, articulo primo bucculas postice superante. Antenne quadriarticulate, crassie, breviuscule, articulo primo capitis apicem haud attingente, articulo secundo longo, depresso. Thorax postice latissime rotundatus, angulis posticis deletis. Scutellum triangulare, subiequilaterum, parvum, apice ipso leviter producto; frenis fere ad apicem scutelli extensis. Membrana basi areolis pluribus venas emittentibus instructa. Prostethium simplex. Mesostethium vix carinatum. Metasternum haud elevatum, inerme. Abulomen marginibus lateralibus explanatis, foliaceis, fortiter serratis, segmentis utrimque in dentes duos ampliatis; ventre basi inermi. Pedes breves, validi, femoribus inermibus; tibiis prismaticis; tarsis triarticulatis.

1. P. serratus Gers. - Ovatus, fusco-ferrugineus, rugulosus, squamulis parvis sordide flarescentibus parce conspersus, subtus cym antennis pedilusque dilutior; membrana nigra; thoracis marginibus lateralibus explanatis, acutis, vix rotundatis, angulis lateralibus hand frominulis. ㅇ. Long. 19, Lat. 9 mill. Amaurus serratus Gers. in Silb. Rev. Ent. V. p. 158. 81. (1837); H. Sch. Wanz. Ins. VII. p. 75. fig. 748. (1844).

Prionogaster Westwoodi StåL. Öfv. Vet. Ak. Förh. 18503. p. 224.1 .

Patria: Caffraria. (Mus. Holm.) 


\section{HAPLOSTERNA STȦL.}

Aplosterna Wristw. in IIope. Cat. of IIem. I. p. 26. (1837).

Encosternum Spis. Gen. d'ins. artroid. p. 107. (1852).

Lamus STR̊丿. Öfv. Vet. גk. Förh. 1853. p. 222.

Caput subfoliaceum, planum, triangulare, apice rotundatum, lobis lateralibus lobo medio multo longioribus et contiguis; tuberenlis antenniferis parum prominulis; bneculis pereurentibus, modice elevatis. Ocelli inter se quam ab oculis duplo longius remoti. Rostrum breve, coxas anticas attingens, articulo primo bucculis breviore. Antennæ breves, subquinquearticulatx, articulo primo eapitis apicem attingente, secundo brevissimo, a tertio hand bene separato. Thorax angulis posticis obtusissimis, rotundatis, marginibus lateralibus anticis obsolete serratis. Scutellum parvum, triangulare, xquilaterum, apice imo leviter producto; frenis fere ad apicem scutelli extensis. Membrana venis longitudinalibus numerosis, e rena transversa basali emissis, instructa. Prosternum sulcatum. Mesosternum carinatum. Metasternum valde elevatum, inter pedes intermedios leviter productum, postice pro receptione tubereuli medii segmenti secundi ventris subsimuatum. Venter late obtusissimeque carinatus. Pedes breviusculi, femoribus inermibus, tibiis triquetris; tarsis biarticulatis.

1. II. Delegorguei Spin. - Pallidissime olivaceo-flavescens, densissime punctulata; antemis pedibusque testaceis rel in testaceum vergentibus, illis capite thoracique ad unmm æquilongis, articulo tertio levissime depresso; marginibns imis lateralibus thoracis abdominisque nec non margine ino costali corii anterius nigris; membrana alisque vitreis; abdomine lemelytris nomilil latiore, marginibus obsoletissime serrulatis. ơ. \&. Long. 25, Lat. 12 mill.

Encosternum Delegorguei SpL. Gen. d’ins. artroid. p. 109. (1852).

Lamus Dallasi StiL. Öfv. Vet. Ak. Förh. 1853. p. 222. 1. Patria: Caffraria. (Mus. Holm. et Coll. Sigsoretr.) 


\title{
CYCLOGASTER WESTW.
}

\author{
Ent. trans. II. p. 20. (18:37) \\ Gonielytrum Stĩ. Öfv. Vet. Ak. Förh. 1853. p. 223.
}

Caput foliaceum, triangulare, apice rotundatum, lobis lateralibus lobo medio multo longioribus et ante hunc contiguis; tuberculis antenniferis a supero haud distinguendis, parum prominulis, inermibus; bucculis percurrentibus, modice elevatis. Ocelli inter se quam ab oculis duplo longius remoti. Rostrum breve, coxas anticas attingens, articulo primo bucculis subbreviore. Antenne breves, depressa, quadriarticulata, articulo primo capitis apicem hand attingente, secundo tertio multo longiore. Thorax angulis posticis obtusissimis, rotundatis. Scutellum triangulare, requilaterum, apice ipso panllo producto; frenis fere ad apicem scutelli extensis. Margo costalis hemelytrorum anterius obtuse angulatmm. Membrana venis numerosis, e margine basali emissis, instructa. Prosternum sulcatum. Mesosternum carina alta foliacea instructum. Netasternum cruciatim leviter eleratum, parte elevata excavata. Venter segmento secundo basi tuberculo breviter conico, antrorsum prominulo et metasterni basin tangente, armato. Pedes breves, femoribus inermibus, tibiis prismaticis, tarsis biarticulatis.

1. C. pallidus Westw. - Pallidissime olivaceo-stramineus vel virescens, dense punctulatus; membrana alisque vitreis; thoracis marginibus lateralibus explanatis, acutis, rotundatis; abdomine hemelytris multo latiore, utrimque rotundato-explanato; margine imo capitis interdum nigro. \&. Long. 25-28, Lat. 12-13 mill.

Cyclogaster pallidus Westw. Ent. Trans. II. p. 20. Pl. 2. fig. 6. (1837); DALL. List of Hem. I. p. 346. 1. (1851).

Natalicola Delegorguei SPIN. Gen. d'ins. artroid. p. 110.(1852). Gonielytrum circulicentre STÅL. Öfv. Vet. Ak. Förh. 1853. p. 223. 1.

Patria: Caffraria. (Mus. Holm.); Gabon. (Coll. Signoret); Gambia. (sec. Dallas.) 


\section{Suluf. PHYLLOCEPIIALIDA STÄL.}

Tabula synoptica generum.

1 (2). Capite parro; antemnarm articulo primo capitis apicem superante. - Cressona DALL.

2 (1). Capite magno rel majusculo; antenuarum articulo primo capitis apicem haud superante.

3 (14). Thoracis margine postico scutelli basi haud latiore, angulis posticis haud productis, obtusis.

4 (13). Lobis lateralibus capitis planis vel concaviusculis, dilatatis vel acute marginatis.

5 (8). Thorace processubus lateralibus antrorsum rergentibus destituto, angulis lateralibus obtusis vel extrorsum nonnihil productis et interdum acuminatis.

6 (7). Capite apice distincte rotundato vel lobis lateralibus haud acuminatis, apicem versus extus distincte rotundatis. - Phyllocephala LAP.

7 (6). Capite triangulari, sæpissime acuto, lobis lateralibus apicem versus sensim angustatis, sæpissime acuminatis, raro obtusiusculis. - Schizops SPLN.

8 (5). Thorace utrimque processu antrorsum rergente armato.

9 (12). Parte thoracis laterali anteriore in lobum depressum, acutum vel ohtusiusculum, antrorsum producta.

10 (11). Capite lateribus ad oculos distincte inciso, lobis lateralibus latis, extus distincte rotundatis, liberis, haud divergentibus. - Gellia STÁL.

11 (10). Capite ante oculos haud inciso, lobis lateralibus elongatis, sensim acuminatis, leviter divergentibus, extus subrectis. - Tetroda $\mathrm{A}$. et $\mathrm{S}$.

12 (9). Parte thoracis laterali media in processum subtriquetrum, subacuminatum, oblique antrorsum producta. Macrina $\mathrm{A}$. et $\mathrm{S}$.

13 (t). Lobis lateralibus capitis conrexis, sensim acuminatis. Dichelorhinus STiL.

14 (3). Thoracis margine basali scutelli hasi latiore, angulis posticis plus minus prominentibus. - Megarhynchus LAP. 


\section{$-235-$}

Obs. Placosternum, quod genus ab auctoribus ad Phyllocephalida est relatum, ad Pentatomida pertinet.

\section{PHYLLOCEPHALA LAP.}

Ess. Hém. p. 57. (1832).

Caput magnum, obtusum, lobis lateralibus dilatatis, planis vel concavinsculis, apice rotundatis. Thorax cornubus vel lobis lateralibus destitutus, angulis lateralibns haud vel parun prominulis.

a. Corpore ovali, subtus valde concexo; capite maximo, longo, lobis lateralibus lobo medio plus duplo, fere ter longioribus, concavis, apicem versus haud angustatis, apice extus valde rotundatis; antemis brevibus; thoracis angulis lateralibus rotundatis, haud prominulis.

1. P. senegalensis LAP. - Dilute griseo-flavescens, supra fortiter, minus dense punctata; thoracis macula antica plagaque posteriore, interdum in duas divisa, nigro-punctatis; ruga transversa subtili thoracis ante medinm calloque in angulis basalibus scutelli levibus, pallidis; membrana grisea, nigro-venosa; ventre umbilicato-rugoso. ㅇ. Long. 15, Lat. $8 \frac{1}{2}$ mill.

Phyllocephala senegalensis LAP. Ess. Hém. p. 58. P1. 54. fig. 6. (1832); BLanch. Ilist. nat. ins. III. p. 144. 1.

Aelia senegalensis Burm. Handb. II. I. p. 357. 4. (1835).

Phyllocephala congesta II. ScH. Wanz. Ins. VII. p. 68. fig. 741. (1844).

Patria: Senegal. (Mus. Holm.) Etiam in Abyssinia.

Caput lateribus parallelis, lobis lateralibus contiguis. Thorax marginibus lateralibus denticulatis.

Specimen vidi lobis lateralibus capitis divaricatis, marginibusque lateralibus anticis thoracis integris instructum; an species distincta?

aa. Corpore ovali, subtus modice convexo; capite distincte longiore quam inter oculos latiore, obtuso, lobis lateralibus lobo medio circiter duplo longionibus; antennis brevilus; thoracis marginibus lateralibus anticis integris vel obsoletissime crenulatis.

Dalsira Am. et Serv. Hist. des Hém. p. 175. (1843). 
b. Thoracis marginibus lateralibus anticis nonnillil rotundatis, intergits.

c. Thorace intra margines laterales anticos leviter impresso.

2. P. foreata DALL. - Sordide albida, distincte ferrugineo-fusco-punctata, thoracis marginibus lateralibus anticis fasciaque lata fere media, scutelli callis tribus parvis basalibus, margine costali corii ante medium margineque angust 0 abdominis lavibus, nitidis; thorace anterius pallidiore, ante fasciam illam levem maculis duabus impressis, rugulosis, opacis, nigris ornato; pectore utrimque nigro-maculato; membrana grisescente, nigro-conspersa. o’. ․ Long. 14-16, Lat. 8! 10 mill.

Phyllocephala foveata DALL. List of Hem. I. p. 352. 1. (1851). Patria: Caffraria. (Mus. Holm.)

cc. Thorace intra margines laterales aiticos haud impresso, his explanatis.

3. P. fasciata STÅL. - Ovalis, sordide eburnea, thorace posterius, scutello hemelytrisque infuscatis et fusco-punctulatis; thoracis macula oblonga laterali submarginali ante medium nigra; antennis articulo ultimo fusco; membrana grisescente,

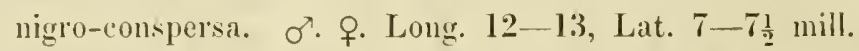

Phyllocephala fasciata S'TAL. Öfr. Vet. Ak. Förh. 1853. p. 224. 3.

Patria: Caffriria. (Mus. Holm.)

Statura $P$. foveater. Ar $P$. modestem valde appropinquat. Supra cum pectore distinete, minus dense punctulata, parte pallida thoracis punctis obsoletioribus et decoloribus instructa. Caput ante oculos utrimque leviter sinnatum, dein antrorsum vix angiustatum, apice semicirculariter rotundatmm, paullo longius quam inter oculos latius, lobis lateralibus contiguis. Antenna articnlo sceundo tertio dimidio longiore. Thorax limbis laterilibus anticis ante medium nigris, margine imo ihiclem eburneo, parte nigra retrorsum angustata; angulis lateralibus rotundatis. Scutellum basi maculis tribus minutis pallidis interdum notatum. Prostethium et mesostethium utrimque macula una, metastethium maculis duabus indeteminatis nigris ornatil. Venter unbilicato-subrugosus, ntrimque vittis duabus plus minus distinctis et continuis, nigris vel uigro-conspersis, ornatus. 
4. P. Ientiginosa STÅL. - Subanguste ovalis, sordide eburnea, supra cum pectore distincte punctata, thoracis parte posteriore et parte laterali marginali anteriore, scutello hemelytrisque levissime infuscatis, punctis nigris conspersis; maculis obsoletis lateralibus pectoris vittisque duabus obsoletissimis lateralibus ventris nigro-punctatis; membrana grisescente, nigro-conspersal antennarum articulo ultimo fusco. f. Long. 14, Lat. 7 mill.

Phyllocephala lentiginosa S'TÁL. Öfr. Vet. Ak. Förh. 1853. p. 224. 2.

\section{Patria: Caffraria. (Mus. Holm.)}

$P$. fascinte maxime affinis, differt punctura paullo distinctiore, statura angustiore capiteque longiore. Caput distincte lougius quam eum oculis latius, utrimque ante oculos denticulo obtuso obsoleto armatum, dein leviter sinuatum, ante sinum subampliatum, lobis lateralibus apice paullo divaricatis. Antenuie artieulo tertio capitis apicem vix superante. Thorax angulis lateralibus obtusatis, levissime subsinnatis. Scutellum in angulis basalibus macula parva levi pallida notatum.

Specimen pallidum descripsi; adsunt verisimiliter exempla obsemriora, $P$. fasciate quoad colores picturamque similia.

bb. Thoracis marginibus lateralibus anticis rectis, obsoletissime subcrenulatis.

5. P. porosa STÁL. - Subanguste ovalis, griseo-albida, sat fortiter ferrugineo-fusco-punctata, tota vel hic illic plus minus obscure ferrugineo-fusco-induta; membrana grisescente, nigroconspersa; antemis obscure ferrugineo-fuscis; pedibus punctatis. \&. Long. 17, Lat. 9 mill.

Phyllocephala porosa StÅL. Öfv. Vet. Ak. Förh. 1853."p.

\section{1.}

Patria: Caffiraria. (Mus. Holm.)

Caput distincte longins quam cmm oculis latius, antrorsum sensim nonnihil angustatum, apice integrum, ante oculos vix sinuatum. Antenna artieulo tertio secundo vix dimidio longiore. Thorax angulis lateralibus rotundatis, subprominentibus. Hemelytra quam thorax et scutellum minus profunde punctata. Venter umbilicatorugosus.

aaa. Corpore obovato; capite sapissime brevi, parum longiore quam inter oculos latiore, lobis lateralitus lobo medio haud 


\section{- 238}

plus quam duplo longioribus; antennis longinsculis, urticulo secundo cupitis apicem superante; thoracis marginibus lateralibus anticis distincte denticulatis.

Basicryptus H. ScH. Wanz. Ins. VII. p. 81. (1844).

d. Capite longiore, antrorsum magis angustuto, lubis lateralibus lolio medio duplo longioribus; thorace marginibus lateralibus anticis fere totis rectis, angulis lateralibus distincte productis.

6. P. distimcta Sign. - Distincte punctata, griseo-flarescens, parce nigro-conspersa, subtus cum capite parteque plus quam dimidia anteriore thoracis pallidior; antemnis maculaque laterali metastethii nigris; thorace inter angulos laterales linea nigra ornato, ante illam lineam, excepta parte apicali, punctis decoloribus instructo; margine costali corii minute nigromaculato; antennarum articulo secundo tertio nonnihil longiore; membrana grisescente, nigro-conspersa. ơ. Long. 20, Lat. 10 mill.

Pleyllocephala distincta SIGN. Rev. et Mag. Zool. 1851. p. 446. 12.

Patria: Gabon. (Coll. SigroneT); Calabar. (Coll. STAL.)

dd. Capite breviore, lobis lateralibus lobo medio haud duplo longioribus; thoracis maryinilus lateralibus unticis posterius distincte rotundutis, ungulis lateralibus rotundatis, leviter prominulis. 7. P. costalis Germ. - Flavo-testacea vel testaceo-flavescens, parce minutissimeque nigro-conspersa, distincte punctata; thorace inter angulos laterales ruga transversa destituto, macula triangulari nigra pone angulos laterales ornato; sentelli macula apieali margineque costali hemelytrorum abidis, loc lavigato, subcalloso, impressionibus transversis compluribus nigris instructo; membrana grisescente, parce nigroconspersa; antennarum articulis secundo et tertio aqualibus. o' ㅇ. Long. 17-22, Lat. 10-12 mill.

Edessa custulis Gerar. in Silb. Rer. ent. V. p. 159. 83. (18:37).

Basicryptus costulis 1I. ScH. Wanz. Ins. VIl. p. 82. fig. 749 . (1844). 
Phyllocephala costalis DALL. List of Hem. I. p. 353. 6. (1851). Patria: Caffraria. (Mus. IIolm.)

$P$. marginate $\Lambda$. et $\mathrm{S}$. valde aftinis.

8. P. gibhosa DaLL. - Pallide griseo- vel rufescente-flavescens, sat dense distincteque punctata, sulitus cum capite thoraeisque antico siepe parce nigro-conspersa; thorace scutelloque transversim subrugosis, illius ruga inter angulos laterales extensa distinctiore, punctulata; margine costali corii albido, transversim multimpresso, impressionibns sæpe nigris; antennis apicem versus obscurioribus vel fuscis, articulo secundo tertio tertia parte longiore; membrana decolore, parce ininutissimeque nigro-conspersa. $\sigma$. ․ Long. 14--18, Lat. 810 mill.

Phyllocephala gibbosu DaLL. List of IIem. I. p. 354. 8. (1851). Basicryptus russatus STÃL. Öfv. V'et. Ak. Förlı. 1853. p. 224. 1 .

Basicryptus çnosus STÃL. Öfv. Vet. Ak. Förh. 1853. p. 225. 2.

Patria: Caffraria. (Mus. Holm.)

A P. (Aelia) strigosa Buru., quam in Museo Berolinensi examinavi, differre videtur capite ot priesertim antennis longioribus thoraceque paullo latiore.

\section{SCIIIZOPS SPIN.}

Ess. Hém. p. 297. (1840).

Gonopsis A. et S. Hist. des Hém. p. 180. (1843).

Caput triangulare, apicem versus sensim angustatum, lobis lateralibus sensin acuminatis, raro apicem versus extus subrotundatis et apice obtusiusculis. Thorax lobis vel cornubus lateralibus destitutus, angulis lateralibus nune rotundatis, nunc extrorsum nonnilil productis et plus minus acuminatis.

a. Corpore latiore, obovato; capite basi levissime convexo, triangulari, lobis sensim acuminatis, vix contiguis; thorace marginibus luteralibus unticis rectis, distincte denticulatis, angulis lateralibus rectis, distincte productis.

Schismatops DALL.(?) 
1. S. striata SIGN. - Sordide testaceo-flarescens, distincte punctata, thorace scutelloque anterius transversim irregulariter fusen-striatis, striis subimpressis, illo inter angulos laterales ruga transversa obsoletissima, punctati, concolore, instructo; anteunis apicem rersus infuscatis, articulo secundo capitis apicem paullo superante, articulis secundo et tertio aque longis; membrana grisea. \&. Long. 23, Lat. $11 \frac{1}{2}$ mill.

Phyllocephala striata SIGN: Rer, et Mlag. Zool. 1851. p. 446. 11. Pl. 12. fig. 5 .

Patria: Gabon. (Coll. Sigroret.)

Linea transversa elevata nigra thoracis, de qua mentionem facit Sigmorer, deest.

2. S. vicina SIGN. - Sordide testaceo-flavescens, distincte punctata; thorace scutelloque obsoletissime transversim fuscosublineatis; antennis obscurioribus, apicen versus infuscatis, articulo secundo tertio paullo breviore, illo capitis apicem haud attingente; membrana fuscescente-grisea. ㅇ․ Long. 20 , Lat. 10 mill.

Phyllocephala vicina SIGs. Rev, et Mag. Zool. 1851. p. 446. 13.

Patria: Gabon. (Coll. Signoret.)

s. striate maxime affinis et simillima.

aa. Corpore angustiore, suboblongo-obovato vel valde anguste. obovato; capite antrorsum sensim angustato, thoracis angulis lateralibus distincte prominentibns, rectis, denticulatis vel serratis.

b. Thoracis angulis lateralibus apice rotundatis, leviter preminentibus, marginibus lateralibus anticis obsoletins denticulatis.

Schizops Spis. Ess. Hém. p. 297. (1840).

3. S. ingyptiaca LEF. - Anguste oralis rel obovata, ferrugineofusca rel nigricans, dense distincteque punctulata; scutelli vitta utrimque laterali limboque costali corii dilute sordide flavescentibus; membrana griseo-albida, nigro-renosa; antennis nigris. ơ. ㅇ. Long. 15-18, Lat. 8-9 mill.

Pentatoma agyptiaca LEF. in GuÉr. Mag. Zool. I. pl. 20. $(1831)$ 
Aelia agyptiaca Burm. Handb. II. I. p. 358. 5. (1835).

Schizops agyptiaca A. et S. Hist. des Hém. p. 177. 1. (1843); Freb. Eur. Hem. p. 341. 1. (1861).

Phyllocephala agyptiaca H. ScH. Wanz. Ins. VII. p. 69. fig. 739. (1844); BLANCH. Hist. nat. ins. III. p. 144. 2; DALL. List of Hem. I. p. 353. 4. (1851).

Patria: Aegyptus, Nubia. (Mus. Holm., et Coll. StTäL.); Turcia. (sec. FIEBER.)

bb. Thoracis angulis lateralibus magis prominentibus, acutis vel upice imo obtusatis.

Gonopsis A. et S. Ilist des Hém. p. 180. (1843).

4. S. hottentotta STÅL. -- Ferrugineo-nigra, antennis fuscis, articulis duobus ultimis sordide subferrugineo-flavescentibus; membrana decolore, parce minutissimeque fusco-conspersa. ․ Long. 17, Lat. 8 mill.

Macrina hottentottu STẢL. Öfv. Vet. Ak. Förlı. 1853. p. 225.1. Patria: Caffraria: (Mus. Holm.)

Statura S. denticulatee, eapitis lobis lateralibus apice subrotundatis, angulis lateralibus thoracis apicc haud acmminatis differt. Caput rigoso-punctatum, ante oculos utrimque haud sinuatum. Antennx articulis secundo et tertio subaequalibus, illo capitis apicem attingente. Thorax transversim rugosus et ruga distinctiore, inter angulos laterales extensa, iustructus, distincte punctulatus, anterius subdepressis et ruguloso-punctatus. Scutellum punctato-rugosum. Hemelytra distincte punctata. Pectus rugulosum, ante medium utrimque vitta lavigata instructum. Venter ruguloso-aciculatus.

5. S. denticulata A. et S. - Suboblongo-obovata; griseo-flavescens vel dilute sordide flavescens, supra nonnihil obscurior, distincte punctulata; thorace scutelloque rugosis, illius ruga inter angulos laterales extensa distinctiore; limbo costali corii vittaque lævi laterali ante medium pectoris pallidis, hac vitta utrimque plus minus obscure infuscata; capite lobis lateralibus angulisque lateralibus thoracis acutissimis, his extrorsum sat productis; membrana grisescente, nigro-conspersa. ○. ㅇ. Long. 14-18, Lat. $7-8$ mill.

Gonopsis denticulata A et S. Hist. des Hém. p. 180. I. (1843). Ilesmiptera africrua. 
$\sigma^{7}$. Obscurior, supria subinfuscatus et fusco-punctatus, scutelli vitta lata antice trifida, indeterminata, pallidiore; ventre plus minus distincte fusco-sexvittato, vittis duabus mediis valde appropinquatis.

q. In omnibus pallidior, subtus vix rel obsoletissime fuscovittata.

Patria: Senegal. (Mus. Holm. et Coll. SigNoretr.)

aaa. Corpore anguste ovali vel suboblomo: antemis brevibus, articulo tertio capitis apicem nomithil superante; thorace angulis lateralibus sat rotundatis, hand. vel levissime prominulis, marginibus luteralibus anticis anterius obsolete cremulatis.

6. S. Mlantis STiL. - Suboblongal, ferrugineo-fusea rel nigricans, subtus cum antennis ferrugineo-flarescens; pectore obscuriore, nigro-punctato, ante medium vitta laterali levigata straminea ornat 0 , extra vittan nigricante; rentre parce fusco-consperso, latera versus vittis duabus obsuletis fusco-punctatis et conspersis; scutello rugis tribus longitudinalibus, posterius evanescentibus, sublevibus, sape pallidius fusco-subferrugineis; membrana grisescente, parcissime minutissimeque fusco-conspersa. q. Lons. 16, Lat. 6 , mill.

Macrinu mantis StiL. Öv. Vet. Ak. Förh. 1853. p. 225. 2. Patria: Caffraria. (Mus. Holm.)

Statura fere S. crgyptiaca, minor, capite longiore, angulis lateralibus thoracis hand vel vix prominulis, obtuse rotundatis. Sat dense distincteque punctulata, ventre subacienlato. Caput sat longum, lobis lateralibus valde acuminatis. Antenne interdum basin versus fusce, articulis serundo ct tertio aequalibus. Thorax subrugulosus, ante medinn leviter depressus, marginibus lateralibus anticis rectis, ruga transversa minus distincta, inter angulos laterales extensa, instructus.

7. S. natalensis StaL. - Subanguste ovilis, pallide griseo-flavescens, pedibus, thorace posterius, scutelli lateribus hemelytrisque, hujus margine costali excepto, plus minus obscure infuscatis; thorace ante medium maculis duabus parvis nigris ornato; scutelli ruga longitudinali laterali levigata, pallida, pone medium obsoletiore et fnsco-punctata; pectore utrimque 
ante medium vitta laterali lævi, albida, intus anguste; extus Jate nigro-marginata, ornato; ventre utrimque vittis duabus, plus minus distinctis, nigro-conspersis ornato. †. Long. 13, Lat. 6 mill.

Phyllocephala natalensis STȦL. Öfv. Vet. Ak. Förh. 1853. p. 224.4.

Patria: Caffraria. (Mus. Holm.)

Dense distincteque punctata, ventre aciculato-subrugoso. Caput apicem versus sensin angrustatum, lobis lateralibus contiguis vel nonnihil divaricatis, extus ipicem versus levissime rotundatis, apice obtusinseulis. Antenuxe articulis secundo et tertio requalibus vel illo hoc paullo longiore. Thorax subrugulosus, versus margines laterales anticos leviter explanitos rt rotundatos fusco-punctatus, anterius depressus, ruga lievi paliidat inter angulos latcrales cxtensa cet ante medium riga transversa ablreviata obsoletiore lacriuscula instructus, angulis laterạlibus levissimc prominulis, obtuse rotundatis. Membrana grisescens, parce fusco-conspersa.

\section{GELLIA STTẢ.}

Corpus ovale. Caput valde dilatatum, foliaceum, marginibus lateralibus ad oculos distincte incisis, ante incisuram subito dilatatis et rotundatis, lobis lateralihus levissime distantibus. Thorax parte laterali anteriore in lobum depressum antrorsum producta.

a. Thoracis lobis lateralibus apice subrotundatis et inermibus, brevibus, paullo ante oculos procluctis.

1. A. albivittis GERM. - Nigra vel subferrugineo-nigra, acervatim distincte punctata; limbo costali corii latiusculo flavescente-griseo-subsericeo; antennis piceis, articulis secundo, tertio et quarto æqualibus; membrana grisescente. q. Long. 18, Lat. 912 mill.

Aelia albivittis Germ. in SIlb. Rev. ent. V. p. 182. 125. (1837). Phyllocephala albivittis H. ScH. Wanz. Ins. VII. p. 69. fig. 737. (1844).

Tetroda africana DALL. List of Hem. I. p. 358. 7. (1851). Tetroda damon STÅL. Öfv. Vet. Ak. Förh. 185̌3. p. 225. 1. Patria: Caffraria. (Mus. Holm.) 
a. Thoracis lobis lateralibus ad vel ultra medium capitis productis, apice denticulo minuto armatis; lobis lateralibus capitis extus valde rotundatis.

2. (i. angulicollis STÂL. - Ovalis, dilute fuscescente-flavescens, distincte fusco-punctata, ventre, limbo excepto, obscuriore; thoracis fascia lata fere media, utrimque angustata, dilute testaceo-flavescente; maculis duabus ante medium thoracis transversis, nigris, nitidis, macula fusco-flavescente ipsis notatis; membrana fuscescente; pectore utrimque fusco vel nigro-maculato. ơ. Long. 13, Lat. 7 mill.

Tetroda angulicollis STÄL. Öfv. Vet. Ak. Förh. 1853. p. 225. 2.

Patria: Caffraria. (Mus. Holm.)

Statura fere $G$. albivittis, minor, capite latiore, lobis thoracis magis procluctis. Caput vix longins quam enu oculis latius, coneaviusculum. Antennie breves, articulo sceundo tertio multo breviore. Thorax medio subrugosus, marginibus integris, lobis lateralibus fere ad medium capitis productis. Venter remote punctulatus.

3. (i. Nilatata SIGs. - Ovalis, nigra, rugulosa, subpunctulata; antemarum articulo secundo tertio multo breviore; thoracis lobis lateralibus fere ultra medium capitis productis. or. Long. 1.3, Lat. 7 mill.

Phyllocephala dilatata Sign. Ann. ent. Ser. 2. IX. p. 346. PI. 10. tig. 13. (1851).

Patria: Guimea lusitanica. (Coll. Sigronet.)

P'recedenti maxime affinis, supra magis rugosa et obsoletius punctulata, thoracis lobis magis prorluctis; specimen obscurum descripsimus Sigxoner et ipse; excmpla rerisiniliter adsunt dilutiora, quoad colores picturampue $G$. angulicolli similia.

\section{MACRINA $A$, et S.}

Hist. des Hém. p. 179. (1843).

Corpus oblongo-obovatum. Caput triangulare, lobis lateralibus planis, acutissimis. Thorax parte laterali media in processum longum subtriquetrum, rectum, oblique antrorsum producta.

1. II. Jurenca BURM. - Griseo-flavescens, supra varicolor, sat dense distincteque subrugoso-punctata; scutelli vittis tribus 
subcallosis, remotius punctatis, in partem posteriorem thoracis continuatis, sæpissime pallidiusculis; membrana grisescente; vitta laterali ante medium pectoris, in caput continuata, lævi; ventre utrimque vittis duabus nigro-punctatis ornato; antennarum articulis secundo et tertio subæqualibus, illo capitis apicem nonnilil superante. $\sigma^{7}$. ㅇ. Long. 14-17, Lat. $6-7 \frac{1}{2}$ mill.

8. Obscurior, thoracis lateribus, hemelytris, antennis, tibiis tarsisque nigris; corii margine costali dimidioque apicali articuli ultimi antennarum sordide flavescentibus.

Aelia juvencus BurM. Handb. 1I. 1. 1. 358. 6. (1835).

Aelia (Megarleynchus) conosa White. Ent. Trans. IIl. p. 91. (1842).

Macrina juvencus DALL. List of Hem. I. p. 360. 3. (1851).

ㅇ. Pallidior, supra in dilute flavo-testaceum vergens, margine costali corii pallido.

Megarlynchus marginellus WESTW. in IIOPE. Cat. of Hem. I. p. 20. (1837).

Mareina furcata A. et S. Hist. des Hém. p. 179. 1. Pl. 2. fig. 8. (1843).

Macrina marginella DALL. List of Hem. I. p. 360. 2. (1851). Patria: Senegal. (Mus. Holm., Coll. Signoret et Strål.) ricata.

Antennie graciles, longiusculae. Cornua thoracis parnu diva-

Varictatem maris fere totam nigrieantem, disco thoracis seutelloque sordide flavo-testaceis, corii margine concolore, nigro, e Sierra Lcona ante multos annos reportavit Cel. A. Afzelius, Suecus.

2. II. rubens StÅL. - Dilute ferruginea, interdum in subsanguineum vergens; thoracis cornubus sat divaricatis, posterius nigris; membrana grisescente. $\sigma^{7}$. ㅇ. Long. 14-17, Lat. $6-7$ mill.

Macrina rubens STÁL. Öfv. Vet. Ak. Förh. 1853. p. 226. 3. Macrina afjinis StÅL. Öfv. Vet. Ak. Förh. 1853. p. 226. 4. Patria: Caffraria. (Mus. Holm.)

Statura $M$. Juvence, cormubus thoracis nomnihil longioribus et magis divaricatis. Oblongo-obovata, dense distincteque, capite tho- 


\section{$-246-$}

racequc anterius subtilius, punctata. Caput acutum, lobis contiguis. Antemna breviusculic, articulo secundo tertio paullo longiore, illo capitis apiecm haud attingente. Thorax inter angulos literales ruga transversi minus distincta instructus, marginibus lateralibus anticis distincte denticulatis. Vene hemelytrorum leviusculae. Venter aciculato-subrugosus.

\section{DICHELORHINUS STAL.}

Öfv. Vet, Ak. Förh. 1853. p. 226.

Corpus suboblongum. Caput elongatum, haud foliaceum, sensim acuminatum, lobis lateralibus contiguis, acutiusculis, supra convexis. Thorax lobis vel cornulus lateralibus destitutus, angulis lateralibus obtuse rotundatis, haud vel rix prominulis, margine basali basi scutelli haud latiore, angulis posticis obtusis, haud productis.

a. Marginibus lateralibus anticis thoracis leviter rotundatis, integris.

1. I). histricus STÅL. - Sordide flavescens, sat dense distincteque punctulatus; capitis parte inferiore vittaque superiore, thoracis limbis latis lateralibus anticis. maculis duabus minutissimis mediis late distantibus, macula majuscula trapezoidea antica plagaque posteriore transiersa, utrimque truncata, medio interrupta, scutello, parte costali hemelytrorum, pectoris lateribus ventrisque vittis duabus lateralibus obsoletis nigricantibus; scutelli linea longitudinali media, posterius abbreviata, lineola in angulis basalibus, lineola laterali media lineolisque duibus posterioribus longitudinalibus stramineis, subcallosis; membrana sordide albidia, subfusco-renosa; pectoris vitta laterali lævi, pallida, antrorsum angustata et in eaput continuata. ㅇ. Long. I4, Lat. $5 \frac{3}{3}$ mill.

I)ichelorhinus histricus STÅL. Öfv. Vet. Ak. Förh. I853. 1. 226. I.

Patria: Caffirarial. (Mus. Holm.)

Caput thorace multo longins. Antemne breves, articulo secundo tertio paullo breviore, hoc apicem capitis haud attingente, duabus ultimis subdepressis, subsulcatis. Thorax ante medium distincte d'pressus, ruga transversa levi subtili inter angulos laterales extensa et ante illam mga subtiliore abbreviata instructus. 
aa. Thoracis marginilus lateralibus unticis sulmectis vel subsimutis, distincte crenulatis.

2. I. vittatus SIGx. - Pallide sordide flavescens, sat dense distincteque punctulatus; capitis parte inferiore vittaque supera retrorsum dilatata, thoracis marginibus lateralibus anticis, maculis duabus minutissimis mediis valde distantibus, macula trapezoidea majuscula anteriore plagalyue transversa posteriore, medio interrupta, scutello, lateribus pectoris pedibusque, femorum basi fasciaque lata tibiarum posticarum exceptis, nigricantibus; lineolis longitudinalibus obsoletis subcallosis scutelli pallidis; hemelytris margine costali parteque posteriore infuscatis, pallido-rariis, pone medium macula parva oblonga pallida leviuscula notatis; vitta laterali pectoris, in caput continuata, levi, pallida; membrana decolore; antennarum articulo secundo tertio distincte longiore, hoc apicem capitis subattingente; thorace ante medium distincte depresso. o'. Long. 14, Lat. $5 \frac{1}{3}$ mill.

Megarlynnchus vittutus SIGN. Ann. ent. Sier. ‥ IX. 1. 347. Pl. 10. fig. 14. (1851).

Patria: Guinea lusitanica. (Coll. Signoretr)

Precedenti simillima, thoracis marginibus lateralibus subrectis vel subsinuatis, antennis nonnihil longioribus earumque structura distinctissimus; Megarhynchus gambiensis DALL., quem in Museo Britannico examinari, antenuarum articulis secundo tertioque atqualibus differt, cieterum Dichelorhino vittato sinillimus.

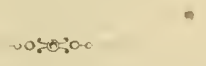




\section{Index.}

\begin{tabular}{|c|c|c|c|}
\hline ACANTHOSOMA & 1 & ALPHOCORIS & ag. \\
\hline ACROST & 223. & crassus ......... & 61. \\
\hline $\begin{array}{l}\text { ACROSTERA } \\
\text { AELIA }\end{array}$ & $19: 3$ & $\begin{array}{l}\text { indutus.. ............ } \\
\text { lixoides ........ }\end{array}$ & $\begin{array}{l}61 . \\
60 .\end{array}$ \\
\hline AELIA & & ALYDUS & \\
\hline & & fimbriatus.. & \\
\hline ua..................... & & $\begin{array}{l}\text { indercus. } \\
\text { ANACOSIA }\end{array}$ & \\
\hline 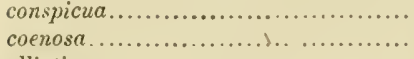 & $\begin{array}{r}64 . \\
245 .\end{array}$ & Delegorguei................... & 10 \\
\hline iptica .......... & & AMAUROCORIS & \\
\hline (sis ....... & & laticeps..... & 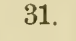 \\
\hline tsis ....... & & AMAURUS & \\
\hline oftard........... & & IYS & \\
\hline stata ............... & & $\begin{array}{c}\text { MISCHYS } \\
\ldots \ldots \ldots \ldots \ldots \ldots\end{array}$ & \\
\hline $\begin{array}{l}\text { fuscrta........... } \\
\text { vencus........... }\end{array}$ & & ANTESTIA & \\
\hline ta..... & & ena & \\
\hline & & & \\
\hline $\begin{array}{l}\text { la } \ldots \ldots . . . \\
\text { uinea }\end{array}$ & & ala & \\
\hline $\begin{array}{l}\text { nea } \ldots \ldots \ldots \\
\text { lensis.......... }\end{array}$ & & & 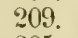 \\
\hline 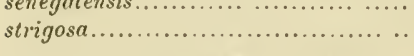 & 2 & ntris ........ & \\
\hline AELIONOR & & (n...... & \\
\hline simulans ............ & 176. & ... & \\
\hline A ESCIIRUS & 8 & & \\
\hline A & & 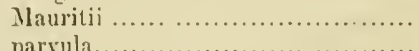 & \\
\hline . & 21 & & \\
\hline & 26. & .. & \\
\hline ollis. & 23 & .... & \\
\hline & 23 & 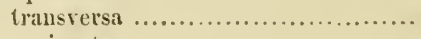 & \\
\hline is & 21 & & \\
\hline ascariensis & 21 & versicolor .............. & \\
\hline is $\ldots \ldots \ldots$. & $\begin{array}{l}24 \\
20\end{array}$ & ANTONIA & \\
\hline$\ldots \infty \ldots$ & 20 & Comma & \\
\hline & 25 & ANUBIS & \\
\hline & 29 & tus .... & \\
\hline 115. & 2. & 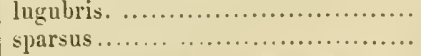 & \\
\hline$\triangle F R A N I$ & & APHANO & \\
\hline bers & & $\begin{array}{l}\text { oba } \ldots \ldots . . \\
\text { lata ....... }\end{array}$ & \\
\hline color... & 181 & APLOS & \\
\hline$\Lambda \mathrm{GO}$ & & ARADUS & \\
\hline a.. & & hystrix & \\
\hline & & ASOPUS & \\
\hline & & $c$ & \\
\hline & & atus. & \\
\hline
\end{tabular}




\begin{tabular}{|c|c|c|c|}
\hline$\ldots-\ldots, \ldots \ldots \ldots \ldots$ & $\begin{array}{r}\text { Pag. } \\
74 .\end{array}$ & BOLBOCORIS & Pag. \\
\hline oestus. & 64. & inxqualis.. & 8 \\
\hline tis.. & 65. & misellus.... & 134. \\
\hline ASPAVIA & 136. & obscuricornis........ & 87 \\
\hline ASPONGOPUS & & fus $\ldots \ldots .$. & 86 \\
\hline staneus. & 213. & - didus. & 86 \\
\hline & 218. & iolosus....................... & 86 \\
\hline ginatus & 215 & $\begin{array}{l}\text { arnolosus } \\
\text { scththopus } \ldots \ldots \ldots \ldots \ldots \ldots \ldots \ldots \ldots \ldots\end{array}$ & \\
\hline Is ...... & 217. & BRACIYPELTA & \\
\hline is ... & $\begin{array}{l}215 . \\
216 .\end{array}$ & $\begin{array}{l}\text { BRACHYPELTA } \\
\ldots \ldots \ldots \ldots \ldots \ldots \ldots \ldots \ldots \ldots \ldots\end{array}$ & \\
\hline ........... & 218 & HYPLATYS & \\
\hline $1 \mathrm{~s} \ldots \ldots \ldots$ & 218 & $\begin{array}{r}\text { BRAC } \\
\text { pallipes ........... }\end{array}$ & \\
\hline ilus..... & 216. & unicolor ........ & \\
\hline lus..... & $\begin{array}{l}218 . \\
213\end{array}$ & BROCHYMIENA & \\
\hline & 215. & frondosa ........... & \\
\hline & 214 & eticulata ........... & \\
\hline ....... & $\begin{array}{l}217 . \\
219\end{array}$ & $\begin{array}{r}\mathrm{CA} \\
\mathrm{i} \ldots \ldots \ldots \ldots\end{array}$ & \\
\hline Is & 214 & ... & \\
\hline & 219 & nda.......... & \\
\hline & 2 & anctata ............. & \\
\hline & 216. & unctata ................. & \\
\hline $\begin{array}{r}\text { xanthopterus } \ldots \ldots \ldots \ldots \ldots \ldots \\
\text { ATELOCERA }\end{array}$ & 214. & ricusis $\ldots \ldots \ldots, \ldots, \ldots, \ldots$ & \\
\hline $\begin{array}{r}\text { A'TELOCERA } \\
\operatorname{rmata} \ldots \ldots \ldots \ldots \ldots \ldots \ldots\end{array}$ & & , n................... & \\
\hline & 96. & remmaculata .................. & \\
\hline & 99. & signata $\ldots \ldots \ldots \ldots \ldots \ldots \ldots$ & \\
\hline - & 97. & CALLIPHARA & \\
\hline .... & $\begin{array}{l}97 \\
95\end{array}$ & C..... & \\
\hline & 95. & $\begin{array}{r}\mathrm{C} \\
\text { coccinelloides ...... }\end{array}$ & \\
\hline (........ & 97. & $\begin{array}{r}\text { coccinelloides ................... } \\
\text { CANTHECONA }\end{array}$ & \\
\hline & 98. & $\begin{array}{l}\text { CANTHECONA } \\
\text {................. }\end{array}$ & \\
\hline & 93. & … & \\
\hline ….... & 96. & ....... & \\
\hline sa............ & $\begin{array}{l}94 . \\
96\end{array}$ & ................. & \\
\hline 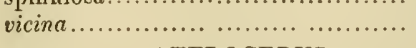 & 100 & $\begin{array}{l}\text { la } \ldots \ldots \ldots \ldots \ldots \ldots \ldots \\
\operatorname{cens} \ldots \ldots \ldots \ldots \ldots \ldots \ldots\end{array}$ & \\
\hline ATELOCERUS & & escens ....................... . & \\
\hline$u s$. & 93. & (n........ & \\
\hline$s$. & 96 & A & \\
\hline & 98 & $\mathrm{CA}$ & \\
\hline (......... & 94 & $\begin{aligned} \mathrm{CA} \\
\mathrm{CH}\end{aligned}$ & \\
\hline ...$\ldots \ldots$ & 97 & CATA & \\
\hline AXONA $\ldots \ldots$ & 224 & 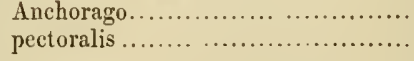 & \\
\hline BAGRADA & & CAURA. & \\
\hline hilaris ............... & 187. & CAYS & \\
\hline BASICR & & 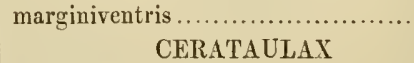 & \\
\hline & 238 & $\begin{array}{r}\text { CERATAULAX } \\
\text { quadrivittatus ........................ }\end{array}$ & \\
\hline ssatus..... & 239 & $\begin{array}{r}\text { quadrivittatus ................. } \\
\text { CERATOCORIS }\end{array}$ & \\
\hline В ВАТНYСО & & 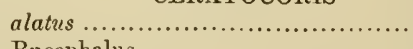 & \\
\hline ziensis ... & & alus..... & \\
\hline & & $\mathrm{CHOI}$ & \\
\hline
\end{tabular}




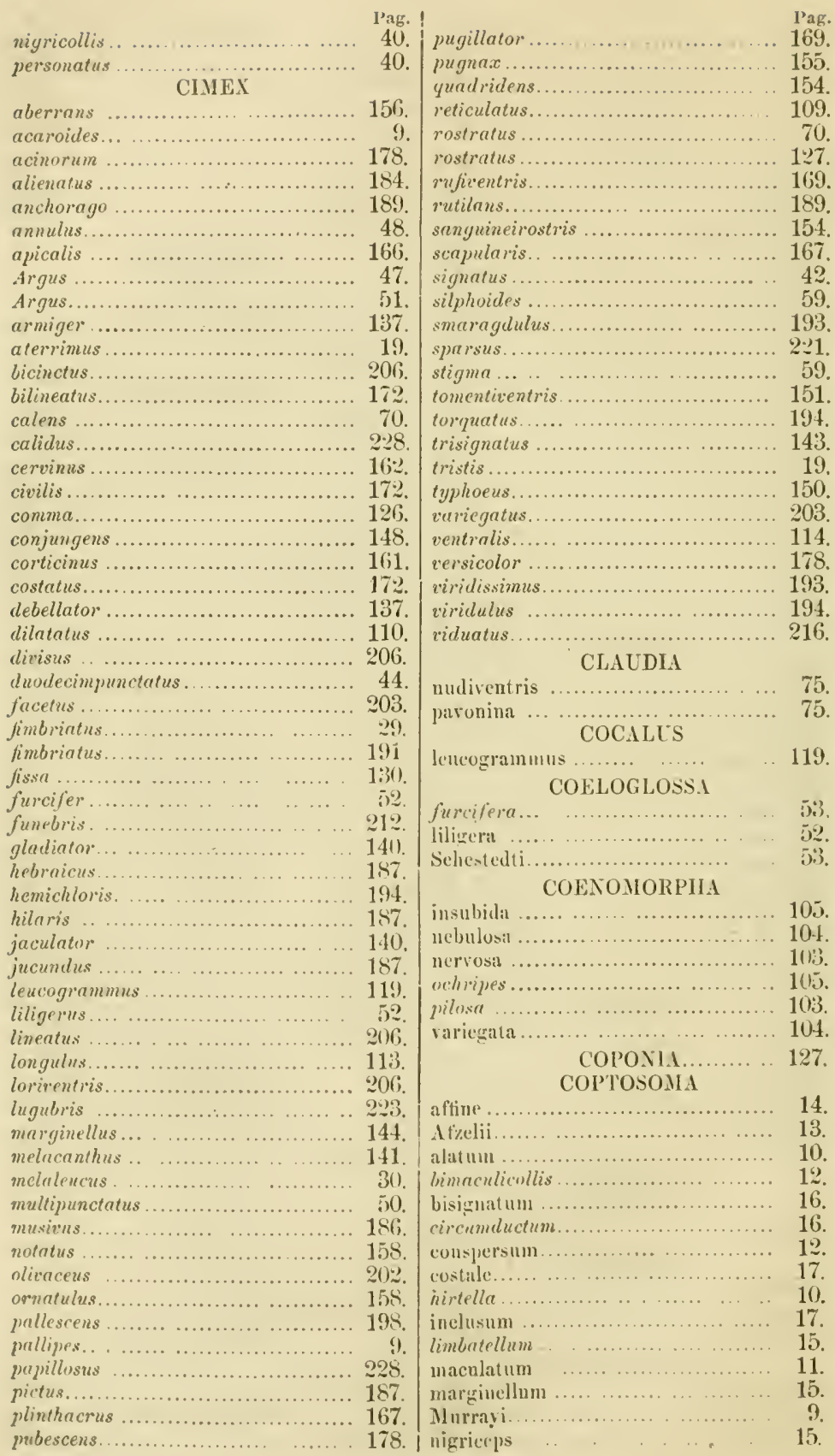


nigro-punctatum

nubilum

Oculator

pictulum

sexnotatum

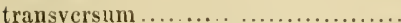

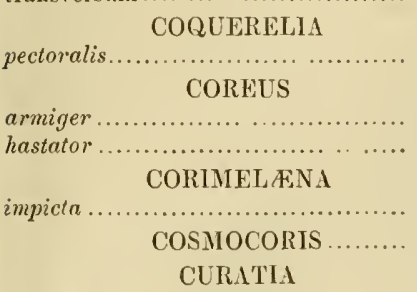

denticornis

CURATIA

truncaticornis

\section{CYCLOGASTER}

pallidus

CYCLOPEL'TA

patruelis

CYDNUS

abyssinicus.

aterrimus

circumcinctus

cruralis.

lautipennis

sanguinolentus.

tristis.

torvidus.

\section{CYPTOCORIS}

Lundii ..

Lundii.

WValbergi

DALCAN'THA

platygastra

DALPADA

vittata

DALSIRA DICHELOCEPHALA

lanceolata...

virescens

DICHELOPS

commia.

fissa.

DICIIELORHINUS

histricus

vittatus

funebris

DINIDOR

tristis

unicolor.

\section{DIPLOXYS}

acanthura

acutispina

bipunctata
Pag.

11.

16.

14.

15.

12.

189.

137.

140.

31.

34.

130.

130.

233.

213.

28.

19.

29.

2ด.

21.

28.

19.

20.

S2.

83.

83.

230.

101.

235.

131.

$13 \%$.

126

129.

246.
247.

212 .

212.

216.

128.

130.

$1: 8$.

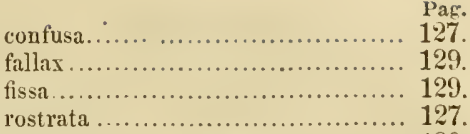

senegalensis......................... 129.

DISMEGISTUS
binotatus $\ldots \ldots \ldots \ldots \ldots \ldots \ldots \ldots \ldots \ldots . \ldots \ldots$

costalis.............................. 28.

fimbriatıs $\ldots \ldots \ldots \ldots \ldots \ldots \ldots \ldots \ldots .28$.

circumcinctus........................ 29

DURMIIA ........ 146.

DYMANTIS

110.

111.

EDESSA

costalis ............................. 238.

moestn ............................ 64

rutilans............................. 189

ricina ............................... 1288

viduata...................... . 216 .

ENCOSTERNUM

Delcgorguei $\ldots \ldots \ldots \ldots \ldots \ldots \ldots \ldots . . .232$.

ENNIUS .......... 112

ERACHTHEUS....... 115.

EURHINOCORIS

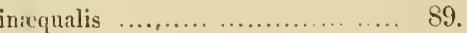

straminipes ...... ................. 89.

EURUS

dilatitus ........................ 109.

rotundatus ....................... 110.

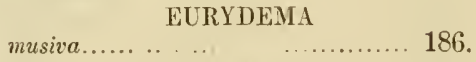

natalensis ......................... 58.

sculpturatus ..................... 61.

Helferi ........................... 135.

nigromarginatus .................... 154.

EISARCOCORIS ...... 135.

EISARCORIS

misellus .......................... 135.

natalensis. ....................... 200.

FLAMINIA

natalensis ... .................. 200 .

thalassinus . .................. 191.

GELLIA

albivittis .. ....................... 243.

angulicollis ........................ 244 .

dilatata......................... 244

conspicuus ...................... 64

moestus ............................... 63

pictiventris......................... 64

GNATHOCONUS ..... 29. 


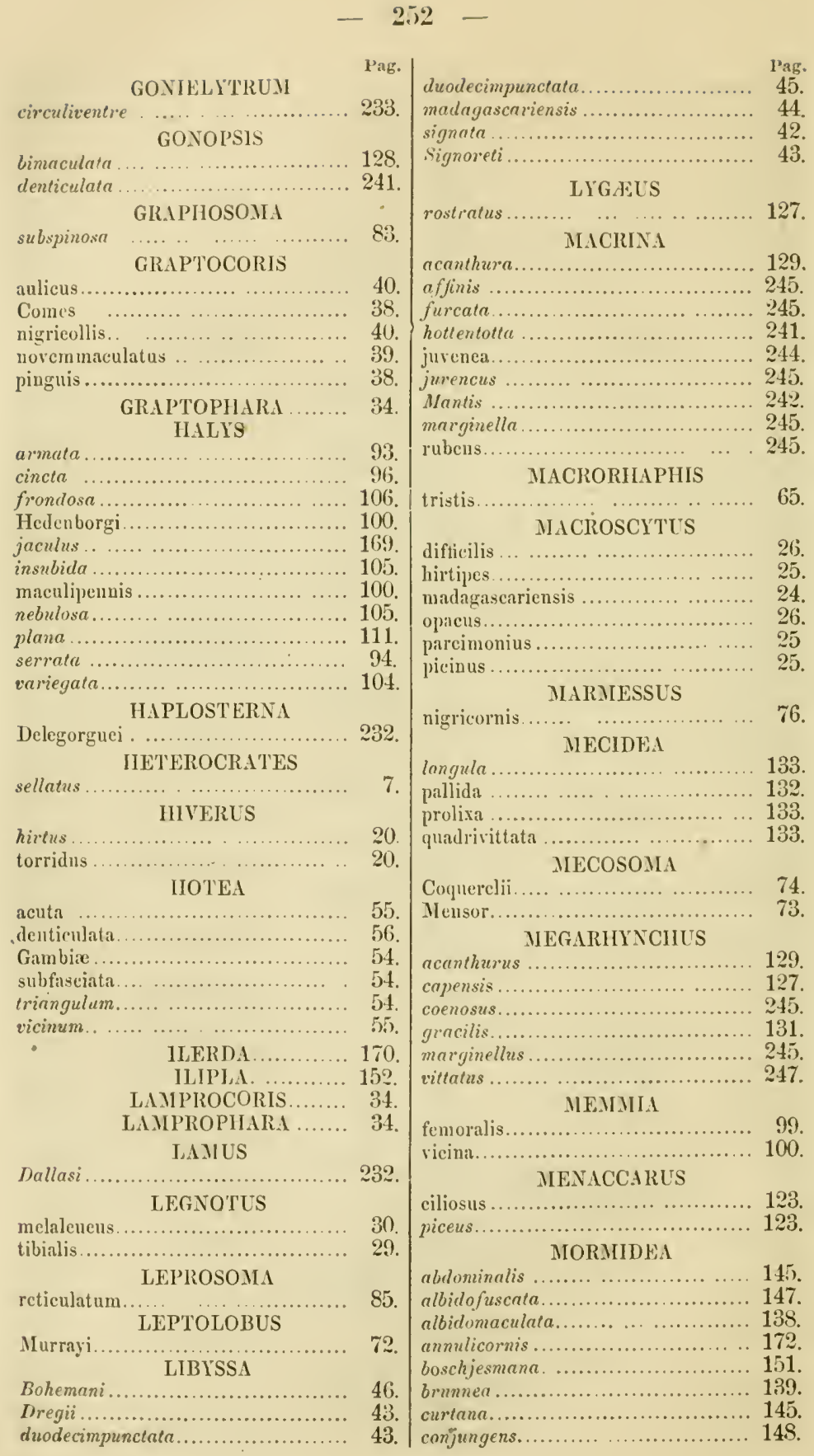




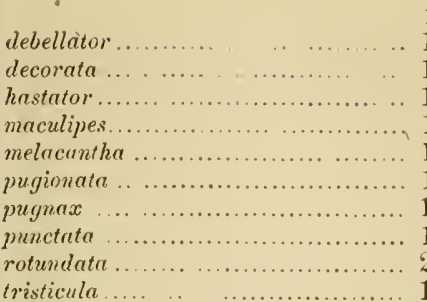

\section{MYROCHEA}

aculeata ....

viltata

\section{NAT'ALICOLA}

Delegmguei.

NEZARA

acuta

approximaln

capjicola

Dohrni

Fieberi

faro-punctate

incerta.

0 .

pallescens.

pallido-conspers

punctato-rugosa

pura

smaragdula

teretipcs

viridula

\section{ODONTOTARSUS}

Coquerelii ........

illutus.

obscurns.

silphoides

glaber

OETHUS

parcimonizs .

\section{ONCYLASPIS ORTIIOSCHIZOPS}

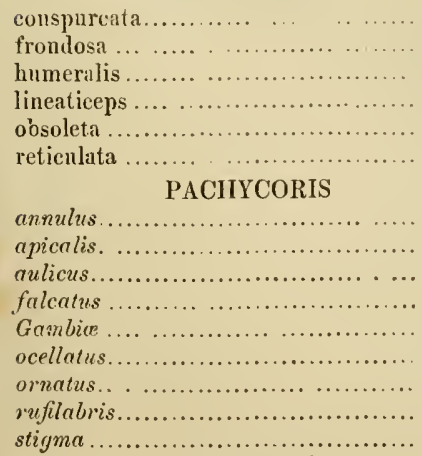

PANATIUS
Pag.

137.

141.

140.

141.

138.

157

155.

171.

204.

159.

117.

118.

233

197

194.

195.

195.

196.

196.

192.

197.

198.

196.

196.

198.

193.

198.

193.

60.

58

59.

25.

25.

2.

107.

106.

107.

108.

107.

108.

48.

54.

41.

55.

54.

47.

41.

39.

59.

220.

\section{PARAMECOCORIS}

Pag.

112.

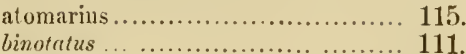

ellipticus .............................. 115

fatidicus ............................. 115 .

lautus .......................... 113.

lungulus........................... 112.

lutulentis............................ 115

phaleratus ........................ 113.

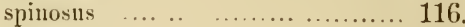

ventralis ......................... 114

vittiventris ..................... 114

PARAIIECUS

marginiventris . . ........ 117.

PELTAGOPUS

faro-marginatus ..................... 217.

PENTATOMA

abdominalis .......................... 144

aberrans........................... 155 .

acinorum . ........................ 178.

aculenta. ............................. 118

regyptiaca ........................... 240

albidumaculata ..................... 138.

annulicomis...................... 164.

apicalis ............................ 165 .

armigera .......................... 136.

bella ............................. 176.

bellieosa ... ...................... 147.

binotata ................................ 28

bipartita ............................ 169.

bipunctipes ........................ 166.

blanda ............................ 142.

br

bnonopoziensis ... ................... 190.

cacnosula............................... 152

Capicola ............................. 195.

Capito ........................... 146.

Capreola ........................ 149.

cervina .......................... 161.

chinensis ........................... 194.

chloris . ......................... 194.

cincta .............................. 29.

confusa . ............................... 202.

conjungens .......................... 147.

corticina ........................... 160 .

costata .......................... 172.

crudelis ............................ 154

enrtana.............................. 145 .

Debellotor ........................... 137.

deeorata........................... 140.

discolor ............................. 68

elegans ................................ 184.

fimbriata .................................. 192

fimbriolatum.......................... 191.

flavicollis ........................ 194.

frontalis ........................... 195.

gloriosa ................................ 186.

Goniodes ........................... 167. 


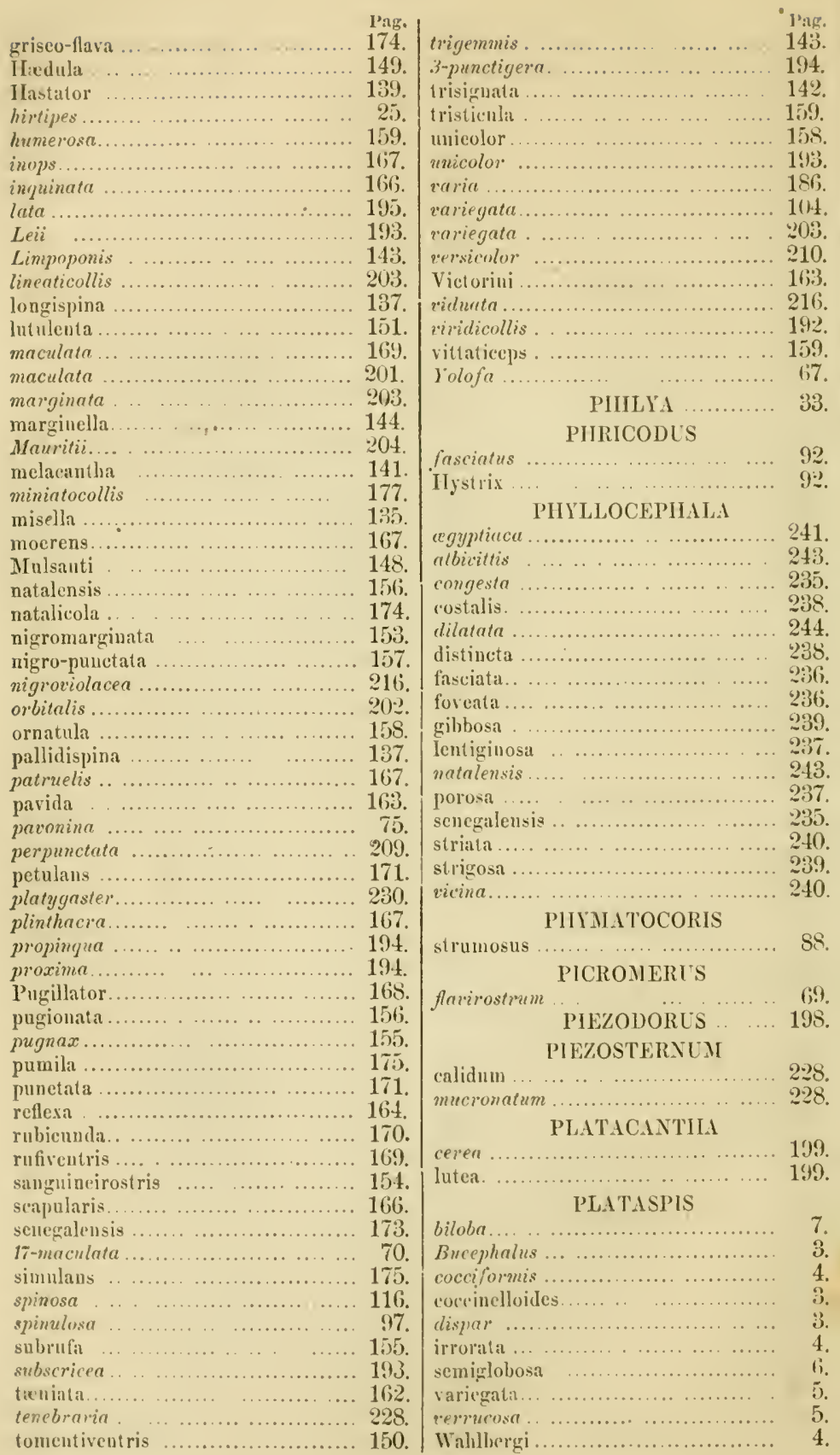


variegata

\section{PLATYNOPLS}

\begin{tabular}{|c|c|}
\hline $\begin{array}{l}\text { Reichii .. } \\
\text { rostratus }\end{array}$ & ........ \\
\hline Thomsonii & \\
\hline & PLAUTIA \\
\hline fimbriata & 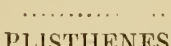 \\
\hline & PODODUS \\
\hline
\end{tabular}

obtısaugulus

orbiculiris

\section{PODOPS}

fibulata.

natalensis.

pallipes.

sinuatus.

spinicollis

tibialis

\section{POECILOCORIS}

comes

pinguis

PONSILA

luctans

\section{PRIONOGASTER}

serratus

IVestwood

PROBENOPS

Dromedarius .

\section{PROCILIA}

nigricornis

priet oria

scintillans.

PSACASTA

afra

\section{RHAPHIGASTER}

acutus

amoenus

bicinctus.

capicola

cincticeps...

decoratulus

divisus

elongatus

flavulus.

fuscoirvoratus

fuscosparsus.

impluviatus.

incerta

lorirentris

luteus

maculirentris

mensor.

$$
0
$$

orbus
Pag.

4.

5.

71.

71.

70.

69

191.

234 .

125.

124.

90.

91.

90.

91.

90.

90.

38

39.

7.

231.

231.

18.

36.

37.

36.

60.

198.

208.

206.

195.

207.

208 .

206.

207.

198.

$22 \%$.

222

223.

192.

207.

199.

$20 \%$.

74.

197. pallescens

198

196.

211.

193.

196.

199.

208.

221 .

193.

194.

194.

199.

211.

219.

239.

SCHISMATOPS ...... 239.

SCHIZOPS

iegyptiaca ........................... 240.

denticulata .......................... 241.

hottentotta...................... 241.

Mantis ........................... 24:

natalensis ........................... 242.

striata ............................... 240.

vicina .......................... 240.

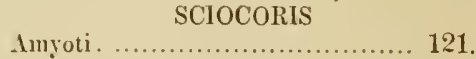

ater................................ 112.

atonarius ........................... 115.

capensis .............................. 125.

fusco-sparsus ................... 121.

leucogrammus ..................... 119.

longulus............................ 113.

orbicularis ............................. 125.

planus ................................... 111.

rusticus ......................... 121.

rentralis ........................... 115.

Wolfii............................. 120.

SERIBONIA
pilosa $\ldots \ldots \ldots \ldots \ldots \ldots \ldots \ldots \ldots \ldots \ldots \ldots \ldots \ldots$
102.

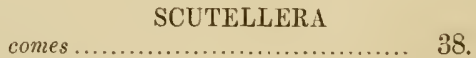

furcifera................................ 52.

gibbosa ............................... 48.

pinguis ........................... 39.

signata ........................... 42.

SCIIIRUS

cinctus ............................. 29.

ligutus ................................. 29.

melaleucus ........................ 30.

SEPHELA

linearis ............................ 118.

SEPINA

Urolabidoides ...................... 226

Urolaboides ........................ 227.

misella ........................... 134

SERGIA 


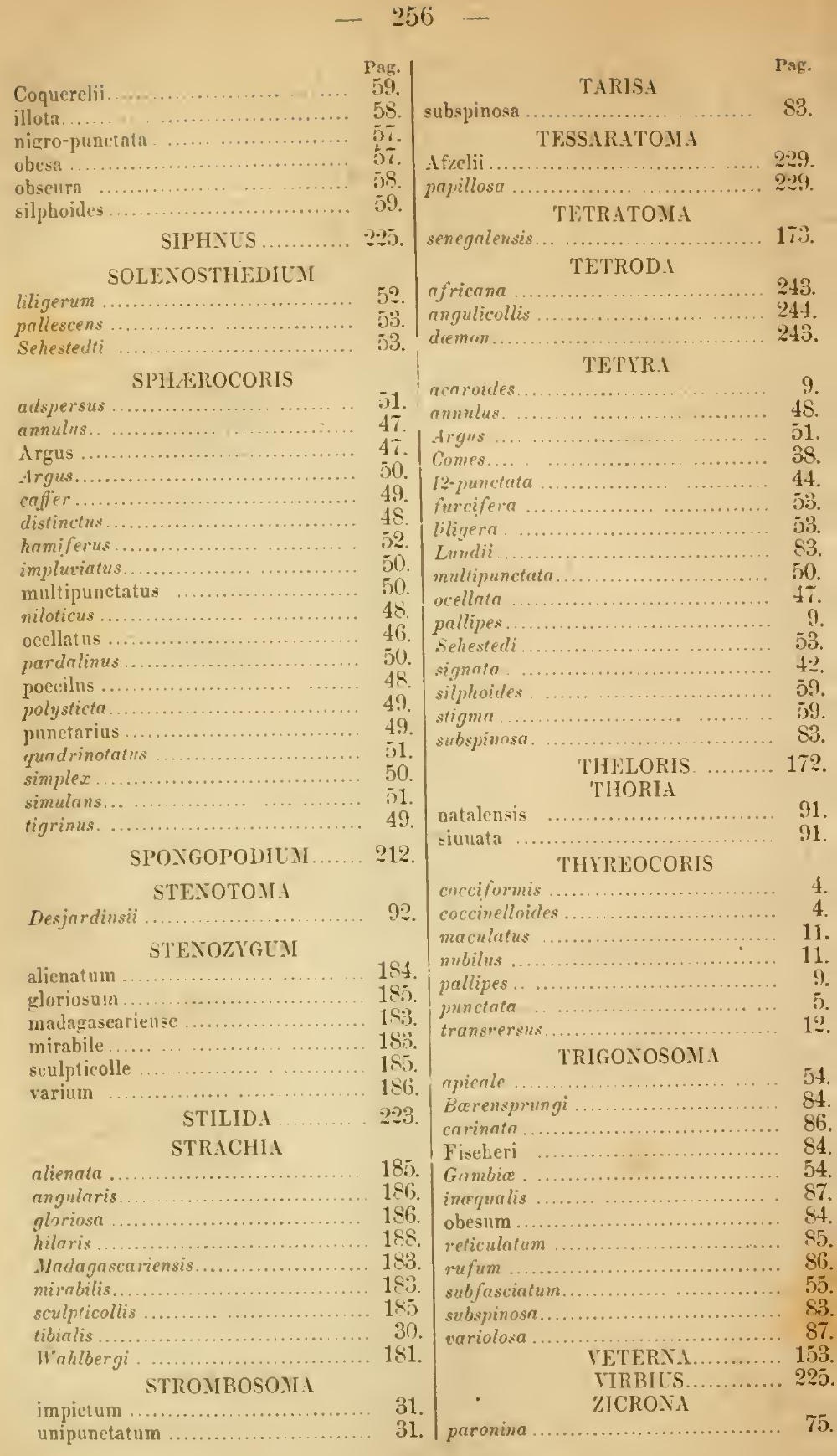




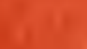

th.

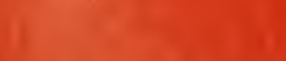

1)

a. 10 


\section{HEMIPTERA AFRICANA}

1) E-GCIRIP-IT'

CAROIUU STAI.

TOMUS SECUNDUS.

HOLHLLE, HUCCCLAV.

EX OFFICINA NORSTEDTIAN. 


\title{
VIRO CELERERLLIMO
}

\section{F. A. DOHR N}

\author{
HANC SUI OPERIS PARTEN
}

in festimoniUM VERECUNUIAE aMICITIAEQUE 

Fam. COREIJA STẢL.

Caput nec clypeatum, nec ante ocellos transversim impressum, tuberculis antenniferis partem capitis superiorem vel lateralem superiorem occupantibus. Ocelli adsunt. Antennæ quadriarticulatæ. Rostrum quadriarticulatum. Scutellum parvum aut mediocre. Hemelytra sæpissime completa, e clavo, corio et membrana composita, hac venis compluribus, interdum anastomosantibus, instructa. Tarsi triarticulati.

Conspectus subfamiliarum.

I. Segmentis dorsalibus abdominis quarto et quinto basi medio sinuatis. - Coreida STÅL.

II. Segmento dorsali abdominis quarto basi et apice vel apice saltem medio sinuato. - Rhopalida StåL.

Subf. COREIDA STÅL.

Conspectus generum.

1 (116). Alarum vena decurrente glochide destituta.

2 (115). Lateribus segmentorum abdominis in lobos foliaceos haud productis.

3 (44). Femoribus posticis plus minus incrassatis et spinosis; tuberculis antenniferis contiguis vel paullo distantibus, magnam partem lateris superioris capitis occupantibus, lobis capitis ante tubercula illa haud productis, lobo medio inter eadem interdum elevato.

4 (5). Coxis posticis subcontiguis. - Dalader A. et S.

5 (4). Coxis posticis distantibus.

6 (31). Capitis tuberculis antenniferis distincte prominulis, liberis, paullo distantibus vel contiguis, lobo medio a Hemiptera africana. II. 
basi deflexo, inter tubercula illa haud elevato, nec ante eadem prominulo.

7 (10). Spiraculis ventris transversis.

8 (9). Capitis parte anteoculari diametro longitudinali oculorum fere ter Iongiore; abdomine dilatato, hemelytris multo latiore. - Oxypristis Sign.

9 (8). Capitis parte anteoculari diametro longitudinali oculorum paullo longiore; abdomine haud vel vix dilatato. Petilliu ŚTÃL.

10 (7). Spiraculis ventris rotundatis.

11 (18). Tibiis omnibus vel saltem anticis et posticis in utroque sexu dilatatis.

12 (13). Femoribus anterioribus prope apicem subtus utrimique dente armatis. -- Petascelis SIGN.

13 (12). Femoribus anterioribus subtus prope apicem in latere anteriore bidentatis.

14 (15). Tibiis posticis femoribus brevioribus. - Sulpicia STAL.

15 (14). Tibiis posticis femoribus aque longis vel sublongioribus.

16 (17). Tuberculis antemniferis apice intus productis. - Cipia STARL.

17 (16). Tuberculis antenniferis apice intus haud productis. Dereptery.r. WHITE.

18 (11). Tibiis anterioribus simplicibus, triquetris.

19 (20). Tibiis posticis supra subtusque dilatatis. -- Mygdonia STÂL.

20 (19). Tibiis posticis haud nisi subtus dilatatis.

21 (26). Mesosterno antice sulco destituto.

22 (25). Thorace apice collari destituto.

23 (24). Metasterno bituberculato. - Puppeiı STíl.

24 (23). Metasterno tuberculis destituto. - Mictis Leacu.

25 (22). Thorace apice collari instructo. - Cossutia STiL.

26 (21). Mesosterno, anterius saltem, sulco instructo.

27 (30). Capite pone oculos calloso; scutello subæquilatero.

28 (29). Lobo medio capitis inter tubercula antennifera haud distinguendo, haul prominulo. - Amorbus DALL. 
29 (28). Lobo medio capitis inter tubercula antennifera distinguendo, paullo prominulo, inter illa tubercula tamen haud elevato. - Gelonus ŚTẢL.

30 (27). Capite usque ad oculos immerso, pone oculos haud calloso; scutello longiore quam latiore. - Myprilus STÀL.

31 (6). Capitis tuberculis antenniferis raro libere prominulis, lobo medio solo vel lobis omnibus inter illa tubercula elevatis et interdum antrorsum productis.

32 (33). Rostro gracili, inter coxas intermedias extenso, articulo primo longissimo, capite inulto Iongiore. - Notobitus STAL.

33 (32). Rostri articulo primo capite haud vel vix longiore.

34 (35). Lobis capitis inter tubercula antennifera distinguendis et antrorsum productis. - Cloresmus STÅL.

35 (34). Lobo medio capitis solo inter tubercula antennifera distinguendo.

36 (39). Thorace postice rotundato, nec medin ante scutellum truncato.

37 (38). Mesosterno antice sulco destituto. - Carlisis Stâl.

38 (37). Mesosterno antice sulco instructo, sulci marginibus interdum in laminam altam elevatis. - Phelans STÅL.

39 (36). Thorace postice ante scutellum truncato.

40 (41). Antennarum articulo apicali gracili, haud fusiformi, præcedenti æque longo vel paullo breviore; venis membranæ subsimplicibus, haud reticulatis. - Physomerus BuRM.

4l (40). Antennarum articulo apicali fusiformi et præcedente breviore; corii margine apicali recto, suturæ clavi æque longo vel breviore, angulo apicali exteriore haud producto, venis membranæ plus minus anastomosantibus.

42 (43). Hemelytris basin versus parallelis, dein leviter ampliatis. - Acanthocoris A. et S.

43 (42). Hemelytris subparallelis vel margine costali a basi ad apicem levissime rotundato. - Petalocnemis STÅL. 
44 (3). Femoribus posticis interdum incrassatis et spinosis, sxpissime gracilibus et inermibus; lobis capitis, apud genera femoribus posticis incrassatis et multispinosis instructa, ante tubercula antennifera, valde distantia et libere haud prominula, productis, nec usque a basi deflexis.

45 (98). Femoribus posticis haud vel vix incrassatis, sxpissime inermibus vel spinula armatis, raro spinulis pluribus instructis, articulo basali tarsorum posticorum articulis duobus apicalibus ad unum in hoc casu haud longiore.

46 (93). Capite pone oculos nec subito valde coarctato nec collo retrorsum gracilescente instructo.

47 (86). Angulis posticis metastethii rectis, raro acutiusculis, antennarum articulo primo tunc clavato.

48 (83). Bucculis variabilibus, numquam tamen triangularibus.

49 (52). Margine apicali corii recto, sutura clavi breviore vel eidem xque longo; rostro brevi.

50 (51). Capitis lobo medio spatium inter tubercula antennifera replente. - Choerommatus A. et $\mathrm{S}$.

51 (50). Capitis lobo medio inter tubercula antennifera libere prominula haud elevato. - Elasmogaster STẢL.

52 (49). Margine apicali corii raro recto, rostro in hoc casu longissimo.

53 (68). Tuberculis antenniferis libere prominnlis, lobo medio capitis inter illa tubercula interdum distinguendo, laad tamen elevato; rostro coxas intermedias hand superante.

54 (55). Femoribus subtus prope apicem dente armatis; pedibus posticis a lateribus corporis et inter se fere rque longe distantibus; capite basi utrimque pone oculos calloso; thorace collari destituto; abdomine hemelytris paullo latiore; angulo apicali corii land producto. - Cneius STẢL.

55 (54). Femoribus inermibus; pedibus posticis a lateribus corporis quam inter se multo longius remotis.

56 (57). Articulo secundo rostri tertio longiore. - Ornytus DaLL. 
57 (56). Articulis rostri secundo et tertio æque longis vel secundo tertio breviore.

58 (61). Articulis rostri secundo et tertio æque longis.

59 (60). Capite pone oculos modice prominulos callo instructo. Prismatocerus A. et S.

60 (50). Capite pone oculos globosos et valde prominulos haud calloso, usque ad oculos immerso. - Ceratopachys WESTW.

61 (58). Rostri articulo secundo tertio breviore.

62 (63). Rostri articulo quarto tertio breviore. - Tagus STẢL.

63 (62). Rostri articulis tertio et quarto æque longis.

64 (65). Capite pone oculos calloso. - Tliponius STÁL.

65 (64). Capite pone oculos hand calloso, usque ad oculos immerso.

66 (67). Angulo apicali corii paullo producto; abdomine utrimque ampliato, hemelytris latiore. - Diocles STÅL.

67 (66). Angulo apicali corii longissime angusteque producto; abdomine haud ampliato, hemelytris haud vel vix latiore. - Homoeocerus BurM.

68 (53). Tuberculis antenniferis raro libere prominulis, rostro in hoc casu inter coxas posticas producto.

69 (82). Bucculis brevibus.

70 (73). Antennarum articulo primo clavato.

71 (72). Corpore valde oblongo; scutello vix longiore quam latiore; margine apicali corii versus angulum apicalem sinuato. - Hydara DALL.

72 (71). Corpore elongato; scutello multo longiore quam latiore; margine apicali corii recto. - Corduba STÅL.

73 (70). Antennarum articulo primo haud clavato.

74 (79). Thorace collari destituto.

75 (76). Capite pone oculos haud calloso, usque ad oculos immerso. - Latimbus STÅL.

76 (75). Capite pone oculos plus minus distincte calloso, usque ad oculos haud immerso. 
77 (78). Lobis eapitis ante tubercula antennifera nonnilil distantia hand vel leviter deftexo-productis. - Cletus S'TÁL.

$78(77)$. Lobis capitis ante tubercula antennifera valde distantia antrorsum sat longe productis. - Plinacletus S'TiL.

79 (74). Thorace collari instructo.

80 (81). Lobis capjitis ante tubercula antennifera, libere breviter prominula, vix productis, valde deflexis. - Theraptus STÅL.

81 (80). Lobis capitis ante tubercula antennifera, libere haud prominula, antrorsum productis, paullo deflexis. $-G(t-$ lesus DaLL.

82 (69). Bucculis longis, eapite producto nonnihil brevioribus; rostro longissimo. - Cyllurus STil.

83 (48). Bucculis brevibus, triangulauibus, deorsum angulatim prominentibus; rostro gracili; ventre sulcato.

84 (85). Capite ante tubercula antennifera sat producto; oculis modice prominulis. - Lybas DALL.

85 (84). Capite lato, ante tubercula antennifera leviter producto, inter oculos et insertionem antennarum antrorsum leviter angustato, lobo medio dente acuto armato. Agathyma STŔL.

86 (47). Angulis posticis metastethii acute productis.

87 (88). Lobis capitis antrorsum leviter productis, lateralibus lobo medio hand longioribus. - Noliphus STÄL.

88 (87). Lobis capitis valde productis, lateralibus medio multo longioribus.

89 (92). Corpore elongato; thorace basi leviter bisinuato.

90 (91). Antennarum articulo primo gracili, apicen versus subincrassato. - Leptocorisa LATR.

91 (90). Antennarum articulo primo incrassato, apicem versus sensim gracilescente. - Mutusca S'TÁL.

92 (89). Cotpore oblongo; thorace basi latissime truncato. Stenocephalus LATR.

93 (46). Capite pone oculos subito coaretato vel collo retrorsum sensim gracilescente instructo. 
94 (97). Capite collo retrorsum gracilescente instructo; scutello spina armato.

95 (96). Rostri articulo primo capite longiore; venis longitudinalibus membranæ obsoletis, uti videtur e margine basali emissis; abdomine basin versus coarctato. Marcius STÅL.

96 (95). Rostri articulo primo capite breviore; venis membranæ distinctis, e vena transversa, a basi membranæ remota, emissis; abdomine basin versus haud coarctato.Dulichius STÁL.

97 (94). Capite pone oculos subito coarctato. - Euthetus DaLL. 98 (45). Femoribus posticis incrassatis et multispinosis.

99 (114). Tibiis posticis simplicibus, haud dilatatis, interdum compressis.

100 (109). Tibiis posticis spinis destitutis, apice interdum in dentem acutum prominulis.

101 (108). Tibiis posticis femoribus brevioribus, apice subtus in dentem productis.

$102(107)$. Pedibus posticis vix vel paullo distantibus.

103 (104). Oculis stylatis. - Camptopus A. et S.

104 (103). Oculis sessilibus.

105 (106). Thorace collari distincto instructo, margine basali ante scutellum bisinuato. - Riptortus STÅL.

$106(105)$. Thorace collari nullo vel obsoletissimo, margine basali ante scutellum recto, angulis posticis in dentem vel lobulum productis. - Tupalus STẢL.

107 (102). Pedibus posticis valde distantibus. - Tenosius STÅL. 108 (101). Tibiis posticis femoribus æque longis vel paullo longioribus. - Alydus FABR.

$109(100)$. Tibiis posticis subtus spinosis.

110 (113). Tarsorum posticorum articulo primo apicalibus duobus ad unum circiter duplo longiore.

111 (112). Antennarum articulo primo capiteque fere æque longis, illo hujus apicem longissime superante; tibiis posticis serie una spinarum armatis. - Hypselopus Burm. 
112 (111). Antennarum articulo primo capite breviore, lujus apicem nonnihil superante; tibiis posticis biseriatim spinosis. - Nariscus STÅ.

113 (110). Tarsorum posticorum articulo primo apicalibus duobus ad unum nonnihil longiore; articulo primo antennarum capite breviore. - Nemausus STẢL.

114 (99). Tibiis posticis dilatatis. - Theognis STẢL.

115 (2). Lateribus segmentorum abdominis in lobos foliaceos dilatatis. - Phyllomorpha LAP.

116 (1). Alarum vena decurrente glochide instructa.

117 (118). Scutello convexo, elevato; antennarum articulo primo capite longiore, articulo secundo primo breviore vel vix aque longo. - Clavigralla SpIN.

118 (117). Scutello plano vel planiusculo.

119 (120). Antennarum articulo primo capite breviore, incrassato, basin versus graciliore; capite multispinoso. Mevania STẢL.

120(119). Antennarum articulo primo capiti subæquilongo, basin versus haud gracilescente; capite inermi. - Myk STÁL.

In hoc conspectu genera quoque asiatica et australica, qua continet Museum Holmiense, disposui.

\section{OXYPRISTIS SIGN.}

Aun. ent. Sér. 3. VIII. p. 937. (1861).

Corpus maximum. Caput quadratum, tuberculis antenniferis contiguis, lobo medio nec elevato, nec producto, a supero haud distinguendo. Antennæ crassiusculæ. Rostrum breve. Corium margine apicali versus angulum apicalem leviter sinuato, angulo apicali exteriore nonnihil producto. Abdomen utrimque rotundato-ampliatum, hemelytris multo latius. Pedes postici valde distantes; femoribus anterioribus apice utrimque spina armatis, posticis sat incrassatis; tibiis anterioribus simplicibus, triquetris, nonnihil compressis, posticis femoribus longioribus, supra subtusque dilatatis, parte dilatata supera superne sulcata. 
1. 0. Leroyi Sign. - Nigricans, remote silaceo-sericea; antennis ultra medium dense sericeis, articulo tertio apicem versus utrimque valde dilatato, ultimo flavo-testaceo, reliquis graciliore; thorace angulis lateralibus acutissinis, extrorsum et sursum longissime productis, marginibus lateralibus anticis spinis sat longis, marginibus lateralibus posticis spinulis remotis armatis; hemelytris abdomineque obscure ferrugineis, hujus dorso testaceo; alis ante medium sordide flavescentibus, apicem versus sordide subvinaceis. $\sigma^{\top}$. . Long. 32, Lat. 13 mill.

$\sigma^{7}$. Femoribus posticis valde incrassatis, levissime curvatis, subtus apicem versus spinulis nonnullis, apice utrimque spina distincta et basi dente distincto armatis.

․ Femoribus posticis sat incrassatis, rectis, subtus apicen versus serie spinularum, apice duplicata, armatis.

Oxypristis Leroyi Sign. Ann. ent. Sér. 3. VIIl. p. 938. 112. Pl. 14. fig. 1. (1861).

Patria: Madagascar. (Coll. Signoret et StảL.)

Femora postica subtus biseriatim minute remoteque tuberculata. Tibia postice supra leviter rotundatie, subtus denticulata, prope basin obtuse angulato-ampliate, dein apicem versus sensim angustatie.

\section{PETASCELIS SIGN.}

Ann. ent. Sér. 2. V. p. 302. (1847).

Corpus maximum, oblongum. Caput subquadratum, tuberculis antenniferis subcontiguis, lobo medio nec elevato, nec producto, a supero haud distinguendo. Rostrum breve. Scutellum triangulare, æquilaterum. Corium margine apicali versus angulum apicalem exteriorem, leviter productum, sinuato. Pedes posteriores, præsertim postici, valde distantes; femoribus anterioribus apice subtus utrimque dente armatis, posticis valde incrassatis; tibiis omnibus supra subtusque dilatatis, parte dilatata tibiarum posticarum supra sulcata; tarsis posticis articulo primo apicalibus duobus ad unum æeque longo.

Oxypristi affine genus.

1. P. remipes Sign. - Umbrina vel fusco-cinnamomea, subtus cum articulo prirno antennarum pedibusque remote silaceo- 
sericea; antennis, membrana dorsoyue abdominis nigris; vittis tribus capitis, thoracis margine ommi, linea longitudinali percurrente lineolisque anastomosantibus anterioribus, reticulam formantibus, scutelli macula magna triangulari, margine costali ipso ante medium, lineisque pluribus oblique longitudiualibus pectoris dense sordide flavescente-sericeis; abdomine utrimque ampliato, macula marginali basali segmenti sexti nec non segmento dorsali sexto fere toto flarescentibns; alis obscure cærulescentibus. $\sigma$. ․ Long. 37, Lat. 12 mill.

o. Ventris segmento secundo medio in tuberculum sat magnum elevato; femoribus posticis valde incrassatis, fusiformibus, subtus biseriatim minute tuberculatis.

ㅇ. Ventris segmento secundo hand tuberculato; femoribus posticis quam in mare nonnihil minus incrassatis.

Petascelis remipes Sign. Ann. ent. Sér. 2. V. p. 302. Pl. 3. IV. (1847).

Patria: Natalia. (Mus. Holm.)

Antenne simplices, crassinsculie. Thorax anterius transwersim impressus, marginibus lateralibus anticis subrectis, denticulatis, angulis lateralibus rectis, levissime prominentibus, margine posteriore rotundato, medio sinuato. Abdomen hemelytris multo latius. Tibiae anteriores ab apice ultra medium, subtus leviter, supra valde rotundato-dilatatae, subtus a basi ultria medimm dilatate, medio leviter sinuate et ante et pone sinum obtuse subdentatie.

Ad hoe genus verisimiliter pertinent Petascelis affinis DALl. et laminipes Fanka.

\section{SULPICIA STÁL.}

Caput quadratum, tubereulis antenniferis subcontiguis, lobo medio nec producto, nec elevato, a supero haud distinguendo. Rostrum breviusculum. Scutellum triangulare, aquilaterum. Corium margine apicali versus angulum apicalem exteriorem leviter sinuato. Pedes validi, postici valde distantes, femoribus anterioribus apice subtus in latere anteriore bidentatis, posticis valde incrassatis; tibiis omnibus supra subtusque dilatatis, posticis femoribus distincte brevioribus; tarsis posticis articulo primo apicalibus duobus ad unum aque longo. 
Hoc genus et duo sequentia femoribus anterioribus apice subtus in latere anteriore lidentatis, nec utrimque unidentatis, a Petascelide divergunt et ad Nictidem magis appropinquant.

I. S. distincta SIGN. - Fusco-cinnamomea, remote silaceo-sericea, capite, marginibus, linea longitudinali lineaque transversa anteriore thoracis densius sericeis; antennis, membrana dorsoque abdominis nigris, hujus segmentis dorsalibus secundo, tertio et quarto flavis; alis fuscis. $\sigma^{7}$. Long. 22, Lat. 8 mill.

or. Ventris segmentis primo apice et secundo basi medio conjunctim in tuberculum parvum elevatis, segmento secundo medio retrorsum producto et cum media basi segmenti tertii transversim leviter elevato, parte elevata utrimque subtuberculata; femoribus valde incrassatis, subfusiformibus.

Petascelis distinctus Sign. in Thoms. Arch. ent. II. p. 293. 553. (1858).

Patria: Calabar. (Coll. Signoret.)

Anteuna eorpore tertia parte breviores, articulis primo et quarto reque longis, secundo et tertio, prasertim tertio, illis brevioribus, seeundo prope apieem superne in dentem dilatato, tertio ab apice ultra medium utrinque, licet supra magis subtus, dilatats, articulo apieali fuseo-flavesecnte, medio obseuriore. Thorax marginibus lateralibus dentieulatis, antieis leviter sinuatis, angulis lateralibus acntiuseulis, extrorsum nonnihil prominentibus. Abdomen hemelytris paullo latius, prope apicem angustatum. Femora anteriora superne erista parum elevata, prope apicem subito abbreviata, instrueta: postica superne prope apicem eristula distincta, subtus crista leviter elevata percurrente, medio undata, ibidem paullo altiore et obsoletissime erenulata, prope apicem bidentata, instructa. Tibia antica supra quam subtus magis dilatate, parte dilatata superiore infra medium dente obtuso armata; intermedia fere ut tibiæ antica formatre, lieet magis dilatate, superne prope apieem sinnata; postica supra valde, subtus leviter dilatatie, illie infra medium sinuatæ, ante sinum in lobulum ampliate, lic fere in medio in lobum dentiformem dilatatie.

\section{CIPIA STÅL.}

Corpus valde oblongum, compressum. Caput subquadratum, tuberculis antenniferis subcontiguis, apice intus productis, lobo medio nec elevato, nec producto, a supero haud distinguendo. 
Rostrum breviusculum. Thorax marginibus lateralibus convexis, inerinibus. Scutellum triangulare, subequilaterum. Corium margine apicali versus angulum apicalem exteriorem leviter productum nomilil sinuato. Pedes postici valde distantes; femoribus anterioribus apice subtus in latere anteriore bidentatis, posticis valde incrassatis; tibiis omnibus presertim posticis, supra subtusque dilatatis, his femoribus paullo longioribus; tarsis posticis articulo primo apicalibus duobus ad unum vix breviore.

1. C. lilatata Sigr. - Nigra, supra raguloso-punctata; abdominis segmentis dorsalibus, ultimo excepto, macula flavescente ornatis; alis sordide hyalinis; maculis tribus lateralibus majusculis pectoris flavo- vel rufescente-testaceis. $\sigma^{7}$. ㅇ. Long. 23, Lat. 6 mill.

o?. Ventris segmentis secundo et tertio apice tuberculis duobus compressis, retrorsum nutantibus, valde distantibus, armatis; trochanteribus posticis postice spina armatis; femoribus posticis valde incrassatis, nomnihil curvatis, superne ante medium cristula instructis, subtus ruga leviter elevata percurrente præditis, apice utrimque spina distincta armatis; tibiis posticis subtus leviter, supra valde dilatatis, subtus apicem versus leviter sinuatis, supra rotundatis, levissime subundatis, apice calcare parvo armatis.

Petuscelis dilatatus Sign. Ann. ent. Sér. 2. VHI. p. 68. 1. Pl. 4. fig. 1. (1850).

9. Ventre inermi; trochanteribus posticis inermibus; femoribus posticis sat incrassatis, rectis, supra non nisi obsoletissime cristulatis, subtus crista percurrente, prope apicem bidentata, instructis; tibiis posticis quam apud marem magis dilatatis, parte dilatata inferiore apicem versus sensim multo angustata, parte superiore basi et apice sensim nomnilil angustata, subundata.

Patria: Calabar. (Coll. Signonet et Stíl.)

Quoad staturam Mygdonice bellicose hand dissimilis. Antenne corpore quarta parte breviores, articulis primo et quarto reque longis, secundo et tertio etiam xque longis licet illis brevioribus, tertio 
supra subtusque leviter dilatato. Abdomen hemelytris paullo latius. Tibia anteriores supra subtusque leviter dilatate, marginibus rectis.

\section{DEREPTERYX WHITE.}

Mag. Nat. Hist. New Ser. 1II. p. 522. (1839).

Corpus oblongun vel subelongatmm. Caput quadratum, tuberculis antenniferis subcontiguis, lobo medio nec elevato, nec producto, a supero haud distinguendo. Thorax marginibus lateralibus denticulatis. Scutellum subequilaternm. Corium margine apicali versus angulum apicalem nonnihil productum leviter sinuato, suturæe clavi rque longo vel nonnilil longiore. Pedes postici valde distantes; femoribus anterioribus subtus prope apicem in latere anteriore bidentatis, dente subapicali minuto; tibiis omnibus vel saltem anticis et posticis, anticis interdum obsolete, supra subtusque dilatatis, posticis femoribus fere aque longis vel longioribus; tarsis posticis articulo basali apicalibus duobus ad unum longitudine subæquali.

Mygdonice affine genus.

a. Tibiis anticis sat dilatatis, parte dilatata superiore parte inferiore latiore.

1. D. biloba Sign. - Nigricans; rostro apicem versus, margine basali medio segmentorum abdominis dorsalium quarti et quinti nec non apertura apparatus odoriferi sordide stramineis; alis subviolaceo-fuscis; thorace distincte alutaceo. ․ Long. 24, Lat. 8 mill.

$\sigma$. Ventris segmento secundo prope apicem tuberculis duobus valde distantibus armato, apice medio retrorsum producto et cum parte media segmenti tertii in tuberculum transversum, apice subsinuatum, elevato; femoribus posticis subrectis, sat incrassatis, prope apicem subtus in latere exteriore dentibus duobus, apicali minuto, armatis; tibiis posticis præsertim superne dilatatis, parte dilatata superiore lata, infra medium apicem versus subito sinuato-angustata, parte inferiore a medio basin et apicen versus angustata. 
Petascelis bilobus Sign. Ann. ent. Sér. 2. VIII. p. 69. 3. PI. 4. fig. 2. (1850).

Patria: Guinea lusitanica. (Coll. Sigxorfí.)

Antenne articulo tertio secundo panllo latiore, leviter compresso. Thorax marginibus lateralibus denticulatis, angulis litteralibus extrorsum ef nonnilil antrorsum foliaceo-productis, apice in dentem promimuli:. Abdomen hemelytris paullo latius Tibire anteriores prasertim supra dilatate, parte dilatata superiore basi et apicem versus subito valde angustata, partc inferiore angusta, basi obsoleta.

2. D. Falx DrurY. - Obscure cinnamomea; abdomine dorso dilute sordide flavescente; alis sordide vinaceis, limbo posteriore pallide subinfuscato. \&. Long. 23, Lat. 7 mill.

f. Femoribus posticis leviter incrassatis, rectis, subtus prope apicem lobo obtuse dentiformi, posterius serrulato, armatis; tibiis posticis supra valde, subtus leviter dilatatis, ante medimm latissimis, hinc basin versus valde, apicem versus leviter sensim angustatis.

Cimex Falx Drury. Ill. nat. list. III. p. 62. 1'l. 45. fig. 2. (I782).

Petuscelis lunutus Sign. in THoms. Arch. ent. II. p. 294. 555. (1858).

Patria: Calabar. (Coll. SigNonet.)

Antenne artieulo secuudo supra subtusque obsolete subearinato, articulis tertio et quarto exempli descripti mutilatis. Thorax alutareus, marginibus lateralibus denticulatis, angulis lateralibus in processum depressum, foliaceum, oblique antrorsum ot sursum vergentem, sat longaun (minus longam tanen quan in icone Druryi) productis. Seutellum apier imo pallido. Abdomen hemelytris nommihil latins. Tibie anteriores utrimque distinete, lieet supra magis quam sulutus, dilatatie, basi simpliees, pone medium leviter angustatie.

aa. Tibiis unticis leviter vel levissime, supra subtusque ceque late dilatutis.

3. 1. alata WESTW. - Nigricans, remote silaceo-sericea, vitta laterali angusta obliqua pectoris dense sericea; antennarum articulis secundo et tertio basi apiceque nec non tarsis testaceis; maculis duabus pone medium abdominis dorsi flavescentibus; scutelli apice imo pallido. \&. Long. 26, Lat. 8 unill. 
ơ. Ventre segmento secundo prope apicem tuberculis duobus minutis, valde distantibus instructo; femoribus posticis vix curvatis, modice incrassatis, subtus prope apicem in latere exteriore crista, dentem obtusum simulante, minute crenulata, instructis; tibiis posticis supra subtusque modice dilatatis, basi angustatis, subtus prope basin subampliatis.

Myctis alata Westw. in Hope. Cat. of Hem. II. p. 12. (1842).

Mictis alata DALL. List of Hem. II. p. 393. 25. (1852).

Patria: Terra capensis. (Coll. Signorer.) Sierra Leona. (sec. Hope. Cat., ubi tamen patria haud raro incorrecte est indicata.)

In multis cum Mygdonia valga, cui subsimilis, congruit, tibiis anterioribus subrlilatatis, tibiis posticis latioribus, angulis thoracis latcralibus magis productis, latioribus, marginibus fortius denticulatis divergit. Antennae articulo tertio secundo vix breviore, suprai subtusque obsolete carinato, ultimo in excmplo descripto inutilato. Thorax unarginibus lateralibus distincte denticulatis, angulis lateralibus in processum sat latum, depressum, extrorsum et leviter sursum vergentem, sat longe productis Abdomen hemelytris nonmihil latius. Tibiae antcriores supra subtusque levissime dilatatie, lineares.

4. D. Rothii DaLL. - Ferrugineo-nigricans, remote silaceo-sericea; hemelytris ventreque obscure ferrugineis; antennis, apice tuberculorum antenniferorum rostroque flavo-testaceis; apice imo scutelli pallido; alis vinaceis: abdominis dorso medio macula magna flavescente notato; pectore vitta laterali obliqua dense silaceo-sericea ornato. f. Long. 24, Lat. $7 \frac{1}{2}$ mill.

Mictis Rothii DaLl. List. of Hem. II. p. 395. 28. (I852).

ㅇ. Ventris segmentis secundo et tertio pone medium tuberculis duobus parum elevatis, valde distantibus, nigris, instructis; femoribus posticis rectis, leviter incrassatis, subtus prope apicem in latere exteriore dente sat magno armatis; tibiis posticis, præsertim subtus, sat dilatatis, linearibus, basi angustatis.

Patria: Abyssinia. (Coll. Signoret.)

Exemplum pessime conservatum, anteunis pedibusque, exceptis pede postico recto articuloque basali antennarum, mutilatis, exami- 
navi. Thorax marginibus lateralibus denticulatis, angulis lateraliłus in processum latum, depressum, foliaceum, oblique antrorsum of nomnihil sursum rergentem, sat longe productis, acutis. Nbolomen hemelytris nonnihil latins; angulis imis segmentorum pallidis.

Pedes rufo nigroque varii. see. DALl is.

Propter affinitatem magnam crm D. alata hanc speciem ad hoe genus retuli. Tibie anteriores dilatatie, neene?

5. D. foliaceipes STÅ. - Obscure cinnamomea, remote silaceosericea; pectoris vitta laterali obliqua dense sericea; antennis pallide cinnamomeis, articulis primo, secundo et tertio apicem versus infuscatis, ultimo flavo-cinnamomeo; membrana fusca; alis levissime infuscatis; abdomine dorso nigro, maculis duabus basalibus segmenti dorsalis quarti nec non angulis basalibus segmentorum sordide flavescentibus. ㅇ. Long. 24, Lat. $7 \frac{1}{2}$ mill.

ㅇ. Ventris segmento secundo latera versus tuberculo obsoleto instructo; femoribus posticis vix curvatis, apicem versus sensim sat incrassatis, prope apicem subtus in latere exteriore crista dentiformi, serrulata, armatis; tibiis posticis supra subtusque sat dilatatis, ante mecium utrimque rotundato-ampliatis, marginibus pone nedium parallelis.

Mictis folicicipes STAL. Öfv. Vet. Ak. Förh. 1855. p. 28.13. Patria: Caffiraria. (Mus. Holm.)

Anteune graciliusenlac, corpore nomnihil breviores, articulis primo et quarto ieque longis, intermediis duobus, presertim tertio, illis brevioribus, tertio superne medio subcarinato. Thorax marginibus lateralibus denticulatis, angulis lateralibus cxtrorsum nonnihil produetis, subrectis, apice in deuticulum abientibus. Sentellum apice imo pallido. Aldomen hemelytris nomihil latius. Tibie antiea leviter dilatate, intermedia tricnetrex, supra late sulcatie.

\section{MYGDONIA STÁL.}

Caput subquadratum, tuberculis antenniferis subcontiguis, lobo medio nec elevato nec producto, raro*) inter tubercula antennifera distinguendo. Rostrum breviusculum. Scutellum æquilaterum. Corium margine apicali sæpissime leviter sinuato, angulo apicali nonnihil producto. Pedes postici valde distantes;

•) in M. bellicosa FABR. 
femorihus anterioribus subtus prope apicem in latere anteriore bidentatis, dente apicali interdum obsoletissimo; femoribus posticis, præsertim apud mares, incrassatis; tibiis anterioribus simplicibus, triquetris; posticis supra subtusque, ad parten saltem, dilatatis; tarsis posticis articulo primo apicalibus duobus ad unum longitudine subrequali.

a. Angnelis upicalilus segnenti penultimi abdominis spinula amnatis; cupite breviusculo, lobo medio inter tubercula antennifera distinguenulo; antennis yrucilibus, teretilus.

1. I. bellicosa FABR. - Nigra, dense punctulata, remote silaceo-sericea; pedibus anterioribus tarsisque posticis fusco-testaceis; alis sordide vitreis, fusco-venosis; apice ino scutelli maculisyne neto vel sex dorsi abdominis dilute sordide flavescentibus. ơ. Long. 17-20, Lat. 4-5 mill.

c. Ventris segmentis secundo et tertio spinis duabus validis, sat Inngis, apice interdum compressis, armatis; femoribus posticis valde (licet plus minus) curvatis et incrassatis, basi gracilioribus, apicem versus in latere interiore denticulis nonnullis et apice in latere exteriore dente majore armatis; tibiis posticis leviter dilatatis, apicem versus leviter incurvis, apice paullo ampliatis, intus prope apicem dente parvo armatis, inter dentem et basin subtilissine denticulatis, supra in apice calcaratis.

Cimex lellicosus FABR. Spec. ins. II. p. 361. 137. (1781). Mant. ins. I1. p. 297. 178. (1787).

Lygaus bellicosus FABR. Ent. syst. IV. p. 145. 36. (1794); Syst. Rlıyng. P. 215. 47. (1803).

Patria: Calabar. (Coll. Signorér et śtrál.)

Thorax margiuibus lateralibus convexis, inermibus. Abdomen et hemelytra aque lata. Corium margine apicali subrecto.

aa. Angulis apiculibus seqmenti penultimi abdominis inermibus; lobo medio capitis inter tubercula antennifera subcontigua haud distinguendo.

b. Antemis teretibus, articulo tertio raro subcompresso.

c. Thorace gramulis destituto.

Hemiptera afrisant. II. 
d. - Iutenunum articulis nltimo et penultimo fere ceque lonyis, busali brevioribus; rentris segmentis secundo et tertio apud nuren lispinosis; tibiis posticis leviter dilutatis, sublineuribus, upud nurem subtus upicem versus dente armatis.

2. I. valga Lis. - Ferrugineo-nigricans, silaceo-sericea, ventris disco vittaque laterali pectoris densissime sericeis; antennarum articulis secundo et tertio basi apiceque, quarto toto flavo-testaceis; alis obscure fuscis; apice imo scutelli margineque basali medio segmentorum abdominis dorsalium quarti et quinti testaceo-flavescentibus; thoracis marginibus lateralibus denticulatis, angulis lateralibus acutis, plus minus oblique antrorsum et sursum valde productis. $\sigma^{7}$. ㅇ. Long. 19-25, Lat. 5-7 mill.

○. V'entris segmentis secundo et tertio spinis dnabus valde distantibus, armatis, apice medio leviter productis; femoribus posticis modice incrassatis, plus minus curvatis, subtus apicem versus obsolete crenulatis, apice utrimque spina armatis; tibiis posticis linearibus, apice superne calcaratis, subtus prope apicem dente armatis.

․ Ventris segmento secnndo obsoletissime bituberculato; femoribus leviter incrassatis, levissime curvatis, basin versus sensim gracilescentibus, subtns seriatim minutissime granulatis, apice in latere exteriore dente obtuso armatis; tibiis linearibus, apice superne obliqne truncatis, inermibus.

Cimea valgus Lis. Mus. Lnd. Ulr. p. 171. 5. (1764); Syst. Nat. ed. XII. p. 720. 36. (1767); De Geer. Mém. VII. p. 618. 16. Pl. 46. fig. 6. (1778); Faßk. Syst. Ent. p. 708. 54. (1775); Mant. Ins. II. p. 288. 91. (1787).

Cimed hottentotta Herbst. Gemeinn. Naturg. des Thierr. VI. 1. 256. 6. PI. 39. 1. fig. 5. (1784).

lygacus calyns FABR. Ent. syst. IV. P. 133. 1. (1794); syst. Rhyng. 1. 203. I. (1803).

Alyclus volyus Thunb. Hem. rostr. cap. III. p. 2. (1822).

Cerbus vulgus HaIn. Wanz. Ins. I. p. 14. fig. 7. (1831); Bткм. Handh. II. 1. p. 340. 4. (18:35). 
C'erbus affinis 11. ŚCH. Wanz. Ins. VI. p. 29. (1842).

Mictis valgus BLANCH. Hist. nat. Ins. p. 120. 1. Pl. 4. fig. 5 ; A. et S. Hist. des Hém. P. 190. 1. (1843); DALL. List of Hem. II. p. 393. 23. (1852).

Patria: Terra capensis. (Mus. Holm., Coll. Signoret et STẢL.)

Species quoad magnitudinem, formam et erassitiem femorum postieorum, latitudinem tibiarun posticarum et magnitudinem spinarum ventris apnd marem, valde varians.

dd. Antennis gracilitus, crticulis mimo et quarto fere coque longis, singnlatim tertio et secundo nonnilhil longiorilns; rentre apud mares quadrispinoso, apud feminas duadrituberculato; tibiis posticis sat dilatatis, apud mares subtus denticulo armatis of supra in apice calcarcotis.

3. II. cruciata DALL. -- Dilute sordide subtestaceo-flavescens, silaceo-puberula, dense punctulata; abdomine pedibusque posticis, exceptis tarsis, fusco-testaceis, illius dorso rufescente, connexivo pallido-maculato; scutello nigricante; corio a basi ultra medium, membrana alisque fuscis, his antice interdum flavescentibus. $0^{7}$. ․ Long. 19, Lat. 6 mill.

o. Abdomine hemelytrisque aque latis; rentris segmentis secundo et tertio spinis duabus sat validis nigris armatis; femoribus posticis sat incrassatis, hasi gracilioribus et leviter curvatis, subtus prope apicem in latere interiore denticulo et in latere exteriore dentibus duobus distinctioribus armatis; tibiis posticis supra subtusque totis modice dilatatis, basin versus sensim leviter angustatis, apice superne sinuato-truncatis, calcaratis, subtus inter medium et apicem denticulo armatis, pone denticulum subsinuatis.

․ Abdomine hemelytris nonnihil latiore, ventris segmentis secundo et tertio nigro-bituberculatis, femoribus posticis rectis, apicem versus sensim modice incrassatis, pone medium crista, apicem versus sensim magis elevata, apice crenulata, instructis; tibiis posticis quam apud marem paullo latioribus, basi angustatis, apice superne oblique truncatis, inermilus. 
Mictis cruciutu DALL. List of Hem. II. p. 396. 31. (18:2).

Mictis cruciatus Sign. in Troms. Arch. ent. 11. PI. 9. fig. 7. (1858).

Patria: Calabar. (Mus. Holm., Coll. Signoret et Stid.)

Antenna corpore nonnihil breviores. Thorax marginibus lateralibus inermibus, angnlis lateralibus rectis vel subacutis, extrorsum nounilil prominentibus, margine minute serrulatis.

ddd. Antennis gracilibus, articulo ultimo omnium longissimo.

e. Tibiis postiris subtus, saltem in medio et apice, alistincte dilututis*).

f. Sermentis rentris secundo et tertio apud mares medio retrorsinn. fore ad apicem segmenti quarti conjunction productis et ibidem cun lnijus medio plus mimus distincte transversion elevatis.

4. I. Lavis P. B. - Fermerineo-nigricans, remote silaceo-serirea; macula laterali mesosterni dense sericea; antennis apicem versus dilute ferrugineis; scutelli apice imo tarsisque forrugineu-albidis; alis sordide hyalinis, fusco-venosis; abdominis dorso nigro. $\sigma$. ․ Long. 22, Lat. 6 mill.

o'. Abdomine hemelytrisque xque latis; ventris segmentis secundo et tertio medio retrorsum fere an apicem segmenti quarti anguste productis, ihidem rum medio segmenti quarti transversim elevatis, parte elevata ntrimque tuberculata, seguento secundo tubereulis duobus transversis, leviter elevatis, valde distantibns armatis; femoribus posticis modice incrassatis, subrectis, subtus prope apicen in latere exteriore dentibus duwhus armatis, inter dentes denticulatis; tibiis posticis prope basin levissine, dein apiecen rersus distincte dilatatis, supra in apice calcaratis, subtus paullo pone medium in dentem ampliatis. pone dentem sinuatis.

lygerus serratus P. B. Ins. H. 202. Hém. PI. 12. fig. 2. (180i)

․ Atelomine hemelytris paullo latiore; ventris segmento recundo tubersulis duobus obsoletissinis instructo, apice medio

7) Ad hane divisionem pertinct Lygueus oblongipes lishu, secundum descriptio-

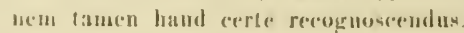


leviter obtuseque producto; femoribus posticis nonnihil incrassatis, subtus apicem versus crista levi, obsolete serrulata, prope apicem dentis instar elevata, instructis; tibiis posticis sat dilittatis, inermibus, basi valde angustatis et vix dilatatis.

Lygèus lavis P. B. Ins. p. 202. Hém. Pl. 12. fig. 1. (1805).

Patria: Calabar. (Coll. Signoket et Stíl.)

Thorax marginibus lateralibus anticis rectis, vix nisi obsoletissime denticulatis, angulis lateralibus rectis, distinete nonnihil prominulis, marginibus obsolete serrulatis. Nembrana fusca, basi obseurior.

5. I. rufitorsis STÅL. - Obscure fusco-ferrugineal, renote silacen-sericea, mesostethii macula laterali dense sericea; apice imo scutelli, angulis basalibus segmentorum abdominis tarsisque dilute testaceo-flarescentibus; alis sordide hyalinis, fusco-venosis; abdominis dorso rufescente vel Havo-rufescente; membrana fusca, basi olscuriore. $\sigma^{7}$. ․ Long. 20 - 23, Lat. $5-6 \frac{1}{2}$ mill.

o'. Abdomine hemelytrisque ieque latis; rentris segmentis secundo et tertio medio retrorsum fere ad apicem segmenti quarti anguste productis, ibidem cum medio segmenti quarti transversim elevatis, farte elevata utrimque tuberculata, segmento secundo tuberculis duobus transversis, leviter elevatis, valde distantibus, armato; femoribus posticis modice incrassatis, subrectis, subtus prope apicem in latere exteriore dentibus duobus armatis, inter dentes denticulatis; tibiis posticis prope basin levissime, dein apicem versus distincte dilatatis, supra in apice calcaratis, subtus paullo pone medium in elentem ampliatis, pone dentem sinuatis.

ㅇ. Abdomine hemelytris paullo latiore; ventris segnento secundo tubereulis duobus obsoletissimis instructo, apice medio leviter obtuseque producto; femoribus posticis nonuihil incrassatis, subtus apicem versus crista levi, obsolete semulata, prope apicen dentis instar elevata, instructis; tiliis posticis sat dilatatis, inermibus, basi ralde angustatis et vix dilatatis.

Patria: Calabar. (Mus. Ilolm., Coll. Sicinoker et s'TAL.)

l'recerdenti maxime althis, colore dorsi abdoninis divergit. 
ff. Seymentis centris secundo et tertio ajunl marem apice medio conjunctim $n$ segmentum yuurtum haul productis, illo spi"is vel tuberculi: duobus armaro, segment, yuarto etiam obtusissime bituberculato.

6. II. granulata STAL. - Obscure ferrugineo-fisca, remote silaceo-sericea, macula laterali mesostethii dense sericea; antennis totis nigris; membrana fusca, basi obscuriore; alis soldide hyalinis, limbo posteriore infuscato, venis nigro-fuscis; dorso abdominis rufescente, sumentis duobus ultimis nigris; tarsis anterioribus fusco-testaceis, postiojs cum apice imo scutelli flavo-testaceis; thorace ruguloso-punctato; ventre femoribusque posticis granulatis. o'. Long. 27. Lat. 7 mill.

o' Ventris segmento secumdo prope apicem spinis duabus apice obtusis, late distantibus armato, apice medio levissime producto, segmento quarto tuherculis duolus majusculis, leviter elevatis, instructo; femoribus posticis salt incrassatis, leviter curvatis, supra serie denticulorum instructis, subtus apice utrimque spina mediocri et prope apicem intus spinula armatis; tibiis posticis a basi apicem versus semsim dilatatis, apice latissimis, superne in apice calcaratis, subtus fere aute merliun denticulo armatis, pone dentem sinuatis, apice oblique truncatis et in medio partis truncatae spinula prieditis.

Patria: (inimea. (Coll. TígNuRE'T.)

P'recerlentibus duabus simillina, majos'. granulis distinctis ventris femorumque posticorum structuraque hormm partinm rorporis distinctissima. Antennae corpore nonnihil brevores. Thorax marginibus lateralibus remote distincteque denticulati-, angulis lateralibus subacutis, extrorsum nomilil prominentibus.

7. П. spimblosa GIGN. - Fuscescente-ferruginea, silaceo-seriora; antemis nigris; apice imo scutelli tarsisque flavo-testaceis; membrana fusca, basi obscuriore; abdomine dorso flaro-testaceo (vel rufescente), segmentis duobus ultimis fere totis nigris; alis subrinaceis, limbo postico obsolete infuscato. o long. 19, Lit. 5 mill.

$c^{\lambda}$ Ventre segmento secundo prope apicen tuberculis duobus hreviter conicis, valde distantibus, armatn, apice medio le- 


\section{$-23-$}

vissime producto, segmento quarto tuberculis duobus levissime elevatis, obsoletis, instructo; femoribus posticis modice incrassatis, levissime curvatis, subtus serie tuberculorum minutorum et apice dente distincto armatis; tibiis posticis ante medium subcompressis, haud dilatatis, pone medium supra subtusque distincte dilatatis, superne in apice subcalcaratis, sultus poue medium denticulo armatis, pone dentem sinuatis.

Mictis spinulosus Sign. in Thoms. Arch. ent. II. ๒. 296. 560 . (1858).

Patria: Calabar. (Coll. SIGYORET.)

M. Levi et mujulorsi simillima, tibiis posticis ante medium, apud minem saltem, hand dilatatis, apice quan in medio latioribus structuraque ventris divergit. Antenne exempli deseripti mutilatre. Thorax marginibus lateralibus remote dentienlatis, angnlis lateralibus subaentis, distincte prominentibus.

In exemplo unieo, quod vidi, minus bene conservato, maculau lateralem sericearn mesostethii haud inveni.

8. II. holtentotta 1'. B. - Obscure ferrugineo-fusca, remote silaceo-sericea, pectoris vitta laterali obliqua densissime sericea; articulo ultimo antennarmu dilute subferngineo; apice imo scutelli tarsisque flavo-testaceis; alis sulvinaceis, limbo postico infuscato; abdomine dorso nigricante, incisuris in flavoferrugineum vergentibus: membrana fusca, basi nigra. ơ Loug. 2I, Lat. $5 \frac{1}{2}$ mill.

\%. Ventris segmento secundo tuberculis duobus frarvis subconicis armato, segmento quarto medio posterius nonnihil elevato, parte elevata subbituberculata; femoribus posticis leviter incrassatis, levissime curvatis, subtus prope apicem intus dentibus duobus, extus dente nno armatis; tibiis posticis basin versus simplicibus, subtus in medio dente obtuso armatis, apice nomihil dilatatis, supra a parte tertia basali apicem versus sensim nonnihil dilatatis, apice calcaratis.

Lygous Hottentottus P. B. Ins. p. 203. Hém. Pl. 12. fig. 3. (1805).

Patria: Calabax. (Coll. Nitil.) 
Pracedentibus simillima, vitta dense scric a pectoris farcile rerogrescenda. Thorax marginibus latralibus versus angulos laterales, arnte nomihil prominentes, minute denticulatis.

ee. Tibiis posticis subtus vir dilatatis, apud feminam ante medium superne obtuse lobatis.

9. II. histrica STAL. - Nigricans, remote silaten-sericea, mesnstethii lateribns macula sericea destitutis; antenuis, rostro pedibusque anterioribus ferrugineo-fiscis; apice inn scutelli tarsisyne flavo-testaceis; membrana nigro-fusca; alis soldide hyalinis, fusco-venosis; ahdomine dorso nigro, segmentis secundo, tertio et quarto macula Havescente notatis. \&. Long. 17, Lat. $4 \frac{1}{2} \mathrm{mill}$.

․ Ventre ante medium convexiore, segmento secundo apice medio leviter obtuse producto; femoribus posticis sat incrassatis, hasi gracilioribus et vix curvatis, subtus crista levissime elevata, pone medium paullo ampliata, minute serrulata, et propr apiom denticulo armatis; tibiis posticis subtus compressis, vix dilatatis, apice denticulo armatis, supra pone medium haud dilatatis, ante medium in lobum obtusum ampliatis.

Patria: Granil bassam Guinea. (Coll. Signorba)

Species parvinscula, structura tibiamm posticamm maxime insignis. Antenne ad partem mutilatac. Tholax marginibus lateralihus integris, angulis lateralibus subacutis, leviter prominentibus. Abromen bemelytris paullo latius.

\section{ic. Thorace gromulato.}

10. П. tuberculosa SIGN. - Nigra vel subferrugineo-nigra, parce silaceo-sericea; thorace distincte remoteque granulato, marginibus lateralibus distincte denticulatis, angulis lateralibus rectis vel subobtusis, nonnihil prominentibus; scutelli apice imo tarsisque, saltem posticis, dilute flaro-testareis; alis fuscocarrulescentibus; abdomine dorso concolore. o. ㅇ. Long. 26, Lat. 9 mill.

б. Ventris segmento secundo apice et segmento tertio basi medio in tuberculum mediocrem conjunctim elevatis, segmentis tertio apice et quarto basi medio leviter vel levissime elevatis; femoribus posticis valde incrassatis, hasi gracilinrihus et sat 
curvatis, sulotus pone medium in latere interiore denticulis nonmullis, in latere exteriore apicen versus dentibus duobus distinctioribus armatis; tibiis posticis supra per totam longitudinem nomihil dilatatis, subtus valde dilatatis, pone medium in dentem acutum ampliatis, pone dentem subito angustatis et dein ad apicem haud dilatatis.

Mictis tuberculuste: SIGN. Rev. et Mag. Zool. 1851. p. 448. 15. Pl. 15. fig. 6.

7. Ventre inermi, laud tuberculato; femoribus posticis rectis, apicem versus spnsim nonnihil incrassatis, subtus pone medium crista, apicem versus dentato-ampliata, apice serrulata, instructa; tibiis posticis supra subtusque sat dilatatis, apicem rersus sensim, basi magis angustatis.

Patria: Gabon, Calabar. (('oll. Signonet et StaL.)

bb. Antenumrnm articulis serundo et tertio supra subtusque leviter curinati:

11. I. cormuta DALL. - Remote silaceo-sericea, nigra, subtus cum antemnis, rostro, predihus, lateribus dorsi abdominis fasciisque incisurarum comexivi testaceo-flavescens; alis fuscis; thoracis marginibus spinis majusculis armatis, angulis lateralibus acutissimis, sursum et extrorsum longe productis. ․ Long. 24, Lat. 7 mill.

ㅇ. Ventris segmento secundo tuberculis duobus parvis valde distantibus instructo; femoribus prosticis apicem versus sensim levissime incrassatis, rectis, subtus prope apicem in latere exteriore dente armatis; tibiis posticis leviter dilatatis, linearibus, inermibus.

Mictis connute DALL. List of Hem. Il. p. 397. 27. (1852). Mictis sulcicon nis SIGN. in THoms. Arch. ent. 11. p. 295. 558. Pl. 11. fig. 5. (1858).

Patria: Calabar. (Coll. Signonet et STÁL.)

Antennarum articulus ultimus in exemplis, quie vidi, mutilatus.

\section{PUPPEIA STAL.}

Corpus oblongum. Caput quadratum, tuberculis antenniferis paullo distantibus, lobo merlio nec inter illa elevato, nec pro- 
ducto. Rostrum ad coxas intermedias extensum. Scutellum - paullo brevius quam latius. Corium margine apicali versus angulum apicalem exteriorem, acute nonnihil productum, distincte sinuato. Metasternum leviter elevatum et distincte bituberculatum. Pedes postici sat distantes, a latere corporis quam inter se tamen multo longius remoti; femoribus anterioribus subtus prope apicem in latere anteriore dente acuto armatis, posticis apod marem valde incrassatis; tiliis triquetris, præsertim postieis compressis, his apud utrumque sexum femoribus paullo brevioribus; tarsis posticis articulo primo apicalibns duobus ad unum fere æque longo.

1. P. cincta SIGN. - Cinnanomeo-Havescens, parce silaceo-sericea, supra subtiliter punctulata; antennis, marginibus lateralibus et postico thoracis, scutello fasciisque dorsalibus abdominis nigris; lemelytris cinnamomeis, membrana subcupreonigra; alis subviolaceo-fuscis; fasciis obsoletis lateralibus pectoris infuscatis; thoracis marginibus lateralibus anticis distincte serratis, angulis lateralibus apice acuminatis, extrorsum nonnihil prominentibus. ơ. \&. Long. 24, Lat. 8 mill.

Mictis cincetus SIGN. Inn. ent. Sír. 2. VIII. p. 71. Pl. t. fig. 3. (1850).

$\sigma^{7}$. Ventre lateribus distincte punctato, segmento secundo apice medio nonnihil producto et ibidem cum media basi segmenti tertii leviter elevato; femoribus posticis admodum incrassatis, rectis, subtus obtusissime suberistatis, crista pone medimm obsolete crenulata; tibiis posticis subtus leviter dilatatis, ante medium dente armatis.

9. Ventris semmento secundo apice medio vix producto, nec elevato; femoribus posticis paullo incrissatis, subtus prope apicem in latere exteriore dente aruatis; tibiis posticis compressis, inermibus.

Patria: Guinea lusitanica. (Mus. Holm. et Coll. Signoner.)

Antemax corpore vix breviores. 


\section{MICTIS LEACH.}

Zool. misc. 1. p. 92. (1814).

Corpus magnum, oblongum. Caput quadratum, tuberculis antenniferis contiguis vel subcontiguis, lobo medio nec elevato, nee froducto, inter illa haud vel regre distinguendo. Rostrum breve. Thorax antrorsum sat declivis, apice collari destitutus. scutellum triangulare, subxquilaterum. Metasternum tuberculis destitutum. Pedes postici valde distantes; femoribus anterioribus prope apicen subtus in litere anteriore denticulis duobus vel uno armatis, raro inermibus, posticis, presertim apud mares, incrassatis; tibiis triquetris, posticis plus minus compressis, subtus interdum subdilatatis.

a. Angulis lateralibus thoracis prominentibus, rectis vel acutis, numquam rotundatis; femorilus unterioribus subtus prope apicen bidentutis, dente upicali interdum obsoleto.

b. Alis totis sulsordide vitreis, fusco-venosis; ventre inermi; femoribus posticis marium basi spina armatis.

1. II. Inctuosa STAL. - Nigricans, parce sericea; antennarum articulo ultimo flavescente-ferrugineo; membrana subrneofusca; alis sordide vitreis, fusco-renosis; macula laterali pectoris, aperturam apparatus odoriferi includente, carnea; abdominis dorso concolore, immaculato. o’. o, Long. 25-29, Lat. 7-9 mill.

Mictis curvipes Sign. Ann. ent. Sér. 3. VIII. 1. 938. 1 I3. (186I).

б. Abdomine hemelytrisque aque latis, segmento ventris secundo apice medio levissime producto; femoribus posticis valde incrassatis, basin versus multo graeilioribus et ibidem valde curvatis, basi subtus tuberculo spiniformi distinctissimo armatis, pone medium subtus in dentem validissimum ampliatis; tibiis posticis femoribus distincte brevioribus, valde compressis, apicem versus subangustatis, apice subtus leviter dentato-productis.

․ Abdomine hemelytris nonnihil latiore; femoribus posticis rectis vel prope basin levissime curvatis, modice incrassatis, 
subtus obsolete subcristatis, crista subtilissime crenulata, prope apicen in dentem distinctum elevata; tibiis posticis femoribus paullo hrevioribus, sat compressis, apicem versus leviter angustitis.

Patria: Madagascar. (Mus. Holm., Coll. Signorét et ŚtẢL.)

Antenna in fusco-ferrugineun vergentes, graciliuseulie, articulis ultimo et basali anue longis. Thorax marginibus lateralibus obsolete crenulatis, angulis lateralibus acutis, cxtrorsum prominentibus, nargine minute serrulatis.

2. II. malagaseariensis ŚLGN. - Subobscure ferruginea, interdum ferrugineo-nigricans, silaceo-sericea; articulo ultimo antennarum concolore, interdum pallidiore; alis sordide vitreis, fusco-venosis; membrana cuprescente-fusca; abdomine dorso nigro, pone medium maculis duabus flavescentibus notato; macula laterali pectoris dilute carnea. $0^{7}$. ‥ Long. 25, Lat. 8 mill.

Mictis Madayascariensis Nigr. Ann. ent. Sér. 3. VIII. p. 938. 114. (1861).

o. Abdomine hemelytrisifue aque latis, ventris segmento secundo apice medio levissime producto; femoribus posticis valde incrassatis, basin versus nulto gracilioribus et ibidem valde curvatis, basi subtus tubereulo spiniformi armatis, pone medium in dentem validissimum ampliatis; tibiis posticis femoribus nonnilil brevioribus, valde compressis, apicem rersus subangustatis, apice subtus leviter dentato-jroductis.

ㅇ. Abdomine hemelytris nomnilnil latiore; femoribus posticis rectis vel prope hasin levissime curvatis, modice incrassatis, subtus longitrorsum obsolete subcristatis, crista subtilisissime cremulata, prope apicem in dentem distinctum elevata; tibiis posticis femoribus paullo brevioribus, sat compressis, apicem versus leviter angustatis.

l'atria: Madagascar. (Mus. Molm. et Coll. Nignoner.)

Antenne quam in precedente paullo erassiores, articulis basali et ultimo aeque longis. Thorax marginibus lateralibus obsoletissime remote crenulatis, angulis literalibus acutissimis, extrolsum ct sursum sat longe et magis quam in ulla specic encueris produetis. 
b). Alis bicoloribus, ritreis vel subsordide vitris, parte fere dimidia basali nigro-fusca; femoribus posticis marium losi subtus spina obtusiuscula armatis; rentre marium inerni.

c. Antennamum articulo tertio subtereti, sulco levissino instructo.

3. II. curvipes FABR. - Nigricans vel phus minus obscure ferruginea, silaceo--sericea; antennarum articulo ultimo dilute flavoferrugineo, prope apicem interlum leviter infuscato; abdomine dorso nigro, pone medium maculis duabus transversis, raro obsoletis, flavescentibus notato, snbtus toto ferrugineo vel plus mims late ferrugineo-livittato; macula laterali pectoris pallide carnea; membrana subeneo-fusea; alis vitreis, ante medium nigrofuscis. $\sigma^{7}$. ㅇ. Long. 22-28, Lat. $6 \frac{1}{2}-8$ mill.

$\sigma^{7}$. Ventre inermi, segmento secundo apice medio leviter producto; femoribus posticis valde incrassatis, basin versus gracilioribus et valde (licet plus minus) curvatis, subtus pone medium in dentem validissimum ampliatis, basi spina obtusa armatis; tibiis posticis femoribus brevioribus, valde compressis, pone medim subangustatis.

f. Femoribus posticis subrectis, basin versus levissime curvatis, modice incrassatis, subtus pone medium obsolete subcristatis, crista crenulata, prope apicem in dentem elevata; tibiis posticis longitudine paullo variabilibus, femoribus vix vel nomihil brevioribus, valde compressis, linearibus.

Cimex curvipes Fabr. Mant. Ins. I1. p. 288. 96. (1787).

Lygceus curcipes FABR. Ent. syst. IV. l. 137. 11. (1794); Syst. Rlyyng. p. 206.14 (1803).

Myctis apicalis Westw. in Hope Cat. of Hem. II. p. 12. (1842).

Cerbus fuliginosus KLug. Preisverz. 1842. p. 11. 214; Ent. Keit. XX. p. 86. 214. (1859).

Coreus heteropus Latr. in Calllaud. Voy. en Meroë. iV. 287. 30. Atl. Vol. II. Pl. 58. fig. 30. (sec. Schaum).

Mirtis curripes DALL. List. of Hem. II. W. 392. 20. (1852). 
Mictis Jibyssa DaLl. List. of Ilem. 11. p. 342. -2I. (I852).

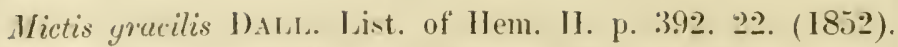

Wictis Bohememi șaL. Öfv. Vet. Ak. Fürh. 185.r. 1. 28. 11.

. Wietis heteropus SCHATM. in PETERs Reise nach Mossamb. Ins. p. 4l. (1862).

Patria: Caffraria, Srakop Atrie meridionalis occidentalis et Senegal. (Mus. Holm.); Mossambique. (Coll. STÁL); Sierra Leona. (Mus. Holm., Coll. Sigronet, et Stád); Congo et Gambia. (sec. Dallas.); Mbysinia. (sec. Latr., Schaum.).

Species per magnam partem Ifricie occurrens, quoad magnitulinem, longitudinem et crassiticm antemarum tibiarumque posticarum, crassitiem et curvaturam femorum posticormm variabilis. Thomx angulis lateralibus acutis, apice in spinulau abientibus, extrorsum productis, leviter antrorsum et sursum ctian vergentibus.

ce. Antennarum artionlo tertio sumu sulitusque distincte carinato vel compresso.

4. I. tartarea STÂL. - Nigricans, remote silaceo-sericea ; capite rostroque testaceo-Harescentibus; pectoris macula laturali dilute carnea; alis vitreis, ante medium nigro-fuscis; al domine dorso pone medium lineolis duabus transversis Havescentibus notato. $\sigma^{7}$. Long. 25 , Lait. 7 mill.

$\sigma^{3}$. Ventre inermi, segmento secundo apice medio levissime producto; femoribus posticis valde incrassatis, basin rersus graciliorihus et valde curvatis, sultus pone medium in dentem validissimum ampliatis, hasi spina amatis; tibiis 'ponticis femoribus brevioribus, valde compressis, pone medimm subangustatis.

Patria: Gabon. (Coll. signuret.)

M. curvipedi maxime affinis, structura articuli tertii antennarum coloregue capitis rostrique (an fortuito in exemplo descripto?) flavescente differt. Antennic corpore tertia parte breviores, airticulo ipicali olssenre testaceo, basali paullo breviore, tertio supra subtusque levissine compresso-ampliato, Jeliquis articulis paullo latiore. Thorax angulis lateralibus acutissinis, apice in spinulam abientibus, extrorsun nomnihil productis, antrorsum et sursum leviter vergentibu-

bbb. Alis nigro-fuscis, basi ipsa albidis; ventre murium tuberculo instructis; femorilus posticis basi subtus inermibus: antemarnm urticulo tertin leviter sulnuto. 
5. M. pectoralis GERM. - Nigra vel ferruginea, silaceo-sericea; antennarum articulo ultimo dilute ferrugineo, prope apicem infuscato; apice imo scutelli pallido; membrana subcupreofusca; alis nigro-fuscis, basi ipsa albidis; abdomine dorso nigro, flavo-bimaculato; macula laterali pectoris dilute carnea; angulis lateralibus thoracis plus minus productis, rectis rel acutis. $\sigma^{7}$. +. Long. 22-30, Lat. 6 $6 \frac{1}{2}-9$ mill.

万. Ventris segmento secundo basi medio retrorsum sat longe producto et cum medio segmenti tertii in tuberculum transversum, magnitudine varians, elevato; femoribus posticis valde (licet plus minus) incrassatis, basin versus gracilioribus et plus minus curvatis, subtus pone medium dente validissimo rel valido armatis, basi inermibus; tibiis posticis sat compressis, apicem versus sensim leviter angustatis, apice subtus subcalcaratis.

ㅇ. Ventre inermi; femoribus posticis nomihil incrassatis, basin versus gracilioribus et levissime curvatis, subtus prope apicem dente obtuso armatis; tibiis posticis compressis, sublinearibus.

Var. a. - Maxima, ferruginea; angulis lateralibus thoracis acutinsculis, sat productis; tubereulo ventrali maris magno.

Mictis validipes STÅL. Öfv. Vet. Ak. Förh. I855. p. 28. 12.

Vur. b. - Magna, nigricans; angulis lateralibus thoracis acutiusculis, nonnihil prokuctis; tuberculo ventrali maris sat magno.

Cerbus pectoralis Germ. in Silb. Rev. ent. V. p. 154. 74. (1837) sec. ex. typ. e Coll. Dregei.

Myctis parallelus Westw. in Hope. Cat. of Hem. II. p. 12. (1842).

Myctis horrificus Westw. in Hope. Calt. of Hem. II. p. 12 (1842).

Var. c. - Ninor, nigra vel ferrugineo-nigra; angulis lateralibus thoracis subrectis, minus prominentibus; tuberculo ventrali maris mediocri vel parvo; femoribus posticis maris minus curvatis, dente inferine minus ralido. 


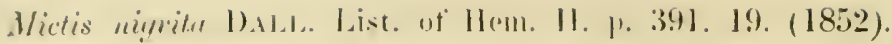

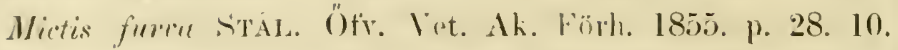

l'atria: Terra rapensis, Caffraria. (Als. Holm., Coll. SigNORET.)

Species quoarl magnitndinem, formam coloremque sit variabilis

al. Angulis lateralitons theracis hand imominentilus, rotundatis.

d. Scutello vittu cel linea dense sericea instmeto.

6. M. Mayri stital. - Fusescentr-fermginea, remote silaceosericra, vitta scutelli (") peetorisque dense sericeis; antennarum articulo ultimo pallidiore. proper apicem infuscato; abdomine dorso sordide subsanguimen, segmentis hasali et apicali nigris; alis fuscis: memhrana obsule fuscia. Q. Long. 22, Lat. 7 mill.

ㅇ. Abdomine hemelytris nomnihil latiore. ventris semmento secundo apice medio leviter producto; femoribus posticis recris, leviter incrassatis, subtus apieem rersu- leviter romplessis et crenulatis, prope apicem dente armatis; tibiis posticis rectis, compressis, femorihus vix hrevioribus.

Patria: Abyssinia. (Mus. Hohm.)

Antenna eorpore cireiter tertia parte breviores, articulis primo et quarto ieque longis, secundo paullo longrioribus. Rostrum articulis secundo et tertio aeque longis. Thorax marginibus lateralibus integris. Femora mteriorit subtus prope apieem spinulis duabus armata.

7. II. sentellaris DALL. Fusco-ferruginea rel nigra, silaceosericea; vitta scutelli vittalue obliquil pectoris, per ventris latera moducti, lense sericeis; antemis dorsoyue ablominis nigris, illormm articulo quarto basin versus flavo-ferrugineo: alis obsolete sublacteo-lyalinis, apicem rersus levissime infuscentis. o’. Long. 23, Lat. 7 mill.

o'. Abdomine hemelytris rix latiore, ventris segmento secundo apice retrorsum sat producto et cum hasi media segmenti tertii in tuberculum, partm altum, elevato, preterea tuberculis duotons parvis, minus distinctis, valde distantibus, instructo; trochanteribus posticis postiee tuberento parro subeonien in- 
structis; femoribus posticis sat incrassatis, basi nonnilhil curvatis, subtus pone medium leviter angulatim compresso-ampliatis, apice spinula armatis; tibiis posticis femoribus nonnihil brevioribus, compressis, apicem versus sensim leviter angustatis, apice subtus dentato-prominulis.

Mictis scutellaris DALL. List. of Ilem. II. p. 390. 17. (1852).

Patria: Caffraria. (Mus. Holm. et Coll. śtẢL).

Precerlenti affinis, antennis distincte longioribus, paullo crassioribus. Rostri articulus sccundus tertio nomihil longior.

8. II. scutellata Reiche et FAIRM. - Nigra vel fusco-ferruginea, sat dense silaceo-sericea, lineola anteriore longitudinali thoracis, vitta scutelli, vitta laterali pectoris ventrisque nec non lujus disco lense sericeis; antennarum articulo quarto basi flavo-ferrugineo; membrana obscure fusca; alis sordide hyalinis, pallide fusco-renosis; abdominis dorso niggro. ơ. Long. 20, Lat. 6 mill.

$\sigma^{7}$. Abclomine hemelytris paullo latiore, ventris segmento secundo tuberculis duobus parvis valde distantibus instructo, apice medio nomnilil producto et cum segmento tertio transversim leviter elevato; trochanteribus posticis inermibus; femoribus posticis rectis, modice incrassatis, pone medium subtus leviter obtuseque angulato-ampliatis; tibiis posticis rectis, linearibus, femoribus nomnihil brevioribus.

Mictis scutellata REICHE et FaIRM. Voy. en Abyss. Entom. p. 447. Pl. 29. fig. 4. (1848).

Patria: Abyssinia. (Coll. Signoretr.)

M. scutellari simillima, minor, antemnis brevioribus, articulo primo breviore, femoribus posticis minus incrassatis, basi vix curvatis, et ceteris distinctissima. Antennæ corpore dimidio breviores, articulis secundo et quarto aeque longis, primo sublougioribus. Rostrum articulo secundo tertio vix longiore. Thorax marginibus lateralibus integris. Femora anteriora subtus prope apicem bidenticulata.

9. II. castaneicornis STÅL. - Obscure ferruginea, remote silaceosericea, scutelli vitta maculisque tribus lateralibus pectoris prope coxas dense sericeis; antennis pallide ferrugineo-flaveHemiptera africanu. II. 
scentibus, articulo ultimo apicen versus infuscato; membrana subcupreo-fusca; alis obscure fuscis, basi ipsa albidis, parte apicali sordicle subvinacea; abrlomine dorso nigro. o’. Long. 23 , Lat. $7 \frac{1}{2}$ mill.

8. Abdomine hemelytris paullo latiore, rentris segmento secundo haud bitnberculato, apice medio nonnihil producto et cum media basi segmenti tertii levissime elevato; trochanteribus. posticis subtus tuberculo parvo subconico armatis; femoribus posticis modice incrassatis, hasi gracilioribus et distincte curvatis, apice subtus in latere exteriore bidentatis; tibiis posticis femoribus nomiluil brevioribus, compressis, ante medium paullo latioribus.

Mictis castanicomis S'TAL. Öfv. Vet. Ak. Förh. 1855. p. 27.1.

Patria: Caftraria. (Mus. Holm.)

M. scutcllari quoad forman partium maxime affinis. Antenuse corpore quarta partc breviores, articulis primo et quarto aeque longis, secundo paullo longioribus. Vargines thoracis integri. Femora anteriora subtus prope apicem bilenticulata.

10. II. tomento-rirgata STẢL. - Cinnamomea, sat dense silaceosericea, vitta pectoris laterali lineisque septem longitudinalibus thoracis, media per scutellum producta, densissime sericeis; antennarum articulis secundo, tertio et quarto dilute rufescente-ferrugineis, articulis secundo et tertio apice imo infuscatis; membrana subcupreo-fusca; alis nomilil infuscatis; dorso abdominis nigro, segmentis quarto et quinto basi medio anguste cinnamomeo-marginatis. ㅇ. Long. 20, Lat. 621 mill.

9. Abdomine hemelytris nonnihil latiore, ventris segmento secundo apice medio haud producto; femoribus posticis leviter incrassatis, rectis, subtıs prope apicem denticulo armatis; tibiis posticis rectis, leviter compressis, linearibus, femoribus æque longis.

Mictis tomento-virgata STẢL. Öfv. Vet. Ak. Förl. 1855. p. 27. 4 .

Patria: Caffraria. (Mus. Holm.)

Antennae crassiuscula, corpore dimidio nomnihil longiores, articulis secundo et quarto aque Jongis, primo illis vix breviore. Rostrum articulo secundo tertio subbreviorc. Thorax marginibus late- 
Jalibus integris. Femora anteriora subtus prope apicem spinula miuntissima armata.

dd. Scutello vitta dense sericea destituto.

e. Abdominis dorso toto vel saltem basi vel apice nigro.

f. Alis sulviolaceo-nigricuntibus, basi ipsa albidis.

11. I. Tristator FABR. - Nigra vel obscure ferruginea, remote silaceo-sericea; apice scutelli, tarsis antennarumque articulo ultimo sordide flavo-ferrugineis, hoc medio plus minus late infuscato; abdomine dorso nigro, sapissime flavo-bimaculato. o?. ‥ Long. $24-26$, Lat. S-9 mill.

o7. Abdomine hemelytrisque fere aque latis; ventris segmento secundo apice medio sat longe producto et cum medio segmenti tertii in tuberculum subtransversum elevato; femoribus posticis fusiformibus, sat incrassatis, subtus in medio angulatoampliatis; tibiis posticis femoribus brevioribus, compressis, subtus pone medium levissime sinuatis.

f. Abdomine hemelytris nomihil latiore, ventris segmento secundo apice medio vix producto; femoribus posticis leviter incrassatis, subtus obsolete crenulatis, prope apicem denticulo armatis; tibiis posticis quan in mare angustioribus et longioribus, femoribus aque longis.

Lygacus tristator FABR. Syst. Rhyng. p. 206. 13. (1803).

Mictis tristator DaLl. List of Hem. II. p. 390. 16. (1852).

Var. - Abdomine dorso immaculato.

Var. b. - Alis apice sordide hyalinis.

Var. c. - Corpore subtus dilute ferrugineo, nigro-maculato.

Patria: Sierra Leona. (Mus. Holm. et Coll. Signoret); var. a. Calabar. (Coll. StÅL.)

- Antenne articulis primo et quarto aeque longis, secundo nonnihil longioribus. Rostrum articulo secundo tertio nonnihil longiore. Thorax marginibus lateralibus obsolete cremulatis. Femora anteriora subtus prope apicem bidenticulata.

12. M. melaucholica STẢL. - Subferrugineo-nigricans, parce silaceo-sericea, subtus pallide ferruginea, pectoris lateribus ventrisque medio maculis magnis nigris ornatis; scutelli apice, tarsis antennarumque articulo apicali flavo-ferrugineis, hoc 
medio fusco; ablominis dorso rufescente, segmento basali, lateribus segmenti secundi, segmento ultimo fere toto, connexivo segmentisque analibus nigris; membrana nigricante. q. Long. 29, Lat. 9 mill.

․ Abdomine hemelytris latiore, ventre inermi; femoribus posticis leviter incrassatis, rectis, subtus prope apicem dente armatis; tibiis posticis sat gracilihus. nonnihil compressis, linearibus, femoribus seque longis.

Patria ignota. (Coll. Śgnorer.)

M. Tristutori maxime affinis, colore dorsi abdominis tibiisqu posticis distincte gracilioribus differt.

fi. Alis varicoloribus, numquam violaceo-nigris.

g. Abdomine dorso toto nigro vel nigro-rufescente.

h. Antennis totis vel sultem articulis primo, secundo et tertio nigricantibus.

13. II. grallatoria S'TÁL. - Obscure ferruginea, presertim subtus sat dense silaceo-sericea; antennis, limbis lateralibus thoracis, dorso abdominis pedibusque nigricantibus; articulo apicali antemnarum concolore vel fusco; margine basali segmentorum quarti et quinti dorsi ahdominis medio testaceo; alis sordide hyalinis, renis pallide fuscis; membrana subcupreofusea; rostri articulo secundo tertio distincte longiore. o’. Long. 21, Lat. 6 mill.

o. Abdomine hemelytris vix latiore, ventris segmento secundo apice medio leviter producto, haud elevato; femoribus posticis modiee incrassatis, prope basin sat curvatis, subtus pone medium dente minore obtuso et prope apicem denticulo acuto armatis; tibiis posticis femoribus nounihil brevioribus, compressis, ante medium paullo latioribus.

Mictis grallatoria STAL. Ofv. Vet. Ak. Förh. 1855. p. 27. 6. Patria: Caffraria. (Mus. Holm.)

Antenne rorpore tertia parte breviores, modice incrassitte, articulis primo, secunde at quarto aque longis. Thorax marginibus lateralibus integris vel obsoletissime crenulatis. Femora anteriora subtus prope apicem denticulo armatis. 
14. I. grisen-sericen șTÁL. - Cinnamomea rel subferruginea, presertim subtus griseo-sericea; antennis, dorso abdominis pedibusque nigricantibus; articulo ultimo antennarum, interdum etian margine basali medio segmentorum dorsalium quarti et quinti abdominis pallide ferrugineis, illo apicem versus infuscato; alis subsordide hyalinis, haud vel vix infuscatis; membrana subcupreo-fusca; articulis rostri secundo et tertio aque longis. $\sigma^{7}$. Long. 17, Lat. 5 mill.

o. Abdomine hemelytris paullo latiore, ventris segmento secundo apice medio levissine producto, haud elevato; femoribus posticis rectis, modice incrassatis, subtus obtusissime angulatoampliatis, pone angulum obsolete crenulatis et prope apicen denticulo instructis; tibiis posticis femoribus brevioribus, rectis, compressis, apicem versus vix angustatis.

Mictis griseo-sericans STẢL. Öfr. Vet. Ak. Förl. 1855. p. 27. 5 .

\section{Patria: Caffiraria. (Mus. Holm.)}

Pracedenti simillima, minor. Antemna corpore tertia parte breviores, modice inerassate, articulis primo, secundo et quarto aeque longis. Thorax marginibus lateralibus integris, infuscatis. Margo costalis rorii anterius infuseatus. Femora anteriora subtus prope ipicem spiunla minuta armata.

Obs. Ad hane subdivisionem verisimiliter pertinent $M$. nigricornis Germ. et inconspicua DALL., seeundum deseriptiones anctorum haud determinandie.

hlh. Antennis magnam ad partem, articulis secundo et tertio saltem, pallide ferrugineis vel ferrugineo-flavescentibus.

15. II. natalensis STẢL. - Fusco-ferruginea vel ferruginea, antennis, marginibus lateralibus thoracis, pedibus dorsoque abdominis nigris, hujus segmentis quarto et quinto basi medio interdum anguste subferrugineo-marginatis; antennarum articulis secundo et tertio flavo- vel rufo-ferrugineis, ambobus apice, secundo interdum etiam basi, nigris; membrana subcupreo-fusca; alis pallidissime sublacteo-hyalinis; rostri articulo secundo tertio distincte longiore; femoribus anterioribus subtus prope apicen spinula armatis. $\sigma^{7}$. ․ Long. 22, Lat. 7 mill. 
o7. Ventris segmento secundo apice medio nonnihil producto, haud elevato; femoribus posticis modice incrassatis, prope basin valde curvatis, subtus pone medium obtuse angulato-ampliatis, prope apicem in latere exteriore dente acuto armatis; tibiis posticis femoribus brevioribus, sat compressis, apicem versus subangustatis.

․ Ventris segmento secundo apice medio levissime producto; femoribus posticis rectis, leviter incrassatis, subtus prope apicem denticulo armatis; tibiis posticis femoribus aque longis, linearibus, leviter compressis, quam apud marem gracilioribus.

Mictis ratalensis STiL. Öfv. Vet. Ak. Förl. 185j. p. 28.8. Patria: Caffraria. (Mus. Molm.)

Antennae modice incrassata, eorpore dinidio nonnihil longiores, articulis primo, scinndo et quarto ieque longis, ultimo interdum basi ipsa obsolete rufescente. Thorax marginibus lateralibus integris.

16. I. annulicornis GERM. - Fusco-ferruginea, interdum dilute ferruginea vel cinnamomea, griseo-sericea; antennis nigris, articulis secundo et tertio rufo-ferrugineis, apice nigris, ultimo interdum basi ipsa ferrugineo; membrana subcupreo-fusca; alis pallidissime sublacteo-hyalinis; dorso abdominis nigro, segmentis quarto et quinto basi medio obsolete subferrugineo-marginatis; femoribus anterioribus inermibus; rostri articulo secundo tertio distincte longiore. \%. Long. 20, Lat. 6 mill.

Cerbus annulicornis Gers. in Silb. Rev. ent. V. p. 156. 78. (1837).

ㅇ. Ventris segmento secundo apice, medio levissime producto; femoribus posticis rectis, leviter incrassatis, subtus prope apicem denticulo armatis; tibiis posticis femoribus aque longis, linearibus, leviter compressis.

Patria: Terra capensis. (Coll. Signonet.)

Mr. natalensi maxime affinis, hand differt nisi femoribus anterioribus incrmibus.

Obs. Ad hane speciem forte referenda est M. varicornis WEsTW. in Hope. Cat. of Hem. II. p. 12. 
17. M. lugubrima STẢL. - Nigricans, silaceo-sericea; hemelytris in ferrugineum vergentibus, margine costali anterius nigricante; antennarum articulis secundo, tertio et quarto flavescente-ferrugineis, secundo et tertio apice nigris; membrana subcupreo-fusca; alis infuscatis; abdominis dorso nigro-rufescente; rostri articulis secundo et tertio æque longis; femoribus anterioribus subtus prope apicem spinula armatis. $\sigma$. Long. 20, Lat. 6! mill.

ot. Abdomine hemelytris vix latiore, rentris segmento secundo apice medio producto et cum basi media segmenti tertii leviter elevato; femoribus posticis rectis, modice incrassatis, fusiformibus, subtus in medio dente distincto armatis, pone dentem minutissime denticulatis, denticulo uno distinctiore; tibiis posticis femoribus brevioribus, rectis, compressis, linearibus.

Mictis lugubrina STÅL. Öfv. Vet. Ak. Förh. 1855. p. 28. 7.

Patria: Caffraria. (Mus. Holm.)

Ant nne corpore dimidio nonnihil lougiores, articulis primo, secundo et quarto reque longis, basali reliquis paullo crassiore. Thorax marginibus lateralibus integris.

gg. Abulomine dorso rufescente vel lutescente, basi vel apice, vel basi et apice nigricante.

i. Metanoto toto nigro.

18. I. amicta STAL. - Cimamomea, griseo-sericea, linea media longitudinali thoracis margineque apicali imo corii densius sericeis; antennis ferrugineo-flavescentibus, articulo primo obscuriore, secundo et tertio dimidioque apicali articuli quarti nigris; membrana cupreo-fusca; alis lacteo-hyalinis; abdomine dorso sanguineo, segmentis primo toto et secundo, excepta lıujus parte media postica, nec non lateribus segmenti tertii maculaque segmenti ultimi nigris. $\sigma^{7}$. ‥ Long. 16, Lat. 5 mill.

Mictis amicta StåL. Öfv. Vet. Ak. Förh. 1855. p. 28. 9.

$\sigma^{7}$. Abdomine hemelytris paullo latiore, ventris segmento secundo apice medio nonnihil producto et cum media basi segmenti tertii leviter elevato; femoribus posticis rectis, fusifor- 
mibus, modice incrassatis, subtus in medio leviter obtuseque angulato-ampliatis, pone angulum denticulatis; tibiis posticis femoribus brevioribus, rectis, compressis.

9. Abdomine hemelytris nonnilil latiore, segmento secundo ventris apice medio nec producto, nec elevato; femoribus posticis quam apud marem paullo minus incrassatis, subtus crenulatis et pone medium leviter compressis, apicem versus denticulo armatis; tibiis posticis rectis, compressis, linearibus, femoribus nonnihil brevioribus.

Patria: Caffraria. (Mus. Ilolm. et Coll. SignoreT.)

Antenna corpore dimidio paullo longiores, crassiusculie, articulis secusdo et quarto ieque longis, primo vix longioribus, hoc subincrassato Rostrum articulis secmudo et quarto ieque longis. Thorax marginibus lateralibus integris. Femora antica incruia, intermedia subtus prope apicen interdum spinula armata.

19. M. pagana DALL. - Cinnamomea vel fusco-cinnamomea, griseo-sericea, margine imo apicali corii deusius sericeo; pedibus interdum nigris; antennis flavo-ferrugineis, articulis secundo et tertio apice nigris, ultimo, basi excepta, infuscato; membrana subcupreo-fusca; alis infuscatis; abdomine dorso rufescente vel croceo, segmento basali toto, interdum etiam lateribus segmentorum secundi, tertii et quarti nigris, segmento ultimo disco infuscato. $\sigma$. ‥ Long. 18, Lat. $5 \frac{1}{2}$ mill.

Myctis annulicomis WESTW. in HOPE. Cat. of Hem. II. p. 13. (1842).

Mictis pagana DALL. List of IIem. II. p. 386. 3. (I852).

$\sigma^{7}$. Ventris segmento secundo apice medio producto et cum basi media segmenti tertii nonnihil elerato; femoribus posticis rectis, fusifornibus, modice incrassatis, subtus in medio obtusissime angulato-inpliatis; tibiis posticis femoribus brevioribus, compressis, littiusculis, linearibus.

f. Ventris segmento secumlo apice medio levissime producto, haud elevato; femoribus posticis quam apud marem paullo minus incrassatis, subfusiformibus, subtus pone medium levissime compresso-ampliatis et denticulatis, apicem rersus den- 
ticulo distinctiore instructis; tibiis posticis femoribus paullo brevioribus, compressis, linearibus, rectis.

Patria: Terra capensis. (Mus. Hohm.); Simons Bay. (Coll. SIGNORE'I.)

$M$. amicte simillima. Antenne corpore dimidio nomilil longiores, crassinsculie, articulis primo, secundo et quarto subiequalibus. Rostrum articulis secundo et tertio aque longis. Thorax marginibus lateralibus integris. Abdomen hemelytris nonnihil latius. Femora anteriora subtus prope apicem spinula armata.

20. M. caffra STÀL. - Cinnamomea, silaceo-sericea; pedibus interdum fusco-cinnamomeis; antennis ferrugineo-flavescentibus, articulo primo obscuriore, secundo et tertio apice plus minus distincte infuscatis vel nigris, ultimo interdum apicem versus infuscato; membrana subcupreo-fusca; alis leviter infuscatis; abdomine dorso sordide croceo, segmento primo semper toto, interdum etiam lateribus segmenti secundi et disco segmenti sexti nigris. $\sigma^{7}$. ㅇ. Long. 20, Lat. 6 mill.

Mictis cuffra SträL. Öfv. Vet. Ak. Förh. 1855. p. 27. 2.

$\sigma^{7}$. Ventris segmento secundo apice medio producto et cum media basi segmenti tertii leviter elevato; femoribus posticis rectis, sat incrassatis, fusiformibus, subtus pone medium nomnihil angulato-aupliatis, apicem versus denticulis nonnullis minutis et uno distinctiore armatis; tibiis posticis femoribus brevioribus, rectis, linearibus, compressis.

ㅇ. Ventris segmento secundo apice medio nonnilil producto, haud elevato; femoribus posticis nomihil incrassatis, apicem versus subtus leviter compresso-ampliatis, denticulatis et prope apicem dente distinctiore armatis; tibiis posticis femoribus paullo brevioribus, compressis, linearibus.

Patria: Caffraria. (Mus. Holm.)

Antenna corpore dimidio nomnilil longiores, articulis primo, secundo et quarto aque longis. Rostrum articulis secundo et tertio aque longis. Thorax marginibus lateralibus integris. Femora anteriora subtus prope apicem spinula armata.

21. M. apicalis GERM. - Fusco-ferruginea, silaceo-sericea; antennis ferrugineo-nigris, articulo quarto ferrugineo-flavescente, medio leviter infuscato; scutello apice pallido; membrana 
subcupreo-fusca; alis fuscescentibus; dorso abdominis subcroceo, segmento basali subinfuscato, (an fortuito? an interdum nigro?), segmento apicali segmentisque analibus feminæ nigris. \&. Long. 20, Lat. 6 mill.

Cerbus apicalis Germ. in Silb. Rev. ent. V. p. 157. 79. (18:37). sec. exemplum e coll. DregeI.

ㅇ․ Ventris segmento secundo apice medio nommihil producto, haud elevato; femoribus posticis rectis, nomnihil incrassatis, subtus pone medium leviter compressis et'crenulatis, prope apicem dente armatis; tibiis posticis femoribus fere aque longis, linearibus, compressis.

Patria: Terra capensis. (Mus. Holm.)

Antenure corpore tertia parte breviores, articulis primo et quarto reque longis, secundo paullo longioribus. Rostrum artienlis secundo et tertio aeque longis. Thorax marginibus lateralibus integris. Femoria anteriora denticulis duobus armata.

ii. Metanoto posterius nee non dorso abdominis, excepta luejus parte apicali, flavescentibus vel rufescentibus; antennis gracillimis.

22. II. gracilicornis STÅL. - Ferrugineo-fusca aut nigricans, silaceo-sericea; antennis nigricantibus, articulo ultimo sordide flavescente, prope apicem infuscato; membrana subcupreofusca; alis fuscis; abdominis dorso flavescente vel rufescente, parte apicali nigricante. $\sigma^{7}$. ㅇ. Long. 18-20, Lat. 5!-6 mill.

$\sigma^{7}$. Abdomine hemelytris haud vel vix latiore; ventris segmento secundo apice medio retrorsum sat longe producto et cum segmento tertio in tuberculum plus minus altum elevato; femoribus posticis rectis, sat incrassatis, fusiformibus, subtus in medio obtuse angulato-subampliatis, pone angulum obsolete crenulatis; tibiis posticis rectis, linearibus, compressis, femoribus paullo brevioribus.

오 Abdomine hemelytris nonnihil latiore, ventris segmento secundo apice medio retrorsum leviter producto, haud elevato; femoribus posticis nonnihil incrassatis, subtus pone medium le- 
viter compresso-ampliatis, obsolete crenulatis et prope apicem dente armatis; tibiis posticis femoribus vix brevioribus, linearibus, nonnihil compressis.

Patria: Calabar. (Mus. Holm., Coll. Signoret et Stĩl.)

Antemne graciles, corpore paullo breviores, articulis primo et quarto aque longis, secundo nomihil longioribus. Rostrum articulis secundo et tertio aque longis. Thorax marginibus lateralibus obsolete cremulatis. Femora anteriora subtus prope apicem denticulis duobus, apicali obsoletissimo, armata.

ee. Abdominis dorso toto flavescente vel rufescente.

23. II. Monacha STÁL. - Cinnamomea, parce silaceo-sericea, thorace puberulo; antennis gracillimis, articulo ultimo flavo-ferrugineo, prope apicem infuscato; membrana fusca; alis vinaceis, limbo postico leviter, parte fere dimidia apicali obscure subviolaceo-fuscescentibus; abdominis dorso sordide subcroceo. \&. Long. 20, Lat. 6 mill.

ㅇ․ Abdomine hemelytris vix latiore, ventris segmento secundo apice medio levissime producto; femoribus posticis leviter incrassatis, basin versus subcurvatis, subtus obsoletissime crenulatis, apicem versus denticulis duobus distinctis, subapicali minore, armatis; tibiis posticis rectis, gracilibus, sublinearibus, nonnilil compressis, femoribus æque longis.

\section{Patria ignota. (Coll. Signoret.)}

Ir. gracilicomi affinis, angustior; $M$. vidue etiam simillima, antennis longioribus et multo gracilioribus dirersa. Antenne corpore circiter quarta parte breviores, articulis primo et quarto aeque longis, tertio nomnihil longioribus. Rostrum artienlo secundo tertio longiore. Thorax marginibus lateralibus integris. Femora antica subtus prope apicem denticulo uno, intermedia denticulis duobus armata.

24. II. tenuicornis STÅL. - Cinnamomea, silaceo-sericea; antennis gracillimis, fusco-cinnamomeis; membrana subcupreo-fusca; alis obscure fuscis, margine costali ante medium flavotestaceo; abdomine dorso dilute sordide lutescente. $\quad$. Long. 20, Lat. 5 mill.

ㅇ. Abdomine hemelytris vix latiore, ventris segmento secundo apice medio levissime producto; femoribus posticis leviter incrassatis, basin versus subcurvatis, subtus obsolete crenulatis, 
prope apicem in latere exteriore dente distincto armatis; tibiis posticis femoribus apue longis, gracilibus, nomnilil compressis, rectis, linearibus.

Patria: Guinea. (Coll. Signoret.)

Statura pricecdentis, cui aftinis, colore alanun distineta. Angusta. Antenue articulo primo secundo longiore, nltimo in exemplo descripto mutilato. Rostrum articulis secundo et tertio aeque longis. Thorax marginibus lateralibus subintesris. Femora anteriora subtus prope apicem denticulo instructa.

25. I. Carmelita śtís. - Angusta, plus ninus obscure cinnamomea, silaceo-sericea, pectoris vitta ad coxas densius sericea; antenuis articulo ultimo flarescente vel flavo-ferrugineo, prope apicem infuscato; membrana subcupreo-fusca; alis obscure fuscis, costa dilute flavo-cimamomea; abdominis dorso dilute cinnabarino, apice infuscato. $\sigma^{7}$. Long. 20, Lat. 6 mill.

o. Abdomine hemelytris rix latiore, ventris segmento secundo apice medio sat longe producto et ibidem eum medio segmenti tertii nomniluil elevato; femoribus posticis sat incrassatis, rectis, fusiformibus, subtus paullo pone medium obtuse angulatoampliatis, apicem versus spinulis obsoletissimis duabus vel una armatis; tibiis posticis femoribus aque longis, classiusculis, compressis, rectis, linearibus.

Patria: Caftraria. (Mus. Holm. et Coll. Signoker.)

M. tenuicomi similis, antennis crassioribus divergit. Antenua colpore dimidio nommihil longiores, articulis primo et quarto aeque lon:-is, secundo nomihil longioribus. Rostrum articulis secundo et tertio acque longis. 'Thorax marginibus integris. Femora anteriora subtus prope apicem elenticulis duobus, subapicali obsoleto et interdum deficiente, armata.

26. M. vilua Schaum. - Cinnamomea, silaceo-sericea, pectoris vitta ad coxas densins sericen; antemnis plus minus infuscatis, articulo ultimo flavo-ferrugineo, prope apicen infuscato; alis sordide flavescente-hyalinis, limbo postico parteque vix dimidia apicali fuscis; abdominis dorso luteo. ㅇ. Long. 20, Lat. 6 mill.

o. Abdomine basi tuberculato; femoribus posticis modice incrassatis, ante apicen dentatis, rectis (sec. ScIlAuM). 
Mictis vidua Schaum. Ber. Ak. Berl. 1853. p. 357; PETERS. Reise nach Mossamb. Ins. p. 41. Taf. 2. fig. 5. (1862).

q. Abdomine hemelytris paullo latiore, ventris segmento secundo apice medio nonnihil producto; femoribus posticis apicem versus sensim nonnihil incrassatis, rectis, subtus pone medium obsolete crenulatis, prope apicem dentibus duobus armatis; tibiis graciliusculis, linearihus, leviter compressis, femoribus vix brevioribus.

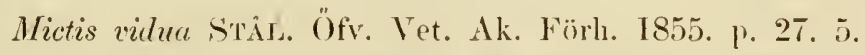

Patria: Caffraria. (Mus. Holm.) Mozambique. (sec. Schaum.)

M. Monache similis, antennis crassioribus et brevioribus differt. Antenna corpore dimictio nomihil longiores, articulis primo et quarto subequalibus, secundo nomihil longioribus. Rostrum articulis secumlo et tertio aeque longis. Thorax marginibus integris, Femora anteriora subtus prope ippicem hidenticulatal, dente subapicali minutissimo, obsoleto.

27. II. capurina stal. - Cinnamomea, silaceo-sericea, pectoris maculis tribus prope coxas densius sericeis; antemnis articulo ultimo dilnte flavo-ferrugineo, prope apicem interlum leviter infuscato; membrana subcupreo-fusca; alis vinaceis, basin versus obscure infuscatis; abdominis dorso dilute croceo; apire imo scutelli pallido. ‡. Long. 20, Lat. 6 mill.

․ Abdomine hemelytris nonnihil latiore, ventris segmento secundo apice medio nounihil producto; femoribus posticis apicem versus sensim nomnihil incrassatis, rectis, subtus pone medium leviter compressis et crenulatis, apicem versus dente acuto armatis; tibiis posticis femoribus vix brevioribus, compressis, linearibus, rectis.

\section{Patria: Caffiaria. (Mus. Holm.)}

Precedentibus valde affinis. Antenne corpore dimidio nomnilil longiores, articulis primo et quarto reque longis, secundo nonnilil longioribus. Rostrum articulis secundo et tertio aeque longis. Thorax marginibus lateralibus integris. Femora anteriora subtus prope apicem denticulis duobus armata.

28. M. africana STẢL. - Cinnamomea, silaceo-sericea, pectoris vitta interrupta prope coxas densius sericea, minus distincta; antennarum articulo ultimo flavescente-ferrugineo; alis sub- 


\section{$-46-$}

obseure vinaceis; abdominis dorso croceo. ㅇ. Long. 22, Lat. 6 mill.

ㅇ. Alulomine hemelytris nonnihil latiore, ventris segmento secundo apice medio nonnihil producto; femoribus posticis apicem versus sensim nonnihil incrassatis, rectis, subtus prope apicem in latere exteriore dente acuto armatis; tibiis posticis rectis, linearibus, nomnihil compressis, femoribus æque longis.

Patria: Caffraria. (Mus. Holm.)

Pracedentibus affinis. Antennae eorpore dimidio nonnihil longiores, artieulis primo ret quarto aque longis, secundo nonnihil longioribus. Rostrum artirulis secundo et tertio eque longis. Thorax marginibus lateralibus integris. Femora anteriora subtus prope apicem denticulis duobus armata.

\section{COSSUTIA STÅL.}

Corpus magnum, oblongum vel subelongatum. Caput subquadratum, tuberculis antenniferis paullo remotis, lobo medio inter illa distinguendo, nec tamen elevato, nec producto. Rostrum breve. Thorax apice collari instructus. Pedes postici sat distantes; femoribus anterioribus subtus prope apicem in latere anteriore dentibus duobus vel uno armatis; femoribus posticis presertim apud mares incrassatis; tibiis simplicibus, triquetris, posticis nomnilil compressis, apud mares dente subtus armatis; tarsis posticis articulo primo apicalibus duobus ad unum xque longo vel paullo longiore.

a. Corpore subelo gato; scutello longiore quam latiore.

1. C. metallica SIGN. - Sordide flavescens, nudiuscula; antennis, basi capitis, pronoto, seutello hemelytrisque nigris; pronoto, scutello et hemelytris remote, subacervatim, parmm profunde, licet distincte punctatis, punctis splendide viridi-aneis; membrana olivaceo-nigra; alis obscure fuscis; abdominis dorso nigro-fasciato et maculato; apertura apparatus odoriferi, femoribus superne tibiisque, parte harum apicali excepta, nigricautibus. o’. Long. 28, Lat. 8 mill.

o. Abdomine hemelytrisque atque latis, rentris segmentis secundo et tertio spinis duabus nigris, valde distantibus, armatis; 


\section{$-47-$}

femoribus posticis modice incrassatis, basin versus gracilescentibus et leviter curvatis, subtus pone medium obsolete denticulatis, apice dente distincto armatis; tibiis posticis femoribus xque longis, rectis, nomnilil compressis, subtus pone medium dente majusculo armatis.

Mictis metallicus Sign. Rev. et Mag. Zool. 1851. p. 447. 14; Sign. in Thoms. Areh. ent. II. Pl. 9. fig. 6. (1858).

Patria: Gabon. (Coll. Signorest.)

Antenrace graciliusenle, artienlo primo secundo multo longiore, ultimo mutilato in exemplo descripto. Thorax marginibus lateralibus subobtusis, haud rotundatis. Femora anteriora subtus prope apicem biclentata.

\section{aa. Corpore oblongo; scutello aqnilatero.}

2. C. fireola Drury. - Varicolor, punctulata; antennis nigris, articulo ultimo interdum basin versus stranineo; alis fuscis; abdomine dorso sanguineo, apice nigro. c’. ㅇ. Long. 1921, Lat. 6-7 mill.

o. Abdomine hemelytris vix latiore; ventre inermi, segmento secundo medio haud producto; femoribus posticis valde incrassatis, fusiformibus, rectis, subtus ante medium tubereulo crasso, breviter conico, et prope apicem dentibus lluobus parvis armatis; tibiis posticis femoribus aque longis, rectis, gracilibus, compressis, subtus prope basin dente acuto majusculo armatis.

ㅇ. Abdomine hemelytris nomnihil latiore; fenoribus posticis rectis, leviter incrassatis, subtus prope apicem dente armatis; tibiis posticis rectis, linearibus, femoribus æque longis, inermibus.

Var. a. - Supra sordide flavescens, scutello membranaque fuscis vel nigricantibus; subtus testacea, segmentis pallide flavescente-marginatis.

Var. b. - Fusco-testacea; capite, limbo thoracis, clavo, margine apicali corii marginibusque segmentorum pectoris ventrisque pallide testaceo-flavescentibus.

Paryphes Andrea Burm. Handb. II. 1. p. 336. 5. (1835).

Cerbus Boerhavioe H. ScH. Wanz. Ins. VI. p. 85. fig. 655. (1842). excl. syn. 


\section{$-48-$}

Var. e. _ supra uti varietas i, picta; sulitus cum pedibus dilute testaceo-flarescens, femoribus medio tibiisque fuscis.

Cimex flaveolus Druny. Ill. nat. hist. III. p. 59. Pl. 4.3. fig. 3. (1782).

Mictis fluveola DALL. List of llem. II. p. 401. 42. (1852).

I'ar. d. - Nigricans vel nigro-fusca.

Patria: Sierra Leona. (Mus. IIolm., Coll. Signoket et S'Tít.)

Anteune graciles, corpore quarta parte breviores, a ticulis primo et quirto aque longis, secundo nomnihil l ngioribus. Thorax marginibus later libus minute crenulatis, angulis lateralibus obtnsinsenlis, vix prominulis. Femora anteriora subtus prope apicem dente unico armata.

3. C. Stålii SIGN. - Nigrricans; alis sordide hyalinis, fusco-renosis, apicem versus infuscatis; antemnarum articulo ultimo basi nec non articulo primo tarsorm posticorum flaro-testaceis; abdominis dorso nigro. $\sigma^{7}$. Long. 19, Lat. 5 mill.

○. Abdomine hemelytrisque aque latis, ventre inermi; femoribus posticis valde incrassatis, fusiformibus, subtus fere in medio tuberculo crasso, breviter subconico, armatis, prope apicem denticulatis; tibiis posticis rectis, femoribus aque longis, subtus basin versus in tentem acutum ampliatis.

Mictis stálii Sigx. in Thoms. Arch. ent. II. 1. 298. 565. (1858).

Patria: Grand Bassam. (Coll. Sigroret.)

Priecedenti valdie affinis et forte uti illa quoad colores valde variabilis, colore dorsi abdominis alarumpne ut et dente tibiarum posticarmm majore et latiore distinctio.

\section{CARLISIS STAL.}

\section{Öfv. Vet. Ak. Förh. 1858. p. 314.}

Corpus magnum, oblongmm. Caput subquadratum, tuberculis antenniferis nonnihil distantibus, lobo medio inter illa elevato, antrorsum haud prominente. Rostrum coxas intermedias subattingens. Thorax antice collari distinctissimo instructus, posterius rotundatus, medio ante scutellum haud truncatus. Scutellum subaquilaterum. Mesosternum antice haud sulcatum. Pedes postici valde distantes; femoribus anterioribus subtus apicem 
versus spinulis armatis, posticis sat incrassatis; tibiis simplicibus, triquetris, posticis compressis; tarsis posticis articulo basali duobus apicalibus ad unum subbreviore.

Capitis lobo medio inter tubercula antennifera elerato, thorace posterius rotundato femoribusque anterioribus subtus apicem versus utrimque spinosis a Mictide et affinibus differt hoc genus.

1. C. Wahlbergi STÅL. - Flavescente-cinnamomea; antennis, thoracis marginibus lateralibus maculisque duabus posticis, scutelli marginibus lateralibus maculisque duabus ante medium positis, basin attingentibus, maculis hemelytrorum, interdum spatium totum inter venas occupantibus, connexivo, limbo ventris, basi apiceque tibiarum nigris; dimidio basali articulorum secundi, tertii et quarti antennarum maculisque connexivi et limbi ventris difute flavescentibus; membrana cupreofusca, nitida, fasciis duabus flexuosis nigris, opacis, ornata; alis flavescentibus, opacis, limbo postico parteque vix dimidia apicali nigro-fuscis. \&. Long. 22-24, Lat. 8-9 mill.

․ Abdomine hemelytris nonnihil latiore; femoribus posticis sat incrassatis, rectis, subtus pone medium levissime compressosubampliatis spinulisque pluribus armatis; tibiis posticis medio leviter curvatis, compressis, subtus minute denticulatis.

Carlisis Wahlbergi STÅL. Öfv. Vet. Ak. Förh. 1858. p. 314.1. Patria: Territorium lacus N'Gami. (Mus. Holm.)

Variat thorace pedibusque obscure fusco-cinnamomeis.

Antennæ corpore dimidio paullo longiores, articulis primo et quarto fere reque longis, intermediis nonnihil longioribus, his basin versus sensim leviter gracilescentibus. Thorax marginibus lat ralibus medio leviter sinuatis, integris, angulis lateralibus subrectis, levissime prominuli-. Femora intica subtus prope apicem utrimque spinula armata, intermedia ibidem in latere anteriore spinula una, in litere posteriore spinulis duabus vel tribus instructa. .

\section{PHELAUS STÅL.}

Corpus magnum, anguste ovatum vel oblongo-ovatum, paullo depressum. Caput quadratum, tuberculis antenniferis nonnilil distantibus, lobo medio inter illa elevato, haud producto. 
Antenna corpore dimidio nonnihil longiores. Rostrum breve, coxas anticas subsuperans. Thorax collari destitutus, posterius rotundatus, medio ante scutellum haud truncatus. Scutellum subequilaterum. Corium margine apicali versus angulum apicalem exteriorem leviter sinuato, suturæ clavi reque longo. Membranx venæ plus minus anastomosantes. Mesostemum antice sulcatum, marginibus sulci plus minus, sæpissime tamen in laminam altam elevatis. Abdomen hemelytris latius, utrimque rotundato-ampliatum. Pedes validiusculi, postici valde distantes; femoribus anterioribus apicem versus sensim nonnihil incrassatis, subtus pone medium utrimque spinulis pluribus distinctis armatis, posticis præsertim apud mares incrassatis; tibiis anterioribus triquetris, posticis femoribus longioribus, compressis, subtus subdilatatis; tarsis posticis articulo basali apicalibus duobus ad unum aque longo.

Pracedenti affine genus, a Plysomero cum quo hucusque est confusum, valde divergens.

a. Antennarum articulis duolus intermediis apicem versus compressis; marginibus sulci mesosterni leviter elevatis.

1. P. dilaticornis Sign. - Subferrugineo-fuscus, supra punctulatus, subtus granulatus; antennarum articulo apicali dilute fusco-flavescente; membrana obscure subæneo-fusca; alis vinaceis; dorso abdominis rufescente, in eroceum rergente, macula angulorum basalium segmenti sexti, supra subtusque distinguenda, sordide straminea. f. Long. 25, Lat. 8 mill.

ㅇ. Ventre inermi; femoribus posticis sat incrassatis, basin versus paullo gracilioribus et subcurvatis, leviter compressis, tuberculis parvis, in series duas dispositis, in latere anteriore instructis, subtus serie tuberculorum et apicen versus utrimque dentibus nonnullis armatis; tibiis posticis femoribus longioribus, medio levissime curratis, sat compressis, pone medium apicem versus leviter angustatis, subtus ibidem minute denticulatis.

Physomerus dilaticomis Sign. Anm. ent. Sér. 3. VIII. p. 939. 115. (1861).

lat ria: Madagascas. (Coll. Signorér.) 
Statura sequentium, paullo angustior. Antenne articulis primo et secundo reque longis, tertio quartoque inter se aequalibus nonnihil longi: ribus, sieundo apicem versus sensim leviter compresso, tertio apicem versus utrimque sensim distincte dilatato. Thor:ix marginibus lateralibus distincte sinuatis, pone sinum nonnihil ampliatis.

aa. Antennis simplicibus, articulis secundo et tertio subteretibus, vix compressis; sulco mesosterni utrimque lamina alta instructo.

2. P. spinipes P. B. - Ferrngineo-niger, supra parce punctulatus, subtus remote granulatus; thorace rugoso; antennarum articulo ultimo, interdum etiam tibiis anterioribus tarsisque dilute flavo-testaceis; membrana subæneo-nigricante; alis cæruleo-nigricantibus; abdomine dorso sanguineo, macula angulorum basalimm segmenti sexti, supra subtusque distinguenda, sordide straminea. $\sigma^{7}$. ㅇ. Long. 23, Lat. 8 mill.

o'. Ventre prope basin haud tuberculato-elevato; trochanteribus posticis supra tuberculo subconico instructis; femoribus posticis maxime incrassatis, superne tuberculis compluribus minutis spiniformibus conspersis, subtus in latere posteriore tuberculis duobus, uno prope basin, altero fere in medio positis, apicem versus spinulis tribus vel quattuor armatis, in latere anteriore apicem versus dente majusculo et prope hunc denticulis nonnullis instructis; tibiis posticis valde compressis, medio leviter curvatis, subtus dilatatis, in medio angulatis, pone angulum sensim angustatis et denticulatis.

Lygaus spinipes P. B. Ins. p. 203. Hem. Pl. 12. fig. 5. (1805).

Physomerus spinipes DALL. List of Hem. II. p. 412. 2. (1852).

․ Femoribus posticis sat incrassatis, fusiformibus, tuberculis minutis parce conspersis, subtus in latere posteriore per totam longitudinem, in latere anteriore pone medium spinis armatis; tibiis posticis levissime curvatis, compressis, quam in mare angustioribus, pone medium sensim angustatis et subtus parce denticulatis.

Patria: Calabar. (Mus. Holm., Coll. Signoret et Stås.) 
Antenne articulis primo et quarto aque longis, secundo vix brevioribus. Thorax marginibus lateralibus pone medinm sat profunde sinuatis, pone sinum ampliatis et obtuse prodnctis.

3. P. terminalis Burs. - Niger vel ferrugineo-niger, supra punctulatus, subtus parce granulatus; antennarum articulo ultimo flavo-ferrngineo, basi fusco; tarsis fuscis; alis cæruleo vel inescente-nigris; abdomine dorso nigro, macula angulorum basalium segmenti ultimi, supra subtusque distinguenda, testaceo-flavescente. $\sigma$. + . Long. 19-23, Lat. $7-8$ mill.

Physomerus terminalis BurM. Handb. II. 1. p. 341. 2. (1835); DALL. List of Ilem. II. p. 412. 1. (1852).

Cerbus crassiclunis GerM. in Silb. Rev. ent. V. p. 157. 80. (1837).

o. Ventris segmento secundo medio plano, apicem rersus cum basi media segmenti tertii nounihil elevato; trochanteribus posticis supra tuberculo subconico instructis; femoribus posticis valde incrassatis, superne tuberculis compluribus minutis spiniformibus conspersis, subtus in latere posteriore tuberculis duobus, uno prope basin, altero fere in medio positis, apicem versus spinulis tribus vel quattuor armatis, in latere anteriore apicem versus dente majusculo et prope hunc denticulis nonnullis instructis; tibiis posticis valde compressis, medio leviter curratis, subtus dilatatis, in medio angulatis, pone angulum sensim angustatis et denticulatis.

ㅇ. Femoribus posticis sat incrassatis, fusiformibns, tuberculis minutis parce conspersis, subtus in latere posteriore per totam longitudinem, in latere anteriore pone medium spinis armatis; tibiis posticis levissime curvatis, compressis, quam in mare angustioribus, pone medium sensim angustatis et subtus parce denticulatis.

\section{Patria: Caffraria. (Mus. Ilolm.)}

Priecedenti simillima. Antenna articulis prino, sccundo et quarto subiequalibus. Thorax marginibus lateralibus medio levissime simuatis, pone sinum haud ampliatis, angulis lateralibus obtuse rotundatis, leviter prominulis. 


\section{ACANTHOCORIS A. et s.}

Hist. des Hém. p. 213. (1843).

Corpus ovatum. Caput quadratum, basi pone oculos callosum, tuberculis antenniferis paullo distantibus, lobo medio inter illa elevato, vix producto. Rostrum breve. Antennæ articulo apicali præcedente breviore, fusiformi. Hemelytra basin versus parallela, dein leviter ampliata, corii margine apicali recto, sutura clavi áque longo vel paullo breviore; membrana reticulata. Pedes postici valde distantes, femoribus anterioribus subtus biseriatim denticulatis, superne plus minus distincte, interdum acute tuberculatis, posticis valde incrassatis, apice superne spina vel tuberculo terminatis; tibiis anticis sat compressis, oblongis, supra plus minus distincte quadridentatis, intermediis leviter compressis, linearibus, supra denticulis nonnullis, interdum obsoletissimis vel deficientibus, instructis, posticis valde compressis, subtus dilatatis, apicem versus sensim angustatis, subtus minute denticulatis; tarsis posticis articulo primo apicalibus duobus ad unum aque longo vel paullo breviore.

a. Connexivi segmentis margine inermibus vel obsoletissime crenulatis, denticulis nullis distinctioribus instructis.

b. Scutello haud carinato.

I. A. Ingens STÅL. - Cinnamomeus, sat dense granulatus, setulosus, subtus silaceo-sericeus; antennis brevibus, crassiusculis, antennarum articulis secundo, tertio et quarto flavo-ferrugineis; membrana alisque fuscis; abdomine dorso subsanguineo; margine basali segmentorum connexivi, in segmento sexto lato, sordide stramineo; tarsis lividis. $\sigma^{7}$. \&. Long. 10-11, Lat. 4 mill.

Physomerus lugens STÅL. Öfv. Vet. Ak. Förh. 1855̃. p. 28. I. $\sigma^{7}$. Femoribus posticis valde incrassatis.

․ Femoribus posticis quam apud marem nonnihil minus incrassatis.

Patria: Caffraria. (Mus. Holm.)

Antennæe corpore dimidio breviores, setulosa, crassinscula, articulis primo et secundo seque longis, tert o paullo brerioribus, ultino 
fusiformi distinete longioribus. Thorax marginibus lateratibus medio leviter sinuatis, angulis lateralibus obtusis, levissime prominulis, Abdomen hemelytris nounilil latius. Femora anteriora supra rix, subtus distinete spinulosa, postica gramulata, subtus apicem versus denticulata. Tibia antice supra denticulis nomullis obtusis obsoletis armate, intermediae inermes, postice supra inermes, subtus minute denticulatie.

2. A. granulosus SigN. - Obscure cinnamomeus, punctulitus, parce setulosus; antemnis longiusculis pedibusque nigricantibus, illorum articulo ultimo, basi excepta, tarsisque flivoferrugineis; membrana fusca; alis fuscescentibus, basin versus in sordide vinaceum subvergentibus; abdomine dorso dilute sordide croceo; segmento ultimo comnexivi basi sordide stramineo. ơ. Long. 11, Lat. 4 mill.

o. Femoribus posticis valde incrassatis.

Acanthocoris gramulosus Sign. in Tioms. Arch. ent. Il. p. 304. 580. (1858).

\section{Patria: Gabon. (Coll. Signoret.)}

Precedenti valde affinis et similis, intennis longioribus differt. Antenna corpore circiter tertia parte breviores, articulo primo crassiore, obsolete denticulato, secundo basali vix longiore et tertio subbreviore, ultimo fusiformi, tertio fere dimidio breviore. Thorax parec gramulatus, marginibus lateralibus pone mcdium leviter ampliatis, angulis lateralibus obtusis vix prominulis. Femora anteriora supra obsolete minute tubereula'a, subtus spinulis minutis amata, postica subtiliter granulata, subtus pone medium minute denticulata. Tibia antice superne obsolete, intermedice obsoletissime obtuse denticulatx, postica supra subincrues, subtus, parte basali execpta, minutissime spinulosit.

\section{bb. Scutello distincte carinato.}

3. A. tilialis SIGN. - Fusco-cinmamomeus, griseo-tomentosus, antennis, excepto articulo basali, sordide flavo-testaceis, tarsis lividis; alis sordide vinaceis; nembrana pallide fuscescente, basin versus obscuriore, minute fusco-conspersa; abdomine croceo vel rufescente; segmento ultimo comnexivi basi sordide stramineo-marginato. ․ Long. 12, Lat. 4! mill.

9. Abdomine utrimque sat ampliato, hemelytris tamen vix latiore, ventre gramulis cousperso; femoribus posticis sat incrassatis, hasin rersus leviter gracilescentibus. 
Acanthocoris tibialis Sign. Ann. ent. Sér. 3. VIII. p. $9 \pm 7$. 132. (1861).

Patria: Madagascar. (Coll. Signoret); Caffraria. (Mus. Holm.)

Statura A. fasciculati, cui sat similis et cum eodem haud confundendus. Antenna corpore circiter tertia parte breviores, secundo et tcrtio subæqualibus, gracilibus, supra clenticulis tribus obtusis obsoletissimis instructis, primo nomilhil longioribus, hoc denticulato. Thorax distincte granulatns, marginibus latcralibus parce minuteque denticulatis, pone medium distincte ampliatis, angulis lateralibus rectis, apice subacuminatis, leviter prominulis. Femora anteriora supra subtusque distincte denticulata, postica supra obsoletissime tuberculata, subtus pone medium denticulatiı. Tibia ommes supra denticulis nonnullis obtusis instructe, postica subtus minute denticulatre, denticnlo uno pone mediun posito distinctiore.

4. A. spinosus Sign. - Fusco-cinnamomeus, griseo-tomentosus, antennis pedibusque nigris; membrana fusca; alis infuscatis, basin versus pallidioribus; abdomine dorso dilute flavo-testaceo. ㅇ. Long. 12, Lat. 4 mill.

ㅇ. Abdomine utrimque sat ampliato, ventre inermi; femoribus posticis sat incrassatis.

Acanthocoris spinosus Sign. in Thoms. Arch. ent. II. p. 304. 579. (1858).

\section{Patria: Calabar. (Coll. Signonet.)}

Precedenti valde affinis. Antennæe articulo secundo basali longiore, tertio et quarto mutilatis. Thorax marginibus lateralibus pone medium nonnihil rotundato-ampliatis, angulis lateralibus apice acuminatis, leviter prominulis. Femora anteriora obsolete tubereulata, postica obsoletissime tuberculata, apice superne tuberculo subconico parvo terminata, subtus poue medinon denticulis nonnullis armata. Tibia antica superne obsolete, intermedia obscletissime denticulata: posticæ supra subinermes.

aa. Connexivi segmentis in angulis apicalibus et in medio marginis exteriores denticulo minuto armatis.

c. Thoracis marginibus lateralibus pone medium in processum acutum, antrorsum productum, ampliatis.

5. A. granosus STÅL. - Nigricans, griseo-tomentosus; ventre sordide flavo-testaceo; antennis, excepto articulo primo, sordide flavescente-ferrugineis; membrana pallide fusca, obscure 
fusco-conspersa; alis sordide vinaceis; abdominis dorso croceo. \&. Long. 1I, Lat. 4 mill.

․ Abdomine hemelytris latiore, ventre tuberculis minutissimis sat elevatis consperso; femoribus posticis valde incrassatis, basin versus sensim nomnilil gracilioribus.

Physomerus granosus StïL. Öfv. Vet. Ak. Förh. 1855. p. 29. 2.

Patria: Caffraria. (Mus. Holm.)

Forma thoracis distinctissinus. Antenne corpore cireit r tertia parte breviores, articulo primo reliquis crassiore et secundo breviore, multidenticulato, secundo et tertio fere aque longis supra denticulis tribus minutissimis instructis Thorax tuberculis minutis conspersus, tubereulis duobus disci paullo majoribus; marginibus lateralibus ante medium spina longa armatis, pone medium in processum acutum, sat longe antrorsum productum, ampliatis. Seutellum nee carinatum, nec apice productum. Margo costalis eorii ante medium obsolete granulatus. Femora omnia supra subtusque distincte dentata. Tibic omnes supra dentibus nonnullis obtusis armatre, postica subtus minnte denticulatie.

cc. Thoracis marginibus lateralibus pone medium haud vel nonnihil rotundato-umpliatis; scutello distincte carinato.

6. A. obscuricornis DALL. - Fusco-cinnamomeus, griseo-tomentosus; antennis nigris, articulo ultimo ferrugineo-flavescente; membrana fusca; alis fuscescentibus, basin versus dilutioribus; abdomine dorso sordide lutescente. $\sigma^{7}$. ․ Long. 1214, Lat. $4 \frac{1}{2}-5$.

Acanthocoris rotundatus SIGN. in THoms. Arch. ent. II. p. 303. 578. (1858).

o'. Abdomine utrimque parum ampliato, ventris segmento secundo medio spinis duabus distinctis, segmentis reliquis, ultimo excepto, serie transversa spinularum minutarum instructis; femoribus posticis valde incrassatis.

Acanthocoris obscuricomis DALL. List of Hem. II. p. 516. 4. (1852).

ㅇ. Abdomine utrimque sat ampliato, ventre spinulis destituto, segmento secundo tuberculis duobus minutissimis instructo; femoribus posticis sat incrassatis. 
Patria: Calabar. (Coll. SIgnoret); Sierra Leona. (Coll. STÅL.)

Antennx corpore circiter tertia parte breviores, articulis secundo et tertio aeque longis, primo ct presertim ultimo longioribus, primo obtuse denticulato. Thorax remote et ubsolete gramulatus, disco pone medium tubercu is duobus minutis, minus distinctis, instructo, marginibu= lateralibus anticis vix vel leviter sinuatis, erosulis, angulis lateralibus obtusis, raro apice subacuminitis, levissime prominulis. Femora distincte tuberculata et spinosa, postica subtus apicem versus parce denticulata. Tibire omnes supra denticulis nonnullis distinctis, obtusis, armatre, postica subtus minute denticulate.

7. A. fasciculatus FABR. - Ferrugineo-fuscus vel niger, griseotomentosus; antennis, excepto articulo primo, dilute flavo-ferrugineis; corii margine costali ante medium distincte multispinuloso; alis fuscescentibus; abdomine dorso lutescente, macula prope basin tibiarum obsolete testacea, sæpe deficiente. $\sigma^{7}$. ․ Long. 11-12! Lat. 4-5 mill.

Cimex fusciculatus FABr. Mant. ins. II. p. 287. 85. (1787).

Coreus fasciculatus Fabr. Ent. syst. IV. p. 130. 14. (1794).

Coreus fasciculatus (fusciculator) FABR. Syst. Rhyng. p. 197. 27. (1803).

Crinocerus grylloides BuRM. Handb. II. 1. p. 319. 5. (1835).

Crinocerus aper GERM. in Silb. Rev. ent. V. p. I49. 66. (1837). Acunthocoris fasciculatus DALL. List of Hem. II. p. 516. 3. (1852).

Stoll. Pl. 16. fig. 114.

ऽ. Ventre tuberculis minutissimis spiniformibus consperso, tuberculis duobus segmenti secundi distinctioribus; femoribus posticis valde incrassatis, basi vix gracilioribtis.

ㅇ. Ventre tuberculis minutissimis obtusis parce consperso; femoribus posticis sat incrassatis, basin versus sensim nonnihil gracilioribus.

Patria: Terra capensis. (Mus. Holm., Coll. Signoret et StÅL.)

Antenna corpore circiter tertia parte breviores, articulo primo denticulato, secundo et tritio fere rque longis, primo longioribus et gracilioribus, supra denticulis tribus vel quattuor minutis obtusis instructis. Thorax tuberculis acutiuscnlis parvis conspersus, marginibus lateralibus parce denticulatis, pone medium uonnihil ampliatis, 
angulis ateralibus acutis, leviter productis. Sentelium distincte carina $и m$. apice nomnihil productum. Abdomen utrimque sat ampliatum. Femora supra subtusque distincte denticulato-tuberculosa. Tibie onmes smpra denticulis nommulis distinctis armata, postica sul)tus minute denticulatie.

\section{PETALOCNEMIS STȦL.}

Öfv. Vet. $\Lambda$ k. Fürh. 1853. p. 259.

Corpus depressum, oblongo-ovatum. Caput subquadratum, basi pone oculos callosum, lobo medio inter tubercula antennifera elevato, vix prominulo. Antennæ longitudine et crassitie variabiles, articulo ultimo brevi, fusiformi. Rostrum breve. Scutellum triangulare. Hemelytra abdomine angustiora, tota subparallela vel margine costali a basi ad apicem levissime rotundato, margine apicali recto, sutura clavi distincte breviore; membrana reticulata. Pedes postici valde distantes; femoribus anterioribus subtus per totam longitudinem denticulatis, posticis incrassatis; tibiis compressis, anticis oblongis, posticis subtus nonnilil dilatatis, apicem versus sensim angustatis; tarsis posticis articulo primo apicalibus duobus ad umum subbreviore.

Acanthocoridi valde affine genus, differt præcipue hemelytris basin versus laud parallelis et dein versus medium ampliatis, sed subparallelis totis vel a basi ad medium subampliatis, dein apicem versus subangustatis.

a. Antennis corpore tertia fere parte breviorilus; rostro inter coxas intermedias extenso, articulo secundo tertio dimidio longiore; tibiis posticis femoribus nonnilil longioribus.

1. P. spiumlosa STriL. - Fusca, griseo-sericea et paree subsetulosa; antennarum articulo tertio nigro, dilatato, apicali fusco, basi stramineo; membrana alisque sordidis, fusco-venosis; abdomine dorso dilute sanguineo. $\sigma^{7}$. ㅇ․ Long. 11, Lat. 4 mill.

Acanthocoris spinulosus STÃL. Öfv. Vet. Ak. Förlı. 1858. p. 316.22.

c’. Femoribus posticis valıle inerassatis, sulfusiformibus. 
․ Femoribus posticis sat incrassatis, basin versus sensim nonnihil gracilescentibus.

Patria: Campi arenosi ad fluvium Svakop. (Mus Holm.)

Antennæe articulis primo, secundo et tertio fere aque longis, primo reliquis crassiore, secundo compresso, lineari, tertio a basi apicem versus sensim utrimque dilatato, oblongo-ovato. Thorax spinulis obtusis setigeris parce conspersus, marginibus lateralibus anticis spinis nonuullis nigris armatis, posterius in processum acutum, antrorsum productum, ampliatis. Scutellum apice productum et compresso-incrassatum. Fenora anterior، supra subtusque distincte denticulata, postica tuberculis ninutis conspersa, subtus pone medium denticulata. Tibia antice supra denticulis minutis obtusis quatuor instructr, posteriores supra inermes, postice subtus distincte denticulatie.

aa. Antennis corpore dimidio vel phes dimidio brevioribus; rostro coxas anticas subsuperante, articulis secundo et tertio fere arque longis; tiliies posticis femurilnes vix longioribus.

b. Thorace ante angulos laterales utrimque in processum brevem amplicto; corpore setosu.

2. P. denticulata STÅL. - Cinnamomea; antenuarum articulis secundo et tertio vix compressis, linearibus; membrana levissime infuscata; alis sordide hyalinis; abdominis dorso croceo. ơ. \&. Long. 9, Lat. 3 mill.

Acanthocoris denticulatus STÅL. Öfv. Vet. Ak. Förh. 1855.

p. 32. 1 .

o7. Femoribus posticis valde incrassatis, fusiformibus.

ㅇ. Femoribus posticis sat incrassatis, basin versus sensim nomihil gracilescentibus.

Patria: Caffraria. (Mus. Holm.)

Antennæ corpore dimidio breviores, articulis primo et secundo fere aquilongis, illo crassiore, obsolete denticulato, tertio precedentibus paullo longiore, ultimo infuscato. Thorax tuberculis parvis sat elevatis, dnobus discoidalibus distinetioribus, conspersus, marginibus lateralibus spinis nommullis obtusis armatis, posterins in processum, antrorsum acute nonnihil productum, ampliatis. Scutellum apice hand productum, subcarinatum. Vene hemelytrorum haud tuberculate. Pedes dentato-tuberenliti, femoribus apice superne tuberculo distinctiore dentiformi terminatis; tibiis anticis supra obsolete, posteriores obsoletissime denticulatis, posticis subtus minute denticulatis. 
3. P. sabulosa STÅL. - Griseo-cimamomea, griseo-sericea, tuberculis minutis distinctis, ptian in venis hemelytrorum, conspersa; alis subsordide lyalinis; membrana livida, punctis nomullis nigris adipersa; abdominis dorso croceo. o. Long. 8, Lat. $2 \frac{2}{3}$ mill.

o. Femoribus posticis valde incrassatis, fusiformibus. Patria: Caffraria. (Mus. Holm.)

Statura precedentis. Antenna erassa, articulis prino, secundo et tertio fere ieque longis, secundo et tertio distincte compressis, tertio basin versus gracilescente. Thorax linea inedia, per eaput et seutellum extensa, grisea notatus, marginibus lateralibus posterins in processum breve, truıcatum, extrorsum anpliatis. Sentellun medio longitrorsum rugoso-elevatum et tubereulis duobus instruetum. Pedes tubereulis dentiformibus distinctis conspersi; femoribus apice superne tubereulo distinctiore turminatis; tibiis posticis supra ante medium leviter dilatatis, subtus acute denticulatis.

\section{bb. Thorace utrimque processu destituto.}

4. P. pachycera Stal. - Sat oblonga, terrea, tota densissime griseo-subsquamulosa; antennarum articulo ultimo clorsoque abdominis croceis, illo, basi excepta, nudo; alis membranaque sordidis, hoc punctis raris nigris conspersa. \&. Long. 13, Lat. 3 mill.

․ Femoribus posticis leviter incrassatis.

Petalocnemis pachycerus S'TẢL. Öfv. Vet.Ak.Förh. 185̌5. p. 29.1.

Patria: Caffraria. (Mus. Holm.)

Species insignis, Choerommatum farinosum simulans. Antenna crassie, tertia parte corporis paullo longiores, articulis secundo et tertio aeque longis, primo panllo longioribus. Thorax paullo longior quam latior, marginibus lateralibus ante medium lerissime sinuatis, angulis lateralibus haud products, obtusis, rugia lougitudinali uedia distincta pereurrente instruetus. Scutellum longius yuam latius. Femora anteriora supra obsolete tubereulata, subtus distinete denticulata postiea vix tulb:reulata, subtus apieem versus dentieulati. Tibie subinermes.

\section{CHOEROMMATUS $\Lambda$. et $\mathrm{S}$.}

Hist. des Hém. p. 204. (1843).

Veurodederrhis Srår. Öfr. Vet. Ak. Förh. 1853. p. 260.

Corpus oblongo-ovatum, depressum. Caput subquadratum, leviter transversum, basi pone oculos utrimque callosum, lobo medio inter tubereula antemnifera elevato, hand prominulo. An- 
tennæ breves, crassiusculæe vel crassæ, articulis ultimo et basali æque longis, illo fusiformi, graciliore, intermediis duobus fere reque longis, illis nonnihil longioribus. Rostrum breve. Scutellum vix longius quam latius. Hemelytra subparallela, margine apicali corii recto, sutura clavi paullo breviore; membrana reticulata. Mesosterum anterius leviter sulcatum. Abdomen utrimque sat ampliatum. Pedes breviusculi, simplices, postici valde distantes; tibiis anticis nomnihil compressis; tarsis posticis articulo primo apicalibus duobus ad unum fere rque longo.

Petalocnemidi affine genus, tibiis posticis simplicibus, nec compressis, nee dilatatis differt.

1. C. furimosus A. et S. - Fuscus, tegumento argillaceo totus tectus; antennis crassis, parce setulosis, articulis secundo et tertio basali paullo gracilioribus, sulcis obsoletis in tegumento instructis, articulo apicali apicem versus nudo, fusco; thorace æque longo ac lato, marginibus lateralibus levissime sinuatis, haud reflexis, rugis quattuor longitudinalibus leviter elevatis, basi et apice evanescentibus, instructo; membrana livida; alis fuscescentibus; abdomine dorso sordide sanguineo; femoribus minute tuberculatis; tibiis anterioribus supra tuberculis nonnullis parvis instructis. क: Long. 13, Lat. $3 \frac{1}{2}$ mill.

Choerommatus farinosus A. et S. Hist. des Hém. p. 204. 1. Pl. 4. fig. 4. (1843), sec. ex. typ.

Patria: Senegal. (Coll. Signoret.)

Antenna breviores et crassiores quam in icone Amyotr et SerVILLEI supra citato.

2. C. argillacers STÅL. - Fuscus, remote setulosus, tegumento argillaceo præsertim subtus indutus; antennis haud argillaceis; thorace aque longo ac lato, marginibus lateralibus distincte sinuatis, leviter reflexis, pone medium subampliatis, rugis quattuor longitudinalibus obsoletissimis instructo; membrana livida; alis fuscescentibus; abdomine dorso subsanguineo; femoribus minute tuberculatis, anterioribus subtus tuberculis dentiformibus distinctis armatis; tibiis anterioribus supra denticulis nonullis instructis. \&. Long. 13, Lat. $3 \frac{1}{2}$ mill. 
Patria: Madagasear. (Coll. Signoret.)

Pracedenti maxime affinis, terumento aroillaceo minus denso, thoracis marginibus lateralibus distincte sinuatis, pone sinum subampliatis, diftert.

3. C. indutus StÅL. - Fuscus, setulosus, argillaceo-conspersus et lic illic indutus; antennarum articulo ultimo apicem rersus nudo; thorace paullo breviore quam latiore, obsolete granulato, marginibus lateralibus anticis rectis, posterius rotundatis; alis fuscescentibus; membrana livida; ablomine supra croceo; femoribus minntissime tuberculatis; tibiis anticis supra obsolete obtuseque denticulatis. ․ Long. 13, Lat. $3 \frac{1}{2}$ mill.

Patria: Caffraria. (Mus. Holm.)

Pracerlenti maxime affinis, thorace breviore, abdomint. minus ampliato tibiisque anticis angustior bus differt.

\section{ELASMOGASTER STÅL.}

Öfv. Vet. Ak. Förh. 1853. p. 259.

Corpus depressum. Caput subquadratum, basi pone oculos callosum, tuberculis antenniferis prominentibus, interdum contiguis, lobo medio inter illa tubercula haud distinguendo. Rostrum breve, pone coxas anticas haud extensum. Antenne crassa, triquetra, articulo apicali reliquis breviore. Thorax collari destitutus. Scutellum xquilaterum. Hemelytra interdum abbreviata; corii margine apicali recto, suturæ clari xquilongo vel breviore; membranx venis hic illic anastomosantibus. Abdomen utrimque valde rotundato-ampliatum, hemelytris multo latius. Pedes validi, postici nonnilil distantes; femoribus inermibus, posticis haud incrassatis; tarsis posticis articulo primo apicalibus duobus ad unum aque longo.

1. F. africanus DALL. - Cinnamomeus, in ferrugineum vergens, granulis squamuligeris conspersus; antennis ferrugineis, articulo primo nigricante, ultimo apicem versus fusco; margine apicali corii anguste griseo; membrana fusca; alis infuscatis; pedibus obscurioribus. $\sigma^{7}$. ㅇ. Long. 17, Lat. $5 ! 1$ mill.

Brachytes afiricanus DALL. List of Hem. II. p. 379. 2. (1852). 
Elasmogaster brumescens STẢL. Öfv. Vet. Ak. Förh. 1855. [?: 27. 1.

Patria: Caffrarial. (Mus. Holm.)

Antenne corpore dimidio paullo longiores, articulo primo capiti longitudine requali, crasso, secundo et tertio inter se reque longis, basali nounihil longioribus, tertio leviter sulcato. Thorax marginibus lateralibus lcvissime sinuatis; angulis anticis acutiuscule prominulis, I teralihus rotundatis, hand productis. Himclytr', aleque interdum abbreviata et medium abdominis paullo tantum superantia.

\title{
PRISMATOCERUS $\Lambda$, et $\mathrm{S}$.
}

\author{
Hist. des Hem. p. 185. (1813).
}

Thitom,s 1)A1.. List of Hem. II. p. 448. (1852).

Corpus oblongum vel subelongatum. Caput quadratum, basi pone oculos callosum, tuberculis antenniferis libere prominulis, paullo distantibus, lobo medio inter illa tubercula haud elevato. Rostrum breve, articulis secundo et tertio aque longis. Antennie quoad formam variabiles, articulo primo capite longiore, ultimo penultimo breviore. Thorax collari destitutus. Scutellum xquilaterum. Corii margo apicalis leviter sinuatus, sutura clavi hand vel paullo longior, angulus apicalis nonnihil productus. Membrana venis simplicibus, raro hic illic anastomosantibus. Pedes mediocres, postici distantes; femoribus inermibus, posticis haud incrassatis; tarsis posticis articulo primo apicalibus duobus ad unum aque longo.

a. Antennis crassis, triquetris, articulis secundo et tertio compressis, ultimo cylindrico: thorace posterius utrimque processu lato depresso instructo; pedibus posticis a lateribus corporis quam inter se vix duplo longins remotis.

\section{Prismatocerus A. et S.}

1. P. magnicornis Burm. - Pallide griseo-stramineus, fusco-ferrugineo-punctatus; thoracis disco hemelytrisque acervatim nigro-punctatis, illo ante medium macula nigra parva notato; antemnis ferrugineis; membrana alisque sordide hyalinis, illius venis subinfuscatis; abdomine dorso testaceo, incisuris maculisque duabus sordide stramineis; connexivo fusco, segmentis 
ante medium griseo-stramineis; thoracis angulis lateralibus cum processubus lateralibus omnino confusis. \&. Long. 20, Lat. 6 mill.

Homoeocerus magniromis BuRM. Handb. II. 1. p. 316. 2. (18:35).

Prismatocerus anritulus A. et S. Ilist. des Hém. p. 185. 1. Pl. 4. fig. 3. (1843).

Ceratopachys magnicomis DALL. List of Hem. II. p. 503. 8. (1852).

Patria: Terra capensis. (Mus. Holm. et Coll. Signoret.)

Antcnnie crasse, articulis secundo et tertio nonnihil compressis, primo et secundo axue hatis, hoc apicem versus sensim nomnilil angustato, tertio magis compresso, ab apice basin rersus sensim distimete angustato. Thorax marginibus lateralibus posterius in processum aliformem, latum, apicem versus subampliatum, apice ar gulum rectum vel subobtusum formantem, posterius crenulatum, leviter antrorsum et valde sursmm vergentem, dense punctatum, usque ad angulos posticos thoracis extensum, productis. Abdomen vix ampliatum, spiracnlis ventris a basi et latere segmentorum fere aque longe remotis.

2. P. auriculatus STÅL. - Pallide griseo-stramineus, acervatim fusco-ferrugineo-punctatus, subtus dilute punctatus, punctis nonnullis nigris, pectore maculis nonnullis parvis nigris notato; membrana alisque sordide hyalinis, venis infuscatis; abdomine dorso connexivoque nigris, illius maculis duabus mediis maculaque oblonga segmenti ultimi, hrjus segmentis anterius stramineis; processubus lateralibus thoracis ab angulis lateralibus paullo remotis. q. Long. 18, Lat. 6 mill.

Patria: Caffraria. (Mus. Holm.)

$P$. magnicomi simillimus, antennis paullo minus incrassatis, thoracis processubus lateralibus obtusioribus, minus sursum vergentibus, panllo ante angulos laterales ortis, abdomineque paullo latiore differt. Antennie fusco-pnuctulatic, corpore nomihil breviores, articulis secundo et tertio compressis, sccundo lineari, apicem rersus vix angustato, tertio basin rersus leviter angustato. Thorax marginibus lateralibus convexis, posterins processu lato, apice subtrmeato, obtuso, extrorsum et leviter sursum vergente, ib angulis lateralibus paullo remoto, instructis. Abdomen leviter ampliatum, spiraculis ventris a lateribus ynam a basi segmentorum panllo longius remotis. 
aa. Antemis minus incrassatis; thorace posterius utrimque processu lato destituto, angulis posticis haud vel leviter prominulis; pedibus posticis a lateribus corporis quam inter se plus duplo vel fere triplo longius remotis.

\section{Philonus Dall. List of Hen. II. p. 448. (1852).}

3. P. bicolor Germ. - Pallidissime olivaceo-stramineus, supra sordide rufescente-tinctus et ferrugineo vel fusco-ferrugineopunctatus, subtus dilute punctatus; antennis rufo-ferrugineis, articulo ultimo fusco- vel flavo-ferrugineo; corii margine costali sordide stramineo; membrana infuscata; alis sordide hyalinis vel leviter infuscatis; abdominis dorso sanguineo vel sanguineo-flavescente; tibiis tarsisque dilute sordide sanguineis. $\sigma^{7}$. \&. Long. 13-16, Lat. 4-5 mill.

Homoeocerus bicolor Germ. in Silb. Rev. ent. V. P. 148. 64. (1837).

Var. b. - Corio pone medium maculis parvis duabus vel una albidis.

Patria: Terra capensis, Caffraria. (Mus. IIoln. et Coll. StGNORET.)

Antenna corpore circiter tertia parte breviores, articulis primo, secundo et tertio subtriquetris, primo et tertio fere aeque longis, secundo nomnihil brevioribus, quarto primo paullo breviore. Thorax marginibus lateralibus antiris rectis, angulis lateralibus obtusis, apice plus minus rotundatis, interdum nomnihil prominulis. Abdomen hemelytris nounihil latius.

4. P. discolor STriL. - Distincte punctulatus, supra dilute testaceus, subtus cum pedibus dilute testaceo- vel olivaceo-flavescens; antennis ferrugineis; membrana alisque infuscatis; abdomine dorso subsanguineo vel eroceo. 子. Long. 16-18, Lat. $5 \frac{1}{3}$ mill.

\section{Patria: Caffraria. (Mus. Holm.)}

Precedenti valde affinis, margine costali corii concolore, antenuis distinctius triquetris, articulis quarto breviore, tertio leviter compresso, haud timmen dilatato, divergit. Antennie corpore circiter tertia parte breviores, articnlo primo tertio paullo breviore, secundo illis nomuibil longiore, tertio quarto vix duplo longiore. Thorax marginibus late- 
ralibus anticis vix sinuatis, obsoletissime crenulatis, angulis lateralibus apice plus minus obtuse rotundatis et prominulis.

5. P. plagiatus Geru. - Fusco-cinnamomeus, puberulus, subtus pallidior, fusco-punctulatus; abdominis limbo pallido, dilute punctato, dorso sanguineo, vitta angusta utrimque laterali segmentisque apicalibus nigris; antennarum articulis primo et quarto obscure fuscis, secundo et tertio flaro-ferrugineis, apice nigris, tertio apice distincte dilatato; hemelytris flavo-cinnamomeis, davo dense fusco-punctato, corio vitta irregulari nigra prope marginem costalem ornato; membrana obscure fusca; alis infuscatis. $\sigma$. ․ Long. 15-17, Lat. 4-5 12 mill.

Homoeocerus plagiatus Germ. in Silb. Rev. ent. V. p. 147. 63. (1837).

Philonus nigrovittatus STÅL. Öพ. Vet. Ak. Förlı. 185.j. p. 29.1. Ceratopachys plagiatus DALL. List of Hem. II. 1. 502. 6. (1852).

Patria: Terra capensis, Caffraria. (Mus. Holnı., Coll. SIGNORET.)

Antennac corpore dimidio nomihil longiores, articulo primo vix triquetro, secmudo et tertio triquetris, tertio apjecm versus supra subtusque distinete nomilil dilatato, secundo nonnihil breviore et primo subbreviore, quarto prino nomihil breviore. Thorax marginibus lateralibus rectis, angulis lateralibus rotundatis, vix prominuli-

6. P. insubidus GerM. - Fusco-cinnamomeus, puberulus, dense punctulatus; antemnis fuscis vel nigris, articulis secundo et tertio basi vel fere totis rufo-ferrugineis, tertio apicen versus leviter compresso, vix ampliato; hemelytris limboque abdominis plus minus obscure aut dilute Havo-cimamomeis, fuscopunctulatis, corio interdum vitta fusca ornato; membrana fusca; alis infuscatis; abdomine dorso croceo, vitta vel linea laterali parteque apicali nigris. ơ. ㅇ. Long. 14-18, Lat. $5-5$ ! mill.

Homococerus insubidus Germ. in SIL13. Rer. ('nt. V. p. 147. (i2. (18:37).

Hhilome fuscus DALL. List of Hem. II. P. 448. 2. PI. 12. fig. 6. (185.2). 
Philonus insubidus DaLL. List of Hem. II. p. 449. 3. (1852).

Patria: Terra capensis, Caffraria. (Mus. Holm., Coll. A. DOHRN et SigNoRET.)

Praeedenti maxime affinis, autemnarum articulis quarto et primo fere reque longis, tertio apice vix ampliato, differt.

Antenna variant fere tote nigrae vel articulis secundo et tertio basi vel fere totis fermingineis.

Gonocerus marginellus Westw. (in Hore. Cat. of Hem. II. p. 25) ad Prism. plagiatum vel insubidum referendus est.

\section{TAGUS STÅL.}

Corpus valde oblongum. Caput subquadratum, basi pone oculos leviter callosum, tuberculis antenniferis libere prominulis, lobo medio inter illa haud elevato. Rostrum breve, articulo tertio reliquis longiore. Antennæ triquetræ, articulo ultimo fusiformi, brevi. Thorax collari destitutus. Scutellum vix vel paullo longius quam latius. Corium margine apicali leviter sinuato, angulo apicali leviter producto. Membrana venis simplicibus instructa. Pedes longiusculi, postici nonnilil distantes; femoribus inermibus; tarsis posticis articulo primo apicalibus duobus ad unum vix longiore.

Præcedenti affine genus.

1. T. productus STẢL. - Flavo- vel fusco-cinnamomeus, remote sericeus, parce punctatus, subtus pallidior; thorace callis minutis lævibus parce adsperso, angulis lateralibus valde productis; corii venis maculaque irregulari ad marginem apicalem pallidis; membrana fuscescente; alis sordide hyalinis; abdomine dorso croceo, maculis connexivi et marginis ventris nigro-fuscis; antennis nigris, articulis secundo et tertio a basi ultra medium flavo-testaceis; femoribus posticis tibiisque apicem versus nec non tarsis nigricantibus. $\sigma^{7}$. Long. 15, Lat. $4 \frac{1}{2}$ mill.

Patria: Sennaar, Senegal. (Coll. SignoRet.)

Antenua longa, corpore paullo breviores, artienlis primo et tertio aeque longis, seeundo nomnihil brevioribus, seeundo et tertio leviter eompressis, tertio sat graeili. Thorax angulis lateralibus acutis, oblique sursum longe productis. 


\section{DIOCLES STAL.}

Corpus anguste ovatum. Caput quadratum, basi pone oculos haud callosum, tuberculis antenniferis libere leviter prominulis, lobo medio inter illa distinguendo, nee elevato. Rostrum breve, articulis duobus apicalibus reque longis et dnobus basalibus longioribus. Antennæ articulis duobus apicalibus fere æque longis. Thorax collari destitutus. Scutellum xquilaterum. Corium margine apicali ad angulum apicalem levissime productum nonnihil sinuato. Membrana basi subcoriacea, renis hic illic anastomosantibus. Abdomen utrimque rotundato-ampliatm. Pedes mediocres, postici paullo distantes, femoribus inermibus; tarsis posticis articulo primo duobus apicalibus ad unum æque longo.

Præcedentibus affine genus.

1. D. dilutus StäL. - Pallide olivaceo-stramineus, supra in pallidissime subtestaceum vergens, ventris disco excepto distincte punctatus; membrana alisque vitreis, his pallidissime subvinaceis. ơ. Loug. 16, Lat. 5 mill.

Patria: Caftraria. (Mus. Holm.)

Antenue corpore nom ihil breviores, grincilinscule, articulis primo et secundo ieque longis, capite triplo longiolibus, duobus apicalibus etiam aeque longis, illis uomihil brevioribus, primo, secundo et tertio triquetris, hoc subcompresso, ultimo eylindrieo. Thorix marginibus lateralibus anticis rectis, obsolete crenulatis, angulis lateralibus rotundatis, vix prominulis. Membrana margine basili olivaceo-stramineo, opaco, coriarcco.

\section{CERATOPACHYS WESTW.}

IIopr. Cat. of IIem. II. p. 22. (1842).

Corpus oblongum. Caput subquadratum, basi pone neulos globosos et vilde prominulos haud callosum, usque ail oculos immersum, tuberculise antenniferis libere paullo prominulis, distantibus, lobo medio inter illin distinguendo, vix tamen elevato. Rostrun breve, articulis ommibus fere arque longis. Antemne crassiuscular. Thorax apice collari minus distincto, parte subapicali thoracis haul angustiore, instructus. Scutellum aquala- 
terum. Corium margine apicali versus angulum apicalem subproductum levissimo sinuato. Venæ membranæ simplices. Pedes postici nomnihil distantes; femoribus inermibus; tarsis posticis articulo primo apicalibus duobus ad unum æque longo.

I. C. nigricornis Germ. - Olivaceo-flavescens vel dilute rufescente-testaceus, ventre excepto distincte punctatus; antennis nigris, articulo primo nec non basi articulorum secundi et tertii subferrugineis, articulo ultimo stramineo; capitis vittis duabus, thoracis fascia posteriore, sæpissime tri-interrupta, hemelytrorum punctis ante medium sparsis maculaque irregulari pone medium, nec non macula parva angulorum apicalium segmentorum ventris nigris; membrana fuscescente; alis decoloribus; abdomine dorso dilute sanguineo vel croceo. ․ Long. 12-13, Lat. 41 mill.

Homoeocerus nigricornis GERM. in SILB. Rev. ent. V. p. 148. 65. (1837).

Ceratopachys capensis Westw. in Hope. Cat. of Hem. II. p. 22. (1842).

Ceratopachys nigricornis DALL. List of Hem. II. p. 503. 7. Tliponius rugifer StåL. Öfv. Vet. Ak. Förh. 185̃9. p. 465.9. Patria: Terra capensis, Caffraria. (Mus. Holm. et Coll. SIGNORET.)

Antenne corpore dimidio paullo longiores, articulis fere aque crassis, primo subtereti, secundo et tertio subtriquetris, ultimo fusiformi, primo, tertio et quarto fere aeque longis, seeundo nonnilil brevioribus, eapite vix longioribus. Thorax marginibus lateralibus anticis leviter sinuatis, angulis lateralibus rectis, leviter prominulis et reflexis. Pectoris vitta subrugosa, interrupta, sape obsoleta vel oblittcrata, nee non ventris ruga utrimque lateralis longitudinalis pallida, interdum eburnea.

\section{ORNYTUS DALL.}

List of Hem. II. p. 447. (1852).

Corpus valde oblongum. Caput subquadratum, basi pone oculos vix vel leviter callosum, tuberculis antenniferis libere leviter prominulis, distantibus, lobo medio inter illa distingneudo. Rostrum breve, articulo secundo tertio longiore. Antennæ sub- 
teretes. Thorax collari destitutus. Scutellum subæquilaterum. Corium margine apicali vix vel leviter sinuato, angulo apicali vix producto. Pedes mediocres, postici nonnihil distantes; femoribus inermibus; tarsis posticis articulo primo apicalibus duobus ad unum paullo longiore.

Pracedentibus affine genus.

1. 0. alternans WESTW. - Sordide stramineus, exceptis marginibus lateralibus thoracis et costali corii supra in flavotestaceum vergens et fusco-punctatus; abdominis dorso testaceo vel subsanguineo, hujus parte apicali antennarumque articulis secundo et tertio apicem versus nigris; alis sordide vinaceis; membrana fusca. $\sigma^{7}$. ․ Long. I4-18, Lat. 4-5 mill.

Coreus altemuns Westw. in Hope. Cat. of Hem. II. p. 24. (1842).

Ornytus alternans DALL. List of HIem. II. p. 447. I. (I852). Patria: Sierra Leona, Calabar. (Mus. Holm., Coll. A. Dohrs, SigNoRET et ŚTÁL.)

Antenuxe graciles, corpore nomnihil breviores, articulis tertio et quarto fore aque longis, basali paullo brevioribus, sccundo reliquis nomnihil longiore, basali capite plus duplo longiore. Thorax marginibus lateralibus rectis, integris, angulis lateralibus rotundatis, haud prominulis.

2. 0. anmulatus Thuns. - Flavo vel rufo-cimamomeus, subtus cum connexivo sordide stramineus, punctatus; antennis rufoferrugineis, articulo primo toto, secundo et tertio apice, marginibus lateralibus thoracis, vitta angusta intril marginem costalem stramineum corii, lateribus capitis, maculis minutis sparsis pectoris ventrisque nigris; alis fuscis, basin versus pallidioribus; membrana obscure fusca; abdomine dorso croceo, apice nigro; pedibus ferrugineis vel nigro-ferrugineis. o?. ㅇ. Long. 14-16, Lat. 4-5 mill.

Alydus annulatus Thunß. Hem. rostr. cap. III. p. 4. (1822). Homoeocerus migripes BuRM. Ilandb. H. 1. p. 316. 3. (1835); A. et S. Hist. des Hém, p. 203. 1. (IS43).

Philonus nigripes DaLL. List of HIem. II. p. 448. 1. (1852). 


\section{Patria: Terra capensis. (Mus. Holm.)}

Antemne breviuscula, corpore dimidio vix longiores, articulis primo et tertio fere acque longis, capite nonnihil longioribus, secundo et quarto fere aeque longis, primo nomnihil longioribus. Thorax marginibus lateralibus rectis, angulis lateralibus rotundatis, hand prominulis, pone marginem apicalem inpressione levi lineari instructus.

\section{LATIMBUS S'TÅL. \\ Öfv. Ve. Ak. Förh. 1859. p. 4166}

Corpus oblongum vel nomihil elongatum. Caput subquadratım, basi pone oculos haud callosum, tuberculis antenniferis haud libere prominulis, paullo distantibus, lobis subreclinato-deflexis, lobo medio basi inter illa tubercula elevato. Rostrum breve, articulo tertio secundo breviore. Antennæ variabiles. Thorax collari destitutus. Scutellum xquilaterum vel paullo longius quam latius. Corium margine apicali vix sinuato, angulo apicali vix producto. Membrana venis furcatis. Pedes mediocres, postici nonnihil distantes, femoribus ineruibus vel spinosis; tarsis posticis articulo primo apicalibus duobus ad unum axque longo.

a. Tuberculis antenniferis apice extus acute prominulis; scutello subarquilatero; abdomine hemelytris paullo latiore; corpore nonnitil depresso; antemis concoloribus.

1. L. punctatus DALL. - Ferrugineo-flavescens, subtus pallidior, dense distincteque punctulatus; marginibus lateralibus anticis thoracis anguste fuscis; maculis minutis tribus lateralibus pectoris nigris; alis vinaceis; membrana subfusco-vinacea; femoribus inemibus; antennis crassiusculis. ․ Long. 13, Lat. 4 mill.

Philonus? punctatus DALL. List of Hem. II. p. 449. 4. (1852).

Patria: Caffraria. (Mus. Holm., Coll. StÅL.)

Antemne crassinsculie, corpore dimidio nonnihil longiores, articulis omuibus fere aque crassis, articulis primo, sccundo et tertio fere aque longis, quarto paullo brevioribus, primo capite haud duplo longiore. Thorax marginibus lateralibus anticis subrectis, minutissime creunlatis, angulis lateralibus rectis, paullo prominulis. Venter maculis nonmullis minutis impressis nigris, latera ver'sus in seriem irregularem positis, ornatus. 


\section{$-72-$}

2. L. concolor GerM. - Ferrugineo-flarescens, subtus pallidior, dense distincteque punctulatus; marginibus imis lateralibus anticis thoracis infuscatis; maculis tribus minutis lateralibus pectoris nigris; abdomine dorso croceo; alis vinaceis, apicem versus leviter infuscatis; membrana infuscato-vinacea; femoribus subtus prope apicem spinulis duabus minutissimis, interdum deficientibus, armatis; antennis gracilibus. $\sigma$. ૧. Long. 12-14, Lat. 4 mill.

Syromaster concolor Gers. in Silis. Rev. Eut. It. p. 146. 59. (1837).

Homoeocerus concolor DALL. List of Hem. Il. 1. 446. 9. (1852). Paryphes hilarus STÃL. Öfr. Vet. Ak. Förl. 1855. I. 29. 1. Patria: Caffraria, Terra capensis. (Mlus. Holm., Coll. A. DOHRN, Signoret et STÁL.)

L. punctato simillimus, antennis longioribus et gracilioribus presertin differt. Antenne graciles, corpore panllo breviores, articulis primo et quarto reliquis nonnihil crassioribus, prino capite circiter duplo et dimitio vel fere triplo longiore, omnium longissimo, secunclo et quarto aeque longis, tertio paullo longioribus. Thorax marginibus lateralibus anticis leviter sinuatis, minute crenulatis, angulis lateralibus subrectis, leviter prouinentibus.

aa. Tuberculis antenniferis apice exths haud acute prominulis; antennis fere totis nigris.

3. I. punctiventris SIGr. - Sordide subferrugineo-flavescens, dense distincteque subfusco-punctulatus, lateribus pectoris rentrisque interdum obscurius punctatis; antennis, marginibus lateralibus anticis thoracis nec non maculis parvis lateralibus ventris, in seriom dispositis, nigris; maculis marginalibus connexivi fuscis; antennarum articulo apicali sordide stramineo, hasi ipsa nigro; alis vinaceis; membrana fuscescente. q. Long. 14, Lat. 4 mill.

Homococens punctiventris SIGs. in THous. Arch. ent. II. 1. 299. 571 . (1858).

Patria: Calabar. (Coll. Signoret et Stil.)

Staturia fore L. concoloris. Antemne graciles, corpori longitudine iequales, articulo primo omnium longissimo, capite thoraceque ad umm vix breviore, articulis sceundo et quarto aeque longis, tertio 
paullo longioribus. Thorax marginibus lateralibus subrectis, anterius obsoletissime eremulatis, angulis literalibus acutinsculis, nomnihil prominentibus. Scutellum aequilaterum. Abdomen hemelytris paullo latius. Femora sultus prope apicem spinulis duabus minutissimis obsoletis almata.

4. I. armipes STẢL. - Elongatus, sordide stramineus, supra in ferrugineum vergens, dense punctulatus; antennis, marginibus lateralibus anticis thoracis, dorso abdominis membranaque nigris; antennarum articulo apicali basin versus, basi ipsa excepta, sordide albido; alis sordide hyalinis, fusco-venosis. or. ㅇ. Loug. 13-15, Lat. 4 mill.

Latimbus armipes STAL. Öv. Vet. Ak. Förh. 1859. p. 466. 1. Patria: Calabar. (Coll. A. Dohrs, Signoret et ŚtẢl.)

Congenericis angustior, femoribus subtus multispinulosis insignis. Antenne longie, gracillinie, artienlo primo omnimm longissimo, capite thoraceque ad nmm aeque longo, secmido, tertio et quarto aeque longis. Thorax marginibus lateralibus anticis rectis, angulis lateralibus rectis, haud prominulis. Sentellum longius quam latius. Ablomen hemelytris aeque latum ( $\left(^{\circ}\right)$, vel paullo latius (q). Fenora subtus multispinulosa.

\section{HYDARA DALL.}

\section{List of 1lem. II. p. 492. (1852).}

Corpus valde oblongum. Caput basi pone oculos laud callosum, tuberculis antenniferis haud libere prominulis, lobis ante illa leviter deflexo-productis. Rostrum coxas posticas subattingens, articulo tertio omnium levissimo. Antemm longæ, gracillime, artienlo primo apice clavato, quarto incrassato. Thorax collari destitutus. Scutellum subæquilaterum. Corium margine apicali prope angulum apicalem nonnihil sinuato. Membrana venis subsimplicibus. Anguli postici metastethii subacuti. Pedes graciles, longi, femoribus apice nonnihil incrassatis, inermibus; tarsis posticis articulo primo apicalibus duobus ad unum sublongiore.

1. II. tenuicornis WEsTw. - Pallide subferrugineo-flavescens, dense granulata; alis pallidissime vinaceis; membrana sordide hyalina; abdomine dorso dilute miniato; articulo quarto antennarum fusco. $\sigma^{\text {’ }}$. Long. 11, Lat. 3 mill. 
Corens temicomis WEstw. in Hope. Cat. of Ifem. II. p. 24. (1842).

Iydara tenuicornis DALL. List of Hem. II. p. 493. 1. Pl. 14. fig. 5. (1852).

Hydara gracilicornis STÅL. Öfv. Vet. Ak. Förh. 1855. p. 30. I; Sign. Ann. ent. Sér. 3. VIII. p. 942. 122. (1861).

Patria: Caffiraria, Madagascar. (Mus. Holm. et Coll. SigroRET); Sierra Leona. (Mus. Brit.)

Antemne corpore vix longiores, articulo primo longissimo, tertio nomihil longiore, secundo tertio nomihil breviore et quarto paullo longiore. Thorax marginibus lateralibus leviter sinnatis, angulis lateralibus in spinam aeutissimam extrorsum productis. Abdomen hemelytris paullo latius.

\section{CORDUBA STÅL.}

Ent. Zeit. XXIII. ]). 305. (1862).

Corpus ralde elongatum. Caput usque ad oculos haud immersum, ante tubercula antenniferi haud prominula triangulariter deflexo-productum. Rostrum coxas posticas subsuperans, articulo primo capite nomnihil breviore. Antenne graciles, articulo primo apice incrassato, quarto brevi, fusiformi. Thorax collari destitutus. Scutellum longius quam latius. Corium margine apicali recto. Membrana venis longitudinalibus e vena transversa, a margine basali renota, emissis. Anguli postici metastethii acutiusculi. Pedes gracillimi, femoribus apice nomnihil incrassatis.

Priecedenti affine genus.

1. C macra STÁL. - Sordide straminea, dense granulata; articulo quarto antemarum fusco; ablomine dorso dilute sanguineo; alis sordide hyalinis. or. Long. 9, Lat. $1 \frac{1}{2}$ mill.

Corduba macre stís. Ent. Zeit. XX111. p. 305. (1862).

Patria: Sierrat Leona. (Mus. Ilohm.)

Antenue corpore circiter quinta parte breviores, articulo primo eapite vix duplo longiore. Thorax marginibus lateralibus rectis, angulis lateralibus rotundatis, haud prominulis. Abdomen lineare, hemelytris haud latius. segmento dorsali ultimo. alpud marem saltem, reliquis hand angustione, apiece subsinuato-truncato. 


\section{CLETUS STAL.}

Freg. Eug. Resa. Ins. Hem. p. 236. (1858).

Corpus oblongum. Caput basi pone oculos callosum, lobis ante tubercula antennifera interdum productis, tunc tamen usque a basi plus minus deflexis. Rostrum articulo tertio reliquis breviore. Thorax collari destitutus. Scutellum aquilaterum. Corium angulo apicali haud vel leviter producto. Mesosternum et metasternum leviter sulcata. P'edes mediocres, postici vix vel paullo distantes, femoribus inermibus; articulo primo tarsorum posticorum apicalibus duobus ad unum reque longo vel sublongiore.

Gonocero affine genus.

a. Intennis gracilibus, articulis primo et quarto crassioribus.

b. Thorace linea transversa pallida destituto.

c. Limbo costali corii a basi ad medium pallido, punctis fuscis destituto; macula parva ad marginem apicalem corii albicla, levi.

1. C. pusillus DALL. - Straminens, supra dilute ferrugineofusco, subtus pallidissime subferrugineo-punctatus; capite thoraceque ante medium acervatim nigro-punctatis, marginibus lateralibus pallidis; artienlo apicali antennarum fusco; maculis minutissinis punctiformibus tribus lateralibus pectoris, duabus coxarum et numerosis ventris, in series sex longitudinales dispositis, nec non macula parva angulorum basalium segmentorum abdominis nigris; corii limbo costali a basi ad medium nec $110 n$ macula parva levigata ad marginem apicalem pallidis. +. Long. $7 \frac{1}{2}$, Lat. $2 \frac{2}{3}$ mill.

Gonocerus pusillus DALL. List of Hem. II. p. 497. 13. (1852).

Patria: Territorium lacus N'Gami. (Mus. Holm.)

C. parvulo Westw. ") valde affuis et simillimus, antennis brevioribus divergit. Caput ante tubercula antennifera levissime prominulum. Antenna corpore dimidio paullo longiores, articulis primo et quarto fere aque longis, capite subbrevioribus, secundo et tertio

*) Coreus parvulus Westw. (in Hope Cat.) = Gonocerus capitulatus H. ScH. = Homoeocerus minimus $\mathrm{A}$. et $\mathrm{S}$. 
gracilibus, illis longioribus, secundo tertio vix breviore. Thorax angulis lateralibus paullo prominulis, apice sinuatis. Membrana alieque sordide hyaline. Abdomen dorso renote ferrugineo-punctatum, apice minute fusco-maculatum, comexivo finseo-punctulato.

2. C. claratus Sigx. - Sordide stramineus, supra interdum in pallidissime ferrugineum vergens, distincte punctatus, subtus maculis puntiformibus nigris destitutus; articulo quarto antennarum fusco; vittis luabus capitis thoraceque anterius interdum pallide fusco-punctatis; corii limbo costali a basi ad medium pallido, macula minuta ad marginem apicalem albida, levi; memlirana alisque sordide lyalinis; abdomine dorso croceo, impunctato. o $\sigma^{\text {. }}$. . Long. 8, Lat. 23 mill.

Gonocerus clacatus Sigr. Ann. ent. Sér. 3. VIII. p. 943. 126. (1861).

Patria: Madagascar. (Coll. SigNoret et STẢL.)

C. pusillo maxime aftinis, antemis paullo longioribus, corpore subtus coriogue maculis migris destitutis divergit. Antenuxe articulo primo capiti exunilongo, secundo et tertio f'ere aeque longis, primo multo longioribus, quarto fusiformi, crasso, basili paullo breviore. Thorax angulis lateralibus leviter prominulis, oblique sinuatis

3. C. biuntulatus STAL. - Stramineus, supra cum antennis in pallide ferrugineum vergens, dense punctatus; maculis minutis punctifomibus tribus laterabibus pectoris, duabus coxarm, nee non numerosis rentris, in series sex longitudinales dispositis, nigris; corii limbo costali a basi ad medium pallido, maculis duabus vel una parra ad marginem apicalem albidis; antemarum articulo quarto infuscato; membrana alisque subsordicle hyalinis; angulis lateralibus thoracis acutis. o. Long. 8 , Lat. 3 mill.

Gonocerus linotulatus STAL. Öfi. Vet. Ak. Förh. 1858. p. 316. 21 .

Patria: Territorium lacus N"Gami. (Mus. Holm.)

C. acuto DALL. valde affinis, angulis lateralibus thoracis miuus acutis et productis, antemis brevioribus, mesonoto et metanoto, execptal regione nigra scutellari, bisique abelominis dorsi concol ribus vel croceis differt. Antemnac corpore eirciter tertia parte breviores, articulo primo capiti fere requilongo, secundo et tertio subacqualibus, 
quarto crasso, fusiformi, primo panllo breviore. Thorax angulis lateralibus acntis, extrorsum nommibil productis.

4. C. bis-bipuctatıs S'TÅL. - Stramineus, supra dilute fuscopunctatus, pectore distincte, ventre obsolete dilute punctatis; angulis lateralibus thoracis acutis, apice fuscis; corio pone medium maculis duabus minutis pallidis, lrevibus notato, limbo costali a basi paullo ultra medium dilutiore, punctis fuscis destituto; membrana sordide hyalina; alis leviter infuscatis; regione scutellari metanoti nigra; naculis minutis tribus lateralibus pectoris, numerosis ventris, in series quattuor vel sex dispositis, unaque coxamm nigris. ơ. Long. 11, Lat. 4 mill.

Gonocerus bis-bipunctatus S'TÃ. Öfv. Vet. Ak. Förl. 1858. p. 316. 20.

Patria: Eikhams Africe meridionalis occidentalis. (Mus.IIolm.)

Statura et magnitudine fere C. bipunctuti H. Scr. "), angulis thoracis lateralibus leviter antrorsum et sursum productis divergit. Antema exempli descripti mutilatie. Caput ante tubereula antennifera levissime prominens. Thorax angulis lateralibus acute extrorsum productis, leviter" sursum et antrorsum preterea vergentibus, apice nigris, posterius obsolete crenulatis.

cc. Corio limlso costali concolore vel angustissime pallido, ad marginem apicalem macula allida destituto.

5. C. ochraceus H. ScH. - Stramineus, supra dilute ferrugineofusco-punctatus; antennis in ferrugineum vergentibus, articulo apicali infuscato; venis corii posterius lævigatis; membrana alisque leviter infuscatis; abdomine dorso croceo; comnexivo segmentis primo, secundo, tertio et quarto totis, quinto et sexto basi plus minus obscnre fusco-punctulatis; regione scutellari metanoti nigro; maculis minutissimis tribus lateralibus pectoris, duabus coxarum et numerosis ventris, in series sex dispositis, nigris. or. q. Long. 8, Lat. 3 mill.

Gonocerus ochraceus. H. ScH. Wanz. Ins. VI. p. 7. fig. 563. (1842); Dall. List of Hem. II. p. 496. 9. (1852).

Cletus modestus STẢ. in litt.

") Gonocerus bipunclatus II. Scu. = F. pugnator. DALL. sec. Mus. Brit. 
Patria: Terra capensis, Madagascal, Insula Mauritii et Bourbon. (Mus. Holm., Coll. Signoret et S'TÁL.)

Antemne corpore circiter quinta parte breviores, articulis primo et tertio fere aeque longis, secundo nomihil brevioribus, eapite nonnihil longioribus, quarto fusiformi, primo paullo brevione. Thiorax angulis lateralibus extrorsum acute productis, apice infuscatis, posterius ercuulatis.

6. C. caffer STȦL. - Grisescente-stramineus, nigro-punctatus, thorace anterius pallidiore et minus lense punctato; articulo apicali antemnarum fusco; membrana alisque infuscatis, his fusco-renosis, basin versus decoloribus; renis corii apicem rersus lievigatis; abdomine dorso sanguineo vel croceo, vittis duabus segmenti ultini nec non segmentis connexiri basi et apice nigro-fuscis; maculis minutis duabus coxarum compluribusque ventris, in series sex dispositis, nigris; pedibus fuscopunctatis. $\sigma^{7}$. ㅇ. Long. 7-81, Lat. 21-3 mill.

Gonocerus caffer STÃL. Öfr. Vet. Ak. Förh. 1855. p. 31. 2. Patria: Caffraria. (Mus. Ilolm.); Madagascar. (Coll. SIGNORET.)

Antenuie articulo primo capiti fere seque longo, secundo tertio nonnihil longiore, anbolus primo longioribns, quarto fusiformi et primo eque longis. Thorax angulis lateralibus leviter prochetis, apice rix acuminatis, posterins hand crenulatis.

Quoad formam thoracis ad C. parvulum appropinquat.

7. C. varius DALL. - Grisescente-stramineus, nigro-punctatus, thorace anterius pallidiore et minns dense punctato; articulo apicali antennarum fusco; membrana alisque infuscatis, his fusco-renosis, basin versus decoloribus; renis corii apicem versus levigatis; abdomine lorso sangnineo rel croceo, vittis duabus segmenti ultimi nec non segmentis commexivi basi et apice nigro-fuscis; maculis minutis duabus coxarum compluribusque rentris, in series sex dispositis, nigris; pedibus fuscopunctatis; angulis lateralibus thoracis acutis. $\sigma^{7}$. ․ Long. 7, Lat. $3 \frac{1}{2}$ mill.

Gonocernes varius D.MLL. List of Item. II. p. 496. 11. (1852). Patria: ('atfliaria. (Mus. Ilolm.) 
Precedenti simillimus, thoracis angulis lateralibus acntissimis, productis, posterius cremulatis, articnloque antemnarum primo paullo graciliore differt. Thorax fere uti in $C$. acuto formatus.

8. C. Lanciger FABR. - Sordide stramineus, dilute fuscescentepunctatus, thorace posterius hemelytrisque dense obscureque punctatis et interdum infuscatis, horum fascia angusta laviuscula, pone medium posita, pallida; membrana fuscescente; alis leviter infuscatis; abdomine dorso croceo; apice segmenti tertii, segmento quarto toto, basi segmentorum quinti et sexti connexivi fuscis rel nigris; pedibus minute remoteque fuscoconspersis. $\sigma^{7}$. ․ Long. $7-8$, Lat. $2 \frac{2}{3}-3$.

Coreus lanciger FABR. Lint. syst. IV. p. 128. 7. (1794); Syst. Rhyng. p. 195. 17. (1803).

Gonocerus lanciger DALL. List of Ilem. II. 1). 496. 8. (1852).

Patria: Calabar, Grand Bassam. (Coll. A. Domrn, SignoRET et STẢL.)

Statura fere $C$. ochracei, angulis latcralibus thoraeis acutioribus. Caput ante tubercula antennifera levissime deflexo-prominulum. $\Lambda$ ntenne graciles, sat longa, articulis primo, secundo et tertio fere reque longis, capite longioribus, ultimo in exenplis deseriptis mutilato. Thorax angulis lateralibus in spinam acutissimatm nigram extrorsum productis, posterius serrulatis.

\section{bb. Thorace linea transiersa pallida omato.}

9. C. lituripenuis STÀL. - Pallide stramineus, supra sat dense fusco-punctatus, subtus remotius pallicliusque punctatus; marginibus lateralibus anticis, linea transversa inter angulos laterales nec non linea longitudinali ante lineam illam transversam thoracis, marginibus lineaque longitudinali media scutelli, limbo costali corii ante medium pallidis, punctis fuscis destitutis; venis hemelytrorum pone medium levigatis, pallidis; membrana alisque leviter infuscatis; maculis tribus lateralibus pectoris maculisque compluribus ventris, in series longitudinales dispositis, nigris; abdomine dorso croceo; connexivi segmentis primo, secundo et tertio fuscis, extus pallido-marginatis, quarto toto, quinto basi et apice, sexto intus fuscis. ㄱ. 우. Long. 10, Lait. $3 \frac{1}{2}$ mill. 
Gonocenss lituripennis STTÁs. Öf. Vet. Ak. Fürh. 1855. p. 30. 1.

Gonocerns lineatus Sigs. Ann. ent. Sér. 3. VIII. p. 942. 123. (1861).

Patria: Caffraria. (Mus. Holm.); Madagascar. (Coll. SiGNORET.)

Species insignis. Caput ante tubereula antennifera nomilil prominens, a latere visum apier perpendiculariter truncatum, tuberculis antenniferis apice extus obsolete acutiuscule prominulis. Antemnie corpore quinta parte breviores, articulis primo, tertio et quarto fere ieque longis, secundo nomnilil brevioribus, capite vix vel paullo longioribus. Thorax angulis lateralibus acutis, extrorsum nomihil productis, posterius haud vel vix simuatis.

aa. Intennis crassis, articulo apicali breviter fusiformi, primo breviore.

10. C. Scurra Gens. - Supra sordide ferrugineus, subtus fer-. rugineo-stramineus, cum pedibus fusco-punctatus et conspersus; antennis obscure ferrugineis, articulis primo et quarto infuscatis; thorace disco plaga transversa marginibusque lateralilus ante melium grisescentibus, gramulatis; hemelytris pone medium litura albida lavi notatis; membrana alisque leviter infuscatis; abdomine dorso dilute ferrugineo, comnexivi segmentis fuscis, fascia media pallida notatis. \&. Long. 8, Lat. 2: 111 ill.

Syromaster scurra Gerir. in Silb. Rev. ent. T. p. 146. 60. (18:3i).

Gonocerus? crassicornis DALL. List of IIem. II. p. 498. 14. (1852).

Patria: Terra capensis. (Coll. Sigroket.)

Caput inte tuberenla antenuifera paullo productum. Antemne articulo primo capite paullo breviore, secmulo et tertio aepue longis, primo rlimielio longioribus, tertio apicem rersus leviter incrassato, fuarto apice articuli tertii haud crissiore. Rostrum pedes posticos attingens, artieulo primo basin capitis vix superante. Thorax angulis literalibus extrorsum nomilil produetis, leviter convexis, apice subacuminatis, posterius prope apiecm leviter sinuatis.

11. C. Ieprosus Burar. - Sordide stranineus, dense punctatus, supra com antennis in firmoneum rergens, subtus interdum 
tilute ferrugineo-conspersus; thorace marginibus lateralibus plagaque transversa media sordide albidis, disco nigro-consperso; membrana alisque subdecoloribus; maculis minutis marginalibus abtominis pluribusque ventris, in seriem longitudinalem utrimque lateralem dispositis, nigris; rostro coxas posticas superante. $\sigma^{7}$. ㅇ. Long. 9-10, Lat. 3 mill.

Gonocems leprosus Burm. Ilandb. II. 1. p. 311. 3. (1835).

Gonocerus spissicornis STÅL. Öfv. Vet. Ak. Förh. 1856. p. 195. 4 .

\section{Patria: Terra capensis. (Mus. 11olnı.)}

Precedenti afthis, angustior, angulis lateralibus thoracis minus prominentibus rostroque longiore distinctissimus. Caput ante tubercula antemifera distincte nonnihil deflexo-prominulum. Antenna corpore dimidio panllo longiores, crassie, articulo primo eapite paullo breviore, secundo primo dimidio longiore et tertio subbreviore, quarto brevi. Rostrum bisin segmenti rentris tertii attingens, articulo primo capite nomnilil longiore. Thorax marginibus lateralibus inticis simutis, angulis laferalibus nomnihil prominulis, obtusis, posterins subsimuatis.

\section{PLINACHTUS STÄL.}

Öfv. Vet. Ak. lörh. 1859. p. 470.

- Corpus oblongum. Caput a latere visum apice rotundatum, lobis ante tubercula antennifera, latera capitis occupantia, sat productis, in eodem plano ac parte discoidali jacentibus. Antennæ articulo primo triquetro, apicali præcedenti æque longo vel longiore, secundo tertio longiore. Rostrum coxas posticas subattingens, articulo primo basin capitis haud superante. Scutellum aquilaterum. Corium angulo apicali nonnihil producto. Membrana venis subsimplicibus. Pedes mediocres, inermes, postici paullo distantes; tarsis posticis artienlo primo apicalibus duobus ad unum vix longiore.

1. P. pungens Thunb. - Pallide stramineus, dense punctatus, supra incarnatus et nigro-punctatus; spatio parvo transverso disci thoracis læviusculo; limbo costali corii a basi ad medinm pallido, dilute punctato; lineis duabus longitudinalibus capitis, marginibus imis lateralibus anticis spinaque anguloHemiptera africana. II. 
rum lateralium thoracis, maculis minutis duabus lateralibus pectoris, macula ad spiracula segmentorum ventris secundi, tertii et quarti nee non maculis connexivi nigris; membrana fusco-vinacea; alis pone medium fuscis, costa incarnata; antennis articulis primo et secundo dilute ferrugineis, articulis secundo et tertio apice nigris, ultimo medio infuseato. ㅇ. Long. 17, Lat. 4 mill.

Cimex pungens Tiruxb. Nov. ins. spec. II. p. 36. (1783). Alydus pungens Tirnis. Hem. rostr. cap. III. p. 2. (1822). Gonocerus pungens STiL. Öf. Vet. Ak. Förlı. 1856. p. 195. 3.

Patria: Terra capensis. (Mus. Ilolm.)

Statıra fere Gonoceri Insidiatoris, angulis lateralibus thoracis acutioribus, magis antrorsum vergentibus. Antenne gracilinsculer, articulis primo et quarto crassioribus, primo et tertio fere ieque longis, secundo multo, ultimo panllo brevioribus, sicundo apice livissime, tertio ibiclem distincte compresso-inerassatis. Thorax angulis lateralibus in spinam gracilem, oblique antrorsum et sursum vergentem, productis.

2. P. dubius H. ScH. - Pallide stramineus, distincte punctatus, supra obscurior; thorace posterius hemelytrisque nigro-punctatis, his leviter incarnatis; antennis dilute ferrugineis, articulo ultimo flavo-ferrugineo, medio infuscato; lineis dualus longitudinalibus capitis, angulis lateralibus thoracis, scutelli apice maculisque duabus minutis lateralibus pectoris, nigris; limbo costali corii toto, pone medium angustiore, pallido, dilute punctato; membrana alisque subfusco-vinaceis; abdomine dorso croceo, dilute sanguineo-birittato. o. ł. Long. 11 - 13 , Lit. 3-4 mill.

Gonocerus dulius II. Sch. Wanz. Ins. VI. ए. 9. fig. 565. (1842).

Patria: Terra capensis. (Mus. Holm. et Coll. SigNoret.)

Antenna corpore circiter quarta parte breviores, articulis duobus apieatibus aque longis, primo vix brevioribus, secundo reliquis fare dimidio longiore, simpliei, tertio apicem versis leviter incrissato. Thorax angulis latcralibus antuis, leviter sursum at antrorsum produetis. 


\section{THERAPTUS S'TÅL.}

()fv. Vet. $1 \mathrm{k}$. Förh. 1859. p. 46:.

Corpus oblongum. Caput ante tubercula antennifera libere leviter prominula vix productum, basi prone oculos callo distincto instructum. Antenne longie, graciles. Rostrum inter pedes posticos extensum, articulo primo capite hand longiore, tertio omnium brevissimo. Thorax collari distincto instructum. Scutellum a equilaterum. Corium angulo apicali nonnihil producto. Membrana venis simplicibus instructi. Pedes longiusculi, graciles, inermes, postici paullo distantes; tarsis posticis articulo primo duobus apicalibus ad unum sublongiore.

Gulceso affine genus.

1. T. Carmelita Burm. - Pallide testaceo-flavescens, subtus dilute stramineus, supra cum pectore sat dense distincteque punctatus; antennis, fasciis duabus pectoris, fascia basali, interdum deficiente, segmentorum ventris nigris; basi apiceque articulorum antennarum flaro-testaceis; membrana alisque infuscatis; alodomine dorso croceo. $\sigma$. $₹$. Long. 11! , Lat. $3 \frac{1}{3}$ mill.

Chariesterus carmelita Burm. Landb. II. 1. p. 317. 1. (1835). La arice? africana DALL. List of Hem. II. p. 443. 2. (1852). Homoeocerus apicatus FAIRM. in THoms. Arch. ent. II. p. 299. 517. (1858).

Patria: Sierra Leona, Calabar, Gabon, Congo. (Mus. Holm., Coll. Signoret et StåL.)

Antenux articulis primo et secundo fere reque longis, capiti thoracique ad num longitudine requalibus, reliquis in exemplis descriptis mutilatis. Thorax angulis lateralibus subacutis, panllo prominulis, marginibus lateralibus anticis rectis, minute crenulatis. Abdomen hemelytris hand latius.

\section{GALASUS DALL.}

List of Hem. II. p. 440. (1852).

Pendulinus t'nuxb. Hem. rostr. (ap. IV. p. 5. (1822).

Corpus valde oblongum. Caput basi pone oculos callosum, lobis ante tubercula antennifera distantia et libere haud promi- 
nula antrorsum et nonnihil deorsum productis. Rostrum longitudine varians, longum vel longiusculum, coxas intermedias saltem sulsuperans, articulo primo capite sæpissime paullo longiore, tertio reliquis breviore. Antenne graciles, articulo quarto tertio longiore, hoc interdum dilatato. Thorax apice collari instructus. Scutellum nomnihil longius quam latius. Corium margine apicali sinuato, angulo apicali nonnihil producto. Pedes graciles, longi, postici nonnihil distantes, femoribus inemibus; tarsis posticis articulo primo apicalibus duobns ad unum longiore.

a. Antemnarum articulo primo secunulo longiore, secundo et tertio arue longis, hoc valde dilatato.

1. di. hasicornis Thusb. - Supra flaro-testaceus, subtus cum rostro rufo-testaceus, abdomine excepto dense distincteque punctulatus; antennis, rostro apicem versus, pedibus, metanoto, basi maculaque posteriore dorsi abdominis, fasciis tribus lateralibus pectoris fasciarue hasali segmentorum ventris nigris; fasciis tribus pectoris fasciaque apicali segmentorum ventris eburneis; membrana olivaceo-nigra; alis obscure fuscis, basin versus decoloribus, vitreis, basi pallide sanguineis. o7. ㅇ. Long. 21, Lat. 6 mill.

Cimex hasticornis Thunb. Nov. ins. spec. III. p. 53. Tab. 3. fig. 64. (178t).

Pendulimes hasticonis Thusb. Hem. rostr. cap. IV. p. 5. (1822); Ins. hem. tria gen. p. 3. 2. (1825).

Cimex bicolor GraY. in GrifF, An. kingd. $\mathrm{XY}$. Pl. 92. fig. 4. (18:32).

Gulasus hasticomis DALL. List of Hem. II. p. 441. 1. Pl. 13. fig. 2. (1852).

Patria: Caffraria. (Mus. Holm. et Coll. S'TiL.)

Antennae corpore circiter quinta parte breviores, articulo tertio parte plus quam dimidia apicali sujua subtusque valde dilatata, parte hac dilatata paullo longiore quam latiore. Rostrum inter coxas posticas extensum, articulo primo cilpite vix longiore. Thorax marginibus lateralibus subtilissime crenulatis, angulis lateralibus obtusis, haud rotundatis, nec prominulis. Scutelhun nonnilil longius quam latius. 
aa. Antennarum articulis primo et tertio secundo nonnilil breviorims, tertio simplici.

2. 4. mulanomemis S'TÁL. - Supra flavo-testacens, subtus cum rostro femoribusque mito-testacens, abdomine excepto distincte denseque punctulatus; antemis, metanoto, basi maculaque pone medium dorsi abdominis, fasciis tribus lateralibus pectoris, fascia basali segmentorum rentris secundi, tertii et quarti, tibiis tarsisque nigris; fasciis tribus lateralibus pectoris nec non fascia lata apitali seguentorm ventris eburneis; membrana olivaceo-nigricante; alis fuseo-cærulescentibus, basin versus decoloribus, basi cum costa cinnabarinis. 7 . Long. 2:3, Lat. 6 mill.

Homoeocerus melunocnemis Sild. Öfv. Vet. Ak. Förh. I858. p. 4.39. 1.

\section{Patria: Mozambique. (Coll. ג. Doukx et STÁL.)}

Statura $G$. hasticomis, eui siujllimus, structura antennarum rostroque I ngiore priescrtim differt. Antenna graciles, corpore nonnilil breviores, simplices. Rostrum ultra medium segmenti tertii rentris exteusum, asticu o primo capite nonnihi longiore. Thurax marginibus literalibus rectis, anterins obsoletissime cremulatis, angulis lateralibus obtusis, subrotundatis. Scutellum paullo longius quan latius.

Ad ha c divisionem generis etiam pertinet Galesws mfifemoretus DALL., quem in Museo Britannico vidi, $G$. melanocnemi vald: atfinis, ante' nis simplicibus verisimiliter instructus.

Parylhes Linea DALL., qux ad Galcesum etiam pertinet, antennarum articulis primo et secundo aeque longis gaudet.

\section{THEOGNIS STAL.}

Ent. Zeit. XXIII. p. 294. (1862).

Anisoscelis Sprx. Éss. Hém. p. 200. (1840).

Corpus oblongum. Caput subcylindricum, longum, pone oculos in collum retrorsum subangustatum abiens, lobis ante tubercula antennifera lateralia et haud prominula antrorsum valde productis. Rostrum longum. Thorax antrorsum valde declivis, apice collari distincto instruetum. Sentellum subæquilaterum. Corium angulo apicali sat longe acuteque producto. Membranæ venæ simplices. Pedes sat longi, postici valde distantes; femo- 
ribus subtus plus minus spinosis, posticis incrassatis; tibiis posticis clilatatis; tarsis posticis articulo primo apicalibus duobus ad unum vix vel paullo longione.

1. T. membranacens FABR. - Niger, punctulatus; annulo lato articulorum secundi et tertii nec non articulo quarto antennalum, hujus parte basali excepta, lineola anteriore lineolisque duabus posterioribus superioribus vittaque utrimque laterali inferiore capitis, fascia arcuata ante medium thoracis, angulis scutelli, macula minuta media corii, maculis numerosis sparsis pectoris rentrisque nec non macula partis inferioris dilatatiu tibiarum posticarum lutescentibus; thoracis angulis lateralibus in spinam acutissimam productis, marginibus lateralibus serrulatis. o'. Long. 18, lat. 5 mill.

Cimex membranaceus FABR. Mant. ins. II. p. 299. 98. (1787).

Lygans membranacens FABR. Ent. syst. IV. I. I:39. I6. (1794); Syst. Rlyyng. p. 209. 23. (1803) excl. syn. WorfFil, yuie ad Theognem orientalem DALL. pertinet.

Anisoscelis flacopumbtutus SIGx. in MaILLARD Not. sur l’ile de la Réunion. Ins. p. 27. Pl. 21. fige. 4.

Patria: Caffraria, Senegal, Ins. Réunion (Bourbon). (Mus. Holm. et Coll. STAL.)

Antemuse articulis primo et tertio ieque longis, secundo et quarto, etian longitudiue subequalibus, brevioribus. Femora postica apud marem sat incrassata, aranulis arutis vel spinulis conspersa, subtus multispinosa. Tibia posticae subtus ante medium nomihil dilatata, supra a basi ultra medium valele dilatate, parte hac dilatata bi- rel rarius tridentati.

\section{C'YLLARUS S'TAL.}

Corpus oblongo-ovatum, subdepressum. Caput ante tubercula antemifera distantia et haut prominula antrorsum sat deflexo-productum, basi pone oculos callosum. Rostrum longissimum, articulo primo capite paullo longiore, articulo ultimo omnium longissimo. Antemne graciles, articulo primo capite subbreviore et secundo bruviore. Thorax ante medium depressus, posterius latissime rotunclatus, nec medio ante scutellum truncatus, margine apicali depresso, collari distincto nullo. Scutel- 
lum subsquilaterum. Hemelytra pone medium subdilatata, margine apicali corii recto, angulo apicali haud producto. Membrana reticulata. Abdomen utrimque ampliatum, hemelytris latius; spiraculis a basi et apice segmentorum ventris fere æque longe remotis. Pedes longiusculi, postici sat distantes; femoribus inermibus, subincrassatis; tarsis posticis articulo primo apicalibus duobus ad unum longitudine æquali.

\section{Lybunti affine genus.}

1. C. Iongirostris STAL. - Dilute sordide testaceo-flavescens, supra fusco-nebulosus, subtus nigro-conspersus, remote silaceo-sericeus; abdomine dorso sordide croceo, hujus segmento apicali, connexivo, scutello, exceptis marginibus lateralibus, antennis rostroque nigricantibus; basi ipsa articuli secundi antemnarum maculisque connexivi flavo-testaceis; membrana fusco-grisea, fusco-venosa; alis subviolaceo-fuscis; femoribus fusco-nebulosis; tibiis fusco-innulatis. \&. Long. 18, Lat. 5 mill.

Gonocerus longirostrum SIGN. in THoys. Arch. ent. II. p. 302. 576 . (1858).

\section{Patria: Grand Bassam. (Coll. Signoretr.)}

Antenne exempli descripti maximam ad partem mutilatie. Thorax marginibus lateralibus sat profunde sinuatis; ante mediun crenulatis, angulis lateralibus obtusissimis, vix prominulis. Pectus distincte, venter subtiliter alutacea.

\section{GERRIS FABR.}

Ent. syst. IV. p. 187. (1794).

Leptocorisa Latr. Fam. nat. p. 421. (1825).

Corpus gracile, valde elongatum. Caput longum, basi pone oculos callosum, lobis ante tubercula antennifera, latera capitis occupantia, antrorsum productis, lateralibus lobo medio longioribus, anterius contiguis. Rostrum gracile. Antennæ gracillimæ, longa, articulo primo apicem versus sènsim levissime incrassato. Thorax multo longior quam latior, basi leviter bisinuatum. Scutellum longius quam latius. Corium angulo apicali longissime angusteque producto, margine apicali longissimo. Anguli postici 
metastethii acuti, producti. Abdomen lineare, haud ampliatum. Pedes longi, graciles, postici subcontigui; femoribus inemibus; tibiis cylindricis, haud suleatis; tarsis posticis articulo primo longissimo.

I. (i. apicalis Westw. - Pallide straminea, thorace hemelytrisque dilute fusco-punctatis, marginibus lateralibus dilute punctatis; antennis nigris rel fuscis, articulo primo intus, reliquis basi ipsa, sapissime etian annulo plus minus distincto articulorm secundi et tertii sordide stranineis; lineola capitis pone oculos, lineola laterali antica maculaque parva angulorum lateralium thoracis nigris rel fuscis. $\sigma^{7}$. ㅇ․ Long. 13! Lat. $2 \frac{1}{3}$ mill.

Leptocorisa apicalis WEsTw. in IIOPE. Cat. of Hem. II. p. 18. (18:37).

Leptocoris annulicornis SIGN. Aun. ent. Sér. 3. VIII. p. 941. 120. (1861).

Var. b. - Clavo fere toto nec non corio, linbo costali excepto, nigro fuscis.

Patria: Sierra Leona, Madagascar, Insula Mauritii. (Mus. Holm. et Coll. Signoret.)

\title{
STENOCEPIIALU'S LATR.
}

\author{
lam. nat. p. 4:1. (18.5).
}

Corpas oblongum, pilosulum. Caput longum, pone oculos collo cylindrico, ocellos ferente, instructum, lobis ante tubercula antennifera, latera capitis occupantia, antrorsum sat longe productis, lobis lateralibus lobo medio longioribus, acutis. Rostrum mediocre. Antenna articulo primo crasso, prope hasin graciliore, secundo tertio longiore. Thorax tripezoideus, basi latissime truncatus. Scutellum nonnihil longrus quam latius. Corium angulo apicali haud producto, margine apicali recto. Anguli postici metastethii acuti, producti. P'edes mediocres, postici basi subcontigui; femoribus inermibus; tibiis cylindricis; tarsis posticis articulo primo apicalibus duobus ad unum multo longiore. 1. S. testacew. S'TiL. - Pallide ferrugineus, supra obscurius punctatus, pectore nigro-punctato; rentre nigro-consperso; 
antennarum articulo tertio apicem versus infuscato, ultimo basin versus pallide stramineo; membrana pallide infuscata, fusco-conspersa; femoribus posticis apicem versus alticuloque apicali tarsorum nigricantibus. ㅇ. Long. 11, Lat. 3 mill.

Stenocephalus testaceus STÅL. Öfv. Vet. Ak. Förh. 1859. p. 468. 2.

\section{Patria: Terra capensis. (Coll. SignoRE'i.)}

Antenna articulo tertio quarto vix graciliore, b sin virsus leviter gracilescente. Thorax angulis posticis imis pallidis, lievibus. acutiusculis.

2. S. punctarius StÄL. - Sordide pallide stramineus, nigro-punctatus; capite, antennarum articulis primo et quarto, hujus basi ipsa excepta, nec non apice articulorum secundi et tertii nigris; membrana griseo-hyalina, parce fusco-conspersa; alis decoloribus; ventre in ferrugineum vergente, remote griseosericeo, fusco-variegato; comexivo fusco, albido-maculato; pedibus parce fusco-conspersis, parte apicali femorum posteriorum, apice tibiarum, articulo primo tarsorum nec non horum articulis duobus apicalibus nigro-fuscis. ․ Long. 11, Lat. $2 \frac{1}{2}$ mill.

Patria: Insula Réunion. (Coll. Signorér.)

Articuli antemnarum secundus et tertius graciles, hic quarto gracilior. Thorax angulis posticis mucrone parro retrorsum vergente, albido, armatis.

\section{DULICIIIUS STAL.}

Corpus elongatum. Caput oblongum, thorace longius, ante aculos antrorsum valde productum, pone oculos retrorsum sensim angustatum, supra sat convexum. Oculi paullo pone medium capitis positi, sat prominuli. Ocelli in linea ficta inter partem postican oculorum positi, ab oculis quam inter se paullo magis remoti. Rostrum inter coxas intermedias productum, articulo primo nonnihil incrassato, capite breviore, articulo secundo basali longiore, tertio et quarto brevissimis. Antennæ graciles, corpore paullo longiores, paullo ante oculos in lateribus capitis insertæ, articulo quarto longissimo, primo capitis apicem sub- 
superante, omnium hrevissimo. Thorax basi depressus et trun('itus, posterius prope angulos lateriles spina armatus. Scutellum longius quam latius, apice spina sat longa armatum. Corium angulo apicali acute producto. Membrana venis longitudinalibus simplicibus, e vena transversa, a margine basali sat remota, emissis, minus numerosis. Abdomen basi haud coarctatum. Pedes graciles, longiusculi, femoribus inermibus, posticis reliquis vix crassioribus; tibiis simplicibus, cylindricis; tarsis posticis articulo primo apicalibus duobus ad unum fere duplo longiore.

Genus insigne, Marcio affine.

1. I). trispinosus STÄL. - Pallide testaceo-flavescens, ventre excepto sat dense distincteque punctatus; macula capitis posteriore basique spinarum thoracis nigris; abdomine dorso croceo, basi apiceque fusco; femoribus remote minuteque fusco-conspersis. ơ. Long. 9, Lat. $1 \frac{1}{2}$ mill.

Patria: Caffraria. (Mus. Holm.)

Antennic artieulis secundo et tertio apice imo nee non quarto, basi excepta, leviter ifuseatis. Thorax angulis posterioribus rotundatis: haud prominulis. Pedes remote pilosi.

\section{EUTHETUS DALL.}

\section{List of Hem. II. p. 479. (1852).}

Corpus elongatum, compressum. Cilput magnum, ante oculos globosos oblique deorsum conico-productum, pone oculos subito nomihil coarctatum, thorace vix brevius. Ocelli inter oculos fositi, ab his et inter se aque longe distantes. Rostrum pedes intermedios attingens, articnlo primo apicalibus duobus ad unum aque longo, incrissato, capite nomihil breviore. Antenna prope oculos in lateribus capitis inserta, corpore loreviores, sat graciles, articulo secundo omnium brevissimo, quarto omnium longissimo. Thorax apice colliri obsoleto instructus, basi truncatus. Scutellum triangulare, longius quam latius. Corium angulo apicali longissime producto. Membrana venis simplicibus. Pedes graciles, longiusculi, coxis posticis subcontiguis; femoribus inermibus; tibiis setulosis. gracilibus, posticis cylindricis; articulo primo tarsorum posticorum apicalibus duobus al unum fere triplo longiore. 
1. Le Arorestiefus STÁl- Niger, opacus, obsolete punctulatus, parce pilosus; lineola postica longitudinali capitis, in thoracis partem antiram producta, apice imo scutelli annuloque prope apicem femorum sordide flavo-albidis; capitis macula utrimgue laterali basali, maculis duabus pectoris ad coxas posteriores, margine angulorum posticorum metastethii fasciaque obliqua laterali segmenti tertii ventris albidis; hemelytris obsolete minuteque pallido-conspersis, corii margine apicali lineolis duabus albidis notato; tibiis tarsisque luridis, apice nigris. ․ Long. 11, Lat. $2 \frac{1}{2}$ mill.

Euthetus leucostictus STẢL. Öfv. Vet. Ak. Förh. 1855. 1). 30. 1 .

\section{Patria: Caftraria. (Mus. IIolm.)}

Antemie pallide flavo-griseae, articnlis primo. secundo et tertio apice nigris, illo fusco-consperso nltimo leviter infuscato, secundo

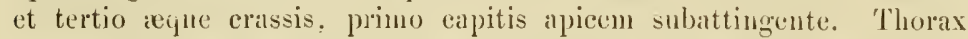
angulis posticis acutiusculis, vix promimulis. Femora postica levissine incrassata, apicem versus gracilescentia.

2. E. leucopoecilus STÅL. - Niger, opacus, supra dense punctulatus, parce pilosus; annulo prope apicen femorum, lineola postica capitis, apice scutelli corioque pallide sordide stramineis, hoc pallide fusco-punctulato, macula anguli interioris anguloque apicali nigris; macula utrimque laterali basali capitis, maculis duabus pectoris ad coxas posteriores, angulis posticis metastethii fasciaque obliqua laterali segmenti ventris tertii albidis; membrana fusco-hyalina; macula anteriore parva thoracis holosericea. $\sigma^{7}$. Long. 11, Lat. $2 \frac{1}{2}$ mill.

Euthetus leucopoecilus StẢL. Öfv. Vet. Ak. Förl. 1855. 1. 30. 2 .

Patria: Caffraria. (Mus. Holm.)

Priecedenti maxime affunis, an cjusdem mas? exceptis coloribus hand differt nisi articulo tertio antennarun leviter incrissato.

3. F. sordidus STÅL. - Pallide testaceo-stramineus, dilute fuscopunctulatus, parce pilosus; apice articulorum triun basalium antennarum, capite, rostro, thorace antice, scutello, excepto apice, pectoreque nigris, macnlis hujus duabus ad coxas po- 
sticas nee non fascia obliqua laterali segmenti tertii ventris albidis; thoracis linea longitudinali fusca; membrana dilute fusco-hyalina; femoribus apice infuscatis. ơ. Long. 11, Lat. $2 ! 2$ mill.

Enthetus sondidus STiL. Öf. Vet. Ak. Förh. 1855. 1, 30.3.

Patria: Caffraria. (Mus. Holm.)

Precedentibus maxime affinis, differt articulo primo antemarum capitis apicem paullo superante femoribusque posticis grarilioribus. Antemarum articulus tertius leviter incrassatus. Thorax angulis postris acutis, subpromiunlis.

\section{RIPTORTUS STAL.}

Öfr. Vet. Ak. Fïrh. 1859. p. 460.

Corpus elongatum, compressum. Caput majusculum, pone oculos valde prominentes subito coarctatum, ante oculos triangulariter productum, levitẹr nutans, supra planiusculum, tubereulis antenniferis lateralibus, haud productis. Ocelli inter oculos positi, inter se et ab oculis fere reque longe distantes. Rostrum pedes intermedios paullo superans, articulo primo nonnihil incrassato, capite nomnihil breviore, articulis duobus apicalibus ad unum secundo longioribus. Antenne graciles, corpori longitudine fere aquales vel paullo longiores, articulis quarto omnium longissimo, primo capitis apicem superante, secundo et tertio breviusculis, conjunctim apicali brevioribus. Thorax antrorsum modice declivis, apice collari distincto instructus, basi ante scutellum bisinu tum, angulis lateralibus prominulis. S'cutellum longius quam latius. Corim angulo apicali longissime producto. Membrana venis simplicibus. Metastethum sulco curvato, ab ostiolis odoriferis oblique antrorsum currente, instructum. Abdomen prope basin leviter coarctatum. Pedes longiusculi, postici subcontigui; femoribus posticis incrassitis, subtus seriatim multispinosis; tibiis posticis femoribus paullo brevioribus, leviter curvatis, subcompressis, supra convexis, apice in latere inferiore in dentem prominulis; tarsis posticis articulo primo apicalibus duobus ad unum multe longiore. 


\section{a. Flaro-cimnamomei.}

1. R. Alaro-limeatus StÀL. - Flaro-cinnamomeus, remote flavescente-sericeus, supra cum pectore sat dense punctulatus; apice articulorum secundi et tertii antennarum, macula supera basali, linea marginali infra antennas ante oculos nec non parte inferiore media capitis, spinis longiusculis angulorum latéralium thoracis, disco pectoris, vitta laterali metanoti maculisque comnexivi nigris; vitta laterali inferiore capitis, maculis majusculis longitulinalibus tribus pectoris ad coxas maculaque minuta pone maculam majorem mesostethii dilute stramineis, levigatis; sulco medio mesosterni nec non maculis duabus oblongis metasterni rentreque pallide cinnamomeoflavescentibus, hoc fusco-vario, segmento tertio leviter gibboso; femoribus posticis subtus subæneo-fuscis. ơ. Long. $17 \frac{1}{2}$, Lat. $3 \frac{1}{4}$ mill.

Alydus flavolinea Sign. in Thoms. Arch. ent. II. p. 30I. 574. (1858).

\section{Patria: Gabon. (Coll. Signoretr.)}

Sequentibus duobus maxime affinis, rostro spinaque angulorum lateralium thoracis longioribns, illo coxas posticas attingente, segmentoque ventris tertio convexiore d.ffert.

2. R. Fabricii SIGN. - Flavo-cinnamomeus, parce sericeus, supra cum pectore sat dense punctulatus; capitis macula postocellari, linea marginali ante oculos parteque inferiore media, spina longiuseula angulorum lateralim thoracis, vitta laterali metanoti, disco pectoris maculisque oblongis marginalibus connexivi nigris; eapitis vitta laterali inferiore, pectoris maculis tribus magnis longitudinalibus lateralibus maculaque minuta mesostethii pone maculam majorem posita, nec non ventre stramineis, lævibus, hujus vittis duabns, pone medium conjunctis, signaturis segmentorum duorum ultimorum uti littera $V$ formatis femoribusque posticis subtus ienescentefuscis; maculis duabus metasterni stramineis. o. Long. 15, Lat. 3 mill. 
Alydus Fabricii Sign. Ann. ent. Sér. 3. VIII. p. 940. 118. (1861).

Patria: Marlagascar. (Coll. SignoreT.)

Statura R. fluro-lineati et quoad longitudinem spinarum lateralinm thoracis cum colem conveniens; sequenti maxime affinis, vix differt nisi spinis illis longioribus. Rostrum inter coxas intermedias extensmm.

3. R. flavo-vitfatus StÅL. - Flavo-cinnamomeus, parce sericeus, supra cum pectore sat dense punctulatus; angulis lateralibus thoracis acutis, distincte productis; macula postoculari, linea marginali ante oculos parteque inferiore media capitis, vitta laterali metanoti, disco pectoris maculisque nomnullis marginalibus connexiri nigris; capitis vitta laterali inferiore, pectoris maculis tribus magnis longitudinalibus lateralibus maculaque minuta pone maculam majorem mesostethii posita, nec non ventre stramineis, levibus, hujus vittis duabus, pone medium conjunctis signaturaque segmentorum duorum ultimorum uti littera $\mathrm{V}$ formata femoribusque posticis subtus rnescente-fuscis. $\sigma^{7}$. Long. 16, Lat. $3 \frac{1}{2}$ mill.

Alydus flavo-rittatus STiL. Off. Vet. Ak. Förh. 1855. p. 30. 2.

Patria: Caffraria. (Mus. Holm.)

R. Fubricii maxime aftinis, vix diftert nisi angulis lateralibus thoracis arute productis, in spinam vix abeuntibns, fenoribusque posticis magis incrissatis.

aล. Nigri.

4. R. Stallii Sign. - Niger, nitidus, supra cum pectore sat dense punctatus; fascia obliqua laterali segmenti rentris secundi fasciaque basali abbreviata segmenti tertii stramineis; angulis lateralibus thoracis rectis, haud productis; membrana violaceofusca; alis leviter infuscatis. †. Long. 16, Lat. 3 mill.

Alyclus Stålii SIgx. in THouss. Arch. ent. II. p. 301. 573. (1858).

\section{Patria: Calabar. (Coll. Sigronet.)}

Specimen pessime conservatum, antennis pedibnsque posticis destitutun, misit SugNoRET. Rostrum coxas intermedias multo superans. 


\section{$-95-$ \\ TUPALUS ŚTÂL. \\ Öfv. Vet. Ak. Förh. 1859. 1. 460}

Corpus elongatum, compressum. Cajut majusculum, triangulare, pone oculos subito nomihil coarctatum, tuberculis antenniferis lateralibus, haud productis, nonnilil ante oculos positis. Oculi globosi, valde prominuli, sessiles. Ocelli ab oculis et inter se reque longe distantes. Rostrum longitudine varians, articulis primo et secundo eque longis. Thorax collari destitutus, margine basali recto, angulis posticis ad angulos basales scutelli productis. Scutellum longius quam latius. Corium angulo apicali longissime angustissimeque producto. Nembrana renis simplicibus. Mesosternum sulcatum. Margines ostiolorum odoriferorum valde elevati. Pedes mediocres, femoribus posticis incrassatis, in latere inferiore apicem versus impressione levi parra instructis, subtus serie spinarum armatis, spinis apicalibus minoribus et numerosioribus; tibiis posticis femoribus brevioribus, compressis, arcuatis, apice subtus in dentem productis; tarsis posticis articulo primo apicalibus duobus ad unum paullo longiore. Camptopo affine genus, oculis sessilibus presertim insigne.

a. Rostro coxas intermedias superante; tuberculis antenniferis inermilius.

Tupalus STÅL. Öfr. Vet. Ak. Förh. 1859. p. 460.

I. T. arcuatus FABR. - Nigricans, remote griseo-sericeus, punctatus; thorace alutaceo-punctato, hujus fiscia arcuata pone medium nec non articulo ultimo antemarmm flavo-testaceis; antennarum articulis secundo et tertio testaceis, apice nigris; hemelytris fusco-lividis, fusco-punctatis, margine costali obscuriore; membrana dilnte fusco-liyalina; apice imo scutelli, maculis parvis comnexivi, fascia prope basin maculisque duabus pone medium dorsi abdominis, apice coxarum, basi femorum anteriorum parteque vix dimidia basali femorum posticorum stramineis; ventre fusco-testaceo; angulis lateralibus thoracis rectis, haud prominulis, angulis posticis acute productis. $c^{\prime}$. Long. 23, Lat. 3 mill. 
Lyganes arcuatus FABle. Ent. syst. Suppl. p. 538. 21-2. (1798).

Mlydus arcuatus FABR. Syst. Rlyng. p. 248. 1. (1803).

Patrial: Madagascar. (Coll. Signoret.)

2. T. fasciatus DALL. - Fuseo-testaceus, remote griseo-sericens, supra sat dense punctatıs; antennarum articulis secundo et tertio, excepto apice, nec non basi articuli quarti, rostro, fascia latissima media thoracis, apice imo scutelli, abdomine, pedibus anticis, coxis trochanteribusque posticis nec non parte tertia basali femorum posticorum testaceo-stramineis; hemelytris fusco-lividis, pellucidis, margine costali obscuriore; fasciis nonnullis interuptis dorsi ablominis nigro-fuscis; ventre disco fusco-testaceo; angulis lateralibus thoracis rectis, haud prominulis, angulis posticis in lobulum rotundatum productis. 7. Long. 25, Lat. 4 mill.

Alydus fasciatus Dals. List of Hem. II. p. 471. 5. (1852). Patria ignota. (Coll. Signoret); Africa. (Mus. Brit.)

Pracedenti maxime affiuis, exceptis coloribus differt angulis postieis thoracis hand acutis, femoribusque posticis basin versus minns incrissatis.

aa. Rostro coxas intermedias subattingente: tuberculis antenniferis apice extus acute prominentibus.

Mirperus StÀL. Öfr. Vet. Ak. Förh. 1859. p. 460.

3. T. Jaculus Thusb. - Plus minus obscure cimnamomeus vel rufo-cinnamomeus, subtus sordide stramineus vel cinnamomeo-stramineus, remote griseo-sericeus; rostro, antennis, ad partem saltem, capite, marginibus lateralibus et postico thoracis, scutello, metanoto, dorso abdominis, pectoris medio vittaque laterali, interdum obsoleta, nec non rentris disen serieque laterali macularum parvarum nigris; vittis tribus superioribus rapitis cinnamomeis; ritta latitudine rariabili scutelli, vitta laterali inferiore capitis, connexivo, maculis duabus dorsi abdominis, una transversa basali, altera ovali fere media, medio interdum coarctata, nee non margine anIrusto costali enrii sordide stramineis, hoc intus linea fusea 
terminato; membrana alisque leviter infuscatis. $\sigma$. \&. Long. 10-15, Lat. 2-3 mill.

Vur. a. - Major, obscurior, pedibus posticis infuscatis; tibiis posticis apud marem valde incrassatis, subfusiformibus, tibiis posticis ejusdem sexus latiusculis, sat curvatis.

Alydus crassifemur StẢL. Öfv. Vet. Ak. Förh. 1855. p. 30.1. Alydus Madagascariensis Sign. Ann. ent. Sér. 3. VIIl. p. 938. 114. (1861).

Var. b. - Minor, dilutior, femoribus posticis maris sat incrassatis, basin versus gracilioribus, tibiis posticis ejusdem sexus leviter curvatis.

Cimex Jaculus Tuuns. Nov. ins. spee. II. p. 34. Tab. 2. fig. 50. (1783).

Alydus Jaculus 1)aLl. List of Hem. 1I. p. 470. 4. (1852).

Patria: Caffraria. (Mus. Holm.); Madagascar. (Coll. SIGNORET.)

Species quoal magnitudinem, colores, crassitiem femorum posticormu et curaturam tibiarum posticarum varians. Antenna nigra, articulis secundo et tertio, vel tertio saltem, nec non basi articuli quarti testaceis, illis apice nigris. Anguli laterales thoracis sapissime in dentem acutum prominnli. Tibiae postice in exemplis obscurioribus apicem versus fascia pallida notatie. Tenter disco interdum stramineo-vario.

4. T. albidens WEsTw. - Cinnamomeus, subtus cum apice scutelli sordide stramineus, remote griseo-sericeus; capitis basi superne nec non disco inferiore, rostro, antennarum articulo primo toto nec non apice articulorum secundi et tertii, thoracis marginibus angustis lateralibus, metanoto, dorso abdominis, disco pectoris rentrisque nigris; connexivo, maculis duabus dorsi abdominis, una subbasali, altera media, nec non fascia prope apicem tibiarum posticarum stramineis; membrana alisque leviter infuscatis. $\sigma$. ㅇ. Long. 11, Lat. $2 \frac{1}{3}$ mill.

Alydus albidens Westw. in Hope. Cat. of Hem. II. p. 20. (1842); DALL. List of Hen. II. p. 470. 2. (1852).

Hemiptera africana. II. 
Patria: Sierra Leona. (Mus. Holm.. (Coll. Signorer.)

Precedenti maxime affinis, sapissime minor, anteunis paullo gracilioribus, scutello vitta straminea destituto tintum diverwit. Inguli laterales thoracis in dentem plus minus acnt..m prominuli.

\section{IIYPSELOPUS BURM.}

\section{Handb. II. 1. p. 3:8, (1835)).}

Meloza A. it S. Hist. des Hém. p. 221. (1843).

Corpus elongatum. Caput triangulare. porrectum, sat magnum, pone oculos subito paullo coarctatum, tuberculis antenniferis lateralibus, vix prominulis. Oculi glohosi, valde prominentes. Ocelli inter se quam ab oculis fere duplo longius remoti. Rostrum pedes intermedios attingens rel nonnibil superans, articulo primo capite multo breviore, ultimo reliquis paullo longiore. Corium angulo apicali longe angusteque producto. Margines ostiolorum odoriferorum sat elevati. Spiracula rentris ad margines laterales posita. Pedes postici nomnihil distantes, femoribus nomihil incrassatis, suhtus spinulis armatis; tibiis rectis, subtus pone medium sexspinosis, ibidem dense nigro-pilosis.

1. II. prolisus STiL. - Obscure ferrugineus vel fuscescenteferrugineus, remote griseo-sericeus, ventre excepto sat dense et distincte punctatus; antennarum articulis secundo et tertio flavo- vel rufo-testaceis, apice nigris; maculis quattuor discoidalibus orbicularibus, duabus ante medium, duabus pone medium positis, vitta ablıreviata media, marginibus lateralibus, angulis posticis maculaque minutissima marginis postici thoracis, regione acetabulorum, parte laterali prostethii, angulis posticis mesostethii et metastethii, connexivo nec non fasciis interruptis incisurarum dorsi abdominis rentreque sordide stramineis, hujus maculis parvis lateralibus, in seriem positis, nigris; hemelytris lividis vel fusco-lividis. $\sigma^{7}$. Long. 19, Lat. 4 mill.

Hypselopus prolixus ŚTÁL. Freg. Eug. Resa. Ins. Hem. p. 233. 35. (1858).

Patria: Insula Bourbon. (Coll. Signonet); Terra capensis. (Mus. Holm.) 
Caput lobo medio apice antrorsum sat prodacto, acuminato. Antemna articulo primo dimidio apicen capitis superante. Thorax for iefque longus ac latus, antrolsum leviter angustatus, angulis lateralibus rectis, haud prominentibus. Hemelytra abdominis apicem valde suprerantia. Femoral postica longissima, corpore quarta parte breviora, abdominis apicen longissime superantia. Tibiæ postice femoribus vix breviores. Tarsi postici articulo primo apicalibus dnobus ad $110 \mathrm{~m}$ plus duplo longiore.

2. II. villosipes $A$. et $S$. - Obscure ferrugineus, sat dense punctatus, remote griseo-sericeus; capite fusco-bivittato; articulis secundo et tertio antennarum rufo-ferrugineis, apice nigris; maculis quattuor orbicularibus, vittula media, marginibus angustissinis lateralibus, vittula laterali intramarginali posteriore, angulis posticis maculaque minuta marginis postici thoracis, apice scutelli, fisciis lateralibus dorsi nigri abdominis, maculis parvis comnexivi fusci, maculis pectoris ad coxas, annulo prope basin tibiarum posticarum ventreque testaceo-flavescentibus, hujus maculis lateralibus parvis, in seriem dispositis, nigris; alis fusco-lividis; membrana alisque sordide hyalinis. ㅇ. Long. 18, Lat. 4 mill.

Meloza villosipes A. et S. Hist. des Hém. p. 221. 1. (1843). Patria: Insula Mauritii. (Coll. Signoret.)

An varietas femi ina precetentis? Tertia pars articuli primi antemmarum capitis apicen supcrans. Femora postica corpore multo breviora, abdominis apicum nomniliil superantia. Tibie posticae femoribus distincte nomihil breviores. In cateris cum H. prolixo congruit.

3. II. Gigas Burur. - Fusco-ferrugineus, griseo-pilosus, ventre excepto sat dense punctatus; antennarum articulis primo et secundo apicem versus nigris, tertio et quarto basin versus nec non annulo lato prope basin tibiarum posticarum flavoferrngineis; naculis duabus ante medium, fascia pone medium, interdum cum maculis illis confluente, angulis posticis maculaque minuta marginis postici thoracis, nec non prostethii fascia laterali postica dilute testaceo-flavescentibus; abdomine dorso flavo-testaceo, macula basali connexivoque nigris aut fuscis, hujus incisuris ventreque griseo-stramineis, hoc maculis lateralibus parvis, in seriem dispositis, nigris, ornato; 
hemelytris fusco-lividis; membrana alisque sordide hyalinis. ơ. Long. 16, Lat. 4 mill.

Hypselopus gigas Burm. Handb. II. 1. p. 329. 1. (1835).

Hypselopus pallidiventris ȘTẢ. Öfv. Vet. Ak. Förh. 1858. p. 315. 16.

Patria: Territorium lacus N'Gami. (Mus. Holm.)

Statura $I$. villosipedis, angulis lateralibus thoracis acutis, leviter prodnctis, sursum nomilhil vergentibus apiceque lobi nedii capitis minus produc o, obtusiore, nomnihil deflexo, presertim differt. Antenne articnlo primo plus dinidio apiceu capitis superante. Caput nigro-bivitatum. Tarsi postici articulo primo apicalibus duobus ad unum plus duplo longiore.

4. II. anulicornis STẢL. - Fusen-ferrugineus, subtus dilutior, griseo-pilosus, sat dense punctatus; antennis, vittis duabus indistinctis capitis tibiisque posticis nigris, horum annulo prope basin nee non basi articulorum tertii et quarti antennarum flavo-ferrugineis; maculis duabus ante medium, maculis quattuor pone medium in seriem transversam positis, nec non macula minuta marginis postici thoracis, apice imo scutelli ventreque ferrugineo-stramineis, hujus maculis hateralibus parvis, in seriem positis, nigris; abdomine dorso nigricante, utrimque seriatim dilute ferrugineo-maculato; hemelytris fuscolividis; membrana alisque sordide hyalinis. \&. Long. 19, Lat. $4 \frac{1}{2}$ mill.

Hypselopus annulicornis STiL. Öf. Vet. Ak. Förh. 1855. p. 29. 1.

Patria: Citfraria. (Mus. Holm.)

An femina II. Gigantis? differt stutura robustiore, antennis pedibusque posticis brevioribus, illarum articulo primo rix dimidio e pitis apicem superante picturatque paullo divergente. Tarsi postici articulo primo apicalibus duobus ad unum duplo longiore.

\section{NARISCUS STẢL.}

Corpus elongatum. Caput triangulare, porrectum, magnum, pone oculos subito coarctatum, tuberculis antenniferis lateralibus, extus acute prominulis. Antennæ articulo primo capite breviore, hujus apicem paullo superante. Rostrum articulo primo capite 
multo breviore. Scutellum nomihil longius quam latius. Corium angulo apicali longe producto. Membrana venis simplicibus. Pedes mediocres, postici paullo distantes; femoribus posticis subtus spinulosis; tibiis posticis subtus biseriatim spinosis; tarsis posticis articulo primo apicalibus duobus ad unum circiter duplo longiore.

\section{Hypselopo atfine grenus.}

1. N. cinctireutris Germ. - Griseo-stramineus, excepto capite supra dense functatus; marginibus lateralibus thoracis albidis; membrana alisque sordicle hyalinis, illa obsolete fusco-varia; abdomine dorso ventreque apud marem obsolete, apud feminam distincte fusco-bivittatis; connexivo fusco-maculato; pedibus obscurioribus, in ferrugineum rergentibus; tibiis posticis fuscis, apud feminam basin versus pallido-annulatis. $\sigma$. Long. 12-15, Lat. $23-3$ mill.

o'. Pallidior; femoribus posticis valde incrassatis, intus apicem versus spina longa pallida armatis; tibiis posticis crassiusculis, distincte compressis, apicem versus leviter angustatis.

Hypselopus validipes STAL. Öfv. Vet. Ak. Förh. 1858. p. 315. 17.

Hypselopus spinosus Sigs. in Thoms. Arch. ent. II. p. 300. 572. (1858).

ㅇ. Obscurior, fusco-conspersa; femoribus posticis nonnihil incrassatis, intus apicem versus spina destitutis.

Hypselopus cinctiventris GerM. in Silb. Rev. ent. V. p. 152. 71. (1837).

Patria: Terra capensis, Territorium fluvii Svakop. (Mus. Holm.); Gabon. (Coll. Signoret.)

Caput inter oculos et antennas leviter sinuato-angustatum. Antenna corpore breviores. Thorax - aque longus ac litus vel paullo longior quam latior, antrorsum nonnihil angustatus, carina longitudinali media minus distincta instructus, angulis lateralibns subrectis, haud vel vix prominulis.

\section{NEMAUSUS STÅ.}

Corpus elongatum. Caput magnum, triangulare, porrectum, basi pone oculos subito leviter constrictum, tuberculis antenni- 
feris lateralibus, haud productis. Oculi globosi, valde prominentes. Rostrum coxas intermedias attingens rel subsuperans, articulo primo capite multo breviore. Antenne articulo primo capite breviore, hujus apicem superante. Corium angulo apicali longe producto. Pedes mediocres; femoribus posticis leviter incrassatis, subtus pone medium spinulis armatis; tibiis posticis femoribus paullo brevioribus, subtus pone medium serie duplici spinularm quinque vel sex armatis; tarsis posticis articulo primo apicalibus duobus ad unum paullo longiore.

Hypselopo aftine genus.

a. Ocellis maxime distuntibus, ad orulos valde apropinquectis.

1. I. sordidatus STẢL. - Griseo-stramineus, thorare hemelytrisque dilute fusco-punctatis; capite superne fuscescente, vittis tribus angustis, anterius abbreviatis, pallidis, uotato; abdomine dorso medio maculis duabus pallidis, basin et apicem rersus macula gemina nigra notato, segmento ultimo nigro; connexivo fusco, anguste palliclo-fasciato; vitta indistincta laterali pectoris fusca; capitis linea longitudinali media inferiore, nec non sulco prostemi et mesosterni nigris. ?. Long. 10, Lat. $2 \frac{1}{3}$ mill.

Hypselopus sordidatus Stal. Öfr. Vet. Ak. Förh. 1858. p. 315. 18.

Patria: Territnrium fluvii Srakop. (Mus. Iolm.)

Antennac corpore nounihil breviores, articulis prino, secundo et tertio longitudine fere aequalibus, ultimo nomnilil brevioribus. Thorax vix latior qunan longior, antrorsum levissime angustitus, angulis posticis obtnsis, angulis lateralibus hand prominulis. Membrana alieqne decolores. Fenoria postica levitur incrissata.

2. N. inormatus StíL. - Griseo-straminens; thorace, scutello hemelytrisque remote diluteque subfuseo-punctatis; maculis duabus parvis posterioribus superioribus vittaque inferiore media capitis, nee non sternis nigris; membrana alisque vitreis; abdomine dorso lutescente. fusco-maculato; connexivo fusco, anguste pallido-fisciato. ơ. Long. 8, Lat. $2 \frac{1}{3}$ mill. 
त. Femoribus posticis valde incrassatis, subtus spinulis nonnullis et intus apicem versus spina longa armatis.

Hypselopus inornatus STAL. Öfv. Vet. Ak. Förh. 1858. p. 315. 19.

Patria: Territorium fluvii Srakop. (Mus. Holm.)

$N$. sordidato maxime affinis, an ejnsdem mas:- differt magr.itudine minore, antenuis horaceque paullo brevioribus.

aa. Ocellis inter se quam ub oculis nomnitil longius distantibus, ab ocnlis remotis.

3. N. miknlatus Trunb. - Sordide t'errugineus, parce griseosericeus; thorace, hemelytris prostethioque distincte punctatis; thorace, exceptis partibus basali et apicali, nec non ejusdem macula minutissima marginis postici, angulis imis scutelli, hemelytris, limbo laterali pectoris, ventre, pedibus anticis tarsisque posticis grisen-stramineis; ventris vitta utrimque laterali ferruginea, intus vitta erosa nigra terminata; maculis connexivi et marginalibus ventris nigris; abdomine dorso luteo; pedibus anticis terrugineo-variis, posticis fusco-conspersis; membrania alisque sordide hyalinis. \&. Long. 12! Lat. $2 \frac{1}{2}$ mill.

A ydus maculatus ThunB. Hem. rostr. cap. 1Il. p. 3. (I822). Hypselopus linearis STAL. Öv. Vet. Ak. Förh. 1855. p. 29. 2. Patria: Caffraria. (Mus. Holm.)

Antemxe corpo e nomnihil breviores, articulo prino secundo nonnihil longiore. Thorax subtransversus, antrorsum leviter angustatns, angulis lateralibus et posticis obtusis. Tibize postice crassiusculæ.

\section{PHYLLOMORPHA LAP.}

Ess. Hém. p. 47. (1832).

Corpus, priesertim subtus et marginibus thoracis abdominisque, spinis gracilibus armatum. Caput ante tubercula antennifera distantia nomihil deflexo-productum; bucculis sat elevatis, brevibus. Rostrum gracile, pedes posticos superans. Antennæ graciles, articulis primo et quarto incrassatis, illo spinoso, hoc brevi, fusiformi. Thorax lateribus in lobum maximum foliaceum 
ampliatus. Scutellum parrum. Hemelytra angulo apicali corii longe producto; membranie venis longitudinalibus. Abdomen lateribus foliaceum, segmentis, prasertim quarto et quinto, utrimque in lobum ampliatis. Pedes graciles, mediocres, postiei paullo distantes, femoribus spinosis; tarsis posticis articulo primo apicalibus duobus ad unum breviore.

a. Thorace margine postico recto, nec bilobato; lobis segmenti abdominis ultimi latissimis, apice truncatis.

Craspedum A. et S. Hlist. des Hém. P. 234. (1843).

1. P. Latreillei GuÉr. - Griseo-straminea, interdum parce fusco-conspersa; thorace lobis lateralibus maximis, antice medio antrorsum valde productis, apice retrorsum vergentibus; lobis segmentorum abdominis quarti et quinti maximis, latis, segmenti quarti apice latioribus et truncatis, segmenti quinti apice rotundato-truncatis, pone lobos segmenti sexti haud productis. ơ. ․ Long. 9 mill.

Syromastes plyyllomorpha LATR. in Cuv. Regn. an. 111. p. 438. 3. Pl. 19. fig. 3. (1829). see. Dall.

Phyllomorpha Jatreillei GUÉR. Dict. pitt. d'hist. nat. Pl. 673. fig. 6; Rev. Zool. 1839. p. 233; WEsTw. Are. ent. I. 1. 8. 3. Pl. 2. fig. 3. (1845); DALL. List of Hem. 1I. p. 492. 4. (1852). Craspedum phyllomorpha A. et S. Ilist. des Ilem. p. 234. 1. (1843).

Patria: Senegal. (Coll. Sigrorex); Caffraria, Eikhams Africie meridionalis occidentalis. (Mus. Holm.)

2. P. madagascariensis COQUER. - Griseo-straminea, parce fusconebulosa; thoracis lobis lateralibus maximis, anterius medio antrorsum valde productis, apice retrorsum vergentibus; lobis segmentorum abdominis quarti et quinti maximis, longis, apicem versus ampliatis, apice obtusissime rotundatis, dimidio apicali loborum segmenti quinti ultra lobos segmenti sexti productis. ๙7. Long. 5 mill.

Phyllomorpha madagascariensis Coquer. Ann. ent. Sér. 2. VI. p. 185. P. 7. fig. 6. (1848). 
Patria: Madagascar. (Coll. SIgnoret.)

P. Latreillei valde affinis, lobis corpors lateralibus ingustioribus, lobis segmenti ultimi aldominis brevioribus, lobis sumentorum quarti et quinti angustiorilus, segmenti quinti pone lobos segmenti sexti obliquie extensis, divergit.

aa. Thorace margine postico recto vel merlio levissime sinuato, nec bilobato; lobis segmenti ultimi abdominis angustis, apice rotundatis.

Pephricus A. et S. Hist. des Hém. P. 235. (1843).

3. P. paraloxa Sparrir. - Griseo-straminea; thorace margine basali recto, lobis lateralibus maximis, antice medio sat productis, apice truncatis et retrorsum vergentibus; lolis segmentorum abdominis quarti et quinti minus latis, apice dilatatis et sinuato-truncatis; articulo primo rostri capiteque fere æque longis. or. ㅇ. Long. 11 mill.

Cimex paradoxns Sparrar. Vet. Ak. Handl. XXXVIIl. p. 236. Pl. 6. fig. A. B. C. (1777).

Acantlia paradoxa FABR. Spec. ins. II. p. 510. (1781); Ent. syst. IV. p. 73. 24. (1794).

Coreus paradoxus FABR. Syst. Rhyng. p. 194. 14. (1803).

Phyllomorphus paradoxus BURM. Handb. II. 1. p. 310. 2. (1835).

Phyllomorpha paradoxa Gúr. Dict. pitt. d'hist. nat. PI. 673. fig. 5; Rev. Zool. 1839. p. 232. 3; Westw. Arc. ent. I. p. 7. 1. Pl. 2. fig. 1. (1845); DALL. List of Hem. II. p. 492. 2. (1852).

Pephricus paradoxus A. et S. Hist. des Hém. p. 235. 1. (1843).

Patria: Terra capensis. (Mus. Holm. et Coll. STåL.)

4. P. Capicola Westw. - Griseo-straminea; thorace lobisque segmentorum abdominis quarti et quinti apud marem plus minus obscure fusco-testaceis, illius lobis lateralibus antice medio leviter productis, apice obtuse rotundatis, margine basali ante scutellum levissime sinuato; lobis segmentorum abdominis quarti et quinti angustis, longis, apice dilatatis et 
sinuato-truncatis; rostri articulo primo capite longiore. $c^{7}$. $q$. long. $8-10$ mill.

Phyllomomphe capicola WEstw. Arc. ent. I. p. 8. 2. Pl. 2. fig. 2. (1845); I)ALL. I.ist of llem. II. p. 492. 3. (1852).

Patria: Terra aupensis. (Mus. Ilolm. et Coll. Signoret.) distinct:.

P. pararloxe simillima, longitudine articuli primi rostri mox

\section{CLATIGRALLA SPIN.}

\section{Ess. Hém. p. 200. (1840).}

Corpus oblongum vel subelongatum, compressum. Caput pone oculos levissime callosum, ad oculos haud immersum, ante tubercula antennifera leviter detlexo-productum, spinulis compluribus destitutum, ante oculos raro spina armatum; bucculis brevibus, distincte elevatis. Rostrum graciliusculum, inter pedes posticos extensum. Antenne graciles, corpori longitudine aquales vel longiores, articulo primo capite longiore, secundo primo subaquilongo vel paullo breviore, ultimo elongato. Thorax valde declivis. Scutellum convexum, elevatum, triangulare. Membrana venis longitudinalibus, e vena transversa, a margine basali remota, emissis. Abdominis margo spinosus. Ala vena decurrente glochide instructa. Pedes mediocres rel longiusculi, posteriores nonnilil distantes; femoribus, prasertim posticis, apicem versus incrassatis, his apicem versus subtus spinis pluribus incequalibus armatis; tibiis gracilibus, simplicibus; tarsis posticis articulo primo apicalibus duobus ad unnm longitudine subrequali.

a. Capite utrimiue ante venlos spina armato.

I. C. pilosicollis STíc. - Flavo-testacea, stramineo-pilosa, thorace, scutello pectoreque tomentosis; antemis, pedibus anterioribus, femoribus posticis basin versus, tibiis tarsisque posticis sordide stramineo-albidis; thorace macula ovali anteriore fuscia, raro deficiente; hemelytris ante medium pallidioribus, posterius fusco-conspersis; membrana sordide hyalina; alis vitreis; femoribus minute obsoleteque testaceo-conspersis; abdomine dorso pallido, fusco-testaceo-punctato, ante medium utrimque nigricante. $\sigma^{7}$. 
Clavigralla pilosicollis STÅL. Öfv. Vet. Ak. Förh. 1855. p. 31. 4 .

V'ar. b. - Macula thoracis deficiente.

Clavigralla similis Sigr. Ann. ent. Sér. 3. VIII. p. 944. 129. (1861).

Patria: Caffraria. (Mus. Holm.); Zanzibar. (Coll. Signoretr.)

Antennæ corpori fere equilonga, articulo primo secundo nonnilhil longiore, tertio secundo paullo breviore. Thoriax pilis in vittas quattuor dense arecrvatis instructus, disco spinulis destitutus, angulis lateralibus in spinan magnan acutissinam, nonnilis antrorsum vergentem, productis. Scutellum inerne, modice convexum. Anguli apicales segmentorm abdominis spina longinscula armati.
aa. Capite inermi.
b. Antennis dilute stramineis rel flaro-fernugineis.
c. Scuiello inermi.

2. C. tomentosicollis STÁL. - Cinnamomea, punctata, remote sordide stramineo-sericea, thorace, parte prosteriore excepta, scutelloque dense griseo-stramineo-pilosis et tomentosis; thorace inter angulos laterales fascia fusca notato; antemnis, hemelytris, basi femorum, tibiis tarsisque griseo-stramineis; hemelytris fusco-punctatis; antennarum articulo primo apice nec non quarto fusco-testaceis; tibiis fusco-annulatis. q. Long. I1, Lat. $3 \frac{1}{2}$ mill.

Clavigralla tomenticollis STÅL. Öfv. Vet. Ak. Förh. 1855. p. 31. 3.

\section{Patria: Caffraria. (Mus. Holm.)}

Antennae corpori lonuitudine subequales, articulo primo secundo paullo longiore, tertio secundo paullo breviore Thorax spinulis discoidalibus destitntus, ante medimm utrimque tuberculo parvo instructus, angulis lateralibns spina gracilinsenla extrorsum vergente, nigra armatis. Scutellum sat convexum. Segmenta abdominis apice ntrimque dente acuto brevi armata.

3. C. matulomsis STÁL. - Griseo-ferruginea, griseo-sericea et pilosula, punctata; antennis flavo-ferrugineis, articulo apicali fusco; hemelytris dilute griseo-flavescentibus, costa venaque intracostali fuscis; membrana alisque sordide hyalinis, illa dilute fusco-venosa; abdomine dorso lutescente, basin versus 
nigro, spinis marginalibus brevibus; tibiis tarsisque sordide stramineis, illis basi et apice, his apicem versus fuscis. + . Long. 10, Lat. 3 mill.

Clavigralla natalensis StảL. Öfr. Vet. Ak. Förh. 1855. p. 31. 2. Patria: Caffraria. (Mus. Holm.)

Antenne minus graciles, corpori vix aquilongæ, articulo primo secundo panllo longiore. Thorax diseo marginibusque lateralibus spinis nonnullis minutissimis, ante medium utrimque ad margines later.ules spinula cistinctiore armatus, angulis lateralibus acutissimis, in spinam brevinseulan extrorsum productis. Sentellum modice convexum, inerne. Spine marginales abdominis breves, nigra.

4. C. horrida Geru. - Griseo-ferruginea, griseo-sericea, punctata; antemis dilute sordide flavo-ferrugineis, articulo apicali fusco; hemelytris dilute griseo-stramineis, fusco-punctulatis; membrana sordide hyalina, venis obscurioribus; alis vitreis; abdomine dorso testaceo, basi lateribusque nigr'is, spinis marginalibus longiusculis, nigris; tibiis tarsisque sordide stramineo-albidis. $\sigma^{7}$. ㅇ. Long. 8-10, Lat. 2-3 mill.

Syromaster horridus GERM. in SilB. Rev. ent. V. p. 145. 58. (18:37).

Clavigralla elongata Sign. Ann. ent. Sér. 3. VIII. p. 944. 130. (1861). o'.

Clavigralla flavipennis Sigs. Ann. ent. Sér. 3. VIII. p. 945. 1:31. (1861). ㅇ.

Patria: Caffraria, Insula. Mauritii. (Mus. Holm. et Coll. StäL); Madagascar, Zanzibar. (Coll. Sigr̃oretr.)

C. nutulensi affinis, antennis grieilioribus, angulis thoracis literalibus longius prodnetis spinisque marginalibus abdominis longioribus distiuctissimit. Antemna gracilinsculie, corpori longitndine subacquales, articulo p ino sceundo distincte nonnihil longiore. Thorax disco ante medium spinulis distinetis sex arenatim dispositis, nigris, armatus, angulis lateralıbus acutissimis, extrorsum et interdum leviter antroisum sat lon_e productis. Abdomen feminarmm leviter ampliatum, marium angustins, lateribus parallclis.

cc. Scutello disco utrimque spinis duabus vel tribus armato.

5. C. arantharis Thunb. - Ferruginea, griseo-sericea, punctata; antennis flavo-ferrugineis, articulo apicali obscuriore; thorace disco marginibusque lateralibus spimulis nonnullis minutis. 
ante medium utrimque ad margines laterales spina distinctiore armato; hemelytris flavo-cimmamomeis; membrana sordide hyalina, venis infuscatis; alis vitreis; abdomine dorso rufescente, basi nigro; tibiis tarsisque sordide stramineis. o․ 우. Long. 9-11, Lat. 2!-3 mill.

Alydus acantharis Trunb. IIem. rostr. cap. III. p. 1. (1822).

Clavigralla muricata S'TẢL. Öfv. Vet. Ak. Förh. 1855. p. 31. 1. Patria: Terra capensis, Caffraria. (Mus. Holm., Coll. SiGNORET et STÅL.)

C. horride simillima, scutello spinoso mox distincta. Antenna minus graciles, corpori longitudine subequales, articulis primo et secundo fere aeque longis. Thorax angulis lateralibus in spinam validam acutissimam, extrorsmu ct leviter antrorsum vergentem, prodnctis. Abdomen utrinsque sexus leviter ampliatum, spinis marginalibus magnis.

bb. Antennis nigricantilus, pallido-annulatis.

6. C. Ilystrix DALL. - Nigricans, flavo-griseo-sericea, punctata; annulo articulorum primi, secundi et tertii nec non articulo quarto antennarum, annulis duobus tibiarum articuloque primo tarsorum sordide flavo-albidis; thorace macula oblonga anteriore atra ornato, disco spinulis pluribus et ante medium utrimque ad margines laterales spina majore instructo, angulis lateralibus acutissimis, longissime productis; hemelytris ferrugineo-fuscis; membrana fusca, apicem versus dilutiore, fascia angusta arcuata subbasali sordide albida; abdomine dorso ferrugineo. $\sigma^{7}$. ㅇ. Long. 8-9!, Lat. 2!-3 mill.

Clavigralla Hystrix DaLL. List of Hem. II. p. 512. 4. (1852).

Patria: Calabar. (Coll. A. Dohrs, Signoret et Stål.)

Antenne corpore nomihil longiores, graciles, articulo primo secundo dimidio longiore, capite fere duplo longiore. Thorax angulis lateralibus in spinam longissimam et acutissimam, dentionlatan, extrorsun productis. Scutellum sat c nvexnm, inerme. Abdomen utrinsque sexus leviter ampliatmm, spinis marginalibus longis.

7. C. Ifystricodes STÂL. - Fusco-cinnamomea, griseo-sericea, supra punctulata; antemis rostroque nigro-fuscis; basi annuloque articulorum primi, secundi et tertii antennarum, annulis duobus tibiarum articuloque primo tarsorum sordide albidis; 
hemelytris obsolete pallido-conspersis; femoribus basin versus pallilis, apicem versus pallido-biannulatis; membrana dense fusco-variegata. ?. Long. 9, Lat. 3 mill.

Patria: Sierra Leona. (Mus. Holm.)

C. Hystrici affinis, antennis brevioribus, thoracis angulis lateralibus in spinam breviorem it minus acutam productis, spinisque abdominis marginalibus paullo brevioribus differt. Articulus ultimus antenuarum cxempli descripti mutilatus. Thorax disco utrimque tulerenlis parvis pluribus acutinsculis instructus, marginibus lateralibus medio spina brevi armatis. Scutellum valde convexnm.

\section{MEVANIA STÅL.}

Corpus oblongo-ovatum. Caput spinis compluribus armatum ante tubercula antennifera lateralia et paullo prominula nonnihil productum; bucculis brevibus. Rostrum gracile, pedes posticos attingens. Antennæ graciles, articulo primo brevi, incrassato, capite breviore, secundo et tertio primo longioribus. Thorax valde declivis. Scntellum subæquilaterum, planiusculum. Abdomen hemelytris latius. Membrana renis longitudinalibus, e vena transversa a margine basali remota emissis. Alæ vena decurrente glochide instructa. Pedes mediocres; femoribus posticis incrassatis, omnibus, presertim posticis, subtus pone medium spinulosis.

\section{Clacigralla atfine genus.}

1. II. spiniceps SIGx. - Pallide testaceo-flarescens, remote griseo-pilosa, punctata; thorace, scutello, pectore, basi lateribusque dorsi abdominis ante medium nigris; thorace ante medium pallido-vario; scutello apice stramineo, lavi; hemelytris dilute griseo-flavescentibus, fusco-punctatis; membrana sordide hyalina, venis obscurioribus; alis vitreis; femoribus scabris, fuscis, pallido-variegatis, basin versus stramineis; ventre fusco-vario. ․ Long. 8, Lat. 2! mill.

Clarigralla spiniceps Sign. Ann. ent. Sér. 3. VIII. p. 944. 128. (1861).

Patria: Madagalscar. (Coll. SIgnoret).

Antenna articulo primo spinuloso. Thorax disco marginibusque jateralibus spimulis nounullis distinctis armatus, angulis lateralibus 


\section{$=111-$}

in spinam acutissiman, cxtrorsum et leviter antrorsum rergentem, apice pallidam, productis. Abdomen utrinque impliatum, spinis marginalibus sat magnis armatum; commexivo ante medium nigro, pallido-fasciato, pone medium stramineo

\section{MYLA STÁL.}

Corpus subelongatum, subdepressum. Caput ante tubercula antemnifera lateralia et jaullo prominula antrorsum nonnibil deflexo-prodnctum, pone oculos leviter callosum; bucculis brevibus. Rostrum inter coxas intermedias extensum. Antenni corpore breviores, modice crassæ, articulo frimo capiti aequilongo, reliquis paullo crassiore. Scutellum aquilaterum, planum. Membrana venis longitudinalibus e vena transversa, a margine basali remota, emissis. Ala vena decurrente grlochide instructa. Mesosternum sulcatum. Pedes mediocres, postici leviter distantes, femoribus anterioribus subtus prope ajicem spinula armatis, posticis apicem versus sensim incrassatis, subtus apicem versus spinis monnullis inaqualibus amatis.

Clacigrallo aftine genus.

1. M. nigrispiua STÅL. — Pallicle griseo-flavescens, supra cum pectore punctata; antennarum articulo ultimo fusco; membrana alisque sordide liyalinis; abdomine dorso croceo, punctato. ㅇ. Long. 10, Lat. 3 mill.

Patria: Guinea. (Coll. Signoret.)

Caput incrme. Antenne corpore tertia parte breviores, articulis secundo et quarto aequalibus, tertio paullo brevioribus. Thorax angulis lateralibus in spinam nigram, acutissimam, oblique antro sum vergentem, productis. Abdonten hemelytris nomnihil latins, segmentorum angulis apicalibus spinis gracilibus armatis. Femora postica intus nierrofinsea.

\section{Subf. RHOPALIDA STTA․}

Conspectus generum.

1 (2). Tarsis posticis articulo primo apicalibus duobus ad unum longiore. - Serinetha SPIN.

2 (1). Tarsis posticis articulo primo apicalibus duobus ad unum paullo breviore. - Corizus Falc. 


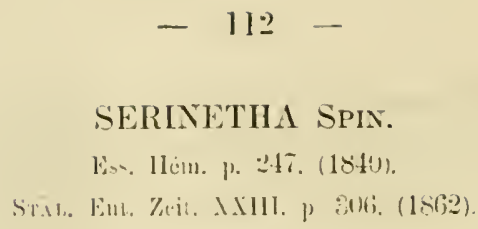

Corpus oblongum, depressum. Caput cum oculis thoracis antico paullo latius, pone oculos callosum, lobis ante tubercula antennifera lateralia nomihil productis; bucculis capite dimidio raro paullo longioribus. Ocelli inter se quam ab oculis longius remoti. Rostrum gracile. Antennæ graciles, articulo primo brevi, capitis apicem paullo superante, ultimo penultimo paullo longiore, vix incrassato. Thorax trapezoideus, antice impressione lineari transversa instructus. Scutellum triangulare, apice acutum. Hemelytra coriacea; membrana venis longitudinalibus numerosis instructa. Segmentum rentrale ultimum feminarum retrorsum productum, genitalia tegens, rotundatum. Pedes graciles, inermes; tibiis cylindricis; tarsis posticis articulo primo apicalibus duobus ad unum paullo longiore.

\section{a. Collari thoracis distincte punctato.}

1. S. fraterua DALL. - Dilute griseo-flavescens, thorace distincte punctato; capitis vitta media parteque posteriore, exceptis callis postocularibus, antennis, thoracis fascia antica pone collare, scutello, hemelytris, rostro pedibusque nigris; alis obscure fuscis; abdomine dorso croceo. ơ. Long. 13, Lat. 4 mill.

Serinetha fraterna Dall. List of Hém. II. p. 462. 9. (1852).

\section{Patria: Senegal. (Mus. IIolm.)}

Caput utrimque ante oculos ruga obliqua instructum, lobis apicem versus vix deflexis. lateralibus lobo medio longitudine aequalibus. Thoriax carina media, antice abbreviata, distincta instruetus.

aa. Collari thoracis laviusculo vel obsolete punctato.

b. Corpore supra nigro-fusco.

Tynotoma A. et S. Hist. des Hém. p. 220. (1843).

2. S. hesuphthahma Tuсхв. - Brevissme griseo-sericea, nigrofusca, supra obsoletissime punctulata, capite subtus, orbitis 
oculorm, thoracis marginibus lateralibus et angustissimo postico nec non carina abbreviata longitudinali media, marginibus lateralibus scutelli, margine apicali corii, ventre coxisque rufescente-testaceis; pectore fusco, margine postico segmentorum testaceo-albido, limbo laterali prostethii testaceo; membrana fusca; abdomine dorso dilute sanguineo; renis hemelytrorum pallide fuscis. \&. Long. 11, Lat. 3 mill.

Cimex hexophthalmus Thuns. Nov. ins. spec. III. 1. 54. (1784).

Lygaus hexophthalmus ThuNB. Ilem. rostr. cap. IV. p. 5. (1822).

Corizus fulcratus Germ. in Silb. Rer. ent. V. p. 144. 57. (18:37).

Serinetha fulcrata DALL. List of Ilem. II. p. 462. 14. (1852). Patria: Terra capensis. (Mus. Holm.)

3. S. amiria Geru. - Brevissime griseo-sericea, supra obsolete punctulati, capite subtus, orbitis oculormm angustis, callo postoculari, margine postico thoracis, marginibus lateralibus scutelli, margine apicali corii, pectore, ventre coxisque flavotestaceis; pectore ventreque albido-mucoreis, illius segmentis postice subdenudatis, limbo laterali prostethii, membrana alisque fuscis. $\sigma^{7}$. Long. 15, Lat. 4 mill.

Leptocoris amicta Germ. in SILb. Rev. ent. V. p. 144. 55. (18:37).

Tynotoma vittata A. et S. Hist. des Hém. p. 220. 1. (1843). Serinetha anicta DALL. List of Hem. II. p. 462. 13. (1852). Serinetha moesta STÀL. Öfv. Vet. Ak. Förh. 1855. p. 29. 1. Patria: Caffraria. (Mus. Holm); Gambia. (Mus. Brit.)

bb. Corpore supra rufescente.

4. S. hamatica GERM. - Dilnte sordide sangninea vel rufo-testacea, breviter fusco-pilosa; antennis, rostro pedibusque, exceptis coxis, nigricantibus, pedibus interdum fusco-sanguineis; membrana nigro-fusca; alis plus minus obscure aut dilute infuscatis; thorace hemelytrisque dense subtiliterque punIIemiptera africana. II. 
ctulatis, illins callis anticis sapissime fuscis. o?. \&. Long. 1 I-14, Lat. 3-4 mill.

Leptocoris hamatica Gris. in Silb. Rev. ent. V. p. I44. 54. (1837).

Serinetha hematica DALL. List of 11 em. II. p. 462. II. (1852).

Var. b. - Disco capitis, pectore, excepta parte postica segmentorum, interdum etiam scutello, fuscis.

Serinetha lateralis Sign. Ann, ent. Sér. 3. VIII. 1. 939. 117. (1861).

Patria: Caffraria, Sierra Leona. (Mus. Holm. et Coll. S'TẢ); Senegal, Madagascar, Insula Mauritii. (Coll. SIgroret); Calabar. (Coll. A. Dohrs.)

Thorax apud marem quam apud feminam posteriora versus angustior, carina media distincta, antice abbrevinta, instructus, marginibus latcralibus rectis, collari subdepresso. Scutellum iequilaterum. Rostrum pedes posticos attingens.

5. S. griseiventris WEstw. - Dilute subsanguinea vel rufo-testacea, thorace subfortiter, hemelytris subtiliter punctatis; antemnis, capite superne, exceptis lobo medio, orbitis oculorum callisque postocularibus, thoracis callis anticis, rostro, pedibus, exceptis coxis, pectoreque nigricantibus, hujus segmentis posterius rufo-testaceis; ventre fusco-griseo, limbo laterali marginegue apicali segmentorum rufo-testaceis; membrana olivaceo-nigricante; alis fuscescentibus. or. ․ Long." 14-15, Lat. 4 mill.

Pyrrhotes griseicentris WEsTw. in Hope. Cat. of Ilem. II. p. 26. (1842).

Patria: Sierra Leona. (Mus. Holm. et Coll. ŚTÁL.)

Precedenti maxime aftinis, paullo major; punctis thoracis multo fortioribus differt. Rostrum coxas posticas attingens. Thorax collari subdepresso, leviusculo, marginilus lateralibus rectis, carina media distincta. Seutellom paullo longius puan latins.

Exemplum typicum Westwoon hamd examinari.

\section{CORIZL'S FALL.}

Spec. nov. Hem. disp. meth. exhib. p. 8. (1814).

Corpus anguste ovatum vel oblongo-ovatum. Caput ante tubercula antennifera lateralia breviter conico-productum, pone 
oculos callosum. Rostrum coxas posticas attingens. Antemne graciles, articulis primo et quarto incrassatis, illo brevi, capitis apicem haud vel vix superante. Thorax trapezoidens. Scutellum paullo longius quam latius. Membrana venis sat numerosis simplicihus instructa. Metastethimm postice dilatatum. Pedes mediocres, inermes, postici paullo distantes; tarsorum posticorum articulo primo apicalibus duobus ad unum paullo breviore.

a. Metastethii angulis posticis haud productis; capite pone antenus inter oculos suliquadrato.

b. Capite apice modice producto; articulo prino antennarum capitis apicen panllo superante; tuberculis antemiferis apice extus acute productis.

1. C. seutellaris DALL. - Griseo-stranineus, pilosus; thorace, scutello dimidioque exteriore laterum pectoris dense punctatis; capitis lituris duahus basalibus, ocellos includentibus, impressionibus duabus linearibus anticis thoracis, maculis basalibus vel vittis duabus scutelli nigris; apice scutelli Havoalbido, lævi, rotundato; venis hemelytrorum interdum remote obsoleteque subtestaceo-conspersis; vena corii intracostali pone medium venaque intermedia apicem rersus plus minus infuscatis; membrana sordide hyalina; parte laterali punctata pectoris lateribusque ventris sæpissime pallide testaceis; maculis marginalibus abdominis fuscis; femoribus, basi excepta,

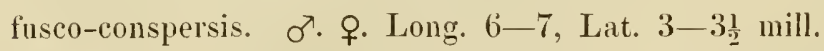

Var. a. - Abdomine dorso flavo-testaceo, segmento apicali vitta media maculisque duabus parvis nigris; parte laterali pectoris rentrisque subtestaceis.

Rhopalus scutellaris DALL. List of Hem. II. p. 526.4. (1852).

Corizus pilosicollis StÅL. Öfv. Vet. Ak. Förh. 1855. p. 31. 1; Sign. Amn. ent. Sér. 3. VII. p. 76. 1. (1859).

Var. b. - Abdomine dorso nigro, macula media segmenti quarti, vittis duabus segmenti quinti nec non segmento sexto griseo-stramineis, hoc vitta media maculaque utrimque laterali nigris notato. 
Ver. c. - Ut varietas b, sed therace posterius maculis nonmullis nigris notato, una inter has in angulis posticis posita.

Corizus Stilii Sigi. Ann. ent. Sér. 3. VII. 1. 78. 3. (1859).

Var. d. - Abelomine dorso nigro, maculal sogmeniti quarti segmentoque ultimo griseo-stramineis, lujus vitta media maculacue utrimgue laterali farva nigris; thorace posterius minute nigro-maculato; pectore ventrerue totis grisen-stramineis.

Corizus Corperelii. SIGX. Am1. ent. Sér. 3. V11. p. 78. 4. (1859).

Patria: Terra capensis, Calfraria. (Mus. Iloln. et Coll. STAL); ear. d. Marlagascar. (Coll. SignoreT.)

species malrgine postico thorileis lateria versus anguste deprosso et pallido insignis. Suboblongus $\left(\sigma^{7}\right)$ vel ovatus $(\zeta)$. Intenuxe artieulo scenuclo tertio sublongiore, nltimo merlio late snbinfuse to, primo supral paree nigropunctito, subtus lineola nigra notito. Thorax carinal subtili ongitudinali instructus. Scutelhum arina hevi instruetum, apiec leviter impressum et rotundatum. Hemelytra hyalina. impunctatil. Femora postica nomihil incrassata. 'Tibie postiea apice subtus tarsigue apiec fusci rel nigri.

bb. Caprite aprice sut producto; articulo primo anternumum capitis apicem haud attingente; tuberculis antenniferis olitusis, apice extus haud prominulis.

2. C. nigro-marulatus STAL. - Griseo-stramineus vel pallide testaceo-flavescens, pare pilosulus; capite, thorace, seutello pectoreque totis sat dense distineteque punctatis; maculis parvis sparsis dimidii postici thoracis, maculis nonmullis venarum hemelytrorun, lasciis medio interruptis dorsi abdominis, vitta maculaque utrimque laterali parval segmenti dorsalis ultimi, maculis commexivi, vitta interiore cappitis sternisque nigris. o'. ․ Long. 5, Lat. 2 mill.

Corizus nigromaculatus S'lat. Öfi. Vot. Ak. Fïrls. 1855. p. 32. 4; Sign. Amu. ent. Súr. 3. VII. 1. 100. 42. (18.9).

Patria: Caffraria. (Mus. Holm.)

Species distinctissima, appite lomgo, longins producto quan in

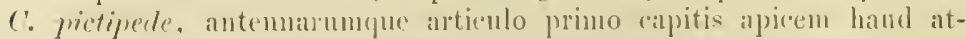
tingente insignis, Anguste ovatus, Antennae brevinsenlae, articulo primo subtus paree nim-consperso, secundo et tertio ieque longis, interom minntissime fuseo-punctatis, ultimo penultimo nomnihil longiore. Caput thorace rix rel pautlo hrevius. 'Thorax ruga transrersa 
antica impressionibusque lincaribus transversis anticis destitutus, caJiua longitudinali subtilissima et obsoletissina nee non margine angusto postico lavilus, pallidis. Membrana sordide hyalina. Femora parce minuteque fusco-conspersa.

aa. Angulis posticis metastethii acnte productis; capite pone antennas inter oculos subquadrato, tuberculis antenniferis upice extus leviter acute prominentibus; henelytris hyalinis, lavibus; pectore puncteto.

c. Scutelli apice pallido, lavi vel larinsculo.

3. C. truncatus Ramb. - Valde olingugus, farce puberulus, griseo-stramineus vel pallide testaceo-flavescens, interdum in rufescentem veregens; capite parce, thorace, scutello pectoroque sat dense distincteque punctatis; apice scutelli acutiusculo, pallido, lievigato; antennarm articulo primo femoribusque nigro-conspersis, illarm articulis secundo et tertio supra subtiliter nigro-punctulatis; abdomine dorso nigro, macula media segnenti tertii, maculis una vel tribus apicalibus segmenti quinti, interdum etiam vittula apicali segmenti sexti stramineis; impressione lineari pone rugam transversam an-

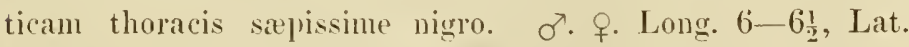
$2-21$ mill.

Corizus gracilis SIGN. Ann. ent. Sìr. 3. VI1. p. S8. 17. (1859). Rhopalus, truncatus Fies. Eur. Heıl. p. 234. 4. (1861).

Var. a. - Capite, antennarum articulo primo, thorace, exceptis lateribus, scutello, exceptis marginibus lateralibus apiceque levibus, fasciis comnexivi, vitta inferiore capitis, sternis, lateribus rittisque duabus rentris nigris.

Tar. b. - Capite nigro-liturato; thorace scutelloque fuscovel nigro-punctatis, lateribus illios dilute punctatis; fasciis connexivi sternisque nigris.

Corizus siculus Sign. Ann. ent. Sér. 3. V1I. p. 91. 24. (1859).

Var. c. - Ut rarietas $b$, sed ventre utrimque vitta abbreviata fusca notato.

Corizus variegatus Srgn. Ann. ent. Sér.'3. VII. p. 89. 20. (1859). 
lar. d. - Ut varietas b, sed pallidior, connexiro maculis vel fascriis nigris destituto.

I'ur. e. - Pallide punctatus; connexivo fasciis nigris destituto.

Vur. $f$. - Ut valietas $b$, sed pallidior, pallide fusco-junctatus; mesosterno fusco; membrana dimidia apicem abdominis superante.

Corizus dilatipennis Sign. Ann. ent. Sér. 3. VII. p. 89. 18. (1859).

Patria: I'ar. a. et b. Terra capensis. (Mus. IJolm.); Vur.c. Insula Mauritii. (Coll. Sigronet); rar. d. et e. Aegyptus; var. f. Nulia. (Mus. Ilolm.) Hæc species praterea Europam meridionalem, Americam meridionalen et Novam Hollandian inlabitat.

4. C. natalensis STÃL. - Oblongus, puberulus, griseo-stramineus, interdum in rufescentem leviter vergens; capite parce, thorace scutelloque dense fusco-punctatis, hujus apice acutiusculo marginibusque lateralibus, basin versus latioribus, pallidis, levibus; lateribus thoracis parcius et subtilius punctulatis rel dilute punctatis; antemarum articulo primo femoribusque nigro-conspersis, illarum articulis secundo et tertio supra nigro-punctulatis; ruga transversa antica thoracis sat distincta, impressione lineari transversa pone illam lugam fuscescente; sternis, abdominis dorso fasciisque connexivi nigris; maculis parvis tribms apicalibus segmentorum duorum penultimorum, macula media sermenti antepenultimi oblonga, nec non margine apicali maculanue apicali segmenti ultimi dorsi ablominis stranineis; thorace linea subtili longitudinali obsoleta leviuscula, macula parva angulorum posticorum fusca. ․ Long. 7, Lat. $2 \frac{1}{2}$ mill.

Corizus natulensis STAL. Öfr. Vet. Ak. Förh. 1855. 1. 31. 2; Sign. Ann. ent. Sér. 3. VII. p. 87. 16. (1859).

Corizus puncticormis STiL. Öfv. Vet. Ak. Förh. 1855. p. 32. 3.

Patria: Caffraria. (Mus. Ilolm.)

C. truncato vilcle affinis, statura majore, robustiore et latiore rugaque anteriore thoraejs minus elevata differt. 
ce. Scutello toto punctato, apice concolore.

5. C. flavo-maculatus Sign. - Dilute ferrugineus vel ferrugineostramineus, puberulus; thorace scutelloque totis distincte fusco-punctatis, hoc apice acuto, marginibus imis lateralibus lavigatis; hemelytris sordide hyalinis, area costali corii rufescente; sternis, abdominis dorso fasciisque connexivi nigris; macula segmenti tertii, maculis tribus parvis apicalibus segmenti quinti, margine apicali maculaque vel vittula apicali segmenti sexti dorsi abdominis stramineis; antennarum articulo primo femoribusque nigro-conspersis, articulis illarum secundo et tertio supra subtiliter nigro-punctulatis; apice tarsorum fusco; capite postice nigro-liturato. o’. \&. Long. $6-7$, Lat. 2-21 mill.

Corizus flavo-maculatus Sign. Ann. ent. Sér. 3. VII. p. 89. 19. (1859).

Patria: Terra capensis. (Mus. Holm.)

Statura C. natalensis, cui valde aftinis, lateribus thoracis apiceque scutelli concoloribus, dense punctatis, differt.

Fam. BERYTIDA FIEB.

Caput ante ocellos constrictum. Oculi a basi capitis remoti. Antennæ quadriarticulatæ, geniculatæ, articulo primo clavato. Rostrum quadriarticulatum. Scutellum minutissimum. Membrana venis paucis instructa. Pedes longi vel longiusculi, femoribus clavatis; tarsis triarticulatis.

\section{CAPYS STÅL.}

Corpus gracile, valde elongatum. Caput inter antennas processu spiniformi curvato, porrecto, sat longo, armatum. Rostrum pedes posticos attingens, articulo primo capitis basin subsuperante. Antennæ longissimæ, articulo primo sequentibus duobus ad unum longitudine requali. Thorax multo longior quam latior, postice depressus, prope angulos posticos tuberculo obtuse conico instructus. Scutellum oblongo-triangulare. Mesosternum, metasternum et segmentum ventrale prinum sulco instructa. 
Ostiola odorifera processu, apice emarginato, instructa. Pedes longissimi, gracillimi.

\section{Apoplymo affine genus.}

1. C. malacaipus Stríl. - Pallide testaceo-flavescens; thorace distincte punctato; antennis pedibusque nigro-conspersis, articulis illarum primo, secundo et tertio nec non corio apice nigris; articulo antennarum quarto albido, apicem versus fusco; tibiis tarsisque apice fuscis; clava femorum testaceoflavescente. $\sigma^{7}$. ㅇ. Long. $7 !$

Neides malacaipus ȘTÁ. Öfv. Vet. Ak. Förh. 1855. p. 30. 1. Patria: Caftiraria. (Mus. IIolm.)

\section{Fam. LYGAII)A STAL.}

Caput nec clypeatum, nec ante ocellos constrictum; tuberculis antenniferis lateralibus. Ocelli adsunt. Rostrum quadriarticulatum. Antenne quadriarticulatie. Scutellum parrum aut mediocre, triangulare. Hemelytra sæpissime completa et clavo, corio membranaque composita; membrana venis numquam ultra quinque instructa. Tarsi triarticulati.

$$
\text { Conspectus subtamiliarum. }
$$

I. Segmentis abdominis fere aque longis.

1. Acetabulis anticis e disco prostethii excisis, a margine postico remotis. - Blissida STí.

2. Acetabulis e margine postico prostethii excisis.

A. Ventris insisuris omnibus margines laterales attingentibus.

a. IIemelytris non nisi ad partem dilatatis et abdomine latioribus.

b. Hamo e vena subtensa emisso.

c. Prosterno et mesosterno sulco distincto destitutis.

d. Femoribus anticis posterioribus haud vel vix crassioribus, inermibus vel raro spinulis nonnullis armatis. 
e. Membrana in angulo basali interiore areola instructa.

$f$. Areola membrana venas duas emittente. - Lygacida STAL.

$f f$. Areola membrane venam longitudinalem unicam emittente; antennis ad oculos insertis, articulo primo incrassato; ostiolis odoriferis appendice brevi tubuliformi instructis. - Malcida STAL.

ee. Membranil areola basali destituta. Geocorida stitiL.

$d d$. Femoribus anticis posterioribus multo crassioribus, subtus multispinosis, tibiis anticis temoribus brevioribus. - Pachygronthida STÅL.

cc. Prosterno et mesosterno sulco distincto instructis. - Cryptorhamphida STẢL.

b. Hamo e vena connectente emisso. - Phygadicida STAL.

aa. Hemelytris totis abdomine latioribus, corii margine costali toto dilatato. - Cymida STÁL.

$B$. Ventris incisura tertia margines laterales haud attingente, prope latera recurra. - Rhyparochromida STÁL.

II. Abdomine basi angustato, segmeutis secundo et tertio longissimis, hoc apicalibus tribus ad unum longiore vel longitudine æquali; tuberculis antenniferis haud prominulis; clavo longissimo, lineari; angulo apicali corii angustissime longissimeque producto. - Colobathristida STiL.

\section{Subf. BLISSIDA STÅL.}

Conspectus generum.

1 (2). Corpore elongato, leviter depresso; pedibus anticis valde incrassatis, tibiis femoribus multo brevioribus, multispinosis. - Chelochime SPIN. 


\section{$-12 \cdot 2-$}

2 (1). Corpore sat depresso; femoribus tibisque anticis fere aque longis, his nec incrassatis, nec spinosis.

3 (4). Pedibus intermediis valde distantibus: femoribus posticis value incrassatis et compressis. - Bochrus stíl.

4 (3). Pedibus intermediis vix vel paullo distantibus.

5 (6). Femoribus posticis inemibus. - Blissus Klug.

6 (5). Femoribus posticis subtus multispinosis. - Papirius STÁL.

\section{BLISSUS BURM.}

Handb. II. 1. p. 290. (1835).

Ischnodemus Fiels, in WEITENw. Beitr. I. p. 337. (1836).

Mieropus Sprix. Ess. Hém. p. 218. (1840).

Corpus plus minus elongatum aut oblongum, depressum. Caput parvum, ante oculos prominulos breviter productum; bucculis minutissimis. Antennæ articulo primo brevi, capitis apicem haud vel parum superante. Rostrum longitudine valde varians. Thorax lateribus obtusis, antice angustatus. Scutellum triangulare. Hemelytra parallela, interdum valde abbreviata et membrana destituta. Pedes mediocres, intermedii vix rel paullo distantes, femoribus posticis inermibus, haud incrassatis.

a. Corpore elongato.

b. Rostro longo, apicem segmenti primi ventris sulsuperante, articulo primo capite paullo longiore.

1. B. fusco-nervosus STÁL. - Nigro-piceus; cajite, thorace pectoreque punctulatis; lobo medio capitis, antennis, rostro pedibusque testaceis; thorace basi piceo; hemelytris griseis, fusco-renosis, corio apice fusco-testaceo; membrana fuscescente, fusco-renosa, macula ad apicem corii parteque api-

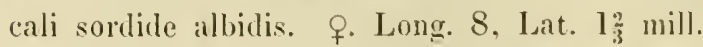

Micropus fusco-nervosus STAL. Öf. Vet. Ak. Förl. 1855. p. 35.1 .

Patria: Caffraria. (Mus. Holm.)

Antenne articulo seeundo primo vix triplo, tertio paullo longiore, ultimo mutilato in exemplo deseripto. Thorax nomilhil longior quam latior, antrorsum leviter angustaus, medio distincte punctatus. postice leviuseulus, marginibus lateralibus medio leviter, margine po- 
stico distinete sinuat's. Scutellum aquilaterum. Hemelytra abdomine nonnihil breviora. Ventre dense alutaceus. Femora antica subincrassata, 'subtus spinulis nonullis minutissimis instructa.

bb. Rostro ad coxas intermedias extenso vel breviore, articulo primo capite breviore.

c. Rostro coxas anticus superante.

2. B. ochropus ŚTẢL. - Nigricans; antennis, rostro pedibusque testaceis, illarum articulo nltimo, basi excepta, nigricante; thorace postice flavo-testaceo; hemelytris griseis, venis pallide flavo-testaceis, utrimque punctatis; membrana sordide albida; limbo angusto abdominis dilute piceo. o?. Long. 6 $\frac{1}{2}$, Lat. $1 \frac{1}{2}$ mill.

Micropus ocheripes S'TÄL. Öf. Vet. Ak. Förh. 1855. p. 35. 3. Patria: Caffraria. (Mus. Holm.)

Rostrum coxas anticas paullo superans. Antenna capite thoraceque ad unmo dimidio longiores, articulis secundo et quarto eque longis, tertio nonnilil longioribus. Thorax ieque longus ac latus, lateribus parallelis, medio levissime sinuatis, anterins rotundato-angustatus, distinete punctulatus, ante medium eallis duobus magnis subtriangul ribus, levissime elevatis, parteque postica lavibus, margine postico nomihil sinuato. Scutellum aquilaterum. Hemelytra abdomine multo breviora, membran exempli descripti maximam ad partem mutilata. Prostethium posterius punctulatum. Femora antica levissime incrassata, subtus spinulis nounullis gracilibus armata.

3. B. rusticns STAL. - Niger, pedibus testaceis; hemelytris brevissimis, rudimentariis. $\sigma^{7}$. 우. Long. $3 \frac{1}{2}-4 \frac{1}{3}$, Lat. $1-1 \frac{1}{4}$ mill.

Var. a. - Limbo abdominis concolore.

Var. b. - Limbo abdominis obscure testaceo.

Patria: Terra capensis, Rondebosch. (Mus. Holm.)

Rostrum inter coxas intermedias extensum. Antenna capite. thoraceque ad unum dimidio longiores, artienlo secundo tertio nonnihil longiore et ultimo paullo breviore. Thorax transversus, antrorsum nonnihil angustatus, punctula us, margine postico recto, interdum obscure testaceo. Scutellum latius quam longius. Hemelytra triangularia, scutcllo paullo longiora. Femora antica paullo inerassata, inermia.

cc. Rostro coxas anticas attingente.

4. B. brevicoruis STÁL. - Niger, breviter pilosus; antennarum articulis secundo et tertio, apice imo femorum, tibiis tarsisque 
dilute flavo-testaceis; hemelytris griseis, corii margine imo apicali anguloque apicali fusco-testaceis; venis membrance fuscis. ㅇ. Long. 6, Lat. $1 \frac{1}{\underline{z}}$ mill.

Micropus brexicomis STAL. Öf. Vet. Ak. Förh. 1855. p. 35. 2. Patria: Caffraria. (Mus. Hohn.)

Antemne breves, capiti thoracique ad unmu longitudine aequals, articulo secundo tertio paullo longiore et ultimo paullo breviore. Thorax fere latior ynam longior, antrorsmu sensim leviter, antice magis angustatns, medio iransversim levissine depressus, punctnlatus, postice levigatus, margine postico dilute piceo, late sinuato. Scutellum vix longius yuan latins. Hemelytra abdomine nomnihi\} breviora. Femora antiea levissime incrassital, subtus pone medium spimula obsoletissimal armata.

5. B. linearis STAL. - Niger; hemelytris griseis; thorace postice, venis hemelytrorum pedibusque flaro-testaceis; femoribus medio late fuscis; limbo abrominis dilute piceo. or. Long. 4, Lat. $\frac{4}{5}$ mill.

Micropus linearis STAL. Öf. Vet. Ak. Förl. 1855. p. 35. 4. Patria: Caffraria. (Mus. Holm.)

Antemne capite thoracerue ad unum dimidio longiores, articulo secmudo tertio nomnihil longiore et ultimo paullo breviore. Thorax acyue longns ac latns, lateribus parallelis, antice rotundato-ingustatus, punctulatus, basi lievinsculus, margine postico recto. Hemelytra abdomine dimidio breviora; membrana fusco-renosa. Femora antica leviter incrassati, pone medium spinula obsoletissima armata.

\section{aa. Corpore oblongo.}

6. B. oblougns StriL. - Niger, fusco-pilosus; hemelytris griseis, renis corii membranalque fuscis, illins angulo apicali nigricante; geniculis piceis; tarsis flavo-piceis. +. Long. 5, Lat. $1 \frac{1}{2}$ mill.

Patria: Terra capensis. (Mus. Hohm.)

Rostrum longissinum, medium rentris subattingens, artienlo primo capite longiore. Lntemne articulo scemndo basali triplo longiore, articulis duobus ultimis exempli descripti mutilatis. Thorax leviter transversus, antrorsum momnihil angustatus, remote distinetegue punrtulatus, medio transversim leviter depressus, postice parcins punctulatus, margine basali late sinnato. Scrutelhum transversum. Hemelytra abdomine paullo breviora. Femora antica posterioribus vix rassiora, incrmia. 


\section{Sulf. LYGAIDA STAL. \\ Conspectus generum.}

1 (2). Oculis peelunculatis. - Astacops Bown.

2 (1). Oculis sexsilihus.

3 (4). Tubereulis antenniferis obtusis. - Lyygens FAzR.

4 (3). Tuberenlis antenniferis afice extus antrorsum acutiuscule prominulis. - Nysins DALI.

\section{ASTACOLS BOIND.}

Foy. de l'Astrol. 1I. p. 637. (1835).

Corpus vilde oblongum rel subelongatum. Calput breviter triangulariter produetum, deflexmm. Oculi pedunculati, pedunculo longitudine variabili. Rostrum pedes posticos haud superans. Antemate articulo primo brevi, capitis apicem hatud superante. Thorax trapezoideus. Ssutellum aquilaterum. Hemelytra completa. Pedes mediocres, femoribus inermibus.

1. A. Ifzelii śtAL - Nigro-fuscus, griseo-sericeus; capite, excepto lobo medio, ostiolis odoriferis, coxis, trochanteribus basique femorum posteriormm flaro-testaceis; membrana leviter infuscata. \%. Long. 7, Lat. 2 mill.

Patria: Sierra Leona. (Mus. Holm.)

Rostrum inter coxas posticis extensum. Antenne gracilinsenlie, articulis secuncto et tertio ieque longis. Oculi breviter pedunculati. Ocelli inter se quam ab ocnlis paullo longius remoti. Thorax antrorsum leviter angustatns, nonnihil transversus, ante medium transversin leviter impressus, pone medinm remote punctintus.

\section{LIGAUS FABR.}

Ent. syst. IV. p. 133. (1794).

Corpus oblongum rel subelongatum. Caput triangulare, convexum, tuberculis antenniferis apice extus laud prominulis, bucculis per totam rel maximam partem capitis extensis. Oculi sessiles. Rostrum longitudine rarians, articulo primo capitis basin attingente rel nomihil superante. Thorax trapezoideus. Scutellum triangulare, interdum convexum. Hemelytra sapissime 
completa. Perles mediocres, femoribus raro spinosis, anticis posterioribus hand vel vix crassioribus.

a. Scutello conrexo; margine postico thoracis ntrimque inter scutellum et angulos posticos plus minus depresso et ampliato; rostri articulo nltimo penultimo breviore.

b. Scutello valde elevato, sulco sat profundo longitudinali instructo.

1. L. excaratus FABR. - Sordide luteus, impunctatus; antemnis, rostro, capitis lateribus anguste, maculis duabus obsoletis parvis anterioribus thoracis, membrana, pectore, exceptis latcribus prostethii, limbo apiceque abolominis rufo-testacei pedibnsque nigricantibus; apice corii alisque infuscatis, o Long. 17, Lat. $5 \frac{1}{2}$ mill.

Cimex excavatus FABR. Spec. ins. II. p. 365. 165. (1781); Mant. ins. II. p. 301. 217. (1787).

Lygeus excaratus FABR. Ent. syst. IV. p. 160. 85. (1794); Syst. Rhyng. p. 226. 107. (1803).

Patria: Africa aquinoctialis. sec. FAbriciun. (Mus. IIolm. et Coll. STiL.)

Thorax arina longitndinali distinctissima percurrente instructus, intria margine's latterales et posticun utrimque impressus, marginibus lateralibus posterius rotundatis, margine postico ntrimyne inter seutellum et ingulos postieos sat ampliato. Henclytral leviter ampliati, margine costali nounila l rotundato, corii margine apicali recto, versus angulum apicalem rotundato. Rostrum segmentum ventrale secundum superans. Perles intcrdum fusco-testacei. Anteme exemplorum deseriptorum mutilatie.

b. Scutello leviter comexo, hand sulcato.

2. I. famelicus Fabr, - Sordicle flarescens vel crocens, fuscopilosus; antemnis, rostro, capitis lobo medio lateribmsipue, thoracis fascia anteriore, utrimpue angulos anticos attingente, scutello, membrana, macula laterali prostethii, mesostethio, metastethio, excepto horum limbo postico, fascia lata seguentorum trimm penultimorum ventris, ano pedibnsque nigris; angulo imo hasali maculaque transversa ante medium membrana alhidis. ơ . . Long. 11-14, Lat. 3-4 mill. 
Var.a. - Thorace, excepta fascia antica, hemelytrisque flavescentilıs, impictis.

Var. b. - Ilemelytris fascia latissima nigra ornatis.

Var. c. - Thoracis vitta media limboque postico, hemelytrorum fascia lata media anguloque apicali corii nigris.

Var. d. - Thorace, hemelytrorum fascia lata media anguloque apicali corii nigris; thoracis margine antico fere toto maculisque duabus magnis Havescentibus.

Cimex funclicus Fabr. Sprec. ins. II. 1. 365. I59. (178I). Mant. ins. II. p. 300. 208. (1787).

Lygous famelicus FABR. Ent. syst. IV. p. 156. 73. (1794); Syst. Rhyng. p. 223. 92. (1803); Thicrb. Hem. rostl. cap. IV. p. 3. (I822); DALL. List of Hem. I1. P. 537. 13. (1852).

Cimex aulicus $\beta$ crocatus Tinns. Nor. ins. spec. III. p. 55. Pl. 3. tig. 65. (I78t).

Lygeus crocutus ThunB. Hem. rostr. cap. IV. p. 3. (1822).

Patria: Terra capensis. (Mus. Holm., Coll. Sigrorer et STAiL.)

Impunctatns. Caput interdum magnam ad partem nigrum, vitta supera ante medium furcata bucculisque croceis vel testaceis. Rostrum pedes posticos nomihil superans. Thorax erina media abbreviata, minus distinctil, iustructus, margine postico utrimgue inter sentellum et angulos posticos sat ampliato. Scutellum leviter conrexum, carrina destitutum. Hemelytra medio leviter ampliata, marginibus litteralibus anterins parallelis.

aa. Scutello plano; margine postico thoracis recto.

c. Thorace carina longitudinali, marginem anticum attingente, instructo, pone medium remote punctulato; rostri articulis tertio quartoque aque longis vel hoc illo panllo longior.

3. L. sterualis DALL. - Coccineus; capitis basi, tuberculis antenniferis loboque medio, antennis, rostro, thoracis maculis duabus magnis subquadratis, margines laterales attingentibus, a margine postico paullo remotis, scutello, apice imo excepto, clavo, basi apiceque exceptis, macula subrotundata majuscula media corii, membrana, pectoris maculis tribus lateralibus magnis, mesosterno, metasterno, ventris maculis lateralibus 
fasciisque discoidalibus, interdum cum maculis illis confluentibus. ano pedihusyue nigris; membranse angulo ino hasali limboque anguste albidis. $\sigma$. Lomg. 8, Lat. 2⿺ mill.

laygens sternalis J)AL. List of Hem. II. p. 546. 4:3. (18:52). Tyygens occipitulis Famm. in THOMs. Areh. ent. II. P. 305. 582. (1858).

Patria: Sierra Leona, Calabar. (Mus. llolm., Coll. A. J)olns, SIGAORET et STAL.)

L. familiari et fimbriuto, qui arl hane divisionem etiam sunt referendi, similis; $I$. fimbriato priesertim maxime affinis et simillimus, thoraris maculis margines latrales attingentibus, corii macula subrotmulata, nee obovata, rentris segmentis postice coceineis, nee diseo nigro, differt. /. jumiliari angustior, thorace inter carinam minus -levatam rot margine's laterales multo minns distincte impresso, obsoletius punctulato. Rostrum pedes posticos hand vel vix attingens.

ce. Thorace carina mulla vel obsoleta, maryinem anticum letud attingente, instructo.

d. Corpore superne dilute griseo-vel coccineo-flacescente, impunctato, scutello concolore, impicto.

e. Angulis posticis metustethii rectis, margine postico leviter rotundato.

4. I. contaminatus DALL. - Pallide griseo-flarescens; antennis, rostro, lobo modio marulisque duabus basalibus anptis, sulculis anticis thoracis, macula parra pone medium clavi, maculis duabus mediis parvis corii, lineola laterali prostethii, marula farra laterali antica mesostethii et metastethii, mesosterno et metasterno nigrix; membrana albido-hyalina, macula media marginis hasalis fusea; pedihus sordide.flarotestaresis, trochanteribus geniculisque fuscis. or. ㅇ. Long. 13-16, Litt. $4 \frac{1}{2}-6$ mill.

Lygurus contaminatus 1)ALL. List of Hem. II. p. 533.3. I. (1852).

Patria: Terra capensis. (Mus. Ilolm, et Coll. Signoretr.)

5. L. prosimus DALL. - Dilute grisen-flarescens; antennis, rostro, lineat media longitudinali parteque basali capitis, sulculis anticis thoracis, maculis parvis hemelytrormm, mal pone medium 
clavi, altera media corii, lineola laterali prostethii, macula minuta laterali antica mesostethii et metastethii, mesosterno pedibusque nigris; membrana fusca, angulo basali albido. \&. Long. 20, Lat. 7 mill.

Lygceus p oximus DALL. List of Hem. I1. p. 534. 2. (1852). Lygceus Stollianus StåL. Öfv. Vet. Ak. Förh. 1858. p. 440. 1. STOLL. Pun. p. 162. fig. 293.

Patria: Terra eapensis. (Mus. Holm.)

Precedenti valde affinis et simillimus.

ee. Metastethii angulis posticis productis, acutis.

6. L. apicalis DALL. - Dilute flarescens vel coccineo-flavescens; abdomine sordide sanguineo; capitis lobo medio tuberculisque antenniferis, antemnis, rostro, thoracis margine antico, scutelli basi ijsa, membrana, pectore, apice abrlominis pedibusque nigris; acetabulis, limbo laterali prostethii angulisque posticis metastethii flavescentibus vel coccineo-flavescentibus; macula anguli basalis fasciolaque anteriore membranæ griseis. \&. Long. 13, Lat. 5 mill.

Lygaus apicalis DALL. List of IIem. II. p. 534. 3. (1852). Microbasis? rufiventris STÁL. Öfv. Vet. Ak. Förh. 1855. p. 185. 1 .

Patria: Sierra Leona. (Mus. Holm.); Senegal. (Coll. SIGNORET.)

7. L. ruffemoratus DALL. - Sordide flavescens vel coccineoflavescens; abdomine sanguineo; capitis lobo medio, antennis, rostro, thoracis margine antico fasciaque angusta media, utrimque abbreviata et medio interrupta, scutelli margine basali, fascia media hemelytrorum, membrana, pectore, waculis vel fasciis lateralibus ventris pedibusque nigris; acetabulis, limbo postico segmentorum pectoris limbisque antico et lateralibus prostethii dilute griseo-flavescentibus; femoribus coccineis vel coccineo-flavescentibus, basi nigris; membranæ angulo basali maculaque transversa ad marginem basalem testaceo-griseis, obsoletis. ㅇ. Long. 11, Lat. 4 mill. 
Lygeus rufifemoratus DaLl. List of Hell. II. p. 534. 4. ( I852). Pyrrhocoris transversus SIgN. in Thoms. Arch. ent. II. p. 306. 584. (1858).

Patria: Guinea, Grand Bassam. (Coll. Signorer et StẢl.)

dd. Corpore superne nigro coccineoque vel flavescente-vario; scutello nigro, apice interdum coccineo rel favescente.

f. Thorace pectoreque haud totis nigris.

g. Antennis articulo teritio toto nigro.

h. Pectore nigro coccineoque rario vel coccineo, limbo postico metastethii semper nigro.

i. Clavo coccineo, margine commissurali solo nigro; antennarum articulo quarto secundo multo longiore.

8. L. furcatus FABR. - Coccineus; capitis lobo medio apicem versus, tuberculis antenniferis margineque angusto basali, ad oculos dilatato, antennis, rostro, scutello, margine commissurali clavi, membrana pedibusque nigris. $\sigma$. ․ Long. 14-15, Lat. 4-41 mill.

Var. a. - Thoracis margine antico vittisque duabus, anterius convergentibus, interdum medio interruptis, basi ipsa ampliatis, limbo postico segmentorum pectoris, limbo exteriore mesostethii et metastethii, mesosterno et metasterno vel saltem horum vittis duabus, limbo vel maculis marginalibus apiceque ventris nigris; limbo postico nigro prostethii ramulum antrorsum emittente; segmento ventrali sexto macula coccinea notato.

Cimex furcatus FABR. Mant. ins. II. p. 301. 218. (1787).

Lygous furcatus FABR. Ent. syst. IV. 1. 160. 86. (1794); Syst. Rhyng. p. 226. 108. (1803); DALL. List of Hem. II. p. 535. 6. (1852).

Var. b. - Uti varietas $a$, sed corii margine costali medio vel macula parva costali nigris.

Lygaus convergens DaLL. List of Hem. II. p. 535. 7. (1852).

Var. c. - Thoracis maculis duabus discoidalibus ante medium, corii margine costali medio maculaque parva discoidali, limbo exteriore mesostethii et metastethii, hujas etiam limbo postico, mesosterno, metasterno, maculis marginalibus segmen- 
toque apicali ventris nee non ano nigris; segmento ventris apicali utrimque macula magna coccinea ornato.

Lygaus Fairmairii SIgN. Ann. ent. Sér. 3. VIII. p. 946. 135. (1861).

Patria: Africa meridionalis occidentalis. (Mus. Holm.); Guinea, Senegal. (Coll. STÅL); var. c. Madagascar. (Coll. Signoret.)

Antenna breviuscula. Rostrum pedes posticos vix attingens, articulo quarto tertio breviore. Thorax apiee remote punetatus, versus margines laterales leviter lateque impressus, marginibus lateralibus pone medium rotundatis, carinula discoidali obsoletissima. Hemelytra medio vix ampliata.

ii. Clavo coccineo, ad suturam clavi plu: minus late nigro.

k. Scutello nigro, apice imo rarissime obsolete coccineo.

I. Clavo macula posteriore nigra destituto.

9. L. crudelis FABR. - Niger, griseo-sericeus; capitis vittula basali, thoracis macula utrimque laterali anteriore, oblonga, curvata, limbo laterali pone medium, margine basali bis interrupta vittaque media antice abbreviata, clavi limbo scutellari, corii vittis duabus, macula laterali segmentorum pectoris, limbo laterali prostethii pone medium abdomineque coccineis; corii vittis coccineis macula vel fascia media interruptis; membrana albida, sæpissime leviter infuscata, margine basali nigro; ventris maculis lateralibus in seriem dispositis, macula angulorum basalium segmentorum, sæpe cum maculis illis confluente, interdum etiam fasciis abbreviatis discoidalibus, segmento apicali anoque nigris; segmento ventrali apicali utrimque macula coccinea notato. $\sigma^{7}$. ㅇ. Long. 11-13, Lat. $4-4 \frac{1}{2}$ mill.

Cimex crudelis FABR. Spec. ins. I1. p. 362. 143. (1781); Mant. ins. II. p. 298. 187. (1787).

Lygceus albidus Thunb. Nov. ins. spec. III. p. 56. (1784); Hem. rostr. cap. IV. p. 2. (1822).

Lygous crudelis FABR. Ent. syst. IV. p. 148. 45. (1794); Syst. Rhyng. p. 318. 60. (1803); Dall. List of Hem. II. p. 542. 31. (1852) excl. syn. Germari et Stolli; H. Sch. Wanz. Ins. IX. p. 198. (1853). 
Lygceus sceves Girru. in SILB. Rev. ent. Y. P. 142.50. (1837). Patria: Terra capensis. (Mus. Holm., Coll.Signonet et STẢL.)

10. I. rivularis GERM. - Niger, griseo-sericeus; capitis vitta fureata, thoracis macula ntrimque laterali antica, vittis tribus, basin attingentibus, media prope apicem, lateralibus prope maculas illas anticas abbreviatis, his intramarginalibus, nec non margine toto postico, clavi limbo latissimo scutellari, corii vittis duabus obliquis, macula laterali magna segmentorum pectoris, limbo laterali prostethii pone medium abdomineque coccineis; rentris uaculis parvis in seriem lateralem dispositis, angulis basalibus segmentorum, segmento ultimo anoque nigris; segmento ventrali ultimo utrimque macula magna triangulari coccinea ornato; membrana fuscescente, margine basali nigro. $\sigma^{7}$. ㅇ. Long. 12-14, Lat. 4-5 mill.

Lygaus rivularis GERM. in SILB. Rev. ent. V. p. 141. 49. (1837).

Lygeus fecialis STÅL. Öf. Vet. Ak. Für. 1855. 1. 32. 1. Patria: Terra capensis, Caffraria. (Mus. Holm. et Coll. SI(iNORET.)

L. cruleli vake aftinis, capitis vitta furcata, cujus brachia fere ad inscrtionem antcunarum sunt extensa, marginibus lateralibus thoracis uigris, corii vittis coccineis macula vel fascia nullia interruptis, membranaque fuscesecente differt.

11. L. trilineatus FABR. - Niger, griseo-sericeus; eapitis macula basali, tubereulis antenuferis extus, rarissime etiam lineolis duabns ante medimn, thoracis maculis duabns lateralibus, oblongis, nua anteriore, curvata, altera pone medium posita, nec non vitta media, anterius abbreviata, clavi limbo scutellari, corii vittis duabus latitudine variabilibus, interiore brevi, macula laterali segmentorum pectoris, limbo laterali prostethii pone inedium, fascia apicali segmentorum ventris, margines laterales hand vel vix attingentibus, prope margines eosdem sæpe interruptis, maculaque laterali segmenti ultimi coccineis; membrana albida, margine basali nigro. o․ ㅇ․ Long. .3-10. Lat. 2! -3 nill. 
Lyyous trilineatus FABR. Ent. syst. IV. p. 157. 74. (1794); Syst. Rhyng. p. 223. 93. (1803); II. Scr. Wanz. Ins. IX. p. 198. (1853).

Lygcous mundus DaLL. List of Hem. II. p. 542. 32. (1852). $V a r . b . \quad-$ Capitis tubereulis antenniferis nigris; thoracis margine postico utrimque anguste coccineo.

Lygaus lemniscatus STÂL. Öfr. Vet. Ak. Förh. 185̌̃. p. 32. 2.

Patria: Terra capensis. (Mus. Holın., Coll. Signonet et S'TȦ..)

L. crudeli et rivulari aftinjs, magnitudine multo minore ventreque nigro, coccineo-fasciato, ab ambobus mox distinctus. Thorax antice et medio plus minus distincte ant obsolete, interdum sat fortiter punctitus.

12. L. taniatus S'til. - Coccineus; antennis, rostro, capitis lobo medio, maculis duabus basalibus nee non vittis duabus inferioribus ad bucculas, thoracis vittis duabus latis percurrentibus, anterius constrictis, marginibusque lateralibus, parte antica excepta, scutello, vitta abbreviata excepta, clavi limbo ad suturam clavi, corii vitta media, marginem apicalem vix attingente nec non limbo costali pone medium, margine basali membranæ fusco-albidie, pectore, fasciis ventris, utrimque interruptis, nec non pedibus nigris; acetabulis, macula transrersa segmentortum pectoris, prostethii limbo laterali pone medium nec non antico coccineis. $\sigma^{7}$. ㅇ. Long. 10, Lat. 3 mill.

Patria: Terra capensis. (Mus. Holm., Coll. Signonet et STÅ̊.)

L. trilineato affinis, major, colore capitis, acetabulis limboque antico prostethii coccineis, rittis coceineis thoracis hemelytrorumque latioribus distinctissimus. Thorax parec et plus minus distinete punctatus.

H. Clavo macula posteriore nigra ornato.

13. L. militaris FABR. -- Coccinens; capite, antennis, rostro, thoracis limbo antico vittisque duabus percurrentibus, distantibus, ante medium subito convergentibus, dein parallelis, undatis, seutello, rlavi sutura maculaque rotmodata posteri- 
ore, corii fascia media et interdum margine custali, pecture, ventris maculis marginalibus aliisque utrimque in seriem longitudinalem dispositis nec non pedibus nigris; capitis vitta furcata, cujus brachia ad antennas sunt extensa, macula magna laterali segmentorum pectoris nec non limbo laterali prostethii pone medium coccineis. $\sigma^{7}$. ㅇ․ Long. 14-16, Lat. $4-6$ mill.

$\gamma^{7}$. Femoribus subtus spinulosis.

Var. a. - Membrana sorlide albida, angulo basali, macula media marginis basalis venaque, areolam extus terminante, nigris.

Cimex militaris FABR. Syst. ent. p. 717. 103. (1775); Spec. ins. II. p. 362. 141. (1781); Mant. ins. 11. p. 297. 184. (1787).

Lygaus militaris FABR. Ent. syst. IV. p. 147. 42. (1794); Syst. Rliyng. p. 217. 56. (1803); A. et S. Ilist des llém. 1. 249. 1. (1843).

Var. b. - Membrana fusca, maculis tribus parvis, una in angulo basali, una ad marginem basalem prope angulum apicalem corii unaque discoidali ante medium albidis.

Lygous civilis WoLFF. 1c. cim. I. p. 25. 25. Tab. 111. fig. 25. (1800).

Lygaus militaris BurM. Handb. II. 1. p. 298. 2. (1835); H. ScH. Wanz. Ins. IX. p. 198. (1853).

Var. c. - Membrana fusca, maculis albidis basalibus obsoletissimis, basali nulla; margine costali corii fere toto nigro.

Lygaus asiaticus KoL. Mel. ent. 1I. p. 72. 36. Tab. VIlI. fig. 12. (1845); H. ScH. Wanz. Ins. IX. p. 198. (1853).

Patria: var. b. Sierra Leona. (Mus. Holm.); var. c. Ins. Bourbon et Mauritii. (Coll. Signoret). Specinina africana varietatis a haud vidi.

14. L. elegans Wolff. - Coccineus; antennis, rostro, capite, thoracis vittis duabus late distantibus, ante nedium subito convergentibus, dein curvatis et ad apicem continuatis, ante medium ramulun obliquum angustum ad margines laterales emittentibus, scutello, clavi limbo ad suturam clavi maculaque posteriore, corii margine ad suturan clavi, vitta media, limbo 
costali fere toto, fascia media limboque apicali, pectore, ventris fasciis, basin segmentorum occupantibus, interdum etiam vitta laterali pedibusque nigris; capitis vitta furcata, macula laterali segmentorum pectoris limboque laterali prostethii pone medium coccineis; thorace pone medium inter vittas nigras maculis duabus griseo-ștramineis ornato; membrana albida, margine basali nigro. $\sigma^{7}$. ‥ Long. 11-15, Lat. $4-5$ mill.

o7. Femoribus subtus spinulosis.

Lygceus elegans WoLfF. Ic. cim. IIl. p. 112. 106. Tab. X1. fig. 106. (1802); BuRM. Ilandb. I1. 1. p. 298. 1. (1835); Dall. List of Hem. II. p. 541. 29. (1852); H. Scrr. Wanz. Ins. IX. p. 199. (1853).

Patria: Africa meridionalis. (Mus. Holm., Coll. Signoret et ST'ÅL.)

L. militari affinis, thoracis maculis duabus pallidis, vitta media corii fasciisque latiusculis ventris nigris distinctus.

kk. Scutello nigro, apice coccineo.

15. L. festirus Thunb. - Coccineus; antennis, rostro, capite, thoracis vittis duabus latis, ante medium constrictis, limboque antico, scutello, excepta parte apicali, margine suturali parteque dimidia apicali clavi, corii macula sat magna triangulari marginali media, membrana, pectore, ventris fasciis abbreviatis maculisque marginalibus nec non pedibus nigris; capite superne tuberculisque antenniferis coccineis, lobo medio maculaque basali utrimque ad oculos nigris; macula laterali segmentorum pectoris limboque laterali prostethii pone medium coccineis; membrana immaculata. ơ. ㅇ. Long. 9-13, Lat. 3-4 mill.

o'. Femoribus subtus spinulosis.

Lygaus festivus Thunв. Hem. rostr. cap. IV. p. 3. (1822).

Lygoeus furcula H. ScH. Wanz. Ins. IX. p. 197. (1853); DALL. List of Hem. II. p. 543. 34. (I852).

Lygceus spinipes SIGN. Ann. ent. Sér. 3. VIIl. p. 946. 136. (1861). 
Patria: Sierra Leuna, Caffraria, Madagascar. (Mus. Holur.. Coll. Signoret et S'TAlı.)

L. Hospiti") maxime affinis. Thorax vittis nigris ante medium extus ramulum angustum, postice ramulum transversum, interdum ad angulos posticos extensum, marginem posticum raro ocenpantem, siepissine enittentibus.

16. L. Lomgulus Dall. - Coccineus; capite, rostro, antennis, thoracis limbo antico vittisque duabus latis, basin attingentibus, ibidem extus ampliatis et ad margines laterales continuatis, antrorsum ultra medium extensis, intus sinuatis, scutello, clavo apicem rersus rel pone medium, fascia media corii, membrana, pectore, rentris maculis quinque marginalibus et quattuor lateralibus, in seriem longitudinalem dispositis, nee non pedibus nigris; capitis macula ovali posteriore maculisque duabus distantibus anticis, interdum cum matcula posteriore conjunctis, parte apicali scutelli, macula majuscula laterali segmentorum pectoris limboque laterali prostethii coccineis; membrance maculis tribus parvis albidis, una in angulo basali interiore, secunda ad marginem basalem prope angulum exteriorem, tertia discoidali ante medium posita. ơ. 우. Long. 12-14, Lat. 3-4 mill.

$\sigma^{7}$. Femorilus subtus pone medium spinulis armatis.

Lygar longulus 1)ALL. List of Ilem. II. 1. 545. 39. (1852). ser. Mus. Brit.

Patria: Eiklans Africat meridionalis oceilentalis. (Mus. Holm.); Aeryptus. (Mus. Brit.)

P'urimis congencricis mili cognitis proportionaliter angustior. Thorax marginibus lateralibus antice leviter simuatis. Hemelytra parallela.

Exemplum typicum DaLLAsi mutilitum, sordidum, apice seutetli maculisque pectoris obseure fusco-coccincis, his obsoietissimis.

17. I. Mimus StaL. - Dilute sordide flavescens; capite, rostro, antennis, thoracis limbo antico vittisque duabus latis, intus

") L. Hospes FaBr. $=$ L. affinis WolfF. (Ic. cim. tig. 104.) = L. Lanio H. Scr. $=L$. squalidus MoNTr. et SigN. (Ann. ent. Sèr. 4. I. p. 66. 27.) Exemplum typicum L. squalidi amicissime communicavit Sigxoret. Apex scutclli coceincus in hac specie. 


\section{7}

sinuatis, antice sepissime abbreviatis et angustatis, basin attingentibus, ibidem dilatatis et ad margines laterales extensis, scutello, parte apicali vel macula posteriore clavi, fascia media corii, extus postice dilatata, membrana, pectore, ventris maculis quinque marginalibus et quattuor utrimque lateralibus, in seriem longitudinalem dispositis, nee non pedibus nigris; capitis macula oblonga postica maculisque duabus distantibus anticis, scutelli parte apicali, macula majuscula laterali segmentorum pectoris nee non limbo laterali prostethii sordide dilute flavescentibus; membrana maculis tribus, una in angulo basali interiore, secunda ad marginem basalem prope angulum exteriorem, tertia discoidali ante medium posita, albidis. $\sigma^{7}$. ㅇ. Long. 9, Lat. $2 \frac{2}{3}$ mill.

$\sigma^{7}$. Femoribus subtus pone medium spinulis armatis.

Patria: Nubia superior. (Mus. Ilolnn.); Senegal. (Coll. SiGNORET.)

L. Ionyulo simillimus, minor, colore coccineo in Havescentem verso, thoracis marginibus lateralibus anterins rectis, fasciaque corii extus postice dilatata, maculan subtriangularm, postice sinuatam, simulante differt.

hh. Pectore nigro vel coccineo, limbo postico segmentorum elnurneo vel coccineo.*)

m. Pectore nigro, limbo postico segmentorum elurneo.

18. L. concinm DaLl. - Coccinens; capite subtus, lobo medio, marginibus lateralibus orbitisque, antennis, rostro, thoracis vittulis duabus undatis anticis, scutello, excepta carina, puncto poné medium clavi, macula minutissima media corii, margine basali membranx albidæ, pectore, ventris apice, maculis minutis marginalibus aliisque in seriem lateralem dispositis, nec non pedibus nigris; bucculis, acetabulis, limbo postico se-

*) Uti incolas insula Madagascar L. variegrtum DE GeEr et L. bitransversum Sigs. (Anu. ent. Sér. 3. VIII. p. 947. 140.) misit Signonet. Ambæ species tamen Americam inhabitant et habitum prebent plane americanum. Exemplum $L$. bitransversi ipsum typicum, pessime conservatum, valde mutilatum, colore coccineo in sordide griseo-flarescentem verso, cxaminavi. L. bitranszersus idem est ac L. Aavo-marginellus SrÅt. 


\section{$-138$}

gmentorum pectoris limboque antico prostethii eburneis; membranæ venis areolatque infuscatis. $\sigma^{7}$. 9 . Long. 9, Lat. $2 \frac{1}{2}$ mill.

Var. b. - Marginibus lateralibus thoracis et costali hemelytrorum pone medium nigris.

Lygaus concinnus 1)ALL. List of Hem. II. p. 542. 30. (1852).

Patria: Africa meridionalis occidentalis, prope fluvium Svakop. (Mus. Holm., Coll. Signoret et Stål.)

Thorax paullo brevior quam latior, pone medium earma levi instructus, limbo antico parce punctulato, marginibus lateralibus rectis.

19. L. fulvipes DALL. - Dilute coccineus; capite, thorace, scutello, macula minutissina pone medim clavi, macula parva media corii, apice abdominis maculisque minutis latera'ibus ventris, in seriem dispositis, nigris; capitis lobo medio, macula parva basali apiceque tuberculorum antenniferorum, carina vel apice scutelli angulisque posticis thoracis fusco-ceccineis; membrana infuscata, macula transversa ante mediun limboque albidis; acetabulis, limbo postico segmentorum pectoris, limbo antico prostethii bucculisque eburneis. $\sigma^{7}$. + . Long. 8, Lat. 2 ! mill.

Lygaus fulvipes DALL. List of Hem. II. p. 536. 9. (1852). Patria: Nubia. (Mus. Holm.)

L. concinno affinis et statura similis, colore insigni antennarum pedumque distinctus.

$\mathrm{mm}$. Pectore fere toto vel saltem limbo postico segmentorum coccineis vel flavo-coccineis.

n. Pecto e flavo-coccineo rel griseo-carneo, maculis nonnullis parvis nigris notato.

20. L. delicatulus STÁL. - Dilute coccineo-flavescens; capitis basi vittaque media postice dilatata, antennis, rostro, maculis duabus magnis posticis thoracis, margines laterales attingentibus, a margine basali subremotis, scutello, excepta carina, macula media corii ad marginem costalenı, membrana, macula parva prope angulos posticos segmentorum pectoris, ostiolis orloriferis, maculis marginalibus abdominis pedibusque nigris; 
maculis duabus membranæ, una ante medium posita, altera apicali, rotundatis, albidis. ․ Long. 7-8, Lat. 2-21 mill. Lygceus delicatulus STẢL. Őfv. Vet. Ak. Förh. 1855. p. 32. 3. Patria: Terra capensis, Caffraria. (Mus. Holm.)

Rostrum articulo basali bucculas nonnihil superante.

21. L. villosulus StåL. - Dilute sordide coccineo-flavescens vel griseo-carneus, pilosus; capite, antennis, rostro, maculis duabus parvis oblongis anticis et duabus magnis posticis thoracis, maculis duabus parvis mediis scutelli, membrana, maculis tribus parvis pectoris, ad margines laterales positis, segmento ventrali ultimo, ano pedibusque nigris; membranæ angulo basali interiore, macula transversa marginis basalis ad angulum exteriorem maculaque apicali albidis. o' Long. 6, Lat. 2 mill.

Lygaus villosulus STÅL. Öfv. Vet. Ak. Förl. 1855. p. 32.4. Patria: Caffraria. (Mus. Holm.)

L. bipunctato DALL., cui est articulus primus rostri bucculis distincte longior, simillimus. Rostrum articulo primo bucculas postice haud vel vix superante. Thorax et pectus obsolete parceque punctulati.

Genus Lygroosoma Spin.. Fieb., ad quod etiam pertinet L. villosulus, a Lygcoo haud est distinguendum.

nn. Pectore nigro, limbo postico segmentorum omninm limboque antico prostethii coccineis.

22. I. Servus FABR. - Coccineus; vitta percurrente basique capitis, thoracis fasciis duabus, posteriore interrupta, maculisque duabus mediis, cum fasciis interdum conjunctis, scutello, hemelytrorum maculis duabus magnis, una oblonga, obliqua, partem clavi et corii occupante, altera ad marginem costalem corii pone medium posita, interdum confluentibus et limbum scutellarem clavi limbosque corii apicalem et costalem ante medium solos coccineos relinquentibus, membrana pectore pedibusque nigris; margine postico segmentorum pectoris, limbo antico et laterali prostethii acetabulisque coccineis; maculis quattuor parvis pectoris atris; membrana albido-limbata; macula parva basali capitis griseo-flavescente; 
angulis posticis metastethii distincte productis. $\sigma$. ․ Long. 8-10, Lat. $23-4$ mill.

Var. a. - Capite subtus coccineo; ventre nigro, coccineolimbato.

Cimex servus Fank. Mant. ins. II. 1. 300. 207. (1787).

Lygous servus FABR. Ent. syst. IV. P. 156. 72. (1794); Syst. Rhyng. p. 2203. 91. (1803); DALI. List of Hem. II. p. $547.47 .(1852)$.

Lygaus incomptus H. ScH. Wanz. Ins. VIII. p. I04. fig. 875. (1848); 1. ․ IX. p. 196. (I8.)3).

Var. b. - Ut varietas a, sed capite subtus nigro, buceulis cocrineis.

Var. c. - Ut varietas b, serl ventre coccineo, maculis lateralibus et discojdalilus nigris.

Patria: Sierna Leona, Madagascar, Jasa, China. (Mus. Holm. et Coll. Strí); ver. c. Insula Mauritii. (Coll. Sigroretr.)

23 L. fasciatirentris șíl. - Niger, griseo-sericeus; eapite malculis duabus magnis anteocularibus, thoracis limbis antico et postico, vitta media percurrente, anterius angustata, maculaque utrimque laterali pone medium, carina scutelli, clavi margine scutellari, corii limbo ad suturam clavi limboque costali ultra medium, limbo postico segmentorum pectoris, limbis lateralibus et antico prostetliii, acetabulis ventreque coccineis; macula parva limbi postici segnentorum, pectoris matrginibus basali et apicali maculanue angulorum basalium segmentorum ventris nigris; membrane limbo maculaque ante medium posita, ramulum ad manginem basalem emittente, albidis; bucculis coccineo-albidis. o'. Long. 7, Lat. $2 \frac{1}{3}$ mill. Lygaus fasciutiventris STiL. Öf. Vet. Ak. Förh. 1858. p. 316. 23.

Patria: Territorium lacus N"Gami. (Mus. Holm.)

24. L. unimaculatus Sigx. - Coccineus; antennis, rustro, capite, exceptis maculis duabus magnis anteocularibus, thoracis maculis majusculis quattuor, luabus ante medium et duabus fone medium positis, in vittas duas snbenflnentibus, scutello. 
exceptal carina, membrana, pectore, ventris macula utrimque laterali prope basin, ano pedibusque nigris; acetabulis, limbo postico segmentorum pectoris, limbis lateralibus et antico prostethii coccineis; limbo postico segmentorum pectoris malcula parva nigra notitis; membrane macula parra discoidali ante medium parteque tertia apicali sordide albidis. $\sigma^{\text {T }}$. Long. 7 , Lat. 12 mill.

Lygaus unimaculatus SIGX. Ann. ent. Sér. 3. VIII. I. 947. 141. (1861).

Patria: Madagascar. (Coll. SigionerT.)

L. fasciativentri valde affinis.

grg. Antemnarum articulo tertio apicem rersus tlavo-albido.

25. L. discoidalis SiGx. - Niger; antennarum articulo tertio apicem versus sordide flavo-albido; thorace ante medinm marginibusque lateralibus, parte coriacea hemelytrorum, limbis latis antico et lateralibus prostethii nee non abdomine coccineis, lujus segmento ultimo anoque nigris; membrana anguste albido-limbata. q. Long. 11, Lat. 4 mill.

Lygaens discoidalis Sigr. Ann. ent. Sér. 3. VIIr. p. 947. 139. Pl. 14. 'fig. 2. (1861).

Patria: Madagascar. (Coll. SignoReT.)

ff. Thorace pectoreque totis nigris.

26. L. bipartitus SIGN. - Niger; parte coriacea hemelytrorum abdomineque coccineis, hujus segmento ultimo anoque nigris; macula parva basali capitis testaceo-albida; membrana angustissime albido-limbata. \%. Long. 81, Lat. 3 mill.

Lygceus bipartitus Sign. Ann. ent. Sér:' 3. VIII. p. 947. 138. (I861).

Patria: Madagascar. (Coll. SignoRet.)

27. L. marginatus Thunb. - Niger, griseo-sericeus; macula parva basali capitis, corio abdomineque coccineis; corii limbo costali, utrimque abbreviato, nec non macula media cum limbo colitrente, abdominis limbo, segmento ultimo anoque nigris; 
membrana fusca. macula rotundata ante medium posita limboque albidis. ㅇ. Long. 6 $\frac{1}{2}$, Lat. 2 mill.

Lygaus marginatus THLNB. Hem. rostr. cap. IV. p. 2. (1822).

Lygaus melanurus Germ. in Silb. Rev. ent. V. p. 143. 52. (1837).

Var. b. - Membrana sordide albida, renis basin versus nigris.

Patria: Terra capensis. (Mus. Holm. et Coll. Stål.)

\section{Subf. GEOCORIDA STÅL.}

Conspectus generum.

1 (8). Clavo apicem versus ampliato vel marginibus lateralibus parallelis.

2 (3). Corpore elongato; capite ad oculos retrorsum valde prominulos haud immerso; antennarum articulo primo capitis apicem attingente; hemelytris, parte basali excepta, dilatatis et abdomine latioribus; pedibus longiusculis. Ninus STÅL.

3 (2). Corpore oblongo.

4 (7). Pedunculo oculorum brevi, extrorsum vergente.

5 (6). Bucculis pone insertionem antennarum extensis. - Henestaris SPIN.

6 (5). Bucculis brevissimis, pone insertionem antennarum haud extensis. - Germalus StÃL.

7 (4). Pedunculo oculorum longo, extrorsum et antrorsum vergente. - Hamus STäL.

8 (1). Clavo apicem versus sensim angustato, interdum cum corio arcte connexo. - Geocoris FaLL.

\section{GERMALUS STȦL.}

Ent. Zeit. XXIII. p. 311. (1862).

Corpus oblongum, modice depressum. Caput latum, thoraci latitudine æquale, breviter triangulariter prominens; bucculis parvis, pone insertionem antennarum haud extensis. Oculi pedun- 


\section{3}

culo brevi, extrorsum vergente, suffulti. Antenuæ corpore tertia parte breviores, articulo primo apicem capitis paullo superante, articulo secundo tertio nonnihil longiore. Rostrum gracile, niediocre. Thorax transversus, antrorsum leviter angustatus. Scutellum aquilaterum. Hemelytra completa, pellucida, clavi marginibus lateralibus parallelis. Pedes mediocres, femoribus inermibus, anticis posterioribus paullo crassioribus.

Henestari et Geocoridi affine genus.

1. G. Kinbergi StÅL. - Griseo-stramineus; thorace, scutello lateribusque pectoris remote nigro-punctatis; maculis duabus superioribus articuli primi antennarum maculaque parva angulorum posticorum thoracis fuscis; seriebus punctorum nigrorum duabus clavi, una ad suturan clavi, altera ad commissuram et partem posteriorem marginis scutellaris, seriebusque tribus corii, una ad suturam clavi, secunda media, prope basin incipiente, ad medium marginis apicalis extensa, tertia percurrente, intramarginali, basin versus ad marginem costalem valde appropinquata, dein a margine remota et cum hoc parallela, nec non serie brevi ad marginem apicalem, inter apices serierum duarum exteriorum; margine apicali corii inter medium et angulum exteriorem subsanguineo; membrana sordide hyalina. ․ Long. $5 \frac{1}{4}$, Lat. 2 mill.

Henestaris Kinbergi STẢL. Freg. Eug. Resa. Ins. Hem. pr 248. 73. (1858).

\section{Patria: Insula Mauritii. (Mus. Holm.)}

G. sobrino major, serie punctorum intracostali corii basin versus ad nuarginem valde appropinquata, nec a basi a margine sensim divergentc, prosertim differt.

\section{GEOCORIS FALL.}

Spee. nov. Hem. disp. meth. exh. p. 10. (1814).

Corpus ovatum, depressum. Caput latissimum, cum oculis thorace latius, ante oculos brevissime triangulariter prominulum, tuberculis antenniferis levissime prominulis; bucculis minutis. Oculi magni, valde prominuli, obliqui, leviter retrorsum vergentes. Rostrum pedes posticos attingens, articulo primo ad basin ca- 
pitis extenso. Antemine corpore multo breviores, articulo primo brevissimo. Thorax transversus, quatrangularis, antrorsum leviter angustatus. Scutellum triangulare, majusculum. IIemelytra srepissime completa, clavo angusto, retrorsum sensim angustato, raro cum corio connato. Pedes mediocres, femoribus inermibus.

1. d. amabilis STÁL. - Niger; capite, rostro, articulo ultimo antennarum, limbis latis lateralibus, margine postico maculaque magna pone metium thoracis et hujus basin tangente. hemelytris, margine antico prostethii, regione acetabulorum, margine abdominis pedibusque sordide stramineis; punetis maculaque transversa ad marginem apicalem corii nigricantibus; menbrana sordide hyalina. ๔. Long. 4, Lat. 2 mill.

Geocoris amabilis STÁl. Öfv. Vet. Ak. Förh. 1855. p. 35. 1. Patria: Caffriria. (Mus. Holm.)

Statura G. erythrocephali. Caput leve, cum oculis thorace paullo latius, parte laterali oculos ferente thoracis marginem anticum tangente. Thorax antrorsum vix angustatus, duplo latior quam longior, punctis raris nigris adspersus. Scutellum aequilatermm, apice acutum. pone medium interdum maculis duabus parvis oblongis obliquis, obsolete stramineis, notatum. Clarns ad sutmam clari serie punctorum nigrorum. Corium apicem versus nigro-pmetulatum, seriebus punctorum nigrormm, luabus ad sutmam clari unaque af marginem costalem instructum, serie hac pone medium abbreviata.

2. A. signicollis STí - Pallide griseo-stramineus; rapitis parte posteriore loboque medio, antennarum articulis primo et secundo a basi ultra medimm nee non tertio basi, thoracis falscia subapicali, medio subinterrupta, maculisque duabus magnis, antice subconfluentibus, cum fascia conjunctis, basin thoracis fere attingentibus, scutelli parte plus quam dimidia basali, pectore lateribusque ventris nigris; margine antico prostethii, margine postico segmentorum pectoris omuium, acetabulis limboque abdominis pallide griseo-stramineis, hoc fusco-maculato; femoribus, basi apiceque exceptis, rostroque fuscis, hujus articulis primo, secundo et tertio apice pallidis. ‥ Long. $3 \frac{1}{4}$, Lat. 1! mill.

Geocoris signicollis STAL. Öf. Vet. Ak. Förh. 1854. p. 235. 2. Piltria: Syrkut Nubiæ. (Mus. Holm.) 
Caput cum oeulis thorace paullo latius, parte laterali oculos ferente marginem anticum thoracis tangente. Thorax antrorsum leviter angustatus, duplo atior quam longior, minus dense fusco-pumctatus, rallis anticis levilus, vix clevatis. Sentellum paullo longius quam latius, punctatmm. Hemelytra ad suturam clavi seriatim punctulati, rorio pone inediun remote punctulato; inenbrana vitrea. Peetus sat den:e punctulatum.

3. G. Mauritii STÀL. - Niger; antennarum articulo ultimo, thoracis angulis posticis maculaque minutissima media marginis postici, hemelytris, margine antico merlio marginibnsque lateralibus prostethii, angulis posticis metastethii, apice femorum, tibiis tarsisque griseo-stramineis; membrana vitrea. ?. Long. 3, Lat. $1 \frac{1}{3}$ mill.

Geocoris Mauritii StAL. Öf. Vet. Ak. Förh. 1854. p. 236. 3; Freg. Eng. resa. Ins. Ilem. p. 249. 76. (1858).

Patria: Insula Mauritii. (Mus. Molm.)

Statura precedentis. Caput eum oculis thoracis parte basali hind latius, lave. mope apicem maculis nomullis minutissimis griseo-strimineis notatum. Thorax antrorsum nomnihil angustatus, postice fere duplo latior gnam longior, distincte punctatus, angulis posticis partegue pallida adjacente parce finsco-punctatis. Scutellum distinete et minus dense punctatum. Clavus ad suturam clavi serie punctorum instructus. Corium pone medium remote punctulatum, ad suturam clavi seriebus punctorum duabus, retrorsum panllo divergentibus, instructum margine costali sat rotundato. Pect s dense punctatum.

\section{Subf. PACHYGRONTHIDA STÁL.}

\section{Conspectus generum.}

l (4). Antemnarum articulo primo brevissimo, capitis apicem haud attingente.

2(3). Oculis leviter prominulis; rostri articulo primo capitis basin attingente; capite subtus pone bucculas breves et sat altas haud vel vix elevato. - Teracrius STÅL.

3 (2). Oculis sat prominulis; rostri articulo primo capitis basin haud attingente; capite subtus pone bucculas breves et sat altas bigibboso. - Phlegyas STÅL. 
4 (1). Antemuarum articulo primo omnimm longissino, capitiapicem superante.

5) (6). Antennarum articulo primo apicem versus semsim leviter incrassato, thorace siejiswime breviore, raro sublenginge. Oedancala A. et $\mathrm{x}$.

6 (5). Antennarum articulo primo alyice subito leviter incransato, clavato, thorace longiore; capite anterius inter antennas utrimque longitrorsum alte carinato. - I'achy. grontha GERM.

TERACRIUT S゙AL.

Öfv. Vet. Ak. Förl. 1858. p. 317

Corpus valde oblongum. Gaput parviusculum, triangulare. deflexum, ad oculos immersum; tubereulis antemiferic levisime prominulis, ab oculis paullo remotis; bucculis sat altis. brevibus. Rostrum paullo pone pedes anticos extensum, articulo primo capitis basin attingente. Intennæ breves, articulo primo capitis apicem haud attingente. Thorax trapezoideus, antrorsum angustatus, convexiusculus, marginibus lateralibus obtusis, rectis. Scutellum aquilaterum. Hemelytral completa. Pedes mediocres. femoribus anticis sat incrassatis, subtus multispinosi..

1. T. namaquensis STÁt. - Griseo-stramineus, remote albidosericeus; antemnis, capite posterius, thoracis fascia anteriore, corii apice ino maculisque duabus minutinsinis. una pone medinm marginis costalis, altera ad medimm marwinis apiralis, mesostethio, metastethio, rentre, femoribus anticis sulitus, posterioribus basi, nec non tibiis hasi apiceque nigricantibus; antennarum articulo tertio apicem versus fuartoque flavotestaceis; membrana vitrea; limbo posticu motistetlii limboque abdominis sordide albidis. f. Long. 4 , Lat. $1_{3}^{1}$ mill.

Teracrius namaquensis STAL. Öfv. Vet. Ak. Förh. 1858. 1. 317. 24.

Patria: Africa meridionalis occilentalis inter Eiklanms et lacum N Grami. (Mus. Holm.)

Autennac thorace paullo longiores, apicem versus leviter incrissatie. Thorax postice quam antice duplo latior. fere aeque lougns 
are posties latus, sat dense punctulatus. Hemelytrat punctata. Mrtasfethium postice parce punctulatum.

\section{OEDANCALA A. et S.}

Hist. des IIém. p. 258. (1813).

Corpus oblongum vel elongatum. Caput triangulare, subporrectum, al oculos immersum, tuberculis antemniferis extus leviter prominulis; bucculis parris, brevibus. Rostrum mediocre vel breviusculum, articulo primo capite breviore. Antenna mediocres, articulo primo omnimm longissimo, capitis apjicem multo superante, apicem rersus subsensim leviter incrassato, nee subito clavato. Oculi sat frominuli. Thorax trapezoideus, antrorsum angustatus, marginibus lateralibus obtusis. Scutellum triangulare. Hemelytra completa. Pedes mediocres, femoribus anticis incrassatis, subtus multispiunsis.

1. 0. pallidipennis STẢL. Elongata, ænescente-nigra; thorace, hemelytris, basi apiceque femorum, tibiis tarsisque griseoalbirlis; antennarum articulis primo et secundo limboque abdominis dilute testaceis; vittis duabus parum distantibus ante medium lineaque longitudinali utrimque laterali posteriore thoracis, macula minutissima marginis apicalis apiceque imo anguli apicalis corii nigricantibus; membrana vitrea. $q$. Long. $4_{\frac{1}{2}}$, Lat. 1 mill.

Ischnodemus pallidipennis STẢL. Freg. Eug. Resa. Ins. Hem. 1. 248. 72. (1858).

Patria: Terra capensis. (Mus. Holm.)

Antennie capite thoraceque ad unum vix longiores, artienlo primo secundo dimidio longiore. Caput dense punctatum. Thorax minus dense fusco-punctatus, antrorsum leviter anıustatus, aque longus ac postice latus, marginibus lateralibus pone medinm leviter sinuatis. Hemelytra parallela. Pectus sat dense punetatum. Venter lavis. Pedes antici exempli descripti mutilati.

\section{PACHYGRONTHA GERN.}

Silb Rev. ent. V. p. 152. (1837).

Pachygroncha SPIN. Gen. d'ins. artrold. p. 140. (1852).

Atractophora StäL. Öfv. Vet. Ak. Förh. 1853. p. 260.

Corpus valde oblongum vel elongatum. Caput porrectum subquadratum, ad oculos immersum, ante tubercula antennifera 
ab oculis sat remota, deflexum, anterius utrimque inter antennas carina longitudinali ralde elevata instructun, bucculis parvis, apicem capitis occupantibus. Rostrum perles auticos attingens vel paullo superans, articulo primo capite multo breviore. Antenne geniculatæ, corpore Iongiores, interdum fere duplo Inngiores, articulo primo omnium longissimo. apice leviter clavato, clava oblonga. Thorax trapezoideus. Scutellum triangulare, paullo longius quam latius. Hemelytra completa, parallela. Pedles mediocres, femoribus anticis incrassatis. subtus multispinosis.

1. P. quadripunctata SIGs. - - Pallide testaceo-straminea, subtus griseo-sericea; supra cum pectore distincte testaceo-Iunctata; capite subtus, pectore, abdomine femoribusque anticis subtus ohscure testaceis; macula minuta prope medimm marginis apicalis anguloque imo apicali corii nigris; antemus corpore multo longioribus. o?. Long. 12, Lat. $2 \frac{2}{3}$ mill.

Atractophora quadripunctata SIGN. Ann. ent. Sér. 3. V'llI. p. 948. 142. Pl. 14. fig. 4. (1861).

Patria: Madagasear. (Coll. Signoret.)

Antemne corpore multo longiores, articulo primo corpore dimidio nonnihil longiore, apicalibus tribus ad mnum dintincte breviore. Rostrum nonnihil pone coxis anticas extensum. Thorax distinete longior yuam la ior, ruga distinetissima marginum lateralium mganue longitudinali nedia, posterius evanescente, levibus. Scutellum rug: transversa arcuata anteriore mqaque longitudinali percurrente levibus instructum.

2. P. lineata Girur - Pallide testaceo-straminea. supra c'un pectore distincte fuscescente-punctata; capite subtus in medio, thorace intra margines laterales, angulis basalibus sentelli, margine apicali corii, excepta parte tertia interiore, mesosterno, vittis duabus dorsi abdominis et duabus ventris nee non femoribus anticis subtus nigris. Y. I nng. $7 \frac{1}{2}$, Lit. 2 mill.

Pachygrontha lineata Germ. in Silb. Rev. ent. V. p. 153. 72. (1837).

Pachygroncha lineola SPIN. Gen. d'ins. artroid. p. 141. (1852). Atractophora fusifemur STÅL. Öfv. Vet. Ak. Fürh. 1855. p. 34. 1. 


\section{Patria: Caffraria. (isius. Holm.)}

Rostrum coxas anticas subsuperans. Antenne corpori reque longie, articulo primo capite thoraceque ad unum vix breviore, tribus ultimis ad mum basali plus dimidio longioribus. Thorax paullo longior quam basi latior, ruga marginum lateralimm rugaque longitndinali media, per caput et scutellum extensa, distinctissimis, lavisatis, pallidis. Caput subtus et pertus griseo-sericea.

3. P. Lipumetata S'TAL. - Dilute testaceo-straninea, supra cum prectore distincte punctata; macula minutissima fere media marginis apicalis corii, metasterno vittaque abbreviata utrimque laterali ventris nigro-fuscis. \&. Long. $6_{\bar{\Xi}}$, Lat. $1 \frac{1}{3}$ mill. latria: Insula Mauritii. (Mus. Holm.)

$P$. limenter angustior. Rostrum nonuihil pone coxas antieas extensum. Antennac corpore paullo longiores, articulo primo capite th raceque ad mum sublongiore, secundo et tertio ad unum distincte nomulil breviore. Thorax aeque longus ac postice latus, ruga subtili marginum lateralium nee non ruga longitndinali media, ab apice vix ultria medinm extensi, lievibus, pallidis. Scutellum ruga longitndinali laevi hasin vix attingente, iustructum. Vitta obsoletissimal lateralis pectoris leviter infuscata.

\section{Subf. CYMIIDA S'TẢL.}

Conspectus generum.

1 (2). Tuberculis antenniferis apice extus antrorsum acutiuscule prominulis; articulo primo antemarum longo, capitis apicem multo superante. - Cymodema SPIN.

2 (1). Tubereulis antemiferis obtusis, apice extus haud prominulis; antemnarum articulo primo capite breviore, hujus apicem haud vel parum superante. - Oxycaremus FieB.

\section{CYMODEMA SPIN.}

Ess. Hém. p. 213. (1810).

Bedus StäL. Freg. Eug. Resa. Ins. Hem. p. 251. (1858).

Corpus valde oblongum. Caput subtransversum, lineis duabus impressis, curvatis, longitudinalibus instructum; lobis ante tubercula antennifera, apice extus acutiuscule prominula, leviter prominentibus; subtus sulco percurrente instructum, bucculis brevibus. Rostrum nonnihil pone coxas anticas extensum. An- 
tenna corpore breviores, anticulo primo incrassato, cappite vis breviore, hujus apicem longe superante, tertio omnium longissimo, ultimo fusiformi. Thorax trapezoideus, antrorsum nonnihil angustatus. Scutellum triangulare, latius quam longins, ruga elevata longitudinali instruetum. Hemelytra completil, apicem abdominis superantia, margine costali leviter rotumlato et dilatato. Pectus inter pedes sulco pereurrente instructum. Peden heses, femoribus inermibus.

Cymo aftine genus.

1. C. Mauritii STAL. - Testaceo-straminea, supra "um peetoren distincte punctata. hemelytris ventreyue falliclingibus, antennarum articulo ultimo, maculis duabus oblongis pone medium! thoracis margineque commissurali angusto clavi nigro-fuscis; rusula longitudinali antica thoracis nulla vel obsoleta; vitta laterali ventris dilute fusco-testaceal. ç. \&. Long. 4, Lat. 1 mill.

Bedus Mauritii StiL. Freg. Lng. Resa. Ins. Ilem. p. 251. Tab. III. fig. 4. (1858).

Patria: Insula Manritii. (Mus. Holm, et Coll. STAı.)

OXYCARENUS FEB.

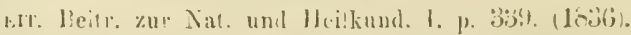

Slenggaster Haux. Wanz. Ins. 111. p. 15. (1835).

Corpus oblongum vel nounihil enngatum. Caput triangulare. porrectum, ante tubercula antennifera, obtusa et parum prominula, sat productum, hucculis basin capitis siejissimo attingentibus. Rostrum sat lougum, gracile. Thorax trapezoideus, medio leviter coarctatus, marginibns lateralibus obtusis. Scutellum triangulare, paullo latitis quam longrius. Hemelytra completa, abdomine longiora et latiora, ma rone costali recto, dilatato. Pedes mediocres. femoribus anticis incrassatis et subtus spinis pluribus amitis.

a. Capite thoracerue fere aque longis vel illo hoc paullo breviore.

1. 0. rufiventris Germ. - Dilute rufo-testaceus; antennis, rostro. capite, scutello, clavo, angnlo imn apirali corii, mesostethio, 
metastethio, apice abdominis pedibusque nigris; maculis pectoris ad coxas limboque postico metastethii albidis; limbo costali corii membranaque decoloribus, hyalinis; tibiis anticis interdum fusco-testaceis; ostiolis odoriferis Havo-albidis. ․ Long. +1-5, Lat. $1 \frac{1}{2}-2$ mill.

Stenogaster mufiventris Germ. in SILB. Rev. ent. V. p. 141. 48. (18:37).

Oxycarenus mefiventris FIEB. Rhynchotogr. 11. 42. 9. (1851). Patria: Caffraria. (Mus. Holm.)

Capnt, thorax, scutellum et prostethinm sat dense distineteque punctata. Caput thorace paullo brevins. Rostrum pone pedes posticos extensum. Antemuarum articulus primus c pitis apicem sequans. Hemelytri obsolete punctulata.

2. V. Vieberi Strif. - Niger, parce puberulus; corio parteque dimidia basali ventris dilute rufo-testaceis; corii margine costali membranaque decoloribus, hyalinis; angulo imo apicali corii nigro; pectoris maculis ad coxas limboque postico metastethii albidis; ostiolis odoriferis annuloque lato medio tibiarum posteriorum flavo-albidis. $\sigma^{7}$. $q$. Long. $3 \frac{1}{2}-4$, Lat. $1 \frac{1}{3}-1 \frac{1}{2}$ mill.

Oxycarcenus Fieberi Stal. Öfv. Vet. Ak. Förh. 1855. 1. 35. 1. Patria: Caffraria. (Mus. Holm.)

Statura precedentis et cum eodem quoat puneturam et formam partiuu roligruens.

3. O. albilipennis ŚTÁL. - Niger, puberulus; hemelytris albidohyalinis, clavo anguloque apicali corii nigris; ventre, exceptis limbis lateralibus parteque apicali, sanguineo; pectoris maculis ad coxas, ostiolis odoriferis annuloque tibiarum posteriorum albidis. क. Long. $4 \frac{1}{2}$, Lat. $1 \frac{1}{2}$ mill.

Oxycarcenus albidipennis STẢ. Öfr. Vet. Ak. Förh. 1853. p. 35.2 .

\section{Patria: Caffiraria. (Mus. Holm.)}

Statura præcedentium, quibus valde affinis.

4. O. cruralis STẢL. - Niger, griseo-puberulus; hemelytris griseis, angulo imo apicali corii nigro; annulo lato subbasali 
articuli secundi antemnamm apiceque fenorum flavo-testaceis; maculis pectoris ad coxas, limbo postico metastetlii, tibiis, excepta basi, tarsisque albidis. \&. Long. 4, Lat. I! mill.

Oxycarcuns cruralis STiL. Öv. Vet. Ak. Förh. 1856. p. 196. 7 .

l'atria: Terra capensis. (Mus. Holm.)

Statura preecolentimu. Caput, thorax, sentellum et peetus dense distincteque punctata. Antenuac articulo primo eapitis apicem subsuperante.

5. 0. tabidus STí. - Testaceo-albidus, renote puberulus; thorace posterius hemelytrisque sordide allidis. †. Long. 3, Lat. 1 mill.

Patria: Terra eapensis. (Mus. Iolm.)

Caput, thorax, soutellum et pertus dense distincteque punctata. Caput thorace uomihil brevins. Antenne articulo primo capitis apieem subsuperante. Clavus seriatim punctulatus.

ala. Capite thorace nonnihil longiore.

6. 0. maculatus Stal. - Niger; fascia prope basin rorii, limbo hasali membrance, limbo postico metastethii, macula parva al coxas posticas nee non medio tibiarum posticarum albidis. o. \&. Long. 5-6, Lat. $1 \frac{1}{2}-1 \frac{2}{3}$ mill.

Oxycarcenus maculatus STÅl. Öf. Vet. Ak. Förh. 1854. \}. 235. 1; Freg. Lng. Resa. Ins. Hem. p. 247. 69. (1858).

Patria: Terra capensis. (Mus. Holm.)

('ilput, thorax, scitellum et peetus sat dense distincte pinctatil. Antemuce articulo primo eapitis apiecen haud attingente. Rostrum longe pone medium, iuterdum ad apicem ventris extensum.

\section{Subf. RIIPAROCHROMIDA ŚTAL.}

Conspectus generum.

I ( $x$ ). Ocellis quam oculis magis distantibus, pone oculos in latterilus capitis positis; capite ad oculos laud immerso.

2 (3). Capitis parte postoculari brevi, retrorsum haud angustato. - Clevalla Sigs.

3 (2). Capite pone oculos sensim anenstate et collo cylindrico suffulto; thorace medio constricto, lobr antico angusto, marginibus lateralibus obtusis. -- P'uctye STal. 
4 (1). Ocellis quam ocmlis minus distantibus.

5 (6). Rostro brevi, crasso, articulis duobus basalibus brevissimis, annuliformibus, tertio longissimo. - Panchace STí.

6 (5). Rostro gracili, articulis basalibus elongatis.

7 (10). Oculis longe a basi capitis remotis, hoc ovali, interdum collo cylindrico suffulto.

8 (9). Capite collo destituto. - Hercus StäL.

9 (8). Capite collo cylindrico instructo. - Myodocha Latr.

10 (7). Capite ad vel fere ad oculos immerso.

11 (22). Thorace constricto, marginibus lateralibus obtusis vel convexis, raro carinatis, numquam foliaceo-explanatis, sinu laterali nec carinato nec membrana repleto.

12 (13). Antennarum articulo primo capite longiore et lujus apicem multo superante; capite ad oculos immerso; rostro pedes intermedios attingente, articulo primo pone oculos vix extenso; thorace longiore quam latiore, distincte constricto, lateribns convexis, marginibus lateralibus subcarinatis, lobo postico utrimque in denticuInm obtusum prominulo; scutello acute triangulari; hemelytris completis, parallelis; pedibus longis, gracilibus, femoribus anticis levissime incrassatis, subtus per totam longitudinem biseriatim spinosis; tarsis posticis articulo primo apicalibns duobus ad unum triplo longiore; corpore elongato. - Narbo STẢL.

13 (12). Antennarum articulo primo capite breviore.

14 (21). Thoracis marginibus lateralibus obtusiusculis vel valde convexis, haud carinatis.

15 (18). Thoracis lobo antico lobo postico triplo vel quadruplo longiore; tibiis anticis marium subtus dente armatis.

16 (17). Capite ad oculos harid immerso, longiore quam latiore; articulo primo antennarum capitis apicem longe superante. - Criemodus H. ScH.

17 (16). Capite ad oculos immerso, triangulari, subæquilatero; antennarum articulo primo capitis apicen vix superante. - Fontejus STÅL. 
Is (15). Thoraris lohis aeque longis vel antico postico haud plus quam duplo longiore, raro paullo breviore.

19) (20). Capite inter oculos et insertionem antennarum antrorsum leviter angustuto, maguo, thoracis lobo postico hatul angustiore, pone oculos subito coarctato; thorace sat fortiter constricto. - Gyudes STÁL.

20 (19). Capite thoracis lobo postico angustiore. - Plociomera SAY.

21 (14). Marginibus lateralibus lobi antici thoracis carinatis. Polycrates STAL.

22 (11). Thorace rarissime subconstricto, sinu laterali tunc carinato vel membrina repleto, marginibus lateralibus sapissime distincte carinatis vel foliaceo-explanatis.

23 (32). Venis membranæ longitudinalibus vena transversa haud conjunctis.

24 (25). Thoracis apice capiteque cum oculis æque latis, illius marginibus lateralibus obtusis, ad apicem incisis; tibiis anticis marium subtus dente armatis; antennarum articulo primo brevi, capitis apicem vix superante; articulo primo rostri pone oculos subjroducto; tarsis posticis articulo primo apicalibus duobus ad unum duplo longiore. - Euander STȦı.

25 (24). Thoracis marginibus lateralibus prope apicem integris, nec incisis.

26 (31). Fenoribus anticis subtus spinosis.

27 (28). Tarsis posticis articulo primo apicalibus duobus arl unum nomihil longiore; antennarum articulo primo capitis apicem aquante; capite ad oculos immerso. Phoroneus S'TAL.

$28(27)$. Tarsis posticis articulo primo apicalibus duobus ad unum fere duplo longiore vel ultra.

29 (30). Antennarm articulo primo capitis apicem haud attingente; femoribus posticis apicem abdominis superantihus. - Pocantius Stil. 
30 (๕9). Antennarun articulo primo capitis apicen plus minus longe superante; femoribus posticis apicem abdominis interdum attingentibus, numquan superintibus. - Beosus $\Lambda$. et $\mathrm{s}$.

31 (26). Femoribus anticis inermibus. - Androgeus Stät.

32 (23). Venis membrane tribus exterioribus venula transversa. conjunctis. - Lethaus DALL.

Genera mihi cognita extraeuropea omnia in conspertu memoravi.

\section{CLERADA SIGA.}

Malleard. Nutes sur l'ile de la Rimnion. Ins. p. 28.

Corpus anguste ovatum. depressum. Caput porrectum, thorace paullo longius, ad oculos haud immersum, parte postoculari brevissime cylindrico, utrimque pone aeulos ocellos ferente. Rostrun pedes intermedios attingens, gracile, articulis primo et secundo ad unum capite longitudine fere aqualibus. Antennse articulo primo capite breviore, hujus apicem tamen superante. Thorax transversus, trapezoideus, antrorsun valde angustatus, marginibus lateralibus acutis, reflexis, medio leviter sinuatis, margine basali recto. Scutellum triangulare, subæquilaterum. Hemelytra completa, margine costali leviter rotundato. Pelles mediocres, femoribus inermibus, anticis vix incrassatis, tarsis posticis articulo primo apicalibus duobus ad unum longitudine fere æquali.

Situ ocellorum maxime insigne genns, quoad habitum $H_{1-}$ malodemam simulans.

1. C. apicicornis SIGN. - Plus minus obscure fusco-ferruginea, marginibus imis lateralibus thoracis, limbo lato exteriore indeterminato corii vittisque duabus vel disco ventris pallidioribus; antennis fuscis, articulo ultimo albido; rostro pedibusque pallide testaceo-flavescentibus; capite pone medium subtiliter, thorace, scutello hemelytrisque distincte et sat dense punctulatis. $\sigma^{7}$. ․ Long. $6-7$, Lat. $2 \frac{1}{2}-3$ mill.

Clerada apicicornis Sign. in MaILLaRd. Notes sur l'ile de la Réunion. Ins, p. 28. Pl. 20. fig. 8. 
Patria: Insula Réunion |Bourbon] (Coll. SigsoreT); Bengalia Asies. (Mus. IIolm.); Insula S:cti Thomse et La Guayra Americie. (Coll. ŚIgnoret); Cuba. (Coll. ŚtàL.)

\section{PANCHAL STAL.}

Corpus anguste ovatum, ralde depressum. Caput porrectum, thorace fere longius, ad oculos inmersum, ante tubercula antennifera, ad oculos appropinquata, breviter conico-productum; bucculis pereurrentibus, levissime elevatis. Ocelli ad oculorum angulum posticun positi, fere sque longe ac oculi distantes. Rostrum breve, pedes anticos attingens, depressum, articulis primo et presertim secundo brerissimis, hoc annuliformi, tertio omnium longissimo. Antenne articulo primo capitis apirem paullo superante. Thorax transversus, trapezoideus, marginibus lateralibus acutis, leviter reflexis. Scutellum subxquilaterum. Hemelytra completa, margine costali pone medium rotundato. Pedes mediocres, femoribus anticis land incrassatis, inermibus; tarsis posticis articulo primo apicalibus duobus ad unum vix longiore.

Cleradce affine et quoad habitum simillimum genus, situ ocellorum structuraque rostri distinctissimum.

I. P. Iepressa STÁ. - Ferruginea; thorace pone medium marginibusque angustis lateralibus, hemelytris, rostro pedibusque pallide ferrugineo-flavescentibus; membrana infuscata, venis pallidis. Q. Long. 53 , Lat. 2 mill.

Patria: Sierra Leona. (Mus. Holm.)

Clerade apicicorni sat similis. Supla cum pectore distincte punctulati. Thorax postice yuam antice plus cuplo latior, cruciatim levissime impressus, marginibus lateralibus medio leviter sinuatis. Antennie articulo secundo primo vix longiore, articulis duobus ultimis in exemplo descripto mutilatis.

\section{PLOCIOMERA SAY.}

Ptochiomera SAY. New Harm. Ind. Dec. 1831. Plociomerus A. et S. Hist. Jes Hem. p. ¿55. (1843).

Paromius Fieb. Eur. Hem. p. 45 et 170. (1861).

Corpus elongatum vel oblongum. Caput triangulare, tuberculis antenniferis obtusis. Rostrum longitudine varians. An- 
tenna articulo primo omnium brevissimo. Thorax medio vel pone mediun plus minus constrictus, apice collari instructus, marginibus lateralibus convexis. Scutellum triangulare. IIemelytra completa, parallela. Pedes mediocres; femoribus anticis incrassatis, subtus spinosis; tarsis posticis articulo primo apicalibus duobus ad unum dimidio vel duplo longiore.

a. Corpore sat elo suto; thorace pone malinm leviter constricto; hemelytris pallidis, fusco-punctulatis, impictis; scutello multo longiore quam lations: femoribus antieis sultus spinis compluribus distinctis armatis.

Paromius Fieb.

b. Rostro panllo pone coxas posticus producto, articulo primo capiti longitudine repuali, pone ocu os extenso.

1. P. apicata STÁL. - Obscure fermginea, antennis pallidioribus; marginibus lateralibus maculisque duabus parvis obsoletis mediis basalibus lobi postici thoracis, hemelytris pedibusque pallide sordide stramineis vel subferrugineo-stramineis; hemelytris fusco vel ferrugineo-punctulatis, corio fere ad medium marginis apicalis macula minutissima nigricante notato; capite subtus in medio, sternis, ventris vitta ante medium, interdum etiam apud marem vitta utrimque laterali nigris. $\sigma^{7}$. 9 . Long. 9-10, Lat. 2 mill.

Rhyparochromus apicatus STÅL. Öfv. V'et. Ak. Förb. 1855. p. 34. 10.

Patria: Caffraria, Insula Mauritii. (Mus. Holm. et Coll. STÅL.)

Longitudine rost i insignis species. Antennæ unicolores, articulo secundo primo paullo plus quam duplo longiore, tertio secundo nonnihil breviore. Thorax lobo postico punctulato

bb. Rostro pone coxas anticas haud vel vix producto, articulo primo capite breviore, pone oculos haud rel vix extenso.

c. Antennis pallide fermoineo-favescentilus, apicem versus obscurioribus.

2. P. proxima Dall. - Nigricans, raro fusco-ferruginea, griseosericea; thoracis collari loboque postico, antennis, rostri articulis primo et secundo, acetabulis, limbo postico prostethii 
rt metastethii pedihusigue sordide stramineis vel pallinle ferrugineo-stramineis; abdomine ferrugineo, basi vittaque laterali interdum nigris. $\sigma$. ㅇ. Long. 5-8, Lat. $1-1 \frac{2}{3}$ mill.

hhyparochromus proximus DALL. List of Hem. II. p. 579. 51. $(18.32)$.

Rhyparochromus natalensis S'TAL. Öf. V'et. Ak. Förh. 1855. 1). 34. 12.

Plociomerus nalizoides SIGx. Ann. ent. Sér. 3. VIII. 1. 951. 149. (1861).

Patria: Africa meridionalis, Sierra Leona. (Mus. Holm.); Madagascar. (Coll. SignoRET.)

Statura priecedentis, sed minor, capite minus acuminato rostroque breviore distinctissima. Antenna irticulo secundo basali circiter duplo longiore, tertio secundo nomnihil breviore. Thorax lobo postico puncetulato, angulis posticis maenlisque duabus parvis basalibus pallidioribus. Hemelytra fusco vel ferrugineo-punctulata, prope medium marginis apicalis macula minutissinta fusca vel nigra notata; membrana sordida, hỵalina.

spceinen e Sicilia missum, quod cum descriptione Paromï nabiformis Fres. quadrat, a seciminibus aficanis $P$. proxime vix sperifice liffert.

\section{cc. Antennis nigris, articulo primo flavo-fermgineo.}

3. P. attenuata DALL. - Nigra, parce griseo-sericea, antennarum articulo primo, thoracis collari loboque postico, acetabulis, margine postico prostethii et metastethii, ventris limbo maculisque nonnullis lateralibus disci nec non femoribus ferrugineis vel flavo-ferrugineis; femoribus anticis subtus, posterioribus 'xtus et intus vel, basi et apice exceptis, totis nigris; hemelytris, tibiis tarsisque sordide stramineis vel ferrugineo-stramineis. $\sigma^{7}$. ․ Long. 7-8, Lat. $1_{3}^{2}$ mill.

Rhyparochromus attenuatus DALL. List of Hem. II. P. 579. 52. (1852).

Rhyparochromus paganus STÀL. O̊fv. Vet. Ak. Förh. 1855. p. 34. 11 .

Patria: Caffraria. (Mus. Holm.)

Statura P'. proxima, cui, excepto colore anteunar um, simillima. Antenna articulo sceundo primo paullo plus quam duplo longiore, 
tertio secundo tertia rel quarta parte breviore, nltimo in ferruginem obsolete vergente. Thorax lobo postico punctulato, melio sepissimc linea loneritudinali nigra notato, m roinibus lateralibus maculisque duabus basalibus mediis pallidis. Hemelytra fusco-fermanco-punctulata, prope medium marginis aporalis macula minutissima niorrat satpissime notata; membraua inter venas pallidissime infiscata.

aa. Corpore relde olulongo rel leviter elongato, henelytris fusco-pictis vel punctis, in maculas acervatis, instructis, rel limbo apicali corii fusco.

d. Hemelytris palli.is, subtiliter spursim fuscon-punctulatis, margine apicali coris nigricante.

4. P. parrula DALL. - Nigra, antennis, limbo ventris pedibusque pallicle testaceo-flarescentibus; articulo ultimo antemnarum, femorihus anticis, basi apiceque pxceptis, sæpe etiam anmulo lato apicali femorum posteriorum nigris; apice imo scutelli, hemelytris angulisque posticis metastethii sordide albidis, illis fusco-punctulatis, rorii limho costali maculaque parva prope angulum anteriorem lavibus, margine apicali nigricante; lobo postico thoracis interdum obscure ferrugineo, fusco vel nigromaculato; membrana griseo-hyalina, inter venas interdum infuscata. $\sigma^{7}$. . Long. 4, Lat. 1 mill.

Var. a. - Margine angusto apicali corii nigro.

Var. b. - Margine apicali corii, versus angulum apicalem sensim dilatato, nigro.

Rhyparochoromus parvulus DALL. List of Hem. II. Р. 576. 45. (1852).

Plociomerus Amyoti GuÉr. in SAgra. Hist. fis. de Cuba. VII. (1857).

Rhyparochromus (Plociomerus) vinulus S'TẢL. Bidr. Rio Jan. Hem. I. p. 40. 6. (I860).

Patria: var. $a$. Rondebosch Terra capensis; var. $b$. Carolina Americæ borealis, Rio Janeiro Brasiliæ, Cuba, Java. (Mus. Holm.)

Specimina tria ex Africa meridionali a Dom. WAHLberg reportata a speciminibus numerosis americanis, quæ examinavi, haud differunt nisi margine apicali nigro corii angustissimo. 
dd. Hemelytris pallidis, fermuineo vel fusco-punctulatis, margine apicali concolure.

5. P. afra STÁL. - Nigricans, griseo-sericea; antennis, rostro pedibusque sordide stramineis; antennarum articulo ultimo ammloque obsoleto subapicali femorum fuscescentibus; thoracis lobo postico hemelytrisque sortide albidis, ferrugineopunctatis, corio intus seriatim punctato, limbo costali maculaque parra oblonga prope angulun interiorem laevigatis, maculis parvis, una prope basin, una costali pone medium unique ante maculam illam levem, nec non angulo imo apicali ferrugineo-fuscis; acetabulis rentreque obscure ferugineis; membrana griseo-liyalina, fusco-nebulosa. o'. Long. 5, Lat. 14 mill.

\section{Patria: Caffraria. (Mus. Holm.)}

Statura fere $P$. fracticollis. Caput paullo longius quam $\mathrm{cum}$ oculis latins. Antenne articulo primo capitis alpicem distincte paullo superante. Rostrum articulo primo pone oculos subproducto. Thorax medio distinete constrictus. Femora antica leviter incrassata, subtus prope apicem spinnlis, una distincta et nonnullis minutissimis, obsoletis, instructa.

6. P. capucina STAL. - Nigricans, griseo-sericea; antennis, rostro pedibusque pallide sordide stramineis, antennarum articulo primo et quarto basique ipsa tibiarum fuscis; thoracis lobo postico ferrugineo, fusco-punctato et nebuloso; hemelytris sordide albidis, fusco-ferrugineo-punctulatis, corii macula ad angulum interiorem limboque costali lævigatis, macnlis minutis costalibus, una ante, altera pone medium posita, macula ante maculam illam lævem anguloque imo apicali fuscis; membrana grisea, inter venas infuscata. $\sigma^{7}$. ㅇ. Long. $3-3 \frac{1}{2}$, Lat. 1$1 \frac{1}{5}$ mill.

\section{Patria: Insula Bourbon. (Coll. Signoret et StåL.)}

Precclenti maxime affinis, minor, articulo primo antenuarum fusco, capitis apicem vix superante, articulo primo rostri pone oculos haud exte so direregit.

P. oblongw SrÂL, c Mexico, haud dissimilis, angustior, antennis longioribus, thorace fere in uedio, nec paullo pone mediun constrieto, differt. 


\section{POLYCRATES STTÅ.}

Corpus nonnihil elongatum. Caput parviusculum, triangulare, subæquilaterum, ad oculos sat prominulos immersum. Rostrum inter pedes anticos productum, articulo primo pone oculos haud extenso. Antennæ corpore multo breviores, articulo primo capitis apicem subsuperante. Thorax ante partem tertiam posticam sat constrictus, margine basali subrecto, lobo antico convexo, magno, marginibus lateralibus rotundatis et distincte carinatis. Scutellum acute triangulare. IIemelytra completa, pone mediun corii levissime ampliata. Pedes mediocres, femoribus anticis validis, subtus spinis compluribus armatis; tibiis anticis curvatis; tarsis posticis articulo primo apicalibus duobus ad unum circiter dimidio longiore.

Rhyparochromo affine genus, thorace longiore, pone medium sat fortiter constricto, margine ojusdem basali recto, femoribusque anticis multispinosis differt.

1. P. cousutus Germ. - Niger vel fusco-ferrugineus, parce et sat longe fusco-pilosus; hemelytris, apice imo femorum anticorum, pedibus posterioribus tibiisque anticis testaceo-albidis; hemelytris fusco-punctulatis, corio pone medium migricante, prope apicem macula transversa, triangulari, marginem costalem tangente, albida notato; membrana fuscescente, apice interdum macula obsoleta pallida notata; femoribus posticis prope apicem annulo, latitudine variabili, nigricante ornatis. ${ }^{7}$. ㅇ. Long. $5 \frac{2}{3}-7$, Lat. $1 \frac{3}{4}-2 \frac{1}{3}$ mill.

Pachymerus consutus Germ. in Silb. Rev, ent. V. p. 139. 44. (1837).

Rhyparochromus curvipes STÅL. Öfv. Vet. Ak. Förh. 1855. p. 34. 8 .

o. Major; femoribus anticis crassissimis, subtus spinis tribus magnis et pluribus parvis armatis; tibiis anticis apice subtus leviter ampliatis, parte ampliata tridenticulata, denticulo superiore distinctiore.

Hemiptern africann. II. 
q. Minor; fenoribus anticis minus incrassatis; tibiis anticis apice subtus vix ampliatis, ibidem inernibus.

Patria: Terra capensis ad Rondebosch, Caftruria. (Mus. Holm.)

Antennae articulis secundo et tertio fere aeque longis, quarto illis paullo longiore. Caput, thorax et scutellum sat dense, thoriax posterius distinetius, punctulata. Lobus anticus thoracis lobo postico hand vel vix angustior, c pite fere duplo latior, apire subito valde rotundato-angustatus.

\section{PIIORONEUS STTAL.}

Corpus oblongum. Caput triangulare, apuilaterum, ad oculos immersum. Rostrum pedes intermedios attingens, anticulo primo pone oculos haud producto. Antenna corpori dimidio longitudine fere aquales, articulo primo capitis apicem aquante. Thorax pone medium transversim levissime inpressus, ante inpressionem levissine convexus, xque longus ac latus, margine basali recto, marginibus lateralibus carinatis, rectis, antice rotundatis. Scutellum paullo longius quam latius. Hemelytra completa, parallela. Pedes mediocres, femoribus anticis sat incrassatis, subtus spinis duabus vel tribus majusculis et pluribus minutissinis armatis; tibiis anticis subcurvatis; tarsis posticis articulo primo apicalibus duobus ad unum nonnilil longiore.

Rhyparochromo affine genus.

1. P. Crassifemur STAL.- Niger, glaber; anteunis, rostro, tibiis tarsisque dilute Haro-testaceis, articulo antennarum ultimo obscuriore; thorace posterius, apice scutelli, hemelytris, macula pone, medium marginum lateralium prostethii, angulis posticis metastethii femoribusque posticis a basi ad medium sordide stramineo-ilbidis; thorace posterius hemelytrisque fusco-ferrugineo-punctatis; macula angulorum posticorum thoracis, interdum deficiente, corii macula transversa mijuscula pone medium posita, intus postice ramulos duos versus margineın apicalem enittente, limboque apicali versus angulum apicalem nigris; inembrana fusca, inacula minutissina ad angulum apicalem corii maculaque apicali griseis; femoribus 
posticis a basi al vel ultra medium albidis. ơ ㅇ. Long. $5 \frac{1}{2}$, Lat. 2 mill.

Rliyparochromus crassifemur STẢs. Öfr. Vet. Ak. Förh. 1855. p. 34. 9.

Patria: Citfraria. (Mus. Holm.)

Caput sat dense punctulatum. Thorax apice capite cum oculis paullo ingustior, marginibus lateralibus paralle is, anterius rotundatis, lobo antico latera rersus obsoletissime punctulato, lobo postico distimete punctulato. Sen ellum obsolete punctulatum. Hemelytra punctis in series longitudinales ordinatis. Peetus remote distincteque punctulatum. Venter obsolete siricens.

\section{POEANTIUS STÅ.}

Corpus paullo elongatum. Caput deflexum, ad oculos immersum, triangulare, rix longius quam latius; bucculis pone medium capitis extensis, parallelis, postice subito conjunctis. Rostrum inter pedes intermedios extensum, articulo primo pone oculos haud producto. Antennæ corpore nonnilil breviores, articulo primo capitis apicem laud attingente. Thorax longior quam latior, pone medium transversim levissime impressus, marginibus lateralibus carinatis. Scutellum longius quam latius. Hemelytra completa, parallela. Pedes longiusculi, femoribus anticis incrassatis, subtus spinulis pluribus armatis; femoribus posticis apicem abdominis superantibus; tarsis posticis articulo primo apicalibus duobus ad unum fere triplo longiore.

Beosu affine genus.

1. P. nigro-pictus STAL. - Niger; annulo lato ad basin articuli quarti antemnarum, carina marginum lateralium fasciaque angusta pone medium thoracis, acetabulis, limbo postico prostethii et metastethii basique femorum posteriorum dilute sordide stramineis; thoracis parte posteriore pone fasciam hemelytrisque sordide albidis, illa densiuscule distincteque, his parce obsoleteque fusco-punctulatis; clavi vitta, corii vitta ad suturam clavi, fascia lata pone medium limboque apicali nigris; membrana sordide albido-hyalina; articulo primo antennarum, apice femorum anticorum tibiisque anticis sordide flavo-testaceis. o’. Long. 6, Lat. $1_{4}^{3}$ mill. 


\section{4}

Rhyparochromus nigropictus S'TAL. Öfv. Vet. Ak. Förh. 1855. p. 33. 7 .

\section{Patria: Caffraria. (Mus Holm.)}

Thorax antrorsum nomihil angustatus, apice capite cum oculis nonnikil angustior, marginilus lateralibus pone mcdium levit: $\mathrm{r}$ sinuatis, margine antico in flaro-fermgineum obsolete vergente. Tibia antice subtus spinnlis compluribus armate.

\section{BEOSUS A. et $\mathrm{S}$.}

Beosus A. ('t S. Hist. des Hém. p. 2j4. (1843).

Dieuclies Dohrs. Ent. Zeit. Xxi. p. 159. (1860).

Ischnotarsus FIER. Eur. Hem. p, 50 et 191. (1861).

Rhyparochromus Fieß. Eur. Hem. p. 50. et 193. (1861).

Beosus Fieb. Fur. Hem. p. 51 et 196. (1861)`).

Corpus oblongum vel nonnilil elongatum. Caput triangulare, æquilaterum vel nonnilhil longius quam cum oculis latius, ad vel fere ad oculos immersum. Rostrum pone pedes anticos productum, articulo primo pone oculos interdum extenso. Antennæ articulo primo capitis apicem attingente vel plus minus longe superante. Thorax marginibus lateralibus totis acutis, foliaceo-explanatis vel alte carinatis. Scutellum longius quam latius. Hemelytra completa. Pedes mediocres, femoribus anticis sæpissime incrassatis, subtus spinosis, posticis apicem abdominis haud superantibus, tarsis posticis articulo primo apicalibus duobus ad unum duplo longiore vel ultra.

a. Thoracis marginibus lateralibus disti.cte explanatis, land vel levissime sinuatis.

b. Clavo regulariter seriatim punctuto, punctis sparsis destituto; antennarum articulo primo capite plus dimidio breviore, ejusdem apicem paullo superante.

c. Thoruce nigricante, marginibus lateralibus parteque posteriore dilute griseo-stramineis; corio in angulo interiore macula nigra notato; corpore anguste ovali vel oblongo.

-) Obs. Beosus FiEB. - Rhyparochromus FiEB.

Beosus A. et $\mathrm{S}$. = Ischnotarsus. FЕв. = Jieuches DoHR.

Hegolonotus ГіЕв. = Rhyparochromus CiRT. 
1. B. apicalis DALL. - Anguste ovalis, obscure ferrugineus vel niger; antennis rostroque griseo-ferrugineis; thoracis marginibus lateralibus explanatis, margine angusto antico parteque posteriore, scutello pone medium, hemelytris, acetabulis, margine laterali prostethii, margine angusto postico segmentorum omnium pectoris pedibusque dilute griseo-stramineis; femoribus anticis nigris, supra ferrugineo-flavescentibus; thorace scutelloque posterius nee non hemelytris ferrugineo-fuscopunctulatis, corio in angulo interiore macula irregulari nigra notato; membrana fusca, apice sordide albida. $\sigma^{7}$.. Long. $7-8 \frac{1}{2}$, Lat. $3-3 \frac{1}{2}$ mill.

$\sigma^{7}$. Thorace fere aeque longo ac lato, apice et intra margines laterales explanatos distincte punctulato; tibiis anticis distincte curvatis, subtus prope apicem dente armatis.

Rhyparochromus turyidifernur STÅL. Öfv. Vet. Ak. Förh. 1855. p. 32. 1.

․ Thorace nomnihil latiore quam longiore, apice et intra margines laterales explanatos obsolete punctulato; tibiis anticis basin versus levissine curvatis, subtus prope apicem inermibus.

Rhyparochromus apicalis DALL. List of HIen. II. p. 562. 6. (1852).

Rhyparochromus nigro-maculatus STÅL. Öfv. Vet. Ak. Förh. 1855. p. 33. 2.

Patria: Caffraria, Eikhams Africe meridionalis occidentalis. (Mus. Holm.)

B. Pini latior, thoracis marginibus lateralibus pallidis latioribus, femoribus anticis crassioribus, subtus in latere anteriore spinulis minutis pluribus et spinis duabus vel tribus majoribus armatis et cateris divergens. Thorax apice capiti cum oculis latitudine æequalis, marginibus lateralibus anterius sat rotundalis, margine antico late sinuato. Series dua punctormm interiores c'avi medio valde appropinquatre, media curvata, in medio a sutura clavi sat remota. Coxæ anticie spina armate.

cc. Thorace nigro, pone medium fascia interrupta albida ornato; corpore paullo elongato.

2. B. albo-fasciatus STג̇. - Niger; thorace fascia interrupta, pone medium posita, ad margines laterales leviter ampliata, 
hemelytris ante medium, maculis duabus prope apicem corii, angulo basali interiore maculisque nonnultis parvis sparsis membranx, acetabulis, fascia basali prostethii limboque apicali metastethii albidis; hemelytris ante medium longitrorsum nigro-lineatis; articulo primo antennarum testaceo; tibiis anticis in fusco-testaceum vergentibus. o’. Long. 6, Lat. 2 mill.

Patria: Terra capensis. (Mus. Holm.)

Statura fere B. notati DALI. Articulus ultimus antennarum in exemplo descripto mutilatus. Thorax antrorsum scusim nomilil angustatus, aque longus ae basi litus, antice capite vix la ior, remote subtiliterguc, postice paullo densius et distinctius punctulatus, malginibus lateralibus leviter explanatis, medio vix simuatis, antice leviter rotundatis, margine postico latissime sinuato. Ilemelytra in parte dimidia interiore distincte striato-punctulata, in parte exteriore remote subtiliterque subseriatim punctulata. Femora antica sat incrassata, subtus spinis tribus distinctis armata. Tibie antica sulycurvie.

bb. Clavo al margines laterales interdum seriutim functato, disco inter series sparsim punctato.

d. Corpore anguste ovali vel oblongo; antemarum articulo primo capite breviore, hajus apicen attingente vel numihil superante; thorace pone medium limboque laterali, sat explanato, nec non hemelytris sordide furo-allidis; lineola, interdum curcata, ad basin marginum lateralium thoracis posita et margines ipsos al partem occupante, macula parea pone medium marginis costalis apiceque anguli upicalis corii fuscis rel vigris; muryine apicali corii concolure; angulis anticis thoracis oculos tangentibus.**)

3. B. caffer StẢL. - Oblongo-ovalis, finsco-ferrugineus, subtus parce griseo-sericeus; antennis, rostro pedibusque pallicle ferrugineo-Havescentibus, articulo ultimo antemarum, basi excepta, fuscescente; thoracis marginibus lateralibus explanatis parteque dimidia fostica, scutcllo, hemelytris, marginibus lateralibus et postion prostethii, margine postico metastethii

-) Ad hanc divisionem etian pertinet B. sordidus Fabr., cujus exemplum, licet vix recte, e Senegallia misit SIgnoreT; hee species Indiam Orientalem inhabitat. 
aretabulisque sordide albidis; thorace postice, scutello hemelytrisque ferrugineo-punctatis; macula ante medium marginum lateralium marginibusque lateralibus thoracis postice, macula parva pone medium marginis costalis apiceque anguli apicalis corii fuscis; membrana griseo-hyalina, minute fusco-conspersa. 오. Long. $5 \frac{1}{4}$, Lat. 2 mill.

Rhyparochromus caffer STȦL. Öfr. Vet. Ak. Förh. 1855. p. 33.3. 3.

Patria: Caffraria. (Mus. Holm.)

B. I. albo similis, antennarum articulo prino breviore, concolore, nee fusco, thorace breviore, postice latiore pedibusque impictis differt. Antenne rorpore nomilit breviores. altienlo primo eapitis apicern vix superante, eoncolore. Thorax transversus, antrorsun angrustatus, postice quan antice vix duplo latior, margine apicali recto, capite cum oculis vix latiore, marginibus lateralibus anterius leviter rotundatis, angulis anticis h ud prominulis, rotundatis. Corium intus subseriatim punctatum, margine costali lievi. Femora antica nonnihil incrassata, subtus pone medium spina distincta et spinulis nonnullis parvis armata. Tibie anticie recte.

4. B. transversus SigN. - Oblongo-ovalis, niger, in ferrugineum vergens; antennis, rostro pedibusque pallide fermgineo-flavescentibus; antemarum articulo tertio apicem versus femoribusque anticis ante medium in fusco-ferrugineum vergentibus; maculis duabus minutis transversis marginis antici, marginibus lateralibus explanatis parteque dimidia postica thoracis, limbis lateralibus scutelli pone medium, hemelytris, limbis lateralibus et postico prostethii, nec non angusto postico metastethii acetabulisque sordide flavo-albidis; thorace scutelloque posterius hemelytrisque ferrugineo-punctatis; macula media marginum lateralium marginibusque lateralibus thoracis postice, macula costali pone medium anguloque apicali corii nigricantibus; membrana grisea, minute fusco-conspersa. q. Long. 5논, Lat. 2 mill.

Rhyparochromus transversus Sign. Ann. ent. Sér. 3. VIII. p. 950.147 . (1861).

Patria: Madagasear. (Coll. SignoRet.) 
B. cuffro valde aftinis, auteunarum articulo primo paullo longiore, thorace breviore, antrorsum minus angustato, anticc latiore, marginc, antico capite panllo latiore, angulis anticis nomnilil prominulis scutelloque magnam ar partem nigro differt. Articulus ultimus exempli deseripti mutilatus.

dd. Corpore oblongo vel nonnihil elongato; antennarum articulo primo capitis apicem semper et sapissime longe superante; thoracis marginibus lateralibus pallidis ante medium macula fusca destitutis; hemelytris sapissime pallido fuscoque variis, raro pallidis et maculis fuscis vel nigris destitutis, macula parva pone medium marginis costalis semper nulla, margine apicali corii supissime fusco vel nigro.

e. Mesosterno spinis luabus validis armato.

5. B. mucronatus STÅL. - Elongatus, nigricans; antennis, rostro, thoracis marginibus lateralibus explanatis, parte basali excepta, nec non maculis duabus parvis obsoletis posterioribus, scutelli apice imo, hemelytris, marginibus lateralibus prostethii, margine postico metastethii, acetabulis pedibusque sordide pallide stramineis; hemelytris fusco-punctulatis; corii macula magna pone medium margineque apicali nigris; membrana fusca, macula apicali pallidiore. o’. Long. 11, Lat. 3 inill.

Patria: Nubia superior. (Mus. IIolm.)

Statura B. albo-striati. Antenne articulo primo capite paullo breviore, hujus apicem longe supcrante, articulo quarto infuscato, basi albido-annulato. Rostrum articulo primo poue oculos paullo extenso. 'Thorax nonuhil I ugior quam basi latior, antrorsum leviter anzustatus, apice capiti latitudine vix acyualis, pouc medium transversim leviter impressus, posterius punctulatus, marginibus lateralibus antice nomulhil rotumdatis, angulis anticis haud prominulis. Hemelytra fusco-punctulata. Coxie antice spimula amatie. Femora antica modice incrassata, subtus per totan longitudinem hiscriatiun distincte multispinosa. Tibie antice subtus denticulis pluribus armate.

ee. Mesosterno inermi.

6. B. albo-striatus FABR. - Elongatus, niger; antennis, rostro, thoracis margine angusto antico interrupto marginibusque lateralibus explanatis ab apice ultra medium, scutelli maculis duabus parvis mediis apiceque, hemelytrolum lineolis longi- 
tudinalibus sparsis interioribus, margine çostali ante medium maculaque subapicali majuscula marginali corii, limbo laterali prostethii, margine apicali angusto met sstethii, maculis oblongis marginalibus ventris pedibusque pallide sordide flavoalbidis; antennarum articulis apice obscurioribus, ultimo fusco, basi albido-annulato; membrana fusca, venis prope basin lineola pallida notatis; femoribus anticis pone medium, posterioribus apice nigris. \&. Long. 1I-I21, Lat. 3-31 mill.

Lygacus albostriatus FABR. Syst. Rliyng. p. 229. 122. (I803).

Rhyparochromus albostriatus DALL. List of Ilem. II. p. 567. 21. (1852).

Patria: Senegal, Sierra Leona, Calabar, Africa meridionalis occidentalis. (Mus. Holm., Coll. A. Dohrs et Signoret.)

Antenna articulo primo capitis apicem multo superante. Thorax vix longior quam basi latior, antrorsum angustatus, apice capiti cum oculis latitudine sequalis, postice interdum pallidus, dense acervatim nigro-punctatus. Coxae antice spina armate. Femora antica distinete incrassata, subtus spinulis parvis compluribus et prope apicem spina majore armata.

7. B. ammulatus Sign. - Niger; annulo subbasali articuli quarti antennarum, thoracis marginibus lateralibus explanatis, apice et parte postica exceptis, scutelli maculis duabus ante medium positis apiceque, lineolis sparsis longitudinalibus ante medium liemelytrorum, limbo costali margineque marginali subapicali corii, prostethii marginibus lateralibus, basi excepta, margine apicali metastethii, maculis duabus marginalibus mediis ventris femoribusque basin versus sordide flavo-albidis; tibiis tarsisque fusco-testaceis. $\sigma^{7}$. Long. 11, Lat. 3 mill.

Rhyparochromus annulatus SIGN. Ann. ent. Sér. 3. VIII.p. 949. 145. (1861).

Patria: Madagascar. (Coll. Signoret et Stảl.)

$B$. albo-striato simillimus, antennis fere totis nigris, marginibus lateralibus thoracis apice nigris, nec usque ad apicem albidis, parte basali pallida femorum breviore differt.

8. B. Imbrifer STÅL. - Elongatus, niger; antennis, rostro, lineolis duabus marginis antici, marginibus lateralibus expla- 
natis parteque tertia postica thoracis, maculis duabus parvis oblongis ante medium apiceque scutelli, hemelytris, limbo laterali prostethii, margine postico metastethii, acetabulis, limbo interrupto ventris pedibusque griseo-stramineis; antennarmm articulo apicali, amnulo subhasali excepto, sape etiam parte apicali femorum fuscis; thorace posterius hemelytrisque fusco-ferrugineo-punctatis, horum limbo costali levi, macula subapicali majuscula pallidissime obsoleteque fusco-punctata, fascia interrupta media fusca; membrana fuscescente, venis pallidis. ơ. Long. 9!1, Lat. 3 mill.

Rhyparochromus mulrifer ṠTAL. Öfv. Vet. Ak. Förh. 1855. p. 33. 5 .

\section{Patria: Caffraria. (Mus. Holm.)}

B. albo-striato quoad staturam sat similis. Anteunarum articulus prinus eapitis apicem multo superans. Thorax paullo longior quam basi latior, postice quam antice vix dimidio latior, antrorsum leviter angustatas, apice capiti latitudine equalis, angulis anticis haud proninulis, angulis posticis lineolis oblique longitudinali fusea notatis. Nembrana apieem abdominis haud attingens. Coxa antice spina armatie. Femora intica subtus utrimque spinulis compluribus et antice apiecm rersus spina majore armata. Tibia antica subtus denticulis nonnullis instruetse.

9. B. placilns STAL. - Dilute ferrugineus; antennis, marginibus lateralibus lineolaque posteriore thoracis, marginibus lateralibus prostethii pedibusque ferrugineo-stramineis; antennarum articulo primo, apice articulorum secundi et tertii nec non articulo quarto, annulo lato subbasali abbido excepto, marginibus lateralibus thoracis posterius, parte apicali femorum, basi apiceque tibiarum hemelytrisque nigro-fuscis, his in ferrugineum vergentibus, maculis nonnullis parvis sparsis interioribus, limbo costali ante medium maculaque costali subapicali sordide stramineis, membrana fusca, ante medium pallido-notulata. ㅇ. Long. 1I, Lat. 3 mill.

Patria: Insula Bourbon. (Mus. Holm.)

Antennarum articulus primus capiti longitudine rqualis, hujus apicem longissime superans. Rostrum articulo primo pone oeulos distincte extenso. Caput ad oculos hand immersus. Thorax paullo brevior quam basi latior, antrorsum sat angustatus, postice quam 
antice plus duplo latior, paullo ante medium transversim leviter impressus, distincte 't minus dense punctulatus. Hemelytra obsolete punctata. Coxae antice spina armate. Femora antica vix incrassata, subtus prope apicem spina distincta armata.

10. B. patruelis STẢL. - Valde oblongus, niger; antennarum articulis secundo et tertio, apice excepto, thoracis parte fere dimidia postica marginibusque lateralibus explanatis ab apice ultra medium, scutelli maculis duabus minutis ante medium apiceque ino, hemelytris, limbo laterali prostethii, margine imo apicali metastethii, margine ventris pedibusque griseostramineis; thorace posterius dense, hemelytris remote nigropunctatis, margine costali lævi; corii macula magna media interiore margineque apicali, femoribus anticis, basi excepta, parte apicali femorum posteriorum, basi apiceque tibiarum nigris; annulo subbasali articuli quarti antennarum stramineo; membrana fusca. o’. q. Long. 10, Lat. vix $3 \frac{1}{2}$ mill.

Rhyparochromus patruelis STÅL. Öfv. Vet. Ak. Förlı 1855. p. 33.6 .

Patria: Caffraria. (Mus. Holm. et Coll. STÃL.)

Antenna articulo primo capite dimidio vix longiore, hujus apicem nomnihil superante. Rostrum articulo primo pone ocnlos sat producto. Thorax nonnihil brevior quam basi latior, antrorsum valde angus'atus, postice quam antice cluplo latior, apice capiti latitudine requalis, medio transversim leviter impressus. Coxæ antica spinula armate. Femora antica subtus pone medium spinulis nonnullis parvis et nna distinctiore armata.

11. B. lateralis SIGN. - Nonnihil elongatus, ferrugineo-niger; antennarum articulis secundo et tertio, apice excepto, thoracis marginibus lateralibus explanatis maculisque minutis duabus marginis antici, scutelli apice imo, hemelytris, limbo laterali prostethii, maculis pectoris ad coxas margineque interrupto ventris griseo-stramineis; thorace posterius pallidovario, distincto punctato; hemelytris ferrugineo-punctatis, limbo costali lævi, macula oblonga media interiore margineque apicali nigris; membrana fusca. $\sigma^{7}$. ㅇ. Long. 11, Lat. 3 mill. 
Dieuches lateralis Sign. in Malluard. Notes sur l'ile de la Réunion. Ins. P. 29.

Patria: Insula Bourbon. [Ile de la Réunion.] (Coll. SIG.YORET.)

Pracedenti simillimus, panllo magis elongatus, artieulo primo antemnarum longiore, capite vix breviore differt.

In exemplo typico, a Dom. Signoret misso, pedes fere omnes desunt; pedes duo (an vere ad hane speciem pertinentes?) toti nigri corpori sunt agglutinati.

12. B. coenosus Stål. - Niger; antennis, rostro, marginibus lateralibus explanatis, margine angusto antico parteque fere dimidia postica thoracis, apice imo vittaque utrimque laterali intramarginali scutelli ante medium abbreviata, hemelytris, limbo laterali prostethii, margine angusto postico prostethii et metastethii, acetabulis, margine laterali medio rentris pedibusque griseo-stramineis; thorace posterius, scutelli vittis hemelytrisque nigro-punctatis; angulo imo apicali corii nigro; membrana fusca; apice articulorum antennarum fusco. $\sigma^{2}$. Long. 11, Lat. 31 mill.

Patria: Caffraria. (Mus. Holm.)

B. patrueli quoad staturam simillimus, antcunarum articulo primo longiore, capiti longitudine aunali et hujus apicem longe superante, hemelytris macnla nigra destitutis, fenoribus apicem versus vix infuscatis differt. Femora antica spinulis pluribus et apicem versus spina una majore armata.

Autcmiarum articulus ultimus in exemplo deseripto mutilatus.

aa. Thoracis marginibus lateralibus carinatis distincte sinuatis.

13. B. marginipennis STAL. - Niger; marginibus lateralibus angustis thoracis ab apice ultra medium, apice imo scutelli, limbo costali maculaque mijuscula costali subapicali corii, marginibus lateralibus prostethii, basi excepta, trochanteribus, basi femorum anticorum femoribusque posterioribus a basi ultra medium flavo-albidis. $\sigma$. $q$. Long. $10-11$, Lat. 3 mill.

Rhyparochromus marginipennis STÂL. Ōfv. Vet. Ak. Förl. 1855. p. 33. 4. 
Patria: Caffraria. (Mus. Holm.)

Caput ad oculos haud immersum. Antemnarum articulus primus capite paullo brevior, apicem capitis longe superans. Rostri articulus primus pone oculos haud extensus. Thorax longior quam basi latior, antrorsum sat angustatus, apice capite angustior, paullo pone medium transversin distincte impressus. Coxie antice spina armatse. Femora antica distincte incrassata, subtus spinulis nonnullis minutissimis et prope apicem spina magua armata.

\section{ANDROGEUS STÅ.}

Corpus anguste ovale. Caput triangulare, subtransversum, ad oculos immersum. Antennæ corpore multo breviores, articulo primo capitis apicem æquante. Rostrum articulo primo pone oculos extenso. Thorax trapezoideus, transversus, antrorsum leviter angustatus, apice capite cum oculis subangustior, convexiusculus, margine basali recto, marginibus lateralibus haud explanatis, acutiusculis. Scntellum triangulare, paullo longius quam latius. Hemelytra completa, pone medium leviter angustata; membranæ venis longitudinalibus venis transversis haud conjunctis. Pedes mediocres, femoribus anticis levissime incrassatis, inermibus.

Lethaco affine genus.

1. A. marginatus SIgN. - Niger, nitidus, glaberrimus; corii margine costali ante medium nec non tarsis flavo-albidis; apice articulorum antennarum femorumque nec non tibiis flavopiceis; membrana pallide fusco-hyalina. ㅇ. Long. 4, Lat. 2 mill.

Lethceus(?) margina:us Sign. Ann. ent. Sér. 3. VIII. p. 948. 143. (1861).

Patria: Madagascar. (Coll. Signoret.)

Lavis. Scutellum intra margines laterales serie punctorum instructum. Hemelytra remote punctulata, clavo coricque ad suturam clavi seriatim distinctius punctatis. Prostethium antice et metastethium distincte punctulata. 


\section{$17 t$ \\ LETII EUS DALL. \\ List of Hem. II. p. $55 \%$. (185\%).}

Corpus anguste ovatum vel oblongum. Caput triangulare, ad oculos immersum. Antennæ articulo primo capiti longitudine xquali vel paullo breviore, capitis apicem tamen sat longe superante. Rostrum ad vel fere ad pedes posticos extensum, articulo primo capite nonnilil longiore. Thorax trapezoidens, antrorsum nonnihil angustatus, apice capite haud vel paullo latior, margine basali recto, marginibus lateralibus haud vel leviter explanatis. Scutellum paullo longius quam latius. Hemelytra completa, membranæ venis longitudinalibus tribus exterioribus vena transversa conjunctis. Pedes mediocres, femoribus anticis leviter incrassatis; tarsis posticis articulo primo apicalibus duobus ad unum dimidio vel duplo longiore.

a. Corpore supra nigro-piceo, dense punctato; angulo apicali capitis oltusiusculo.

1. L. tartareus StåL. - Anguste ovatus, nigro-piceus, supra cum pectore dense distincteque punctulatus, pectore subtilius et remotius punctato; thorace paullo longiore quam apice latiore, distincte transverso, ante medium plaga transversa lævigata instructo, marginibus lateralibus haud explanatis, acutiusculis; angulis posticis thoracis, rostro pedibusque dilute piceis; membrana fusco-livida. ㅇ. Long. $7 \frac{1}{3}$, Lat. $3 \frac{1}{5}$ mill.

Lethanes africanus DALI. List. of Hem. II. p. 557. I. (1861). ad partem.

Patria: Terra capensis. (Mus. Holm.)

L. cribratissimo Stî, Douns, valde aftinis, thorace apice paullo angustiore, postice paullo latiore, antice plaga impunctata instructo marginibusque lateralibus hand explanatis differt. Pedes antici exempli descripti mutilati.

2. L. africanus DALL. -- Oblongus, nigro-piceus, supra cum pectore sat dense distincteque punctatus; rentre nitido, punctulis raris obsoletissimis adsperso; thorace ante nedium 
plaga transversa impunctata instructo; rostro tibiisque rlilute piceis; membrana fusco-livida. ㅇ. Long. 7 , Lat. $2 \frac{2}{3}$ mill.

Lethceus africanus DALL. List of Hem. I1. p. 557. 1. Pl. 15. fig. 3. (1861), ad partem.

\section{Patria: Sierra Leona. (Mus. IIolm.)}

Pracedenti affinis, angustior, thorace longiore, vix breviore quan b:si latiore, margiuibus lateralibus obtusioribus ventreque fere omnino lavi differt. Antenna pedesque fere omnes in exemplo descripto mutilati.

Thorax in ex mplo a me descripto longior est quam in figura Dallasi.

aa. Hemelytris dilute piceis, pallido-rotulatis; angulo apicali capitis recto.

3. I. guttulatus STÅL. - Oblongus, nigricans; antennis, rostro, thoracis marginibus angustis lateralibus et angulis posticis, hemelytris pedibusque pallicle piceis, femoribus hemelytrisque obscurioribus, maculis parvis duabus clavi, duabus vel tribus ante medium unaque marginali pone medium corii sordide flavo-albidis; membrana fusco-hyalina, basi pallidiore. $\sigma^{7}$.

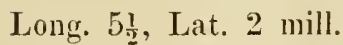

Patria: Sierra Leona. (Mus. Holnı.)

Supra cum pectore minus dense punctulatus. Caput aequilaterum, paullo longius quam in speciebus pracedentibus. Thorax paullo brevior quam apice latior, ante medium plaga transversa laevi instructus, marginibus lateralibus levissime rotundatis, leviter explanatis et subreflexis. Clavus utrimque serie percurrente intramarginali et medio serie abbreviata punctorum instructus. Venter levis. Femora antica nomnihil incrassata, subtus prope apicem spinulis nonnullis minutissimis armata. 


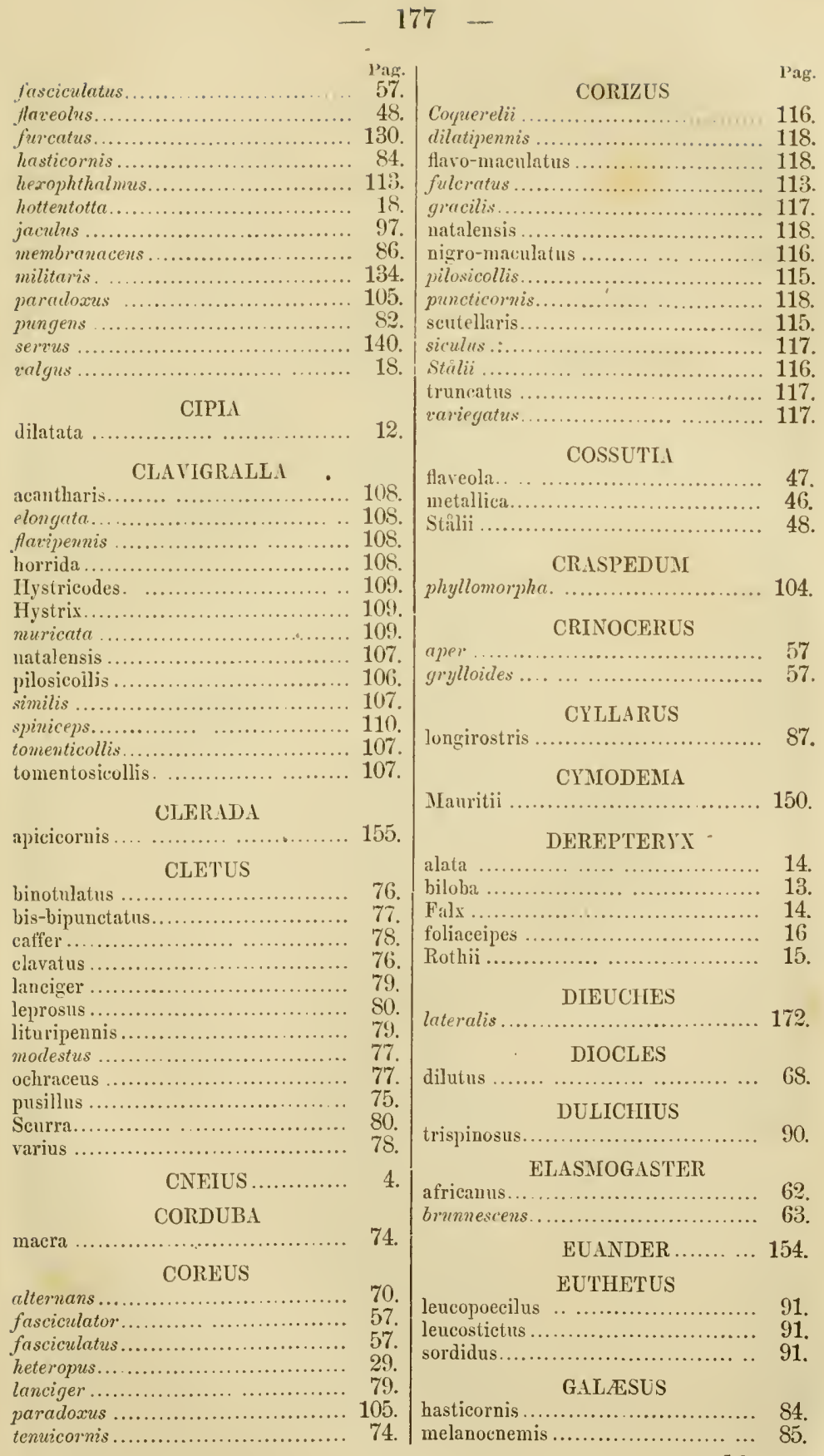

Hemiptera africana. II. 
GELONUS

GEOCORIS

amabilis

Mauritii.

signicollis

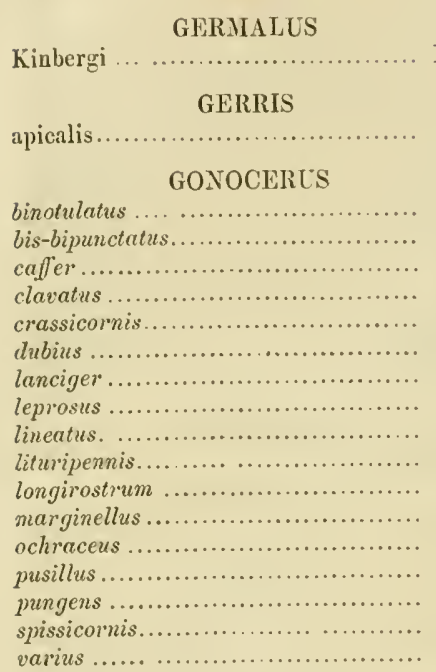

\section{HENESTARIS}

Kinbergi

HERAUS

\section{HOMOEOCERUS}

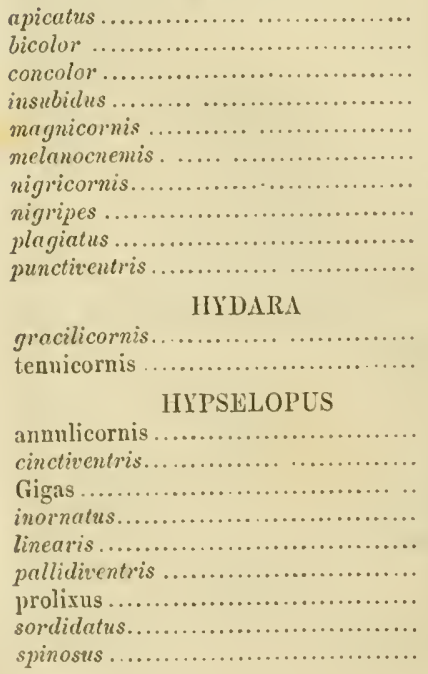

143.

153.

83.

65.

72.

66.

64.

85.

69.

70.

66.

72.

74.

73.

100.

101.

99.

103.

103.

100.

98.

102.

101.
I'ag.

101.

99.

villosipes

ISCINODEMUS

pallidipennis ...................... 147.

LAGARIA

a fricana ......................... 83 .

\section{LATIMBUS}

armipes .......................... 73 ,

concolor.......................... 72.

punctatus ............................ 71.

punctiventris. ................... $7 \%$.

LEPTOCORIS

amicta ............................ 113.

hematica........................... 114.

\section{LEPTOCORIS $A$}

annulicornis ......................... 88

apicalis............................. 88.

\section{LETIIAUS}

africanus........................... 174

africanus ........................... 175.

guttulatus ........................ 175 .

marginatus.......................... 173.

tartareus....................... 174.

albidus ........................... 131

albostrianus ........................... 169.

apicalis............................ 129

arcuatus.......................... 96

asiaticus............................ 134.

bellicosus............................ 17 .

bipartitus ......................... 141.

bitransversus........................ 137.

civilis .............................. 134.

concinuns .......................... 137.

contaminatus .......................... 128.

convergens ........................ 130.

crocatus ........................... 127.

crudelis .............................. 131.

curvipes ................................ 29.

delicatnlus.......................... 138.

discoidalis ........................... 141.

clegans.............................. 134

cxeivatus .............................. 126

Fairmairei.......................... 131.

famelicus ......................... 126.

fasciativentris .................... 140

fecialis ............................. 132.

festivis................................ 135.

fulvipes ........................... 138.

fureatus.............................. 130.

furcula ............................... 135.

hexophthalmus........................ 113.

Hottentottus ......................... 23.

incomptus ........................... 140.

leveis .............................. 21 


\section{$-\quad 179$}

\begin{tabular}{|c|c|c|}
\hline & 133 & \\
\hline mniscatus. & 133. & foliacipes \\
\hline rginatus. & $\begin{array}{l}136 . \\
141 .\end{array}$ & 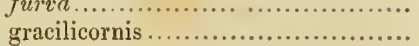 \\
\hline lañurus..... & 142. & gracilis.............................. \\
\hline branaceus.. & 86. & grallatoria .......... \\
\hline ris ........ & 133. & griseo-sericans ..... \\
\hline (.......... & 136. & grisco-sericea....... \\
\hline … & $\begin{array}{r}133 . \\
20 .\end{array}$ & n.......... \\
\hline ..... & 128. & 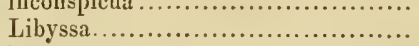 \\
\hline & 128. & luctuosa .......................... \\
\hline & 2. & $a \ldots \ldots \ldots \ldots \ldots \ldots \ldots$ \\
\hline & & ensis ....... \\
\hline & $\begin{array}{r}132 . \\
20\end{array}$ & cholice................ \\
\hline & 139. & (n......................... \\
\hline & 51. & 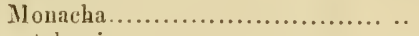 \\
\hline & 135. & (n) \\
\hline & & uis............................ \\
\hline …..... & & 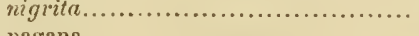 \\
\hline (n................ & & 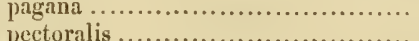 \\
\hline & 35. & …..... \\
\hline 80. & 14 & $\mathrm{~s}$. ......................... \\
\hline (n........... & & 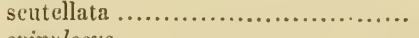 \\
\hline ....... & 139. & 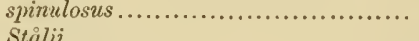 \\
\hline MARCIUS.......... & 7. & rnis ....................... \\
\hline ME & & $\ldots \ldots \ldots \ldots \ldots \ldots$ \\
\hline llosipe & 99 & 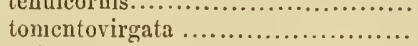 \\
\hline $\begin{array}{l}\text { MEV } \\
\text {....... }\end{array}$ & & , n.............. \\
\hline miceps .. & 10. & 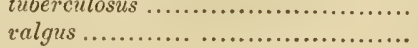 \\
\hline Mfiventris............ & 129. & (n....................... \\
\hline$M 11 \mathrm{C}$ & & rnis \\
\hline evicornis..... & & \\
\hline$\cdots$ & & MIRPERUS \\
\hline ........... & & IUTUSCA \\
\hline MIIC' & & 1U1USUA \\
\hline • & 45 & MI \\
\hline & 1 & apicalis.... \\
\hline & 9. & icus... \\
\hline & & parallelus.... \\
\hline & 4 & $\mathrm{M}$ \\
\hline .... & 3 & a........ \\
\hline & 4 & .. \\
\hline & & \\
\hline & 4 & ..... \\
\hline & & \\
\hline & 26. & totta..... \\
\hline & 25. & ...... \\
\hline & $\begin{array}{l}20 . \\
27 .\end{array}$ & $\cdots$ \\
\hline & & a.... \\
\hline & & \\
\hline
\end{tabular}




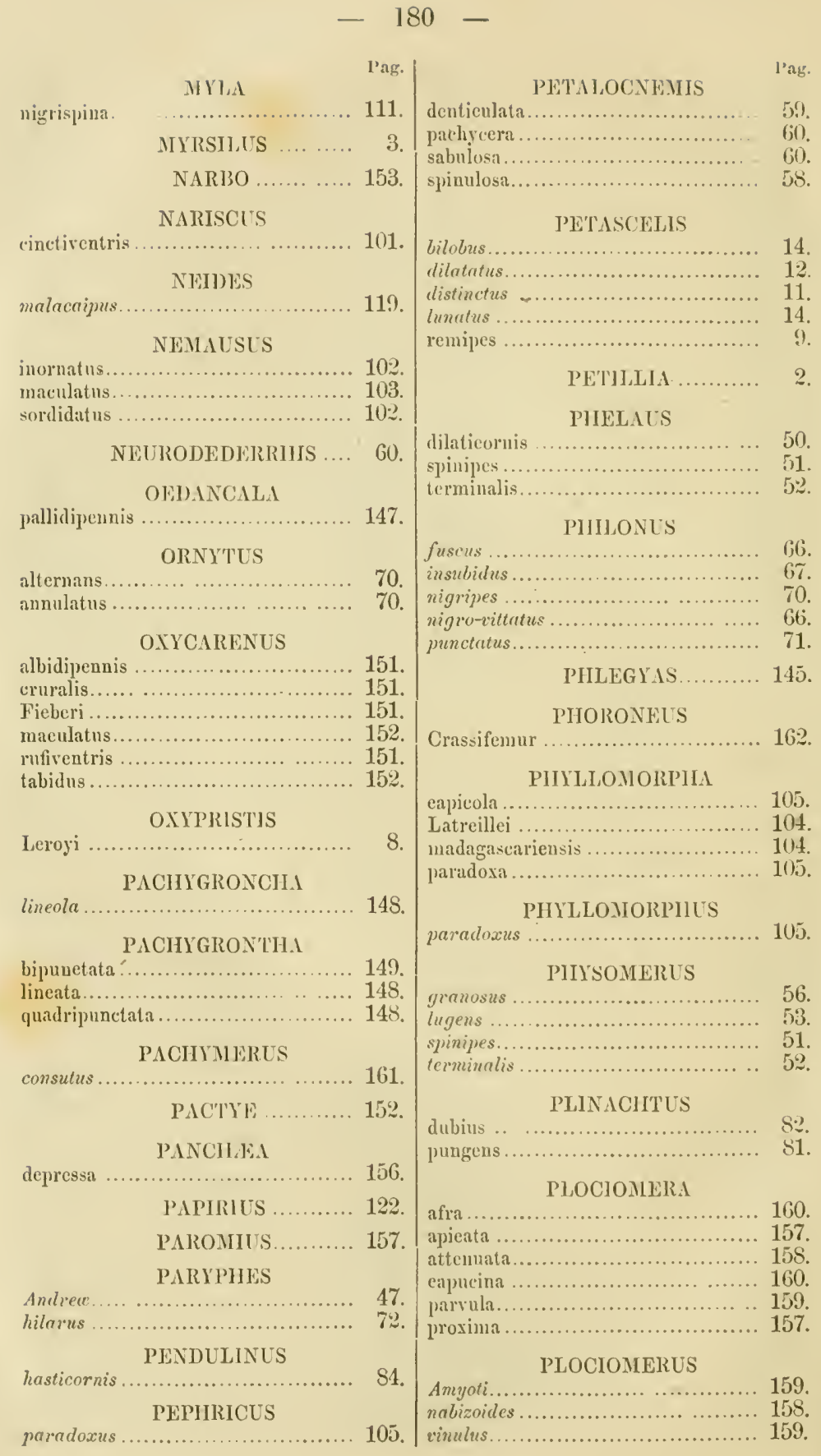




\section{$-\quad 181$}

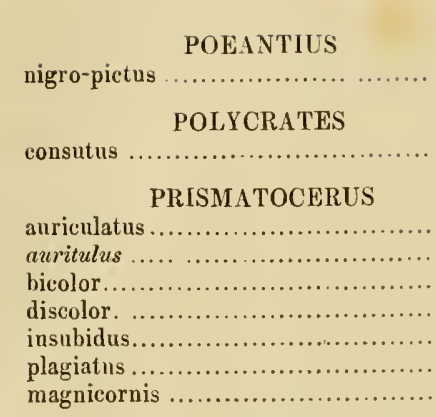

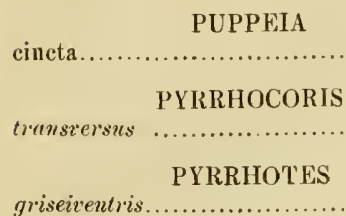

\section{RHOPALUS \\ scutellaris..................... 115 . \\ truncatus \\ RHYPAROCHROMUS}

albostriatus.

apicalis.

apicatus

attemuatus

caffer

crassifemur

curvipes

marginipennis

natalensis...

nigronaculatus

nigropictes .

peganus

parvulus.

patruelis

proximus

traustersus.

turgidifemur

umbrifer

vinulus

\section{RIPTORTUS}

Fabricii

Havo-lineatus
Pag.
163.
161.

64.
64.
65.
65.
66.
66.
63.

26.

130.

114.

117.

169.

169.

165.

157.

158.

167.

163.

161.

172.

158.

165

164.

158.

159.

171.

158 .

167.

165.

170.

159.

93.

93. vittato l'ag

94.

94.

SERINE'THA

amicta......................... 113.

fraterna ............................. 112.

fulcrata ............................... 113.

griseiventris .......................... 114.

hiematica ............................. 113.

hexophthalma ..................... 112.

lateralis ............................ 11t.

mnesta ............................. 113

\section{STENOCEPHALIS}

testaccus ........................ 88

punctarius ..................... 89

STFNOGASTER

mufiventris...................... 151

SULPICIA

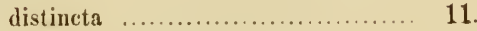

\section{SYROMASTES}

concolor ............................. 72

horridus ............................. 108.

phyllomorpha..................... 104.

scurra ........................... $\$$

TAGUS

productus ....................... $6 \pi$

\section{TERACRIUS}

namaquensis $\ldots \ldots \ldots \ldots \ldots .146$.

THEOGNIS

membranaceus ................... 86 .

Carmelita ......................... 83

THERAPTUS

TLIPONIUS

rugifer ........................... 69

TUPALUS

albidens .......................... 97.

arcuatus............................. 95

fasciatus ................................ 96.

Jaculus............................. 96.

TYNOTOMA 
x

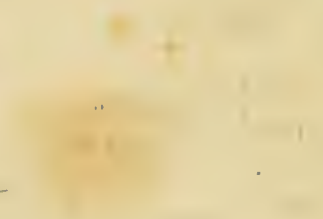




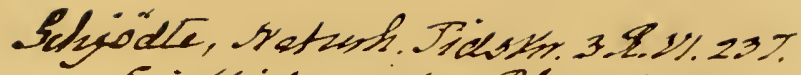

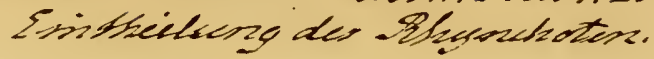

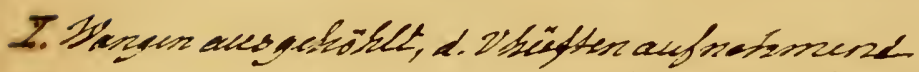
suborte : Homontera.

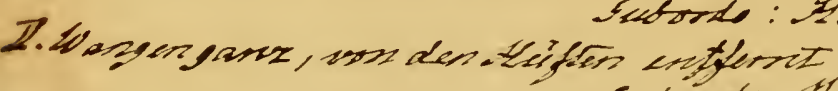
ceno ondo: Heterngtera

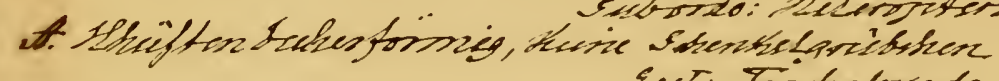
Sect. Tridieloroda

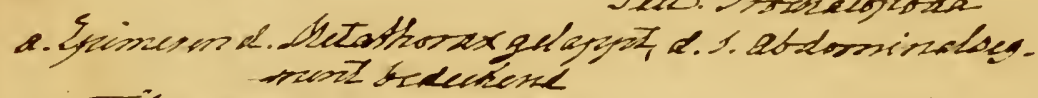

S. Tither am gruade cederkt

Cuscrics:

$\therefore$. Tither fric

+ Fucter 200 der Reygen

tx. Titsles sonter én augen

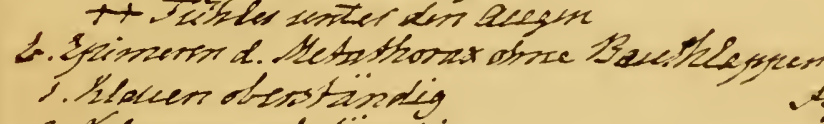

2. Flaveen endofindis - Hydronctorae

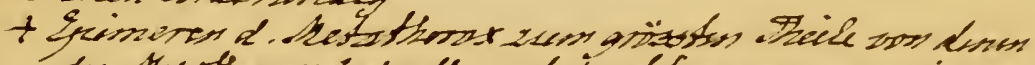

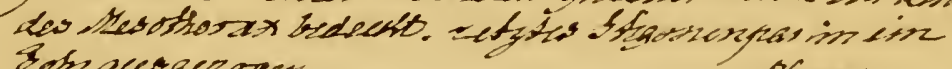
Ioh acc gezoyer

- Sspree

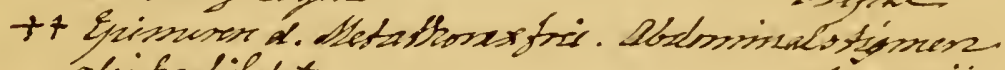
gleingetildetet Aieduric

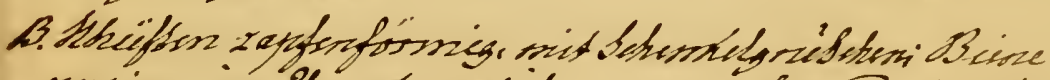

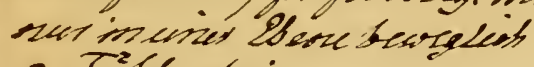
a. Finster fric

Sed. Sagijzode. cunithice

6. Trester sidectit.

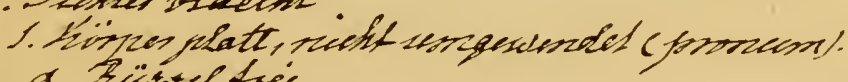

a. - isurese free

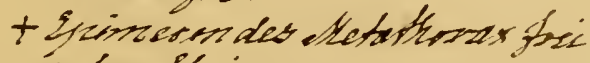

- taufbirze

- Schuovimordine

selegoní

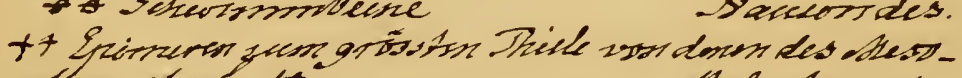
Simper bedicute.

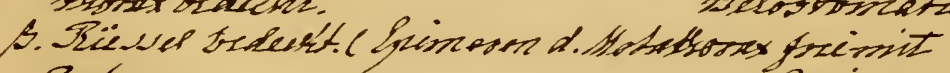
Anthezg

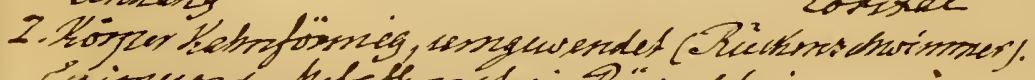

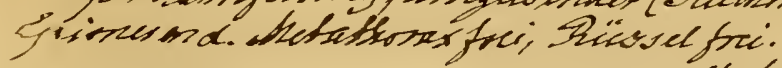

Sotonectee 






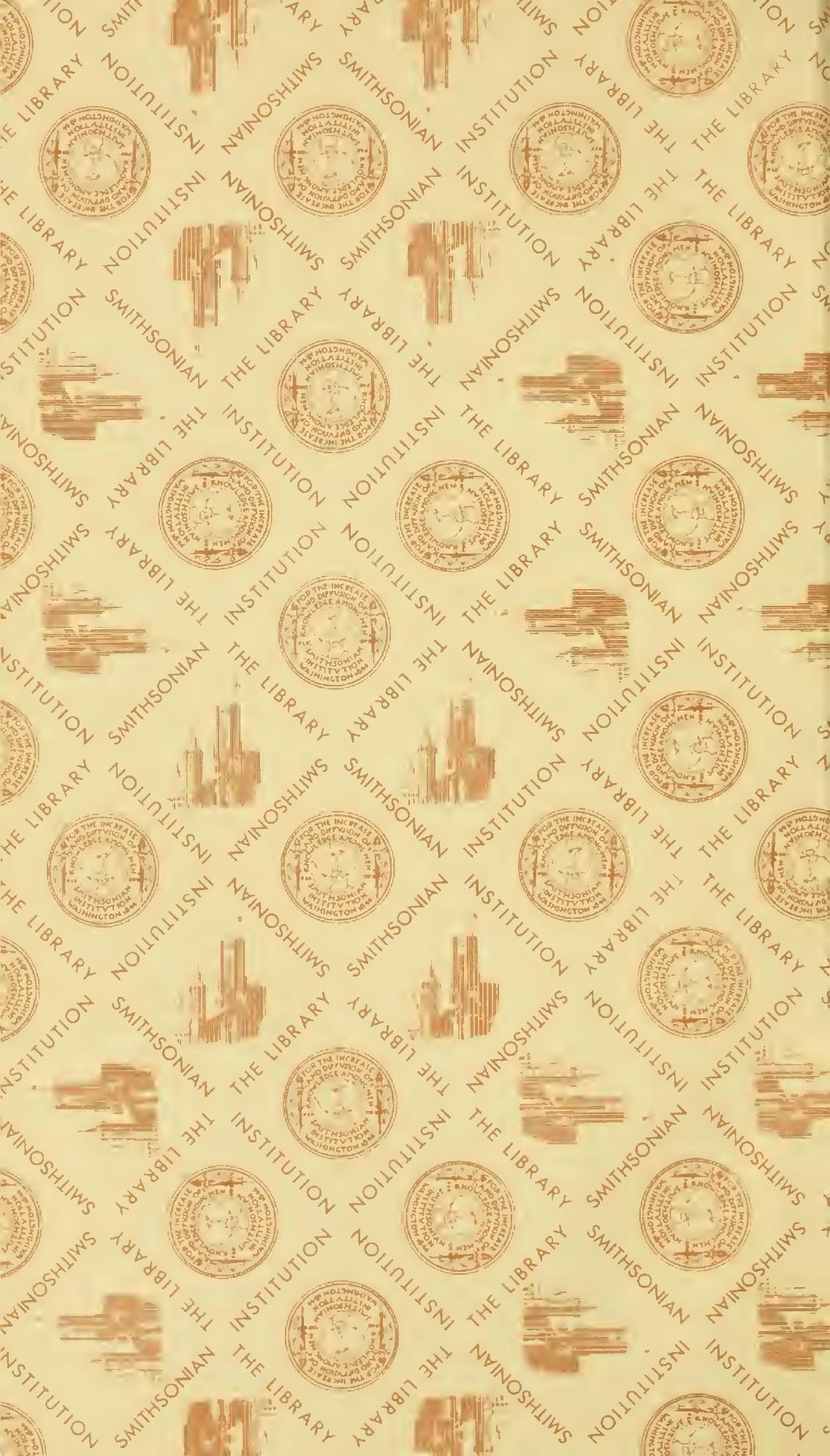




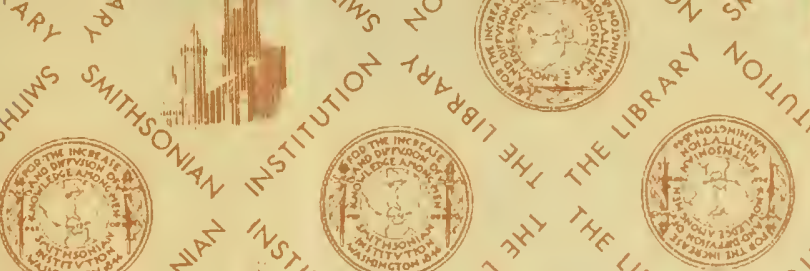

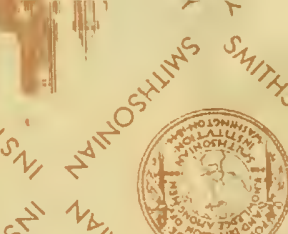

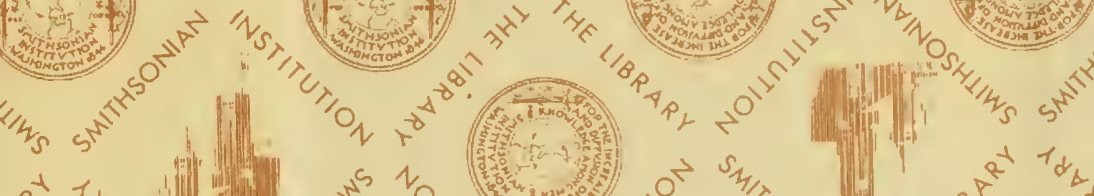

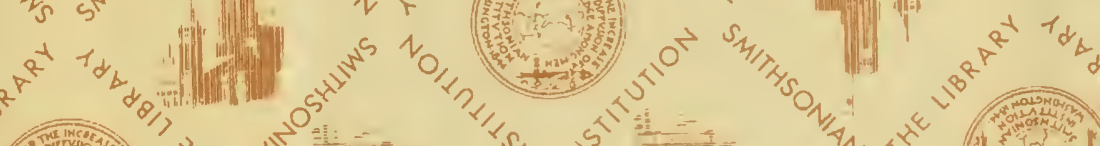

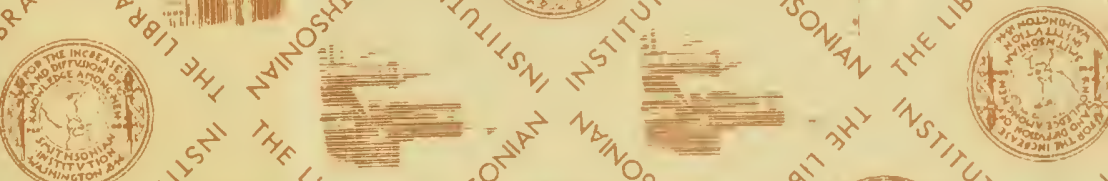

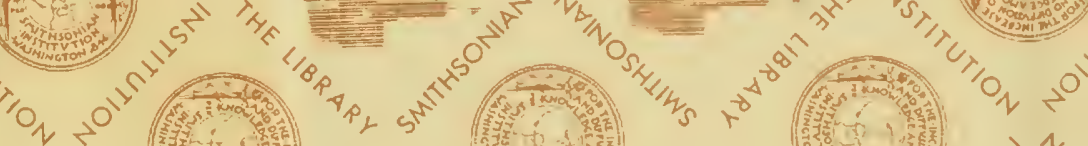

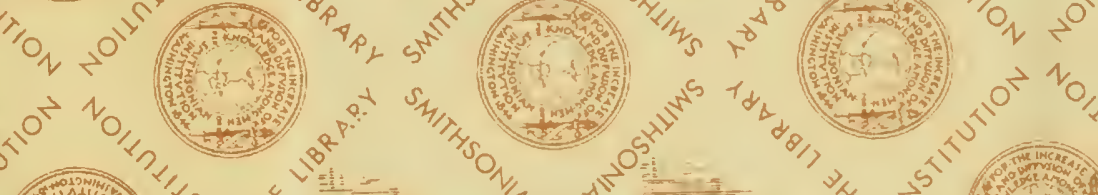

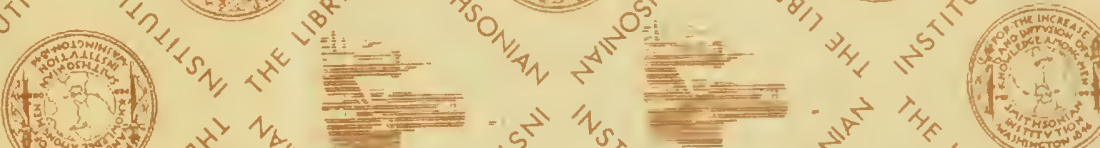

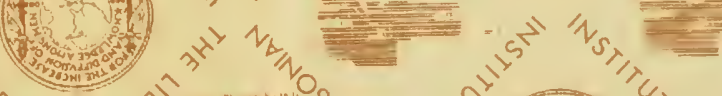

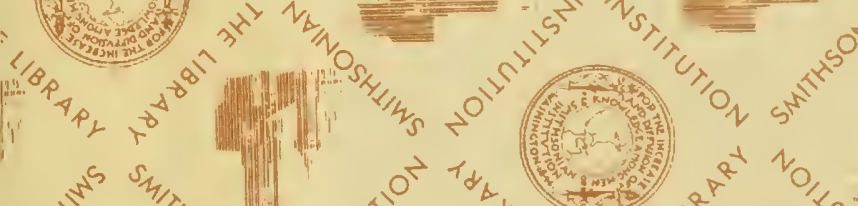

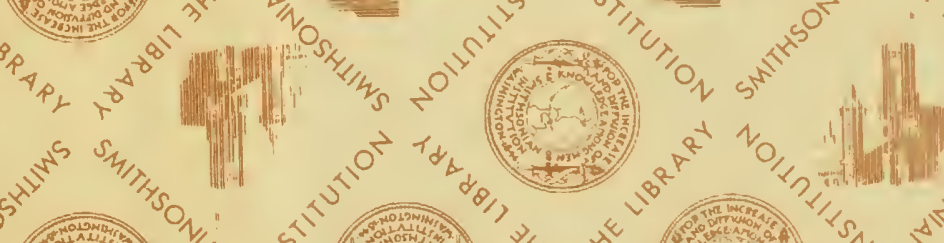

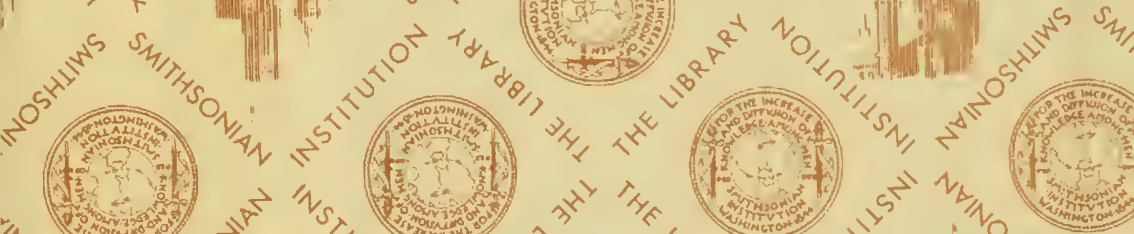

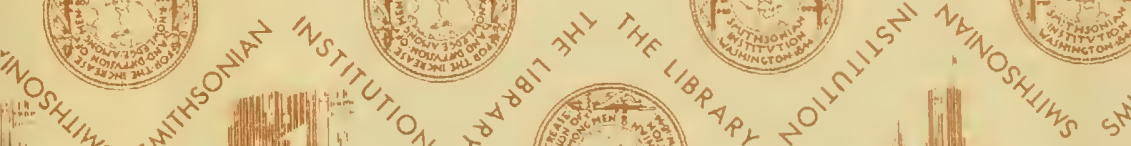

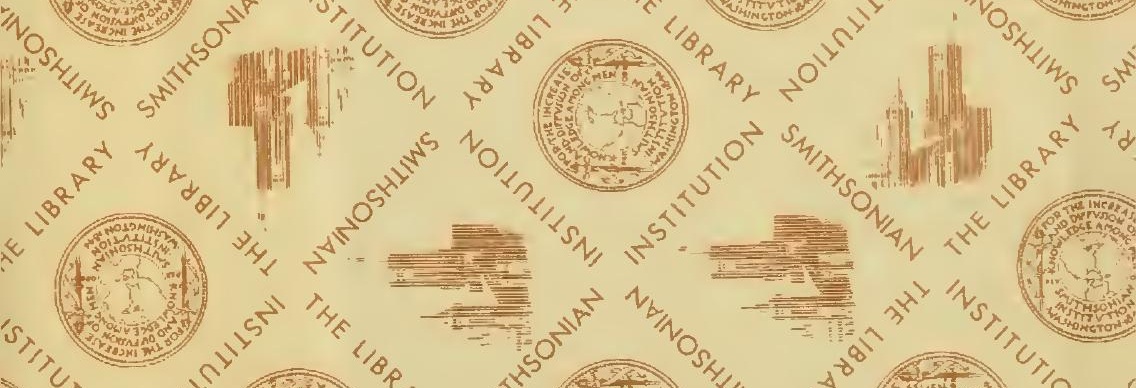

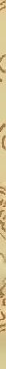

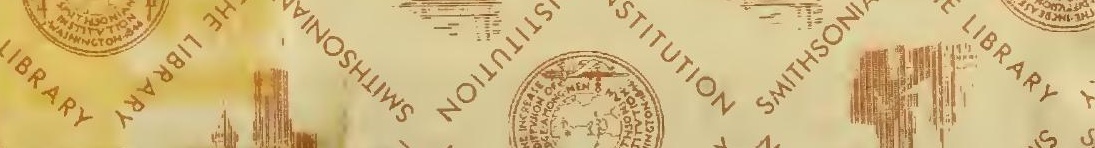


